\title{
VOLTAIRE
}

Écrivain, Philosophe

(1694-1778)

\section{Essai sur les Mœurs et l'esprit des nations}

Avec préfaces, avertissements, notes, etc. Par M. Beuchot

Paris, 1829

Tome 1.

Un document produit en version numérique par Jean-Marc Simonet, bénévole,

Courriel : Jean-Marc_Simonet@,uqac.ca

Dans le cadre de la collection: "Les classiques des sciences sociales"

Site web : http://classiques.uqac.ca/

Une collection développée en collaboration avec la Bibliothèque

Paul-Émile-Boulet de l'Université du Québec à Chicoutimi

Site web : http://bibliotheque.uqac.ca/ 
Cette édition électronique a été réalisée par Jean-Marc Simonet, ancien professeur des Universités, bénévole.

Courriel : Jean-Marc_Simonet@uqac.ca

À partir de :

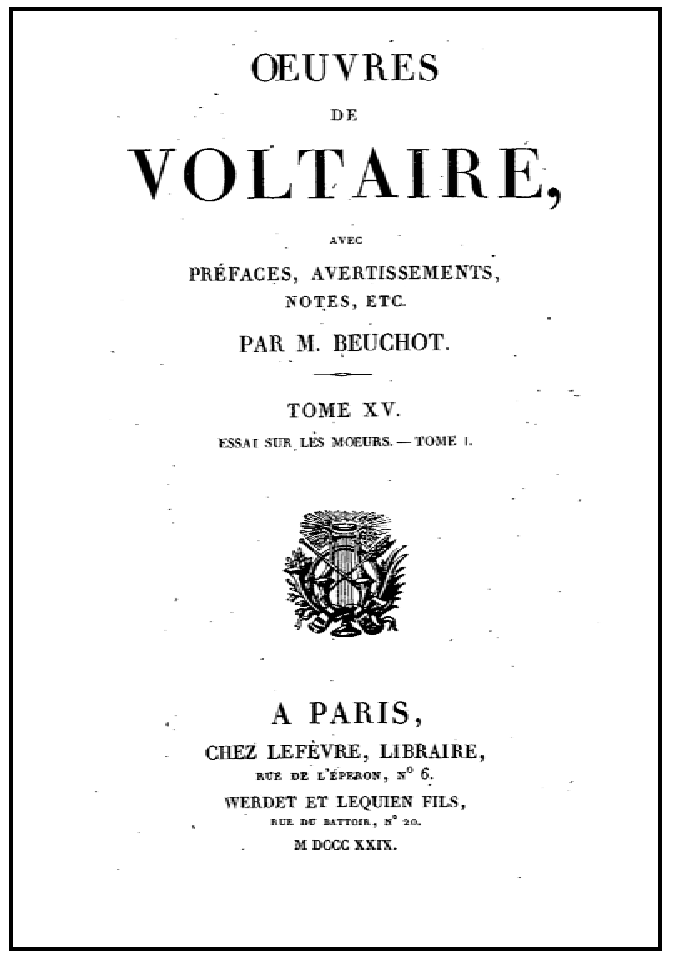

\section{François-Marie Arouet dit Voltaire \\ Écrivain, Philosophe français}

(1694-1778)

\section{Essai sur les mours et l'esprit des nations}

Avec préfaces, avertissements notes, etc. Par M. Beuchot

Tome 1.

chez Lefèvre, libraire, Werdet \& Lequien fils, Paris, 1829, 4 volumes de 549, 551, 538 et 502 p.

Polices de caractères utilisées :

Pour le texte: Times New Roman, 14 et 12 points.

Pour les notes de bas de page : Times New Roman, 10 points.

Édition électronique réalisée avec le traitement de textes Microsoft Word 2008 pour Macintosh.

Mise en page sur papier format : LETTRE US, $8.5^{\prime \prime}$ x 11 ',

Édition numérique réalisée le 23 février 2011 à Chicoutimi, Ville de Saguenay, Québec.

\section{Fait avec}




\section{Table des matières}

PRÉFACE DU NOUVEL ÉDITEUR (Beuchot)

AVIS DES ÉDITEURS (de Kehl)

INTRODUCTION. - 1. Changements dans le globe. - 2. Des différentes races d'hommes. - 3. De l'antiquité des nations. - 4. De la connaissance de $\underline{\text { l'âme. }}-\underline{5}$. De la religion. Des premiers hommes. $-\underline{6 \text {. Des usages et des }}$ sentiments communs à presque toutes les nations anciennes. $-\underline{7}$. Des sauvages. $-\underline{8}$. De l'Amérique. - 9 . De la théocratie. - 10. Des Chaldéens. - 11. Des Babyloniens devenus Persans. - 12. De la Syrie. - 13 . Des Phéniciens et de Sanchoniaton. - 14. Des Scythes et des Gomérites. - 15. De l'Arabie. - 16. De Bram, Abram, Abraham. - 17. De l'Inde. - 18. De la Chine. - 19. De l'Égypte. - 20. De la langue des Égyptiens, et de leurs symboles. - 21. Des monuments des Égyptiens. - 22. Des rites égyptiens, et de la circoncision. - 23. Des mystères des Égyptiens. - 24. Des Grecs, de leurs anciens déluges, de leurs alphabets, et de leurs rites. -25 . Des législateurs grecs, de Minos, d'Orphée, de l'immortalité de l'âme. - 26. Des sectes des Grecs. - 27. De Zaleucus, et de quelques autres législateurs. 28. De Bacchus. - 29. Des métamorphoses chez les Grecs, recueillies par Ovide. - 30. De l'idolâtrie. - 31. Des oracles. - 32. Des sibylles chez les Grecs, et de leur influence sur les autres nations. -33 . Des miracles. - 34 . Des temples. -25 . De la magie. -36 . Des victimes humaines. $-\underline{37}$. Des mystères de Cérès-Éleusine. - 38. Des Juifs au temps où ils commencèrent à être connus. - 39. Des Juifs en Égypte. - 40. De Moïse, considéré simplement comme chef d'une nation. - 41. Des Juifs après Moïse, jusqu'à

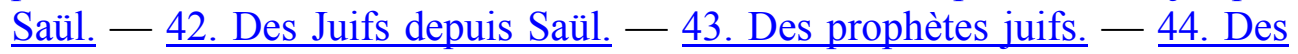
prières des Juifs. - 45. De Josèphe, historien des Juifs. - 46. D'un mensonge de Flavien Josèphe, concernant Alexandre et les Juifs. - 47. Des préjugés populaires auxquels les écrivains sacrés ont daigné se conformer par condescendance. - 48. Des anges, des génies, des diables, chez les anciennes nations et chez les Juifs. - 49. Si les Juifs ont enseigné les autres nations, ou s'ils ont été enseignés par elles. - 50. Les Romains. Commencement de leur empire et de leur religion; leur tolérance. - 51 . Questions sur les conquêtes des Romains, et leur décadence. $-\underline{52}$. Des premiers peuples qui écrivirent l'histoire, et des fables des premiers historiens. -53 . Des législateurs qui ont parlé au nom des dieux. 


\section{ESSAI SUR LES MEURS ET L'ESPRIT DES NATIONS ET SUR LES PRINCIPAUX FAITS DE L'HISTOIRE, DEPUIS CHARLEMAGNE JUSQU'À LOUIS XIII.}

AVANT-PROPOS, Qui contient le plan de cet ouvrage, avec le précis de ce qu'étaient originairement les nations occidentales, et les raisons pour lesquelles on commence cet essai par l'orient. - Stérilité naturelle de nos climats. - Nul ancien monument en Europe. - Anciens Toscans. - Anciens Espagnols. - Gaule barbare. - Ridicule des histoires anciennes. - Hommes sacrifiés. - Germains barbares. - Anciens Anglais. - Changements dans le globe.

Chap. 1. - De la Chine, de son antiquité, de ses forces de ses lois, de ses usages et de ses sciences. - Éclipses calculées. - Prodigieuse antiquité de la Chine prouvée. - Ridicule supposition de la propagation de l'espèce humaine. - Population. - Libéralités singulières. — État des armées. — Grande muraille. - Anciens Quadriges. - Finances. — Manufactures. — Imprimerie. - Astronomie. - Géométrie, Voyez les Lettres de Parennin. — La Chine, monarchie tempérée. — Usages utiles. — Loi admirable.

Chap. 2. - De la religion de la Chine. Que le gouvernement n'est point athée; que le christianisme n'y a point été prêché au VII ${ }^{\text {e }}$ siècle. De quelques sectes établies dans le pays. - Morale de Confutzée. - Culte de Dieu très ancien. - Gouvernement chinois accusé à-la-fois d'athéisme et d'idolâtrie. Secte de Fo ou Foé. — Grand Lama. — Matérialistes. — Fausse inscription. — Juifs à la Chine.

Chap. 3. - Des Indes. - Pythagore n'est pas l'inventeur des propriétés du triangle rectangle. - Belle idée d'un brame. - Chiffres indiens. - Année indienne. - L'homme est-il originaire de l'Inde ? - L'Inde autrefois plus étendue. - Affreuse superstition. - Chrétiens de saint Thomas.

Chap. 4. - Des brachmanes, du Veidam et de l'Ézour-Veidam. - Fausse idée qu'on a des Brachmanes en Europe. - Paroles tirées du Veidam même. Le Veidam, origine des fables de la Grèce. - Peu de christianisme dans l'Inde.

Chap. 5. - De la Perse au temps de Mahomet le prophète, et de l'ancienne religion de Zoroastre. - Antiquité des Perses. - Baptême des anciens Perses. - Les deux principes.

Chap. 6. - De 1'Arabie et de Mahomet. - Mœurs des Arabes. - Enfance de Mahomet. - Marié à vingt-cinq ans. - Son caractère. — D'abord prophète chez lui. - Ses premiers disciples. - Il attaque l'empire romain. — Ses progrès. - Sa mort. - Mahomet savant pour son temps. - Naïveté des 
écrivains orientaux. - Arabes infiniment supérieurs aux Juifs. - Abubéker. - Testament remarquable d'Abubéker. - Omar. - Des mages. Bibliothèque d'Alexandrie brûlée. - Mœurs des Arabes, semblables à celles des guerriers de VIliade. - Beaux siècles des Arabes. - Aaron-alRaschild. - Arts des Arabes. - Beaux vers arabes.

Chap. 7. - De l'Alcoran, et de la loi musulmane. Examen si la religion musulmane était nouvelle, et si elle a été persécutante. - Polygamie. - Paradis de Mahomet, le même que chez tous les anciens. - L'alcoran. - Que la religion mahométane était très ancienne. - Islamisme. - Sectes mahométanes.

Chap. 8. - De l'Italie et de l'Église avant Charlemagne. Comment le christianisme s'était établi. Examen s'il a souffert autant de persécutions qu'on le dit. - Juifs toujours privilégiés. - Examen des persécutions contre les chrétiens. - Dioclétien protecteur des chrétiens. - Origine de la persécution. - Faux martyrs. - Vrais martyrs.

Chap. 9. - Que les fausses légendes des premiers chrétiens n'ont point nui à $\underline{\text { l'établissement de la religion chrétienne. }}$

Chap. 10. - Suite de l'établissement du christianisme. Comment Constantin en fit la religion dominante. Décadence de l'ancienne Rome. - Eusèbe, historien romanesque. - Conduite de Constantin. - Donation de Constantin.

Chap. 11. - Causes de la chute de l'empire romain.

Chap. 12. - Suite de la décadence de l'ancienne Rome. - Entière liberté de conscience en Italie, mais courte. - Papes ne peuvent être consacrés qu'avec la permission de l'exarque.

Chap. 13. - Origine de la puissance des papes. Digression sur le sacre des rois. Lettre de Saint-Pierre à Pepin, maire de France, devenu roi. Prétendues donations au Saint Siège. - Le pape vient implorer le maire Pepin. - Pepin n'est pas le premier roi sacré en Europe, comme ou le dit. - Second sacre de Pepin. — Origine du sacre. — Usage de baiser les pieds. — Donation de Pépin aux papes très suspecte.

Chap. 14. - État de 1'Église en Orient avant Charlemagne. Querelles pour les images. Révolution de Rome commencée. - Lettre admirable d'un pape qu'on croit Hérétique.- Nulle dispute dogmatique chez les anciens. Images. - Guerre civile pour les images. — L'évêque de Rome.

Chap. 15. - De Charlemagne. Son ambition, sa politique. Il dépouille ses neveux de leurs états. Oppression et conversion des Saxons, etc. - Conduite de Charlemagne. - Saxons. - Vitikind. - Saxons convertis à coups de sabre. - Colonies.

Chap. 16. - Charlemagne, empereur d'Occident. - Polygamie. - Fin du royaume lombard. - Rome. - Charlemagne, patrice. - Charlemagne, 
empereur. Donation de Charlemagne très douteuse. - Charlemagne ordonne à son fils de se couronner lui-même.

Chap. 17. - Mœurs, gouvernement et usages, vers le temps de Charlemagne. Barbarie de ces siècles. - Mœurs atroces. - Premiers rois francs ne sont pas reconnus rois par les empereurs. - Maires du palais. - Le clergé ne fait un ordre dans l'état que sous Pepin. - Lettre remarquable.

Chap. 18. - Suite des usages du temps de Charlemagne, et avant lui. S'il était despotique, et le royaume héréditaire.

Chap. 19. - Suite des usages du temps de Charlemagne. Commerce, finances, sciences. - Milices. - Armes. - Forces navales. - Commerce. Monnaies. - Sciences.

Chap. 20. - De la religion, du temps de Charlemagne. - Second concile de Nicée. - Anathématisé par le concile de Francfort. - Habileté du pape. Grande dispute sur le Saint-Esprit. — Fausses décrétales. — Gouvernement ecclésiastique. - Fausse loi. — Moines riches. — Fin du monde annoncée. - Abbés seigneurs. - Clercs.

Chap. 21. - Suite des rites religieux du temps de Charlemagne. - De la messe. - Communion. - Confession. - Carêmes. - Laïques ont droit de confesser. - Ancienneté de la confession. - Angleterre.

Chap. 22. - Suite des usages du temps de Charlemagne. De la justice, des lois. Coutumes singulières. Épreuves. - Comtes. - Duels, jugements de Dieu. — Épreuves. - Épreuves païennes. — La loi salique regardée comme barbare.

Chap. 23. - Louis-le-Faible, ou le Débonnaire, déposé par ses enfants et par des prélats. - Le Débonnaire fait crever les yeux à son neveu Bernard. Saint : nom honorifique. — L'abbé Vala. — Abbé séditieux. — Évêques contre l'empereur. - Évêques des Francs résistent au pape. - Champ du mensonge. - Louis-le-Faible en pénitence. - Exemple de pénitence. Louis en prison. - Mort de Louis-le-Faible.

Chap. 24. - État de l'Europe après la mort de Louis-le-Débonnaire ou le Faible. L'Allemagne pour toujours séparée de l'empire franc, ou français. - Empereurs déposés par des évêques. - Ordonnance que le pape ne sera plus élu par le peuple, mais par l'empereur. - Charles-le-Chauve achète l'empire du pape. - Le Chauve empoisonné, à ce qu'on dit. - Rome toujours pillée. - Tribut payé par le pape aux mahométans. — Charles-le-Gros déposé. - Un bâtard empereur.

Chap. 25. - Des Normand vers le IX ${ }^{\mathrm{e}}$ siècle. - Normands, bêtes féroces, égorgent d'autres bêtes. - Ils désolent l'Allemagne, l'Angleterre, et la France. - Sottises de nos légendaires. - Belle résistance des Parisiens. - Évêque courageux et grand homme. - Rollon s'établit à Rouen. - Bassesse de la cour de France. 
Chap. 26. - De l'Angleterre vers le IX ${ }^{\mathrm{e}}$ siècle. Alfred le Grand.

Chap. 27. - De l'Espagne et des Musulmans maures aux VIII ${ }^{\mathrm{e}}$ et IX ${ }^{\mathrm{e}}$ siècles. L'Espagne, qui résista aux Romains, ne résista point aux barbares. Ariens en Espagne. - Révolte de saint Herminigilde. - Imbécillité du roi Vamba. - Histoire du comte Julien et de Florinde, très-suspecte. — Deux évêques appellent les musulmans en Espagne. - Veuve d'un roi d'Espagne épouse d'un mahométan. - Alfonse-le-Chaste : pourquoi.

Chap. 28. - Puissance des musulmans en Asie et en Europe aux VIII ${ }^{\mathrm{e}}$ et IX ${ }^{\mathrm{e}}$ siècles. L'Italie attaquée par eux. Conduite magnanime du pape Léon IV. Aaron-al-Raschild. — Pape Léon.

Chap. 29. - De l'empire de Constantinople aux VIII ${ }^{\mathrm{e}}$ et IX ${ }^{\mathrm{e}}$ siècles. - Horreurs abominables des empereurs chrétiens grecs. - Théodora, persécutrice sanguinaire.

Chap. 30. - De l'Italie; des papes; du divorce de Lothaire, roi de Lorraine; et des autres affaires de l'église, aux VIII ${ }^{\mathrm{e}}$ et IX ${ }^{\mathrm{e}}$ siècles. - Gouvernement de Rome. - Polygamie très ordinaire en Europe, chez les princes. - Aventure d'un roi de Lorraine et de sa femme. - Nicolas I ${ }^{\mathrm{er}}$ juge un roi. - Excommunications.

Chap. 31. - De Photius, et du schisme entre 1'Orient et l'Occident. - Mépris des Grecs pour l'Église latine. - Variations remarquables. - Tolérance nécessaire. - L'église de Constantinople dispute sa supériorité à celle de Rome. - Moine fouetté pour la grâce efficace. - Convulsionnaire.

Chap. 32. - État de l'empire d'Occident à la fin du IX ${ }^{\mathrm{e}}$ siècle. - Papes veulent régner à Rome. - Les Romains ne veulent plus d'empereur.

Chap. 33. - Des fiefs, et de l'empire. - Évêques et abbés princes.

Chap. 34. - D'Othon-le-Grand au $\mathrm{X}^{\mathrm{e}}$ siècle. - L'empereur semble juger les rois.

Chap. 35. - De la papauté au $X^{\mathrm{e}}$ siècle, avant qu'Othon-le-Grand se rendît maître de Rome. - Scandales de Rome. - Le pape Formose exhumé et condamné. - Une prostituée gouverne Rome. - Son amant est fait pape par elle. - Marozie fait pape son fils, bâtard d'un pape. - Jean XII appelle les Allemands en Italie ; c'est la source de tous les malheurs de ce pays. 


\section{PRÉFACE DU NOUVEL ÉDITEUR}

L'Essai sur les Mours, dans sa forme actuelle, se compose de deux parties bien distinctes, rédigées toutes deux pour madame du Châtelet, si l'on s'en rapporte à Voltaire ; mais les éditeurs de Kehl pensent que la première partie, écrite beaucoup plus tard que la seconde, n'a pas été composée pour cette dame.

I.

Les cinquante-trois paragraphes qui forment l'Introduction furent publiés, en 1765, sous le titre de : La Philosophie de l'histoire, par feu l'abbé Bazin, en un volume in- $8^{\circ}$. En tête du volume était une dédicace à l'impératrice Catherine II, imprimée en petites capitales, et que voici :

À TRÈS HAUTE ET TRÈS AUGUSTE PRINCESSE CATHERINE SECONDE, IMPÉRATRICE DE TOUTES LES RUSSIES, PROTECTRICE DES ARTS ET DES SCIENCES, DIGNE PAR SON ESPRIT DE JUGER DES ANCIENNES NATIONS, COMME ELLE EST DIGNE DE GOUVERNER LA SIENNE : Offert très humblement par le neveu de L'AUTEUR.

La Philosophie de l'histoire fut l'occasion de quelques écrits. Larcher (né en 1726, mort en1842) publia un Supplément à la Philosophie de l'histoire, 1767 , in $8^{\circ}$, qui eut une seconde édition en 1769 . En critiquant l'ouvrage de Voltaire, Larcher avait usé d'un droit qu'a tout le monde, il est vrai ; mais il s'était laissé emporter à des expressions violentes qu'on peut qualifier d'odieuses.

Dans sa préface (page 34, soit de la première, soit de la seconde édition), à propos de quelques phrases qu'il citait d'un autre ouvrage de Voltaire (voyez le Dictionnaire philosophique, au mot GUERRE), 
Larcher prétendait que c'était de la part de l'auteur «s'exposer à la haine du genre humain et vouloir se faire chasser de la société comme une bête féroce dont on a tout à craindre. " Ce n'est donc pas sans raison qu'on a reproché à Larcher d'avoir traité Voltaire de bête féroce.

En réponse à l'écrit de Larcher, Voltaire publia la Défense de mon oncle, qu'on trouvera dans les Mélanges, année 1767. Larcher y répliqua par la Réponse à la Défense de mon oncle, précédée de la relation de la mort de l'abbé Bazin, 1767, in- $8^{\circ}$; il ne s'y montre pas bon prophète quand il dit (page 27) : «Dans un demi-siècle le Dictionnaire philosophique, la Philosophie de l'histoire, les Honnêtetés littéraires, ... l'Ingénu, et autres pareilles rapsodies, ne se trouveront plus, pas même chez les épiciers. »

La même année que parut l'ouvrage de Larcher, le P. Viret, cordelier, dont le nom se retrouve dans quelques écrits de Voltaire, fit imprimer une Réponse à la Philosophie de l'histoire, 1767, in-12, opuscule tout à fait oublié.

Trois ans après, l'abbé François donna ses Observations sur la Philosophie de l'histoire et sur le Dictionnaire philosophique, avec des réponses à plusieurs difficultés, 1770,2 volumes in- $8^{\circ}$. C'est ce même abbé François qui a fourni le sujet de la première section de l'article IGNORANCE dans le Dictionnaire philosophique, et duquel Voltaire a dit (dans son Épître à d'Alembert, en 1771) :

L'abbé François écrit ; le Léthé sur ses rives

Reçoit avec plaisir ses feuilles fugitives.

Ce fut en 1769, dans 1'édition in- $4^{\circ}$ de ses œuvres, que Voltaire mit la Philosophie de l'histoire, sous le titre de Discours préliminaire, en tête de l'Essai sur les Mœurs; et cette disposition a dû être respectée par ses éditeurs. Le titre d'Introduction donné dans les éditions de Kehl a été conservé depuis.

La Philosophie de l'histoire, à laquelle est consacré l'article $\mathrm{X}$ des Fragments sur l'histoire, etc. (voyez les Mélanges, année 1773), et qui a été le sujet de quelques autres écrits que je puis passer sous silence, a été réimprimée en entier, sauf le paragraphe XLVI, dans le volume intitulé Résumé de l'Histoire générale, par Voltaire, 1826, in18 , et en fait la plus grande partie. Elle avait été comprise dans la cen- 
sure du clergé de France, du 22 août 1765 et mise à l'Index à la cour de Rome, par décret du 12 décembre 1768.

II.

Il parut, on 1753, en deux volumes in-12, sous le nom de Voltaire, un Abrégé de l'histoire universelle depuis Charlemagne jusqu'à Charles-Quint. Le libraire Néaulme prétendait avoir acheté le manuscrit cinquante louis, d'un domestique du prince Charles de Lorraine. Vers la fin de 1739, alors que Frédéric n'était encore que prince royal, Voltaire lui avait en effet donné un manuscrit qui se trouvait dans l'équipage que les hussards autrichiens prirent au roi à la bataille de Sorr, le 30 septembre 1745.

Voltaire, contrarié de cette publication, fit des réclamations, et, pour les appuyer, employa un singulier moyen. Ce fut de publier un volume qu'il intitula Essai sur l'Histoire universelle, tome troisième. Il avait mis à la tête une espèce de dédicace et une préface. On trouvera cette préface dans les Mélanges, année 1754. Mais Voltaire avait déjà donné quelques détails dans sa lettre à $M^{* * *}$, professeur d'histoire (voy. les Mélanges, année 1753). On peut aussi voir dans la Correspondance, la lettre à Néaulme, du 28 décembre 1753.

L'espèce de dédicace était : À Son Altesse sérénissime électorale, monseigneur l'Électeur palatin. La voici :

Monseigneur, le style des dédicaces, les ancêtres, les vertus du protecteur et le mauvais livre du protégé, ont souvent ennuyé le public. Mais il est permis de présenter un Essai sur l'histoire à celui qui la sait. La modestie extrême, jointe à de très grandes connaissances, le soin de cultiver son esprit pour s'instruire et non pour en faire parade, la défiance de ses propres lumières, la simplicité qui, sans y penser, relève la grandeur, le talent de se faire aimer sans art, et la crainte de recevoir des témoignages de cette tendresse respectueuse qu'on inspire, tout cela peut imposer silence à un faiseur de panégyriques, mais ne peut empêcher que la reconnaissance ne paye un faible tribut à la bonté.

Ce n'est pas même ici une dédicace; c'est un appel au public, que j'ose faire devant Votre Altesse électorale, des éditions qu'on a données du commencement de cette histoire. Votre Altesse électorale a depuis longtemps le manuscrit entre les mains ; elle sait combien ce manuscrit, tout informe qu'il est, diffère de ces éditions frauduleuses; et je peux hardiment démentir et condamner devant votre 
tribunal l'abus qu'on a fait de mes travaux. L'équité de votre âme généreuse me console de ce brigandage, si impunément exercé dans la république des lettres, et de l'injustice extrême de ceux qui m'ont imputé ces volumes défectueux. Je suis forcé d'imprimer ce troisième pour confondre l'imposture et l'ignorance qui ont défiguré les deux premiers. Votre nom, Monseigneur, est ici le protecteur de la vérité et de mon innocence.

Je dois d'éternels remerciements à la bonté avec laquelle Votre Altesse électorale permet qu'une justification si légitime paraisse sous ses auspices. Je suis comme tous vos sujets : j'obtiens aisément justice ; je suis protégé par votre bonté bienfaisante, et je partage avec eux les sentiments de la reconnaissance, de l'amour et du respect.

Le prince que Voltaire appelait ainsi en témoignage de l'infidélité ou de l'inexactitude des chapitres imprimés, était Charles-Théodore, prince de Sultzbach, né le 11 décembre 1724, devenu duc de Bavière en 1777, mort le 16 février 1799. La réponse qu'il fit à Voltaire, sous la date du 27 juillet 1754, se trouvera dans la Correspondance ainsi que plusieurs autres de ses lettres. C'est ce même prince qui eut longtemps pour secrétaire Côme-Alexandre Colini, attaché précédemment à Voltaire au même titre.

C. Walther, libraire de Dresde, qui avait déjà donné deux éditions des Euvres de Voltaire, et qui avait réimprimé, en 1754, les deux volumes sous le titre d'Essai sur l'Histoire universelle, attribué à M. de Voltaire, était celui que Voltaire avait chargé de l'impression du troisième volume, qui porte affirmativement le nom de son auteur. Pour compléter cette édition, il parut, en 1757 , un tome IV, et, en 1758 , les tomes V et VI.

Voltaire, fixé aux environs de Genève, y avait fait imprimer, en 1756, le même ouvrage sous le titre de : Essai sur l'Histoire générale et sur les Mœurs et l'Esprit des nations, depuis Charlemagne jusqu'à nos jours, 7 volumes in- $8^{\circ}$, divisés en 215 chapitres, y compris toutefois le Siècle de Louis XIV, qui y était réimprimé, et qui commence au chapitre 165.

L'édition n'était pas épuisée, et probablement était loin de l'être, lorsque Voltaire imagina d'y joindre à l'article de Joseph Saurin un certificat de trois pasteurs de Lausanne, daté du 30 mars 1757. Il fallut avec les cartons faire de nouveaux frontispices sur lesquels on mit se- 
conde édition, et la date de 1757 ; mais il est arrivé que le brocheur négligent a laissé quelquefois le frontispice daté de 1756 à des exemplaires dans lesquels est le certificat du 30 mars 1757. Je reparlerai de cette variante remarquable en la réimprimant, pour la première fois depuis soixante-dix ans, dans le Siècle de Louis XIV (Catalogue des écrivains).

Une réimpression des sept volumes faite en Hollande, en 1757, est augmentée d'une Table générale des matières.

Quelques années après, Voltaire revit son travail et le fit reparaître en huit volumes in- $8^{\circ}$. Les sept premiers portent la date de 1764 ; le huitième est de 1763. Le Siècle de Louis XIV fait encore partie de cette édition; mais il commence avec le tome VI, et ses 62 chapitres, au lieu d'être numérotés comme suite des 193 de l'Essai, ont leur numérotage particulier (voyez ma préface du Siècle de Louis XIV). Les chapitres XLIII à LX traitaient d'événements postérieurs à la mort de Louis XIV, et ont été depuis employés par l'auteur dans son Précis du Siècle de Louis XV.

Cette nouvelle disposition n'a pas permis à Voltaire de conserver à leur place primitive les chapitres LXI et LXII ; on ne les retrouve même plus dans les éditions de 1768 et années suivantes, in- $4^{\circ}$, et de 1775 , données du vivant de l'auteur. Les éditeurs de Kehl, qui ont tant fait, ont recueilli ces deux morceaux, et leur avaient donné place parmi les Fragments sur l'histoire; on les trouvera dans les Mélanges, année 1763, sous leur intitulé : D'un fait singulier concernant la littérature, et Conclusion et examen de ce tableau historique.

Le huitième volume de 1763 était terminé par des Éclaircissements historiques qu'on pourra voir dans les Mélanges.

C'est là aussi que seront les Remarques pour servir de supplément à l'Essai, etc., publiées en 1763, en un petit cahier de 88 pages.

Un procédé de Voltaire, que je dois faire remarquer, c'est qu'en donnant une nouvelle édition, il avait fait imprimer séparément les Additions à l'Essai sur l'Histoire générale, etc., pour servir de supplément à l'édition de 1756. Ces Additions forment un volume de 467 pages, mais qui ne contient pas les Éclaircissements historiques. 
On a vu qu'en 1769 , dans 1'édition in- $4^{\circ}$, Voltaire fit de sa Philosophie de l'histoire le discours préliminaire. Ce fut en même temps qu'il donna à son livre le titre qu'il porte aujourd'hui d'Essai sur les Mœurs et l'Esprit des nations. Dans cette édition de 1769, et dans celle de 1775, on trouve à la suite de l'Essai, les Remarques, et avec des augmentations les Éclaircissements dont j'ai déjà parlé et qui sont une réponse à Nonotte, auteur des Erreurs de Voltaire dont la première édition est de I762.

Plusieurs chapitres, soit du Pyrrhonisme de l'histoire (voyez les Mélanges, année 1768), soit de Un Chrétien contre six juifs (voyez les Mélanges, année 1776), sont des réponses à des critiques de paragraphes ou chapitres de l'Essai sur les Mours.

Voltaire a fait mieux que de répondre à ses critiques; il a fait quelquefois des changements et corrections. Dans les éditions successives il ne s'est pas contenté de faire des additions qui ont porté l'ouvrage, de 164 chapitres à 197 . Il revoyait chaque chapitre et y ajoutait des phrases ou alinéa, à quelques-uns desquels il a même eu le soin de donner une date. C'est de 1768 qu'est sa réduction ou évaluation en monnaie française des revenus de la Chine, chapitre I ${ }^{\text {er }}$ de l'Essai, tome XV, page 266 ; c'est de 1770 qu'est l'alinéa, page 67 du même volume; en 1778, l'année même de sa mort, il ajoutait quelques mots aux chapitres LVI et LXXXIII, et une note au chapitre CLIII. Parfois, dans ses révisions, il renvoyait à un ouvrage publié dans l'intervalle d'une édition à une autre. On ne doit donc pas être étonné de voir dans l'Essai sur les Mours des renvois à l'Introduction, qui, comme on l'a vu, n'a été publiée que quelques années après, et sous un autre titre.

Dans une note sur le chapitre LXII, les éditeurs de Kehl ont parlé de l'abbé Audra qui avait commencé un abrégé de l'Essai sur les mours à l'usage des collèges, mais qui n'a pu en donner qu'un premier volume.

Les éditions in $-4^{\circ}$ et encadrée, faites sous les yeux de Voltaire, avaient une Table alphabétique des personnages mentionnés dans l'Introduction (ou Philosophie de l'histoire) et dans l'Essai sur les mours. Beaucoup de ces noms ne peuvent avoir place dans la Table générale analytique ; il était cependant nécessaire de donner au lecteur le moyen de les retrouver. L'ancienne Table alphabétique rédigée par 
l'abbé Bigex, reproduite dans l'édition de Kehl et dans quelques autres, n'étant pas complète, il a fallu la refaire. M. J. Ravenel a bien voulu se charger de ce travail; et ce n'est pas la seule fois que j'ai mis à contribution sa bonne volonté et ses lumières.

Les notes signées d'un (V.) sont de Voltaire.

Les notes signées d'un (K.) sont les éditeurs de Kehl, MM. Condorcet et Decroix. Il est impossible de faire rigoureusement la part de chacun.

Les additions que $\mathrm{j}$ 'ai faites aux notes de Voltaire ou aux notes des éditeurs de Kehl en sont séparées par un - et sont, comme mes notes, signées de l'initiale de mon nom (B.).

\section{BEUCHOT.}




\section{AVIS DES ÉDITEURS ${ }^{1}$.}

Nous avons réimprimé le plus correctement que nous avons pu la Philosophie de l'Histoire, composée d'abord uniquement pour l'illustre marquise du Châtelet-Lorraine, et qui sert d'introduction à l'Essai sur les Mours et l'Esprit des nations, fait pour la même dame. Nous avons rectifié toutes les fautes typographiques énormes dont les précédentes éditions étaient inondées, et nous avons rempli toutes les lacunes, d'après le manuscrit original que l'auteur nous a confié.

Ce Discours préliminaire ${ }^{2}$ a paru absolument nécessaire pour préserver les esprits bienfaits de cette foule de fables absurdes dont on continue encore d'infecter la jeunesse. L'auteur de cet ouvrage a donné ce préservatif, précisément comme l'illustre médecin Tissot ajouta, longtemps après, à son Avis au peuple, un chapitre très utile contre les charlatans. L'un écrivit pour la vérité, l'autre pour la santé.

Un répétiteur du collège Mazarin, nommé Larcher, traducteur d'un vieux roman grec intitulé Callirhoé, et du Martinus Scriblerus de Pope, fut chargé par ses camarades d'écrire un libelle pédantesque contre les vérités trop évidentes énoncées dans la Philosophie de l'Histoire. La moitié de ce libelle consiste en bévues, et l'autre en injures, selon l'usage. Comme la Philosophie de l'Histoire avait été donnée sous le nom de l'abbé Bazin, on répondit à l'homme de collège sous le nom d'un neveu de l'abbé Bazin; et l'on répondit, comme doit faire un homme du monde, en se moquant du pédant. Les sages et les rieurs furent pour le neveu de l'abbé Bazin.

Cet avis a paru pour la première fois en 1785, dans les éditions faites à Kehl. Les éditeurs annonçaient qu'il était de Voltaire lui-même, qui s'occupait d'une nouvelle édition de ses ouvrages peu de temps avant sa mort. (B.)

2 Ce que Voltaire appelle ici Discours préliminaire est, depuis les éditions de Kehl, intitulé Introduction. (B.) 
On trouvera la réponse du neveu dans la partie historique de cette édition ${ }^{3}$.

Table des Matières

3 Je l'ai placée dans les Mélanges, année 1767. (B.) 


\section{INTRODUCTION}

1.

\section{CHANGEMENTS DANS LE GLOBE}

Vous voudriez que des philosophes eussent écrit l'histoire ancienne, parce que vous voulez la lire en philosophe. Vous ne cherchez que des vérités utiles, et vous n'avez guère trouvé, dites-vous, que d'inutiles erreurs. Tâchons de nous éclairer ensemble; essayons de déterrer quelques monuments précieux sous les ruines des siècles.

Commençons par examiner si le globe que nous habitons était autrefois tel qu'il est aujourd'hui.

Il se peut que notre monde ait subi autant de changements que les états ont éprouvé de révolutions. Il paraît prouvé que la mer a couvert des terrains immenses, chargés aujourd'hui de grandes villes et de riches moissons. Il n'y a point de rivage que le temps n'ait éloigné ou rapproché de la mer.

Les sables mouvants de l'Afrique Septentrionale, et des bords de la Syrie voisins de l'Égypte, peuvent-ils être autre chose que les sables de la mer, qui sont demeurés amoncelés quand la mer s'est peu à peu retirée ? Hérodote, qui ne ment pas toujours, nous dit sans doute une très grande vérité quand il raconte que, suivant le récit des prêtres de l'Égypte, le Delta n'avait pas été toujours terre. Ne pouvons-nous pas en dire autant des contrées toutes sablonneuses qui sont vers la mer Baltique ? Les Cyclades n'attestent-elles pas aux yeux mêmes, par tous les bas-fonds qui les entourent, par les végétations qu'on découvre aisément sous l'eau qui les baigne, qu'elles ont fait partie du continent? 
Le détroit de la Sicile, cet ancien gouffre de Charybde et de Scylla, dangereux encore aujourd'hui pour les petites barques, ne semble-t-i1 pas nous apprendre que la Sicile était autrefois jointe à l'Apulie, comme l'antiquité l'a toujours cru ? Le mont Vésuve et le mont Etna ont les mêmes fondements sous la mer qui les sépare. Le Vésuve ne commença d'être un volcan dangereux que quand l'Etna cessa de l'être ; l'un des deux soupiraux jette encore des flammes quand l'autre est tranquille : une secousse violente abîma la partie de cette montagne qui joignait Naples à la Sicile.

Toute l'Europe sait que la mer a englouti la moitié de la Frise. J'ai vu, il y a quarante ans, les clochers de dix-huit villages près du Mordick, qui s'élevaient encore au-dessus de ses inondations, et qui ont cédé depuis à l'effort des vagues. Il est sensible que la mer abandonne en peu de temps ses anciens rivages. Voyez Aigues-Mortes, Fréjus, Ravenne, qui ont été des ports, et qui ne le sont plus ; voyez Damiette, où nous abordâmes du temps des croisades, et qui est actuellement à dix milles au milieu des terres ; la mer se retire tous les jours de Rosette. La nature rend partout témoignage de ces révolutions et s'il s'est perdu des étoiles dans l'immensité de l'espace, si la septième des Pléiades est disparue depuis longtemps, si plusieurs autres se sont évanouies aux yeux dans la voie lactée, devons-nous être surpris que notre petit globe subisse des changements continuels?

Je ne prétends pas assurer que la mer ait formé ou même côtoyé toutes les montagnes de la terre. Les coquilles trouvées près de ces montagnes peuvent avoir été le logement de petits testacées qui habitaient des lacs; et ces lacs, qui ont disparu par des tremblements de terre, se seront jetés dans d'autres lacs inférieurs. Les cornes d'Ammon, les pierres étoilées, les lenticulaires, les judaïques, les glossopètres, m'ont paru des fossiles terrestres. Je n'ai jamais osé penser que ces glossopètres pussent être des langues de chien marin ${ }^{4}$, et je suis de l'avis de celui qui a dit qu'il vaudrait autant croire que des milliers de femmes sont venues déposer leurs conchas Veneris sur un rivage, que de croire que des milliers de chiens marins y sont venus apporter leurs langues. On a osé dire que les mers sans reflux, et les

Voyez dans les Mélanges, année 1746, les notes des éditeurs de Kehl à la Dissertation sur les changements arrivés dans notre globe; et année 1768, les Singularités de la nature. (B.) 
mers dont le reflux est de sept ou huit pieds, ont formé des montagnes de quatre à cinq cents toises de haut; que tout le globe a été brûlé ; qu'il est devenu une boule de verre : ces imaginations déshonorent la physique ; une telle charlatanerie est indigne de l'histoire.

Gardons-nous de mêler le douteux au certain, et le chimérique avec le vrai ; nous avons assez de preuves des grandes révolutions du globe, sans en aller chercher de nouvelles.

La plus grande de toutes ces révolutions serait la perte de la terre atlantique, s'il était vrai que cette partie du monde eût existé. Il est vraisemblable que cette terre n'était autre chose que l'île de Madère, découverte peut-être par les Phéniciens, les plus hardis navigateurs de l'antiquité, oubliée ensuite, et enfin retrouvée au commencement du quinzième siècle de notre ère vulgaire.

Enfin il paraît évident, par les échancrures de toutes les terres que l'Océan baigne, par ces golfes que les irruptions de la mer ont formés, par ces archipels semés au milieu des eaux, que les deux hémisphères ont perdu plus de deux mille lieues de terrain d'un côté, et qu'ils l'ont regagné de l'autre ; mais la mer ne peut avoir été pendant des siècles sur les Alpes et sur les Pyrénées : une telle idée choque toutes les lois de la gravitation et de l'hydrostatique.

Table des Matières

2.

\section{DES DIFFÉRENTES RACES D'HOMMES}

Ce qui est plus intéressant pour nous, c'est la différence sensible des espèces d'hommes qui peuplent les quatre parties connues de notre monde.

Il n'est permis qu'à un aveugle de douter que les Blancs, les Nègres, les Albinos, les Hottentots, les Lapons, les Chinois, les Américains, soient des races entièrement différentes.

Il n'y a point de voyageur instruit qui, en passant par Leyde, n'ait vu la partie du reticulum mucosum d'un Nègre disséqué par le célèbre Ruysch. Tout le reste de cette membrane fut transporté par Pierre le 
Grand dans le cabinet des raretés, à Pétersbourg. Cette membrane est noire ; et c'est elle qui communique aux Nègres cette noirceur inhérente qu'ils ne perdent que dans les maladies qui peuvent déchirer ce tissu, et permettre à la graisse, échappée de ses cellules, de faire des taches blanches sous la peau ${ }^{5}$.

Leurs yeux ronds, leur nez épaté, leurs lèvres toujours grosses, leurs oreilles différemment figurées, la laine de leur tête, la mesure même de leur intelligence, mettent entre eux et les autres espèces d'hommes des différences prodigieuses. Et ce qui démontre qu'ils ne doivent point cette différence à leur climat, c'est que des Nègres et des Négresses, transportés dans les pays les plus froids, y produisent toujours des animaux de leur espèce, et que les mulâtres ne sont qu'une race bâtarde d'un noir et d'une blanche, ou d'un blanc et d'une noire.

Les Albinos sont, à la vérité, une nation très petite et très rare : ils habitent au milieu de l'Afrique ; leur faiblesse ne leur permet guère de s'écarter des cavernes où ils demeurent, cependant les Nègres en attrapent quelquefois, et nous les achetons d'eux par curiosité. J'en ai vu deux, et mille Européans en ont vu. Prétendre que ce sont des Nègres nains, dont une espèce de lèpre a blanchi la peau, c'est comme si l'on disait que les noirs eux-mêmes sont des blancs que la lèpre a noircis. Un Albinos ne ressemble pas plus à un Nègre de Guinée qu'à un Anglais ou à un Espagnol. Leur blancheur n'est pas la nôtre ; rien d'incarnat, nul mélange de blanc et de brun ; c'est une couleur de linge, ou plutôt de cire blanchie ; leurs cheveux, leurs sourcils, sont de la plus belle et de la plus douce soie ; leurs yeux ne ressemblent en rien à ceux des autres hommes, mais ils approchent beaucoup des yeux de perdrix. Ils ressemblent aux Lapons par la taille, à aucune nation par la tête, puisqu'ils ont une autre chevelure, d'autres yeux, d'autres oreilles; et ils n'ont d'homme que la stature du corps, avec la faculté de la parole et de la pensée dans un degré très éloigné du nôtre. Tels sont ceux que j'ai vus et examinés ${ }^{6}$.

Voyez Essai sur les Mœurs, chapitre 141. (B.)

6 Voyez, dans l'Histoire Naturelle de M. de Buffon (supplément, tome IV, page 559, édition du Louvre), la description d'une Négresse blanche amenée en France, et née dans nos îles de père et mère noirs. Au reste, ce dernier fait n'est prouvé que par des certificats dont l'autorité, très respectable dans les tribunaux, l'est très peu en physique. (K.) 
Le tablier que la nature a donné aux Cafres, et dont la peau lâche et molle tombe du nombril sur les cuisses; le mamelon noir des femmes samoyèdes, la barbe des hommes de notre continent, et le menton toujours imberbe des Américains, sont des différences si marquées qu'il n'est guère possible d'imaginer que les uns et les autres ne soient pas des races différentes.

Au reste, si l'on demande d'où sont venus les Américains, il faut aussi demander d'où sont venus les habitants des terres australes; et l'on a déjà répondu que la Providence, qui a mis des hommes dans la Norvège, en a mis aussi en Amérique et sous le cercle polaire méridional, comme elle y a planté des arbres et fait croître de l'herbe ${ }^{7}$.

Plusieurs savants ont soupçonné que quelques races d'hommes, ou d'animaux approchants de l'homme, ont péri ; les Albinos sont en si petit nombre, si faibles, et si maltraités par les Nègres, qu'il est à craindre que cette espèce ne subsiste pas encore longtemps.

Il est parlé de satyres dans presque tous les auteurs anciens. Je ne vois pas que leur existence soit impossible ; on étouffe encore en $\mathrm{Ca}$ labre quelques monstres mis au monde par des femmes. Il n'est pas improbable que dans les pays chauds des singes aient subjugué des filles. Hérodote, au livre II, dit que, pendant son voyage en Égypte, il y eut une femme qui s'accoupla publiquement avec un bouc dans la province de Mendès; et il appelle toute l'Égypte en témoignage. Il est défendu dans le Lévitique, au chapitre XVII, de s'unir avec les boucs et avec les chèvres. Il faut donc que ces accouplements aient été communs ; et jusqu'à ce qu'on soit mieux éclairci, il est à présumer que des espèces monstrueuses ont pu naître de ces amours abominables. Mais si elles ont existé, elles n'ont pu influer sur le genre humain; et, semblables aux mulets, qui n'engendrent point, elles n'ont pu dénaturer les autres races.

À l'égard de la durée de la vie des hommes (si vous faites abstraction de cette ligne de descendants d'Adam consacrée par les livres juifs, et si longtemps inconnue), il est vraisemblable que toutes les races humaines ont joui d'une vie à peu près aussi courte que la nôtre.

Voyez Essai sur les Mours, chapitre 145. (B.) 
Comme les animaux, les arbres, et toutes les productions de la nature, ont toujours eu la même durée, il est ridicule de nous en excepter.

Mais il faut observer que le commerce n'ayant pas toujours apporté au genre humain les productions et les maladies des autres climats, et les hommes ayant été plus robustes et plus laborieux dans la simplicité d'un état champêtre, pour lequel ils sont nés, ils ont dû jouir d'une santé plus égale, et d'une vie un peu plus longue que dans la mollesse, ou dans les travaux malsains des grandes villes; c'est-à-dire que si dans Constantinople, Paris et Londres, un homme, sur cent mille, arrive à cent années, il est probable que vingt hommes, sur cent mille, atteignaient autrefois cet âge. C'est ce qu'on a observé dans plusieurs endroits de l'Amérique, où le genre humain s'était conservé dans l'état de pure nature.

La peste, la petite vérole, que les caravanes arabes communiquèrent avec le temps aux peuples de l'Asie et de l'Europe, furent longtemps inconnues. Ainsi le genre humain, en Asie et dans les beaux climats de l'Europe, se multipliait plus aisément qu'ailleurs. Les maladies d'accident et plusieurs blessures ne se guérissaient pas à la vérité comme aujourd'hui ; mais l'avantage de n'être jamais attaqué de la petite vérole et de la peste compensait tous les dangers attachés à notre nature, de sorte qu'à tout prendre il est à croire que le genre humain, dans les climats favorables, jouissait autrefois d'une vie plus saine et plus heureuse que depuis l'établissement des grands empires. Ce n'est pas à dire que les hommes aient jamais vécu trois ou quatre cents ans : c'est un miracle très respectable dans la Bible ; mais partout ailleurs c'est un conte absurde.

Table des Matières

3.

DE L'ANTIQUITÉ DES NATIONS

Presque tous les peuples, mais surtout ceux de l'Asie, comptent une suite de siècles qui nous effraye. Cette conformité entre eux doit au moins nous faire examiner si leurs idées sur cette antiquité sont destituées de toute vraisemblance. 
Pour qu'une nation soit rassemblée en corps de peuple, qu'elle soit puissante, aguerrie, savante, il est certain qu'il faut un temps prodigieux. Voyez l'Amérique ; on n'y comptait que deux royaumes quand elle fut découverte, et encore, dans ces deux royaumes, on n'avait pas inventé l'art d'écrire. Tout le reste de ce vaste continent était partagé, et l'est encore, en petites sociétés à qui les arts sont inconnus. Toutes ces peuplades vivent sous des huttes; elles se vêtissent de peaux de bêtes dans les climats froids, et vont presque nues dans les tempérés. Les unes se nourrissent de la chasse, les autres de racines qu'elles pétrissent : elles n'ont point recherché un autre genre de vie, parce qu'on ne désire point ce qu'on ne connaît pas. Leur industrie n'a pu aller au delà de leurs besoins pressants. Les Samoyèdes, les Lapons, les habitants du nord de la Sibérie, ceux du Kamtschatka, sont encore moins avancés que les peuples de l'Amérique. La plupart des Nègres, tous les Cafres, sont plongés dans la même stupidité, et y croupiront longtemps.

Il faut un concours de circonstances favorables pendant des siècles pour qu'il se forme une grande société d'hommes rassemblés sous les mêmes lois; il en faut même pour former un langage. Les hommes n'articuleraient pas si on ne leur apprenait à prononcer des paroles ; ils ne jetteraient que des cris confus; ils ne se feraient entendre que par signes. Un enfant ne parle, au bout de quelque temps, que par imitation; et il ne s'énoncerait qu'avec une extrême difficulté si on laissait passer ses premières années sans dénouer sa langue.

Il a fallu peut-être plus de temps pour que des hommes, doués d'un talent singulier, aient formé et enseigné aux autres les premiers rudiments d'un langage imparfait et barbare, qu'il n'en a fallu pour parvenir ensuite à l'établissement de quelque société. Il y a même des nations entières qui n'ont jamais pu parvenir à former un langage régulier et à prononcer distinctement : tels ont été les Troglodytes, au rapport de Pline ; tels sont encore ceux qui habitent vers le cap de BonneEspérance. Mais qu'il y a loin de ce jargon barbare à l'art de peindre ses pensées ! la distance est immense.

Cet état de brutes où le genre humain a été longtemps dut rendre l'espèce très rare dans tous les climats. Les hommes ne pouvaient guère suffire à leurs besoins, et, ne s'entendant pas, ils ne pouvaient se 
secourir. Les bêtes carnassières, ayant plus d'instinct qu'eux, devaient couvrir la terre et dévorer une partie de l'espèce humaine.

Les hommes ne pouvaient se défendre contre les animaux féroces qu'en lançant des pierres, et en s'armant de grosses branches d'arbres ; et de là, peut-être, vint cette notion confuse de l'antiquité que les premiers héros combattaient contre les lions et contre les sangliers avec des massues.

Les pays les plus peuplés furent sans doute les climats chauds, où l'homme trouva une nourriture facile et abondante dans les cocos, les dattes, les ananas, et dans le riz, qui croît de lui-même. Il est bien vraisemblable que l'Inde, la Chine, les bords de l'Euphrate et du Tigre, étaient très peuplés, quand les autres régions étaient presque désertes. Dans nos climats septentrionaux, au contraire, il était beaucoup plus aisé de rencontrer une compagnie de loups qu'une société d'hommes.

Table des Matières

4.

DE LA CONNAISSANCE DE L’ÂME.

Quelle notion tous les premiers peuples auront-ils eue de l'âme ? Celle qu'ont tous nos gens de campagne avant qu'ils aient entendu le catéchisme, ou même après qu'ils l'ont entendu. Ils n'acquièrent qu'une idée confuse, sur laquelle même ils ne réfléchissent jamais. La nature a eu trop de pitié d'eux pour en faire des métaphysiciens; cette nature est toujours et partout la même. Elle fit sentir aux premières sociétés qu'il y avait quelque être supérieur à l'homme, quand elles éprouvaient des fléaux extraordinaires. Elle leur fit sentir de même qu'il est dans l'homme quelque chose qui agit et qui pense. Elles ne distinguaient point cette faculté de celle de la vie; et le mot d'âme signifia toujours la vie chez les anciens, soit Syriens, soit Chaldéens, soit Égyptiens, soit Grecs, soit ceux qui vinrent enfin s'établir dans une partie de la Phénicie.

Par quels degrés put-on parvenir à imaginer dans notre être physique un autre être métaphysique ? Certainement des hommes unique- 
ment occupés de leurs besoins n'en savaient pas assez pour se tromper en philosophes.

Il se forma, dans la suite des temps, des sociétés un peu policées, dans lesquelles un petit nombre d'hommes put avoir le loisir de réfléchir. Il doit être arrivé qu'un homme, sensiblement frappé de la mort de son père, ou de son frère, ou de sa femme, ait vu dans un songe la personne qu'il regrettait. Deux ou trois songes de cette nature auront inquiété tout une peuplade. Voilà un mort qui apparaît à des vivants ; et cependant ce mort, rongé des vers, est toujours en la même place. C'est donc quelque chose qui était en lui, qui se promène dans l'air ; c'est son âme, son ombre, ses mânes ; c'est une légère figure de luimême. Tel est le raisonnement naturel de l'ignorance qui commence à raisonner. Cette opinion est celle de tous les premiers temps connus, et doit avoir été par conséquent celle des temps ignorés. L'idée d'un être purement immatériel n'a pu se présenter à des esprits qui ne connaissaient que la matière. Il a fallu des forgerons, des charpentiers, des maçons, des laboureurs, avant qu'il se trouvât un homme qui eût assez de loisir pour méditer. Tous les arts de la main ont sans doute précédé la métaphysique de plusieurs siècles.

Remarquons, en passant, que dans l'âge moyen de la Grèce, du temps d'Homère, l'âme n'était autre chose qu'une image aérienne du corps. Ulysse voit dans les enfers des ombres, des mânes : pouvait-il voir des esprits purs?

Nous examinerons dans la suite comment les Grecs empruntèrent des Égyptiens l'idée des enfers et de l'apothéose des morts; comment ils crurent, ainsi que d'autres peuples, une seconde vie, sans soupçonner la spiritualité de l'âme. Au contraire, ils ne pouvaient imaginer qu'un être sans corps pût éprouver du bien et du mal. Et je ne sais si Platon n'est pas le premier qui ait parlé d'un être purement spirituel. C'est là, peut-être, un des plus grands efforts de l'intelligence humaine. Encore la spiritualité de Platon est très contestée, et la plupart des pères de l'Église admirent une âme corporelle, tout platoniciens qu'ils étaient. Mais nous n'en sommes pas à ces temps si nouveaux, et nous ne considérons le monde que comme encore informe et à peine dégrossi. 
5.

DE LA RELIGION DES PREMIERS HOMMES

Lorsque, après un grand nombre de siècles quelques sociétés se furent établies, il est à croire qu'il y eut quelque religion, quelque espèce de culte grossier. Les hommes, alors uniquement occupés du soin de soutenir leur vie, ne pouvaient remonter à l'auteur de la vie; ils ne pouvaient connaître ces rapports de toutes les parties de l'univers, ces moyens et ces fins innombrables, qui annoncent aux sages un éternel architecte.

La connaissance d'un dieu, formateur, rémunérateur et vengeur, est le fruit de la raison cultivée.

Tous les peuples furent donc pendant des siècles ce que sont aujourd'hui les habitants de plusieurs côtes méridionales de l'Afrique, ceux de plusieurs îles, et la moitié des Américains. Ces peuples n'ont nulle idée d'un dieu unique, ayant tout fait, présent en tous lieux, existant par lui-même dans l'éternité. On ne doit pas pourtant les nommer athées dans le sens ordinaire, car ils ne nient point l'Être suprême ; ils ne le connaissent pas; ils n'en ont nulle idée. Les Cafres prennent pour protecteur un insecte, les Nègres un serpent. Chez les Américains, les uns adorent la lune, les autres un arbre ; plusieurs n'ont absolument aucun culte.

Les Péruviens, étant policés, adoraient le soleil : ou Manco-Capac leur avait fait accroire qu'il était le fils de cet astre, ou leur raison commencée leur avait dit qu'ils devaient quelque reconnaissance à l'astre qui anime la nature.

Pour savoir comment tous ces cultes ou ces superstitions s'établirent, il me semble qu'il faut suivre la marche de l'esprit humain abandonné à lui-même. Une bourgade d'hommes presque sauvages voit périr les fruits qui la nourrissent; une inondation détruit quelques cabanes; le tonnerre en brûle quelques autres. Qui leur a fait 
ce mal ? ce ne peut être un de leurs concitoyens, car tous ont également souffert : c'est donc quelque puissance secrète ; elle les a maltraités, il faut donc l'apaiser. Comment en venir à bout? en la servant comme on sert ceux à qui on veut plaire, en lui faisant de petits présents. Il y a un serpent dans le voisinage, ce pourrait bien être ce serpent : on lui offrira du lait près de la caverne où il se retire ; il devient sacré dès lors; on l'invoque quand on a la guerre contre la bourgade voisine, qui, de son côté, a choisi un autre protecteur.

D'autres petites peuplades se trouvent dans le même cas. Mais, n'ayant chez elles aucun objet qui fixe leur crainte et leur adoration, elles appelleront en général l'être qu'elles soupçonnent leur avoir fait du mal, le Maître, le Seigneur, le Chef, le Dominant.

Cette idée, étant plus conforme que les autres à la raison commencée, qui s'accroît et se fortifie avec le temps, demeure dans toutes les têtes quand la nation est devenue plus nombreuse. Aussi voyons-nous que beaucoup de nations n'ont eu d'autre dieu que le maître, le seigneur. C'était Adonaï chez les Phéniciens ; Baal, Melkom, Adad, Sadaï, chez les peuples de Syrie. Tous ces noms ne signifient que le Seigneur, le Puissant.

Chaque État eut donc, avec le temps, sa divinité tutélaire, sans savoir seulement ce que c'est qu'un dieu, et sans pouvoir imaginer que l'État voisin n'eut pas, comme lui, un protecteur véritable. Car comment penser, lorsqu'on avait un seigneur, que les autres n'en eussent pas aussi ? Il s'agissait seulement de savoir lequel de tant de maîtres, de seigneurs, de dieux, l'emporterait, quand les nations combattraient les unes contre les autres.

Ce fut là sans doute l'origine de cette opinion, si généralement et si longtemps répandue, que chaque peuple était réellement protégé par la divinité qu'il avait choisie. Cette idée fut tellement enracinée chez les hommes que, dans des temps très postérieurs, vous voyez Homère faire combattre les dieux de Troie contre les dieux des Grecs, sans laisser soupçonner en aucun endroit que ce soit une chose extraordinaire et nouvelle. Vous voyez Jephté, chez les Juifs, qui dit aux Ammonites : «Ne possédez-vous pas de droit ce que votre seigneur Chamos vous a donné ? Souffrez donc que nous possédions la terre que notre seigneur Adonaï nous a promise. » 
Il y a un autre passage non moins fort ; c'est celui de Jérémie, chapitre XLIX, verset I, où il est dit: "Quelle raison a eue le seigneur Melkom pour s'emparer du pays de Gad? " Il est clair, par ces expressions, que les Juifs, quoique serviteurs d'Adonaï, reconnaissaient pourtant le seigneur Melkom et le seigneur Chamos.

Dans le premier chapitre des Juges, vous trouverez que « le dieu de Juda se rendit maitre des montagnes, mais qu'il ne put vaincre dans les vallées. » Et au troisième livre des Rois, vous trouvez chez les Syriens l'opinion établie que le dieu des Juifs n'était que le dieu des montagnes.

Il y a bien plus. Rien ne fut plus commun que d'adopter les dieux étrangers. Les Grecs reconnurent ceux des Égyptiens je ne dis pas le bœuf Apis, et le chien Anubis; mais Ammon, et les douze grands dieux. Les Romains adorèrent tous les dieux des Grecs. Jérémie, Amos, et saint Étienne, nous assurent que dans le désert, pendant quarante années, les Juifs ne reconnurent que Moloch, Remphan, ou Kium $^{8}$; qu'ils ne firent aucun sacrifice, ne présentèrent aucune offrande au dieu Adonaï, qu'ils adorèrent depuis. Il est vrai que le Pentateuque ne parle que du veau d'or, dont aucun prophète ne fait mention ; mais ce n'est pas ici le lieu d'éclaircir cette grande difficulté il suffit de révérer également Moïse, Jérémie, Amos, et saint Étienne, qui semblent se contredire, et que les théologiens concilient.

Ce que j'observe seulement, c'est qu'excepté ces temps de guerre et de fanatisme sanguinaire qui éteignent toute humanité, et qui rendent les mœurs, les lois, la religion d'un peuple, l'objet de l'horreur d'un autre peuple, toutes les nations trouvèrent très bon que leurs voisins eussent leurs dieux particuliers, et qu'elles imitèrent souvent le culte et les cérémonies des étrangers.

8 Ou Réphan, ou Chevan, ou Kium, ou Chion etc. Amos, ch. V, 26 ; act. VII, 43. « si l'on ne savait, à n'en pouvoir douter que les Hébreux ont adoré les idoles dans le désert, non pas une seule fois, mais habituellement et d'une manière persévérante, on aurait peine à se le persuader... C'est cependant ce qui est incontestable, d'après le témoignage exprès d'Amos, qui reproche aux Israëlites d'avoir porté dans leur voyage du désert la tente du dieu Moloch, l'image de leurs idoles, et l'étoile de leur dieu Remphan. " Bible de Vence, Dissertation sur l'idolâtrie des Israëlites, à la tête des Prophéties d'Amos. (K.) 
Les Juifs mêmes, malgré leur horreur pour le reste des hommes, qui s'accrut avec le temps, imitèrent la circoncision des Arabes et des Égyptiens, s'attachèrent, comme ces derniers, à la distinction des viandes, prirent d'eux les ablutions, les processions, les danses sacrées, le bouc Hazazel, la vache rousse. Ils adorèrent souvent le Baal, le Belphégor de leurs autres voisins : tant la nature et la coutume l'emportent presque toujours sur la loi, surtout quand cette loi n'est pas généralement connue du peuple. Ainsi Jacob, petit-fils d'Abraham, ne fit nulle difficulté d'épouser deux sœurs, qui étaient ce que nous appelons idolâtres, et filles d'un père idolâtre. Moïse même épousa la fille d'un prêtre madianite idolâtre. Abraham était fils d'un idolâtre. Le petit-fils de Moïse, Éléazar, fut prêtre idolâtre de la tribu de Dan, idolâtre.

Ces mêmes Juifs, qui, longtemps après, crièrent tant contre les cultes étrangers, appelèrent dans leurs livres sacrés l'idolâtre Nabuchodonosor 1'oint du Seigneur ; l'idolâtre Cyrus, aussi l'oint du Seigneur. Un de leurs prophètes fut envoyé à l'idolâtre Ninive, Élisée permit à l'idolâtre Naaman d'aller dans le temple de Remnon. Mais n'anticipons rien; nous savons assez que les hommes se contredisent toujours dans leurs mœurs et dans leurs lois. Ne sortons point ici du sujet que nous traitons; continuons à voir comment les religions diverses s'établirent.

Les peuples les plus policés de l'Asie, en deçà de l'Euphrate, adorèrent les astres. Les Chaldéens, avant le premier Zoroastre, rendaient hommage au soleil, comme firent depuis les Péruviens dans un autre hémisphère. Il faut que cette erreur soit bien naturelle à l'homme, puisqu'elle a eu tant de sectateurs dans l'Asie et dans l'Amérique. Une nation petite et à demi sauvage n'a qu'un protecteur. Devient-elle plus nombreuse, elle augmente le nombre de ses dieux. Les Égyptiens commencent par adorer Isheth, ou Isis, et ils finissent par adorer des chats. Les premiers hommages des Romains agrestes sont pour Mars ; ceux des Romains maîtres de l'Europe sont pour la déesse de l'acte du mariage, pour le dieu des latrines ${ }^{9}$. Et cependant Cicéron, et tous les philosophes, et tous les initiés, reconnaissaient un dieu suprême et tout-puissant. Ils étaient tous revenus, par la raison, au point dont les hommes sauvages étaient partis par instinct.

Dea Pertunda, Deus Stercutius. (V.) 
Les apothéoses ne peuvent avoir été imaginées que très longtemps après les premiers cultes. Il n'est pas naturel de faire d'abord un dieu d'un homme que nous avons vu naître comme nous, souffrir comme nous les maladies, les chagrins, les misères de l'humanité, subir les mêmes besoins humiliants, mourir et devenir la pâture des vers. Mais voici ce qui arriva chez presque toutes les nations, après les révolutions de plusieurs siècles.

Un homme qui avait fait de grandes choses, qui avait rendu des services au genre humain, ne pouvait être, à la vérité, regardé comme un dieu par ceux qui l'avaient vu trembler de la fièvre, et aller à la garde-robe ; mais les enthousiastes se persuadèrent qu'ayant des qualités éminentes, il les tenait d'un dieu ; qu'il était fils d'un dieu : ainsi les dieux firent des enfants dans tout le monde ; car, sans compter les rêveries de tant de peuples qui précédèrent les Grecs, Bacchus, Persée, Hercule, Castor, Pollux, furent fils de dieu; Romulus, fils de dieu; Alexandre fut déclaré fils de dieu en Égypte; un certain Odin, chez nos nations du nord, fils de dieu ; Manco-Capac, fils du Soleil au Pérou. L'historien des Mogols, Abulcazi, rapporte qu'une des aïeules de Gengis, nommée Alanku, étant fille, fut grosse d'un rayon céleste. Gengis lui-même passa pour le fils de dieu; et lorsque le pape Innocent IV envoya frère Ascelin à Batou-kan, petit-fils de Gengis, ce moine, ne pouvant être présenté qu'à l'un des vizirs, lui dit qu'il venait de la part du vicaire de Dieu : le ministre répondit: Ce vicaire ignore-t-il qu'il doit des hommages et des tributs au fils de Dieu, le grand Batou-kan, son maître ?

D'un fils de dieu à un dieu il n'y a pas loin chez les hommes amoureux du merveilleux. Il ne faut que deux ou trois générations pour faire partager au fils le domaine de son père ; ainsi des temples furent élevés, avec le temps, à tous ceux qu'on avait supposés être nés du commerce surnaturel de la divinité avec nos femmes et avec nos filles.

On pourrait faire des volumes sur ce sujet; mais tous ces volumes se réduisent à deux mots : c'est que le gros du genre humain a été et sera très longtemps insensé et imbécile ; et que peut-être les plus insensés de tous ont été ceux qui ont voulu trouver un sens à ces fables absurdes, et mettre de la raison dans la folie. 
6.

DES USAGES ET DES SENTIMENTS COMMUNS À PRESQUE TOUTES LES NATIONS ANCIENNES

La nature étant partout la même, les hommes ont dû nécessairement adopter les mêmes vérités et les mêmes erreurs dans les choses qui tombent le plus sous le sens et qui frappent le plus l'imagination. Ils ont dû tous attribuer le fracas et les effets du tonnerre au pouvoir d'un être supérieur habitant dans les airs. Les peuples voisins de l'Océan, voyant les grandes marées inonder leurs rivages à la pleine lune, ont dû croire que la lune était cause de tout ce qui arrivait au monde dans le temps de ses différentes phases.

Dans leurs cérémonies religieuses, presque tous se tournèrent vers l'orient, ne songeant pas qu'il n'y a ni orient ni occident, et rendant tous une espèce d'hommage au soleil qui se levait à leurs yeux.

Parmi les animaux, le serpent dut leur paraître doué d'une intelligence supérieure, parce que, voyant muer quelquefois sa peau, ils durent croire qu'il rajeunissait. Il pouvait donc, en changeant de peau, se maintenir toujours dans sa jeunesse ; il était donc immortel. Aussi futil, en Égypte, en Grèce, le symbole de l'immortalité. Les gros serpents qui se trouvaient auprès des fontaines empêchaient les hommes timides d'en approcher: on pensa bientôt qu'ils gardaient des trésors. Ainsi un serpent gardait les pommes d'or hespérides ; un autre veillait autour de la toison d'or; et dans les mystères de Bacchus, on portait l'image d'un serpent qui semblait garder une grappe d'or.

Le serpent passait donc pour le plus habile des animaux; et de là cette ancienne fable indienne que Dieu, ayant créé l'homme, lui donna une drogue qui lui assurait une vie saine et longue; que l'homme chargea son âne de ce présent divin, mais qu'en chemin, l'âne ayant eu soif, le serpent lui enseigna une fontaine, et prit la drogue pour lui tandis que l'âne buvait; de sorte que l'homme perdit l'immortalité par 
sa négligence, et le serpent l'acquit par son adresse. De là enfin tant de contes d'ânes et de serpents.

Ces serpents faisaient du mal; mais comme ils avaient quelque chose de divin, il n'y avait qu'un dieu qui eut pu enseigner à les détruire. Ainsi le serpent Python fut tué par Apollon. Ainsi Ophionée, le grand serpent, fit la guerre aux dieux longtemps avant que les Grecs eussent forgé leur Apollon. Un fragment de Phérécide prouve que cette fable du grand serpent, ennemi des dieux, était une des plus anciennes de la Phénicie. Et cent siècles avant Phérécide, les premiers brachmanes avaient imaginé que Dieu envoya un jour sur la terre une grosse couleuvre qui engendra dix mille couleuvres, lesquelles furent autant de péchés dans le cœur des hommes.

Nous avons déjà vu ${ }^{10}$ que les songes, les rêves, durent introduire la même superstition dans toute la terre. Je suis inquiet, pendant la veille, de la santé de ma femme, de mon fils; je les vois mourants pendant mon sommeil ; ils meurent quelques jours après : il n'est pas douteux que les dieux ne m'aient envoyé ce songe véritable. Mon rêve n'a-t-il pas été accompli, c'est un rêve trompeur que les dieux m'ont député. Ainsi, dans Homère, Jupiter envoie un songe trompeur à Agamemnon, chef des Grecs. Ainsi (au troisième livre des Rois, chap. XXII), le dieu qui conduit les Juifs envoie un esprit malin pour mentir dans la bouche des prophètes, et pour tromper le roi Achab.

Tous les songes vrais ou faux viennent du ciel; les oracles s'établissent de même par toute la terre.

Une femme vient demander à des mages si son mari mourra dans l'année. L'un lui répond oui, l'autre non : il est bien certain que l'un d'eux aura raison. Si le mari vit, la femme garde le silence ; s'il meurt, elle crie par toute la ville que le mage qui a prédit cette mort est un prophète divin. Il se trouve bientôt dans tous les pays des hommes qui prédisent l'avenir, et qui découvrent les choses les plus cachées. Ces hommes s'appellent les voyants chez les Égyptiens, comme dit Manéthon, au rapport même de Josèphe, dans son Discours contre Apion.

Il y avait des voyants en Chaldée, en Syrie. Chaque temple eut ses oracles. Ceux d'Apollon obtinrent un si grand crédit que Rollin, dans

10 Paragraphe V. (B.) 
son Histoire ancienne, répète les oracles rendus par Apollon à Crésus. Le dieu devine que le roi fait cuire une tortue dans une tourtière de cuivre, et lui répond que son règne finira quand un mulet sera sur le trône des Perses. Rollin n'examine point si ces prédictions, dignes de Nostradamus, ont été faites après coup; il ne doute pas de la science des prêtres d'Apollon, et il croit que Dieu permettait qu'Apollon dit vrai : c'était apparemment pour confirmer les païens dans leur religion.

Une question plus philosophique, dans laquelle toutes les grandes nations policées, depuis l'Inde jusqu'à la Grèce, se sont accordées, c'est l'origine du bien et du mal.

Les premiers théologiens de toutes les nations durent se faire la question que nous faisons tous dès l'âge de quinze ans : Pourquoi y at-il du mal sur la terre?

On enseigna dans l'Inde qu'Adimo, fils de Brama ${ }^{11}$, produisit les hommes justes par le nombril, du côté droit, et les injustes du côté gauche; et que c'est de ce côté gauche que vint le mal moral et le mal physique. Les Égyptiens eurent leur Typhon, qui fut l'ennemi d'Osiris. Les Persans imaginèrent qu'Ariman perça l'œuf qu'avait pondu Oromase, et y fit entrer le péché. On connaît la Pandore des Grecs : c'est la plus belle de toutes les allégories que l'antiquité nous ait transmises.

L'allégorie de Job fut certainement écrite en arabe, puisque les traductions hébraïque et grecque ont conservé plusieurs termes arabes. Ce livre, qui est d'une très haute antiquité, représente le Satan, qui est 1'Ariman des Perses et le Typhon des Égyptiens, se promenant dans toute la terre, et demandant permission au Seigneur d'affliger Job. Satan paraît subordonné au Seigneur; mais il résulte que Satan est un être très puissant, capable d'envoyer sur la terre des maladies, et de tuer les animaux.

Il se trouva, au fond, que tant de peuples, sans le savoir, étaient d'accord sur la croyance de deux principes, et que l'univers alors connu était en quelque sorte manichéen. 
Tous les peuples durent admettre les expiations; car où était l'homme qui n'eut pas commis de grandes fautes contre la société ? et où était l'homme à qui l'instinct de sa raison ne fit pas sentir des remords ? L'eau lavait les souillures du corps et des vêtements, le feu purifiait les métaux ; il fallait bien que l'eau et le feu purifiassent les âmes. Aussi n'y eut-il aucun temple sans eaux et sans feux salutaires.

Les hommes se plongèrent dans le Gange, dans l'Indus, dans l'Euphrate, au renouvellement de la lune et dans les éclipses. Cette immersion expiait les péchés. Si on ne se purifiait pas dans le Nil, c'est que les crocodiles auraient dévoré les pénitents. Mais les prêtres, qui se purifiaient pour le peuple, se plongeaient dans de larges cuves, et y baignaient les criminels qui venaient demander pardon aux dieux.

Les Grecs, dans tous leurs temples, eurent des bains sacrés, comme des feux sacrés, symboles universels, chez tous les hommes, de la pureté des âmes. Enfin les superstitions paraissent établies chez toutes les nations, excepté chez les lettrés de la Chine.

Table des Matières

7.

DES SAUVAGES

Entendez-vous par sauvages des rustres vivant dans des cabanes avec leurs femelles et quelques animaux, exposés sans cesse à toute l'intempérie des saisons ; ne connaissant que la terre qui les nourrit, et le marché où ils vont quelquefois vendre leurs denrées pour y acheter quelques habillements grossiers ; parlant un jargon qu'on n'entend pas dans les villes; ayant peu d'idées, et par conséquent peu d'expressions; soumis, sans qu'ils sachent pourquoi, à un homme de plume, auquel ils portent tous les ans la moitié de ce qu'ils ont gagné à la sueur de leur front ; se rassemblant, certains jours, dans une espèce de grange pour célébrer des cérémonies où ils ne comprennent rien, écoutant un homme vêtu autrement qu'eux et qu'ils n'entendent point ; quittant quelquefois leur chaumière lorsqu'on bat le tambour, et s'engageant à s'aller faire tuer dans une terre étrangère, et à tuer leurs semblables, pour le quart de ce qu'ils peuvent gagner chez eux 
en travaillant? Il y a de ces sauvages-là dans toute 1'Europe. Il faut convenir surtout que les peuples du Canada et les Cafres, qu'il nous a plu d'appeler sauvages, sont infiniment supérieurs aux nôtres. Le Huron, l'Algonquin, l'Illinois, le Cafre, le Hottentot, ont l'art de fabriquer eux-mêmes tout ce dont ils ont besoin, et cet art manque à nos rustres. Les peuplades d'Amérique et d'Afrique sont libres, et nos sauvages n'ont pas même d'idée de la liberté.

Les prétendus sauvages d'Amérique sont des souverains qui reçoivent des ambassadeurs de nos colonies transplantées auprès de leur territoire par l'avarice et par la légèreté. Ils connaissent l'honneur, dont jamais nos sauvages d'Europe n'ont entendu parler. Ils ont une patrie, ils l'aiment, ils la défendent; ils font des traités ; ils se battent avec courage, et parlent souvent avec une énergie héroïque. Y a-t-il une plus belle réponse, dans les Grands Hommes de Plutarque, que celle de ce chef de Canadiens à qui une nation européenne proposait de lui céder son patrimoine? «Nous sommes nés sur cette terre, nos pères y sont ensevelis ; dirons-nous aux ossements de nos pères : Levez-vous, et venez avec nous dans une terre étrangère ?»

Ces Canadiens étaient des Spartiates, en comparaison de nos rustres qui végètent dans nos villages, et des sybarites qui s'énervent dans nos villes.

Entendez-vous par sauvages des animaux à deux pieds, marchant sur les mains dans le besoin, isolés, errant dans les forêts, Salvatici, Selvaggi; s'accouplant à l'aventure, oubliant les femmes auxquelles ils se sont joints, ne connaissant ni leurs fils ni leurs pères ; vivant en brutes, sans avoir ni l'instinct ni les ressources des brutes? On a écrit que cet état est le véritable état de l'homme, et que nous n'avons fait que dégénérer misérablement depuis que nous l'avons quitté. Je ne crois pas que cette vie solitaire, attribuée à nos pères, soit dans la nature humaine.

Nous sommes, si je ne me trompe, au premier rang (s'il est permis de le dire) des animaux qui vivent en troupe, comme les abeilles, les fourmis, les castors, les oies, les poules, les moutons, etc. Si l'on rencontre une abeille errante, devra-t-on conclure que cette abeille est dans l'état de pure nature, et que celles qui travaillent en société dans la ruche ont dégénéré? 
Tout animal n'a-t-il pas son instinct irrésistible auquel il obéit nécessairement? Qu'est-ce que cet instinct ? l'arrangement des organes dont le jeu se déploie par le temps. Cet instinct ne peut se développer d'abord, parce que les organes n'ont pas acquis leur plénitude ${ }^{12}$.

Ne voyons-nous pas en effet que tous les animaux, ainsi que tous les autres êtres, exécutent invariablement la loi que la nature donne à leur espèce ? L'oiseau fait son nid, comme les astres fournissent leur course, par un principe qui ne change jamais. Comment l'homme seul aurait-il changé ? S'il eût été destiné à vivre solitaire comme les autres animaux carnassiers, aurait-il pu contredire la loi de la nature jusqu'à vivre en société ? et s'il était fait pour vivre en troupe, comme les animaux de basse-cour et tant d'autres, eut-il pu d'abord pervertir sa destinée jusqu'à vivre pendant des siècles en solitaire ? Il est perfectible ; et de là on a conclu qu'il s'est perverti. Mais pourquoi n'en pas conclure qu'il s'est perfectionné jusqu'au point où la nature a marqué les limites de sa perfection?

Tous les hommes vivent en société : peut-on en inférer qu'ils n'y ont pas vécu autrefois? n'est-ce pas comme si l'on concluait que si les taureaux ont aujourd'hui des cornes, c'est parce qu'ils n'en ont pas toujours eu?

L'homme, en général, a toujours été ce qu'il est : cela ne veut pas dire qu'il ait toujours eu de belles villes, du canon de vingt-quatre livres de balle, des opéras-comiques, et des couvents de religieuses. Mais il a toujours eu le même instinct, qui le porte à s'aimer dans soi-

12 Leur pouvoir est constant, leur principe est divin;

Il faut que l'enfant croisse avant qu'il les exerce ;

Il ne les connaît pas sous la main qui le berce.

Le moineau, dans l'instant qu'il a reçu le jour,

Sans plumes dans son nid, peut-il sentir l'amour?

Le renard en naissant va-t-il chercher sa proie ?

Les insectes changeants qui nous filent la soie,

Les essaims bourdonnants de ces filles du ciel

Qui pétrissent la cire et composent le miel,

Sitôt qu'ils sont éclos forment-ils leur ouvrage ?

Tout s'accroît par le temps, tout mûrit avec l'âge.

Chaque être a son objet ; et, dans l'instant marqué,

Marche, et touche à son but par le ciel indiqué

Poème de la loi naturelle, $\mathrm{II}^{\mathrm{e}}$ partie. (V.) 
même, dans la compagne de son plaisir, dans ses enfants, dans ses petits-fils, dans les œuvres de ses mains.

Voilà ce qui jamais ne change d'un bout de l'univers à l'autre. Le fondement de la société existant toujours, il y a donc toujours eu quelque société ; nous n'étions donc point faits pour vivre à la manière des ours.

On a trouvé quelquefois des enfants égarés dans les bois, et vivant comme des brutes ; mais on y a trouvé aussi des moutons et des oies ; cela n'empêche pas que les oies et les moutons ne soient destinés à vivre en troupeaux.

Il y a des faquirs dans les Indes qui vivent seuls, chargés de chaînes. Oui ; et ils ne vivent ainsi qu'afin que les passants, qui les admirent, viennent leur donner des aumônes. Ils font, par un fanatisme rempli de vanité, ce que font nos mendiants des grands chemins, qui s'estropient pour attirer la compassion. Ces excréments de la société humaine sont seulement des preuves de l'abus qu'on peut faire de cette société.

Il est très vraisemblable que l'homme a été agreste pendant des milliers de siècles, comme sont encore aujourd'hui une infinité de paysans. Mais l'homme n'a pu vivre comme les blaireaux et les lièvres.

Par quelle loi, par quels liens secrets, par quel instinct l'homme aura-t-il toujours vécu en famille sans le secours des arts, et sans avoir encore formé un langage ? C'est par sa propre nature, par le goût qui le porte à s'unir avec une femme ; c'est par l'attachement qu'un Morlaque, un Islandais, un Lapon, un Hottentot, sent pour sa compagne, lorsque son ventre, grossissant, lui donne l'espérance de voir naître de son sang un être semblable à lui ; c'est par le besoin que cet homme et cette femme ont l'un de l'autre, par l'amour que la nature leur inspire pour leur petit, dès qu'il est né, par l'autorité que la nature leur donne sur ce petit, par l'habitude de l'aimer, par l'habitude que le petit prend nécessairement d'obéir au père et à la mère, par les secours qu'ils en reçoivent dès qu'il a cinq ou six ans, par les nouveaux enfants que font cet homme et cette femme ; c'est enfin parce que, dans un âge avancé, ils voient avec plaisir leurs fils et leurs filles faire ensemble 
d'autres enfants, qui ont le même instinct que leurs pères et leurs mères.

Tout cela est un assemblage d'hommes bien grossiers, je l'avoue ; mais croit-on que les charbonniers des forêts d'Allemagne, les habitants du Nord, et cent peuples de l'Afrique, vivent aujourd'hui d'une manière bien différente?

Quelle langue parleront ces familles sauvages et barbares? elles seront sans doute très longtemps sans en parler aucune; elles s'entendront très bien par des cris et par des gestes. Toutes les nations ont été ainsi des sauvages, à prendre ce mot dans ce sens ; c'est-à-dire qu'il y aura eu longtemps des familles errantes dans les forêts, disputant leur nourriture aux autres animaux, s'armant contre eux de pierres et de grosses branches d'arbres, se nourrissant de légumes sauvages, de fruits de toute espèce, et enfin d'animaux même.

Il y a dans l'homme un instinct de mécanique que nous voyons produire tous les jours de très grands effets dans des hommes fort grossiers. On voit des machines inventées par les habitants des montagnes du Tyrol et des Vosges, qui étonnent les savants. Le paysan le plus ignorant sait partout remuer les plus gros fardeaux par le secours du levier, sans se douter que la puissance faisant équilibre est au poids comme la distance du point d'appui à ce poids est à la distance de ce même point d'appui à la puissance. S'il avait fallu que cette connaissance précédât l'usage des leviers, que de siècles se seraient écoulés avant qu'on eût pu déranger une grosse pierre de sa place !

Proposez à des enfants de sauter un fossé ; tous prendront machinalement leur secousse, en se retirant un peu en arrière, et courront ensuite. Ils ne savent pas assurément que leur force, en ce cas, est le produit de leur masse multipliée par leur vitesse.

Il est donc prouvé que la nature seule nous inspire des idées utiles qui précèdent toutes nos réflexions. Il en est de même dans la morale. Nous avons tous deux sentiments qui sont le fondement de la société : la commisération et la justice. Qu'un enfant voie déchirer son semblable, il éprouvera des angoisses subites; il les témoignera par ses cris et par ses larmes ; il secourra, s'il peut, celui qui souffre. 
Demandez à un enfant sans éducation, qui commencera à raisonner et à parler, si le grain qu'un homme a semé dans son champ lui appartient, et si le voleur qui en a tué le propriétaire a un droit légitime sur ce grain ; vous verrez si l'enfant ne répondra pas comme tous les législateurs de la terre.

Dieu nous a donné un principe de raison universelle, comme il a donné des plumes aux oiseaux et la fourrure aux ours; et ce principe est si constant qu'il subsiste malgré toutes les passions qui le combattent, malgré les tyrans qui veulent le noyer dans le sang, malgré les imposteurs qui veulent l'anéantir dans la superstition. C'est ce qui fait que le peuple le plus grossier juge toujours très bien, à la longue, des lois qui le gouvernent, parce qu'il sent si ces lois sont conformes ou opposées aux principes de commisération et de justice qui sont dans son cœur.

Mais, avant d'en venir à former une société nombreuse, un peuple, une nation, il faut un langage ; et c'est le plus difficile. Sans le don de l'imitation, on n'y serait jamais parvenu. On aura sans doute commencé par des cris qui auront exprimé les premiers besoins; ensuite les hommes les plus ingénieux, nés avec les organes les plus flexibles, auront formé quelques articulations que leurs enfants auront répétées ; et les mères surtout auront dénoué leurs langues les premières. Tout idiome commençant aura été composé de monosyllabes, comme plus aisés à former et à retenir.

Nous voyons en effet que les nations les plus anciennes, qui ont conservé quelque chose de leur premier langage, expriment encore par des monosyllabes les choses les plus familières et qui tombent le plus sous nos sens : presque tout le chinois est fondé encore aujourd'hui sur des monosyllabes.

Consultez l'ancien tudesque et tous les idiomes du Nord, vous verrez à peine une chose nécessaire et commune exprimée par plus d'une articulation. Tout est monosyllabes. Zon, le soleil ; moun, la lune ; zé, la mer ; flus, le fleuve ; man, l'homme ; kof, la tête ; boum, un arbre ; drink, boire ; march, marcher ; shlaf, dormir, etc.

C'est avec cette brièveté qu'on s'exprimait dans les forêts des Gaules et de la Germanie, et dans tout le septentrion. Les Grecs et les Ro- 
mains n'eurent des mots plus composés que longtemps après s'être réunis en corps de peuple.

Mais par quelle sagacité avons-nous pu marquer les différences des temps ? Comment aurons-nous pu exprimer les nuances je voudrais, j'aurais voulu; les choses positives, les choses conditionnelles?

Ce ne peut être que chez les nations déjà les plus policées qu'on soit parvenu, avec le temps, à rendre sensibles, par des mots composés, ces opérations secrètes de l'esprit humain. Aussi voit-on que chez les barbares il n'y a que deux ou trois temps. Les Hébreux n'exprimaient que le présent et le futur. La langue franque, si commune dans les échelles du Levant, est réduite encore à cette indigence. Et enfin, malgré tous les efforts des hommes, il n'est aucun langage qui approche de la perfection.

Table des Matières

8.

DE L'AMÉRIQUE

Se peut-il qu'on demande encore d'où sont venus les hommes qui ont peuplé l'Amérique ? On doit assurément faire la même question sur les nations des terres australes. Elles sont beaucoup plus éloignées du port dont partit Christophe Colomb que ne le sont les îles Antilles. On a trouvé des hommes et des animaux partout où la terre est habitable : qui les y a mis ? On l'a déjà dit ${ }^{13}$, c'est celui qui fait croître l'herbe des champs : et on ne devait pas être plus surpris de trouver en Amérique des hommes que des mouches.

Il est assez plaisant que le jésuite Lafitau prétende, dans sa préface de l'Histoire des Sauvages américains, qu'il n'y a que des athées qui puissent dire que Dieu a créé les Américains.

On grave encore aujourd'hui des cartes de l'ancien monde où l'Amérique paraît sons le nom d'île Atlantique. Les îles du Cap-Vert y sont sous le nom de Gorgades ; les Caraïbes sous celui d'îles Hespéri-

Essai sur les Mours, chapitres 45 et 46. (B.) 
des. Tout cela n'est pourtant fondé que sur l'ancienne découverte des îles Canaries, et probablement de celle de Madère, où les Phéniciens et les Carthaginois voyagèrent; elles touchent presque à l'Afrique, et peut-être en étaient-elles moins éloignées dans les anciens temps qu'aujourd'hui.

Laissons le père Lafitau faire venir les Caraïbes des peuples de $\mathrm{Ca}$ rie, à cause de la conformité du nom, et surtout parce que les femmes caraïbes faisaient la cuisine de leurs maris ainsi que les femmes cariennes ; laissons-le supposer que les Caraïbes ne naissent rouges, et les Négresses noires, qu'à cause de l'habitude de leurs premiers pères de se peindre en noir ou en rouge.

Il arriva, dit-il, que les Négresses, voyant leurs maris teints en noir, en eurent l'imagination si frappée que leur race s'en ressentit pour jamais. La même chose arriva aux femmes caraïbes, qui, par la même force d'imagination, accouchèrent d'enfants rouges. Il rapporte l'exemple des brebis de Jacob, qui naquirent bigarrées par l'adresse qu'avait eue ce patriarche de mettre devant leurs yeux des branches dont la moitié était écorcée; ces branches, paraissant à peu près de deux couleurs, donnèrent aussi deux couleurs aux agneaux du patriarche. Mais le jésuite devait savoir que tout ce qui arrivait du temps de Jacob n'arrive plus aujourd'hui.

Si l'on avait demandé au gendre de Laban pourquoi ses brebis, voyant toujours de l'herbe, ne faisaient pas des agneaux verts, il aurait été bien embarrassé.

Enfin Lafitau fait venir les Américains des anciens Grecs ; et voici ses raisons. Les Grecs avaient des fables, quelques Américains en ont aussi. Les premiers Grecs allaient à la chasse, les Américains y vont. Les premiers Grecs avaient des oracles, les Américains ont des sorciers. On dansait dans les fêtes de la Grèce, on danse en Amérique. Il faut avouer que ces raisons sont convaincantes.

On peut faire, sur les nations du nouveau monde, une réflexion que le père Lafitau n'a point faite : c'est que les peuples éloignés des tropiques ont toujours été invincibles, et que les peuples plus rapprochés des tropiques ont presque tous été soumis à des monarques. Il en fut longtemps de même dans notre continent. Mais on ne voit point que les peuples du Canada soient allés jamais subjuguer le Mexique, 
comme les Tartares se sont répandus dans l'Asie et dans l'Europe. Il parait que les Canadiens ne furent jamais en assez grand nombre pour envoyer ailleurs des colonies.

En général, l'Amérique n'a jamais pu être aussi peuplée que l'Europe et l'Asie ; elle est couverte de marécages immenses qui rendent l'air très malsain; la terre y produit un nombre prodigieux de poisons ; les flèches trempées dans les sucs de ces herbes venimeuses font des plaies toujours mortelles. La nature enfin avait donné aux Américains beaucoup moins d'industrie qu'aux hommes de l'ancien monde. Toutes ces causes ensemble ont pu nuire beaucoup à la population.

Parmi toutes les observations physiques qu'on peut faire sur cette quatrième partie de notre univers, si longtemps inconnue, la plus singulière peut-être, c'est qu'on n'y trouve qu'un peuple qui ait de la barbe : ce sont les Esquimaux. Ils habitent au nord vers le cinquantedeuxième degré, où le froid est plus vif qu'au soixante et sixième de notre continent. Leurs voisins sont imberbes. Voilà donc deux races d'hommes absolument différentes à côté l'une de l'autre, supposé qu'en effet les Esquimaux soient barbus. Mais de nouveaux voyageurs disent que les Esquimaux sont imberbes, que nous avons pris leurs cheveux crasseux pour de la barbe. À qui croire ${ }^{14}$ ?

Vers l'isthme de Panama est la race des Dariens, presque semblable aux Albinos, qui fuit la lumière et qui végète dans les cavernes, race faible, et par conséquent en très petit nombre.

Les lions de l'Amérique sont chétifs et poltrons ; les animaux qui ont de la laine y sont grands, et si vigoureux qu'ils servent à porter les fardeaux. Tous les fleuves y sont dix fois au moins plus larges que les nôtres. Enfin les productions naturelles de cette terre ne sont pas celles de notre hémisphère. Ainsi tout est varié ; et la même providence qui a

14 Il paraît qu'il existe réellement en Amérique une petite peuplade d'hommes barbus. Mais les Islandais avaient navigué en Amérique longtemps avant Christophe Colomb, et il est possible que cette peuplade d'hommes barbus soit un reste de ces navigateurs européens.

Carver, qui a voyagé dans le nord de l'Amérique pendant les années 1766, 1767,1768 , prétend, dans son ouvrage imprimé en 1778, que les sauvages de 1'Amérique ne sont imberbes que parce qu'ils s'épilent. Voyez Carver's Travel, page 224 ; l'auteur parle comme témoin oculaire. (K.) - Voyez aussi la note de Voltaire lui-même sur le chapitre CLI. (B.) 
produit l'éléphant, le rhinocéros, et les Nègres, a fait naître dans un autre monde des orignaux, des condors, des animaux à qui on a cru longtemps le nombril sur le dos, et des hommes d'un caractère qui n'est pas le nôtre.

Table des Matières

9.

DE LA THÉOCRATIE

Il semble que la plupart des anciennes nations aient été gouvernées par une espèce de théocratie. Commencez par l'Inde, vous y voyez les brames longtemps souverains; en Perse, les mages ont la plus grande autorité. L'histoire des oreilles de Smerdis peut bien être une fable ; mais il en résulte toujours que c'était un mage qui était sur le trône de Cyrus. Plusieurs prêtres d'Égypte prescrivaient aux rois jusqu'à la mesure de leur boire et de leur manger, élevaient leur enfance, et les jugeaient après leur mort, et souvent se faisaient rois eux-mêmes.

$\mathrm{Si}$ nous descendons aux Grecs, leur histoire, toute fabuleuse qu'elle est, ne nous apprend-elle pas que le prophète Calchas avait assez de pouvoir dans l'armée pour sacrifier la fille du roi des rois?

Descendez encore plus bas, chez des nations sauvages postérieures aux Grecs : les druides gouvernaient la nation gauloise.

Il ne paraît pas même possible que dans les premières peuplades un peu fortes ${ }^{15}$ on ait en d'autre gouvernement que la théocratie ; car dès qu'une nation a choisi un dieu tutélaire, ce dieu a des prêtres. Ces prêtres dominent sur l'esprit de la nation; ils ne peuvent dominer qu'au nom de leur dieu ; ils le font donc toujours parler : ils débitent ses oracles; et c'est par un ordre exprès de Dieu que tout s'exécute.

C'est de cette source que sont venus les sacrifices de sang humain qui ont souillé presque toute la terre. Quel père, quelle mère, aurait jamais pu abjurer la nature, au point de présenter son fils ou sa fille à

On entend par premières peuplades des hommes rassemblés au nombre de quelques milliers, après plusieurs révolutions de ce globe. (V.) 
un prêtre pour être égorgés sur un autel, si l'on n'avait pas été certain que le dieu du pays ordonnait ce sacrifice?

Non seulement la théocratie a longtemps régné, mais elle a poussé la tyrannie aux plus horribles excès où la démence humaine puisse parvenir ; et plus ce gouvernement se disait divin, plus il était abominable.

Presque tous les peuples ont sacrifié des enfants à leurs dieux ; donc ils croyaient recevoir cet ordre dénaturé de la bouche des dieux qu'ils adoraient.

Parmi les peuples qu'on appelle si improprement civilisés, je ne vois guère que les Chinois qui n'aient pas pratiqué ces horreurs absurdes. La Chine est le seul des anciens États connus qui n'ait pas été soumis au sacerdoce ; car les Japonais étaient sous les lois d'un prêtre six cents ans avant notre ère. Presque partout ailleurs la théocratie est si établie, si enracinée, que les premières histoires sont celles des dieux mêmes qui se sont incarnés pour venir gouverner les hommes. Les dieux, disaient les peuples de Thèbes et de Memphis, ont régné douze mille ans en Égypte. Brama s'incarna pour régner dans l'Inde ; Sammonocodom à Siam; le dieu Adad gouverna la Syrie; la déesse Cybèle avait été souveraine de Phrygie ; Jupiter, de Crète ; Saturne, de Grèce et d'Italie. Le même esprit préside à toutes ces fables; c'est partout une confuse idée chez les hommes, que les dieux sont autrefois descendus sur la terre.

Table des Matières

10.

\section{DES CHALDÉENS}

Les Chaldéens, les Indiens, les Chinois, me paraissent les nations le plus anciennement policées. Nous avons une époque certaine de la science des Chaldéens ; elle se trouve dans les dix-neuf cent trois ans d'observations célestes envoyées de Babylone par Callisthène au précepteur d'Alexandre. Ces tables astronomiques remontent précisément à l'année 2234 avant notre ère vulgaire. Il est vrai que cette époque touche au temps où la Vulgate place le déluge ; mais n'entrons point 
ici dans les profondeurs des différentes chronologies de la Vulgate, des Samaritains, et des Septante, que nous révérons également. Le déluge universel est un grand miracle qui n'a rien de commun avec nos recherches. Nous ne raisonnons ici que d'après les notions naturelles, en soumettant toujours les faibles tâtonnements de notre esprit borné aux lumières d'un ordre supérieur.

D'anciens auteurs, cités dans George le Syncelle, disent que du temps d'un roi chaldéen, nommé Xixoutrou ${ }^{16}$, il y eut une terrible inondation. Le Tigre et l'Euphrate se débordèrent apparemment plus qu'à l'ordinaire. Mais les Chaldéens n'auraient pu savoir que par la révélation qu'un pareil fléau eut submergé toute la terre habitable. Encore une fois, je n'examine ici que le cours ordinaire de la nature.

Il est clair que si les Chaldéens n'avaient existé sur la terre que depuis dix-neuf cents années avant notre ère, ce court espace ne leur eut pas suffi pour trouver une partie du véritable système de notre univers ; notion étonnante, à laquelle les Chaldéens étaient enfin parvenus. Aristarque de Samos nous apprend que les sages de Chaldée avaient connu combien il est impossible que la terre occupe le centre du monde planétaire; qu'ils avaient assigné au soleil cette place qui lui appartient ; qu'ils faisaient rouler la terre et les autres planètes autour de lui, chacune dans un orbe différent ${ }^{17}$.

Les progrès de l'esprit sont si lents, l'illusion des yeux est si puissante, l'asservissement aux idées reçues si tyrannique, qu'il n'est pas possible qu'un peuple qui n'aurait eu que dix-neuf cents ans eût pu parvenir à ce haut degré de philosophie qui contredit les yeux, et qui demande la théorie la plus approfondie. Aussi les Chaldéens comptaient quatre cent soixante et dix mille ans; encore cette connaissance du vrai système du monde ne fut en Chaldée que le partage du petit nombre des philosophes. C'est le sort de toutes les grandes vérités; et les Grecs, qui vinrent ensuite, n'adoptèrent que le système commun, qui est le système des enfants.

16 Xixoutrou est le Xissutre dont il est question dans les Fragments sur l'Inde, article VI (voyez Mélanges, année 1773); dans le $\mathrm{II}^{\mathrm{e}}$ des Dialogues d'Evhémère (Mélanges, année 1777), et dans le Dictionnaire philosophique au mot ARARAT. (B.)

17 Voyez l'article SYstÈME, dans le Dictionnaire philosophique. (K.) 
Quatre cent soixante et dix mille ans ${ }^{18}$, c'est beaucoup pour nous autres qui sommes d'hier, mais c'est bien peu de chose pour l'univers entier. Je sais bien que nous ne pouvons adopter ce calcul ; que Cicéron s'en est moqué, qu'il est exorbitant, et que surtout nous devons croire au Pentateuque plutôt qu'à Sanchoniathon et à Bérose ; mais, encore une fois, il est impossible (humainement parlant) que les hommes soient parvenus en dix-neuf cents ans à deviner de si étonnantes vérités. Le premier art est celui de pourvoir à la subsistance, ce qui était autrefois beaucoup plus difficile aux hommes qu'aux brutes ; le second, de former un langage, ce qui certainement demande un espace de temps très considérable; le troisième, de se bâtir quelques huttes ; le quatrième, de se vêtir. Ensuite, pour forger le fer, ou pour y suppléer, il faut tant de hasards heureux, tant d'industrie, tant de siècles, qu'on n'imagine pas même comment les hommes en sont venus à bout. Quel saut de cet état à l'astronomie !

Longtemps les Chaldéens gravèrent leurs observations et leurs lois sur la brique, en hiéroglyphes, qui étaient des caractères parlants; usage que les Égyptiens connurent après plusieurs siècles. L'art de transmettre ses pensées par des caractères alphabétiques ne dut être inventé que très tard dans cette partie de l'Asie.

Il est à croire qu'au temps où les Chaldéens bâtirent des villes, ils commencèrent à se servir de l'alphabet. Comment faisait-on auparavant ? dira-t-on : comme on fait dans mon village, et dans cent mille

18 Notre sainte religion, si supérieure en tout à nos lumières, nous apprend que le monde n'est fait que depuis environ six mille années selon la Vulgate, ou environ sept mille suivant les Septante. Les interprètes de cette religion ineffable nous enseignent qu'Adam eut la science infuse, et que tous les arts se perpétuèrent d'Adam à Noé. Si c'est là, en effet le sentiment de l'Église, nous l'adoptons d'une foi ferme et constante, soumettant d'ailleurs tout ce que nous écrivons au jugement de cette sainte Eglise, qui est infaillible. C'est vainement que l'empereur Julien, d'ailleurs si respectable par sa vertu, sa valeur, et sa science, dit dans son discours censuré par le grand et modéré saint Cyrille, que, soit qu'Adam eut la science infuse ou non, Dieu ne pouvait lui ordonner de ne point toucher à l'arbre de la science du bien et du mal ; que Dieu devait au contraire lui commander de manger beaucoup de fruits de cet arbre, afin de se perfectionner dans la science infuse s'il l'avait, et de l'acquérir s'il ne l'avait pas. On sait avec quelle sagesse saint Cyrille a réfuté cet argument. En un mot, nous prévenons toujours le lecteur que nous ne touchons en aucune manière aux choses sacrées. Nous protestons contre toutes les fausses interprétations, contre toutes les inductions malignes que l'on voudrait tirer de nos paroles. (V.) 
villages du monde, où personne ne sait ni lire ni écrire, et cependant où l'on s'entend fort bien, où les arts nécessaires sont cultivés, et même quelquefois avec génie.

Babylone était probablement une très ancienne bourgade avant qu'on en eût fait une ville immense et superbe. Mais qui a bâti cette ville? je n'en sais rien. Est-ce Sémiramis ? est-ce Bélus ? est-ce Nabonassar? Il n'y a peut-être jamais eu dans l'Asie ni de femme appelée Sémiramis, ni d'homme appelé Bélus ${ }^{19}$. C'est comme si nous donnions à des villes grecques les noms d'Armagnac et d'Abbeville. Les Grecs, qui changèrent toutes les terminaisons barbares en mots grecs, dénaturèrent tous les noms asiatiques. De plus, l'histoire de Sémiramis ressemble en tout aux contes orientaux.

Nabonassar, ou plutôt Nabon-assor, est probablement celui qui embellit et fortifia Babylone, et en fit à la fin une ville si superbe. Celui-là est un véritable monarque, connu dans l'Asie par l'ère qui porte son nom. Cette ère incontestable ne commence que 747 ans avant la nôtre : ainsi elle est très moderne, par rapport au nombre des siècles nécessaires pour arriver jusqu'à l'établissement des grandes dominations. Il paraît, par le nom même de Babylone, qu'elle existait longtemps avant Nabonassar. C'est la ville du Père Bel. Bab signifie père en chaldéen, comme l'avoue d'Herbelot. Bel est le nom du Seigneur. Les Orientaux ne la connurent jamais que sous le nom de Babel, ville du Seigneur, la ville de Dieu, ou, selon d'autres, la porte de Dieu.

Il n'y a pas eu probablement plus de Ninus fondateur de Ninvah, nommée par nous Ninive, que de Bélus fondateur de Babylone. Nul prince asiatique ne porta un nom en $u s$.

Il se peut que la circonférence de Babylone ait été de vingt-quatre de nos lieues moyennes; mais qu'un Ninus ait bâti sur le Tigre, si près de Babylone, une ville appelée Ninive d'une étendue aussi grande, c'est ce qui ne paraît pas croyable. On nous parle de trois puissants empires qui subsistaient à la fois : celui de Babylone, celui d'Assyrie ou de Ninive, et celui de Syrie ou de Damas. La chose est peu vraisemblable; c'est comme si l'on disait qu'il y avait à la fois dans une 
partie de la Gaule trois puissants empires, dont les capitales, Paris, Soissons, et Orléans, avaient chacune vingt-quatre lieues de tour.

J'avoue que je ne comprends rien aux deux empires de Babylone et d'Assyrie. Plusieurs savants, qui ont voulu porter quelques lumières dans ces ténèbres, ont affirmé que l'Assyrie et la Chaldée n'étaient que le même empire, gouverné quelquefois par deux princes, l'un résidant à Babylone, l'autre à Ninive ; et ce sentiment raisonnable peut être adopté, jusqu'à ce qu'on en trouve un plus raisonnable encore.

Ce qui contribue à jeter une grande vraisemblance sur l'antiquité de cette nation, c'est cette fameuse tour élevée pour observer les astres. Presque tous les commentateurs, ne pouvant contester ce monument, se croient obligés de supposer que c'était un reste de la tour de Babel que les hommes voulurent élever jusqu'au ciel. On ne sait pas trop ce que les commentateurs entendent par le ciel : est-ce la lune ? est-ce la planète de Vénus ? Il y a loin d'ici là. Voulaient-ils seulement élever une tour un peu haute ? Il n'y a là ni aucun mal ni aucune difficulté, supposé qu'on ait beaucoup d'hommes, beaucoup d'instruments et de vivres.

La tour de Babel, la dispersion des peuples, la confusion des langues, sont des choses, comme on sait, très respectables, auxquelles nous ne touchons point. Nous ne parlons ici que de l'observatoire, qui n'a rien de commun avec les histoires juives.

Si Nabonassar éleva cet édifice, il faut au moins avouer que les Chaldéens eurent un observatoire plus de deux mille quatre cents ans avant nous. Concevez ensuite combien de siècles exige la lenteur de l'esprit humain pour en venir jusqu'à ériger un tel monument aux sciences.

Ce fut en Chaldée, et non en Égypte, qu'on inventa le zodiaque. Il $\mathrm{y}$ en $\mathrm{a}$, ce me semble, trois preuves assez fortes : la première, que les Chaldéens furent une nation éclairée, avant que l'Égypte, toujours inondée par le Nil, pût être habitable; la seconde, que les signes du zodiaque conviennent au climat de la Mésopotamie, et non a celui de l'Égypte. Les Égyptiens ne pouvaient avoir le signe du taureau au mois d'avril, puisque ce n'est pas en cette saison qu'ils labourent ; ils ne pouvaient, au mois que nous nommons août, figurer un signe par une fille chargée d'épis de blé, puisque ce n'est pas en ce temps qu'ils 
font la moisson. Ils ne pouvaient figurer janvier par une cruche d'eau, puisqu'il pleut très rarement en Égypte, et jamais au mois de janvier ${ }^{20}$. La troisième raison, c'est que les signes anciens du zodiaque chaldéen étaient un des articles de leur religion. Ils étaient sous le gouvernement de douze dieux secondaires, douze dieux médiateurs :

20 Les points équinoxiaux répondent successivement à tous les lieux du zodiaque, et leur révolution est d'environ 26,000 ans. Il est clair que ces points se trouvaient dans la balance, ou dans les gémeaux, à l'époque où l'on a donné des noms aux signes; en effet ils sont les seuls qui présentent un emblème de l'égalité des nuits et des jours. Mais en supposant les points équinoxiaux placés dans une de ces constellations, il reste quatre combinaisons également possibles, puisqu'on peut supposer également, soit l'équinoxe du printemps, soit l'équinoxe de l'automne, dans le signe de la balance, ou dans celui des gémeaux. Supposons $1^{\circ}$ que l'équinoxe du printemps soit dans la balance; le solstice d'été sera dans le capricorne, celui d'hiver dans le cancer, et l'équinoxe d'automne dans le bélier. Supposons $2^{\circ}$ que l'équinoxe d'automne soit dans la balance; le solstice d'été sera dans le cancer, celui d'hiver dans le capricorne, et l'équinoxe du printemps dans le bélier. Supposons $3^{\circ}$ que l'équinoxe du printemps soit dans les gémeaux; le solstice d'été sera dans la vierge, celui d'hiver dans les poissons, et l'équinoxe d'automne dans le sagittaire. Supposons enfin que l'équinoxe d'automne soit dans les gémeaux; le solstice d'été sera dans les poissons, le solstice d'hiver dans la vierge, et l'équinoxe du printemps dans le sagittaire.

Si nous examinons ensuite ces quatre hypothèses, nous trouverons d'abord un degré de probabilité en faveur des deux premières : en effet, dans ces deux hypothèses, les solstices ont pour signes le capricorne et le cancer, un animal qui grimpe, et un qui marche à reculons, symboles naturels du mouvement apparent du soleil et les deux dernières hypothèses n'ont pas cet avantage. En comparant ensuite les deux premières, nous observerons que la balance paraît devoir plus naturellement être supposée le signe du printemps : $1^{\circ}$ parce que le signe de cet équinoxe, regardé partout comme le premier de l'année, doit avoir porté de préférence l'emblème de l'égalité ; $2^{\circ}$ parce que le capricorne, animal qui cherche les lieux élevés, paraît le signe naturel du mois où le soleil est plus élevé ; et que le cancer, quoiqu'il puisse être regardé comme un symbole de l'un ou de l'autre solstice, parait plus propre encore à désigner le solstice d'hiver. Or, si nous préférons la première hypothèse, le capricorne répond à juillet; les mois d'août et de septembre, temps de l'inondation du Nil, répondent au verseau et aux poissons, signes aquatiques ; le Nil se retire en octobre, dont le bélier est le signe, parce qu'alors les troupeaux commencent à sortir; on cultive en novembre sous le signe du taureau, et l'on recueille en mars sous le signe de la moissonneuse. Il suffit donc, pour pouvoir accorder avec le climat de l'Égypte les noms des douze signes du zodiaque, que ces noms leur aient été donnés lorsque l'équinoxe du printemps se trouvait au signe de la balance ; c'est-à-dire qu'il faut reculer d'environ treize mille ans l'invention de l'astronomie. Ce système, le plus naturel de tous ceux qui ont été imaginés jusqu'ici, le seul qui s'accorde avec les monuments, et qui explique les fables de la manière la moins précaire, est dû à M. Dupuis. (K.) - Ce M. Dupuis est l'auteur de l'Origine de tous les cultes. (B.) 
chacun d'eux présidait à une de ces constellations, ainsi que nous l'apprend Diodore de Sicile, au livre II. Cette religion des anciens Chaldéens était le sabisme, c'est-à-dire l'adoration d'un Dieu suprême, et la vénération des astres et des intelligences célestes qui présidaient aux astres. Quand ils priaient, ils se tournaient vers l'étoile du nord, tant leur culte était lié à l'astronomie.

Vitruve, dans son neuvième livre, où il traite des cadrans solaires, des hauteurs du soleil, de la longueur des ombres, de la lumière réfléchie par la lune, cite toujours les anciens Chaldéens, et non les Égyptiens. C'est, ce me semble, une preuve assez forte qu'on regardait la Chaldée, et non pas l'Égypte, comme le berceau de cette science, de sorte que rien n'est plus vrai que cet ancien proverbe latin :

« Tradidit Ægyptis Babylon, Ægyptus Achivis. »

Table des Matières

11.

DES BABYLONIENS DEVENUS PERSANS

À l'orient de Babylone étaient les Perses. Ceux-ci portèrent leurs armes et leur religion à Babylone, lorsque Koresh, que nous appelons Cyrus, prit cette ville avec le secours des Mèdes établis au nord de la Perse. Nous avons deux fables principales sur Cyrus: celle d'Hérodote, et celle de Xénophon, qui se contredisent en tout, et que mille écrivains ont copiées indifféremment.

Hérodote suppose un roi mède, c'est-à-dire un roi des pays voisins de l'Hyrcanie, qu'il appelle Astyage, d'un nom grec. Cet Hyrcanien Astyage commande de noyer son petit-fils Cyrus, au berceau, parce qu'il a vu en songe sa fille Mandane, mère de Cyrus, pisser si copieusement qu'elle inonda toute l'Asie. Le reste de l'aventure est à peu près dans ce goût; c'est une histoire de Gargantua écrite sérieusement.

Xénophon fait de la vie de Cyrus un roman moral, à peu près semblable à notre Télémaque. Il commence par supposer, pour faire valoir 
l'éducation mâle et vigoureuse de son héros, que les Mèdes étaient des voluptueux, plongés dans la mollesse. Tous ces peuples voisins de l'Hyrcanie, que les Tartares, alors nommés Scythes, avaient ravagée pendant trente années, étaient-ils des sybarites?

Tout ce qu'on peut assurer de Cyrus, c'est qu'il fut un grand conquérant, par conséquent un fléau de la terre. Le fond de son histoire est très vrai ; les épisodes sont fabuleux : il en est ainsi de toute histoire.

Rome existait du temps de Cyrus : elle avait un territoire de quatre à cinq lieues, et pillait tant qu'elle pouvait ses voisins; mais je ne voudrais pas garantir le combat des trois Horaces, et l'aventure de Lucrèce, et le bouclier descendu du ciel, et la pierre coupée avec un rasoir. Il y avait quelques Juifs esclaves dans la Babylonie et ailleurs; mais, humainement parlant, on pourrait douter que l'ange Raphaël fût descendu du ciel pour conduire à pied le jeune Tobie vers l'Hyrcanie, afin de le faire payer de quelque argent, et de chasser le diable Asmodée avec la fumée du foie d'un brochet.

Je me garderai bien d'examiner ici le roman d'Hérodote, ou le roman de Xénophon, concernant la vie et la mort de Cyrus ; mais je remarquerai que les Parsis, ou Perses, prétendaient avoir eu parmi eux, il y avait six mille ans, un ancien Zerdust, un prophète, qui leur avait appris à être justes et à révérer le soleil, comme les anciens Chaldéens avaient révéré les étoiles en les observant.

Je me garderai bien d'affirmer que ces Perses et ces Chaldéens fussent si justes, et de déterminer précisément en quel temps vint leur second Zerdust, qui rectifia le culte du soleil, et leur apprit à n'adorer que le Dieu auteur du soleil et des étoiles. Il écrivit ou commenta, diton, le livre du Zend, que les Parsis, dispersés aujourd'hui dans l'Asie, révèrent comme leur Bible. Ce livre est très ancien, mais moins que ceux des Chinois et des brames; on le croit même postérieur à ceux de Sanchoniathon et des cinq Kings des Chinois; il est écrit dans l'ancienne langue sacrée des Chaldéens et M. Hyde, qui nous a donné une traduction du Sadder, nous aurait procuré celle du Zend s'il avait pu subvenir aux frais de cette recherche. Je m'en rapporte au moins au Sadder, à cet extrait du Zend, qui est le catéchisme des Parsis. J'y vois que ces Parsis croyaient depuis longtemps un dieu, un diable, une ré- 
surrection, un paradis, un enfer. Ils sont les premiers, sans contredit, qui ont établi ces idées; c'est le système le plus antique, et qui ne fut adopté par les autres nations qu'après bien des siècles, puisque les pharisiens, chez les Juifs, ne soutinrent hautement l'immortalité de l'âme, et le dogme des peines et des récompenses après la mort, que vers le temps des Asmonéens.

Voilà peut-être ce qu'il y a de plus important dans l'ancienne histoire du monde: voilà une religion utile, établie sur le dogme de l'immortalité de l'âme et sur la connaissance de l'Être créateur. $\mathrm{Ne}$ cessons point de remarquer par combien de degrés il fallut que l'esprit humain passât pour concevoir un tel système. Remarquons encore que le baptême (l'immersion dans l'eau pour purifier l'âme par le corps) est un des préceptes du Zend (porte 251). La source de tous les rites est venue peut-être des Persans et des Chaldéens, jusqu'aux extrémités de la terre.

Je n'examine point ici pourquoi et comment les Babyloniens eurent des dieux secondaires en reconnaissant un dieu souverain. Ce système, ou plutôt ce chaos, fut celui de toutes les nations. Excepté dans les tribunaux de la Chine, on trouve presque partout l'extrême folie jointe à un peu de sagesse dans les lois, dans les cultes, dans les usages. L'instinct, plus que la raison, conduit le genre humain. On adore en tous lieux la Divinité, et on la déshonore. Les Perses révérèrent des statues dès qu'ils purent avoir des sculpteurs ; tout en est plein dans les ruines de Persépolis : mais aussi on voit dans ces figures les symboles de l'immortalité ; on y voit des têtes qui s'envolent au ciel avec des ailes, symbole de l'émigration d'une vie passagère à la vie immortelle.

Passons aux usages purement humains. Je m'étonne qu'Hérodote ait dit devant toute la Grèce, dans son premier livre, que toutes les Babyloniennes étaient obligées par la loi de se prostituer, une fois dans leur vie, aux étrangers, dans le temple de Milita ou Vénus ${ }^{21}$. Je

21 De très profonds érudits ont prétendu que le marché se faisait bien dans le temple, mais qu'il ne se consommait que dehors. Strabon dit en effet qu'après s'être livrée à l'étranger, hors du temple, la femme retournait chez elle. Où donc se consommait cette cérémonie religieuse ? ce n'était ni chez la femme, ni chez l'étranger, ni dans un lieu profane, où le mari, et peut-être un amant de la femme, qui auraient eu le malheur d'être philosophes et d'avoir des doutes sur la religion de Babylone, eussent pu troubler cet acte de piété. C'était donc 
m'étonne encore plus que, dans toutes les histoires faites pour l'instruction de la jeunesse, on renouvelle aujourd'hui ce conte. Certes, ce devait être une belle fête et une belle dévotion que de voir accourir dans une église des marchands de chameaux, de chevaux, de bœufs et d'ânes, et de les voir descendre de leurs montures pour coucher devant l'autel avec les principales dames de la ville. De bonne foi, cette infamie peut-elle être dans le caractère d'un peuple policé ? Est-il possible que les magistrats d'une des plus grandes villes du monde aient établi une telle police; que les maris aient consenti de prostituer leurs femmes ; que tous les pères aient abandonné leurs filles aux palefreniers de l'Asie? Ce qui n'est pas dans la nature n'est jamais vrai. J'aimerais autant croire Dion Cassius, qui assure que les graves sénateurs de Rome proposèrent un décret par lequel César, âgé de cinquante-sept ans, aurait le droit de jouir de toutes les femmes qu'il voudrait.

Ceux qui, en compilant aujourd'hui l'Histoire ancienne, copient tant d'auteurs sans en examiner aucun, n'auraient-ils pas dû s'apercevoir, ou qu'Hérodote a débité des fables ridicules, ou plutôt que son texte a été corrompu, et qu'il n'a voulu parler que des courtisanes établies dans toutes les grandes villes, et qui, peut-être alors, attendaient les passants sur les chemins?

Je ne croirai pas davantage Sextus Empiricus, qui prétend que chez les Perses la pédérastie était ordonnée. Quelle pitié ! comment imaginer que les hommes eussent fait une loi qui, si elle avait été exécutée, aurait détruit la race des hommes ${ }^{22}$ ? La pédérastie, au contraire, était expressément défendue dans le livre du Zend; et c'est ce qu'on voit dans l'abrégé du Zend, le Sadder, où il est dit (porte 9) Qu'il n'y a point de plus grand péché ${ }^{23}$.

dans quelque lieu voisin du temple destiné à cet usage, et consacré à la déesse. Si ce n'était point dans l'église, c'était au moins dans la sacristie. (K.)

Voyez la Défense de mon oncle, chapitre V (Mélanges, année 1767).

Voyez aussi une note sur l'article AMOUR SOCRATIQUE, dans le Dictionnaire philosophique. (K.)

23 Voyez les réponses à celui qui a prétendu que la prostitution était une loi de l'empire des Babyloniens, et que la pédérastie était établie en Perse, dans le même pays. On ne peut guère pousser plus loin l'opprobre de la littérature, ni plus calomnier la nature humaine. (V.) 
Strabon dit que les Perses épousaient leurs mères ; mais quels sont ses garants ? des ouï-dire, des bruits vagues. Cela put fournir une épigramme à Catulle :

« Nam magus ex matre et nato nascatur oportet. »

Tout mage doit naître de l'inceste d'une mère et d'un fils.

Une telle loi n'est pas croyable ; une épigramme n'est pas une preuve. Si l'on n'avait pas trouvé de mères qui voulussent coucher avec leurs fils, il n'y aurait donc point eu de prêtres chez les Perses. La religion des mages, dont le grand objet était la population, devait plutôt permettre aux pères de s'unir à leurs filles, qu'aux mères de coucher avec leurs enfants, puisqu'un vieillard peut engendrer, et qu'une vieille n'a pas cet avantage.

Que de sottises n'avons-nous pas dites sur les Turcs ? les Romains en disaient davantage sur les Perses.

En un mot, en lisant toute histoire, soyons en garde contre toute fable.

Table des Matières

12.

DE LA SYRIE

Je vois, par tous les monuments qui nous restent, que la contrée qui s'étend depuis Alexandrette, ou Scanderon, jusqu'auprès de Bagdad, fut toujours nommée Syrie ; que l'alphabet de ces peuples fut toujours syriaque; que c'est là que furent les anciennes villes de Zobah, de Balbek, de Damas ; et depuis, celles d'Antioche, de Séleucie, de Palmyre. Balk était si ancienne que les Perses prétendent que leur Bram, ou Abraham, était venu de Balk chez eux. Où pouvait donc être ce puissant empire d'Assyrie dont on a tant parlé, si ce n'est pas dans le pays des fables?

Les Gaules, tantôt s'étendirent jusqu'au Rhin, tantôt furent plus resserrées ; mais qui jamais imagina de placer un vaste empire entre le Rhin et les Gaules? Qu'on ait appelé les nations voisines de l'Euphrate assyriennes, quand elles se furent étendues vers Damas, et 
qu'on ait appelé Assyriens les peuples de Syrie, quand ils s'approchèrent de l'Euphrate : c'est là où se peut réduire la difficulté. Toutes les nations voisines se sont mêlées, toutes ont été en guerre et ont changé de limites. Mais lorsqu'une fois il s'est élevé des villes capitales, ces villes établissent une différence marquée entre deux nations. Ainsi les Babyloniens, ou vainqueurs ou vaincus, furent toujours différents des peuples de Syrie. Les anciens caractères de la langue syriaque ne furent point ceux des anciens Chaldéens.

Le culte, les superstitions, les lois bonnes ou mauvaises, les usages bizarres, ne furent point les mêmes. La déesse de Syrie, si ancienne, n'avait aucun rapport avec le culte des Chaldéens. Les mages chaldéens, babyloniens, persans, ne se firent jamais eunuques, comme les prêtres de la déesse de Syrie. Chose étrange ! les Syriens révéraient la figure de ce que nous appelons Priape, et les prêtres se dépouillaient de leur virilité !

Ce renoncement à la génération ne prouve-t-il pas une grande antiquité, une population considérable? Il n'est pas possible qu'on eût voulu attenter ainsi contre la nature dans un pays où l'espèce aurait été rare.

Les prêtres de Cybèle, en Phrygie, se rendaient eunuques comme ceux de Syrie. Encore une fois, peut-on douter que ce ne fût l'effet de l'ancienne coutume de sacrifier aux dieux ce qu'on avait de plus cher, et de ne se point exposer, devant des êtres qu'on croyait purs, aux accidents de ce qu'on croyait impureté ? Peut-on s'étonner, après de tels sacrifices, de celui que l'on faisait de son prépuce chez d'autres peuples, et de l'amputation d'un testicule chez des nations africaines ? Les fables d'Atis et de Combabus ne sont que des fables, comme celle de Jupiter, qui rendit eunuque Saturne son père. La superstition invente des usages ridicules, et l'esprit romanesque invente des raisons absurdes.

Ce que je remarquerai encore des anciens Syriens, c'est que la ville qui fut depuis nommée la Ville sainte, et Hiérapolis par les Grecs, était nommée par les Syriens Magog. Ce mot Mag a un grand rapport avec les anciens mages; il semble commun à tous ceux qui, dans ces climats, étaient consacrés au service de la Divinité. Chaque peuple eut une ville sainte. Nous savons que Thèbes, en Égypte, était la ville de 
Dieu ; Babylone, la ville de Dieu ; Apamée, en Phrygie, était aussi la ville de Dieu.

Les Hébreux, longtemps après, parlent des peuples de Gog et de Magog ; ils pouvaient entendre par ces noms les peuples de l'Euphrate et de l'Oronte : ils pouvaient entendre aussi les Scythes, qui vinrent ravager l'Asie avant Cyrus, et qui dévastèrent la Phénicie ; mais il importe fort peu de savoir quelle idée passait par la tête d'un Juif quand il prononçait Magog ou Gog.

$\mathrm{Au}$ reste, je ne balance pas à croire les Syriens beaucoup plus anciens que les Égyptiens, par la raison évidente que les pays les plus aisément cultivables sont nécessairement les premiers peuplés et les premiers florissants.

Table des Matières

13.

DES PHÉNICIENS ET DE SANCHONIATHON

Les Phéniciens sont probablement rassemblés en corps de peuple aussi anciennement que les autres habitants de la Syrie. Ils peuvent être moins anciens que les Chaldéens, parce que leur pays est moins fertile. Sidon, Tyr, Joppé, Berith, Ascalon, sont des terrains ingrats. Le commerce maritime a toujours été la dernière ressource des peuples. On a commencé par cultiver sa terre avant de bâtir des vaisseaux pour en aller chercher de nouvelles au delà des mers. Mais ceux qui sont forcés de s'adonner au commerce maritime ont bientôt cette industrie, fille du besoin, qui n'aiguillonne point les autres nations. Il n'est parlé d'aucune entreprise maritime, ni des Chaldéens, ni des Indiens. Les Égyptiens même avaient la mer en horreur; la mer était leur Typhon, un être malfaisant; et c'est ce qui fait révoquer en doute les quatre cents vaisseaux équipés par Sésostris pour aller conquérir l'Inde. Mais les entreprises des Phéniciens sont réelles. Carthage et Cadix fondées par eux, l'Angleterre découverte, leur commerce aux Indes par Eziongaber, leurs manufactures d'étoffes précieuses, leur art de teindre en pourpre, sont des témoignages de leur habileté ; et cette habileté fit leur grandeur. 
Les Phéniciens furent dans l'antiquité ce qu'étaient les Vénitiens au quinzième siècle, et ce que sont devenus depuis les Hollandais, forcés de s'enrichir par leur industrie.

Le commerce exigeait nécessairement qu'on eût des registres qui tinssent lieu de nos livres de compte, avec des signes aisés et durables pour établir ces registres. L'opinion qui fait les Phéniciens auteurs de l'écriture alphabétique est donc très vraisemblable. Je n'assurerais pas qu'ils aient inventé de tels caractères avant les Chaldéens ; mais leur alphabet fut certainement le plus complet et le plus utile, puisqu'ils peignirent les voyelles, que les Chaldéens n'exprimaient pas.

Je ne vois pas que les Égyptiens aient jamais communiqué leurs lettres, leur langue, à aucun peuple : au contraire, les Phéniciens transmirent leur langue et leur alphabet aux Carthaginois, qui les altérèrent depuis ; leurs lettres devinrent celles des Grecs. Quel préjugé pour l'antiquité des Phéniciens!

Sanchoniathon, Phénicien, qui écrivit longtemps avant la guerre de Troie l'histoire des premiers âges, et dont Eusèbe nous a conservé quelques fragments traduits par Philon de Biblos ; Sanchoniathon, disje, nous apprend que les Phéniciens avaient, de temps immémorial, sacrifié aux éléments et aux vents; ce qui convient en effet à un peuple navigateur. Il voulut, dans son histoire, s'élever jusqu'à l'origine des choses, comme tous les premiers écrivains ; il eut la même ambition que les auteurs du Zend et du Veidam ; la même qu'eurent Manéthon en Égypte, et Hésiode en Grèce.

On ne pourrait douter de la prodigieuse antiquité du livre de Sanchoniathon, s'il était vrai, comme Warburton le prétend, qu'on en lût les premières lignes dans les mystères d'Isis et de Cérès, hommage que les Égyptiens et les Grecs n'eussent pas rendu à un auteur étranger s'il n'avait pas été regardé comme une des premières sources des connaissances humaines.

Sanchoniathon n'écrivit rien de lui-même; il consulta toutes les archives anciennes, et surtout le prêtre Jérombal. Le nom de Sanchoniathon signifie, en ancien phénicien, amateur de la vérité. Porphyre le dit, Théodoret et Bochart l'avouent. La Phénicie était appelée le pays des lettres, Kirjath sepher. Quand les Hébreux vinrent s'établir dans 
une partie de cette contrée, ils brûlèrent la ville des lettres, comme on le voit dans Josué et dans les Juges.

Jérombal, consulté par Sanchoniathon, était prêtre du dieu suprême, que les Phéniciens nommaient Iao, Jeova, nom réputé sacré, adopté chez les Égyptiens et ensuite chez les Juifs. On voit, par les fragments de ce monument si antique, que Tyr existait depuis très longtemps, quoiqu'elle ne fût pas encore parvenue à être une ville puissante.

Ce mot El, qui désignait Dieu chez les premiers Phéniciens, a quelque rapport à l'Alla des Arabes; et il est probable que de ce monosyllabe El les Grecs composèrent leur Elios. Mais ce qui est plus remarquable, c'est qu'on trouve chez les anciens Phéniciens le mot Eloa, Eloin, dont les Hébreux se servirent très longtemps après, quand ils s'établirent dans le Canaan.

C'est de la Phénicie que les Juifs prirent tous les noms qu'ils donnèrent à Dieu, Eloa, Iao, Adonaï ; cela ne peut être autrement, puisque les Juifs ne parlèrent longtemps en Canaan que la langue phénicienne.

Ce mot Iao, ce nom ineffable chez les Juifs, et qu'ils ne prononçaient jamais, était si commun dans l'Orient que Diodore, dans son livre second, en parlant de ceux qui feignirent des entretiens avec les dieux, dit que «Minos se vantait d'avoir communiqué avec le dieu Zeus; Zamolxis avec la déesse Vesta; et le Juif Moïse avec le dieu Iao, etc. »

Ce qui mérite surtout d'être observé, c'est que Sanchoniathon, en rapportant l'ancienne cosmologie de son pays, parle d'abord du chaos d'un air ténébreux, Chautereb ${ }^{24}$. L'Érèbe, la nuit d'Hésiode, est prise du mot phénicien qui s'est conservé chez les Grecs. Du chaos sortit Mot, qui signifie la matière. Or, qui arrangea la matière ? C'est colpi Iao, l'esprit de Dieu, le vent de Dieu, ou plutôt la voix de la bouche de

24 Dans l'Examen important de Milord Bolingbroke, chapitre VI (voyez les Mélanges, année 1767), l'auteur a écrit Khaütereb. On lit Chaut-ereb dans une note sur le Discours de l'empereur Julien (Mélanges, 1768), et encore dans la seconde note de la Bible expliquée (Mélanges, 1776). (B.) 
Dieu. C'est à la voix de Dieu que naquirent les animaux et les hommes ${ }^{25}$.

Il est aisé de se convaincre que cette cosmogonie est l'origine de presque toutes les autres. Le peuple le plus ancien est toujours imité par ceux qui viennent après lui ; ils apprennent sa langue, ils suivent une partie de ses rites, ils s'approprient ses antiquités et ses fables. Je sais combien toutes les origines chaldéennes, syriennes, phéniciennes, égyptiennes, et grecques, sont obscures. Quelle origine ne l'est pas ? Nous ne pouvons avoir rien de certain sur la formation du monde, que ce que le Créateur du monde aurait daigné nous apprendre lui-même. Nous marchons avec sûreté jusqu'à certaines bornes : nous savons que Babylone existait avant Rome ; que les villes de Syrie étaient puissantes avant qu'on connût Jérusalem; qu'il y avait des rois d'Égypte avant Jacob, avant Abraham: nous savons quelles sociétés se sont établies les dernières ; mais pour savoir précisément quel fut le premier peuple, il faut une révélation.

Au moins nous est-il permis de peser les probabilités, et de nous servir de notre raison dans ce qui n'intéresse point nos dogmes sacrés, supérieurs à toute raison, et qui ne cèdent qu'à la morale.

Il est très avéré que les Phéniciens occupaient leur pays longtemps avant que les Hébreux s'y présentassent. Les Hébreux purent-ils apprendre la langue phénicienne quand ils erraient, loin de la Phénicie, dans le désert, au milieu de quelques hordes d'Arabes?

La langue phénicienne put-elle devenir le langage ordinaire des Hébreux ? et purent-ils écrire dans cette langue du temps de Josué, parmi des dévastations et des massacres continuels? Les Hébreux après Josué, longtemps esclaves dans ce même pays qu'ils avaient mis à feu et à sang, n'apprirent-ils pas alors un peu de la langue de leurs maîtres, comme depuis ils apprirent un peu de chaldéen quand ils furent esclaves à Babylone?

N'est-il pas de la plus grande vraisemblance qu'un peuple commerçant, industrieux, savant, établi de temps immémorial, et qui passe

Cette manière d'entendre Sanchoniathon est très naturelle; elle est appuyée sur l'autorité de Bochart. Ceux qui l'ont critiquée savent sûrement très bien la langue grecque ; mais ils ont prouvé que cela ne suffit pas toujours pour entendre les livres grecs. (K.) 
pour l'inventeur des lettres, écrivit longtemps avant un peuple errant, nouvellement établi dans son voisinage, sans aucune science, sans aucune industrie, sans aucun commerce, et subsistant uniquement de rapines?

Peut-on nier sérieusement l'authenticité des fragments de Sanchoniathon conservés par Eusèbe ? ou peut-on imaginer, avec le savant Huet, que Sanchoniathon ait puisé chez Moïse, quand tout ce qui reste de monuments antiques nous avertit que Sanchoniathon vivait avant Moïse ? Nous ne décidons rien, c'est au lecteur éclairé et judicieux à décider entre Huet et Van Dale, qui l'a réfuté. Nous cherchons la vérité, et non la dispute.

Table des Matières

14.

DES SCYTHES ET DES GOMÉRITES

Laissons Gomer, presque au sortir de l'arche, aller subjuguer les Gaules, et les peupler en quelques années ; laissons aller Tubal en Espagne et Magog dans le nord de l'Allemagne, vers le temps où les fils de Cham faisaient une prodigieuse quantité d'enfants tout noirs vers la Guinée et le Congo. Ces impertinences dégoûtantes sont débitées dans tant de livres que ce n'est pas la peine d'en parler; les enfants commencent à en rire ; mais par quelle faiblesse, ou par quelle malignité secrète, ou par quelle affectation de montrer une éloquence déplacée, tant d'historiens ont-ils fait de si grands éloges des Scythes, qu'ils ne reconnaissaient pas?

Pourquoi Quinte-Curce, en parlant des Scythes qui habitaient au nord de la Sogdiane, au-delà de l'Oxus (qu'il prend pour le Tanaïs, qui en est à cinq cents lieues), pourquoi, dis-je, Quinte-Curce met-il une harangue philosophique dans la bouche de ces barbares? pourquoi suppose-t-il qu'ils reprochent à Alexandre sa soif de conquérir? pourquoi leur fait-il dire qu'Alexandre est le plus fameux voleur de la terre, eux qui avaient exercé le brigandage dans toute l'Asie si longtemps avant lui ? pourquoi enfin Quinte-Curce peint-il ces Scythes comme les plus justes de tous les hommes? La raison en est que, 
comme il place en mauvais géographe le Tanaïs du côté de la mer Caspienne, il parle du prétendu désintéressement des Scythes en déclamateur.

Si Horace, en opposant les mœurs des Scythes à celles des Romains, fait en vers harmonieux le panégyrique de ces barbares, s'il dit (ode XXIV, liv. III),

«Campestres melius Scythae,

Quorum plaustra vagas rite trahunt domos,

Vivunt, et rigidi Getae »;

Voyez les habitants de 1'affreuse Scythie,

Qui vivent sur des chars ;

Avec plus d'innocence ils consument leur vie

Que le peuple de Mars ;

c'est qu'Horace parle en poète un peu satirique, qui est bien aise d'élever des étrangers aux dépens de son pays.

C'est par la même raison que Tacite ${ }^{26}$ s'épuise à louer les barbares Germains, qui pillaient les Gaules et qui immolaient des hommes à leurs abominables dieux. Tacite, Quinte-Curce, Horace, ressemblent à ces pédagogues qui, pour donner de l'émulation à leurs disciples, prodiguent en leur présence des louanges à des enfants étrangers, quelque grossiers qu'ils puissent être.

Les Scythes sont ces mêmes barbares que nous avons depuis appelés Tartares ; ce sont ceux-là mêmes qui, longtemps avant Alexandre, avaient ravagé plusieurs fois l'Asie, et qui ont été les déprédateurs d'une grande partie du continent. Tantôt, sous le nom de Mongols ou de Huns, ils ont asservi la Chine et les Indes; tantôt, sous le nom de Turcs, ils ont chassé les Arabes qui avaient conquis une partie de l'Asie. C'est de ces vastes campagnes que partirent les Huns pour aller jusqu'à Rome. Voilà ces hommes désintéressés et justes dont nos compilateurs vantent encore aujourd'hui l'équité quand ils copient Quinte-Curce. C'est ainsi qu'on nous accable d'histoires anciennes, sans choix et sans jugement; on les lit à peu près avec le même esprit qu'elles ont été faites, et on ne se met dans la tête que des erreurs.

26 Voyez ci-après 1'Avant-Propos de 1'Essai. (B.) 
Les Russes habitent aujourd'hui l'ancienne Scythie européane ; ce sont eux qui ont fourni à l'histoire des vérités bien étonnantes. Il y a eu sur la terre des révolutions qui ont plus frappé l'imagination ; il n'y en a pas une qui satisfasse autant l'esprit humain, et qui lui fasse autant d'honneur. On a vu des conquérants et des dévastations; mais qu'un seul homme ait, en vingt années, changé les mœurs, les lois, l'esprit du plus vaste empire de la terre; que tous les arts soient venus en foule embellir les déserts ; c'est là ce qui est admirable. Une femme qui ne savait ni lire ni écrire perfectionna ce que Pierre le Grand avait commencé. Une autre femme (Élisabeth) étendit encore ces nobles commencements. Une autre impératrice encore est allée plus loin que les deux autres; son génie s'est communiqué à ses sujets ; les révolutions du palais n'ont pas retardé d'un moment les progrès de la félicité de l'empire : on a vu, en un demi-siècle, la cour de Scythie plus éclairée que ne l'ont été jamais la Grèce et Rome.

Et ce qui est plus admirable, c'est qu'en 1770, temps auquel nous écrivons, Catherine II poursuit en Europe et en Asie les Turcs fuyant devant ses armées, et les fait trembler dans Constantinople. Ses soldats sont aussi terribles que sa cour est polie; et, quel que soit l'événement de cette grande guerre, la postérité doit admirer la Thomiris du Nord : elle mérite de venger la terre de la tyrannie turque.

Table des Matières

15.

DE L'ARABIE

Si l'on est curieux de monuments tels que ceux de l'Égypte, je ne crois pas qu'on doive les chercher en Arabie. La Mecque fut, dit-on, bâtie vers le temps d'Abraham; mais elle est dans un terrain si sablonneux et si ingrat qu'il n'y a pas d'apparence qu'elle ait été fondée avant les villes qu'on éleva près des fleuves, dans des contrées fertiles. Plus de la moitié de l'Arabie est un vaste désert, ou de sables ou de pierres. Mais l'Arabie Heureuse a mérité ce nom en ce qu'étant environnée de solitudes et d'une mer orageuse, elle a été à l'abri de la rapacité des voleurs, appelés conquérants, jusqu'à Mahomet; et même alors elle ne fut que la compagne de ses victoires. Cet avantage est 
bien au-dessus de ses aromates, de son encens, de sa cannelle, qui est d'une espèce médiocre, et même de son café, qui fait aujourd'hui sa richesse.

L'Arabie Déserte est ce pays malheureux, habité par quelques Amalécites, Moabites, Madianites : pays affreux, qui ne contient pas aujourd'hui neuf à dix mille Arabes, voleurs errants, et qui ne peut en nourrir davantage. C'est dans ces mêmes déserts qu'il est dit que deux millions d'Hébreux passèrent quarante années. Ce n'est point la vraie Arabie, et ce pays est souvent appelé désert de Syrie.

L'Arabie Pétrée n'est ainsi appelée que du nom de Pétra, petite forteresse, à qui sûrement les Arabes n'avaient pas donné ce nom, mais qui fut nommée ainsi par les Grecs vers le temps d'Alexandre. Cette Arabie Pétrée est fort petite, et peut être confondue, sans lui faire tort, avec l'Arabie Déserte : l'une et l'autre ont toujours été habitées par des hordes vagabondes. C'est auprès de cette Arabie Pétrée que fut bâtie la ville appelée par nous Jérusalem.

Pour cette vaste partie appelée Heureuse, près de la moitié consiste aussi en déserts ; mais quand on avance quelques milles dans les terres, soit à l'orient de Moka, soit même à l'orient de la Mecque, c'est alors qu'on trouve le pays le plus agréable de la terre. L'air y est parfumé, dans un été continuel, de l'odeur des plantes aromatiques que la nature y fait croître sans culture. Mille ruisseaux descendent des montagnes, et entretiennent une fraîcheur perpétuelle qui tempère l'ardeur du soleil sous des ombrages toujours verts.

C'est surtout dans ces pays que le mot de jardin, paradis, signifia la faveur céleste.

Les jardins de Sanaa, vers Aden, furent plus fameux chez les Arabes que ne le furent depuis ceux d'Alcinoüs chez les Grecs; et cet Aden, ou Éden, était nommé le lieu des délices. On parle encore d'un ancien Shedad, dont les jardins n'étaient pas moins renommés. La félicité, dans ces climats brûlants, était l'ombrage.

Ce vaste pays de l'Yemen est si beau, ses ports sont si heureusement situés sur l'Océan indien, qu'on prétend qu'Alexandre voulut conquérir l'Yemen pour en faire le siège de son empire, et y établir l'entrepôt du commerce du monde. Il eût entretenu l'ancien canal des 
rois d'Égypte, qui joignait le Nil à la mer Rouge ; et tous les trésors de l'Inde auraient passé d'Aden ou d'Éden à sa ville d'Alexandrie. Une telle entreprise ne ressemble pas à ces fables insipides et absurdes dont toute histoire ancienne est remplie : il eût fallu, à la vérité, subjuguer toute l'Arabie ; si quelqu'un le pouvait, c'était Alexandre : mais il paraît que ces peuples ne le craignirent point; ils ne lui envoyèrent pas même des députés quand il tenait sous le joug l'Égypte et la Perse.

Les Arabes, défendus par leurs déserts et par leur courage, n'ont jamais subi le joug étranger; Trajan ne conquit qu'un peu de l'Arabie Pétrée : aujourd'hui même ils bravent la puissance du Turc. Ce grand peuple a toujours été aussi libre que les Scythes, et plus civilisé qu'eux.

Il faut bien se garder de confondre ces anciens Arabes avec les hordes qui se disent descendues d'Ismaël. Les Ismaélites, ou Agaréens, ou ceux qui se disaient enfants de Cethura, étaient des tribus étrangères qui ne mirent jamais le pied dans l'Arabie Heureuse. Leurs hordes erraient dans l'Arabie Pétrée vers le pays de Madian; elles se mêlèrent depuis avec les vrais Arabes, du temps de Mahomet, quand elles embrassèrent sa religion.

Ce sont les peuples de l'Arabie proprement dite qui étaient véritablement indigènes, c'est-à-dire qui, de temps immémorial, habitaient ce beau pays, sans mélange d'aucune autre nation, sans avoir jamais été ni conquis ni conquérants. Leur religion était la plus naturelle et la plus simple de toutes; c'était le culte d'un Dieu et la vénération pour les étoiles, qui semblaient, sous un ciel si beau et si pur, annoncer la grandeur de Dieu avec plus de magnificence que le reste de la nature. Ils regardaient les planètes comme des médiatrices entre Dieu et les hommes. Ils eurent cette religion jusqu'à Mahomet. Je crois bien qu'il y eut beaucoup de superstitions, puisqu'ils étaient hommes ; mais, séparés du reste du monde par des mers et des déserts, possesseurs d'un pays délicieux et se trouvant au-dessus de tout besoin et de toute crainte, ils durent être nécessairement moins méchants et moins superstitieux que d'autres nations.

On ne les avait jamais vus ni envahir le bien de leurs voisins, comme des bêtes carnassières affamées ; ni égorger les faibles, en prétextant les ordres de la Divinité ; ni faire leur cour aux puissants, en 
les flattant par de faux oracles : leurs superstitions ne furent ni absurdes ni barbares.

On ne parle point d'eux dans nos histoires universelles fabriquées dans notre Occident; je le crois bien : ils n'ont aucun rapport avec la petite nation juive, universelles, dans lesquelles un certain genre d'auteurs, se copiant les uns les autres, oublie les trois quarts de la terre.

Table des Matières

16.

DE BRAM, ABRAM, ABRAHAM ${ }^{27}$

Il semble que ce nom de Bram, Brama, Abram, Ibrahim, soit un des noms les plus communs aux anciens peuples de l'Asie. Les Indiens, que nous croyons une des premières nations, font de leur Brama un fils de Dieu, qui enseigna aux brames la manière de l'adorer. Ce nom fut en vénération de proche en proche. Les Arabes, les Chaldéens, les Persans, se l'approprièrent, et les Juifs le regardèrent comme un de leurs patriarches. Les Arabes, qui trafiquaient avec les Indiens, eurent probablement les premiers quelques idées confuses de Brama, qu'ils nommèrent Abrama, et dont ensuite ils se vantèrent d'être descendus. Les Chaldéens l'adoptèrent comme un législateur. Les Perses appelaient leur ancienne religion Millat Ibrahim ; les Mèdes, Kish Ibrahim. Ils prétendaient que cet Ibrahim ou Abraham était de la Bactriane, et qu'il avait vécu près de la ville de Balk : ils révéraient en lui un prophète de la religion de l'ancien Zoroastre: il n'appartient sans doute qu'aux Hébreux, puisqu'ils le reconnaissent pour leur père dans leurs livres sacrés.

Des savants ont cru que ce nom était indien parce que les prêtres indiens s'appelaient brames, brachmanes, et que plusieurs de leurs institutions ont un rapport immédiat à ce nom; au lieu que, chez les Asiatiques occidentaux, vous ne voyez aucun établissement qui tire son nom d'Abram ou d'Abraham. Nulle société ne s'est jamais nom-

27 Voyez, dans le Dictionnaire philosophique, l'article ABRAHAM, seconde section. (B.) 
mée abramique; nul rite, nulle cérémonie de ce nom : mais, puisque les livres juifs disent qu'Abraham est la tige des Hébreux, il faut croire sans difficulté ces Juifs, qui, bien que détestés par nous, sont pourtant regardés comme nos précurseurs et nos maîtres.

L'Alcoran cite, touchant Abraham, les anciennes histoires arabes ; mais il en dit très peu de chose : elles prétendent que cet Abraham fonda la Mecque.

Les Juifs le font venir de Chaldée, et non pas de l'Inde ou de la Bactriane ; ils étaient voisins de la Chaldée ; l'Inde et la Bactriane leur étaient inconnues. Abraham était un étranger pour tous ces peuples; et la Chaldée étant un pays dès longtemps renommé pour les sciences et les arts, c'était un honneur, humainement parlant, pour une chétive et barbare nation renfermée dans la Palestine, de compter un ancien sage, réputé chaldéen, au nombre de ses ancêtres.

S'il est permis d'examiner la partie historique des livres judaïques, par les mêmes règles qui nous conduisent dans la critique des autres histoires, il faut convenir, avec tous les commentateurs, que le récit des aventures d'Abraham, tel qu'il se trouve dans le Pentateuque, serait sujet à quelques difficultés s'il se trouvait dans une autre histoire.

La Genèse, après avoir raconté la mort de Tharé, dit qu'Abraham son fils sortit d'Aran, âgé de soixante et quinze ans ; et il est naturel d'en conclure qu'il ne quitta son pays qu'après la mort de son père.

Mais la même Genèse dit que Tharé, l'ayant engendré à soixante et dix ans, vécut jusqu'à deux cent cinq; ainsi Abraham aurait eu cent trente-cinq ans quand il quitta la Chaldée. Il paraît étrange qu'à cet âge il ait abandonné le fertile pays de la Mésopotamie pour aller, à trois cents milles de là, dans la contrée stérile et pierreuse de Sichem, qui n'était point un lieu de commerce. De Sichem on le fait aller acheter du blé à Memphis, qui est environ à six cents milles; et dès qu'il arrive, le roi devient amoureux de sa femme, âgée de soixante et quinze ans.

Je ne touche point à ce qu'il y a de divin dans cette histoire, je m'en tiens toujours aux recherches de l'antiquité. Il est dit 
qu'Abraham reçut de grands présents du roi d'Égypte ${ }^{28}$.Ce pays était dès lors un puissant État ; la monarchie était établie, les arts y étaient donc cultivés ; le fleuve avait été dompté ; on avait creusé partout des canaux pour recevoir ses inondations, sans quoi la contrée n'eût pas été habitable.

Or, je demande à tout homme sensé s'il n'avait pas fallu des siècles pour établir un tel empire dans un pays longtemps inaccessible, et dévasté par les eaux mêmes qui le fertilisèrent? Abraham, selon la Genèse, arriva en Égypte deux mille ans avant notre ère vulgaire. Il faut donc pardonner aux Manéthon, aux Hérodote, aux Diodore, aux Ératosthène, et à tant d'autres, la prodigieuse antiquité qu'ils accordent tous au royaume d'Égypte ; et cette antiquité devait être très moderne, en comparaison de celle des Chaldéens et des Syriens.

Qu'il soit permis d'observer un trait de l'histoire d'Abraham. Il est représenté, au sortir de l'Égypte, comme un pasteur nomade, errant entre le mont Carmel et le lac Asphaltide ; c'est le désert le plus aride de l'Arabie Pétrée ; tout le territoire y est bitumineux ; l'eau y est très rare : le peu qu'on y en trouve est moins potable que celle de la mer. Il $\mathrm{y}$ voiture ses tentes avec trois cent dix-huit serviteurs; et son neveu Loth est établi dans la ville ou bourg de Sodome. Un roi de Babylone, un roi de Perse, un roi de Pont, et un roi de plusieurs autres nations, se liguent ensemble pour faire la guerre à Sodome et à quatre bourgades voisines. Ils prennent ces bourgs et Sodome ; Loth est leur prisonnier. Il n'est pas aisé de comprendre comment quatre grands rois si puissants se liguèrent pour venir ainsi attaquer une horde d'Arabes dans un coin de terre si sauvage, ni comment Abraham défit de si puissants monarques avec trois cents valets de campagne, ni comment il les poursuivit jusque par delà Damas. Quelques traducteurs ont mis Dan pour Damas; mais Dan n'existait pas du temps de Moïse, encore moins du temps d'Abraham. Il y a, de l'extrémité du lac Asphaltide, où Sodome était située, jusqu'à Damas, plus de trois cents milles de route. Tout cela est au-dessus de nos conceptions. Tout est miraculeux dans l'histoire des Hébreux. Nous l'avons déjà dit ${ }^{29}$, et nous redisons

28 La Genèse parle d'un grand nombre d'esclaves et de bêtes de somme donnés à Abraham, lorsque Pharaon le croyait seulement le frère de Sara; et quand il sortit d'Egypte, Pharaon y ajouta beaucoup d'or et d'argent. (K.)

29

Voyez la note de l'auteur sur le paragraphe X. (B.) 
encore que nous croyons ces prodiges et tous les autres sans aucun examen.

Table des Matières

17.

DE L'INDE

S'il est permis de former des conjectures, les Indiens, vers le Gange, sont peut-être les hommes le plus anciennement rassemblés en corps de peuple. Il est certain que le terrain où les animaux trouvent la pâture la plus facile est bientôt couvert de l'espèce qu'il peut nourrir. Or il n'y a pas de contrée au monde où l'espèce humaine ait sous sa main des aliments plus sains, plus agréables et en plus grande abondance que vers le Gange. Le riz y croît sans culture ; le coco, la datte, le figuier, présentent de tous côtés des mets délicieux; l'oranger, le citronnier, fournissent à la fois des boissons rafraîchissantes avec quelque nourriture; les cannes de sucre sont sous la main; les palmiers et les figuiers à larges feuilles y donnent le plus épais ombrage. On n'a pas besoin, dans ce climat, d'écorcher des troupeaux pour défendre ses enfants des rigueurs des saisons ; on les y élève encore aujourd'hui tout nus jusqu'à la puberté. Jamais on ne fut obligé, dans ce pays, de risquer sa vie en attaquant les animaux, pour la soutenir en se nourrissant de leurs membres déchirés, comme on a fait presque partout ailleurs.

Les hommes se seront rassemblés d'eux-mêmes dans ce climat heureux ; on ne se sera point disputé un terrain aride pour y établir de maigres troupeaux; on ne se sera point fait la guerre pour un puits, pour une fontaine, comme ont fait des barbares dans l'Arabie Pétrée.

Les brames se vantent de posséder les monuments les plus anciens qui soient sur la terre. Les raretés les plus antiques que l'empereur chinois Cam-hi eût dans son palais étaient indiennes : il montrait à nos missionnaires mathématiciens d'anciennes monnaies indiennes, frappées au coin, fort antérieures aux monnaies de cuivre des empereurs chinois : et c'est probablement des Indiens que les rois de Perse apprirent l'art monétaire. 
Les Grecs, avant Pythagore, voyageaient dans l'Inde pour s'instruire. Les signes des sept planètes et des sept métaux sont encore, dans presque toute la terre, ceux que les Indiens inventèrent : les Arabes furent obligés de prendre leurs chiffres. Celui des jeux qui fait le plus d'honneur à l'esprit humain nous vient incontestablement de l'Inde ; les éléphants, auxquels nous avons substitué des tours, en sont une preuve : il était naturel que les Indiens fissent marcher des éléphants, mais il ne l'est pas que des tours marchent.

Enfin les peuples les plus anciennement connus, Persans, Phéniciens, Arabes, Égyptiens, allèrent, de temps immémorial, trafiquer dans l'Inde, pour en rapporter les épiceries que la nature n'a données qu'à ces climats, sans que jamais les Indiens allassent rien demander à aucune de ces nations.

On nous parle d'un Bacchus qui partit, dit-on, d'Égypte, ou d'une contrée de l'Asie occidentale, pour conquérir l'Inde. Ce Bacchus, quel qu'il soit, savait donc qu'il y avait au bout de notre continent une nation qui valait mieux que la sienne. Le besoin fit les premiers brigands, ils n'envahirent l'Inde que parce qu'elle était riche et sûrement le peuple riche est rassemblé, civilisé, policé, longtemps avant le peuple voleur.

Ce qui me frappe le plus dans l'Inde, c'est cette ancienne opinion de la transmigration des âmes, qui s'étendit avec le temps jusqu'à la Chine et dans l'Europe. Ce n'est pas que les Indiens sussent ce que c'est qu'une âme : mais ils imaginaient que ce principe, soit aérien, soit igné, allait successivement animer d'autres corps. Remarquons attentivement ce système de philosophie qui tient aux mœurs. C'était un grand frein pour les pervers que la crainte d'être condamnés par Visnou et par Brama à devenir les plus vils et les plus malheureux des animaux. Nous verrons bientôt que tous les grands peuples avaient une idée d'une autre vie, quoique avec des notions différentes. Je ne vois guère, parmi les anciens empires, que les Chinois qui n'établirent pas la doctrine de l'immortalité de l'âme. Leurs premiers législateurs ne promulguèrent que des lois morales : ils crurent qu'il suffisait d'exhorter les hommes à la vertu, et de les y forcer par une police sévère. 
Les Indiens eurent un frein de plus, en embrassant la doctrine de la métempsycose ; la crainte de tuer son père ou sa mère en tuant des hommes et des animaux, leur inspira une horreur pour le meurtre et pour toute violence, qui devint chez eux une seconde nature. Ainsi tous les Indiens dont les familles ne sont alliées ni aux Arabes, ni aux Tartares, sont encore aujourd'hui les plus doux de tous les hommes. Leur religion et la température de leur climat rendirent ces peuples entièrement semblables à ces animaux paisibles que nous élevons dans nos bergeries et dans nos colombiers pour les égorger à notre plaisir. Toutes les nations farouches qui descendirent du Caucase, du Taurus et de l'Immaüs pour subjuguer les habitants des bords de l'Inde, de l'Hydaspe, du Gange, les asservirent en se montrant.

C'est ce qui arriverait aujourd'hui à ces chrétiens primitifs, appelés Quakers, aussi pacifiques que les Indiens; ils seraient dévorés par les autres nations, s'ils n'étaient protégés par leurs belliqueux compatriotes. La religion chrétienne, que ces seuls primitifs suivent à la lettre, est aussi ennemie du sang que la pythagoricienne. Mais les peuples chrétiens n'ont jamais observé leur religion, et les anciennes castes indiennes ont toujours pratiqué la leur : c'est que le pythagorisme est la seule religion au monde qui ait su faire de l'horreur du meurtre une piété filiale et un sentiment religieux. La transmigration des âmes est un système si simple, et même si vraisemblable aux yeux des peuples ignorants; il est si facile de croire que ce qui anime un homme peut ensuite en animer un autre, que tous ceux qui adoptèrent cette religion crurent voir les âmes de leurs parents dans tous les hommes qui les environnaient. Ils se crurent tous frères, pères, mères, enfants les uns des autres : cette idée inspirait nécessairement une charité universelle ; on tremblait de blesser un être qui était de la famille. En un mot, l'ancienne religion de l'Inde, et celle des lettrés à la Chine, sont les seules dans lesquelles les hommes n'aient point été barbares. Comment put-il arriver qu'ensuite ces mêmes hommes, qui se faisaient un crime d'égorger un animal, permissent que les femmes se brûlassent sur le corps de leurs maris, dans la vaine espérance de renaître dans des corps plus beaux et plus heureux ? c'est que le fanatisme et les contradictions sont l'apanage de la nature humaine.

Il faut surtout considérer que l'abstinence de la chair des animaux est une suite de la nature du climat. L'extrême chaleur et l'humidité y pourrissent bientôt la viande; elle y est une très mauvaise nourriture : 
les liqueurs fortes y sont également défendues par la nature, qui exige dans l'Inde des boissons rafraîchissantes. La métempsycose passa, à la vérité, chez nos nations septentrionales ; les Celtes crurent qu'ils renaîtraient dans d'autres corps : mais si les druides avaient ajouté à cette doctrine la défense de manger de la chair, ils n'auraient pas été obéis.

Nous ne connaissons presque rien des anciens rites des brames, conservés jusqu'à nos jours : ils communiquent peu les livres du Hanscrit, qu'ils ont encore dans cette ancienne langue sacrée : leur Veidam, leur Shasta, ont été aussi longtemps inconnus que le Zend des Perses, et que les cinq Kings des Chinois. Il n'y a guère que six-vingts ans que les Européans eurent les premières notions des cinq Kings; et le Zend n'a été vu que par le célèbre docteur Hyde, qui n'eut pas de quoi l'acheter et de quoi payer l'interprète ; et par le marchand Chardin, qui ne voulut pas en donner le prix qu'on lui en demandait. Nous n'eûmes que cet extrait du Zend, ou ce Sadder dont j'ai déjà parlé ${ }^{30}$.

Un hasard plus heureux a procuré à la bibliothèque de Paris un ancien livre des brames; c'est l'Ézour-Veidam, écrit avant l'expédition d'Alexandre dans l'Inde, avec un rituel de tous les anciens rites des brachmanes, intitulé le Cormo-Veidam : ce manuscrit, traduit par un brame, n'est pas à la vérité le Veidam lui-même ; mais c'est un résumé des opinions et des rites contenus dans cette loi. Nous n'avons que depuis peu d'années le Shasta; nous le devons aux soins et à l'érudition de M. Holwell, qui a demeuré très longtemps parmi les brames. Le Shasta est antérieur au Veidam de quinze cents années, selon le calcul de ce savant Anglais ${ }^{31}$. Nous pouvons donc nous flatter d'avoir aujourd'hui quelque connaissance des plus anciens écrits qui soient au monde.

Il faut désespérer d'avoir jamais rien des Égyptiens ; leurs livres sont perdus, leur religion s'est anéantie : ils n'entendent plus leur ancienne langue vulgaire, encore moins la sacrée. Ainsi ce qui était plus près de nous, plus facile à conserver, déposé dans des bibliothèques immenses, a péri pour jamais ; et nous avons trouvé, au bout du mon-

Paragraphe 11. (B.)

Voyez le Dictionnaire philosophique, articles BRACHMANES, ÉzOUR-VEIDAM, etc., et les chapitres 3 et 4 de l'Essai sur les Mœurs, etc. (V.) 
de, des monuments non moins authentiques, que nous ne devions pas espérer de découvrir.

On ne peut douter de la vérité, de l'authenticité de ce rituel des brachmanes dont je parle. L'auteur assurément ne flatte pas sa secte ; il ne cherche point à déguiser les superstitions, à leur donner quelque vraisemblance par des explications forcées, à les excuser par des allégories. Il rend compte des lois les plus extravagantes avec la simplicité de la candeur. L'esprit humain parait là dans toute sa misère. Si les brames observaient toutes les lois de leur Veidam, il n'y a point de moine qui voulût s'assujettir à cet état. À peine le fils d'un brame estil né qu'il est l'esclave de la cérémonie. On frotte sa langue avec de la poix-résine détrempée dans de la farine ; on prononce le mot oum ; on invoque vingt divinités subalternes avant qu'on lui ait coupé le nombril ; mais aussi on lui dit: Vivez pour commander aux hommes; et, dès qu'il peut parler, on lui fait sentir la dignité de son être. En effet, les brachmanes furent longtemps souverains dans l'Inde; et la théocratie fut établie dans cette vaste contrée plus qu'en aucun pays du monde.

Bientôt on expose l'enfant à la lune; on prie l'Être suprême d'effacer les péchés que l'enfant peut avoir commis, quoiqu'il ne soit né que depuis huit jours; on adresse des antiennes au feu; on donne à l'enfant, avec cent cérémonies, le nom de Chormo, qui est le titre d'honneur des brames.

Dès que cet enfant peut marcher, il passe sa vie à se baigner et à réciter des prières ; il fait le sacrifice des morts ; et ce sacrifice est institué pour que Brama donne à l'âme des ancêtres de l'enfant une demeure agréable dans d'autres corps.

On fait des prières aux cinq vents qui peuvent sortir par les cinq ouvertures du corps humain. Cela n'est pas plus étrange que les prières récitées au dieu Pet par les bonnes vieilles de Rome.

Nulle fonction de la nature, nulle action chez les brames, sans prières. La première fois qu'on rase la tête de l'enfant, le père dit au rasoir dévotement: "Rasoir, rase mon fils comme tu as rasé le soleil et le dieu Indro. » Il se pourrait, après tout, que le dieu Indro eût été autrefois rasé ; mais pour le soleil, cela n'est pas aisé à comprendre, à 
moins que les brames n'aient eu notre Apollon, que nous représentons encore sans barbe.

Le récit de toutes ces cérémonies serait aussi ennuyeux qu'elles nous paraissent ridicules; et, dans leur aveuglement, ils en disent autant des nôtres : mais il y a chez eux un mystère qui ne doit pas être passé sous silence, c'est le Matricha Machom. On se donne, par ce mystère, un nouvel être, une nouvelle vie.

L'âme est supposée être dans la poitrine ; et c'est en effet le sentiment de presque toute l'antiquité. On passe la main, de la poitrine à la tête, en appuyant sur le nerf qu'on croit aller d'un de ces organes à l'autre, et l'on conduit ainsi son âme à son cerveau. Quand on est sûr que son âme est bien montée, alors le jeune homme s'écrie que son âme et son corps sont réunis à l'Être suprême, et dit: Je suis moimême une partie de la Divinité.

Cette opinion a été celle des plus respectables philosophes de la Grèce, de ces stoïciens qui ont élevé la nature humaine au-dessus d'elle-même, celle des divins Antonins; et il faut avouer que rien n'était plus capable d'inspirer de grandes vertus. Se croire une partie de la Divinité, c'est s'imposer la loi de ne rien faire qui ne soit digne de Dieu même.

On trouve, dans cette loi des brachmanes, dix commandements, et ce sont dix péchés à éviter. Ils sont divisés en trois espèces : les péchés du corps, ceux de la parole, ceux de la volonté. Frapper, tuer son prochain, le voler, violer les femmes, ce sont les péchés du corps ; dissimuler, mentir, injurier, ce sont les péchés de la parole; ceux de la volonté consistent à souhaiter le mal, à regarder le bien des autres avec envie, à n'être pas touché des misères d'autrui. Ces dix commandements font pardonner tous les rites ridicules. On voit évidemment que la morale est la même chez toutes les nations civilisées, tandis que les usages les plus consacrés chez un peuple paraissent aux autres ou extravagants ou haïssables. Les rites établis divisent aujourd'hui le genre humain, et la morale le réunit.

La superstition n'empêcha jamais les brachmanes de reconnaître un dieu unique. Strabon, dans son quinzième livre, dit qu'ils adorent un dieu suprême; qu'ils gardent le silence plusieurs années avant d'oser parler; qu'ils sont sobres, chastes, tempérants ; qu'ils vivent 
dans la justice, et qu'ils meurent sans regret. C'est le témoignage que leur rendent saint Clément d'Alexandrie, Apulée, Porphyre, Pallade, saint Ambroise. N'oublions pas surtout qu'ils eurent un paradis terrestre, et que les hommes qui abusèrent des bienfaits de Dieu furent chassés de ce paradis.

La chute de l'homme dégénéré est le fondement de la théologie de presque toutes les anciennes nations. Le penchant naturel de l'homme à se plaindre du présent, et à vanter le passé, a fait imaginer partout une espèce d'âge d'or auquel les siècles de fer ont succédé. Ce qui est plus singulier encore, c'est que le Veidam des anciens brachmanes enseigne que le premier homme fut Adimo, et la première femme Procriti. Chez eux, Adimo signifiait Seigneur; et Procriti voulait dire la Vie ; comme Eva chez les Phéniciens, et même chez les Hébreux leurs imitateurs, signifiait aussi la Vie ou le Serpent. Cette conformité mérite une grande attention.

Table des Matières

18.

DE LA CHINE

Oserons-nous parler des Chinois sans nous en rapporter à leurs propres annales ? elles sont confirmées par le témoignage unanime de nos voyageurs de différentes sectes, jacobins, jésuites, luthériens, calvinistes, anglicans ; tous intéressés à se contredire. Il est évident que l'empire de la Chine était formé il y a plus de quatre mille ans. Ce peuple antique n'entendit jamais parler d'aucune de ces révolutions physiques, de ces inondations, de ces incendies, dont la faible mémoire s'était conservée et altérée dans les fables du déluge de Deucalion et de la chute de Phaéton. Le climat de la Chine avait donc été préservé de ces fléaux, comme il le fut toujours de la peste proprement dite, qui a tant de fois ravagé l'Afrique, l'Asie, et l'Europe.

Si quelques annales portent un caractère de certitude, ce sont celles des Chinois, qui ont joint, comme on l'a déjà dit ailleurs ${ }^{32}$, l'histoire du ciel à celle de la terre. Seuls de tous les peuples, ils ont constam-

32 Essai sur les Mours, chapitre I ${ }^{\mathrm{er}}$. 
ment marqué leurs époques par des éclipses, par les conjonctions des planètes ; et nos astronomes, qui ont examiné leurs calculs, ont été étonnés de les trouver presque tous véritables. Les autres nations inventèrent des fables allégoriques ; et les Chinois écrivirent leur histoire, la plume et l'astrolabe à la main, avec une simplicité dont on ne trouve point d'exemple dans le reste de l'Asie.

Chaque règne de leurs empereurs a été écrit par des contemporains ; nulles différentes manières de compter parmi eux ; nulles chronologies qui se contredisent. Nos voyageurs missionnaires rapportent, avec candeur, que lorsqu'ils parlèrent au sage empereur Cam-hi des variations considérables de la chronologie de la Vulgate, des Septante, et des Samaritains, Cam-hi leur répondit : «Est-il possible que les livres en qui vous croyez se combattent?»

Les Chinois écrivaient sur des tablettes légères de bambou, quand les Chaldéens n'écrivaient que sur des briques grossières; et ils ont même encore de ces anciennes tablettes que leur vernis a préservées de la pourriture: ce sont peut-être les plus anciens monuments du monde. Point d'histoire chez eux avant celle de leurs empereurs; presque point de fictions, aucun prodige, nul homme inspiré qui se dise demi-dieu, comme chez les Égyptiens et chez les Grecs ; dès que ce peuple écrit, il écrit raisonnablement.

Il diffère surtout des autres nations en ce que leur histoire ne fait aucune mention d'un collège de prêtres qui ait jamais influé sur les lois. Les Chinois ne remontent point jusqu'aux temps sauvages où les hommes eurent besoin qu'on les trompât pour les conduire. D'autres peuples commencèrent leur histoire par l'origine du monde : le Zend des Perses, le Shasta et le Veidam des Indiens, Sanchoniathon, Manéthon, enfin jusqu'à Hésiode, tous remontent à l'origine des choses, à la formation de l'univers. Les Chinois n'ont point eu cette folie ; leur histoire n'est que celle des temps historiques.

C'est ici qu'il faut surtout appliquer notre grand principe qu'une nation dont les premières chroniques attestent l'existence d'un vaste empire, puissant et sage, doit avoir été rassemblée en corps de peuple pendant des siècles antérieurs. Voilà ce peuple qui, depuis plus de 
quatre mille ans, écrit journellement ses annales. Encore une fois ${ }^{33}$, n'y aurait-il pas de la démence à ne pas voir que, pour être exercé dans tous les arts qu'exige la société des hommes, et pour en venir non seulement jusqu'à écrire, mais jusqu'à bien écrire, il avait fallu plus de temps que l'empire chinois n'a duré, en ne comptant que depuis l'empereur Fo-hi jusqu'à nos jours? Il n'y a point de lettré à la Chine qui doute que les cinq Kings n'aient été écrits deux mille trois cents ans avant notre ère vulgaire. Ce monument précède donc de quatre cents années les premières observations babyloniennes, envoyées en Grèce par Callisthène. De bonne foi, sied-il bien à des lettrés de Paris de contester l'antiquité d'un livre chinois, regardé comme authentique par tous les tribunaux de la Chine ${ }^{34}$ ?

Les premiers rudiments sont, en tout genre, plus lents chez les hommes que les grands progrès. Souvenons-nous toujours que presque personne ne savait écrire il y a cinq cents ans, ni dans le Nord, ni en Allemagne, ni parmi nous. Ces tailles dont se servent encore aujourd'hui nos boulangers étaient nos hiéroglyphes et nos livres de compte. Il n'y avait point d'autre arithmétique pour lever les impôts, et le nom de taille l'atteste encore dans nos campagnes. Nos coutumes capricieuses, qu'on n'a commencé à rédiger par écrit que depuis quatre cent cinquante ans, nous apprennent assez combien l'art d'écrire était rare alors. Il n'y a point de peuple en Europe qui n'ait fait, en dernier lieu, plus de progrès en un demi-siècle dans tous les arts qu'il n'en avait fait depuis les invasions des barbares jusqu'au quatorzième siècle.

Je n'examinerai point ici pourquoi les Chinois, parvenus à connaître et à pratiquer tout ce qui est utile à la société, n'ont pas été aussi loin que nous allons aujourd'hui dans les sciences. Ils sont aussi mauvais physiciens, je l'avoue, que nous l'étions il y a deux cents ans, et que les Grecs et les Romains l'ont été ; mais ils ont perfectionné la morale, qui est la première des sciences.

Leur vaste et populeux empire était déjà gouverné comme une famille dont le monarque était le père, et dont quarante tribunaux de lé-

\footnotetext{
33 Voyez Essai sur les Mours, chapitre II ${ }^{\mathrm{er}}$. (B.)

34 Voyez les lettres du savant jésuite Parennin. (V.)
} 
gislation étaient regardés comme les frères aînés, quand nous étions errants en petit nombre dans la forêt des Ardennes.

Leur religion était simple, sage, auguste, libre de toute superstition et de toute barbarie, quand nous n'avions pas même encore des Teutatès, à qui des druides sacrifiaient les enfants de nos ancêtres dans de grandes mannes d'osier.

Les empereurs chinois offraient eux-mêmes au Dieu de l'univers, au Chang-ti, au Tien, au principe de toutes choses, les prémices des récoltes deux fois l'année; et de quelles récoltes encore ! de ce qu'ils avaient semé de leurs propres mains. Cette coutume s'est soutenue pendant quarante siècles, au milieu même des révolutions et des plus horribles calamités.

Jamais la religion des empereurs et des tribunaux ne fut déshonorée par des impostures, jamais troublée par les querelles du sacerdoce et de l'empire, jamais chargée d'innovations absurdes, qui se combattent les unes les autres avec des arguments aussi absurdes qu'elles, et dont la démence a mis à la fin le poignard aux mains des fanatiques, conduits par des factieux. C'est par là surtout que les Chinois l'emportent sur toutes les nations de l'univers.

Leur Confutzée, que nous appelons Confucius, n'imagina ni nouvelles opinions ni nouveaux rites; il ne fit ni l'inspiré ni le prophète: c'était un sage magistrat qui enseignait les anciennes lois. Nous disons quelquefois, et bien mal à propos, la religion de Confucius; il n'en avait point d'autre que celle de tous les empereurs et de tous les tribunaux, point d'autre que celle des premiers sages. Il ne recommande que la vertu; il ne prêche aucun mystère. Il dit dans son premier livre que pour apprendre à gouverner il faut passer tous ses jours à se corriger. Dans le second, il prouve que Dieu a gravé lui-même la vertu dans le cœur de l'homme ; il dit que l'homme n'est point né méchant, et qu'il le devient par sa faute. Le troisième est un recueil de maximes pures, où vous ne trouvez rien de bas, et rien d'une allégorie ridicule. Il eut cinq mille disciples; il pouvait se mettre à la tête d'un parti puissant, et il aima mieux instruire les hommes que de les gouverner.

On s'est élevé avec force, dans l'Essai sur les Mœurs et l'Esprit des Nations (chap. II), contre la témérité que nous avons eue, au bout de l'Occident, de vouloir juger de cette cour orientale, et de lui attri- 
buer l'athéisme. Par quelle fureur, en effet, quelques-uns d'entre nous ont-ils pu appeler athée un empire dont presque toutes les lois sont fondées sur la connaissance d'un être suprême, rémunérateur et vengeur? Les inscriptions de leurs temples, dont nous avons des copies authentiques ${ }^{35}$, sont : « Au premier principe, sans commencement et sans fin. Il a tout fait, il gouverne tout. Il est infiniment bon, infiniment juste ; il éclaire, il soutient, il règle toute la nature. »

On a reproché, en Europe, aux jésuites qu'on n'aimait pas, de flatter les athées de la Chine. Un Français appelé Maigrot, nommé par un pape évêque in partibus de Conon à la Chine, fut député par ce même pape pour aller juger le procès sur les lieux. Ce Maigrot ne savait pas un mot de chinois ; cependant il traita Confucius d'athée, sur ces paroles de ce grand homme : Le ciel m'a donné la vertu, l'homme ne peut me nuire. Le plus grand de nos saints n'a jamais débité de maxime plus céleste. Si Confucius était athée, Caton et le chancelier de L'Hospital l'étaient aussi.

Répétons ici ${ }^{36}$, pour faire rougir la calomnie, que les mêmes hommes qui soutenaient contre Bayle qu'une société d'athées était impossible, avançaient en même temps que le plus ancien gouvernement de la terre était une société d'athées. Nous ne pouvons trop nous faire honte de nos contradictions.

Répétons encore ${ }^{37}$ que les lettrés chinois, adorateurs d'un seul Dieu, abandonnèrent le peuple aux superstitions des bonzes. Ils reçurent la secte de Laokium, et celle de Fo, et plusieurs autres. Les magistrats sentirent que le peuple pouvait avoir des religions différentes de celle de l'État, comme il a une nourriture plus grossière ; ils souffrirent les bonzes et les continrent. Presque partout ailleurs ceux qui faisaient le métier de bonzes avaient l'autorité principale.

Il est vrai que les lois de la Chine ne parlent point de peines et de récompenses après la mort : ils n'ont point voulu affirmer ce qu'ils ne savaient pas. Cette différence entre eux et tous les grands peuples policés est très étonnante. La doctrine de l'enfer était utile, et le gouver-

35 Voyez seulement les estampes gravées dans la collection du jésuite du Halde. (V.)

36 Voyez l'Essai sur les Mœurs, chapitre 2. (B.)

37 Id. (B.) 
nement des Chinois ne l'a jamais admise. Ils se contentèrent d'exhorter les hommes à révérer le ciel et à être justes. Ils crurent qu'une police exacte, toujours exercée, ferait plus d'effet que des opinions qui peuvent être combattues ; et qu'on craindrait plus la loi toujours présente qu'une loi à venir. Nous parlerons en son temps d'un autre peuple, infiniment moins considérable, qui eut à peu près la même idée, ou plutôt qui n'eut aucune idée, mais qui fut conduit par des voies inconnues aux autres hommes.

Résumons ici seulement que l'empire chinois subsistait avec splendeur quand les Chaldéens commençaient le cours de ces dix-neuf cents années d'observations astronomiques, envoyées en Grèce par Callisthène. Les Brames régnaient alors dans une partie de l'Inde; les Perses avaient leurs lois ; les Arabes, au midi ; les Scythes, au septentrion, habitaient sous des tentes ; l'Égypte, dont nous allons parler, était un puissant royaume.

Table des Matières

19.

DE L'ÉGYPTE

Il me paraît sensible que les Égyptiens, tout antiques qu'ils sont, ne purent être rassemblés en corps, civilisés, policés, industrieux, puissants, que très longtemps après tous les peuples que je viens de passer en revue. La raison en est évidente. L'Égypte, jusqu'au Delta, est resserrée par deux chaînes de rochers, entre lesquels le Nil se précipite, en descendant l'Éthiopie, du midi au septentrion. Il n'y a, des cataractes du Nil à ses embouchures, en ligne droite, que cent soixante lieues de trois mille pas géométriques; et la largeur n'est que de dix à quinze et vingt lieues jusqu'au Delta, partie basse de l'Égypte, qui embrasse une étendue de cinquante lieues, d'orient en occident. À la droite du Nil sont les déserts de la Thébaïde ; et à la gauche, les sables inhabitables de la Libye, jusqu'au petit pays où fut bâti le temple d'Ammon.

Les inondations du Nil durent, pendant des siècles, écarter tous les colons d'une terre submergée quatre mois de l'année ; ces eaux croupissantes, s'accumulant continuellement, durent longtemps faire un 
marais de toute l'Égypte. Il n'en est pas ainsi des bords de l'Euphrate, du Tigre, de l'Inde, du Gange, et d'autres rivières qui se débordent aussi presque chaque année, en été, à la fonte des neiges. Leurs débordements ne sont pas si grands, et les vastes plaines qui les environnent donnent aux cultivateurs toute la liberté de profiter de la fertilité de la terre. Observons surtout que la peste, ce fléau attaché au genre animal, règne une fois en dix ans au moins en Égypte; elle devait être beaucoup plus destructive quand les eaux du Nil, en croupissant sur la terre, ajoutaient leur infection à cette contagion horrible; et ainsi la population de l'Égypte dut être très faible pendant bien des siècles.

L'ordre naturel des choses semble donc démontrer invinciblement que 1'Égypte fut une des dernières terres habitées. Les Troglodytes, nés dans ces rochers dont le Nil est bordé, furent obligés à des travaux aussi longs que pénibles, pour creuser des canaux qui reçussent le fleuve, pour élever des cabanes et les rehausser de vingt-cinq pieds au-dessus du terrain. C'est là pourtant ce qu'il fallut faire avant de bâtir Thèbes aux prétendues cent portes, avant d'élever Memphis et de songer à construire des pyramides. Il est bien étrange qu'aucun ancien historien n'ait fait une réflexion si naturelle.

Nous avons déjà observé ${ }^{38}$ que dans le temps où l'on place les voyages d'Abraham, l'Égypte était un puissant royaume. Ses rois avaient déjà bâti quelques-unes de ces pyramides qui étonnent encore les yeux et l'imagination. Les Arabes ont écrit que la plus grande fut élevée par Saurid, plusieurs siècles avant Abraham. On ne sait dans quel temps fut construite la fameuse Thèbes aux cent portes, la ville de Dieu, Diospolis. Il paraît que dans ces temps reculés les grandes villes portaient le nom de ville de Dieu, comme Babylone. Mais qui pourra croire que par chacune des cent portes de cette ville il sortait deux cents chariots armés en guerre et dix mille combattants ${ }^{39}$ ? Cela ferait vingt mille chariots, et un million de soldats; et, à un soldat pour cinq personnes, ce nombre suppose au moins cinq millions de têtes pour une seule ville, dans un pays qui n'est pas si grand que

\section{Paragraphe 16. (B.)}

39 M. de Voltaire n'a en vue ici que les compilateurs modernes. Homère parle de cent chars qui sortaient de chaque porte de Thèbes ; Diodore en compte deux cents ; et c'est Pomponius Mela qui parle des dix mille combattants. Voyez la Défense de mon oncle, chapitre IX (dans les Mélanges, année 1767). (K.) 
l'Espagne ou que la France, et qui n'avait pas, selon Diodore de Sicile, plus de trois millions d'habitants, et plus de cent soixante mille soldats pour sa défense. Diodore, au livre premier, dit que l'Égypte était si peuplée qu'autrefois elle avait eu jusqu'à sept millions d'habitants, et que de son temps elle en avait encore trois millions.

Vous ne croyez pas plus aux conquêtes de Sésostris qu'au million de soldats qui sortent par les cent portes de Thèbes. Ne pensez-vous pas lire l'histoire de Picrocole, quand ceux qui copient Diodore vous disent que le père de Sésostris, fondant ses espérances sur un songe et sur un oracle, destina son fils à subjuguer le monde; qu'il fit élever à sa cour, dans le métier des armes, tous les enfants nés le même jour que ce fils; qu'on ne leur donnait à manger qu'après qu'ils avaient couru huit de nos grandes lieues ${ }^{40}$; enfin que Sésostris partit avec six cent mille hommes, et vingt-sept mille chars de guerre, pour aller conquérir toute la terre, depuis l'Inde jusqu'aux extrémités du PontEuxin, et qu'il subjugua la Mingrélie et la Géorgie, appelées alors la Colchide ${ }^{41}$ ? Hérodote ne doute pas que Sésostris n'ait laissé des colonies en Colchide, parce qu'il a vu à Colchos des hommes basanés, avec des cheveux crépus, ressemblants aux Égyptiens. Je croirais bien plutôt que ces espèces de Scythes des bords de la mer Noire et de la mer Caspienne vinrent rançonner les Égyptiens quand ils ravagèrent si longtemps l'Asie avant le règne de Cyrus. Je croirais qu'ils emmenèrent avec eux des esclaves de l'Égypte, ce vrai pays d'esclaves, dont Hérodote put voir ou crut voir les descendants en Colchide. Si les Colchidiens avaient en effet la superstition de se faire circoncire, ils avaient probablement retenu cette coutume d'Égypte ; comme il arriva presque toujours aux peuples du Nord de prendre les rites des nations civilisées qu'ils avaient vaincues ${ }^{42}$.

40 Quand on réduirait ces huit lieues à six, on ne retrancherait qu'un quart du ridicule. (V.)

41 Nous avons entendu expliquer cette histoire de Sésostris d'une manière très ingénieuse, en la regardant comme une allégorie. Sésostris est le soleil, qui part à la tête de l'armée céleste pour conquérir la terre; les dix-sept cents enfants, nés le même jour que lui sont les étoiles : les Égyptiens en devaient connaître à peu près ce nombre. Mais que cette fable soit une allégorie astronomique, ou un conte qui ne signifie rien, il est toujours également ridicule de la regarder comme une histoire. (K.)

42

Il peut y avoir eu une colonie égyptienne sur les bords du Pont-Euxin, sans que Sésostris soit parti de l'Égypte avec 600,000 combattants pour conquérir 
Jamais les Égyptiens, dans les temps connus, ne furent redoutables ; jamais ennemi n'entra chez eux qu'il ne les subjuguât. Les Scythes commencèrent. Après les Scythes vint Nabuchodonosor, qui conquit l'Égypte sans résistance; Cyrus n'eut qu'à y envoyer un de ses lieutenants : révoltée sous Cambyse, il ne fallut qu'une campagne pour la soumettre ; et ce Cambyse eut tant de mépris pour les Égyptiens qu'il tua leur dieu Apisen leur présence. Ochus réduisit l'Égypte en province de son royaume. Alexandre, César, Auguste, le calife Omar, conquirent l'Égypte avec une égale facilité. Ces mêmes peuples de Colchos, sous le nom de Mamelucs, revinrent encore s'emparer de l'Égypte du temps des croisades ; enfin Sélim $\mathrm{I}^{\mathrm{er}}$ conquit l'Égypte en une seule campagne, comme tous ceux qui s'y étaient présentés. Il n'y a jamais eu que nos seuls croisés qui se soient fait battre par ces Égyptiens, le plus lâche de tous les peuples, comme on l'a remarqué ailleurs ${ }^{43}$; mais c'est qu'alors les Égyptiens étaient gouvernés par la milice des Mamelucs de Colchos.

Il est vrai qu'un peuple humilié peut avoir été autrefois conquérant; témoin les Grecs et les Romains. Mais nous sommes plus sûrs de l'ancienne grandeur des Romains et des Grecs que de celle de Sésostris.

Je ne nie pas que celui qu'on appelle Sésostris n'ait pu avoir une guerre heureuse contre quelques Éthiopiens, quelques Arabes, quelques peuples de la Phénicie. Alors, dans le langage des exagérateurs, il aura conquis toute la terre. Il n'y a point de nation subjuguée qui ne prétende en avoir autrefois subjugué d'autres : la vaine gloire d'une ancienne supériorité console de l'humiliation présente.

Hérodote racontait ingénument aux Grecs ce que les Égyptiens lui avaient dit; mais comment, en ne lui parlant que de prodiges, ne lui dirent-ils rien des fameuses plaies d'Égypte, de ce combat magique entre les sorciers de Pharaon et le ministre du dieu des Juifs, et d'une armée entière engloutie au fond de la mer Rouge sous les eaux, élevées comme des montagnes à droite et à gauche pour laisser passer les Hébreux, lesquelles, en retombant, submergèrent les Égyptiens ? C'était assurément le plus grand événement dans l'histoire du monde :

la terre. Hérodote pouvait être à la fois un historien fabuleux et un mauvais logicien. (K.)

43 Dictionnaire philosophique, au mot APIS. (B.) 
comment donc ni Hérodote, ni Manéthon, ni Ératosthène, ni aucun des Grecs, si grands amateurs du merveilleux et toujours en correspondance avec l'Égypte, n'ont-ils point parlé de ces miracles qui devaient occuper la mémoire de toutes les générations ? Je ne fais pas assurément cette réflexion pour infirmer le témoignage des livres hébreux, que je révère comme je dois : je me borne à m'étonner seulement du silence de tous les Égyptiens et de tous les Grecs. Dieu ne voulut pas sans doute qu'une histoire si divine nous fut transmise par aucune main profane.

Table des Matières

20.

DE LA LANGUE DES ÉGYPTIENS, ET DE LEURS SYMBOLES

Le langage des Égyptiens n'avait aucun rapport avec celui des nations de l'Asie. Vous ne trouvez chez ce peuple ni le mot d'Adoni ou d'Adonaï, ni de Bal ou Baal, termes qui signifient le Seigneur; ni de Mithra, qui était le soleil chez les Perses ; ni de Melch, qui signifie roi en Syrie; ni de Shak, qui signifie la même chose chez les Indiens et chez les Persans. Vous voyez, au contraire, que Pharao était le nom égyptien qui répond à roi. Oshiret (Osiris) répondait au Mithra des Persans ; et le mot vulgaire On signifiait le soleil. Les prêtres persans s'appelaient mogh ; ceux des Égyptiens choen, au rapport de la Genèse, chapitre XLVI. Les hiéroglyphes, les caractères alphabétiques d'Égypte, que le temps a épargnés, et que nous voyons encore gravés sur les obélisques, n'ont aucun rapport à ceux des autres peuples.

Avant que les hommes eussent inventé les hiéroglyphes, ils avaient indubitablement des signes représentatifs ; car, en effet, qu'ont pu faire les premiers hommes, sinon ce que nous faisons quand nous sommes à leur place? Qu'un enfant se trouve dans un pays dont il ignore la langue, il parle par signes ; si on ne l'entend pas, pour peu qu'il ait la moindre sagacité, il dessine sur un mur, avec un charbon, les choses dont il a besoin.

On peignit donc d'abord grossièrement ce qu'on voulut faire entendre; et l'art de dessiner précéda sans doute l'art d'écrire. C'est ain- 
si que les Mexicains écrivaient; ils n'avaient pas poussé l'art plus loin. Telle était la méthode de tous les premiers peuples policés. Avec le temps, on inventa les figures symboliques : deux mains entrelacées signifièrent la paix, des flèches représentèrent la guerre, un œil signifia la Divinité, un sceptre marqua la royauté, et des lignes qui joignaient ces figures exprimèrent des phrases courtes.

Les Chinois inventèrent enfin des caractères pour exprimer chaque mot de leur langue. Mais quel peuple inventa l'alphabet, qui, en mettant sous les yeux les différents sons qu'on peut articuler, donne la facilité de combiner par écrit tous les mots possibles ? Qui put ainsi apprendre aux hommes à graver si aisément leurs pensées ? Je ne répéterai point ici tous les contes des anciens sur cet art qui éternise tous les arts ; je dirai seulement qu'il a fallu bien des siècles pour y arriver.

Les choen, ou prêtres d'Égypte, continuèrent longtemps d'écrire en hiéroglyphes; ce qui est défendu par le second article de la loi des Hébreux : et quand les peuples d'Égypte eurent des caractères alphabétiques, les choen en prirent de différents qu'ils appelèrent sacrés, afin de mettre toujours une barrière entre eux et le peuple. Les mages, les brames, en usaient de même : tant l'art de se cacher aux hommes a semblé nécessaire pour les gouverner. Non seulement ces choen avaient des caractères qui n'appartenaient qu'à eux, mais ils avaient encore conservé l'ancienne langue de l'Égypte quand le temps avait changé celle du vulgaire.

Manéthon, cité dans Eusèbe, parle de deux colonnes gravées par Thaut, le premier Hermès, en caractères de la langue sacrée ; mais qui sait en quel temps vivait cet ancien Hermès? Il est très vraisemblable qu'il vivait plus de huit cents ans avant le temps où l'on place Moïse ; car Sanchoniathon dit avoir lu les écrits de Thaut, faits, dit-il, il y a huit cents ans. Or Sanchoniathon écrivait en Phénicie, pays voisin de la petite contrée cananéenne mise à feu et à sang par Josué, selon les livres juifs. S'il avait été contemporain de Moïse, ou s'il était venu après lui, il aurait sans doute parlé d'un homme si extraordinaire et de ses prodiges épouvantables; il aurait rendu témoignage à ce fameux législateur juif, et Eusèbe n'aurait pas manqué de se prévaloir des aveux de Sanchoniathon. 
Quoi qu'il en soit, les Égyptiens gardèrent surtout très scrupuleusement leurs premiers symboles. C'est une chose curieuse de voir sur leurs monuments un serpent qui se mord la queue, figurant les douze mois de l'année ; et ces douze mois exprimés chacun par des animaux, qui ne sont pas absolument ceux du zodiaque que nous connaissons. On voit encore les cinq jours ajoutés depuis aux douze mois, sous la forme d'un petit serpent sur lequel cinq figures sont assises : c'est un épervier, un homme, un chien, un lion, et un ibis. On les voit dessinés dans Kircher, d'après des monuments conservés à Rome. Ainsi presque tout est symbole et allégorie dans l'antiquité.

Table des Matières

21.

DES MONUMENTS DES ÉGYPTIENS

Il est certain qu'après les siècles où les Égyptiens fertilisèrent le sol par les saignées du fleuve, après les temps où les villages commencèrent à être changés en villes opulentes, alors les arts nécessaires étant perfectionnés, les arts d'ostentation commencèrent à être en honneur. Alors il se trouva des souverains qui employèrent leurs sujets et quelques Arabes voisins du lac Sirbon à bâtir leurs palais et leurs tombeaux en pyramides, à tailler des pierres énormes dans les carrières de la haute Égypte, à les embarquer sur des radeaux jusqu'à Memphis, à élever sur des colonnes massives de grandes pierres plates, sans goût et sans proportions. Ils connurent le grand, et jamais le beau. Ils enseignèrent les premiers Grecs ; mais ensuite les Grecs furent leurs maîtres en tout quand ils eurent bâti Alexandrie.

Il est triste que, dans la guerre de César, la moitié de la fameuse bibliothèque des Ptolémées ait été brûlée, et que l'autre moitié ait chauffé les bains des musulmans, quand Omar subjugua l'Égypte : on eut connu du moins l'origine des superstitions dont ce peuple fut infecté, le chaos de leur philosophie, quelques-unes de leurs antiquités et de leurs sciences. 
Il faut absolument qu'ils aient été en paix pendant plusieurs siècles pour que leurs princes aient eu le temps et le loisir d'élever tous ces bâtiments prodigieux dont la plupart subsistent encore.

Leurs pyramides coûtèrent bien des années et bien des dépenses ; il fallut qu'une grande partie de la nation et nombre d'esclaves étrangers fussent longtemps employés à ces ouvrages immenses. Ils furent élevés par le despotisme, la vanité, la servitude, et la superstition. En effet il n'y avait qu'un roi despote qui put forcer ainsi la nature. L'Angleterre, par exemple, est aujourd'hui plus puissante que ne l'était l'Égypte : un roi d'Angleterre pourrait-il employer sa nation à élever de tels monuments?

La vanité y avait part sans doute; c'était, chez les anciens rois d'Égypte, à qui élèverait la plus belle pyramide à son père ou à luimême ; la servitude procura la main-d'œuvre. Et quant à la superstition, on sait que ces pyramides étaient des tombeaux; on sait que les chochamatim ou choen d'Égypte, c'est-à-dire les prêtres, avaient persuadé la nation que l'âme rentrerait dans son corps au bout de mille années. On voulait que le corps fût mille ans entiers à l'abri de toute corruption : c'est pourquoi on l'embaumait avec un soin si scrupuleux ; et, pour le dérober aux accidents, on l'enfermait dans une masse de pierre sans issue. Les rois, les grands, donnaient à leurs tombeaux la forme qui offrait le moins de prise aux injures du temps. Leurs corps se sont conservés au delà des espérances humaines. Nous avons aujourd'hui des momies égyptiennes de plus de quatre mille années. Des cadavres ont duré autant que des pyramides.

Cette opinion d'une résurrection après dix siècles passa depuis chez les Grecs, disciples des Égyptiens, et chez les Romains, disciples des Grecs. On la retrouve dans le sixième livre de l'Énéide, qui n'est que la description des mystères d'Isis et de Cérès Éleusine ${ }^{44}$.

« Has omnes, ubi mille rotam volvere per annos, Lethæum ad fluvium Deus evocat, agmine magno ;

Scilicet immemores supera ut convexa revisant, Rursus et incipiant in corpora velle reverti. »

VIRG., Énéide, liv. VI, v. 748.

44 Voyez le Dictionnaire philosophique, article Initiation. (V.) — Voltaire y déclare se dédire de l'opinion qu'il émet ici. (B.) 
Elle s'introduisit ensuite chez les chrétiens, qui établirent le règne de mille ans ; la secte des millénaires l'a fait revivre jusqu'à nos jours. C'est ainsi que plusieurs opinions ont fait le tour du monde. En voilà assez pour faire voir dans quel esprit on bâtit ces pyramides. Ne répétons pas ce qu'on a dit sur leur architecture et sur leurs dimensions ; je n'examine que l'histoire de l'esprit humain.

$\underline{\text { Table des Matières }}$

22.

DES RITES ÉGYPTIENS, ET DE LA CIRCONCISION

Premièrement, les Égyptiens reconnurent-ils un Dieu suprême? si l'on eût fait cette question aux gens du peuple, ils n'auraient su que répondre; si à de jeunes étudiants dans la théologie égyptienne, ils auraient parlé longtemps sans s'entendre; si à quelqu'un des sages consultés par Pythagore, par Platon, par Plutarque, il eût dit nettement qu'il n'adorait qu'un Dieu. Il se serait fondé sur l'ancienne inscription de la statue d'Isis : «Je suis ce qui est; » et cette autre : «Je suis tout ce qui a été et qui sera; nul mortel ne pourra lever mon voile. » Il aurait fait remarquer le globe placé sur la porte du temple de Memphis, qui représentait l'unité de la nature divine sous le nom de Knef. Le nom même le plus sacré parmi les Égyptiens était celui que les Hébreux adoptèrent, I ha ho. On le prononce diversement ; mais Clément d'Alexandrie assure, dans ses Stromates, que ceux qui entraient dans le temple de Sérapis étaient obligés de porter sur eux le nom de I ha ho, ou bien de I ha hou, qui signifie le Dieu éternel. Les Arabes n'en ont retenu que la syllabe Hou, adoptée enfin par les Turcs, qui la prononcent avec plus de respect encore que le mot Allah; car ils se servent d'Allah dans la conversation, et ils n'emploient Hou que dans leurs prières.

Disons ici en passant que l'ambassadeur turc Seid Effendi, voyant représenter à Paris le Bourgeois gentilhomme, et cette cérémonie ridicule dans laquelle on le fait Turc ; quand il entendit prononcer le nom sacré $\mathrm{Hou}$ avec dérision et avec des postures extravagantes, il regarda ce divertissement comme la profanation la plus abominable. 
Revenons. Les prêtres d'Égypte nourrissaient-ils un bœuf sacré, un chien sacré, un crocodile sacré ? oui. Et les Romains eurent aussi des oies sacrées; ils eurent des dieux de toute espèce; et les dévotes avaient parmi leurs pénates le dieu de la chaise percée, deum stercutium; et le dieu Pet, deum crepitum: mais en reconnaissaient-ils moins le Deum optimum maximum, le maître des dieux et des hommes ? Quel est le pays qui n'ait pas en une foule de superstitieux, et un petit nombre de sages?

Ce qu'on doit surtout remarquer de l'Égypte et de toutes les nations, c'est qu'elles n'ont jamais eu d'opinions constantes, comme elles n'ont jamais eu de lois toujours uniformes, malgré l'attachement que les hommes ont à leurs anciens usages. Il n'y a d'immuable que la géométrie ; tout le reste est une variation continuelle.

Les savants disputent, et disputeront. L'un assure que les anciens peuples ont tous été idolâtres, l'autre le nie. L'un dit qu'ils n'ont adoré qu'un dieu sans simulacre ; l'autre, qu'ils ont révéré plusieurs dieux dans plusieurs simulacres; ils ont tous raison : il n'y a seulement qu'à distinguer le temps et les hommes, qui ont changé : rien ne fut jamais d'accord. Quand les Ptolémées et les principaux prêtres se moquaient du bœuf Apis, le peuple tombait à genoux devant lui.

Juvénal a dit que les Égyptiens adoraient des oignons ; mais aucun historien ne l'avait dit. Il y a bien de la différence entre un oignon sacré et un oignon dieu; on n'adore pas tout ce qu'on place, tout ce que l'on consacre sur un autel. Nous lisons dans Cicéron que les hommes, qui ont épuisé toutes les superstitions, ne sont point parvenus encore à celle de manger leurs dieux, et que c'est la seule absurdité qui leur manque ${ }^{45}$.

La circoncision vient-elle des Égyptiens, des Arabes, ou des Éthiopiens? Je n'en sais rien. Que ceux qui le savent le disent. Tout ce que

45 Le passage de Cicéron dont Voltaire rapporte le sens ne se trouve point dans le livre De Divinatione, comme Voltaire le dit ailleurs (chapitre V du Pyrrhonisme de l'histoire, dans les Mélanges, année 1768). Ce passage, habilement employé par Bayle dans son Dictionnaire, note $\mathrm{H}$ de l'article Averroès, est dans le traité De Natura deorum, III, 16: Cum fruges Cererem, vinum Liberum dicimus, genere nos quidem sermonis utimur usitato : ecquem tam amentem esse putas, qui illud quo vescatur deum credat esse?

Cicéron est mort quarante-trois ans avant l'ère vulgaire. 
je sais, c'est que les prêtres de l'antiquité s'imprimaient sur le corps des marques de leur consécration; comme depuis on marqua d'un fer ardent la main des soldats romains. Là, des sacrificateurs se tailladaient le corps, comme firent depuis les prêtres de Bellone; ici, ils se faisaient eunuques, comme les prêtres de Cybèle.

Ce n'est point du tout par un principe de santé que les Éthiopiens, les Arabes, les Égyptiens, se circoncirent. On a dit qu'ils avaient le prépuce trop long ; mais, si l'on peut juger d'une nation par un individu, j'ai vu un jeune Éthiopien qui, né hors de sa patrie, n'avait point été circoncis : je puis assurer que son prépuce était précisément comme les nôtres.

Je ne sais pas quelle nation s'avisa la première de porter en procession le kteis et le phallum, c'est-à-dire la représentation des signes distinctifs des animaux mâles et femelles ; cérémonie aujourd'hui indécente, autrefois sacrée : les Égyptiens eurent cette coutume. On offrait aux dieux des prémices ; on leur immolait ce qu'on avait de plus précieux : il paraît naturel et juste que les prêtres offrissent une légère partie de l'organe de la génération à ceux par qui tout s'engendrait. Les Éthiopiens, les Arabes, circoncirent aussi leurs filles, en coupant une très légère partie des nymphes; ce qui prouve bien que la santé ni la netteté ne pouvaient être la raison de cette cérémonie, car assurément une fille incirconcise peut être aussi propre qu'une circoncise.

Quand les prêtres d'Égypte eurent consacré cette opération, leurs initiés la subirent aussi ; mais, avec le temps, on abandonna aux seuls prêtres cette marque distinctive. On ne voit pas qu'aucun Ptolémée se soit fait circoncire ; et jamais les auteurs romains ne flétrirent le peuple égyptien du nom d'Apella ${ }^{46}$, qu'ils donnaient aux Juifs. Ces Juifs avaient pris la circoncision des Égyptiens, avec une partie de leurs cérémonies. Ils l'ont toujours conservée, ainsi que les Arabes et les Éthiopiens. Les Turcs s'y sont soumis, quoiqu'elle ne soit pas ordonnée dans l'Alcoran. Ce n'est qu'un ancien usage qui commença par la superstition, et qui s'est conservé par la coutume.

46 Credat Judaeus Apella. HoRAT., lib. I, sat. 5, v. 100. (B.) 
23.

\section{DES MYSTÈRES DES ÉGYPTIENS}

Je suis bien loin de savoir quelle nation inventa la première ces mystères qui furent si accrédités depuis l'Euphrate jusqu'au Tibre. Les Égyptiens ne nomment point l'auteur des mystères d'Isis. Zoroastre passe pour en avoir établi en Perse ; Cadmus et Inachus, en Grèce ; Orphée, en Thrace ; Minos, en Crète. Il est certain que tous ces mystères annonçaient une vie future, car Celse dit aux chrétiens ${ }^{47}$ : «Vous vous vantez de croire des peines éternelles; eh ! tous les ministres des mystères ne les annoncèrent-ils pas aux initiés? »

Les Grecs, qui prirent tant de choses des Égyptiens ; leur Tartharoth, dont ils firent le Tartare ; le lac, dont ils firent l'Achéron ; le batelier Caron, dont ils firent le nocher des morts, n'eurent leurs fameux mystères d'Éleusine que d'après ceux d'Isis. Mais que les mystères de Zoroastre n'aient pas précédé ceux des Égyptiens, c'est ce que personne ne peut affirmer. Les uns et les autres étaient de la plus haute antiquité, et tous les auteurs grecs et latins qui en ont parlé conviennent que l'unité de Dieu, l'immortalité de l'âme, les peines et les récompenses après la mort, étaient annoncées dans ces cérémonies sacrées.

Il y a grande apparence que les Égyptiens, ayant une fois établi ces mystères, en conservèrent les rites ; car, malgré leur extrême légèreté, ils furent constants dans la superstition. La prière que nous trouvons dans Apulée, quand Lucius est initié aux mystères d'Isis, doit être l'ancienne prière: «Les puissances célestes te servent, les enfers te sont soumis, l'univers tourne sous ta main, tes pieds foulent le Tartare, les astres répondent à ta voix, les saisons reviennent à tes ordres, les éléments t'obéissent, etc. »

Origène, liv. VIII. (V.) 
Peut-on avoir une plus forte preuve de l'unité de Dieu reconnue par les Égyptiens, au milieu de toutes leurs superstitions méprisables ?

Table des Matières

24.

DES GRECS, DE LEURS ANCIENS DÉLUGES, DE LEURS ALPHABETS, ET DE LEURS RITES

La Grèce est un petit pays montagneux, entrecoupé par la mer, à peu près de l'étendue de la Grande-Bretagne. Tout atteste, dans cette contrée, les révolutions physiques qu'elle a dû éprouver. Les îles qui l'environnent montrent assez, par les écueils continus qui les bordent, par le peu de profondeur de la mer, par les herbes et les racines qui croissent sous les eaux, qu'elles ont été détachées du continent. Les golfes de l'Eubée, de Chalcis, d'Argos, de Corinthe, d'Actium, de Messène, apprennent aux yeux que la mer s'est fait des passages dans les terres. Les coquillages de mer dont sont remplies les montagnes qui renferment la fameuse vallée de Tempé, sont des témoignages visibles d'une ancienne inondation; et les déluges d'Ogygès et de Deucalion, qui ont fourni tant de fables, sont d'une vérité historique : c'est même probablement ce qui fait des Grecs un peuple si nouveau. Ces grandes révolutions les replongèrent dans la barbarie, quand les nations de l'Asie et de l'Égypte étaient florissantes.

Je laisse à de plus savants que moi le soin de prouver que les trois enfants de Noé, qui étaient les seuls habitants du globe, le partagèrent tout entier; qu'ils allèrent chacun à deux ou trois mille lieues l'un de l'autre fonder partout de puissants empires, et que Javan, son petitfils, peupla la Grèce en passant en Italie ; que c'est de là que les Grecs s'appelèrent Ioniens, parce que Ion envoya des colonies sur les côtes de l'Asie Mineure ; que cet Ion est visiblement Javan, en changeant I en $J a$, et on en van. On fait de ces contes aux enfants, et les enfants n'en croient rien :

« Nec pueri credunt, nisi qui nondum ære lavantur. »

JUVÉN., sat. II, v. 153. 
Le déluge d'Ogygès est placé communément environ 1020 années avant la première olympiade. Le premier qui en parle est Acusilaüs, cité par Jules l'Africain. Voyez Eusèbe dans sa Préparation évangélique. La Grèce, dit-on, resta presque déserte deux cents années après cette irruption de la mer dans le pays. Cependant on prétend que, dans le même temps, il y avait un gouvernement établi à Sicyone et dans Argos ; on cite même les noms des premiers magistrats de ces petites provinces, et on leur donne le nom de Basiléis ${ }^{48}$, qui répond à celui de princes. Ne perdons point de temps à pénétrer ces inutiles obscurités.

Il y eut encore une autre inondation du temps de Deucalion, fils de Prométhée. La fable ajoute qu'il ne resta des habitants de ces climats que Deucalion et Pyrrha, qui refirent des hommes en jetant des pierres derrière eux entre leurs jambes. Ainsi le genre humain se repeupla beaucoup plus vite qu'une garenne.

Si l'on en croit des hommes très judicieux, comme Pétau le jésuite, un seul fils de Noé produisit une race qui, au bout de deux cent quatre-vingt-cinq ans, se montait à six cent vingt-trois milliards six cent douze millions d'hommes : le calcul est un peu fort. Nous sommes aujourd'hui assez malheureux pour que de vingt-six mariages il n'y en ait d'ordinaire que quatre dont il reste des enfants qui deviennent pères : c'est ce qu'on a calculé sur les relevés des registres de nos plus grandes villes. De mille enfants nés dans une même année, il en reste à peine six cents au bout de vingt ans. Défions-nous de Pétau et de ses semblables, qui font des enfants à coups de plume, aussi bien que de ceux qui ont écrit que Deucalion et Pyrrha peuplèrent la Grèce à coups de pierres.

La Grèce fut, comme on sait, le pays des fables; et presque chaque fable fut l'origine d'un culte, d'un temple, d'une fête publique. Par quel excès de démence, par quelle opiniâtreté absurde, tant de compilateurs ont-ils voulu prouver, dans tant de volumes énormes, qu'une fête publique établie en mémoire d'un événement était une démonstration de la vérité de cet événement? Quoi ! parce qu'on célébrait dans un temple le jeune Bacchus sortant de la cuisse de Jupiter, ce Jupiter

48

La première édition et ses réimpressions portaient Basiloï. Ce fut le sujet de critiques dures de la part de Larcher. (B.) 
avait en effet gardé ce Bacchus dans sa cuisse ! Quoi ! Cadmus et sa femme avaient été changés en serpents dans la Béotie, parce que les Béotiens en faisaient commémoration dans leurs cérémonies! Le temple de Castor et de Pollux à Rome démontrait-il que ces dieux étaient venus combattre en faveur des Romains?

Soyez sûr bien plutôt, quand vous voyez une ancienne fête, un temple antique, qu'ils sont les ouvrages de l'erreur: cette erreur s'accrédite au bout de deux ou trois siècles; elle devient enfin sacrée, et l'on bâtit des temples à des chimères.

Dans les temps historiques, au contraire, les plus nobles vérités trouvent peu de sectateurs; les plus grands hommes meurent sans honneur. Les Thémistocle, les Cimon, les Miltiade, les Aristide, les Phocion, sont persécutés ; tandis que Persée, Bacchus, et d'autres personnages fantastiques, ont des temples.

On peut croire un peuple sur ce qu'il dit de lui-même à son désavantage, quand ces récits sont accompagnés de vraisemblance, et qu'ils ne contredisent en rien l'ordre ordinaire de la nature.

Les Athéniens, qui étaient épars dans un terrain très stérile, nous apprennent eux-mêmes qu'un Égyptien nommé Cécrops, chassé de son pays, leur donna leurs premières institutions. Cela paraît surprenant, puisque les Égyptiens n'étaient pas navigateurs ; mais il se peut que les Phéniciens, qui voyageaient chez toutes les nations, aient amené ce Cécrops dans l'Attique. Ce qui est bien sûr, c'est que les Grecs ne prirent point les lettres égyptiennes, auxquelles les leurs ne ressemblent point du tout. Les Phéniciens leur portèrent leur premier alphabet; il ne consistait alors qu'en seize caractères, qui sont évidemment les mêmes : les Phéniciens depuis y ajoutèrent huit autres lettres, que les Grecs adoptèrent encore.

Je regarde un alphabet comme un monument incontestable du pays dont une nation a tiré ses premières connaissances. Il paraît encore bien probable que ces Phéniciens exploitèrent les mines d'argent qui étaient dans l'Attique, comme ils travaillèrent à celles d'Espagne. Des marchands furent les premiers précepteurs de ces mêmes Grecs, qui depuis instruisirent tant d'autres nations. 
Ce peuple, tout barbare qu'il était au temps d'Ogygès, paraît né avec des organes plus favorables aux beaux-arts que tous les autres peuples. Ils avaient dans leur nature je ne sais quoi de plus fin et de plus délié ; leur langage en est un témoignage, car, avant même qu'ils sussent écrire, on voit qu'ils eurent dans leur langue un mélange harmonieux de consonnes douces et de voyelles qu'aucun peuple de l'Asie n'a jamais connu.

Certainement le nom de Knath, qui désigne les Phéniciens, selon Sanchoniathon, n'est pas si harmonieux que celui d'Hellen ou Graïos ${ }^{49}$. Argos, Athènes, Lacédémone, Olympie, sonnent mieux à l'oreille que la ville de Reheboth. Sophia, la sagesse, est plus doux que shochemath en syriaque et en hébreu. Basileus, roi, sonne mieux que melk ou shak. Comparez les noms d'Agamemnon, de Diomède, d'Idoménèe, à ceux de Mardokempad, Simordak, Sohasduck, Niricassolahssar. Josèphe lui-même, dans son livre contre Apion, avoue que les Grecs ne pouvaient prononcer le nom barbare de Jérusalem ; c'est que les Juifs prononçaient Hershalaïm : ce mot écorchait le gosier d'un Athénien, et ce furent les Grecs qui changèrent Hershalaïm en Jérusalem.

Les Grecs transformèrent tous les noms rudes syriaques, persans, égyptiens. De Coresh ils firent Cyrus; d'Isheth et Oshireth ils firent Isis et Osiris ; de Moph ils firent Memphis, et accoutumèrent enfin les barbares à prononcer comme eux ; de sorte que, du temps des Ptolémées, les villes et les dieux d'Égypte n'eurent plus que des noms à la grecque.

Ce sont les Grecs qui donnèrent le nom à l'Inde et au Gange. Le Gange s'appelait Sannoubi dans la langue des brames ; l'Indus, Sombadipo ${ }^{50}$. Tels sont les anciens noms qu'on trouve dans le Veidam.

Les Grecs, en s'étendant sur les côtes de l'Asie Mineure, y amenèrent l'harmonie. Leur Homère naquit probablement à Smyrne.

La belle architecture, la sculpture perfectionnée, la peinture, la bonne musique, la vraie poésie, la vraie éloquence, la manière de bien

49 Les premières éditions portaient Hellenos ou Graios. Larcher remarqua qu'il fallait dire Hellen ou Graïcos. (B.)

50 Ces mots sont écrits autrement dans l'Essai sur les Mœurs, chapitre 4. (B.) 
écrire 1'histoire, enfin la philosophie même, quoique informe et obscure, tout cela ne parvint aux nations que par les Grecs. Les derniers venus l'emportèrent en tout sur leurs maîtres.

L'Égypte n'eut jamais de belles statues que de la main des Grecs. L'ancienne Balbek en Syrie, l'ancienne Palmyre en Arabie, n'eurent ces palais, ces temples réguliers et magnifiques, que lorsque les souverains de ces pays appelèrent les artistes de la Grèce.

On ne voit que des restes de barbarie, comme on l'a déjà dit ailleurs ${ }^{51}$, dans les ruines de Persépolis, bâtie par les Perses ; et les monuments de Balbek et de Palmyre sont encore, sous leurs décombres, des chefs-d'œuvre d'architecture.

Table des Matières

25.

DES LÉGISLATEURS GRECS, DE MINOS, D'ORPHÉE, DE L'IMMORTALITÉ DE L'ÂME

Que des compilateurs répètent les batailles de Marathon et de Salamine, ce sont de grands exploits assez connus ; que d'autres répètent qu'un petit-fils de Noé, nommé Sétim, fut roi de Macédoine, parce que dans le premier livre des Machabées, il est dit qu'Alexandre sortit du pays de Kittim ; je m'attacherai à d'autres objets.

Minos vivait à peu près au temps où nous plaçons Moïse ; et c'est même ce qui a donné au savant Huet, évêque d'Avranches, quelque faux prétexte de soutenir que Minos né en Crète, et Moïse né sur les confins de l'Égypte, étaient la même personne ; système qui n'a trouvé aucun partisan, tout absurde qu'il est.

Ce n'est pas ici une fable grecque ; il est indubitable que Minos fut un roi législateur. Les fameux marbres de Paros, monument le plus précieux de l'antiquité, et que nous devons aux Anglais, fixent sa naissance quatorze cent quatre-vingt-deux ans avant notre ère vulgai-

Essai sur les Mours, chapitre 5. (B.) 
re $^{52}$. Homère l'appelle dans l'Odyssée le sage, le confident de Dieu. Flavien Josèphe cherche à justifier Moïse par l'exemple de Minos, et des autres législateurs qui se sont crus ou qui se sont dits inspirés de Dieu. Cela est un peu étrange dans un Juif, qui ne semblait pas devoir admettre d'autre dieu que le sien, à moins qu'il ne pensât comme les Romains ses maîtres et comme chaque premier peuple de l'antiquité, qui admettait l'existence de tous les dieux des autres nations ${ }^{53}$.

Il est sûr que Minos était un législateur très sévère, puisqu'on supposa qu'après sa mort il jugeait les âmes des morts dans les enfers ; il est évident qu'alors la croyance d'une autre vie était généralement répandue dans une assez grande partie de l'Asie et de l'Europe.

Orphée est un personnage aussi réel que Minos ; il est vrai que les marbres de Paros n'en font point mention ; c'est probablement parce qu'il n'était pas né dans la Grèce proprement dite, mais dans la Thrace. Quelques-uns ont douté de l'existence du premier Orphée, sur un passage de Cicéron, dans son excellent livre De la Nature des dieux. Cotta, un des interlocuteurs, prétend qu'Aristote ne croyait pas que cet Orphée eût été chez les Grecs ; mais Aristote n'en parle pas dans les ouvrages que nous avons de lui. L'opinion de Cotta n'est pas d'ailleurs celle de Cicéron. Cent auteurs anciens parlent d'Orphée : les mystères qui portent son nom lui rendaient témoignage. Pausanias, l'auteur le plus exact qu'aient jamais eu les Grecs, dit que ses vers étaient chantés dans les cérémonies religieuses, de préférence à ceux d'Homère, qui ne vint que longtemps après lui. On sait bien qu'il ne descendit pas aux enfers; mais cette fable même prouve que les enfers étaient un point de la théologie de ces temps reculés.

L'opinion vague de la permanence de l'âme après la mort, âme aérienne, ombre du corps, mânes, souffle léger, âme inconnue, âme incompréhensible, mais existante, et la croyance des peines et des ré-

52 Dans cet endroit des marbres d'Arundel, la date est effacée ; mais ils parlent de Minos comme d'un personnage réel; et le lieu où se trouve le passage mutilé suffit pour indiquer à peu près l'époque de sa naissance ou de son règne. (K.)

53 Quoi qu'en aient dit les critiques de M. de Voltaire, ce Josèphe était un fripon qui ne croyait pas plus à Moïse qu'à Minos; son raisonnement se réduit à ceci : «Vous regardez Minos comme un héros, quoiqu'il se soit dit inspiré : pourquoi n'avez-vous pas la même indulgence pour Moïse ?» (K.) 
compenses dans une autre vie, étaient admises dans toute la Grèce, dans les Iles, dans l'Asie, dans l'Égypte.

Les Juifs seuls parurent ignorer absolument ce mystère ; le livre de leurs lois n'en dit pas un seul mot: on n'y voit que des peines et des récompenses temporelles. Il est dit dans l'Exode: "Honore ton père et ta mère, afin qu'Adonaï prolonge tes jours sur la terre ; » et le livre du Zend (porte 11) dit : " Honore ton père et ta mère, afin de mériter le ciel. »

Warburton, le commentateur de Shakespeare, et de plus auteur de la Légation de Moïse, n'a pas laissé de démontrer dans cette Légation que Moïse n'a jamais fait mention de l'immortalité de l'âme : il a même prétendu que ce dogme n'est point du tout nécessaire dans une théocratie. Tout le clergé anglican s'est révolté contre la plupart de ses opinions, et surtout contre l'absurde arrogance avec laquelle il les débite dans sa compilation trop pédantesque. Mais tous les théologiens de cette savante Église sont convenus que le dogme de l'immortalité n'est pas ordonné dans le Pentateuque. Cela est, en effet, plus clair que le jour.

Arnauld, le grand Arnauld, esprit supérieur en tout à Warburton, avait dit longtemps avant lui, dans sa belle apologie de Port-Royal, ces propres paroles : "C'est le comble de l'ignorance de mettre en doute cette vérité, qui est des plus communes, et qui est attestée par tous les pères, que les promesses de l'Ancien Testament n'étaient que temporelles et terrestres, et que les Juifs n'adoraient Dieu que pour les biens charnels. »

On a objecté que si les Perses, les Arabes, les Syriens, les Indiens, les Égyptiens, les Grecs, croyaient l'immortalité de l'âme, une vie à venir, des peines et des récompenses éternelles, les Hébreux pouvaient bien aussi les croire : que si tous les législateurs de l'antiquité ont établi de sages lois sur ce fondement, Moïse pouvait bien en user de même; que, s'il ignorait ces dogmes utiles, il n'était pas digne de conduire une nation; que, s'il les savait et les cachait, il en était encore plus indigne.

On répond à ces arguments que Dieu, dont Moïse était l'organe, daignait se proportionner à la grossièreté des Juifs. Je n'entre point 
dans cette question épineuse, et, respectant toujours tout ce qui est divin, je continue l'examen de l'histoire des hommes. 
26.

\section{DES SECTES DES GRECS}

Il paraît que chez les Égyptiens, chez les Persans, chez les Chaldéens, chez les Indiens, il n'y avait qu'une secte de philosophie. Les prêtres de toutes ces nations étant tous d'une race particulière, ce qu'on appelait la sagesse n'appartenait qu'à cette race. Leur langue sacrée, inconnue au peuple, ne laissait le dépôt de la science qu'entre leurs mains. Mais dans la Grèce, plus libre et plus heureuse, l'accès de la raison fut ouvert à tout le monde ; chacun donna l'essor à ses idées, et c'est ce qui rendit les Grecs le peuple le plus ingénieux de la terre. C'est ainsi que de nos jours la nation anglaise est devenue la plus éclairée, parce qu'on peut penser impunément chez elle.

Les stoïques admirent une âme universelle du monde, dans laquelle les âmes de tous les êtres vivants se replongeaient. Les épicuriens nièrent qu'il y eût une âme, et ne connurent que des principes physiques ; ils soutinrent que les dieux ne se mêlaient pas des affaires des hommes, et on laissa les épicuriens en paix comme ils y laissaient les dieux.

Les écoles retentirent, depuis Thalès jusqu'au temps de Platon et d'Aristote, de disputes philosophiques, qui toutes décèlent la sagacité et la folie de l'esprit humain, sa grandeur et sa faiblesse. On argumenta presque toujours sans s'entendre, comme nous avons fait depuis le treizième siècle, où nous commençâmes à raisonner.

La réputation qu'eut Platon ne m'étonne pas; tous les philosophes étaient inintelligibles : il l'était autant que les autres, et s'exprimait avec plus d'éloquence. Mais quel succès aurait Platon s'il paraissait aujourd'hui dans une compagnie de gens de bon sens, et s'il leur disait ces belles paroles qui sont dans son Timée : «De la substance indivisible et de la divisible Dieu composa une troisième espèce de substance au milieu des deux, tenant de la nature du même et de l'autre : puis, 
prenant ces trois natures ensemble, il les mêla toutes en une seule forme, et força la nature de l'âme à se mêler avec la nature du même ; et, les ayant mêlées avec la substance, et de ces trois ayant fait un suppôt, il le divisa en portions convenables : chacune de ces portions était mêlée du même et de l'autre; et de la substance il fit sa division ${ }^{54}$ !»

Ensuite il explique, avec la même clarté, le quaternaire de Pythagore. Il faut convenir que des hommes raisonnables qui viendraient de lire l'Entendement humain de Locke prieraient Platon d'aller à son école.

Ce galimatias du bon Platon n'empêche pas qu'il n'y ait de temps en temps de très belles idées dans ses ouvrages. Les Grecs avaient tant d'esprit qu'ils en abusèrent ; mais ce qui leur fait beaucoup d'honneur, c'est qu'aucun de leurs gouvernements ne gêna les pensées des hommes. Il n'y a que Socrate dont il soit avéré que ses opinions lui coûtèrent la vie; et il fut encore moins la victime de ses opinions que celle d'un parti violent élevé contre lui. Les Athéniens, à la vérité, lui firent boire de la ciguë ; mais on sait combien ils s'en repentirent; on sait qu'ils punirent ses accusateurs, et qu'ils élevèrent un temple à celui qu'ils avaient condamné. Athènes laissa une liberté entière non seulement à la philosophie, mais à toutes les religions ${ }^{55}$. Elle recevait tous les dieux étrangers; elle avait même un autel dédié aux dieux inconnus.

Il est incontestable que les Grecs reconnaissaient un Dieu suprême, ainsi que toutes les nations dont nous avons parlé. Leur Zeus, leur Jupiter, était le maître des dieux et des hommes. Cette opinion ne changea jamais depuis Orphée; on la retrouve cent fois dans Homère :

${ }_{55}$ Voyez dans le Dictionnaire philosophique, article Platon. (K.)

55 Les prêtres excitèrent plus d'une fois le peuple d'Athènes contre les philosophes, et cette fureur ne fut fatale qu'à Socrate ; mais le repentir suivit bientôt le crime, et les accusateurs furent punis. On peut donc prétendre avec raison que les Grecs ont été tolérants, surtout si on les compare à nous, qui avons immolé à la superstition des milliers de victimes, par des supplices recherchés, et en vertu de lois permanentes; à nous, dont la sombre fureur s'est perpétuée pendant plus de quatorze siècles sans interruption; à nous enfin, chez qui les lumières ont plutôt arrêté que détruit le fanatisme, qui s'immole encore des victimes, et dont les partisans payent encore des apologistes pour justifier ses anciennes fureurs. (K.) 
tous les autres dieux sont inférieurs. On peut les comparer aux péris des Perses, aux génies des autres nations orientales. Tous les philosophes, excepté les stratoniciens et les épicuriens, reconnurent l'architecte du monde, le Demiourgos.

Ne craignons point de trop peser sur cette vérité historique, que la raison humaine commencée adora quelque puissance, quelque être qu'on croyait au-dessus du pouvoir ordinaire, soit le soleil, soit la lune ou les étoiles ; que la raison humaine cultivée adora, malgré toutes ses erreurs, un Dieu suprême, maître des éléments et des autres dieux ; et que toutes les nations policées, depuis l'Inde jusqu'au fond de l'Europe, crurent en général une vie à venir, quoique plusieurs sectes de philosophes eussent une opinion contraire.

Table des Matières

27.

DE ZALEUCUS, ET DE QUELQUES AUTRES LÉGISLATEURS

J'ose ici défier tous les moralistes et tous les législateurs, et je leur demande à tous s'ils ont dit rien de plus beau et de plus utile que l'exorde des lois de Zaleucus, qui vivait avant Pythagore, et qui fut le premier magistrat des Locriens.

«Tout citoyen doit être persuadé de l'existence de la Divinité. Il suffit d'observer l'ordre et l'harmonie de l'univers, pour être convaincu que le hasard ne peut l'avoir formé. On doit maîtriser son âme, la purifier, en écarter tout mal ; persuadé que Dieu ne peut être bien servi par les pervers, et qu'il ne ressemble point aux misérables mortels qui se laissent toucher par de magnifiques cérémonies, et par de somptueuses offrandes. La vertu seule, et la disposition constante à faire le bien, peuvent lui plaire. Qu'on cherche donc à être juste dans ses principes et dans la pratique ; c'est ainsi qu'on se rendra cher à la Divinité. Chacun doit craindre ce qui mène à l'ignominie, bien plus que ce qui conduit à la pauvreté. Il faut regarder comme le meilleur citoyen celui qui abandonne la fortune pour la justice; mais ceux que leurs passions violentes entraînent vers le mal, hommes, femmes, citoyens, simples habitants, doivent être avertis de se souvenir des dieux, et de 
penser souvent aux jugements sévères qu'ils exercent contre les coupables. Qu'ils aient devant les yeux l'heure de la mort, l'heure fatale qui nous attend tous, heure où le souvenir des fautes amène les remords et le vain repentir de n'avoir pas soumis toutes ses actions à l'équité.

«Chacun doit donc se conduire à tout moment comme si ce moment était le dernier de sa vie ; mais si un mauvais génie le porte au crime, qu'il fuie au pied des autels, qu'il prie le ciel d'écarter loin de lui ce génie malfaisant; qu'il se jette surtout entre les bras des gens de bien, dont les conseils le ramèneront à la vertu, en lui représentant la bonté de Dieu et sa vengeance. »

Non, il n'y a rien dans toute l'antiquité qu'on puisse préférer à ce morceau simple et sublime, dicté par la raison et par la vertu, dépouillé d'enthousiasme et de ces figures gigantesques que le bon sens désavoue.

Charondas, qui suivit Zaleucus, s'expliqua de même. Les Platon, les Cicéron, les divins Antonins, n'eurent point depuis d'autre langage. C'est ainsi que s'explique, en cent endroits, ce Julien, qui eut le malheur d'abandonner la religion chrétienne, mais qui fit tant d'honneur à la naturelle; Julien, le scandale de notre Église et la gloire de l'empire romain.

« Il faut, dit-il, instruire les ignorants, et non les punir; les plaindre, et non les haïr. Le devoir d'un empereur est d'imiter Dieu : l'imiter, c'est d'avoir le moins de besoins, et de faire le plus de bien qu'il est possible. » Que ceux donc qui insultent l'antiquité apprennent à la connaître; qu'ils ne confondent pas les sages législateurs avec des conteurs de fables ; qu'ils sachent distinguer les lois des plus sages magistrats, et les usages ridicules des peuples; qu'ils ne disent point : On inventa des cérémonies superstitieuses, on prodigua de faux oracles et de faux prodiges; donc tous les magistrats de la Grèce et de Rome qui les toléraient étaient des aveugles trompés et des trompeurs; c'est comme s'ils disaient: Il y a des bonzes à la Chine qui abusent la populace ; donc le sage Confucius était un misérable imposteur.

On doit, dans un siècle aussi éclairé que le nôtre, rougir de ces déclamations que l'ignorance a si souvent débitées contre des sages qu'il 
fallait imiter, et non calomnier. Ne sait-on pas que dans tous pays le vulgaire est imbécile, superstitieux, insensé ? N'y a-t-il pas eu des convulsionnaires dans la patrie du chancelier de L'Hospital, de Charron, de Montaigne, de La Motte-le-Vayer, de Descartes, de Bayle, de Fontenelle, de Montesquieu ? N'y a-t-il pas des méthodistes, des moraves, des millénaires, des fanatiques de toute espèce, dans le pays qui eut le bonheur de donner naissance au chancelier Bacon, à ces génies immortels, Newton et Locke, et à une foule de grands hommes ?

Table des Matières

28.
DE BACCHUS

Excepté les fables visiblement allégoriques, comme celles des $\mathrm{Mu}-$ ses, de Vénus, des Grâces, de l'Amour, de Zéphyre et de Flore, et quelques-unes de ce genre, toutes les autres sont un ramas de contes, qui n'ont d'autre mérite que d'avoir fourni de beaux vers à Ovide et à Quinault, et d'avoir exercé le pinceau de nos meilleurs peintres. Mais il en est une qui paraît mériter l'attention de ceux qui aiment les recherches de l'antiquité : c'est la fable de Bacchus.

Ce Bacchus, ou Back, ou Backos, ou Dionysios, fils de Dieu, a-t-il été un personnage véritable? Tant de nations en parlent, ainsi que d'Hercule, on a célébré tant d'Hercules et tant de Bacchus différents, qu'on peut supposer qu'en effet il y a eu un Bacchus, ainsi qu'un Hercule.

Ce qui est indubitable, c'est que dans l'Égypte, dans l'Asie, et dans la Grèce, Bacchus ainsi qu'Hercule étaient reconnus pour demidieux ; qu'on célébrait leurs fêtes ; qu'on leur attribuait des miracles ; qu'il y avait des mystères institués au nom de Bacchus, avant qu'on connût les livres juifs.

On sait assez que les Juifs ne communiquèrent leurs livres aux étrangers que du temps de Ptolémée Philadelphe, environ deux cent

56 M. Rolle a publié, en 1824, des Recherches sur le culte de Bacchus, trois vo-

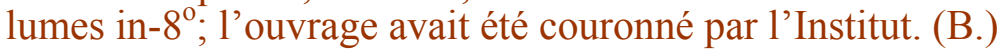


trente ans avant notre ère. Or, avant ce temps, l'orient et l'occident retentissaient des orgies de Bacchus. Les vers attribués à l'ancien Orphée célèbrent les conquêtes et les bienfaits de ce prétendu demi-dieu. Son histoire est si ancienne que les pères de l'Église ont prétendu que Bacchus était Noé, parce que Bacchus et Noé passent tous deux pour avoir cultivé la vigne.

Hérodote, en rapportant les anciennes opinions, dit que Bacchus fut élevé à Nyse, ville d'Éthiopie, que d'autres placent dans l'Arabie Heureuse. Les vers orphiques lui donnent le nom de Misès. Il résulte des recherches du savant Huet, sur 1'histoire de Bacchus, qu'il fut sauvé des eaux dans un petit coffre ${ }^{57}$; qu'on l'appela Misem, en mémoire de cette aventure ; qu'il fut instruit des secrets des dieux; qu'il avait une verge qu'il changeait en serpent quand il voulait; qu'il passa la mer Rouge à pied sec, comme Hercule passa depuis, dans son gobelet, le détroit de Calpé et d'Abyla ; que, quand il alla dans les Indes, lui et son armée jouissaient de la clarté du soleil pendant la nuit ; qu'il toucha de sa baguette enchanteresse les eaux du fleuve Oronte et de l'Hydaspe, et que ces eaux s'écoulèrent pour lui laisser un passage libre. Il est dit même qu'il arrêta le cours du soleil et de la lune. Il écrivit ses lois sur deux tables de pierre. Il était anciennement représenté avec des cornes ou des rayons qui partaient de sa tête.

Il n'est pas étonnant, après cela, que plusieurs savants hommes, et surtout Bochart et Huet, dans nos derniers temps, aient prétendu que Bacchus est une copie de Moïse et de Josué. Tout concourt à favoriser la ressemblance : car Bacchus s'appelait, chez les Égyptiens, Arsaph, et parmi les noms que les pères ont donnés à Moïse, on y trouve celui d'Osasirph.

Entre ces deux histoires, qui paraissent semblables en tant de points, il n'est pas douteux que celle de Moïse ne soit la vérité, et que celle de Bacchus ne soit la fable; mais il parait que cette fable était connue des nations longtemps avant que l'histoire de Moïse fût parvenue jusqu'à elles. Aucun auteur grec n'a cité Moïse avant Longin, qui vivait sous l'empereur Aurélien, et tous avaient célébré Bacchus.

57 Voltaire reparle très souvent de Bacchus et de Moïse : voyez entre autres le chapitre II de l'Examen important de milord Bolingbroke (dans les Mélanges, année 1767). (B.) 
Il parait incontestable que les Grecs ne purent prendre l'idée de Bacchus dans le livre de la loi juive, qu'ils n'entendaient pas et dont ils n'avaient pas la moindre connaissance : livre d'ailleurs si rare chez les Juifs mêmes que, sous le roi Josias, on n'en trouva qu'un seul exemplaire ; livre presque entièrement perdu, pendant l'esclavage des Juifs transportés en Chaldée et dans le reste de l'Asie ; livre restauré ensuite par Esdras dans les temps florissants d'Athènes et des autres républiques de la Grèce : temps où les mystères de Bacchus étaient déjà institués.

Dieu permit donc que l'esprit de mensonge divulguât les absurdités de la vie de Bacchus chez cent nations, avant que l'esprit de vérité fit connaître la vie de Moïse à aucun peuple, excepté aux Juifs.

Le savant évêque d'Avranches, frappé de cette étonnante ressemblance, ne balança pas à prononcer que Moïse était non seulement Bacchus, mais le Thaut, l'Osiris des Égyptiens. Il ajoute même ${ }^{58}$, pour allier les contraires, que Moïse était aussi leur Typhon ; c'est-àdire qu'il était à la fois le bon et le mauvais principe, le protecteur et l'ennemi, le dieu et le diable reconnus en Égypte.

Moïse, selon ce savant homme, est le même que Zoroastre. Il est Esculape, Amphion, Apollon, Faunus, Janus, Persée, Romulus, Vertumne, et enfin Adonis et Priape. La preuve qu'il était Adonis, c'est que Virgile a dit (églog. X, v. 18) :

«Et formosus oves ad flumina pavit Adonis. »

Et le bel Adonis a gardé les moutons.

Or Moïse garda les moutons vers l'Arabie. La preuve qu'il était Priape est encore meilleure : c'est que quelquefois on représentait Priape avec un âne, et que les Juifs passèrent pour adorer un âne. Huet ajoute, pour dernière confirmation, que la verge de Moïse pouvait fort bien être comparée au sceptre de Priape ${ }^{59}$.

« Sceptrum Priapo tribuitur, virga Mosi »

Voilà ce que Huet appelle sa Démonstration. Elle n'est pas, à la vérité, géométrique. Il est à croire qu'il en rougit les dernières années de sa vie, et qu'il se souvenait de sa Démonstration quand il fit son Traité

Proposition IV, pages 79 et 87 . (V.)

Huet, page 110. (V.) 
de la faiblesse de l'esprit humain, et de l'incertitude de ses connaissances.

Table des Matières

29.

DES MÉTAMORPHOSES CHEZ LES GRECS, RECUEILLIES PAR OVIDE

L'opinion de la migration des âmes conduit naturellement aux métamorphoses, comme nous l'avons déjà vu ${ }^{60}$. Toute idée qui frappe l'imagination et qui l'amuse s'étend bientôt par tout le monde. Dès que vous m'avez persuadé que mon âme peut entrer dans le corps d'un cheval, vous n'aurez pas de peine à me faire croire que mon corps peut être changé en cheval aussi.

Les métamorphoses recueillies par Ovide, dont nous avons déjà dit un mot, ne devaient point du tout étonner un pythagoricien, un brame, un Chaldéen, un Égyptien. Les dieux s'étaient changés en animaux dans l'ancienne Égypte. Derceto était devenue poisson en Syrie; Sémiramis avait été changée en colombe à Babylone. Les Juifs, dans des temps très postérieurs, écrivent que Nabuchodonosor fut changé en bœuf, sans compter la femme de Loth transformée en statue de sel. N'est-ce pas même une métamorphose réelle, quoique passagère, que toutes les apparitions des dieux et des génies sous la forme humaine?

Un dieu ne peut guère se communiquer à nous qu'en se métamorphosant en homme. Il est vrai que Jupiter prit la figure d'un beau cygne pour jouir de Léda ; mais ces cas sont rares, et, dans toutes les religions, la Divinité prend toujours la figure humaine quand elle vient donner des ordres. Il serait difficile d'entendre la voix des dieux s'ils se présentaient à nous en crocodiles ou en ours.

Enfin, les dieux se métamorphosèrent presque partout, et dès que nous fûmes instruits des secrets de la magie, nous nous métamorphosâmes nous-mêmes. Plusieurs personnes dignes de foi se changèrent

60 Paragraphe 17. (B.) 
en loups : le mot de loup-garou atteste encore parmi nous cette belle métamorphose.

Ce qui aide beaucoup à croire toutes ces transmutations et tous les prodiges de cette espèce, c'est qu'on ne peut prouver en forme leur impossibilité. On n'a nul argument à pouvoir alléguer à quiconque vous dira : «Un dieu vint hier chez moi sous la figure d'un beau jeune homme, et ma fille accouchera dans neuf mois d'un bel enfant que le dieu a daigné lui faire : mon frère, qui a osé en douter, a été changé en loup ; il court et hurle actuellement dans les bois. " Si la fille accouche en effet, si l'homme devenu loup vous affirme qu'il a subi en effet cette métamorphose, vous ne pouvez démontrer que la chose n'est pas vraie. Vous n'auriez d'autre ressource que d'assigner devant les juges le jeune homme qui a contrefait le dieu, et fait l'enfant à la demoiselle ; qu'à faire observer l'oncle loup-garou, et à prendre des témoins de son imposture. Mais la famille ne s'exposera pas à cet examen; elle vous soutiendra, avec les prêtres du canton, que vous êtes un profane et un ignorant; ils vous feront voir que puisqu'une chenille est changée en papillon, un homme peut tout aussi aisément être changé en bête : et si vous disputez, vous serez déféré à l'inquisition du pays comme un impie qui ne croit ni aux loups-garous, ni aux dieux qui engrossent les filles.

Table des Matières

30.

DE L'IDOLÂTRIE

Après avoir lu tout ce que l'on a écrit sur l'idolâtrie, on ne trouve rien qui en donne une notion précise. Il semble que Locke soit le premier qui ait appris aux hommes à définir les mots qu'ils prononçaient, et à ne point parler au hasard. Le terme qui répond à idolâtrie ne se trouve dans aucune langue ancienne; c'est une expression des Grecs des derniers âges, dont on ne s'était jamais servi avant le second siècle de notre ère. C'est un terme de reproche, un mot injurieux : jamais aucun peuple n'a pris la qualité d'idolâtre : jamais aucun gouvernement n'ordonna qu'on adorât une image, comme le dieu suprême de la nature. Les anciens Chaldéens, les anciens Arabes, les anciens Perses, 
n'eurent longtemps ni images ni temples. Comment ceux qui vénéraient, dans le soleil, les astres et le feu, les emblèmes de la Divinité, peuvent-ils être appelés idolâtres ? Ils révéraient ce qu'ils voyaient: mais certainement révérer le soleil et les astres, ce n'est pas adorer une figure taillée par un ouvrier ; c'est avoir un culte erroné, mais ce n'est point être idolâtre.

Je suppose que les Égyptiens aient adoré réellement le chien Anubis et le bœuf Apis ; qu'ils aient été assez fous pour ne les pas regarder comme des animaux consacrés à la Divinité, et comme un emblème du bien que leur Isheth, leur Isis, faisait aux hommes ; pour croire même qu'un rayon céleste animait ce bœuf et ce chien consacrés ; il est clair que ce n'était pas adorer une statue : une bête n'est pas une idole.

Il est indubitable que les hommes eurent des objets de culte avant que d'avoir des sculpteurs, et il est clair que ces hommes si anciens ne pouvaient point être appelés idolâtres. Il reste donc à savoir si ceux qui firent enfin placer les statues dans les temples, et qui firent révérer ces statues, se nommèrent adorateurs de statues, et leurs peuples, adorateurs de statues: c'est assurément ce qu'on ne trouve dans aucun monument de l'antiquité.

Mais en ne prenant point le titre d'idolâtres, l'étaient-ils en effet ? était-il ordonné de croire que la statue de bronze qui représentait la figure fantastique de Bel à Babylone était le Maître, le Dieu, le Créateur du monde? la figure de Jupiter était-elle Jupiter même ? n'est-ce pas (s'il est permis de comparer les usages de notre sainte religion avec les usages antiques), n'est-ce pas comme si l'on disait que nous adorons la figure du Père éternel avec une barbe longue, la figure d'une femme et d'un enfant, la figure d'une colombe ? Ce sont des ornements emblématiques dans nos temples : nous les adorons si peu que, quand ces statues sont de bois, on s'en chauffe dès qu'elles pourrissent, on en érige d'autres ; elles sont de simples avertissements qui parlent aux yeux et à l'imagination. Les Turcs et les réformés croient que les catholiques sont idolâtres; mais les catholiques ne cessent de protester contre cette injure.

Il n'est pas possible qu'on adore réellement une statue, ni qu'on croie que cette statue est le Dieu suprême. Il n'y avait qu'un Jupiter, 
mais il y avait mille de ses statues : or ce Jupiter qu'on croyait lancer la foudre était supposé habiter les nuées, ou le mont Olympe, ou la planète qui porte son nom ; et ses figures ne lançaient point la foudre, et n'étaient ni dans une planète, ni dans les nuées, ni sur le mont Olympe : toutes les prières étaient adressées aux dieux immortels, et assurément les statues n'étaient pas immortelles.

Des fourbes, il est vrai, firent croire, et des superstitieux crurent que des statues avaient parlé. Combien de fois nos peuples grossiers n'ont-ils pas eu la même crédulité ? mais jamais, chez aucun peuple, ces absurdités ne furent la religion de l'État. Quelque vieille imbécile n'aura pas distingué la statue et le dieu: ce n'est pas une raison d'affirmer que le gouvernement pensait comme cette vieille. Les magistrats voulaient qu'on révérât les représentations des dieux adorés, et que l'imagination du peuple fût fixée par ces signes visibles : c'est précisément ce qu'on fait dans la moitié de l'Europe. On a des figures qui représentent Dieu le père sous la forme d'un vieillard, et on sait bien que Dieu n'est pas un vieillard. On a des images de plusieurs saints qu'on vénère, et on sait bien que ces saints ne sont pas Dieu le père.

De même, si on ose le dire, les anciens ne se méprenaient pas entre les demi-dieux, les dieux, et le maître des dieux. Si ces anciens étaient idolâtres pour avoir des statues dans leurs temples, la moitié de la chrétienté est donc idolâtre aussi ; et si elle ne l'est pas, les nations antiques ne l'étaient pas davantage.

En un mot, il n'y a pas dans toute l'antiquité un seul poète, un seul philosophe, un seul homme d'État qui ait dit qu'on adorait de la pierre, du marbre, du bronze, ou du bois. Les témoignages du contraire sont innombrables : les nations idolâtres sont donc comme les sorciers : on en parle, mais il n'y en eut jamais.

Un commentateur, Dacier, a conclu qu'on adorait réellement la statue de Priape, parce que Horace, en faisant parler cet épouvantail, lui fait dire : «J'étais autrefois un tronc ; l'ouvrier, incertain s'il en ferait un dieu ou une escabelle, prit le parti d'en faire un dieu, etc. » Le commentateur cite le prophète Baruch pour prouver que du temps d'Horace on regardait la figure de Priape comme une divinité réelle : il ne voit pas qu'Horace se moque et du prétendu dieu, et de sa statue. 
Il se peut qu'une de ses servantes, en voyant cette énorme figure, crût qu'elle avait quelque chose de divin ; mais assurément tous ces Priapes de bois dont les jardins étaient remplis pour chasser les oiseaux n'étaient pas regardés comme les créateurs du monde.

Il est dit que Moïse, malgré la loi divine de ne faire aucune représentation d'hommes ou d'animaux, érigea un serpent d'airain, ce qui était une imitation du serpent d'argent que les prêtres d'Égypte portaient en procession : mais quoique ce serpent fût fait pour guérir les morsures des serpents véritables, cependant on ne l'adorait pas. Salomon mit deux chérubins dans le temple ; mais on ne regardait pas ces chérubins comme des dieux. Si donc, dans le temple des Juifs et dans les nôtres, on a respecté des statues sans être idolâtres, pourquoi tant de reproches aux autres nations? ou nous devons les absoudre, ou elles doivent nous accuser.

Table des Matières

31.

DES ORACLES ${ }^{61}$

Il est évident qu'on ne peut savoir l'avenir, parce qu'on ne peut savoir ce qui n'est pas ; mais il est clair aussi qu'on peut conjecturer un événement.

Vous voyez une armée nombreuse et disciplinée, conduite par un chef habile, s'avancer dans un lieu avantageux contre un capitaine imprudent, suivi de peu de troupes mal armées, mal postées, et dont vous savez que la moitié le trahit ; vous prédisez que ce capitaine sera battu.

Vous avez remarqué qu'un jeune homme et une fille s'aiment éperdument; vous les avez observés sortant l'un et l'autre de la maison paternelle ; vous annoncez que dans peu cette fille sera enceinte : vous ne vous trompez guère. Toutes les prédictions se réduisent au calcul des probabilités. Il n'y a donc point de nation chez laquelle on n'ait fait des prédictions qui se sont en effet accomplies. La plus célè-

61 M. Clavier a publié un Mémoire sur les oracles anciens, 1818 , in- $8^{\circ}$. (B.) 
bre, la plus confirmée, est celle que fit ce traître, Flavien Josèphe, à Vespasien et Titus son fils, vainqueurs des Juifs. Il voyait Vespasien et Titus adorés des armées romaines dans l'Orient, et Néron détesté de tout l'empire. Il ose, pour gagner les bonnes grâces de Vespasien, lui prédire, au nom du dieu des Juifs ${ }^{62}$, que lui et son fils seront empereurs : ils le furent en effet; mais il est évident que Josèphe ne risquait rien. Si Vespasien succombe un jour en prétendant à l'empire, il n'est pas en état de punir Josèphe ; s'il est empereur, il le récompense ; et tant qu'il ne règne pas, il espère régner. Vespasien fait dire à ce Josèphe que, s'il est prophète, il devait avoir prédit la prise de Jotapat, qu'il avait en vain défendue contre l'armée romaine ; Josèphe répond qu'en effet il l'avait prédite : ce qui n'était pas bien surprenant. Quel commandant, en soutenant un siège dans une petite place contre une grande armée, ne prédit pas que la place sera prise ?

Il n'était pas bien difficile de sentir qu'on pouvait s'attirer le respect et l'argent de la multitude en faisant le prophète, et que la crédulité du peuple devait être le revenu de quiconque saurait le tromper. Il y eut partout des devins ; mais ce n'était pas assez de ne prédire qu'en son propre nom, il fallait parler au nom de la Divinité ; et, depuis les prophètes de l'Égypte, qui s'appelaient les voyants, jusqu'à Ulpius, prophète du mignon de l'empereur Adrien devenu dieu, il y eut un nombre prodigieux de charlatans sacrés qui firent parler les dieux pour se moquer des hommes. On sait assez comment ils pouvaient réussir : tantôt par une réponse ambiguë qu'ils expliquaient ensuite comme ils voulaient; tantôt en corrompant des domestiques, en s'informant d'eux secrètement des aventures des dévots qui venaient les consulter. Un idiot était tout étonné qu'un fourbe lui dit de la part de Dieu ce qu'il avait fait de plus caché.

Ces prophètes passaient pour savoir le passé, le présent, et l'avenir ; c'est l'éloge qu'Homère fait de Calchas. Je n'ajouterai rien ici à ce que le savant Van Dale et le judicieux Fontenelle, son rédacteur, ont dit des oracles. Ils ont dévoilé avec sagacité des siècles de fourberie ; et le jésuite Baltus montra bien peu de sens, ou beaucoup de malignité, quand il soutint contre eux la vérité des oracles païens par les principes de la religion chrétienne. C'était réellement faire à Dieu une injure de prétendre que ce Dieu de bonté et de vérité eût lâ-

62 Josèphe, liv. III, ch. XXVIII. (V.) 
ché les diables de l'enfer pour venir faire sur la terre ce qu'il ne fait pas lui-même, pour rendre des oracles.

Ou ces diables disaient vrai, et en ce cas il était impossible de ne les pas croire ; et Dieu, appuyant toutes les fausses religions par des miracles journaliers, jetait lui-même l'univers entre les bras de ses ennemis : ou ils disaient faux; et en ce cas Dieu déchaînait les diables pour tromper tous les hommes. Il n'y a peut-être jamais eu d'opinion plus absurde.

L'oracle le plus fameux fut celui de Delphes. On choisit d'abord de jeunes filles innocentes, comme plus propres que les autres à être inspirées, c'est-à-dire à proférer de bonne foi le galimatias que les prêtres leur dictaient. La jeune Pythie montait sur un trépied posé dans l'ouverture d'un trou dont il sortait une exhalaison prophétique. L'esprit divin entrait sous la robe de la Pythie par un endroit fort humain ; mais depuis qu'une jolie Pythie fut enlevée par un dévot, on prit des vieilles pour faire le métier : et je crois que c'est la raison pour laquelle l'oracle de Delphes commença à perdre beaucoup de son crédit.

Les divinations, les augures, étaient des espèces d'oracles, et sont, je crois, d'une plus haute antiquité ; car il fallait bien des cérémonies, bien du temps pour achalander un oracle divin qui ne pouvait se passer de temple et de prêtres; et rien n'était plus aisé que de dire la bonne aventure dans les carrefours. Cet art se subdivisa en mille façons ; on prédit par le vol des oiseaux, par le foie des moutons, par les plis formés dans la paume de la main, par des cercles tracés sur la terre, par l'eau, par le feu, par des petits cailloux, par des baguettes, par tout ce qu'on imagina, et souvent même par un pur enthousiasme qui tenait lieu de toutes les règles. Mais qui fut celui qui inventa cet art? ce fut le premier fripon qui rencontra un imbécile.

La plupart des prédictions étaient comme celles de l'Almanach de Liège. Un grand mourra; il y aura des naufrages. Un juge de village mourait-il dans l'année, c'était, pour ce village, le grand dont la mort était prédite; une barque de pêcheurs était-elle submergée, voilà les grands naufrages annoncés. L'auteur de l'Almanach de Liège est un sorcier, soit que ces prédictions soient accomplies, soit qu'elles ne le soient pas : car, si quelque événement les favorise, sa magie est dé- 
montrée ; si les événements sont contraires, on applique la prédiction à toute autre chose, et l'allégorie le tire d'affaire.

L'Almanach de Liège a dit qu'il viendrait un peuple du nord qui détruirait tout ; ce peuple ne vient point, mais un vent du nord fait geler quelques vignes : c'est ce qui a été prédit par Matthieu Laensbergh. Quelqu'un ose-t-il douter de son savoir, aussitôt les colporteurs le dénoncent comme un mauvais citoyen, et les astrologues le traitent même de petit esprit et de méchant raisonneur.

Les Sunnites mahométans ont beaucoup employé cette méthode dans l'explication du Koran de Mahomet. L'étoile Aldebaran avait été en grande vénération chez les Arabes; elle signifie l'œil du taureau; cela voulait dire que l'œil de Mahomet éclairerait les Arabes, et que, comme un taureau, il frapperait ses ennemis de ses cornes.

L'arbre acacia était en vénération dans l'Arabie ; on en faisait de grandes haies qui préservaient les moissons de l'ardeur du soleil; Mahomet est l'acacia qui doit couvrir la terre de son ombre salutaire. Les Turcs sensés rient de ces bêtises subtiles, les jeunes femmes n'y pensent pas ; les vieilles dévotes y croient ; et celui qui dirait publiquement à un derviche qu'il enseigne des sottises courrait risque d'être empalé. Il y a eu des savants qui ont trouvé l'histoire de leur temps dans l'Iliade et dans l'Odyssée ; mais ces savants n'ont pas fait la même fortune que les commentateurs de l'Alcoran.

La plus brillante fonction des oracles fut d'assurer la victoire dans la guerre. Chaque armée, chaque nation avait ses oracles qui lui promettaient des triomphes. L'un des deux partis avait reçu infailliblement un oracle véritable. Le vaincu, qui avait été trompé, attribuait sa défaite à quelque faute commise envers les dieux, après l'oracle rendu ; il espérait qu'une autre fois l'oracle s'accomplirait. Ainsi presque toute la terre s'est nourrie d'illusion. Il n'y eut presque point de peuple qui ne conservât dans ses archives, ou qui n'eût par la tradition orale, quelque prédiction qui l'assurait de la conquête du monde, c'est-à-dire des nations voisines; point de conquérant qui n'ait été prédit formellement aussitôt après sa conquête. Les Juifs mêmes, enfermés dans un coin de terre presque inconnu, entre l'anti-Liban, l'Arabie Déserte et la Pétrée, espérèrent, comme les autres peuples, d'être les maîtres de l'univers, fondés sur mille oracles que nous ex- 
pliquons dans un sens mystique, et qu'ils entendaient dans le sens littéral.

Table des Matières

32.

\section{DES SIBYLLES CHEZ LES GRECS, ET DE LEUR INFLUENCE SUR LES AUTRES NATIONS}

Lorsque presque toute la terre était remplie d'oracles, il y eut de vieilles filles qui, sans être attachées à aucun temple, s'avisèrent de prophétiser pour leur compte. On les appela sibylles, or $\varsigma \beta$ ovג mots grecs du dialecte de Laconie, qui signifient conseil de Dieu. L'antiquité en compte dix principales en divers pays. On sait assez le conte de la bonne femme qui vint apporter dans Rome, à l'ancien Tarquin, les neuf livres de l'ancienne sibylle de Cumes. Comme Tarquin marchandait trop, la vieille jeta au feu les six premiers livres, et exigea autant d'argent des trois restants qu'elle en avait demandé des neuf entiers. Tarquin les paya. Ils furent, dit-on, conservés à Rome jusqu'au temps de Sylla, et furent consumés dans un incendie du Capitole.

Mais comment se passer des prophéties des sibylles ? On envoya trois sénateurs à Érythrès, ville de Grèce, où l'on gardait précieusement un millier de mauvais vers grecs, qui passaient pour être de la façon de la sibylle Érythrée. Chacun en voulait avoir des copies. La sibylle Érythrée avait tout prédit; il en était de ses prophéties comme de celles de Nostradamus parmi nous; et l'on ne manquait pas, à chaque événement, de forger quelques vers grecs qu'on attribuait à la sibylle.

Auguste, qui craignait avec raison qu'on ne trouvât dans cette rapsodie quelques vers qui autoriseraient des conspirations, défendit, sous peine de mort, qu'aucun Romain eût chez lui des vers sibyllins : défense digne d'un tyran soupçonneux, qui conservait avec adresse un pouvoir usurpé par le crime. 
Les vers sibyllins furent respectés plus que jamais quand il fut défendu de les lire. Il fallait bien qu'ils continssent la vérité, puisqu'on les cachait aux citoyens.

Virgile, dans son églogue sur la naissance de Pollion, ou de Marcellus, ou de Drusus, ne manqua pas de citer l'autorité de la sibylle de Cumes, qui avait prédit nettement que cet enfant, qui mourut bientôt après, ramènerait le siècle d'or. La sibylle Érythrée avait, disait-on alors, prophétisé aussi à Cumes. L'enfant nouveau-né, appartenant à Auguste ou à son favori, ne pouvait manquer d'être prédit par la sibylle. Les prédictions d'ailleurs ne sont jamais que pour les grands, les petits n'en valent pas la peine.

Ces oracles des sibylles étant donc toujours en très grande réputation, les premiers chrétiens, trop emportés par un faux zèle, crurent qu'ils pouvaient forger de pareils oracles pour battre les Gentils par leurs propres armes. Hermas et saint Justin passent pour être les premiers qui eurent le malheur de soutenir cette imposture. Saint Justin cite des oracles de la sibylle de Cumes, débités par un chrétien qui avait pris le nom d'Istape, et qui prétendait que sa sibylle avait vécu du temps du déluge. Saint Clément d'Alexandrie (dans ses Stromates, livre VI) assure que l'apôtre saint Paul recommande dans ses Épîtres la lecture des sibylles qui ont manifestement prédit la naissance du fils de Dieu.

Il faut que cette Épître de saint Paul soit perdue, car on ne trouve ces paroles, ni rien d'approchant, dans aucune des Épîtres de saint Paul. Il courait dans ce temps-là parmi les chrétiens une infinité de livres que nous n'avons plus, comme les Prophéties de Jaldabast, celles de Seth, d'Énoch et de Cham; la pénitence d'Adam ; l'histoire de Zacharie, père de saint Jean ; l'Évangile des Égyptiens ; l'Évangile de saint Pierre, d'André, de Jacques ; l'Évangile d'Ève ; l'Apocalypse d'Adam; les lettres de Jésus-Christ, et cent autres écrits dont il reste à peine quelques fragments ensevelis dans des livres qu'on ne lit guère.

L'Église chrétienne était alors partagée en société judaïsante et société non judaïsante. Ces deux sociétés étaient divisées en plusieurs autres. Quiconque se sentait un peu de talent écrivait pour son parti. Il y eut plus de cinquante évangiles jusqu'au concile de Nicée ; il ne nous en reste aujourd'hui que ceux de la Vierge, de Jacques, de 
l'Enfance, et de Nicodème. On forgea surtout des vers attribués aux anciennes sibylles. Tel était le respect du peuple pour ces oracles sibyllins qu'on crut avoir besoin de cet appui étranger pour fortifier le christianisme naissant. Non seulement on fit des vers grecs sibyllins qui annonçaient Jésus-Christ, mais on les fit en acrostiches, de manière que les lettres de ces mots, Jesous Chreistos ïos Soter, étaient l'une après l'autre le commencement de chaque vers. C'est dans ces poésies qu'on trouve cette prédiction :

Avec cinq pains et deux poissons Il nourrira cinq mille hommes au désert ; Et, en ramassant les morceaux qui resteront, Il en remplira douze paniers.

On ne s'en tint pas là ; on imagina qu'on pouvait détourner, en faveur du christianisme, le sens des vers de la quatrième églogue de Virgile (vers 4 et 7 ) :

« Ultima cumæi venit jam carminis ætas :...

Jam nova progenies cœlo demittitur alto. »

Les temps de la sibylle enfin sont arrivés ;

Un nouveau rejeton descend du haut des cieux.

Cette opinion eut un si grand cours dans les premiers siècles de l'Église que l'empereur Constantin la soutint hautement. Quand un empereur parlait, il avait sûrement raison. Virgile passa longtemps pour un prophète. Enfin on était si persuadé des oracles des sibylles que nous avons dans une de nos hymnes, qui n'est pas fort ancienne, ces deux vers remarquables :
« Solvet sæclum in favilla,
Teste David cum sibylla. »
Il mettra l'univers en cendres,
Témoin la sibylle et David.

Parmi les prédictions attribuées aux sibylles, on faisait surtout valoir le règne de mille ans, que les pères de l'Église adoptèrent jusqu'au temps de Théodose II.

Ce règne de Jésus-Christ pendant mille ans sur la terre était fondé d'abord sur la prophétie de saint Luc, chapitre XXI ; prophétie mal entendue, que Jésus-Christ «viendrait dans les nuées, dans une grande puissance et dans une grande majesté, avant que la génération présen- 
te fût passée ». La génération avait passé ; mais saint Paul avait dit aussi dans sa première Épître aux Thessaloniciens, chap. IV :

«Nous vous déclarons, comme l'ayant appris du Seigneur, que nous qui vivons, et qui sommes réservés pour son avènement, nous ne préviendrons point ceux qui sont déjà dans le sommeil.

«Car, aussitôt que le signal aura été donné par la voix de l'archange, et par le son de la trompette de Dieu, le Seigneur luimême descendra du ciel, et ceux qui seront morts en Jésus-Christ ressusciteront les premiers.

«Puis nous autres qui sommes vivants, et qui serons demeurés jusqu'alors, nous serons emportés avec eux dans les nuées, pour aller audevant du Seigneur, au milieu de l'air ; et ainsi nous vivrons pour jamais avec le Seigneur. »

Il est bien étrange que Paul dise que c'est le Seigneur lui-même qui lui avait parlé ; car Paul, loin d'avoir été un des disciples de Christ, avait été longtemps un de ses persécuteurs. Quoi qu'il en puisse être, l'Apocalypse avait dit aussi, chapitre $\mathrm{xx}$, que les justes régneraient sur la terre pendant mille ans avec Jésus-Christ.

On s'attendait donc à tout moment que Jésus-Christ descendrait du ciel pour établir son règne, et rebâtir Jérusalem, dans laquelle les chrétiens devaient se réjouir avec les patriarches.

Cette nouvelle Jérusalem était annoncée dans l'Apocalypse: «Moi, Jean, je vis la nouvelle Jérusalem qui descendait du ciel, parée comme une épouse... Elle avait une grande et haute muraille, douze portes, et un ange à chaque porte... douze fondements où sont les noms des apôtres de l'agneau... Celui qui me parlait avait une toise d'or pour mesurer la ville, les portes et la muraille. La ville est bâtie en carré ; elle est de douze mille stades ; sa longueur, sa largeur et sa hauteur sont égales... Il en mesura aussi la muraille, qui est de cent quarante-quatre coudées... Cette muraille est de jaspe, et la ville était d'or, etc. »

On pouvait se contenter de cette prédiction; mais on voulut encore avoir pour garant une sibylle à qui l'on fait dire à peu près les mêmes choses. Cette persuasion s'imprima si fortement dans les esprits que saint Justin, dans son Dialogue contre Tryphon, dit «qu'il en est 
convenu, et que Jésus doit venir dans cette Jérusalem boire et manger avec ses disciples. »

Saint Irénée se livra si pleinement à cette opinion qu'il attribue à saint Jean l'Évangéliste ces paroles : « Dans la nouvelle Jérusalem, chaque cep de vigne produira dix mille branches; et chaque branche, dix mille bourgeons; chaque bourgeon, dix mille grappes, chaque grappe, dix mille grains; chaque raisin, vingt-cinq amphores de vin ; et quand un des saints vendangeurs cueillera un raisin, le raisin voisin lui dira : Prends-moi, je suis meilleur que lui ${ }^{63}$. »

Ce n'était pas assez que la sibylle eût prédit ces merveilles, on avait été témoin de l'accomplissement. On vit, au rapport de Tertullien, la Jérusalem nouvelle descendre du ciel pendant quarante nuits consécutives.

Tertullien s'exprime ainsi ${ }^{64}$ : «Nous confessons que le royaume nous est promis pour mille ans en terre, après la résurrection dans la cité de Jérusalem, apportée du ciel ici-bas. "

C'est ainsi que l'amour du merveilleux, et l'envie d'entendre et de dire des choses extraordinaires, a perverti le sens commun dans tous les temps ; c'est ainsi qu'on s'est servi de la fraude, quand on n'a pas eu la force. La religion chrétienne fut d'ailleurs soutenue par des raisons si solides que tout cet amas d'erreurs ne put l'ébranler. On dégagea l'or pur de tout cet alliage, et l'Église parvint, par degrés, à l'état où nous la voyons aujourd'hui.

\footnotetext{
63 Irénée, liv. V, chap. XXXV. (V.)

64 Tertullien contre Marcion, liv. III. (V.)
} 
33.

\section{DES MIRACLES}

Revenons toujours à la nature de l'homme; il n'aime que l'extraordinaire; et cela est si vrai, que sitôt que le beau, le sublime est commun, il ne paraît plus ni beau ni sublime. On veut de l'extraordinaire en tout genre, et on va jusqu'à l'impossible. L'histoire ancienne ressemble à celle de ce chou plus grand qu'une maison, et à ce pot plus grand qu'une église, fait pour cuire ce chou.

Quelle idée avons-nous attachée au mot miracle, qui d'abord signifiait chose admirable? Nous avons dit : C'est ce que la nature ne peut opérer ; c'est ce qui est contraire à toutes ses lois. Ainsi l'Anglais qui promit au peuple de Londres de se mettre tout entier dans une bouteille de deux pintes annonçait un miracle. Et autrefois on n'aurait pas manqué de légendaires qui auraient affirmé l'accomplissement de ce prodige, s'il en était revenu quelque chose au couvent.

Nous croyons sans difficulté aux vrais miracles opérés dans notre sainte religion, et chez les Juifs, dont la religion prépara la nôtre. Nous ne parlons ici que des autres nations, et nous ne raisonnons que suivant les règles du bon sens, toujours soumises à la révélation.

Quiconque n'est pas illuminé par la foi ne peut regarder un miracle que comme une contravention aux lois éternelles de la nature. Il ne lui paraît pas possible que Dieu dérange son propre ouvrage; il sait que tout est lié dans l'univers par des chaînes que rien ne peut rompre. Il sait que Dieu étant immuable, ses lois le sont aussi ; et qu'une roue de la grande machine ne peut s'arrêter, sans que la nature entière soit dérangée.

Si Jupiter, en couchant avec Alcmène, fait une nuit de vingt-quatre heures, lorsqu'elle devait être de douze, il est nécessaire que la terre s'arrête dans son cours, et reste immobile douze heures entières. Mais comme les mêmes phénomènes du ciel reparaissent la nuit suivante, il 
est nécessaire aussi que la lune et toutes les planètes se soient arrêtées. Voilà une grande révolution dans tous les orbes célestes en faveur d'une femme de Thèbes en Béotie.

Un mort ressuscite au bout de quelques jours ; il faut que toutes les parties imperceptibles de son corps qui s'étaient exhalées dans l'air, et que les vents avaient emportées au loin, reviennent se mettre chacune à leur place ; que les vers et les oiseaux, ou les autres animaux nourris de la substance de ce cadavre, rendent chacun ce qu'ils lui ont pris. Les vers engraissés des entrailles de cet homme auront été mangés par des hirondelles; ces hirondelles, par des pies-grièches; ces piesgrièches, par des faucons; ces faucons, par des vautours. Il faut que chacun restitue précisément ce qui appartenait au mort, sans quoi ce ne serait plus la même personne. Tout cela n'est rien encore, si l'âme ne revient dans son hôtellerie.

Si l'Être éternel, qui a tout prévu, tout arrangé, qui gouverne tout par des lois immuables, devient contraire à lui-même en renversant toutes ses lois, ce ne peut être que pour l'avantage de la nature entière. Mais il paraît contradictoire de supposer un cas où le créateur et le maître de tout puisse changer l'ordre du monde pour le bien du monde. Car, ou il a prévu le prétendu besoin qu'il en aurait, ou il ne l'a pas prévu. S'il l'a prévu, il ya mis ordre dès le commencement : s'il ne l'a pas prévu, il n'est plus Dieu.

On dit que c'est pour faire plaisir à une nation, à une ville, à une famille, que l'Être éternel ressuscite Pélops, Hippolyte, Hérès, et quelques autres fameux personnages ; mais il ne paraît pas vraisemblable que le maître commun de l'univers oublie le soin de l'univers en faveur de cet Hippolyte et de ce Pélops.

Plus les miracles sont incroyables, selon les faibles lumières de notre esprit, plus ils ont été crus. Chaque peuple eut tant de prodiges, qu'ils devinrent des choses très ordinaires. Aussi ne s'avisait-on pas de nier ceux de ses voisins. Les Grecs disaient aux Égyptiens, aux nations asiatiques : "Les dieux vous ont parlé quelquefois, ils nous parlent tous les jours ; s'ils ont combattu vingt fois pour vous, ils se sont mis quarante fois à la tête de nos armées ; si vous avez des métamorphoses, nous en avons cent fois plus que vous ; si vos animaux parlent, les nôtres ont fait de très beaux discours. " Il n'y a pas même 
jusqu'aux Romains chez qui les bêtes n'aient pris la parole pour prédire l'avenir. Tite-Live rapporte qu'un bœuf s'écria en plein marché : Rome, prends garde à toi. Pline, dans son livre huitième, dit qu'un chien parla, lorsque Tarquin fut chassé du trône. Une corneille, si l'on en croit Suétone, s'écria dans le Capitole, lorsqu'on allait assassiner

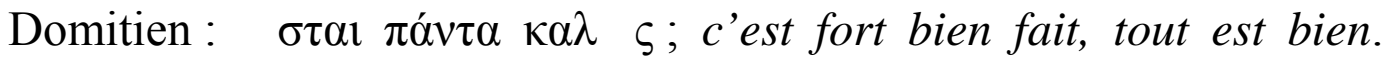
C'est ainsi qu'un des chevaux d'Achille, nommé Xante, prédit à son maître qu'il mourra devant Troie. Avant le cheval d'Achille, le bélier de Phryxus avait parlé, aussi bien que les vaches du mont Olympe. Ainsi, au lieu de réfuter les fables, on enchérissait sur elles : on faisait comme ce praticien à qui on produisait une fausse obligation; il ne s'amusa point à plaider : il produisit sur-le-champ une fausse quittance.

Il est vrai que nous ne voyons guère de morts ressuscités chez les Romains ; ils s'en tenaient à des guérisons miraculeuses. Les Grecs, plus attachés à la métempsycose, eurent beaucoup de résurrections. Ils tenaient ce secret des Orientaux, de qui toutes les sciences et les superstitions étaient venues.

De toutes les guérisons miraculeuses, les plus attestées, les plus authentiques, sont celles de cet aveugle à qui l'empereur Vespasien rendit la vue, et de ce paralytique auquel il rendit l'usage de ses membres. C'est dans Alexandrie que ce double miracle s'opère ; c'est devant un peuple innombrable, devant des Romains, des Grecs, des Égyptiens ; c'est sur son tribunal que Vespasien opère ces prodiges. Ce n'est pas lui qui cherche à se faire valoir par des prestiges dont un monarque affermi n'a pas besoin; ce sont ces deux malades euxmêmes qui, prosternés à ses pieds, le conjurent de les guérir. Il rougit de leurs prières, il s'en moque ; il dit qu'une telle guérison n'est pas au pouvoir d'un mortel. Les deux infortunés insistent : Sérapis leur est apparu ; Sérapis leur a dit qu'ils seraient guéris par Vespasien. Enfin il se laisse fléchir : il les touche sans se flatter du succès. La Divinité, favorable à sa modestie et à sa vertu, lui communique son pouvoir ; à l'instant l'aveugle voit, et l'estropié marche. Alexandrie, l'Égypte, et tout l'empire, applaudissent à Vespasien, favori du ciel. Le miracle est consigné dans les archives de l'empire et dans toutes les histoires contemporaines. Cependant, avec le temps, ce miracle n'est cru de personne, parce que personne n'a intérêt de le soutenir. 
Si l'on en croit je ne sais quel écrivain de nos siècles barbares, nommé Helgaut, le roi Robert, fils de Hugues Capet, guérit aussi un aveugle. Ce don des miracles, dans le roi Robert, fut apparemment la récompense de la charité avec laquelle il avait fait brûler le confesseur de sa femme, et ces chanoines d'Orléans, accusés de ne pas croire l'infaillibilité et la puissance absolue du pape, et par conséquent d'être manichéens : ou, si ce ne fut pas le prix de ces bonnes actions, ce fut celui de l'excommunication qu'il souffrit pour avoir couché avec la reine sa femme.

Les philosophes ont fait des miracles, comme les empereurs et les rois. On connaît ceux d'Apollonios de Tyane ; c'était un philosophe pythagoricien, tempérant, chaste et juste, à qui l'histoire ne reproche aucune action équivoque, ni aucune de ces faiblesses dont fut accusé Socrate. Il voyagea chez les mages et chez les brachmanes, et fut d'autant plus honoré partout qu'il était modeste, donnant toujours de sages conseils, et disputant rarement. La prière qu'il avait coutume de faire aux dieux est admirable : «Dieux immortels, accordez-nous ce que vous jugerez convenable, et dont nous ne soyons pas indignes. » Il n'avait nul enthousiasme; ses disciples en eurent : ils lui supposèrent des miracles qui furent recueillis par Philostrate. Les Tyanéens le mirent au rang des demi-dieux, et les empereurs romains approuvèrent son apothéose. Mais, avec le temps, l'apothéose d'Apollonios eut le sort de celle qu'on décernait aux empereurs romains; et la chapelle d'Apollonios fut aussi déserte que le Socratéion élevé par les Athéniens à Socrate.

Les rois d'Angleterre, depuis saint Édouard jusqu'au roi Guillaume III, firent journellement un grand miracle, celui de guérir les écrouelles, qu'aucuns médecins ne pouvaient guérir. Mais Guillaume III ne voulut point faire de miracles, et ses successeurs s'en sont abstenus comme lui. Si l'Angleterre éprouve jamais quelque grande révolution qui la replonge dans l'ignorance, alors elle aura des miracles tous les jours. 
On n'eut pas un temple aussitôt qu'on reconnut un Dieu. Les Arabes, les Chaldéens, les Persans, qui révéraient les astres, ne pouvaient guère avoir d'abord des édifices consacrés ; ils n'avaient qu'à regarder le ciel, c'était là leur temple. Celui de Bel, à Babylone, passe pour le plus ancien de tous; mais ceux de Brama, dans l'Inde, doivent être d'une antiquité plus reculée : au moins les brames le prétendent.

Il est dit dans les annales de la Chine que les premiers empereurs sacrifiaient dans un temple. Celui d'Hercule, à Tyr, ne paraît pas être des plus anciens. Hercule ne fut jamais, chez aucun peuple, qu'une divinité secondaire; cependant le temple de Tyr est très antérieur à celui de Judée. Hiram en avait un magnifique, lorsque Salomon, aidé par Hiram, bâtit le sien. Hérodote, qui voyagea chez les Tyriens, dit que, de son temps, les archives de Tyr ne donnaient à ce temple que deux mille trois cents ans d'antiquité. L'Égypte était remplie de temples depuis longtemps. Hérodote dit encore qu'il apprit que le temple de Vulcain, à Memphis, avait été bâti par Ménès vers le temps qui répond à trois mille ans avant notre ère ; et il n'est pas à croire que les Égyptiens eussent élevé un temple à Vulcain, avant d'en avoir donné un à Isis, leur principale divinité.

Je ne puis concilier avec les mœurs ordinaires de tous les hommes ce que dit Hérodote au livre second : il prétend que, excepté les Égyptiens et les Grecs, tous les autres peuples avaient coutume de coucher avec les femmes au milieu de leurs temples. Je soupçonne le texte grec d'avoir été corrompu. Les hommes les plus sauvages s'abstiennent de cette action devant des témoins. On ne s'est jamais avisé de caresser sa femme ou sa maîtresse en présence de gens pour qui on a les moindres égards. 
Il n'est guère possible que chez tant de nations, qui étaient religieuses jusqu'au plus grand scrupule, tous les temples eussent été des lieux de prostitution. Je crois qu'Hérodote a voulu dire que les prêtres qui habitaient dans l'enceinte qui entourait le temple pouvaient coucher avec leurs femmes dans cette enceinte qui avait le nom de temple, comme en usaient les prêtres juifs et d'autres : mais que les prêtres égyptiens, n'habitant point dans l'enceinte, s'abstenaient de toucher à leurs femmes quand ils étaient de garde dans les porches dont le temple était entouré.

Les petits peuples furent très longtemps sans avoir de temples. Ils portaient leurs dieux dans des coffres, dans des tabernacles. Nous avons déjà vu ${ }^{65}$ que quand les Juifs habitèrent les déserts, à l'orient du lac Asphaltide, ils portaient le tabernacle du dieu Remphan, du dieu Moloch, du dieu Kium, comme le dit Amos, et comme le répète saint Étienne.

C'est ainsi qu'en usaient toutes les autres petites nations du désert. Cet usage doit être le plus ancien de tous, par la raison qu'il est bien plus aisé d'avoir un coffre que de bâtir un grand édifice.

C'est probablement de ces dieux portatifs que vint la coutume des processions qui se firent chez tous les peuples; car il semble qu'on ne se serait pas avisé d'ôter un dieu de sa place, dans son temple, pour le promener dans la ville ; et cette violence eût pu paraître un sacrilège, si l'ancien usage de porter son dieu sur un chariot ou sur un brancard n'avait pas été dès longtemps établi.

La plupart des temples furent d'abord des citadelles, dans lesquelles on mettait en sûreté les choses sacrées. Ainsi le palladium était dans la forteresse de Troie; les boucliers descendus du ciel se gardaient dans le Capitole.

Nous voyons que le temple des Juifs était une maison forte, capable de soutenir un assaut. Il est dit au troisième livre des Rois que l'édifice avait soixante coudées de long et vingt de large ; c'est environ quatre-vingt-dix pieds de long sur trente de face. Il n'y a guère de plus petit édifice public ; mais cette maison étant de pierre, et bâtie sur une montagne, pouvait au moins se défendre d'une surprise ; les fenê-

Paragraphe 5. (B.) 
tres, qui étaient beaucoup plus étroites au dehors qu'en dedans, ressemblaient à des meurtrières.

Il est dit que les prêtres logeaient dans des appentis de bois adossés à la muraille.

Il est difficile de comprendre les dimensions de cette architecture. Le même livre des Rois nous apprend que, sur les murailles de ce temple, il y avait trois étages de bois ; que le premier avait cinq coudées de large, le second six, et le troisième sept. Ces proportions ne sont pas les nôtres ; ces étages de bois auraient surpris Michel-Ange et Bramante. Quoiqu'il en soit, il faut considérer que ce temple était bâti sur le penchant de la montagne Moria, et que par conséquent il ne pouvait avoir une grande profondeur. Il fallait monter plusieurs degrés pour arriver à la petite esplanade où fut bâti le sanctuaire, long de vingt coudées; or un temple dans lequel il faut monter et descendre est un édifice barbare. Il était recommandable par sa sainteté, mais non par son architecture. Il n'était pas nécessaire pour les desseins de Dieu que la ville de Jérusalem fût la plus magnifique des villes, et son peuple le plus puissant des peuples ; il n'était pas nécessaire non plus que son temple surpassât celui des autres nations; le plus beau des temples est celui où les hommages les plus purs lui sont offerts.

La plupart des commentateurs se sont donné la peine de dessiner cet édifice, chacun à sa manière. Il est à croire qu'aucun de ces dessinateurs n'a jamais bâti de maison. On conçoit pourtant que ces murailles qui portaient ces trois étages étant de pierre, on pouvait se défendre un jour ou deux dans cette petite retraite.

Cette espèce de forteresse d'un peuple privé des arts ne tint pas contre Nabusardan, l'un des capitaines du roi de Babylone, que nous nommons Nabuchodonosor.

Le second temple, bâti par Néhémie, fut moins grand et moins somptueux. Le livre d'Esdras nous apprend que les murs de ce nouveau temple n'avaient que trois rangs de pierre brute, et que le reste était de bois : c'était bien plutôt une grange qu'un temple. Mais celui qu'Hérode fit bâtir depuis fut une vraie forteresse. il fut obligé, comme nous l'apprend Josèphe, de démolir le temple de Néhémie, qu'il appelle le temple d'Aggée. Hérode combla une partie du précipice au bas de la montagne Moria, pour faire une plate-forme appuyée d'un 
très gros mur sur lequel le temple fut élevé. Près de cet édifice était la tour Antonia, qu'il fortifia encore, de sorte que ce temple était une vraie citadelle.

En effet les Juifs osèrent s'y défendre contre l'armée de Titus, jusqu'à ce qu'un soldat romain ayant jeté une solive enflammée dans l'intérieur de ce fort, tout prit feu à l'instant: ce qui prouve que les bâtiments, dans l'enceinte du temple, n'étaient que de bois du temps d'Hérode, ainsi que sous Néhémie et sous Salomon.

Ces bâtiments de sapin contredisent un peu cette grande magnificence dont parle l'exagérateur Josèphe. Il dit que Titus, étant entré dans le sanctuaire, l'admira, et avoua que sa richesse passait sa renommée. Il n'y a guère d'apparence qu'un empereur romain, au milieu du carnage, marchant sur des monceaux de morts, s'amusât à considérer avec admiration un édifice de vingt coudées de long, tel qu'était ce sanctuaire ; et qu'un homme qui avait vu le Capitole fut surpris de la beauté d'un temple juif. Ce temple était très saint, sans doute ; mais un sanctuaire de vingt coudées de long n'avait pas été bâti par un Vitruve. Les beaux temples étaient ceux d'Éphèse, d'Alexandrie, d'Athènes, d'Olympie, de Rome.

Josèphe, dans sa Déclamation contre Apion, dit qu'il ne fallait « qu'un temple aux Juifs, parce qu'il n'y a qu'un Dieu. » Ce raisonnement ne paraît pas concluant ; car si les Juifs avaient eu sept ou huit cents milles de pays, comme tant d'autres peuples, il aurait fallu qu'ils passassent leur vie à voyager pour aller sacrifier dans ce temple chaque année. De ce qu'il n'y a qu'un Dieu, il suit que tous les temples du monde ne doivent être élevés qu'à lui ; mais il ne suit pas que la terre ne doive avoir qu'un temple. La superstition a toujours une mauvaise logique.

D'ailleurs, comment Josèphe peut-il dire qu'il ne fallait qu'un temple aux Juifs, lorsqu'ils avaient, depuis le règne de Ptolémée Philométor, le temple assez connu de l'Onion, à Bubaste en Égypte? 
35.

DE LA MAGIE

Qu'est-ce que la magie ? le secret de faire ce que ne peut faire la nature ; c'est la chose impossible : aussi a-t-on cru à la magie dans tous les temps. Le mot est venu des mag, magdim, ou mages de Chaldée. Ils en savaient plus que les autres; ils recherchaient la cause de la pluie et du beau temps; et bientôt ils passèrent pour faire le beau temps et la pluie. Ils étaient astronomes; les plus ignorants et les plus hardis furent astrologues. Un événement arrivait sous la conjonction de deux planètes; donc ces deux planètes avaient causé cet événement; et les astrologues étaient les maîtres des planètes. Des imaginations frappées avaient vu en songe leurs amis mourants ou morts ; les magiciens faisaient apparaître les morts.

Ayant connu le cours de la lune, il était tout simple qu'ils la fissent descendre sur la terre. Ils disposaient même de la vie des hommes, soit en faisant des figures de cire, soit en prononçant le nom de Dieu, ou celui du diable. Clément d'Alexandrie, dans ses Stromates, livre premier, dit que, suivant un ancien auteur, Moïse prononça le nom de Ihaho, ou Jeovah, d'une manière si efficace, à l'oreille du roi d'Égypte Phara Nekefr, que ce roi tomba sans connaissance.

Enfin, depuis Jannès et Mambrès, qui étaient les sorciers à brevet de Pharaon, jusqu'à la maréchale d'Ancre, qui fut brûlée à Paris pour avoir tué un coq blanc dans la pleine lune, il n'y a pas eu un seul temps sans sortilège.

La pythonisse d'Endor, qui évoqua l'ombre de Samuel, est assez connue ; il est vrai qu'il serait fort étrange que ce mot de Python, qui est grec, eût été connu des Juifs du temps de Saül. Mais la Vulgate 
seule parle de Python : le texte hébreu se sert du mot ob, que les Septante ont traduit par engastrimuthon ${ }^{66}$.

Revenons à la magie. Les Juifs en firent le métier dès qu'ils furent répandus dans le monde. Le sabbat des sorciers en est une preuve parlante, et le bouc avec lequel les sorcières étaient supposées s'accoupler vient de cet ancien commerce que les Juifs eurent avec les boucs dans le désert ; ce qui leur est reproché dans le Lévitique, chapitre XVII.

Il n'y a guère eu parmi nous de procès criminels de sorciers sans qu'on y ait impliqué quelque Juif.

Les Romains, tout éclairés qu'ils étaient du temps d'Auguste, s'infatuaient encore des sortilèges tout comme nous. Voyez l'églogue (VIII) de Virgile, intitulée Pharmaceutria (vers 69-97-98) :

«Carmina vel cœlo possunt deducere lunam. »

La voix de l'enchanteur fait descendre la lune.

« His ego sæpe lupum fieri et se condere sylvis

Mœrim, sæpe animas imis exire sepulcris. »

Mœris, devenu loup, se cachait dans les bois :

Du creux de leur tombeau j'ai vu sortir les âmes.

On s'étonne que Virgile passe aujourd'hui à Naples pour un sorcier : il n'en faut pas chercher la raison ailleurs que dans cette églogue.

Horace reproche à Sagana et à Canidia leurs horribles sortilèges. Les premières têtes de la république furent infectées de ces imaginations funestes. Sextus, le fils du grand Pompée, immola un enfant dans un de ces enchantements.

Les philtres pour se faire aimer étaient une magie plus douce ; les Juifs étaient en possession de les vendre aux dames romaines. Ceux de cette nation qui ne pouvaient devenir de riches courtiers faisaient des prophéties ou des philtres.

66 L'auteur était trop modeste pour expliquer ici par quel endroit parlait cette sorcière. C'est le même par lequel la pythonisse de Delphes recevait l'esprit divin; et voilà pourquoi la Vulgate a traduit le mot $o b$ par Python ; elle a voulu ménager la modestie des lecteurs, qu'une traduction littérale aurait pu blesser. (K.) 
Toutes ces extravagances, ou ridicules, ou affreuses, se perpétuèrent chez nous, et il n'y a pas un siècle qu'elles sont décréditées. Des missionnaires ont été tout étonnés de trouver ces extravagances au bout du monde ; ils ont plaint les peuples à qui le démon les inspirait. Eh ! mes amis, que ne restiez-vous dans votre patrie? vous n'y auriez pas trouvé plus de diables, mais vous y auriez trouvé tout autant de sottises.

Vous auriez vu des milliers de misérables assez insensés pour se croire sorciers, et des juges assez imbéciles et assez barbares pour les condamner aux flammes. Vous auriez vu une jurisprudence établie en Europe sur la magie, comme on a des lois sur le larcin et sur le meurtre : jurisprudence fondée sur les décisions des conciles. Ce qu'il y avait de pis, c'est que les peuples, voyant que la magistrature et l'Église croyaient à la magie, n'en étaient que plus invinciblement persuadés de son existence : par conséquent, plus on poursuivait les sorciers, plus il s'en formait. D'où venait une erreur si funeste et si générale ? de l'ignorance : et cela prouve que ceux qui détrompent les hommes sont leurs véritables bienfaiteurs.

On a dit que le consentement de tous les hommes était une preuve de la vérité. Quelle preuve! Tous les peuples ont cru à la magie, à l'astrologie, aux oracles, aux influences de la lune. Il eût fallu dire au moins que le consentement de tous les sages était, non pas une preuve, mais une espèce de probabilité. Et quelle probabilité encore ! Tous les sages ne croyaient-ils pas, avant Copernic, que la terre était immobile au centre du monde?

Aucun peuple n'est en droit de se moquer d'un autre. Si Rabelais appelle Picatrix mon révérend père en diable ${ }^{67}$, parce qu'on enseignait la magie à Tolède, à Salamanque et à Séville, les Espagnols peuvent reprocher aux Français le nombre prodigieux de leurs sorciers.

La France est peut-être, de tous les pays, celui qui a le plus uni la cruauté et le ridicule. Il n'y a point de tribunal en France qui n'ait fait brûler beaucoup de magiciens. Il y avait dans l'ancienne Rome des

${ }^{67}$ Livre I ${ }^{\text {er }}$, chapitre XXIII. (B.) 
fous qui pensaient être sorciers; mais on ne trouva point de barbares qui les brûlassent.

Table des Matières

36.

DES VICTIMES HUMAINES

Les hommes auraient été trop heureux s'ils n'avaient été que trompés ; mais le temps, qui tantôt corrompt les usages et tantôt les rectifie, ayant fait couler le sang des animaux sur les autels, des prêtres, bouchers accoutumés au sang, passèrent des animaux aux hommes ; et la superstition, fille dénaturée de la religion, s'écarta de la pureté de sa mère, au point de forcer les hommes à immoler leurs propres enfants, sous prétexte qu'il fallait donner à Dieu ce qu'on avait de plus cher.

Le premier sacrifice de cette nature, dont la mémoire se soit conservée, fut celui de Jéhud chez les Phéniciens, qui, si l'on en croit les fragments de Sanchoniathon, fut immolé par son père Hillu environ deux mille ans avant notre ère. C'était un temps où les grands États étaient déjà établis, où la Syrie, la Chaldée, l'Égypte, étaient très florissantes; et déjà en Égypte, suivant Diodore, on immolait à Osiris les hommes roux; Plutarque prétend qu'on les brûlait vifs. D'autres ajoutent qu'on noyait une fille dans le Nil, pour obtenir de ce fleuve un plein débordement qui ne fût ni trop fort ni trop faible.

Ces abominables holocaustes s'établirent dans presque toute la terre. Pausanias prétend que Lycaon immola le premier des victimes humaines en Grèce. Il fallait bien que cet usage fût reçu du temps de la guerre de Troie, puisque Homère fait immoler par Achille douze Troyens à l'ombre de Patrocle. Homère eût-il osé dire une chose si horrible ? n'aurait-il pas craint de révolter tous ses lecteurs, si de tels holocaustes n'avaient pas été en usage ? Tout poète peint les mœurs de son pays.

Je ne parle pas du sacrifice d'Iphigénie, et de celui d'Idamante, fils d'Idoménée : vrais ou faux, ils prouvent l'opinion régnante. On ne 
peut guère révoquer en doute que les Scythes de la Tauride immolassent des étrangers.

Si nous descendons à des temps plus modernes, les Tyriens et les Carthaginois, dans les grands dangers, sacrifiaient un homme à Saturne. On en fit autant en Italie; et les Romains eux-mêmes, qui condamnèrent ces horreurs, immolèrent deux Gaulois et deux Grecs pour expier le crime d'une vestale. Plutarque confirme cette affreuse vérité dans ses Questions sur les Romains.

Les Gaulois, les Germains, eurent cette horrible coutume. Les druides brûlaient des victimes humaines dans de grandes figures d'osier: des sorcières, chez les Germains, égorgeaient les hommes dévoués à la mort, et jugeaient de l'avenir par le plus ou le moins de rapidité du sang qui coulait de la blessure.

Je crois bien que ces sacrifices étaient rares : s'ils avaient été fréquents, si on en avait fait des fêtes annuelles, si chaque famille avait eu continuellement à craindre que les prêtres vinssent choisir la plus belle fille ou le fils aîné de la maison pour lui arracher le cœur saintement sur une pierre consacrée, on aurait bientôt fini par immoler les prêtres eux-mêmes. Il est très probable que ces saints parricides ne se commettaient que dans une nécessité pressante, dans les grands dangers, où les hommes sont subjugués par la crainte, et où la fausse idée de l'intérêt public forçait l'intérêt particulier à se taire.

Chez les brames, toutes les veuves ne se brûlaient pas toujours sur les corps de leurs maris. Les plus dévotes et les plus folles firent de temps immémorial et font encore cet étonnant sacrifice. Les Scythes immolèrent quelquefois aux mânes de leurs kans les officiers les plus chéris de ces princes. Hérodote décrit en détail la manière dont on préparait leurs cadavres pour en former un cortège autour du cadavre royal ; mais il ne paraît point par l'histoire que cet usage ait duré longtemps.

Si nous lisions l'histoire des Juifs écrite par un auteur d'une autre nation, nous aurions peine à croire qu'il y ait eu en effet un peuple fugitif d'Égypte qui soit venu par ordre exprès de Dieu immoler sept ou huit petites nations qu'il ne connaissait pas, égorger sans miséricorde toutes les femmes, les vieillards, et les enfants à la mamelle, et ne réserver que les petites filles; que ce peuple saint ait été puni de 
son dieu, quand il avait été assez criminel pour épargner un seul homme dévoué à l'anathème. Nous ne croirions pas qu'un peuple si abominable eût pu exister sur la terre mais, comme cette nation ellemême nous rapporte tous ces faits dans ses livres saints, il faut la croire.

Je ne traite point ici la question si ces livres ont été inspirés. Notre sainte Église, qui a les Juifs en horreur, nous apprend que les livres juifs ont été dictés par le Dieu créateur et père de tous les hommes; je ne puis en former aucun doute, ni me permettre même le moindre raisonnement.

Il est vrai que notre faible entendement ne peut concevoir dans Dieu une autre sagesse, une autre justice, une autre bonté que celle dont nous avons l'idée; mais enfin il a fait ce qu'il a voulu; ce n'est pas à nous de le juger; je m'en tiens toujours au simple historique.

Les Juifs ont une loi par laquelle il leur est expressément ordonné de n'épargner aucune chose, aucun homme dévoué au Seigneur. " On ne pourra le racheter, il faut qu'il meure ", dit la loi du Lévitique, au chapitre XXVII. C'est en vertu de cette loi qu'on voit Jephté immoler sa propre fille, et le prêtre Samuel couper en morceaux le roi Agag ${ }^{68}$. Le Pentateuque nous dit que dans le petit pays de Madian, qui est environ de neuf lieues carrées, les Israëlites ayant trouvé six cent soixante et quinze mille brebis, soixante et douze mille bœufs, soixante et un mille ânes, et trente-deux mille filles vierges, Moïse commanda qu'on massacrât tous les hommes, toutes les femmes, et tous les enfants, mais qu'on gardât les filles, dont trente-deux seulement furent immolées ${ }^{69}$. Ce qu'il y a de remarquable dans ce dévouement, c'est que ce

68 Des critiques ont prétendu qu'il n'était pas sûr que Samuel fut prêtre. Mais comment, n'étant point prêtre, se serait-il arrogé le droit de sacrer Saül et David ? Si ce n'est pas en qualité de prêtre qu'il immola Agag, c'est donc en qualité d'assassin ou de bourreau. Si Samuel n'était pas prêtre, que devient l'autorité de son exemple employée tant de fois par les théologiens pour prouver que les prêtres ont le droit non seulement de sacrer les rois, mais d'en sacrer d'autres quand ceux qu'ils ont oints les premiers ne leur conviennent plus, et même de traiter les rois indociles comme le doux Samuel a traité l'impie Agag? (K.)

69 On a prétendu que ces trente-deux filles furent seulement destinées au service du tabernacle; mais si on lit attentivement le livre des Nombres, où cette histoire est rapportée, on verra que le sens de M. de Voltaire est le plus naturel. Les israélites avaient massacré tous les mâles en état de porter les armes, et 
même Moïse était gendre du grand-prêtre des Madianites, Jéthro, qui lui avait rendu les plus grands services, et qui l'avait comblé de bienfaits.

Le même livre nous dit que Josué, fils de Nun, ayant passé avec sa horde la rivière du Jourdain à pied sec, et ayant fait tomber au son des trompettes les murs de Jéricho dévoués à l'anathème, il fit périr tous les habitants dans les flammes; qu'il conserva seulement Rahab la prostituée, et sa famille, qui avait caché les espions du saint peuple : que le même Josué dévoua à la mort douze mille habitants de la ville de Haï ; qu'il immola au Seigneur trente et un rois du pays, tous soumis à l'anathème, et qui furent pendus. Nous n'avons rien de comparable à ces assassinats religieux dans nos derniers temps, si ce n'est peut-être la Saint-Barthélemy et les massacres d'Irlande.

Ce qu'il y a de triste, c'est que plusieurs personnes doutent que les Juifs aient trouvé six cent soixante et quinze mille brebis, et trentedeux mille filles pucelles dans le village d'un désert au milieu des rochers ; et que personne ne doute de la Saint-Barthélemy. Mais ne cessons de répéter combien les lumières de notre raison sont impuissantes pour nous éclairer sur les étranges événements de l'antiquité, et sur les raisons que Dieu, maître de la vie et de la mort, pouvait avoir de choisir le peuple juif pour exterminer le peuple cananéen.

n'avaient réservé que les femmes et les enfants. Moïse leur en fait des reproches violents ; il leur ordonne de sang-froid, plusieurs jours après la bataille, d'égorger les enfants mâles et toutes les femmes qui ne sont pas vierges. Après avoir commandé le meurtre, il prescrit aux meurtriers la méthode de se purifier. Il a oublié seulement de nous transmettre la manière dont les Juifs s'y prenaient pour distinguer une vierge d'une fille qui ne l'était pas. Ainsi il est clair que l'on peut, sans faire injure au caractère de Moïse, croire qu'après avoir ordonné le massacre de quarante mille, tant enfants mâles que femmes, il n'a pas hésité à ordonner le sacrifice de trente-deux filles. Comment imagine-t-on que les Juifs aient pu consacrer au service du tabernacle trente-deux filles étrangères et idolâtres ? D'ailleurs la portion des prêtres avait été réglée à part, et ils ne se seraient pas contentés de trente-deux vierges. (Voyez paragraphe XIX de l'ouvrage intitulé : Un Chrétien contre six Juifs, dans les Mélanges, année 1776.) (K.) 
37.

\section{DES MYSTÈRES DE CÉRÈS-ÉLEUSINE}

Dans le chaos des superstitions populaires, qui auraient fait de presque tout le globe un vaste repaire de bêtes féroces, il y eut une institution salutaire qui empêcha une partie du genre humain de tomber dans un entier abrutissement; ce fut celle des mystères et des expiations. Il était impossible qu'il ne se trouvât des esprits doux et sages parmi tant de fous cruels, et qu'il n'y eût des philosophes qui tâchassent de ramener les hommes à la raison et à la morale.

Ces sages se servirent de la superstition même pour en corriger les abus énormes, comme on emploie le cœur des vipères pour guérir de leurs morsures; on mêla beaucoup de fables avec des vérités utiles, et les vérités se soutinrent par les fables.

On ne connaît plus les mystères de Zoroastre. On sait peu de chose de ceux d'Isis ; mais nous ne pouvons douter qu'ils n'annonçassent le grand système d'une vie future, car Celse dit à Origène, livre VIII : "Vous vous vantez de croire des peines éternelles; et tous les ministres des mystères ne les annoncèrent-ils pas aux initiés ?»

L'unité de Dieu était le grand dogme de tous les mystères. Nous avons encore la prière des prêtresses d'Isis, conservée dans Apulée, et que j'ai citée en parlant des mystères égyptiens. ${ }^{70}$

Les cérémonies mystérieuses de Cérès furent une imitation de celles d'Isis. Ceux qui avaient commis des crimes les confessaient et les expiaient : on jeûnait, on se purifiait, on donnait l'aumône. Toutes les cérémonies étaient tenues secrètes, sous la religion du serment, pour les rendre plus vénérables. Les mystères se célébraient la nuit pour inspirer une sainte horreur. On y représentait des espèces de tragédies, dont le spectacle étalait aux yeux le bonheur des justes et les peines

70

Voyez paragraphe 23. 
des méchants. Les plus grands hommes de l'antiquité, les Platon, les Cicéron, ont fait l'éloge de ces mystères, qui n'étaient pas encore dégénérés de leur pureté première.

De très savants hommes ont prétendu que le sixième livre de l'Énéide n'est que la peinture de ce qui se pratiquait dans ces spectacles si secrets et si renommés ${ }^{71}$. Virgile n'y parle point, à la vérité, du Demiourgos qui représentait le Créateur ; mais il fait voir dans le vestibule, dans l'avant-scène, les enfants que leurs parents avaient laissés périr, et c'était un avertissement aux pères et mères.

\section{« Continuo auditæ voces, vagitus et ingens, etc. » VIRG., Énéide, liv. VI, v. 426.}

Ensuite paraissait Minos, qui jugeait les morts. Les méchants étaient entraînés dans le Tartare, et les justes conduits dans les champs Élysées. Ces jardins étaient tout ce qu'on avait inventé de mieux pour les hommes ordinaires. Il n'y avait que les héros demi-dieux à qui on accordait l'honneur de monter au ciel. Toute religion adopta un jardin pour la demeure des justes; et même, quand les Esséniens, chez le peuple juif, reçurent le dogme d'une autre vie, ils crurent que les bons iraient après la mort dans des jardins au bord de la mer car, pour les pharisiens, ils adoptèrent la métempsycose, et non la résurrection. S'il est permis de citer l'histoire sacrée de Jésus-Christ parmi tant de choses profanes, nous remarquerons qu'il dit au voleur repentant : « Tu seras aujourd'hui avec moi dans le jardin ${ }^{72}$. » Il se conformait en cela au langage de tous les hommes.

Les mystères d'Éleusine devinrent les plus célèbres. Une chose très remarquable, c'est qu'on y lisait le commencement de la théogonie de Sanchoniathon le Phénicien; c'est une preuve que Sanchoniathon avait annoncé un Dieu suprême, créateur et gouverneur du monde. C'était donc cette doctrine qu'on dévoilait aux initiés imbus de la créance du polythéisme. Supposons parmi nous un peuple superstitieux qui serait accoutumé dès sa tendre enfance à rendre à la Vierge, à saint Joseph, et aux autres saints, le même culte qu'à Dieu le père ; il serait peut-être dangereux de vouloir le détromper tout d'un coup ; il

71 Voltaire a, depuis, abandonné cette opinion. Je me dédis, dit-il dans ses Questions sur l'Encyclopédie (refondues dans le Dict. philosophique), au mot INITIATION. (B.)

72 Luc, chap. XXIII. (V.) 
serait sage de révéler d'abord aux plus modérés ; aux plus raisonnables, la distance infinie qui est entre Dieu et les créatures : c'est précisément ce que firent les mystagogues. Les participants aux mystères s'assemblaient dans le temple de Cérès, et l'hiérophante leur apprenait qu'au lieu d'adorer Cérès conduisant Triptolème sur un char traîné par des dragons, il fallait adorer le Dieu qui nourrit les hommes, et qui a permis que Cérès et Triptolème missent l'agriculture en honneur.

Cela est si vrai que l'hiérophante commençait par réciter les vers de l'ancien Orphée : «Marchez dans la voie de la justice, adorez le seul maître de l'univers ; il est un; il est seul par lui-même, tous les êtres lui doivent leur existence; il agit dans eux et par eux; il voit tout, et jamais il n'a été vu des yeux mortels. »

J'avoue que je ne conçois pas comment Pausanias peut dire que ces vers ne valent pas ceux d'Homère ; il faut convenir que, du moins pour le sens, ils valent beaucoup mieux que l'Iliade et l'Odyssée entières.

Il faut avouer que l'évêque Warburton, quoique très injuste dans plusieurs de ses décisions audacieuses, donne beaucoup de force à tout ce que je viens de dire de la nécessité de cacher le dogme de l'unité de Dieu à un peuple entêté du polythéisme. Il remarque, d'après Plutarque, que le jeune Alcibiade, ayant assisté à ces mystères, ne fit aucune difficulté d'insulter aux statues de Mercure, dans une partie de débauche avec plusieurs de ses amis, et que le peuple en fureur demanda la condamnation d'Alcibiade.

Il fallait donc alors la plus grande discrétion pour ne pas choquer les préjugés de la multitude. Alexandre lui-même (si cette anecdote n'est pas apocryphe), ayant obtenu en Égypte, de l'hiérophante des mystères, la permission de mander à sa mère le secret des initiés, la conjura en même temps de brûler sa lettre après l'avoir lue, pour ne pas irriter les Grecs.

Ceux qui, trompés par un faux zèle, ont prétendu depuis que ces mystères n'étaient que des débauches infâmes devaient être détrompés par le mot même qui répond à initiés : il veut dire qu'on commençait une nouvelle vie. 
Une preuve encore sans réplique que ces mystères n'étaient célébrés que pour inspirer la vertu aux hommes, c'est la formule par laquelle on congédiait l'assemblée. On prononçait, chez les Grecs, les deux anciens mots phéniciens Kof tomphet, veillez et soyez purs. (Warburton, Lég. de Moïse, livre I.) Enfin, pour dernière preuve, c'est quel'empereur Néron, coupable de la mort de sa mère, ne put être reçu à ces mystères quand il voyagea dans la Grèce : le crime était trop énorme; et, tout empereur qu'il était, les initiés n'auraient pas voulu l'admettre. Zosime dit aussi que Constantin ne put trouver des prêtres paiens qui voulussent le purifier et l'absoudre de ses parricides.

Il y avait donc en effet chez les peuples qu'on nomme païens, gentils, idolâtres, une religion très pure ; tandis que les peuples et les prêtres avaient des usages honteux, des cérémonies puériles, des doctrines ridicules, et que même ils versaient quelquefois le sang humain en l'honneur de quelques dieux imaginaires, méprisés et détestés par les sages.

Cette religion pure consistait dans l'aveu de l'existence d'un Dieu suprême, de sa providence et de sa justice. Ce qui défigurait ces mystères, c'était, si l'on en croit Tertullien, la cérémonie de la régénération. Il fallait que l'initié parût ressusciter; c'était le symbole du nouveau genre de vie qu'il devait embrasser. On lui présentait une couronne, il la foulait aux pieds ; l'hiérophante levait sur lui le couteau sacré : l'initié, qu'on feignait de frapper, feignait aussi de tomber mort ; après quoi il paraissait ressusciter. Il y a encore chez les francsmaçons un reste de cette ancienne cérémonie.

Pausanias, dans ses Arcadiques, nous apprend que, dans plusieurs temples d'Éleusine, on flagellait les pénitents, les initiés ; coutume odieuse, introduite longtemps après dans plusieurs églises chrétiennes ${ }^{73}$. Je ne doute pas que dans tous ces mystères, dont le fond était si sage et si utile, il n'entrât beaucoup de superstitions condamnables. Les superstitions conduisirent à la débauche, qui amena le mépris. Il ne resta enfin de tous ces anciens mystères que des troupes de gueux que nous avons vus, sous le nom d'Égyptiens et de Bohèmes, courir

Pausanias ne dit pas positivement que les coups de verges ne fussent que pour les initiés ; mais il serait plaisant d'imaginer que les prêtres d'Athènes eussent eu le droit de frapper de verges tous ceux qu'ils rencontraient. Passe pour les initiés et les dévotes. (K.) 
l'Europe avec des castagnettes; danser la danse des prêtres d'Isis, vendre du baume, guérir la gale et en être couverts, dire la bonne aventure, et voler des poules. Telle a été la fin de ce qu'on a eu de plus sacré dans la moitié de la terre connue.

Table des Matières

38.

DES JUIFS AU TEMPS OÙ ILS COMMENCÈRENT À ÊTRE CONNUS

Nous toucherons le moins que nous pourrons à ce qui est divin dans l'histoire des Juifs; ou si nous sommes forcés d'en parler, ce n'est qu'autant que leurs miracles ont un rapport essentiel à la suite des événements. Nous avons pour les prodiges continuels qui signalèrent tous les pas de cette nation le respect qu'on leur doit; nous les croyons avec la foi raisonnable qu'exige l'église substituée à la synagogue; nous ne les examinons pas; nous nous en tenons toujours à 1'historique. Nous parlerons des Juifs comme nous parlerions des Scythes et des Grecs, en pesant les probabilités et en discutant les faits. Personne au monde n'ayant écrit leur histoire qu'eux-mêmes avant que les Romains détruisissent leur petit État, il faut ne consulter que leurs annales.

Cette nation est des plus modernes, à ne la regarder, comme les autres peuples, que depuis le temps où elle forme un établissement, et où elle possède une capitale. Les Juifs ne paraissent considérés de leurs voisins que du temps de Salomon, qui était à peu près celui d'Hésiode et d'Homère, et des premiers archontes d'Athènes.

Le nom de Salomon, ou Soleiman, est fort connu des Orientaux ; mais celui de David ne l'est point ; de Saül, encore moins. Les Juifs, avant Saül, ne paraissent qu'une horde d'Arabes du désert, si peu puissants que les Phéniciens les traitaient à peu près comme les Lacédémoniens traitaient les ilotes. C'étaient des esclaves auxquels il n'était pas permis d'avoir des armes : ils n'avaient pas le droit de forger le fer, pas même celui d'aiguiser les socs de leurs charrues et le tranchant de leurs cognées; il fallait qu'ils allassent à leurs maîtres pour les moindres ouvrages de cette espèce. Les Juifs le déclarent 
dans le livre de Samuel, et ils ajoutent qu'ils n'avaient ni épée ni javelot dans la bataille que Saül et Jonathas donnèrent à Béthaven, contre les Phéniciens, ou Philistins, journée où il est rapporté que Saül fit serment d'immoler au Seigneur celui qui aurait mangé pendant le combat.

Il est vrai qu'avant cette bataille gagnée sans armes il est dit, au chapitre précédent ${ }^{74}$, que Saül, avec une armée de trois cent trente mille hommes, défit entièrement les Ammonites; ce qui semble ne se pas accorder avec l'aveu qu'ils n'avaient ni javelot, ni épée, ni aucune arme. D'ailleurs, les plus grands rois ont eu rarement à la fois trois cent trente mille combattants effectifs. Comment les Juifs, qui semblent errants et opprimés dans ce petit pays, qui n'ont pas une ville fortifiée, pas une arme, pas une épée, ont-ils mis en campagne trois cent trente mille soldats? il y avait là de quoi conquérir l'Asie et l'Europe. Laissons à des auteurs savants et respectables le soin de concilier ces contradictions apparentes que des lumières supérieures font disparaître ; respectons ce que nous sommes tenus de respecter, et remontons à l'histoire des Juifs par leurs propres écrits.

$\underline{\text { Table des Matières }}$

39.

DES JUIFS EN ÉGYPTE

Les annales des Juifs disent que cette nation habitait sur les confins de l'Égypte dans les temps ignorés ; que son séjour était dans le petit pays de Gossen, ou Gessen, vers le mont Casius et le lac Sirbon. C'est là que sont encore les Arabes qui viennent en hiver paitre leurs troupeaux dans la basse Égypte. Cette nation n'était composée que d'une seule famille, qui, en deux cent cinq années, produisit un peuple d'environ trois millions de personnes ; car, pour fournir six cent mille combattants que la Genèse compte au sortir de l'Égypte, il faut des femmes, des filles et des vieillards. Cette multiplication, contre l'ordre de la nature, est un des miracles que Dieu daigna faire en faveur des Juifs.

74 Rois, I, chap. XI, v. 8, 11. (V.) 
C'est en vain qu'une foule de savants hommes s'étonne que le roi d'Égypte ait ordonné à deux sages-femmes de faire périr tous les enfants mâles des Hébreux; que la fille du roi, qui demeurait à Memphis, soit venue se baigner loin de Memphis, dans un bras du Nil, où jamais personne ne se baigne à cause des crocodiles. C'est en vain qu'ils font des objections sur l'âge de quatre-vingts ans auquel Moïse était déjà parvenu avant d'entreprendre de conduire un peuple entier hors d'esclavage.

Ils disputent sur les dix plaies d'Égypte, ils disent que les magiciens du royaume ne pouvaient faire les mêmes miracles que l'envoyé de Dieu ; et que si Dieu leur donnait ce pouvoir, il semblait agir contre lui-même. Ils prétendent que Moïse ayant changé toutes les eaux en sang, il ne restait plus d'eau pour que les magiciens pussent faire la même métamorphose.

Ils demandent comment Pharaon put poursuivre les Juifs avec une cavalerie nombreuse, après que tous les chevaux étaient morts dans les cinquième, sixième, septième et dixième plaies. Ils demandent pourquoi six cent mille combattants s'enfuirent ayant Dieu à leur tête, et pouvant combattre avec avantage des Égyptiens dont tous les premiers nés avaient été frappés de mort. Ils demandent encore pourquoi Dieu ne donna pas la fertile Égypte à son peuple chéri, au lieu de le faire errer quarante ans dans d'affreux déserts.

On n'a qu'une seule réponse à toutes ces objections sans nombre, et cette réponse est : Dieu l'a voulu, l'Église le croit, et nous devons le croire. C'est en quoi cette histoire diffère des autres. Chaque peuple a ses prodiges ; mais tout est prodige chez le peuple juif; et on peut dire que cela devait être ainsi, puisqu'il était conduit par Dieu même. Il est clair que l'histoire de Dieu ne doit point ressembler à celle des hommes. C'est pourquoi nous ne rapporterons aucun de ces faits surnaturels dont il n'appartient qu'à l'Esprit Saint de parler; encore moins oserons-nous tenter de les expliquer. Examinons seulement le peu d'événements qui peuvent être soumis à la critique. 


\section{0. DE MOÏSE, CONSIDÉRÉ SIMPLEMENT COMME CHEF D'UNE NATION}

Le maître de la nature donne seul la force au bras qu'il daigne choisir. Tout est surnaturel dans Moïse. Plus d'un savant l'a regardé comme un politique très habile : d'autres ne voient en lui qu'un roseau faible dont la main divine daigne se servir pour faire le destin des empires. Qu'est-ce en effet qu'un vieillard de quatre-vingts ans pour entreprendre de conduire par lui-même tout un peuple, sur lequel il n'a aucun droit? Son bras ne peut combattre, et sa langue ne peut articuler. Il est peint décrépit et bègue. Il ne conduit ses suivants que dans des solitudes affreuses pendant quarante années : il veut leur donner un établissement, et il ne leur en donne aucun. À suivre sa marche dans les déserts de Sur, de Sin, d'Oreb, de Sinaï, de Pharan, de CadèsBarné, et à le voir rétrograder jusque vers l'endroit d'où il était parti, il serait difficile de le regarder comme un grand capitaine. Il est à la tête de six cent mille combattants, et il ne pourvoit ni au vêtement ni à la subsistance de ses troupes. Dieu fait tout, Dieu remédie à tout; il nourrit, il vêtit le peuple par des miracles. Moïse n'est donc rien par lui-même, et son impuissance montre qu'il ne peut être guidé que par le bras du Tout-Puissant; aussi nous ne considérons en lui que l'homme, et non le ministre de Dieu. Sa personne, en cette qualité, est l'objet d'une recherche plus sublime.

Il veut aller au pays des Cananéens, à l'occident du Jourdain, dans la contrée de Jéricho, qui est, dit-on, un bon terroir à quelques égards ; et, au lieu de prendre cette route, il tourne à l'orient, entre Ésiongaber et la mer Morte, pays sauvage, stérile, hérissé de montagnes sur lesquelles il ne croît pas un arbuste, et où l'on ne trouve point de fontaine, excepté quelques petits puits d'eau salée. Les Cananéens ou Phéniciens, sur le bruit de cette irruption d'un peuple étranger, viennent le battre dans ces déserts vers Cadès-Barné. Comment se laisse-t-il battre à la tête de six cent mille soldats, dans un pays qui ne contient pas au- 
jourd'hui deux ou trois mille habitants? Au bout de trente-neuf ans il remporte deux victoires; mais il ne remplit aucun objet de sa légation : lui et son peuple meurent avant que d'avoir mis le pied dans le pays qu'il voulait subjuguer.

Un législateur, selon nos notions communes, doit se faire aimer et craindre ; mais il ne doit pas pousser la sévérité jusqu'à la barbarie : il ne doit pas, au lieu d'infliger par les ministres de la loi quelques supplices aux coupables, faire égorger au hasard une grande partie de sa nation par l'autre.

Se pourrait-il qu'à l'âge de près de six-vingts ans, Moïse, n'étant conduit que par lui-même, eût été si inhumain, si endurci au carnage, qu'il eût commandé aux lévites de massacrer, sans distinction, leurs frères, jusqu'au nombre de vingt-trois mille, pour la prévarication de son propre frère, qui devait plutôt mourir que de faire un veau pour être adoré ? Quoi ! après cette indigne action, son frère est grand pontife, et vingt-trois mille hommes sont massacrés!

Moïse avait épousé une Madianite, fille de Jéthro, grand-prêtre de Madian, dans l'Arabie Pétrée ; Jéthro l'avait comblé de bienfaits ; il lui avait donné son fils pour lui servir de guide dans les déserts : par quelle cruauté opposée à la politique (à ne juger que par nos faibles notions) Moïse aurait-il pu immoler vingt-quatre mille hommes de sa nation, sous prétexte qu'on a trouvé un Juif couché avec une Madianite ? Et comment peut-on dire, après ces étonnantes boucheries, que «Moïse était le plus doux de tous les hommes»? Avouons qu'humainement parlant, ces horreurs révoltent la raison et la nature. Mais si nous considérons dans Moïse le ministre des desseins et des vengeances de Dieu, tout change alors à nos yeux; ce n'est point un homme qui agit en homme, c'est l'instrument de la Divinité, à laquelle nous n'avons aucun compte à demander nous ne devons qu'adorer, et nous taire.

Si Moïse avait institué sa religion de lui-même, comme Zoroastre, Thaut, les premiers brames, Numa, Mahomet, et tant d'autres, nous pourrions lui demander pourquoi il ne s'est pas servi dans sa religion du moyen le plus efficace et le plus utile pour mettre un frein à la cupidité et au crime; pourquoi il n'a pas annoncé expressément l'immortalité de l'âme, les peines et les récompenses après la mort: 
dogmes reçus dès longtemps en Égypte, en Phénicie, en Mésopotamie, en Perse, et dans l'Inde. "Vous avez été instruit, lui dirions-nous, dans la sagesse des Égyptiens ; vous êtes législateur, et vous négligez absolument le dogme principal des Égyptiens, le dogme le plus nécessaire aux hommes, croyance si salutaire et si sainte, que vos propres Juifs, tout grossiers qu'ils étaient, l'ont embrassée longtemps après vous ; du moins elle fut adoptée en partie par les Esséniens et les Pharisiens, au bout de mille années. »

Cette objection accablante contre un législateur ordinaire tombe et perd, comme on voit, toute sa force, quand il s'agit d'une loi donnée par Dieu même, qui, ayant daigné être le roi du peuple juif, le punissait et le récompensait temporellement, et qui ne voulait lui révéler la connaissance de l'immortalité de l'âme, et les supplices éternels de l'enfer, que dans les temps marqués par ses décrets. Presque tout événement purement humain, chez le peuple juif, est le comble de l'horreur; tout ce qui est divin est au-dessus de nos faibles idées : l'un et l'autre nous réduisent toujours au silence.

Il s'est trouvé des hommes d'une science profonde qui ont poussé le pyrrhonisme de l'histoire jusqu'à douter qu'il y ait eu un Moïse ; sa vie, qui est toute prodigieuse depuis son berceau jusqu'à son sépulcre, leur a paru une imitation des anciennes fables arabes, et particulièrement de celle de l'ancien Bacchus ${ }^{75}$. Ils ne savent en quel temps placer Moïse ; le nom même du Pharaon, ou roi d'Égypte, sous lequel on le fait vivre est inconnu. Nul monument, nulles traces ne nous restent du pays dans lequel on le fait voyager. Il leur paraît impossible que Moïse ait gouverné deux ou trois millions d'hommes, pendant quarante ans, dans des déserts inhabitables, où l'on trouve à peine aujourd'hui deux ou trois hordes vagabondes qui ne composent pas trois à quatre mille hommes. Nous sommes bien loin d'adopter ce sentiment téméraire, qui saperait tous les fondements de l'ancienne histoire du peuple juif.

Nous n'adhérons pas non plus à l'opinion d'Aben-Esra, de Maimonide, de Nugnès, de l'auteur des Cérémonies judaïques; quoique le docte Le Clerc, Middleton, les savants connus sous le titre de Théologiens de Hollande, et même le grand Newton, aient fortifié ce senti- 
ment. Ces illustres savants prétendent que ni Moïse ni Josué ne purent écrire les livres qui leur sont attribués : ils disent que leurs histoires et leurs lois auraient été gravées sur la pierre, si en effet elles avaient existé ; que cet art exige des soins prodigieux, et qu'il n'était pas possible de le cultiver dans des déserts. Ils se fondent, comme on peut le voir ailleurs ${ }^{76}$, sur des anticipations, sur des contradictions apparentes. Nous embrassons, contre ces grands hommes, l'opinion commune, qui est celle de la Synagogue et de l'Église, dont nous reconnaissons l'infaillibilité.

Ce n'est pas que nous osions accuser les Le Clerc, les Middleton, les Newton, d'impiété ; à Dieu ne plaise! Nous sommes convaincu que si les livres de Moïse et de Josué, et le reste du Pentateuque, ne leur paraissaient pas être de la main de ces héros israélites, ils n'en ont pas été moins persuadés que ces livres sont inspirés. Ils reconnaissent le doigt de Dieu à chaque ligne dans la Genèse, dans Josué, dans Samson, dans Ruth. L'écrivain juif n'a été, pour ainsi dire, que le secrétaire de Dieu ; c'est Dieu qui a tout dicté. Newton sans doute n'a pu penser autrement; on le sent assez. Dieu nous préserve de ressembler à ces hypocrites pervers qui saisissent tous les prétextes d'accuser tous les grands hommes d'irréligion, comme on les accusait autrefois de magie! Nous croirions non seulement agir contre la probité, mais insulter cruellement la religion chrétienne, si nous étions assez abandonné pour vouloir persuader au public que les plus savants hommes et les plus grands génies de la terre ne sont pas de vrais chrétiens. Plus nous respectons l'Église, à laquelle nous sommes soumis, plus nous pensons que cette Église tolère les opinions de ces savants vertueux avec la charité qui fait son caractère. 
41.

DES JUIFS APRÈS MOÏSE, JUSQU'À SAÜL

Je ne recherche point pourquoi Josuah ou Josué, capitaine des Juifs, faisant passer sa horde de l'orient du Jourdain à l'occident, vers Jéricho, a besoin que Dieu suspende le cours de ce fleuve, qui n'a pas en cet endroit quarante pieds de largeur, sur lequel il était si aisé de jeter un pont de planches, et qu'il était plus aisé encore de passer à gué. Il y avait plusieurs gués à cette rivière; témoin celui auquel les Israélites égorgèrent les quarante-deux mille Israélites qui ne pouvaient prononcer Shiboleth.

Je ne demande point pourquoi Jéricho tombe au son des trompettes ; ce sont de nouveaux prodiges que Dieu daigne faire en faveur du peuple dont il s'est déclaré le roi; cela n'est pas du ressort de l'histoire. Je n'examine point de quel droit Josué venait détruire des villages qui n'avaient jamais entendu parler de lui. Les Juifs disaient : «Nous descendons d'Abraham; Abraham voyagea chez vous il y a quatre cent quarante années : donc votre pays nous appartient; et nous devons égorger vos mères, vos femmes et vos enfants. »

Fabricius et Holstenius se sont fait l'objection suivante : Que dirait-on si un Norvégien venait en Allemagne avec quelques centaines de ses compatriotes, et disait aux Allemands : " Il y a quatre cents ans qu'un homme de notre pays, fils d'un potier, voyagea près de Vienne ; ainsi l'Autriche nous appartient, et nous venons tout massacrer au nom du Seigneur? » Les mêmes auteurs considèrent que le temps de Josué n'est pas le nôtre ; que ce n'est pas à nous à porter un œil profane dans les choses divines; et surtout que Dieu avait le droit de punir les péchés des Cananéens par les mains des Juifs.

Il est dit qu'à peine Jéricho est sans défense que les Juifs immolent à leur Dieu tous les habitants, vieillards, femmes, filles, enfants à la mamelle, et tous les animaux, excepté une femme prostituée qui avait 
gardé chez elle les espions juifs, espions d'ailleurs inutiles, puisque les murs devaient tomber au son des trompettes. Pourquoi tuer aussi tous les animaux qui pouvaient servir?

À l'égard de cette femme, que la Vulgate appelle meretrix, apparemment elle mena depuis une vie plus honnête, puisqu'elle fut aïeule de David, et même du Sauveur des chrétiens, qui ont succédé aux Juifs. Tous ces événements sont des figures, des prophéties, qui annoncent de loin la loi de grâce. Ce sont, encore une fois, des mystères auxquels nous ne touchons pas.

Le livre de Josué rapporte que ce chef, s'étant rendu maitre d'une partie du pays de Canaan, fit pendre ses rois au nombre de trente-etun ; c'est-à-dire trente-et-un chefs de bourgades, qui avaient osé défendre leurs foyers, leurs femmes, et leurs enfants. Il faut se prosterner ici devant la Providence, qui châtiait les péchés de ces rois par le glaive de Josué.

Il n'est pas bien étonnant que les peuples voisins se réunissent contre les Juifs, qui, dans l'esprit des peuples aveuglés, ne pouvaient passer que pour des brigands exécrables, et non pour les instruments sacrés de la vengeance divine et du futur salut du genre humain. Ils furent réduits en esclavage par Cusan, roi de Mésopotamie. Il y a loin, il est vrai, de la Mésopotamie à Jéricho ; il fallait donc que Cusan eût conquis la Syrie et une partie de la Palestine. Quoi qu'il en soit, ils sont esclaves huit années, et restent ensuite soixante-deux ans sans remuer. Ces soixante-deux ans sont une espèce d'asservissement, puisqu'il leur était ordonné par la loi de prendre tout le pays depuis la Méditerranée jusqu'à l'Euphrate ; que tout ce vaste pays ${ }^{77}$ leur était promis, et qu'assurément ils auraient été tentés de s'en emparer s'ils avaient été libres. Ils sont esclaves dix-huit années sous Églon, roi des Moabites, assassiné par Aod ; ils sont ensuite, pendant vingt années, esclaves d'un peuple cananéen qu'ils ne nomment pas, jusqu'au temps où la prophétesse guerrière Débora les délivre. Ils sont encore esclaves pendant sept ans jusqu'à Gédéon.

Ils sont esclaves dix-huit ans des Phéniciens, qu'ils appellent Philistins, jusqu'à Jephté. Ils sont encore esclaves des Phéniciens quaran-

Genèse, chapitre XV, v. 18 ; Deutéronome, chapitre I, v. 7. (V.) 
te années jusqu'à Saül. Ce qui peut confondre notre jugement, c'est qu'ils étaient esclaves du temps même de Samson, pendant qu'il suffisait à Samson d'une simple mâchoire d'âne pour tuer mille Philistins, et que Dieu opérait, par les mains de Samson, les plus étonnants prodiges.

Arrêtons-nous ici un moment pour observer combien de Juifs furent exterminés par leurs propres frères, ou par l'ordre de Dieu même, depuis qu'ils errèrent dans les déserts, jusqu'au temps où ils eurent un roi élu par le sort.

Les Lévites, après l'adoration du veau d'or, jeté en fonte par le frère de Moïse, égorgent

23,000 Juifs

Consumés par le feu, pour la révolte de Coré

250

Égorgés pour la même révolte

Égorgés pour avoir en commerce avec les filles madianites

Égorgés au gué du Jourdain, pour n'avoir pas pu prononcer Shiboleth

Tués par les Benjamites, qu'on attaquait 40,000

Benjamites tués par les autres tribus 45,000

Lorsque l'arche fut prise par les Philistins, et que Dieu, pour les punir, les ayant affligés d'hémorroïdes, ils ramenèrent l'arche à Bethsamès, et qu'ils offrirent au Seigneur cinq anus d'or et cinq rats d'or ; les Bethsamites, frappés de mort pour avoir regardé l'arche, au nombre de

Somme totale 239,020 Juifs

Voilà deux cent trente-neuf mille vingt Juifs exterminés par l'ordre de Dieu même, ou parleurs guerres civiles, sans compter ceux qui périrent dans le désert, et ceux qui moururent dans les batailles contre les Cananéens, etc. ; ce qui peut aller à plus d'un million d'hommes.

Si on jugeait des Juifs comme des autres nations, on ne pourrait concevoir comment les enfants de Jacob auraient pu produire une race assez nombreuse pour supporter une telle perte. Mais Dieu, qui les conduisait, Dieu, qui les éprouvait et les punissait, rendit cette nation si différente en tout des autres hommes qu'il faut la regarder avec 
d'autres yeux que ceux dont on examine le reste de la terre, et ne point juger de ces événements comme on juge des événements ordinaires.

Table des Matières

42.

DES JUIFS DEPUIS SAÜL

Les Juifs ne paraissent pas jouir d'un sort plus heureux sous leurs rois que sous leurs juges.

Le premier roi, Saül, est obligé de se donner la mort. Isboseth et Miphiboseth, ses fils, sont assassinés.

David livre aux Gabaonites sept petits-fils de Saül pour être mis en croix. Il ordonne à Salomon son fils de faire mourir Adonias son autre fils, et son général Joab. Le roi Asa fait tuer une partie du peuple dans Jérusalem. Baasa assassine Nadab, fils de Jéroboam, et tous ses parents. Jéhu assassine Joram et Ochosias, soixante et dix fils d'Achab, quarante-deux frères d'Ochosias, et tous leurs amis. Athalie assassine tous ses petits-fils, excepté Joas ; elle est assassinée par le grandprêtre Joiadad. Joas est assassiné par ses domestiques, Amasias est tué. Zacharias est assassiné par Sellum, qui est assassiné par Manahem, lequel Manahem fait fendre le ventre à toutes les femmes grosses dans Tapsa. Phacéia, fils de Manahem, est assassiné par Phacée, fils de Roméli, qui est assassiné par Ozée, fils d'Éla. Manassé fait tuer un grand nombre de Juifs, et les Juifs assassinent Ammon, fils de Manassé, etc.

Au milieu de ces massacres, dix tribus enlevées par Salmanasar, roi des Babyloniens, sont esclaves et dispersées pour jamais, excepté quelques manœuvres qu'on garde pour cultiver la terre.

Il reste encore deux tribus, qui bientôt sont esclaves à leur tour pendant soixante et dix ans : au bout de ces soixante et dix ans, les deux tribus obtiennent de leurs vainqueurs et de leurs maîtres la permission de retourner à Jérusalem. Ces deux tribus, ainsi que le peu de 
Juifs qui peuvent être restés à Samarie avec les nouveaux habitants étrangers, sont toujours sujettes des rois de Perse ${ }^{78}$.

Quand Alexandre s'empare de la Perse, la Judée est comprise dans ses conquêtes. Après Alexandre, les Juifs demeurèrent soumis tantôt aux Séleucides, ses successeurs en Syrie, tantôt aux Ptolémées, ses successeurs en Égypte; toujours assujettis, et ne se soutenant que par le métier de courtiers qu'ils faisaient dans l'Asie. Ils obtinrent quelques faveurs du roi d'Égypte Ptolémée Épiphanes. Un Juif, nommé Joseph, devint fermier général des impôts sur la basse Syrie et la Judée, qui appartenaient à ce Ptolémée. C'est là l'état le plus heureux des Juifs ; car c'est alors qu'ils bâtirent la troisième partie de leur ville, appelée depuis l'enceinte des Machabées, parce que les Machabées l'achevèrent.

Du joug du roi Ptolémée ils repassent à celui du roi de Syrie, Antiochus le Dieu. Comme ils s'étaient enrichis dans les fermes, ils devinrent audacieux, et se révoltèrent contre leur maître Antiochus. C'est le temps des Machabées, dont les Juifs d'Alexandrie ont célébré le courage et les grandes actions ; mais les Machabées ne purent empêcher que le général d'Antiochus Eupator, fils d'Antiochus Épiphanes, ne fît raser les murailles du temple, en laissant subsister seulement le sanctuaire, et qu'on ne fît trancher la tête au grand-prêtre Onias, regardé comme l'auteur de la révolte.

Jamais les Juifs ne furent plus inviolablement attachés à leurs rois que sous les rois de Syrie ; ils n'adorèrent plus de divinités étrangères : ce fut alors que leur religion fut irrévocablement fixée, et cependant ils furent plus malheureux que jamais, comptant toujours sur leur délivrance, sur les promesses de leurs prophètes, sur le secours de leur Dieu, mais abandonnés par la Providence, dont les décrets ne sont pas connus des hommes.

Ils respirèrent quelque temps par les guerres intestines des rois de Syrie ; mais bientôt les Juifs eux-mêmes s'armèrent les uns contre les autres. Comme ils n'avaient point de rois, et que la dignité de grand sacrificateur était la première, c'était pour l'obtenir qu'il s'élevait de

78 Voyez Essai sur les Mours, chapitre 158. (B.) 
violents partis : on n'était grand-prêtre que les armes à la main, et on n'arrivait au sanctuaire que sur les cadavres de ses rivaux.

Hircan, de la race des Machabées, devenu grand-prêtre, mais toujours sujet des Syriens, fit ouvrir le sépulcre de David, dans lequel l'exagérateur Josèphe prétend qu'on trouva trois mille talents. C'était quand on rebâtissait le temple, sous Néhémie, qu'il eût fallu chercher ce prétendu trésor. Cet Hircan obtint d'Antiochus Sidétès le droit de battre monnaie ; mais comme il n'y eut jamais de monnaie juive, il y a grande apparence que le trésor du tombeau de David n'avait pas été considérable.

Il est à remarquer que ce grand-prêtre Hircan était saducéen, et qu'il ne croyait ni à l'immortalité de l'âme, ni aux anges; sujet nouveau de querelle qui commençait à diviser les saducéens et les pharisiens. Ceux-ci conspirèrent contre Hircan, et voulurent le condamner à la prison et au fouet. Il se vengea d'eux, et gouverna despotiquement.

Son fils Aristobule osa se faire roi pendant les troubles de Syrie et d'Égypte : ce fut un tyran plus cruel que tous ceux qui avaient opprimé le peuple juif. Aristobule, exact à la vérité à prier dans le temple et ne mangeant jamais de porc, fit mourir de faim sa mère, et fit égorger Antigone son frère. Il eut pour successeur un nommé Jean ou Jeanné, aussi méchant que lui.

Ce Jeanné, souillé de crimes, laissa deux fils qui se firent la guerre. Ces deux fils étaient Aristobule et Hircan ; Aristobule chassa son frère, et se fit roi. Les Romains alors subjuguaient l'Asie. Pompée en passant vint mettre les Juifs à la raison, prit le temple, fit pendre les séditieux aux portes, et chargea de fers le prétendu roi Aristobule.

Cet Aristobule avait un fils qui osait se nommer Alexandre. Il remua, il leva quelques troupes, et finit par être pendu par ordre de Pompée.

Enfin Marc-Antoine donna pour roi aux Juifs un Arabe iduméen, du pays de ces Amalécites, tant maudits par les Juifs. C'est ce même Hérode que saint Matthieu dit avoir fait égorger tous les petits enfants des environs de Bethléem, sur ce qu'il apprit qu'il était né un roi des Juifs dans ce village, et que trois mages, conduits par une étoile, étaient venus lui offrir des présents. 
Ainsi les Juifs furent presque toujours subjugués ou esclaves. On sait comme ils se révoltèrent contre les Romains, et comme Titus, et ensuite Adrien, les firent tous vendre au marché, au prix de l'animal dont ils ne voulaient pas manger.

Ils essuyèrent un sort encore plus funeste sous les empereurs Trajan et Adrien, et ils le méritèrent. Il y eut, du temps de Trajan, un tremblement de terre qui engloutit les plus belles villes de la Syrie. Les Juifs crurent que c'était le signal de la colère de Dieu contre les Romains. Ils se rassemblèrent, ils s'armèrent en Afrique et en Chypre: une telle fureur les anima qu'ils dévorèrent les membres des Romains égorgés par eux ; mais bientôt tous les coupables moururent dans les supplices. Ce qui restait fut animé de la même rage sous Adrien, quand Barchochébas, se disant leur messie, se mit à leur tête. Ce fanatisme fut étouffé dans des torrents de sang.

Il est étonnant qu'il reste encore des Juifs. Le fameux Benjamin de Tudèle, rabbin très savant, qui voyagea dans l'Europe et dans l'Asie au douzième siècle, en comptait environ trois cent quatre-vingt mille, tant Juifs que Samaritains ; car il ne faut pas faire mention d'un prétendu royaume de Théma, vers le Thibet, où ce Benjamin, trompeur ou trompé sur cet article, prétend qu'il y avait trois cent mille Juifs des dix anciennes tribus, rassemblés sous un souverain. Jamais les Juifs n'eurent aucun pays en propre, depuis Vespasien, excepté quelques bourgades dans les déserts de l'Arabie Heureuse, vers la mer Rouge. Mahomet fut d'abord obligé de les ménager; mais à la fin il détruisit la petite domination qu'ils avaient établie au nord de la Mecque. C'est depuis Mahomet qu'ils ont cessé réellement de composer un corps de peuple.

En suivant simplement le fil historique de la petite nation juive, on voit qu'elle ne pouvait avoir une autre fin. Elle se vante elle-même d'être sortie d'Égypte comme une horde de voleurs, emportant tout ce qu'elle avait emprunté des Égyptiens : elle fait gloire de n'avoir jamais épargné ni la vieillesse, ni le sexe, ni l'enfance, dans les villages et dans les bourgs dont elle a pu s'emparer. Elle ose étaler une haine irréconciliable contre toutes les nations ${ }^{79}$; elle se révolte contre tous

79 Voici ce qu'on trouve dans une réponse à l'évêque Warburton*, lequel, pour justifier la haine des Juifs contre les nations, écrivit avec beaucoup de haine et d'injures contre plusieurs auteurs français : 
ses maîtres. Toujours superstitieuse, toujours avide du bien d'autrui, toujours barbare, rampante dans le malheur, et insolente dans la prospérité. Voilà ce que furent les Juifs aux yeux des Grecs et des Romains qui purent lire leurs livres ; mais, aux yeux des chrétiens éclairés par la foi, ils ont été nos précurseurs, ils nous ont préparé la voie, ils ont été les hérauts de la Providence.

Les deux autres nations qui sont errantes comme la juive dans l'Orient, et qui, comme elle, ne s'allient avec aucun autre peuple, sont les Banians et les Parsis nommés Guèbres. Ces Banians, adonnés au commerce ainsi que les Juifs, sont les descendants des premiers habitants paisibles de l'Inde; ils n'ont jamais mêlé leur sang à un sang étranger, non plus que les Brachmanes. Les Parsis sont ces mêmes Perses, autrefois dominateurs de l'Orient, et souverains des Juifs. Ils sont dispersés depuis Omar, et labourent en paix une partie de la terre où ils régnèrent; fidèles à cette antique religion des mages, adorant un seul Dieu, et conservant le feu sacré qu'ils regardent comme l'ouvrage et l'emblème de la Divinité.

Je ne compte point ces restes d'Égyptiens, adorateurs secrets d'Isis, qui ne subsistent plus aujourd'hui que dans quelques troupes vagabondes, bientôt pour jamais anéanties.

«Venons maintenant à la haine invétérée que les Israëlites avaient conçue contre toutes les nations. Dites-moi si on égorge les pères et les mères, les fils et les filles, les enfants à la mamelle, et les animaux même, sans haïr ? si un homme avait trempé dans le sang ses mains dégouttantes de fiel et d'encre, oserait-il dire qu'il aurait assassiné sans colère et sans haine ? Relisez tous les passages où il est ordonné aux Juifs de ne pas laisser une âme en vie, et dites après cela qu'il ne leur était pas permis de haïr. C'est se tromper grossièrement sur la haine ; c'est un usurier qui ne sait pas compter.

«Quoi! ordonner qu'on ne mange pas dans le plat dont un étranger s'est servi, de ne pas toucher ses habits, ce n'est pas ordonner l'aversion pour les étrangers ?... Les Juifs, dites-vous, ne haïssaient que l'idolâtrie, et non les idolâtres : plaisante distinction!

«Un jour un tigre rassasié de carnage rencontra des brebis qui prirent la fuite ; il courut après elles, et leur dit : Mes enfants, vous vous imaginez que je ne vous aime point; vous avez tort : c'est votre bêlement que je hais ; mais j'ai du goût pour vos personnes, et je vous chéris au point que je ne veux faire qu'une chair avec vous : je m'unis à vous par la chair et le sang; je bois l'un, je mange l'autre pour vous incorporer à moi. Jugez si on peut aimer plus intimement. » (V.)

* Voyez cette réponse à Warburton, parmi les Mélanges, année 1767. (V.) 
43.

DES PROPHÈTES JUIFS

Nous nous garderons bien de confondre les Nabim, les Roheim des Hébreux, avec les imposteurs des autres nations. On sait que Dieu ne se communiquait qu'aux Juifs, excepté dans quelques cas particuliers, comme, par exemple, quand il inspira Balaam, prophète de Mésopotamie, et qu'il lui fit prononcer le contraire de ce qu'on voulait lui faire dire. Ce Balaam était le prophète d'un autre Dieu, et cependant il n'est point dit qu'il fût un faux prophète ${ }^{80}$. Nous avons déjà remarqué que les prêtres d'Égypte étaient prophètes et voyants. Quel sens attachait-on à ce mot? celui d'inspiré. Tantôt l'inspiré devenait le passé, tantôt l'avenir; souvent il se contentait de parler dans un style figuré : c'est pourquoi $^{81} 1^{\prime}$ 'on a donné le même nom aux poètes et aux prophètes, vates.

Le titre, la qualité de prophète était-ils une dignité chez les Hébreux, un ministère particulier attaché par la loi à certaines personnes choisies, comme la dignité de pythie à Delphes? Non; les prophètes étaient seulement ceux qui se sentaient inspirés, ou qui avaient des visions. Il arrivait de là que souvent il s'élevait de faux prophètes sans mission, qui croyaient avoir l'esprit de Dieu, et qui souvent causèrent de grands malheurs ; comme les prophètes des Cévennes au commencement de ce siècle.

Il était très difficile de distinguer le faux prophète du véritable. C'est pourquoi Manassé, roi de Juda, fit périr Isaïe par le supplice de la scie. Le roi Sédécias ne pouvait décider entre Jérémie et Ananie, qui prédisaient des choses contraires, et il fit mettre Jérémie en prison.

\section{Nombres, chapitre XXII. (V.)}

81 L'édition de 1765 porte : «C'est pourquoi, lorsque saint Paul (Actes des Apôtres, chap. XVII) cite ce vers d'un poète grec, Aratus : Tout vit dans Dieu, tout se meut, tout respire en Dieu, il donne à ce poète le nom de prophète. Le titre, etc. » (B.) 
Ézéchiel fut tué par des Juifs, compagnons de son esclavage. Michée ayant prophétisé des malheurs aux rois Achab et Josaphat, un autre prophète, Tsedekia, fils de Canaa ${ }^{82}$, lui donna un soufflet, en lui disant : L'esprit de l'Éternel a passé par ma main pour aller sur ta joue. Osée, chapitre IX, déclare que les prophètes sont des fous : stultum prophetam, insanum virum spiritualem. Les prophètes se traitaient les uns les autres de visionnaires et de menteurs. Il n'y avait donc d'autre moyen de discerner le vrai du faux que d'attendre l'accomplissement des prédictions.

Élisée étant allé à Damas en Syrie, le roi, qui était malade, lui envoya quarante chameaux chargés de présents, pour savoir s'il guérirait ; Élisée répondit « que le roi pourrait guérir, mais qu'il mourrait ». Le roi mourut en effet. Si Élisée n'avait pas été un prophète du vrai Dieu, on aurait pu le soupçonner de se ménager une évasion à tout événement ; car si le roi n'était pas mort, Élisée avait prédit sa guérison en disant qu'il pouvait guérir, et qu'il n'avait pas spécifié le temps de sa mort. Mais ayant confirmé sa mission par des miracles éclatants, on ne pouvait douter de sa véracité.

Nous ne rechercherons pas ici, avec les commentateurs, ce que c'était que l'esprit double qu'Élisée reçut d'Élie, ni ce que signifie le manteau que lui donna Élie, en montant au ciel dans un char de feu, traîné par des chevaux enflammés, comme les Grecs figurèrent en poésie le char d'Apollon. Nous n'approfondirons point quel est le type, quel est le sens mystique de ces quarante-deux petits enfants qui, en voyant Élisée dans le chemin escarpé qui conduit à Béthel, lui dirent en riant: Monte, chauve, monte; et de la vengeance qu'en tira le prophète, en faisant venir sur-le-champ deux ours qui dévorèrent ces innocentes créatures. Les faits sont connus, et le sens peut en être caché.

Il faut observer ici une coutume de l'Orient, que les Juifs poussèrent à un point qui nous étonne. Cet usage était non seulement de parler en allégories, mais d'exprimer, par des actions singulières, les choses qu'on voulait signifier. Rien n'était plus naturel alors que cet usage ; car les hommes n'ayant écrit longtemps leurs pensées qu'en hié-

Paralipomènes, chapitre XVIII. (V.) 
roglyphes, ils devaient prendre l'habitude de parler comme ils écrivaient.

Ainsi les Scythes (si on en croit Hérodote) envoyèrent à Darah, que nous appelons Darius, un oiseau, une souris, une grenouille, et cinq flèches : cela voulait dire que si Darius ne s'enfuyait aussi vite qu'un oiseau, ou s'il ne se cachait comme une souris et comme une grenouille, il périrait par leurs flèches.

Le conte peut n'être pas vrai; mais il est toujours un témoignage des emblèmes en usage dans ces temps reculés.

Les rois s'écrivaient en énigmes : on en a des exemples dans Hiram, dans Salomon, dans la reine de Saba. Tarquin le Superbe, consulté dans son jardin par son fils sur la manière dont il faut se conduire avec les Gabiens, ne répond qu'en abattant les pavots qui s'élevaient au-dessus des autres fleurs. Il faisait assez entendre qu'il fallait exterminer les grands, et épargner le peuple.

C'est à ces hiéroglyphes que nous devons les fables, qui furent les premiers écrits des hommes. La fable est bien plus ancienne que l'histoire.

Il faut être un peu familiarisé avec l'antiquité pour n'être point effarouché des actions et des discours énigmatiques des prophètes juifs.

Isaïe veut faire entendre au roi Achaz qu'il sera délivré dans quelques années du roi de Syrie et du melk ou roitelet de Samarie, unis contre lui ; il lui dit: "Avant qu'un enfant soit en âge de discerner le mal et le bien, vous serez délivré de ces deux rois. Le Seigneur prendra un rasoir de louage, pour raser la tête, le poil du pénil (qui est figuré par les pieds), et la barbe, etc. » Alors le prophète prend deux témoins, Zacharie et Urie ; il couche avec la prophétesse, elle met au monde un enfant. Le Seigneur lui donne le nom de Maher-Salal-hasbas, Partagez vite les dépouilles; et ce nom signifie qu'on partagera les dépouilles des ennemis.

Je n'entre point dans le sens allégorique et infiniment respectable qu'on donne à cette prophétie ; je me borne à l'examen de ces usages étonnants aujourd'hui pour nous. 
Le même Isaïe marche tout nu dans Jérusalem, pour marquer que les Égyptiens seront entièrement dépouillés par le roi de Babylone.

Quoi! dira-t-on, est-il possible qu'un homme marche tout nu dans Jérusalem, sans être repris de justice ? Oui, sans doute : Diogène ne fut pas le seul dans l'antiquité qui eut cette hardiesse. Strabon, dans son quinzième livre, dit qu'il y avait dans les Indes une secte de brachmanes qui auraient été honteux de porter des vêtements. Aujourd'hui encore on voit des pénitents dans l'Inde qui marchent nus et chargés de chaînes, avec un anneau de fer attaché à la verge, pour expier les péchés du peuple. Il y en a dans l'Afrique et dans la Turquie. Ces mœurs ne sont pas nos mœurs, et je ne crois pas que du temps d'Isaïe il y eût un seul usage qui ressemblât aux nôtres.

Jérémie n'avait que quatorze ans quand il reçut l'esprit. Dieu étendit sa main et lui toucha la bouche, parce qu'il avait quelque difficulté de parler. Il voit d'abord une chaudière bouillante tournée au nord; cette chaudière représente les peuples qui viendront du septentrion, et l'eau bouillante figure les malheurs de Jérusalem.

Il achète une ceinture de lin, la met sur ses reins, et va la cacher, par l'ordre de Dieu, dans un trou auprès de l'Euphrate : il retourne ensuite la prendre, et la trouve pourrie. Il nous explique lui-même cette parabole, en disant que l'orgueil de Jérusalem pourrira.

Il se met des cordes au cou, il se charge de chaînes, il met un joug sur ses épaules ; il envoie ces cordes, ces chaînes et ce joug aux rois voisins, pour les avertir de se soumettre au roi de Babylone, Nabuchodonosor, en faveur duquel il prophétise.

Ézéchiel peut surprendre davantage : il prédit aux Juifs que les pères mangeront leurs enfants, et que les enfants mangeront leurs pères. Mais avant d'en venir à cette prédiction, il voit quatre animaux étincelants de lumière, et quatre roues couvertes d'yeux : il mange un volume de parchemin ; on le lie avec des chaînes. Il trace un plan de Jérusalem sur une brique; il met à terre une poêle de fer; il couche trois cent quatre-vingt-dix jours sur le côté gauche, et quarante jours sur le côté droit. Il doit manger du pain de froment, d'orge, de fèves, de lentilles, de millet, et le couvrir d'excréments humains. «C'est ainsi, ditil, que les enfants d'Israël mangeront leur pain souillé, parmi les nations chez lesquelles ils seront chassés. » Mais Ézéchiel ayant témoi- 
gné son horreur pour ce pain de douleur, Dieu lui permet de ne le couvrir que d'excréments de bœufs.

Il coupe ses cheveux, et les divise en trois parts; il en met une partie au feu, coupe la seconde avec une épée autour de la ville, et jette au vent la troisième.

Le même Ézéchiel a des allégories encore plus surprenantes. Il introduit le Seigneur, qui parle ainsi, chapitre XVI : "Quand tu naquis, on ne t'avait point coupé le nombril, et tu n'étais ni lavée ni salée.... tu es devenue grande, ta gorge s'est formée, ton poil a paru.... J'ai passé, j'ai connu que c'était le temps des amants. Je t'ai couverte, et je me suis étendu sur ton ignominie.... Je t'ai donné des chaussures et des robes de coton, des bracelets, un collier, des pendants d'oreilles.... Mais, pleine de confiance en ta beauté, tu t'es livrée à la fornication.... et tu as bâti un mauvais lieu ; tu t'es prostituée dans les carrefours; tu as ouvert tes jambes à tous les passants.... tu as recherché les plus robustes.... On donne de l'argent aux courtisanes, et tu en as donné à tes amants, etc. »

83 « Oolla a forniqué sur moi ; elle a aimé avec fureur ses amants : princes, magistrats, cavaliers.... Sa sœur, Ooliba, s'est prostituée avec plus d'emportement. Sa luxure a recherché ceux qui avaient le.... d'un âne, et qui.... comme les chevaux ${ }^{84}$. »

Ces expressions nous semblent bien indécentes et bien grossières; elles ne l'étaient point chez les Juifs, elles signifiaient les apostasies de Jérusalem et de Samarie. Ces apostasies étaient représentées très souvent comme une fornication, comme un adultère. Il ne faut pas, encore une fois, juger des mœurs, des usages, des façons de parler anciennes, par les nôtres; elles ne se ressemblent pas plus que la langue française ne ressemble au chaldéen et à l'arabe.

Le Seigneur ordonne d'abord au prophète Osée, chapitre I, de prendre pour sa femme une prostituée, et il obéit. Cette prostituée lui donne un fils. Dieu appelle ce fils Jezraël : c'est un type de la maison

\section{Ézéchiel, chapitre XXIII. (V.)}

84 On a très approfondi cette matière dans plusieurs livres nouveaux, surtout dans les Questions sur l'Encyclopédie, et dans l'Examen important de milord Bolingbroke. (V.) - Les Questions sur l'Encyclopédie font partie du Dict. philosophique. L'Examen important est dans les Mélanges, année 1767. 
de Jéhu, qui périra, parce que Jéhu avait tué Joram dans Jezraël. Ensuite le Seigneur ordonne à Osée, chapitre III, d'épouser une femme adultère, qui soit aimée d'un autre, comme le Seigneur aime les enfants d'Israël, qui regardent les dieux étrangers, et qui aiment le marc de raisin. Le Seigneur, dans la prophétie d'Amos, chapitre IV, menace les vaches de Samarie de les mettre dans la chaudière. Enfin tout est l'opposé de nos mœurs et de notre tour d'esprit; et, si l'on examine les usages de toutes les nations orientales, nous les trouverons également opposés à nos coutumes, non seulement dans les temps reculés, mais aujourd'hui même que nous les connaissons mieux.

Table des Matières

44.

DES PRIÈRES DES JUIFS

Il nous reste peu de prières des anciens peuples; nous n'avons que deux ou trois formules des mystères, et l'ancienne prière à Isis, rapportée dans Apulée ${ }^{85}$. Les Juifs ont conservé les leurs.

Si l'on peut conjecturer le caractère d'une nation par les prières qu'elle fait à Dieu, on s'apercevra aisément que les Juifs étaient un peuple charnel et sanguinaire. Ils paraissent, dans leurs psaumes, souhaiter la mort du pécheur plutôt que sa conversion; et ils demandent au Seigneur, dans le style oriental, tous les biens terrestres.

« Tu arroseras les montagnes, la terre sera rassasiée de fruits ${ }^{86}$. »

« Tu produis le foin pour les bêtes, et l'herbe pour l'homme. Tu fais sortir le pain de la terre, et le vin qui réjouit le cœur; tu donnes l'huile qui répand la joie sur le visage ${ }^{87}$. »

« Juda est une marmite remplie de viandes; la montagne du Seigneur est une montagne coagulée, une montagne grasse. Pourquoi regardez-vous les montagnes coagulées ${ }^{88}$ ?»

85 Voyez cette prière, Introduction, paragraphe XXIII. (B.)

86 Psaume LXXXVIII. (V.)

87 Psaume CIII. (V.)

88 Psaume CVII. (V.) 
Mais il faut avouer que les Juifs maudissent leurs ennemis dans un style non moins figuré.

«Demande-moi, et je te donnerai en héritage toutes les nations; tu les régiras avec une verge de fer ${ }^{89}$.

«Mon Dieu, traitez mes ennemis selon leurs œuvres, selon leurs desseins méchants ; punissez-les comme ils le méritent ${ }^{90}$. $\gg$

«Que mes ennemis impies rougissent, qu'ils soient conduits dans le sépulcre ${ }^{91}$. »

«Seigneur, prenez vos armes et votre bouclier, tirez votre épée, fermez tous les passages ; que mes ennemis soient couverts de confusion; qu'ils soient comme la poussière emportée par le vent, qu'ils tombent dans le piège ${ }^{92}$. » fosse ${ }^{93} . »$

«Que la mort les surprenne, qu'ils descendent tout vivants dans la

« Dieu brisera leurs dents dans leur bouche; il mettra en poudre les mâchoires de ces lions ${ }^{94}$. »

«Ils souffriront la faim comme des chiens; ils se disperseront pour chercher à manger, et ne seront point rassasiés ${ }^{95}$. »

« Je m'avancerai vers l'Idumée, et je la foulerai aux pieds ${ }^{96} . »$

"Réprimez ces bêtes sauvages; c'est une assemblée de peuples semblables à des taureaux et à des vaches.... Vos pieds seront baignés dans le sang de vos ennemis, et la langue de vos chiens en sera abreuvée ${ }^{97} . »$

Psaume II. (V.)

Psaume XXVII. (V.)

Psaume XXX. (V.)

Psaume XXXIV. (V.)

Psaume LIV. (V.)

Psaume LVII. (V.)

Psaume LVII. (V.)

Psaume LIX. (V.)

Psaume LXVII. (V.) 
«Faites fondre sur eux tous les traits de votre colère; qu'ils soient exposés à votre fureur; que leur demeure et leurs tentes soient désertes ${ }^{98}$.»

« Répandez abondamment votre colère sur les peuples à qui vous êtes inconnu ${ }^{99}$. »

«Mon Dieu, traitez-les comme les Madianites, rendez-les comme une roue qui tourne toujours, comme la paille que le vent emporte, comme une forêt brûlée par le feu ${ }^{100}$. »

«Asservissez le pécheur; que le malin soit toujours à son côté droit $^{101}$. »

«Qu'il soit toujours condamné quand il plaidera.

Que sa prière lui soit imputée à péché ; que ses enfants soient orphelins, et sa femme veuve; que ses enfants soient des mendiants vagabonds ; que l'usurier enlève tout son bien. »

«Le Seigneur, juste, coupera leurs têtes : que tous les ennemis de Sion soient comme l'herbe sèche des toits ${ }^{102}$. »

« Heureux celui qui éventrera tes petits enfants encore à la mamelle, et qui les écrasera contre la pierre ${ }^{103}$.»

On voit que si Dieu avait exaucé toutes les prières de son peuple, il ne serait resté que des Juifs sur la terre, car ils détestaient toutes les nations, ils en étaient détestés; et, en demandant sans cesse que Dieu exterminât tous ceux qu'ils haïssaient, ils semblaient demander la ruine de la terre entière. Mais il faut toujours se souvenir que non seulement les Juifs étaient le peuple chéri de Dieu, mais l'instrument de ses vengeances. C'était par lui qu'il punissait les péchés des autres nations, comme il punissait son peuple par elles. Il n'est plus permis aujourd'hui de faire les mêmes prières, et de lui demander qu'on éventre les mères et les enfants encore à la mamelle, et qu'on les écrase contre

\footnotetext{
98 Psaume LXVIII. (V.)

99 Psaume LXXVIII. (V.)

100 Psaume LXXXII. (V.)

101 Psaume CVIII. (V.)

102 Psaume CXXVIII. (V.)

103 Psaume CXXXVI. (V.)
} 
la pierre. Dieu étant reconnu pour le père commun de tous les hommes, aucun peuple ne fait ces imprécations contre ses voisins. Nous avons été aussi cruels quelquefois que les Juifs; mais en chantant leurs psaumes, nous n'en détournons pas le sens contre les peuples qui nous font la guerre. C'est un des grands avantages que la loi de grâce a sur la loi de rigueur : et plût à Dieu que, sous une loi sainte, et avec des prières divines, nous n'eussions pas répandu le sang de nos frères et ravagé la terre au nom d'un Dieu de miséricorde !

Table des Matières

45.

DE JOSÈPHE, HISTORIEN DES JUIFS

On ne doit pas s'étonner que l'histoire de Flavien Josèphe trouvât des contradicteurs quand elle parut à Rome. Il est vrai qu'il n'y en avait que très peu d'exemplaires, il fallait au moins trois mois à un copiste habile pour la transcrire. Les livres étaient très chers et très rares : peu de Romains daignaient lire les annales d'une chétive nation d'esclaves, pour qui les grands et les petits avaient un mépris égal. Cependant il paraît, par la réponse de Josèphe à Apion, qu'il trouva un petit nombre de lecteurs; et l'on voit aussi que ce petit nombre le traita de menteur et de visionnaire.

Il faut se mettre à la place des Romains du temps de Titus pour concevoir avec quel mépris mêlé d'horreur les vainqueurs de la terre connue et les législateurs des nations devaient regarder l'histoire du peuple juif. Ces Romains ne pouvaient guère savoir que Josèphe avait tiré la plupart des faits des livres sacrés dictés par le Saint-Esprit. Ils ne pouvaient pas être instruits que Josèphe avait ajouté beaucoup de choses à la Bible, et en avait passé beaucoup sous silence. Ils ignoraient qu'il avait pris le fond de quelques historiettes dans le troisième livre d'Esdras, et que ce livre d'Esdras est un de ceux qu'on nomme apocryphes.

Que devait penser un sénateur romain en lisant ces contes orientaux ? Josèphe rapporte (liv. X, ch. XII), que Darius, fils d'Astyage, avait fait le prophète Daniel gouverneur de trois cent soixante villes, 
lorsqu'il défendit, sous peine de la vie, de prier aucun dieu pendant un mois. Certainement l'Écriture ne dit point que Daniel gouvernait trois cent soixante villes.

Josèphe semble supposer ensuite que toute la Perse se fit juive.

Le même Josèphe donne au second temple des Juifs, rebâti par Zorobabel, une singulière origine.

Zorobabel, dit-il, était l'intime ami du roi Darius. Un esclave juif intime ami du roi des rois ! c'est à peu près comme si un de nos historiens nous disait qu'un fanatique des Cévennes, délivré des galères, était l'intime ami de Louis XIV.

Quoi qu'il en soit, selon Flavien Josèphe, Darius, qui était un prince de beaucoup d'esprit, proposa à toute sa cour une question digne du Mercure galant, savoir: qui avait le plus de force, ou du vin, ou des rois, ou des femmes. Celui qui répondrait le mieux devait, pour récompense, avoir une tiare de lin, une robe de pourpre, un collier d'or, boire dans une coupe d'or, coucher dans un lit d'or, se promener dans un chariot d'or traîné par des chevaux enharnachés d'or, et avoir des patentes de cousin du roi.

Darius s'assit sur son trône d'or pour écouter les réponses de son académie de beaux esprits. L'un disserta en faveur du vin, l'autre fut pour les rois ; Zorobabel prit le parti des femmes. Il n'y a rien de si puissant qu'elles ; car j'ai vu, dit-il, Apamée, la maîtresse du roi mon seigneur, donner de petits soufflets sur les joues de Sa sacrée Majesté, et lui ôter son turban pour s'en coiffer.

Darius trouva la réponse de Zorobabel si comique que, sur-lechamp, il fit rebâtir le temple de Jérusalem.

Ce conte ressemble assez à celui qu'un de nos plus ingénieux académiciens a fait de Soliman, et d'un nez retroussé, lequel a servi de canevas à un fort joli opéra bouffon. Mais nous sommes contraint d'avouer que l'auteur du nez retroussé n'a eu ni lit d'or, ni carrosse d'or, et que le roi de France ne l'a point appelé mon cousin : nous ne sommes plus au temps des Darius.

Ces rêveries dont Josèphe surchargeait les livres saints firent tort sans doute, chez les païens, aux vérités que la Bible contient. Les Ro- 
mains ne pouvaient distinguer ce qui avait été puisé dans une source impure de ce que Josèphe avait tiré d'une source sacrée. Cette Bible, sacrée pour nous, était ou inconnue aux Romains, ou aussi méprisée d'eux que Josèphe lui-même. Tout fut également l'objet des railleries et du profond dédain que les lecteurs conçurent pour l'histoire juive. Les apparitions des anges aux patriarches, le passage de la mer Rouge, les dix plaies d'Égypte ; l'inconcevable multiplication du peuple juif en si peu de temps, et dans un aussi petit terrain; le soleil et la lune s'arrêtant en plein midi, pour donner le temps à ce peuple brigand de massacrer quelques paysans déjà exterminés par une pluie de pierres : tous les prodiges qui signalèrent cette nation ignorée furent traités avec ce mépris qu'un peuple vainqueur de tant de nations, un peupleroi, mais à qui Dieu s'était caché, avait naturellement pour un petit peuple barbare réduit en esclavage.

Josèphe sentait bien que tout ce qu'il écrivait révolterait des auteurs profanes; il dit en plusieurs endroits : Le lecteur en jugera comme il voudra. Il craint d'effaroucher les esprits ; il diminue, autant qu'il le peut, la foi qu'on doit aux miracles. On voit à tout moment qu'il est honteux d'être Juif, lors même qu'il s'efforce de rendre sa nation recommandable à ses vainqueurs. Il faut sans doute pardonner aux Romains, qui n'avaient que le sens commun, qui n'avaient pas encore la foi, de n'avoir regardé l'historien Josèphe que comme un misérable transfuge qui leur contait des fables ridicules pour tirer quelque argent de ses maîtres. Bénissons Dieu, nous qui avons le bonheur d'être plus éclairés que les Titus, les Trajan, les Antonin, et que tout le sénat et les chevaliers romains nos maîtres; nous qui, éclairés par des lumières supérieures, pouvons discerner les fables absurdes de Josèphe, et les sublimes vérités que la sainte Écriture nous annonce. 
46.

D'UN MENSONGE DE FLAVIEN JOSÈPHE, CONCERNANT ALEXANDRE ET LES JUIFS

Lorsque Alexandre, élu par tous les Grecs, comme son père, et comme autrefois Agamemnon, pour aller venger la Grèce des injures de l'Asie, eut remporté la victoire d'Issus, il s'empara de la Syrie, l'une des provinces de Darah ou Darius; il voulait s'assurer de l'Égypte avant de passer l'Euphrate et le Tigre, et ôter à Darius tous les ports qui pourraient lui fournir des flottes. Dans ce dessein, qui était celui d'un très grand capitaine, il fallut assiéger Tyr. Cette ville était sous la protection des rois de Perse, et souveraine de la mer; Alexandre la prit après un siège opiniâtre de sept mois; et y employa autant d'art que de courage ; la digue qu'il osa faire sur la mer est encore aujourd'hui regardée comme le modèle que doivent suivre tous les généraux dans de pareilles entreprises. C'est en imitant Alexandre que le duc de Parme prit Anvers, et le cardinal de Richelieu, la Rochelle (s'il est permis de comparer les petites choses aux grandes). Rollin, à la vérité, dit qu'Alexandre ne prit Tyr que parce qu'elle s'était moquée des Juifs, et que Dieu voulut venger l'honneur de son peuple ; mais Alexandre pouvait avoir encore d'autres raisons : il fallait, après avoir soumis Tyr, ne pas perdre un moment pour s'emparer du port de Péluse. Ainsi Alexandre ayant fait une marche forcée pour surprendre Gaza, il alla de Gaza à Péluse en sept jours. C'est ainsi qu'Arrien, Quinte-Curce, Diodore, Paul Orose même, le rapportent fidèlement d'après le journal d'Alexandre.

Que fait Josèphe pour relever sa nation sujette des Perses, tombée sous la puissance d'Alexandre, avec toute la Syrie, et honorée depuis de quelques privilèges par ce grand homme? Il prétend qu'Alexandre, en Macédoine, avait vu en songe le grand-prêtre des Juifs, Jaddus (supposé qu'il y eût en effet un prêtre juif dont le nom finît en us); que ce prêtre l'avait encouragé à son expédition contre les Perses, que c'était par cette raison qu'Alexandre avait attaqué l'Asie. Il ne man- 
qua donc pas, après le siège de Tyr, de se détourner de cinq ou six journées de chemin pour aller voir Jérusalem. Comme le grand-prêtre Jaddus avait autrefois apparu en songe à Alexandre, il reçut aussi en songe un ordre de Dieu d'aller saluer ce roi ; il obéit, et, revêtu de ses habits pontificaux, suivi de ses lévites en surplis, il alla en procession au-devant d'Alexandre. Dès que ce monarque vit Jaddus, il reconnut le même homme qui l'avait averti en songe, sept ou huit ans auparavant, de venir conquérir la Perse, et il le dit à Parménion. Jaddus avait sur sa tête son bonnet orné d'une lame d'or, sur laquelle était gravé un mot hébreu. Alexandre, qui, sans doute, entendait l'hébreu parfaitement, reconnut aussitôt le nom de Jéhovah, et se prosterna humblement, sachant bien que Dieu ne pouvait avoir que ce nom. Jaddus lui montra aussitôt des prophéties qui disaient clairement « qu'Alexandre s'emparerait de l'empire des Perses », prophéties qui n'avaient point été faites après la bataille d'Issus. Il le flatta que Dieu l'avait choisi pour ôter à son peuple chéri toute espérance de régner sur la terre promise ; ainsi qu'il avait choisi autrefois Nabuchodonosor et Cyrus, qui avaient possédé la terre promise l'un après l'autre. Ce conte absurde du romancier Josèphe ne devait pas, ce me semble, être copié par Rollin, comme s'il était attesté par un écrivain sacré.

Mais c'est ainsi qu'on a écrit l'histoire ancienne, et bien souvent la moderne.

Table des Matières

47.

DES PRÉJUGÉS POPULAIRES AUXQUELS LES ÉCRIVAINS SACRÉS ONT DAIGNÉ SE CONFORMER PAR CONDESCENDANCE

Les livres saints sont faits pour enseigner la morale, et non la physique.

Le serpent passait dans l'antiquité pour le plus habile de tous les animaux. L'auteur du Pentateuque veut bien dire que le serpent fut assez subtil pour séduire Ève. On attribuait quelquefois la parole aux bêtes: l'écrivain sacré fait parler le serpent et l'ânesse de Balaam. Plusieurs Juifs et plusieurs docteurs chrétiens ont regardé cette histoi- 
re comme une allégorie ; mais, soit emblème, soit réalité, elle est également respectable. Les étoiles étaient regardées comme des points dans les nuées : l'auteur divin se proportionne à cette idée vulgaire, et dit que la lune fut faite pour présider aux étoiles.

L'opinion commune était que les cieux étaient solides; on les nommait en hébreu rakiak, mot qui répond à une plaque de métal, à un corps étendu et ferme, et que nous traduisîmes par firmament. Il portait des eaux, lesquelles se répandaient par des ouvertures. L'Écriture se proportionne à cette physique; et enfin on a nommé firmament, c'est-à-dire plaque, cette profondeur immense de l'espace dans lequel on aperçoit à peine les étoiles les plus éloignées à l'aide des télescopes.

Les Indiens, les Chaldéens, les Persans, imaginaient que Dieu avait formé le monde en six temps. L'auteur de la Genèse, pour ne pas effaroucher la faiblesse des Juifs, représente Dieu formant le monde en six jours, quoique un mot et un instant suffisent à sa toute-puissance. Un jardin, des ombrages, étaient un très grand bonheur dans des pays secs et brûlés du soleil ; le divin auteur place le premier homme dans un jardin.

On n'avait point l'idée d'un être purement immatériel : Dieu est toujours représenté comme un homme; il se promène à midi dans le jardin, il parle, et on lui parle.

Le mot âme, ruah, signifie le souffle, la vie : l'âme est toujours employée pour la vie dans le Pentateuque.

On croyait qu'il y avait des nations de géants, et la Genèse veut bien dire qu'ils étaient les enfants des anges et des filles des hommes.

On accordait aux brutes une espèce de raison. Dieu daigne faire alliance, après le déluge, avec les brutes comme avec les hommes.

Personne ne savait ce que c'est que l'arc-en-ciel; il était regardé comme une chose surnaturelle; et Homère en parle toujours ainsi. L'Écriture l'appelle l'arc de Dieu, le signe d'alliance.

Parmi beaucoup d'erreurs auxquelles le genre humain a été livré, on croyait qu'on pouvait faire naître des animaux de la couleur qu'on voulait, en présentant cette couleur aux mères avant qu'elles conçus- 
sent : l'auteur de la Genèse dit que Jacob eut des brebis tachetées par cet artifice.

Toute l'antiquité se servait des charmes contre la morsure des serpents ; et quand la plaie n'était pas mortelle, ou qu'elle était heureusement sucée par des charlatans nommés Psylles ${ }^{104}$, ou qu'enfin on avait appliqué avec succès des topiques convenables, on ne doutait pas que les charmes n'eussent opéré. Moïse éleva un serpent d'airain dont la vue guérissait ceux que les serpents avaient mordus. Dieu changeait une erreur populaire en une vérité nouvelle.

Une des plus anciennes erreurs était l'opinion que l'on pouvait faire naître des abeilles d'un cadavre pourri. Cette idée était fondée sur l'expérience journalière de voir des mouches et des vermisseaux couvrir les corps des animaux. De cette expérience, qui trompait les yeux, toute l'antiquité avait conclu que la corruption est le principe de la génération. Puisqu'on croyait qu'un corps mort produisait des mouches, on se figurait que le moyen sûr de se procurer des abeilles était de préparer les peaux sanglantes des animaux de la manière requise pour opérer cette métamorphose. On ne faisait pas réflexion combien les abeilles ont d'aversion pour toute chair corrompue, combien toute infection leur est contraire. La méthode de faire naitre ainsi des abeilles ne pouvait réussir; mais on croyait que c'était faute de s'y bien prendre. Virgile, dans son quatrième chant des Géorgiques, dit que cette opération fut heureusement faite par Aristée ; mais aussi il ajoute que c'est un miracle, mirabile monstrum (Géorg., liv. IV, v. 554).

C'est en rectifiant cet antique préjugé qu'il est rapporté que Samson trouva un essaim d'abeilles dans la gueule d'un lion qu'il avait déchiré de ses mains.

C'était encore une opinion vulgaire que l'aspic se bouchait les oreilles, de peur d'entendre la voix de l'enchanteur. Le Psalmiste se prête à cette erreur en disant, psaume LVII : «Tel que l'aspic sourd qui bouche ses oreilles, et qui n'entend point les enchanteurs. »

L'ancienne opinion, que les femmes font tourner le vin et le lait, empêchent le beurre de se figer, et font périr les pigeonneaux dans les colombiers quand elles ont leurs règles, subsiste encore dans le petit

104 Plutarque, Vie de Caton, chapitre LXXIV. (B.) 
peuple, ainsi que les influences de la lune. On crut que les purgations des femmes étaient les évacuations d'un sang corrompu, et que si un homme approchait de sa femme dans ce temps critique, il faisait nécessairement des enfants lépreux et estropiés : cette idée avait tellement prévenu les Juifs que le Lévitique, chapitre $\mathrm{xx}$, condamne à mort l'homme et la femme qui se seront rendu le devoir conjugal dans ce temps critique.

Enfin 1'Esprit Saint veut bien se conformer tellement aux préjugés populaires que le Sauveur lui-même dit qu'on ne met jamais le vin nouveau dans de vieilles futailles, et qu'il faut que le blé pourrisse pour mûrir.

Saint Paul dit aux Corinthiens, en voulant leur persuader la résurrection: "Insensés, ne savez-vous pas qu'il faut que le grain meure pour se vivifier? » On sait bien aujourd'hui que le grain ne pourrit ni ne meurt en terre pour lever; s'il pourrissait, il ne lèverait pas ; mais alors on était dans cette erreur, et le Saint-Esprit daignait en tirer des comparaisons utiles. C'est ce que saint Jérôme appelle parler par économie $^{105}$.

Toutes les maladies de convulsions passèrent pour des possessions de diable, dès que la doctrine des diables fut admise. L'épilepsie, chez les Romains comme chez les Grecs, fut appelée le mal sacré. La mélancolie, accompagnée d'une espèce de rage, fut encore un mal dont la cause était ignorée ; ceux qui en étaient attaqués erraient la nuit en hurlant autour des tombeaux. Ils furent appelés démoniaques, lycanthropes, chez les Grecs. L'Écriture admet des démoniaques qui errent autour des tombeaux.

Les coupables, chez les anciens Grecs, étaient souvent tourmentés des furies ; elles avaient réduit Oreste à un tel désespoir qu'il s'était mangé un doigt dans un accès de fureur ; elles avaient poursuivi Alcméon, Étéocle, et Polynice. Les Juifs hellénistes, qui furent instruits de toutes les opinions grecques, admirent enfin chez eux des espèces de furies, des esprits immondes, des diables qui tourmentaient les hommes. Il est vrai que les saducéens ne reconnaissaient point de diables ; mais les pharisiens les reçurent un peu avant le règne d'Hérode.

105 Voyez, dans le Dictionnaire philosophique, l'article ÉCONOMIE DE PAROLES. (B.) 
Il y avait alors chez les Juifs des exorcistes qui chassaient les diables ; ils se servaient d'une racine qu'ils mettaient sous le nez des possédés ${ }^{106}$, et employaient une formule tirée d'un prétendu livre de Salomon. Enfin ils étaient tellement en possession de chasser les diables que notre Sauveur lui-même, accusé, selon saint Matthieu, de les chasser par les enchantements de Belzébuth, accorde que les Juifs ont le même pouvoir, et leur demande si c'est par Belzébuth qu'ils triomphent des esprits malins.

Certes, si les mêmes Juifs qui firent mourir Jésus avaient eu le pouvoir de faire de tels miracles, si les pharisiens chassaient en effet les diables, ils faisaient donc le même prodige qu'opérait le Sauveur. Ils avaient le don que Jésus communiquait à ses disciples; et s'ils ne l'avaient pas, Jésus se conformait donc au préjugé populaire, en daignant supposer que ses implacables ennemis, qu'il appelait race de vipères, avaient le don des miracles et dominaient sur les démons. Il est vrai que ni les Juifs ni les chrétiens ne jouissent plus aujourd'hui de cette prérogative longtemps si commune. Il y a toujours des exorcistes, mais on ne voit plus de diables ni de possédés ${ }^{107}$ : tant les cho-

106 Cette racine se nomme Barad, Barat ou Barath. Voyez dans les Mélanges, année 1763, le Traité sur la Tolérance, chap. XII ; année 1767, 1'Examen important de milord Bolingbroke, chap. XIV; année 1768, les Instructions à A. J. Rustan ; année 1776, Un Chrétien contre six Juifs, paragraphe XXXVII ; et année 1777, l'Histoire de l'établissement du christianisme, chap. V. (B.)

107 M. de Voltaire fait trop d'honneur à notre siècle. Nous avons encore des possédés, non seulement à Besançon, où le diable les conduit tous les ans pour avoir le plaisir de se faire chasser par la présence du Saint-Suaire, mais à Paris même. Pendant la semaine sainte, la nuit, dans l'église de la Sainte-Chapelle, on joue une farce religieuse où des possédés tombent en convulsion à la vue d'un prétendu morceau de la vraie croix. On imaginerait difficilement un spectacle plus indécent ou plus dégoûtant; mais aussi on trouverait difficilement un qui prouvât mieux jusqu'à quel point la superstition peut dégrader l'espèce humaine, et surtout jusqu'à quel point l'amour de l'argent et l'envie de dominer sur le peuple peuvent endurcir des prêtres contre la honte, et les déterminer à se dévouer au mépris public. Il est étonnant que les chefs du clergé et ceux de la magistrature n'aient pas daigné se réunir pour abolir ce scandale, qui souille également et l'église de Jésus-Christ et le temple de la justice.

En 1777, un de ces prétendus possédés profita de cette qualité pour proférer devant le peuple assemblé tous les blasphèmes dont il se put aviser. Un homme raisonnable qui aurait parlé avec la même franchise eût été brûlé vif. Le possédé en fut quitte pour une double dose d'eau bénite. L'année d'après, la bonne compagnie y courut en foule, dans l'espérance d'entendre blasphémer ; mais la police avait ordonné au diable de se taire, et le diable obéit. (K.) 
ses changent avec le temps ! Il était dans l'ordre alors qu'il y eût des possédés, et il est bon qu'il n'y en ait plus aujourd'hui. Les prodiges nécessaires pour élever un édifice divin sont inutiles quand il est au comble. Tout a changé sur la terre : la vertu seule ne change jamais. Elle est semblable à la lumière du soleil, qui ne tient presque rien de la matière connue, et qui est toujours pure, toujours immuable, quand tous les éléments se confondent sans cesse. Il ne faut qu'ouvrir les yeux pour bénir son auteur.

Table des Matières

48.

DES ANGES, DES GÉNIES, DES DIABLES, CHEZ LES ANCIENNES NATIONS ET CHEZ LES JUIFS

Tout a sa source dans la nature de l'esprit humain. Tous les hommes puissants, les magistrats, les princes, avaient leurs messagers ; il était vraisemblable que les dieux en avaient aussi. Les Chaldéens et les Perses semblent être les premiers hommes connus de nous qui parlèrent des anges comme d'huissiers célestes et de porteurs d'ordre. Mais avant eux, les Indiens, de qui toute espèce de théologie nous est venue, avaient inventé les anges, et les avaient représentés, dans leur ancien livre du Shasta, comme des créatures immortelles, participantes de la Divinité, et dont un grand nombre se révolta dans le ciel contre le Créateur. (Voyez le chapitre de l'Inde.)

Les Parsis ignicoles, qui subsistent encore, ont communiqué à l'auteur de la religion des anciens Persans ${ }^{108}$ les noms des anges que les premiers Perses reconnaissaient. On en trouve cent dix-neuf, parmi lesquels ne sont ni Raphaël ni Gabriel, que les Perses n'adoptèrent que longtemps après. Ces mots sont chaldéens, ils ne furent connus des Juifs que dans leur captivité : car, avant l'histoire de Tobie, on ne voit le nom d'aucun ange, ni dans le Pentateuque, ni dans aucun livre des Hébreux.

Les Perses, dans leur ancien catalogue qu'on trouve au-devant du Sadder, ne comptaient que douze diables, et Arimane était le premier.

108 Hyde, De Religione veterum Persarum. (V.) 
C'était du moins une chose consolante de reconnaître plus de génies bienfaisants que de démons ennemis du genre humain.

On ne voit pas que cette doctrine ait été suivie des Égyptiens. Les Grecs, au lieu de génies tutélaires, eurent des divinités secondaires, des héros, et des demi-dieux. Au lieu de diables, ils eurent Até, Érynnis, les Euménides. Il me semble que ce fut Platon qui parla le premier d'un bon et d'un mauvais génie qui présidaient aux actions de tout mortel. Depuis lui, les Grecs et les Romains se piquèrent d'avoir chacun deux génies; et le mauvais eut toujours plus d'occupation et de succès que son antagoniste.

Quand les Juifs eurent enfin donné des noms à leur milice céleste, ils la distinguèrent en dix classes : les saints, les rapides, les forts, les flammes, les étincelles, les députés, les princes, les fils de princes, les images, les animés. Mais cette hiérarchie ne se trouve que dans le Talmud et dans le Targum, et non dans les livres du canon hébreu.

Ces anges eurent toujours la forme humaine, et c'est ainsi que nous les peignons encore aujourd'hui en leur donnant des ailes. Raphä̈l conduisit Tobie. Les anges qui apparurent à Abraham, à Loth, burent et mangèrent avec ces patriarches; et la brutale fureur des habitants de Sodome ne prouve que trop que les anges de Loth avaient un corps. Il serait même difficile de comprendre comment les anges auraient parlé aux hommes, et comment on leur eût répondu, s'ils n'avaient paru sous la figure humaine.

Les Juifs n'eurent pas même une autre idée de Dieu. Il parle le langage humain avec Adam et Ève ; il parle même au serpent ; il se promène dans le jardin d'Éden à l'heure de midi; il daigne converser avec Abraham, avec les patriarches, avec Moïse. Plus d'un commentateur a cru même que ces mots de la Genèse, Faisons l'homme à notre image, pouvaient être entendus à la lettre; que le plus parfait des êtres de la terre était une faible ressemblance de la forme de son créateur, et que cette idée devait engager l'homme à ne jamais dégénérer.

Quoique la chute des anges transformés en diables, en démons, soit le fondement de la religion juive et de la chrétienne, il n'en est pourtant rien dit dans la Genèse, ni dans la loi, ni dans aucun livre canonique. La Genèse dit expressément qu'un serpent parla à Ève et la séduisit. Elle a soin de remarquer que le serpent était le plus habile, le 
plus rusé de tous les animaux; et nous avons observé ${ }^{109}$ que toutes les nations avaient cette opinion du serpent. La Genèse marque encore positivement que la haine des hommes pour les serpents vient du mauvais office que cet animal rendit au genre humain; que c'est depuis ce temps-là qu'il cherche à nous mordre, que nous cherchons à l'écraser; et qu'enfín il est condamné, pour sa mauvaise action, à ramper sur le ventre, et à manger la poussière de la terre. Il est vrai que le serpent ne se nourrit point de terre, mais toute l'antiquité le croyait.

Il semble à notre curiosité que c'était là le cas d'apprendre aux hommes que ce serpent était un des anges rebelles devenus démons, qui venait exercer sa vengeance sur l'ouvrage de Dieu, et le corrompre. Cependant, il n'est aucun passage dans le Pentateuque dont nous puissions inférer cette interprétation, en ne consultant que nos faibles lumières.

Satan paraît, dans Job, le maître de la terre subordonné à Dieu. Mais quel homme un peu versé dans l'antiquité ne sait que ce mot $S a-$ tan était chaldéen; que ce Satan était l'Arimane des Perses, adopté par les Chaldéens, le mauvais principe qui dominait sur les hommes ? Job est représenté comme un pasteur arabe, vivant sur les confins de la Perse. Nous avons déjà dit que les mots arabes, conservés dans la tradition hébraïque de cette ancienne allégorie, montrent que le livre fut d'abord écrit par des Arabes. Flavien Josèphe, qui ne le compte point parmi les livres du canon hébreu, ne laisse aucun doute sur ce sujet.

Les démons, les diables, chassés d'un globe du ciel, précipités dans le centre de notre globe, et s'échappant de leur prison pour tenter les hommes, sont regardés, depuis plusieurs siècles, comme les auteurs de notre damnation. Mais, encore une fois, c'est une opinion dont il n'y a aucune trace dans l'Ancien Testament. C'est une vérité de tradition, tirée du livre si antique et si longtemps inconnu, écrit par les premiers brachmanes, et que nous devons enfin aux recherches de quelques savants anglais qui ont résidé longtemps dans le Bengale.

109 Paragraphe 6. (B.) 
Quelques commentateurs ont écrit que ce passage d'Isaïe "Comment es-tu tombé du ciel, Ô Lucifer ! qui paraissais le matin »? désigne la chute des anges, et que c'est Lucifer qui se déguisa en serpent pour faire manger la pomme à Ève et à son mari.

Mais, en vérité, une allégorie si étrange ressemble à ces énigmes qu'on faisait imaginer autrefois aux jeunes écoliers dans les collèges. On exposait, par exemple, un tableau représentant un vieillard et une jeune fille. L'un disait : c'est l'hiver et le printemps ; l'autre : c'est la neige et le feu ; un autre : c'est la rose et l'épine, ou bien c'est la force et la faiblesse ; et celui qui avait trouvé le sens le plus éloigné du sujet, l'application la plus extraordinaire, gagnait le prix.

Il en est précisément de même de cette application singulière de l'étoile du matin au diable. Isaïe, dans son quatorzième chapitre, en insultant à la mort d'un roi de Babylone, lui dit : «A ta mort on a chanté à gorge déployée ; les sapins, les cèdres, s'en sont réjouis. Il n'est venu depuis aucun exacteur nous mettre à la taille. Comment ta hauteur est-elle descendue au tombeau, malgré le son de tes musettes ? comment es-tu couchée avec les vers et la vermine ? comment es-tu tombée du ciel, étoile du matin ? Hélel, toi qui pressais les nations, tu es abattue en terre! »

On a traduit cet Hélel en latin par Lucifer : on a donné depuis ce nom au diable, quoiqu'il y ait assurément peu de rapport entre le diable et l'étoile du matin. On a imaginé que ce diable étant tombé du ciel était un ange qui avait fait la guerre à Dieu : il ne pouvait la faire lui seul; il avait donc des compagnons. La fable des géants armés contre les dieux, répandue chez toutes les nations, est, selon plusieurs commentateurs, une imitation profane de la tradition qui nous apprend que des anges s'étaient soulevés contre leur maître.

Cette idée reçut une nouvelle force de l'Épître de saint Jude, où il est dit : « Dieu a gardé dans les ténèbres, enchaînés jusqu'au jugement du grand jour, les anges qui ont dégénéré de leur origine, et qui ont abandonné leur propre demeure.... Malheur à ceux qui ont suivi les traces de Caïn.... desquels Énoch, septième homme après Adam, a prophétisé, en disant : Voici, le Seigneur est venu avec ses millions de saints, etc. » 
On s'imagina qu'Énoch avait laissé par écrit l'histoire de la chute des anges. Mais il y a deux choses importantes à observer ici. Premièrement, Énoch n'écrivit pas plus que Seth, à qui les Juifs attribuèrent des livres; et le faux Énoch que cite saint Jude est reconnu pour être forgé par un Juif ${ }^{110}$. Secondement, ce faux Énoch ne dit pas un mot de la rébellion et de la chute des anges avant la formation de l'homme. Voici mot à mot ce qu'il dit dans ses Égregori. «Le nombre des hommes s'étant prodigieusement accru, ils eurent de très belles filles ; les anges, les veillants, Égregori, en devinrent amoureux, et furent entrânés dans beaucoup d'erreurs. Ils s'animèrent entre eux ; ils se dirent: Choisissons-nous des femmes parmi les filles des hommes de la terre. Semiaxas leur prince dit: Je crains que vous n'osiez pas accomplir un tel dessein, et que je ne demeure seul chargé du crime ; tous répondirent : Faisons serment d'exécuter notre dessein, et dévouonsnous à l'anathème si nous y manquons. Ils s'unirent donc par serment et firent des imprécations. Ils étaient deux cents en nombre. Ils partirent ensemble du temps de Jared, et allèrent sur la montagne appelée Hermonim, à cause de leur serment. Voici le nom des principaux : Semiaxas, Atarculph, Araciel, Chobahiel-Hosampsich, Zaciel-Parmar, Thausaël, Samiel, Tirel, Sumiel ${ }^{111}$. »

« Eux et les autres prirent des femmes, l'an onze cent soixante et dix de la création du monde. De ce commerce naquirent trois genres d'hommes, les géants Naphilim, etc. »

L'auteur de ce fragment écrit de ce style qui semble appartenir aux premiers temps ; c'est la même naïveté. Il ne manque pas de nommer

110 Il faut pourtant que ce livre d'Énoch ait quelque antiquité, car on le trouve cité plusieurs fois dans le Testament des douze patriarches, autre livre juif, retouché par un chrétien du premier siècle : et ce testament des douze patriarches est même cité par saint Paul, dans sa première épître aux Thessaloniciens, si c'est citer un passage que de le répéter mot pour mot. Le Testament du patriarche Ruben porte, au chap. VI, La colère du seigneur tomba enfin sur eux ; et saint Paul dit précisément les mêmes paroles. Au reste, ces douze Testaments ne sont pas conformes à la Genèse dans tous les faits. L'inceste de Juda, par exemple, n'y est pas rapporté de la même manière. Juda dit qu'il abusa de sa belle-fille étant ivre. Le Testament de Ruben a cela de particulier, qu'il admet dans l'homme sept organes de sens, au lieu de cinq; il compte la vie et l'acte de génération pour deux sens. Au reste, tous ces patriarches se repentent, dans ce Testament, d'avoir vendu leur frère Joseph. (V.)

111 Voyez, dans le Dict. philosophique, les articles ANGE et BEKKER. (B.) 
les personnages ; il n'oublie pas les dates; point de réflexions, point de maximes, c'est l'ancienne manière orientale.

On voit que cette histoire est fondée sur le sixième chapitre de la Genèse : «Or en ce temps il y avait des géants sur la terre ; car les enfants de Dieu ayant eu commerce avec les filles des hommes, elles enfantèrent les puissants du siècle. »

Le livre d'Énoch et la Genèse sont entièrement d'accord sur l'accouplement des anges avec les filles des hommes, et sur la race des géants qui en naquit. Mais ni cet Énoch ni aucun livre de l'Ancien Testament ne parle de la guerre des anges contre Dieu, ni de leur défaite, ni de leur chute dans l'enfer, ni de leur haine contre le genre humain.

Il n'est question des esprits malins et du diable que dans l'allégorie de Job, dont nous avons parlé, laquelle n'est pas un livre juif, et dans l'aventure de Tobie. Le diable Asmodée, ou Shammadey, qui étrangla les sept premiers maris de Sara, et que Raphaël fit déloger avec la fumée du foie d'un poisson, n'était point un diable juif, mais persan. Raphaël l'alla enchaîner dans la haute Égypte; mais il est constant que les Juifs n'ayant point d'enfer, ils n'avaient point de diables. Ils ne commencèrent que fort tard à croire l'immortalité de l'âme et un enfer, et ce fut quand la secte des pharisiens prévalut. Ils étaient donc bien éloignés de penser que le serpent qui tenta Ève fût un diable, un ange précipité dans l'enfer. Cette pierre, qui sert de fondement à tout l'édifice, ne fut posée que la dernière. Nous n'en révérons pas moins l'histoire de la chute des anges devenus diables, mais nous ne savons où en trouver l'origine.

On appela diables Belzébuth, Belphégor, Astaroth ; mais c'étaient d'anciens dieux de Syrie. Belphégor était le dieu du mariage ; Belzébuth, ou Bel-se-puth, signifiait le Seigneur qui préserve des insectes. Le roi Ochosias même l'avait consulté comme un dieu, pour savoir s'il guérirait d'une maladie ; et Élie, indigné de cette démarche, avait dit : « N'y a-t-il point de Dieu en Israël, pour aller consulter le dieu d'Accaron ?»

Astaroth était la lune, et la lune ne s'attendait pas à devenir diable. 
L'apôtre Jude dit encore «que le diable se querella avec l'ange Michaël au sujet du corps de Moïse ». Mais on ne trouve rien de semblable dans le canon des Juifs. Cette dispute de Michaël avec le diable n'est que dans un livre apocryphe, intitulé Analyse de Moïse, cité par Origène dans le III livre de ses Principes.

Il est donc indubitable que les Juifs ne reconnurent point de diables jusque vers le temps de leur captivité à Babylone. Ils puisèrent cette doctrine chez les Perses, qui la tenaient de Zoroastre.

Il n'y a que l'ignorance, le fanatisme, et la mauvaise foi, qui puissent nier tous ces faits, et il faut ajouter que la religion ne doit pas s'effrayer des conséquences. Dieu a certainement permis que la croyance aux bons et aux mauvais génies, à l'immortalité de l'âme, aux récompenses et aux peines éternelles, ait été établie chez vingt nations de l'antiquité avant de parvenir au peuple juif. Notre sainte religion a consacré cette doctrine; elle a établi ce que les autres avaient entrevu; et ce qui n'était chez les anciens qu'une opinion est devenu par la révélation une vérité divine.

Table des Matières

49.

SI LES JUIFS ONT ENSEIGNÉ LES AUTRES NATIONS, OU S’ILS ONT ÉTÉ ENSEIGNÉS PAR ELLES.

Les livres sacrés n'ayant jamais décidé si les Juifs avaient été les maîtres ou les disciples des autres peuples, il est permis d'examiner cette question.

Philon, dans la relation de sa mission auprès de Caligula, commence par dire qu'Israël est un terme chaldéen; que c'est un nom que les Chaldéens donnèrent aux justes consacrés à Dieu, qu'Israël signifie voyant Dieu. Il paraît donc prouvé par cela seul que les Juifs n'appelèrent Jacob Israël, qu'ils ne se donnèrent le nom d'Israélites, que lorsqu'ils eurent quelque connaissance du chaldéen. Or ils ne purent avoir connaissance de cette langue que quand ils furent esclaves en Chaldée. Est-il vraisemblable que dans les déserts de l'Arabie Pétrée ils eussent appris déjà le chaldéen ? 
Flavien Josèphe, dans sa réponse à Apion, à Lysimaque et à Molon, livre II, chap. V, avoue en propres termes « que ce sont les Égyptiens qui apprirent à d'autres nations à se faire circoncire, comme Hérodote le témoigne $»$. En effet serait-il probable que la nation antique et puissante des Égyptiens eût pris cette coutume d'un petit peuple qu'elle abhorrait, et qui, de son aveu, ne fut circoncis que sous Josué ?

Les livres sacrés eux-mêmes nous apprennent que Moïse avait été nourri dans les sciences des Égyptiens, et ils ne disent nulle part que les Égyptiens aient jamais rien appris des Juifs. Quand Salomon voulut bâtir son temple et son palais, ne demanda-t-il pas des ouvriers au roi de Tyr? Il est dit même qu'il donna vingt villes au roi Hiram pour obtenir des ouvriers et des cèdres : c'était sans doute payer bien chèrement, et le marché est étrange ; mais jamais les Tyriens demandèrent-ils des artistes juifs?

Le même Josèphe dont nous avons parlé avoue que sa nation, qu'il s'efforce de relever, "n'eut longtemps aucun commerce avec les autres nations »; qu'elle fut « surtout inconnue des Grecs, qui connaissaient les Scythes, les Tartares. Faut-il s'étonner », ajoute-t-il, liv. I, chap. $X$, « que notre nation, éloignée de la mer, et ne se piquant point de rien écrire, ait été si peu connue ?»

Lorsque le même Josèphe raconte, avec ses exagérations ordinaires, la manière aussi honorable qu'incroyable dont le roi Ptolémée Philadelphe acheta une traduction grecque des livres juifs, faite par des Hébreux dans la ville d'Alexandrie ; Josèphe, dis-je, ajoute que Démétrius de Phalère, qui fit faire cette traduction pour la bibliothèque de son roi, demanda à l'un des traducteurs « comment il se pouvait faire qu'aucun historien, aucun poète étranger n'eût jamais parlé des lois juives ». Le traducteur répondit: «Comme ces lois sont toutes divines, personne n'a osé entreprendre d'en parler, et ceux qui ont voulu le faire ont été châtiés de Dieu. Théopompe, voulant en insérer quelque chose dans son histoire, perdit l'esprit durant trente jours ; mais ayant reconnu dans un songe qu'il était devenu fou pour avoir voulu pénétrer dans les choses divines, et en faire part aux profanes ${ }^{112}$, il apaisa la colère de Dieu par ses prières, et rentra dans son bon sens.

112 Josèphe, Histoire des Juifs, liv. XII, chap. II. (V.) 
«Théodecte, poète grec, ayant mis dans une tragédie quelques passages qu'il avait tirés de nos livres saints, devint aussitôt aveugle, et ne recouvra la vue qu'après avoir reconnu sa faute. »

Ces deux contes de Josèphe, indignes de l'histoire et d'un homme qui a le sens commun, contredisent, à la vérité, les éloges qu'il donne à cette traduction grecque des livres juifs ; car si c'était un crime d'en insérer quelque chose dans une autre langue, c'était sans doute un bien plus grand crime de mettre tous les Grecs à portée de les connaître. Mais au moins Josèphe, en rapportant ces deux historiettes, convient que les Grecs n'avaient jamais eu connaissance des livres de sa nation.

Au contraire, dès que les Hébreux furent établis dans Alexandrie, ils s'adonnèrent aux lettres grecques ; on les appela les Juifs hellénistes. Il est donc indubitable que les Juifs, depuis Alexandre, prirent beaucoup de choses des Grecs, dont la langue était devenue celle de l'Asie Mineure et d'une partie de l'Égypte, et que les Grecs ne purent rien prendre des Hébreux.

Table des Matières

50.

LES ROMAINS. COMMENCEMENT DE LEUR EMPIRE ET DE LEUR RELIGION ; LEUR TOLÉRANCE

Les Romains ne peuvent point être comptés parmi les nations primitives : ils sont trop nouveaux. Rome n'existe que sept cent cinquante ans avant notre ère vulgaire. Quand elle eut des rites et des lois, elle les tint des Toscans et des Grecs. Les Toscans lui communiquèrent la superstition des augures, superstition pourtant fondée sur des observations physiques, sur le passage des oiseaux dont on augurait les changements de l'atmosphère. Il semble que toute superstition ait une chose naturelle pour principe, et que bien des erreurs soient nées d'une vérité dont on abuse.

Les Grecs fournirent aux Romains la loi des Douze Tables. Un peuple qui va chercher des lois et des dieux chez un autre devait être un peuple petit et barbare : aussi les premiers Romains l'étaient-ils. Leur territoire, du temps des rois et des premiers consuls, n'était pas si 
étendu que celui de Raguse. Il ne faut pas sans doute entendre, par ce nom de roi, des monarques tels que Cyrus et ses successeurs. Le chef d'un petit peuple de brigands ne peut jamais être despotique : les dépouilles se partagent en commun, et chacun défend sa liberté comme son bien propre. Les premiers rois de Rome étaient des capitaines de flibustiers.

Si l'on en croit les historiens romains, ce petit peuple commença par ravir les filles et les biens de ses voisins. Il devait être exterminé ; mais la férocité et le besoin, qui le portaient à ces rapines, rendirent ses injustices heureuses; il se soutint étant toujours en guerre; et enfin, au bout de cinq siècles, étant bien plus aguerri que tous les autres peuples, il les soumit tous, les uns après les autres, depuis le fond du golfe Adriatique jusqu'à l'Euphrate.

Au milieu du brigandage, l'amour de la patrie domina toujours jusqu'au temps de Sylla. Cet amour de la patrie consista, pendant plus de quatre cents ans, à rapporter à la masse commune ce qu'on avait pillé chez les autres nations : c'est la vertu des voleurs. Aimer la patrie, c'était tuer et dépouiller les autres hommes ; mais dans le sein de la république il y eut de très grandes vertus. Les Romains, policés avec le temps, policèrent tous les barbares vaincus, et devinrent enfin les législateurs de l'Occident.

Les Grecs paraissent, dans les premiers temps de leurs républiques, une nation supérieure en tout aux Romains. Ceux-ci ne sortent des repaires de leurs sept montagnes avec des poignées de foin, manipuli, qui leur servent de drapeaux, que pour piller des villages voisins; ceux-là, au contraire, ne sont occupés qu'à défendre leur liberté. Les Romains volent à quatre ou cinq milles à la ronde les Èques, les Volsques, les Antiates. Les Grecs repoussent les armées innombrables du grand roi de Perse, et triomphent de lui sur terre et sur mer. Ces Grecs, vainqueurs, cultivent et perfectionnent tous les beaux-arts, et les Romains les ignorent tous, jusque vers le temps de Scipion l'Africain.

J'observerai ici sur leur religion deux choses importantes c'est qu'ils adoptèrent ou permirent les cultes de tous les autres peuples, à l'exemple des Grecs; et qu'au fond, le sénat et les empereurs recon- 
nurent toujours un dieu suprême, ainsi que la plupart des philosophes et des poètes de la Grèce ${ }^{113}$.

La tolérance de toutes les religions était une loi nouvelle, gravée dans les cœurs de tous les hommes : car de quel droit un être créé libre pourrait-il forcer un autre être à penser comme lui ? Mais quand un peuple est rassemblé, quand la religion est devenue une loi de l'État, il faut se soumettre à cette loi : or les Romains par leurs lois adoptèrent tous les dieux des Grecs, qui eux-mêmes avaient des autels pour les dieux inconnus, comme nous l'avons déjà remarqué ${ }^{114}$.

Les ordonnances des douze Tables portent : « Separatim nemo habessit deos, neve novos ; sed ne advenas, nisi publice adscitos, privatim colunto ${ }^{115}$. » Que personne n'ait des dieux étrangers et nouveaux sans la sanction publique. On donna cette sanction à plusieurs cultes; tous les autres furent tolérés. Cette association de toutes les divinités du monde, cette espèce d'hospitalité divine fut le droit des gens de toute l'antiquité, excepté peut-être chez un ou deux petits peuples.

Comme il n'eut point de dogmes, il n'y eut point de guerre de religion. C'était bien assez que l'ambition, la rapine, versassent le sang humain, sans que la religion achevât d'exterminer le monde.

Il est encore très remarquable que chez les Romains on ne persécuta jamais personne pour sa manière de penser. Il n'y en a pas un seul exemple depuis Romulus jusqu'à Domitien; et chez les Grecs il n'y eut que le seul Socrate.

Il est encore incontestable que les Romains, comme les Grecs, adoraient un dieu suprême. Leur Jupiter était le seul qu'on regardât comme le maître du tonnerre, comme le seul que l'on nommât le Dieu très grand et très bon, Deus optimus, maximus. Ainsi, de l'Italie à l'Inde et à la Chine, vous trouvez le culte d'un dieu suprême, et la tolérance dans toutes les nations connues.

A cette connaissance d'un dieu, à cette indulgence universelle, qui sont partout le fruit de la raison cultivée, se joignit une foule de su-

\footnotetext{
113 Voyez l'article DiEU dans le Dictionnaire philosophique. (V.)

114 Paragraphe 27. (B.)

115 Cic., de Legibus, II, 8, ex verbis XII Tab. (B.)
} 
perstitions, qui étaient le fruit ancien de la raison commencée et erronée.

On sait bien que les poulets sacrés, et la déesse Pertunda, et la déesse Cloacina, sont ridicules. Pourquoi les vainqueurs et les législateurs de tant de nations n'abolirent-ils pas ces sottises ? c'est qu'étant anciennes, elles étaient chères au peuple, et qu'elles ne nuisaient point au gouvernement. Les Scipion, les Paul-Émile, les Cicéron, les Caton, les Césars, avaient autre chose à faire qu'à combattre les superstitions de la populace. Quand une vieille erreur est établie, la politique s'en sert comme d'un mors que le vulgaire s'est mis lui-même dans la bouche, jusqu'à ce qu'une autre superstition vienne la détruire, et que la politique profite de cette seconde erreur, comme elle a profité de la première.

$\underline{\text { Table des Matières }}$

51.

QUESTIONS SUR LES CONQUÊTES DES ROMAINS, ET LEUR DÉCADENCE

Pourquoi les Romains, qui, sous Romulus, n'étaient que trois mille habitants, et qui n'avaient qu'un bourg de mille pas de circuit, devinrent-ils, avec le temps, les plus grands conquérants de la terre ? et d'où vient que les Juifs, qui prétendent avoir eu six cent trente mille soldats en sortant d'Égypte, qui ne marchaient qu'au milieu des miracles, qui combattaient sous le dieu des armées, ne purent-ils jamais parvenir à conquérir seulement Tyr et Sidon dans leur voisinage, pas même à être jamais à portée de les attaquer ? Pourquoi ces Juifs furent-ils presque toujours dans l'esclavage? Ils avaient tout l'enthousiasme et toute la férocité qui devaient faire des conquérants ; le dieu des armées était toujours à leur tête ; et cependant ce sont les Romains, éloignés d'eux de dix-huit cents milles, qui viennent à la fin les subjuguer et les vendre au marché.

N'est-il pas clair (humainement parlant, et ne considérant que les causes secondes) que si les Juifs, qui espéraient la conquête du monde, ont été presque toujours asservis, ce fut leur faute ? Et si les Romains dominèrent, ne le méritèrent-ils pas par leur courage et par leur 
prudence ? Je demande très humblement pardon aux Romains de les comparer un moment avec les Juifs.

Pourquoi les Romains, pendant plus de quatre cent cinquante ans, ne purent-ils conquérir qu'une étendue de pays d'environ vingt-cinq lieues ? N'est-ce point parce qu'ils étaient en très petit nombre, et qu'ils n'avaient successivement à combattre que de petits peuples comme eux ? Mais enfin, ayant incorporé avec eux leurs voisins vaincus, ils eurent assez de force pour résister à Pyrrhus.

Alors toutes les petites nations qui les entouraient étant devenues romaines, il s'en forma un peuple tout guerrier, assez formidable pour détruire Carthage.

Pourquoi les Romains employèrent-ils sept cents années à se donner enfin un empire à peu près aussi vaste que celui qu'Alexandre conquit en sept ou huit années ? est-ce parce qu'ils eurent toujours à combattre des nations belliqueuses, et qu'Alexandre eut affaire à des peuples amollis?

Pourquoi cet empire fut-il détruit par des barbares ? ces barbares n'étaient-ils pas plus robustes, plus guerriers que les Romains, amollis à leur tour sous Honorius et sous ses successeurs ? Quand les Cimbres vinrent menacer l'Italie, du temps de Marius, les Romains durent prévoir que les Cimbres, c'est-à-dire les peuples du Nord, déchireraient l'empire lorsqu'il n'y aurait plus de Marius.

La faiblesse des empereurs, les factions de leurs ministres et de leurs eunuques, la haine que l'ancienne religion de l'empire portait à la nouvelle, les querelles sanglantes élevées dans le christianisme, les disputes théologiques substituées au maniement des armes, et la mollesse à la valeur; des multitudes de moines remplaçant les agriculteurs et les soldats, tout appelait ces mêmes barbares qui n'avaient pu vaincre la république guerrière, et qui accablèrent Rome languissante, sous des empereurs cruels, efféminés, et dévots.

Lorsque les Goths, les Hérules, les Vandales, les Huns, inondèrent l'empire romain, quelles mesures les deux empereurs prenaient-ils pour détourner ces orages? La différence de l'Homoiousios à 
l'Homoousios mettait le trouble dans l'Orient et dans l'Occident ${ }^{116}$. Les persécutions théologiques achevaient de tout perdre; Nestorius, patriarche de Constantinople, qui eut d'abord un grand crédit sous Théodose II, obtint de cet empereur qu'on persécutât ceux qui pensaient qu'on devait rebaptiser les chrétiens apostats repentants, ceux qui croyaient qu'on devait célébrer la Pâque le 14 de la lune de mars, ceux qui ne faisaient pas plonger trois fois les baptisés : enfin il tourmenta tant les chrétiens qu'ils le tourmentèrent à leur tour. Il appela la sainte Vierge Anthropotokos; ses ennemis, qui voulaient qu'on l'appelât Theotokos, et qui sans doute avaient raison puisque le concile d'Éphèse décida en leur faveur, lui suscitèrent une persécution violente. Ces querelles occupèrent tous les esprits, et, pendant qu'on disputait, les barbares se partageaient l'Europe et l'Afrique.

Mais pourquoi Alaric, qui, au commencement du cinquième siècle, marcha des bords du Danube vers Rome, ne commença-t-il pas par attaquer Constantinople, lorsqu'il était maître de la Thrace ? Comment hasarda-t-il de se trouver pressé entre l'empire d'Orient et celui d'Occident ? Est-il naturel qu'il voulût passer les Alpes et l'Apennin, lorsque Constantinople tremblante s'offrait à sa conquête ? Les historiens de ce temps-là, aussi mal instruits que les peuples étaient mal gouvernés, ne nous développent point ce mystère ; mais il est aisé de le deviner. Alaric avait été général d'armée sous Théodose $\mathrm{I}^{\mathrm{er}}$, prince violent, dévot, et imprudent, qui perdit l'empire en confiant sa défense aux Goths. Il vainquit avec eux son compétiteur, Eugène mais les Goths apprirent par là qu'ils pouvaient vaincre pour eux-mêmes. Théodose soudoyait Alaric et ses Goths. Cette paie devint un tribut, quand Arcadius, fils de Théodose, fut sur le trône de l'Orient. Alaric épargna donc son tributaire pour aller tomber sur Honorius et sur Rome.

Honorius avait pour général le célèbre Stilicon, le seul qui pouvait défendre l'Italie, et qui avait déjà arrêté les efforts des barbares. Honorius, sur de simples soupçons, lui fit trancher la tête sans forme de procès. Il était plus aisé d'assassiner Stilicon que de battre Alaric. Cet indigne empereur, retiré à Ravenne, laissa le barbare, qui lui était supérieur en tout, mettre le siège devant Rome. L'ancienne maîtresse du

116 Voyez, dans la Correspondance, la lettre de d'Alembert, du 8 février 1758. (B.) 
monde se racheta du pillage au prix de cinq mille livres pesant d'or, trente mille d'argent, quatre mille robes de soie, trois mille de pourpre, et trois mille livres d'épiceries. Les denrées de l'Inde servirent à la rançon de Rome.

Honorius ne voulut pas tenir le traité ; il envoya quelques troupes qu'Alaric extermina : celui-ci entra dans Rome en 409, et un Goth y créa un empereur ${ }^{117}$ qui devint son premier sujet. L'année d'après, trompé par Honorius, il le punit en saccageant Rome. Alors tout l'empire d'Occident fut déchiré ; les habitants du Nord y pénétrèrent de tous côtés, et les empereurs d'Orient ne se maintinrent qu'en se rendant tributaires.

C'est ainsi que Théodose II le fut d'Attila. L'Italie, les Gaules, l'Espagne, l'Afrique, furent la proie de quiconque voulut y entrer. Ce fut là le fruit de la politique forcée de Constantin, qui avait transféré l'empire romain en Thrace.

N'y a-t-il pas visiblement une destinée qui fait l'accroissement et la ruine des États? Qui aurait prédit à Auguste qu'un jour le Capitole serait occupé par un prêtre d'une religion tirée de la religion juive aurait bien étonné Auguste. Pourquoi ce prêtre s'est-il enfin emparé de la ville des Scipions et des Césars ? c'est qu'il l'a trouvée dans l'anarchie. Il s'en est rendu le maître presque sans efforts ; comme les évêques d'Allemagne, vers le treizième siècle, devinrent souverains des peuples dont ils étaient pasteurs.

Tout événement en amène un autre auquel on ne s'attendait pas. Romulus ne croyait fonder Rome ni pour les princes goths, ni pour des évêques. Alexandre n'imagina pas qu'Alexandrie appartiendrait aux Turcs, et Constantin n'avait pas bâti Constantinople pour Mahomet II. 
52.

DES PREMIERS PEUPLES QUI ÉCRIVIRENT L'HISTOIRE, ET DES FABLES DES PREMIERS HISTORIENS

Il est incontestable que les plus anciennes annales du monde sont celles de la Chine. Ces annales se suivent sans interruption. Presque toutes circonstanciées, toutes sages, sans aucun mélange de merveilleux, toutes appuyées sur des observations astronomiques depuis quatre mille cent cinquante-deux ans, elles remontent encore à plusieurs siècles au delà, sans dates précises à la vérité, mais avec cette vraisemblance qui semble approcher de la certitude. Il est bien probable que des nations puissantes, telles que les Indiens, les Égyptiens, les Chaldéens, les Syriens, qui avaient de grandes villes, avaient aussi des annales.

Les peuples errants doivent être les derniers qui aient écrit, parce qu'ils ont moins de moyens que les autres d'avoir des archives et de les conserver; parce qu'ils ont peu de besoins, peu de lois, peu d'événements ; qu'ils ne sont occupés que d'une subsistance précaire, et qu'une tradition orale leur suffit. Une bourgade n'eut jamais d'histoire, un peuple errant encore moins, une simple ville très rarement.

L'histoire d'une nation ne peut jamais être écrite que fort tard ; on commence par quelques registres très sommaires qui sont conservés, autant qu'ils peuvent l'être, dans un temple ou dans une citadelle. Une guerre malheureuse détruit souvent ces annales, et il faut recommencer vingt fois, comme des fourmis dont on a foulé aux pieds l'habitation. Ce n'est qu'au bout de plusieurs siècles qu'une histoire un peu détaillée peut succéder à ces registres informes, et cette première histoire est toujours mêlée d'un faux merveilleux par lequel on veut remplacer la vérité qui manque. Ainsi les Grecs n'eurent leur Hérodote que dans la quatre-vingtième olympiade, plus de mille ans après la première époque rapportée dans les marbres de Paros. Fabius- 
Pictor, le plus ancien historien des Romains, n'écrivit que du temps de la seconde guerre contre Carthage, environ cinq cent quarante ans après la fondation de Rome.

Or si ces deux nations, les plus spirituelles de la terre, les Grecs et les Romains, nos maîtres, ont commencé si tard leur histoire ; si nos nations septentrionales n'ont eu aucun historien avant Grégoire de Tours, croira-t-on de bonne foi que des Tartares vagabonds qui dorment sur la neige, ou des Troglodytes qui se cachent dans des cavernes, ou des Arabes errants et voleurs, qui errent dans des montagnes de sable, aient eu des Thucydides et des Xénophons? peuvent-ils savoir quelque chose de leurs ancêtres ? peuvent-ils acquérir quelque connaissance avant d'avoir eu des villes, avant de les avoir habitées, avant d'y avoir appelé tous les arts dont ils étaient privés ?

Si les Samoyèdes, ou les Nazamons, ou les Esquimaux, venaient nous donner des annales antidatées de plusieurs siècles, remplies des plus étonnants faits d'armes, et d'une suite continuelle de prodiges qui étonnent la nature, ne se moquerait-on pas de ces pauvres sauvages ? Et si quelques personnes amoureuses du merveilleux, ou intéressées à le faire croire, donnaient la torture à leur esprit pour rendre ces sottises vraisemblables, ne se moquerait-on pas de leurs efforts ? et s'ils joignaient à leur absurdité l'insolence d'affecter du mépris pour les savants, et la cruauté de persécuter ceux qui douteraient, ne seraientils pas les plus exécrables des hommes? Qu'un Siamois vienne me conter les métamorphoses de Sammonocodom, et qu'il me menace de me brûler si je lui fais des objections, comment dois-je en user avec ce Siamois?

Les historiens romains nous content, à la vérité, que le dieu Mars fit deux enfants à une vestale dans un siècle où l'Italie n'avait point de vestales ; qu'une louve nourrit ces deux enfants au lieu de les dévorer, comme nous l'avons déjà vu ${ }^{118}$; que Castor et Pollux combattirent pour les Romains, que Curtius se jeta dans un gouffre, et que le gouffre se referma; mais le sénat de Rome ne condamna jamais à la mort ceux qui doutèrent de tous ces prodiges : il fut permis d'en rire dans le Capitole.

118 Dict. philosophique, article PrÉJUGÉS. (B.) 
Il y a dans l'histoire romaine des événements très possibles qui sont très peu vraisemblables. Plusieurs savants hommes ont déjà révoqué en doute l'aventure des oies qui sauvèrent Rome, et celle de Camille qui détruisit entièrement l'armée des Gaulois. La victoire de Camille brille beaucoup, à la vérité, dans Tite-Live ; mais Polybe, plus ancien que Tite-Live, et plus homme d'État, dit précisément le contraire ; il assure que les Gaulois, craignant d'être attaqués par les Vénètes, partirent de Rome chargés de butin, après avoir fait la paix avec les Romains. À qui croirons-nous, de Tite-Live ou de Polybe ? au moins nous douterons.

Ne douterons-nous pas encore du supplice de Régulus, qu'on fait enfermer dans un coffre armé en dedans de pointes de fer? Ce genre de mort est assurément unique. Comment ce même Polybe, presque contemporain, Polybe, qui était sur les lieux, qui a écrit si supérieurement la guerre de Rome et de Carthage, aurait-il passé sous silence un fait aussi extraordinaire, aussi important, et qui aurait si bien justifié la mauvaise foi des Romains envers les Carthaginois ? Comment ce peuple aurait-il osé violer d'une manière aussi barbare le droit des gens avec Régulus, dans le temps que les Romains avaient entre leurs mains plusieurs principaux citoyens de Carthage, sur lesquels ils auraient pu se venger?

Enfin Diodore de Sicile rapporte, dans un de ses fragments, que les enfants de Régulus ayant fort maltraité des prisonniers carthaginois, le sénat romain les réprimanda, et fit valoir le droit des gens. N'aurait-il pas permis une juste vengeance aux fils de Régulus, si leur père avait été assassiné à Carthage ? L'histoire du supplice de Régulus s'établit avec le temps, la haine contre Carthage lui donna cours; Horace la chanta, et on n'en douta plus.

Si nous jetons les yeux sur les premiers temps de notre histoire de France, tout en est peut-être aussi faux qu'obscur et dégoûtant; du moins il est bien difficile de croire l'aventure de Childéric et d'une Bazine, femme d'un Bazin, et d'un capitaine romain, élu roi des Francs, qui n'avaient point encore de rois.

Grégoire de Tours est notre Hérodote, à cela près que le Tourangeau est moins amusant, moins élégant, que le Grec. Les moines qui écrivirent après Grégoire furent-ils plus éclairés et plus véridiques ? 
ne prodiguèrent-ils pas quelquefois des louanges un peu outrées à des assassins qui leur avaient donné des terres ? ne chargèrent-ils jamais d'opprobres des princes sages qui ne leur avaient rien donné ?

Je sais bien que les Francs qui envahirent la Gaule furent plus cruels que les Lombards qui s'emparèrent de l'Italie, et que les Visigoths qui régnèrent en Espagne. On voit autant de meurtres, autant d'assassinats dans les annales des Clovis, des Thierri, des Childebert, des Chilpéric, et des Clotaire, que dans celles des rois de Juda et d'Israël.

Rien n'est assurément plus sauvage que ces temps barbares; cependant n'est-il pas permis de douter du supplice de la reine Brunehaut? Elle était âgée de près de quatre-vingts ans quand elle mourut, en 613 ou 614. Frédegaire, qui écrivait sur la fin du huitième siècle, cent cinquante ans après la mort de Brunehaut (et non pas dans le septième siècle, comme il est dit dans l'abrégé chronologique, par une faute d'impression) ; Frédegaire, dis-je, nous assure que le roi Clotaire, prince très pieux, très craignant Dieu, humain, patient, et débonnaire, fit promener la reine Brunehaut sur un chameau autour de son camp ; ensuite la fit attacher par les cheveux, par un bras, et par une jambe, à la queue d'une cavale indomptée, qui la traîna vivante sur les chemins, lui fracassa la tête sur les cailloux, et la mit en pièces; après quoi elle fut brûlée et réduite en cendres. Ce chameau, cette cavale indomptée, une reine de quatre-vingts ans attachée par les cheveux et par un pied à la queue de cette cavale, ne sont pas des choses bien communes.

Il est peut-être difficile que le peu de cheveux d'une femme de cet âge puisse tenir à une queue, et qu'on soit lié à la fois à cette queue par les cheveux et par un pied. Et comment eut-on la pieuse attention d'inhumer Brunehaut dans un tombeau, à Autun, après l'avoir brûlée dans un camp ? Les moines Frédegaire et Aimoin le disent ; mais ces moines sont-ils des de Thou et des Hume?

Il y a un autre tombeau érigé à cette reine, au quinzième siècle, dans l'abbaye de Saint-Martin-d'Autun, qu'elle avait fondée. On a trouvé dans ce sépulcre un reste d'éperon. C'était, dit-on, l'éperon que l'on mit aux flancs de la cavale indomptée. C'est dommage qu'on n'y ait pas trouvé aussi la corne du chameau sur lequel on avait fait mon- 
ter la reine. N'est-il pas possible que cet éperon y ait été mis par inadvertance, ou plutôt par honneur ? car, au quinzième siècle, un éperon doré était une grande marque d'honneur. En un mot, n'est-il pas raisonnable de suspendre son jugement sur cette étrange aventure si mal constatée? Il est vrai que Pasquier dit que la mort de Brunehaut avait été prédite par la sibylle.

Tous ces siècles de barbarie sont des siècles d'horreurs et de miracles. Mais faudra-t-il croire tout ce que les moines ont écrit? Ils étaient presque les seuls qui sussent lire et écrire, lorsque Charlemagne ne savait pas signer son nom. Ils nous ont instruits de la date de quelques grands événements. Nous croyons avec eux que Charles Martel battit les Sarrasins ; mais qu'il en ait tué trois cent soixante mille dans la bataille, en vérité, c'est beaucoup.

Ils disent que Clovis, second du nom, devint fou : la chose n'est pas impossible ; mais que Dieu ait affligé son cerveau pour le punir d'avoir pris un bras de saint Denis dans l'église de ces moines, pour le mettre dans son oratoire, cela n'est pas si vraisemblable.

Si l'on n'avait que de pareils contes à retrancher de l'histoire de France, ou plutôt de l'histoire des rois francs et de leurs maires, on pourrait s'efforcer de la lire ; mais comment supporter les mensonges grossiers dont elle est pleine? On y assiège continuellement des villes et des forteresses qui n'existaient pas. Il n'y avait par delà le Rhin que des bourgades sans murs, défendues par des palissades de pieux, et par des fossés. On sait que ce n'est que sous Henri l'Oiseleur, vers l'an 920, que la Germanie eut des villes murées et fortifiées. Enfin tous les détails de ces temps-là sont autant de fables, et, qui pis est, de fables ennuyeuses. 


\section{3. \\ DES LÉGISLATEURS QUI ONT PARLÉ AU NOM DES DIEUX}

Tout législateur profane qui osa feindre que la Divinité lui avait dicté ses lois était visiblement un blasphémateur et un traître : un blasphémateur, puisqu'il calomniait les dieux; un traître, puisqu'il asservissait sa patrie à ses propres opinions. Il y a deux sortes de lois, les unes naturelles, communes à tous, et utiles à tous. " Tu ne voleras ni ne tueras ton prochain; tu auras un soin respectueux de ceux qui t'ont donné le jour et qui ont élevé ton enfance; tu ne raviras pas la femme de ton frère, tu ne mentiras pas pour lui nuire; tu l'aideras dans ses besoins, pour mériter d'en être secouru à ton tour » : voilà les lois que la nature a promulguées du fond des îles du Japon aux rivages de notre Occident. Ni Orphée, ni Hermès, ni Minos, ni Lycurgue, ni Numa, n'avaient besoin que Jupiter vînt au bruit du tonnerre annoncer des vérités gravées dans tous les cœurs.

Si je m'étais trouvé vis-à-vis de quelqu'un de ces grands charlatans dans la place publique, je lui aurais crié : "Arrête, ne compromets point ainsi la Divinité ; tu veux me tromper si tu la fais descendre pour enseigner ce que nous savons tous; tu veux sans doute la faire servir à quelque autre usage ; tu veux te prévaloir de mon consentement à des vérités éternelles pour arracher de moi mon consentement à ton usurpation : je te défère au peuple comme un tyran qui blasphème. »

Les autres lois sont les politiques : lois purement civiles, éternellement arbitraires, qui tantôt établissent des éphores, tantôt des consuls, des comices par centuries, ou des comices par tribus; un aréopage ou un sénat; l'aristocratie, la démocratie, ou la monarchie. Ce serait bien mal connaître le cœur humain de soupçonner qu'il soit possible qu'un législateur profane eût jamais établi une seule de ces lois politiques au nom des dieux que dans la vue de son intérêt. On ne trompe ainsi les hommes que pour son profit. 
Mais tous les législateurs profanes ont-ils été des fripons dignes du dernier supplice ? non. De même qu'aujourd'hui, dans les assemblées des magistrats, il se trouve toujours des âmes droites et élevées qui proposent des choses utiles à la société, sans se vanter qu'elles leur ont été révélées; de même aussi, parmi les législateurs, il s'en est trouvé plusieurs qui ont institué des lois admirables, sans les attribuer à Jupiter ou à Minerve. Tel fut le sénat romain, qui donna des lois à l'Europe, à la petite Asie et à l'Afrique, sans les tromper; et tel de nos jours a été Pierre le Grand, qui eût pu en imposer à ses sujets plus facilement qu'Hermès aux Égyptiens, Minos aux Crétois, et Zalmoxis aux anciens Scythes ${ }^{119}$.

119 L'édition de 1765 se termine par ce qui suit: Le reste manque. L'éditeur n'a rien osé ajouter au manuscrit de l'abbé Bazin ; s'il retrouve la suite, il en fera part aux amateurs de l'histoire. (B.) 


\section{ESSAI SUR LES MCURS ET L'ESPRIT DES NATIONS}

\section{ET SUR LES PRINCIPAUX FAITS DE L'HISTOIRE, DEPUIS CHARLEMAGNE JUSQU'À LOUIS XIII.}




\begin{abstract}
AVANT-PROPOS
Qui contient le plan de cet ouvrage, avec le précis de ce qu'étaient originairement les nations occidentales, et les raisons pour lesquelles on commence cet essai par l'Orient.
\end{abstract}

Vous voulez enfin surmonter le dégoût que vous cause l'Histoire moderne ${ }^{120}$, depuis la décadence de l'empire romain, et prendre une idée générale des nations qui habitent et qui désolent la terre. Vous ne cherchez dans cette immensité que ce qui mérite d'être connu de vous ; l'esprit, les mœurs, les usages des nations principales, appuyés des faits qu'il n'est pas permis d'ignorer. Le but de ce travail n'est pas de savoir en quelle année un prince indigne d'être connu succéda à un prince barbare chez une nation grossière. Si l'on pouvait avoir le malheur de mettre dans sa tête la suite chronologique de toutes les dynasties, on ne saurait que des mots. Autant il faut connaître les grandes actions des souverains qui ont rendu leurs peuples meilleurs et plus heureux, autant on peut ignorer le vulgaire des rois, qui ne pourrait que charger la mémoire. À quoi vous serviraient les détails de tant de petits intérêts qui ne subsistent plus aujourd'hui, de tant de familles éteintes qui se sont disputé des provinces englouties ensuite dans de grands royaumes? Presque chaque ville a aujourd'hui son histoire vraie ou fausse, plus ample, plus détaillée que celle d'Alexandre. Les seules annales d'un ordre monastique contiennent plus de volumes que celles de l'empire romain.

Dans tous ces recueils immenses qu'on ne peut embrasser, il faut se borner et choisir. C'est un vaste magasin où vous prendrez ce qui est à votre usage.

${ }^{120}$ Cet ouvrage fut composé en 1740, pour madame du Châtelet, amie de l'auteur. Aucune des compilations universelles qu'on a vues depuis n'existait alors. (V.) 
L'illustre Bossuet, qui dans son Discours sur une partie de l'Histoire universelle en a saisi le véritable esprit, au moins dans ce qu'il dit de l'empire romain, s'est arrêté à Charlemagne. C'est en commençant à cette époque que votre dessein est de vous faire un tableau du monde ; mais il faudra souvent remonter à des temps antérieurs. Cet éloquent écrivain, en disant un mot des Arabes, qui fondèrent un si puissant empire et une religion si florissante, n'en parle que comme d'un déluge de barbares. Il paraît avoir écrit uniquement pour insinuer que tout a été fait dans le monde pour la nation juive ; que si Dieu donna l'empire de l'Asie aux Babyloniens, ce fut pour punir les Juifs ; si Dieu fit régner Cyrus, ce fut pour les venger ; si Dieu envoya les Romains, ce fut encore pour châtier les Juifs. Cela peut être ; mais les grandeurs de Cyrus et des Romains ont encore d'autres causes; et Bossuet même ne les a pas omises en parlant de l'esprit des nations.

Il eût été à souhaiter qu'il n'eût pas oublié entièrement les anciens peuples de l'Orient, comme les Indiens et les Chinois, qui ont été si considérables avant que les autres nations fussent formées.

Nourris de productions de leurs terres, vêtus de leurs étoffes, amusés par les jeux qu'ils ont inventés, instruits même par leurs anciennes fables morales, pourquoi négligerions-nous de connaître l'esprit de ces nations, chez qui les commerçants de notre Europe ont voyagé dès qu'ils ont pu trouver un chemin jusqu'à elles?

En vous instruisant en philosophe de ce qui concerne ce globe, vous portez d'abord votre vue sur l'Orient, berceau de tous les arts, et qui a tout donné à l'Occident.

Les climats orientaux, voisins du Midi, tiennent tout de la nature ; et nous, dans notre Occident septentrional, nous devons tout au temps, au commerce, à une industrie tardive. Des forêts, des pierres, des fruits sauvages, voilà tout ce qu'a produit naturellement l'ancien pays des Celtes, des Allobroges, des Pictes, des Germains, des Sarmates, et des Scythes. On dit que l'île de Sicile produit d'elle-même un peu d'avoine ${ }^{121}$; mais le froment, le riz, les fruits délicieux, croissaient vers l'Euphrate, à la Chine, et dans l'Inde. Les pays fertiles furent les

121 Il croît naturellement en Sicile une plante dont le grain ressemble beaucoup au froment, et qu'on a pris pour du froment naturel ; mais les botanistes ont observé des différences très marquées entre cette plante et le froment. (K.) 
premiers peuplés, les premiers policés. Tout le Levant, depuis la Grèce jusqu'aux extrémités de notre hémisphère, fut longtemps célèbre avant que nous en sussions assez pour connaître que nous étions barbares. Quand on veut savoir quelque chose des Celtes, nos ancêtres, il faut avoir recours aux Grecs et aux Romains, nations encore très postérieures aux Asiatiques.

$\mathrm{Si}$, par exemple, des Gaulois voisins des Alpes, joints aux habitants de ces montagnes, s'étant établis sur les bords de l'Éridan, vinrent jusqu'à Rome trois cent soixante et un ans après sa fondation, s'ils assiégèrent le Capitole, ce sont les Romains qui nous l'ont appris. Si d'autres Gaulois, environ cent ans après, entrèrent dans la Thessalie, dans la Macédoine, et passèrent sur le rivage du Pont-Euxin, ce sont les Grecs qui nous le racontent, sans nous dire quels étaient ces Gaulois, ni quel chemin ils prirent. Il ne reste chez nous aucun monument de ces émigrations, qui ressemblent à celles des Tartares; elles prouvent seulement que la nation était très nombreuse, mais non civilisée. La colonie des Grecs qui fonda Marseille, six cents ans avant notre ère vulgaire, ne put polir la Gaule : la langue grecque ne s'étendit pas même au delà de son territoire ${ }^{122}$.

Gaulois, Allemands, Espagnols, Bretons, Sarmates, nous ne savons rien de nous avant dix-huit siècles, sinon le peu que nos vainqueurs ont pu nous en apprendre; nous n'avions pas même de fables : nous n'avions pas osé imaginer une origine. Ces vaines idées que tout cet Occident fut peuplé par Gomer, fils de Japhet, sont des fables orientales.

Si les anciens Toscans qui enseignèrent les premiers Romains savaient quelque chose de plus que les autres peuples occidentaux, c'est que les Grecs avaient envoyé chez eux des colonies; ou plutôt, c'est parce que, de tout temps, une des propriétés de cette terre a été de produire des hommes de génie, comme le territoire d'Athènes était plus propre aux arts que celui de Thèbes et de Lacédémone. Mais quel monument avons-nous de l'ancienne Toscane? aucun. Nous nous épuisons en vaines conjectures sur quelques inscriptions inintelligibles que les injures du temps ont épargnées, et qui probablement sont des

122 Cependant César, dans ses Commentaires (de bello gallico, I, 29), rapporte que le rôle qu'il trouva après une victoire dans le camp des Suisses ou Helvétiens était écrit en grec. (B.) 
premiers siècles de la république romaine. Pour les autres nations de notre Europe, il ne nous reste d'elles, dans leur ancien langage, aucun monument antérieur à notre ère.

L'Espagne maritime fut découverte par les Phéniciens, ainsi que l'Amérique le fut depuis par les Espagnols. Les Tyriens, les Carthaginois, les Romains, y trouvèrent tour à tour de quoi s'enrichir dans les trésors que la terre produisait alors. Les Carthaginois y firent valoir des mines, mais moins riches que celles du Mexique et du Pérou; le temps les a épuisées, comme il épuisera celles du nouveau monde. Pline rapporte qu'en neuf ans les Romains en tirèrent huit mille marcs d'or, et environ vingt-quatre mille d'argent. Il faut avouer que ces prétendus descendants de Gomer avaient bien mal profité des présents que leur faisait la terre en tout genre, puisqu'ils furent subjugués par les Carthaginois, par les Romains, par les Vandales, par les Goths, et par les Arabes.

Ce que nous savons des Gaulois, par Jules César et par les autres auteurs romains, nous donne l'idée d'un peuple qui avait besoin d'être soumis par une nation éclairée. Les dialectes du langage celtique étaient affreux : l'empereur Julien, sous qui ce langage se parlait encore, dit, dans son Misopogon, qu'il ressemblait au croassement des corbeaux. Les mœurs, du temps de César, étaient aussi barbares que le langage. Les druides, imposteurs grossiers faits pour le peuple qu'ils gouvernaient, immolaient des victimes humaines qu'ils brûlaient dans de grandes et hideuses statues d'osier. Les druidesses plongeaient des couteaux dans le cœur des prisonniers, et jugeaient de l'avenir à la manière dont le sang coulait. De grandes pierres un peu creusées, qu'on a trouvées sur les confins de la Germanie et de la Gaule, vers Strasbourg, sont, dit-on, les autels où l'on faisait ces sacrifices. Voilà tous les monuments de l'ancienne Gaule. Les habitants des côtes de la Biscaye et de la Gascogne s'étaient quelquefois nourris de chair humaine. Il faut détourner les yeux de ces temps sauvages, qui sont la honte de la nature.

Comptons, parmi les folies de l'esprit humain, l'idée qu'on a eue, de nos jours, de faire descendre les Celtes des Hébreux. Ils sacrifiaient des hommes, dit-on, parce que Jephté avait immolé sa fille. Les druides étaient vêtus de blanc, pour imiter les prêtres des Juifs; ils avaient, comme eux, un grand pontife. Leurs druidesses sont des ima- 
ges de la sœur de Moïse et de Débora. Le pauvre qu'on nourrissait à Marseille, et qu'on immolait couronné de fleurs et chargé de malédictions, avait pour origine le bouc émissaire. On va jusqu'à trouver de la ressemblance entre trois ou quatre mots celtiques et hébraïques, qu'on prononce également mal ; et l'on en conclut que les Juifs et les nations des Celtes sont la même famille. C'est ainsi qu'on insulte à la raison dans des histoires universelles, et qu'on étouffe sous un amas de conjectures forcées le peu de connaissance que nous pourrions avoir de l'antiquité.

Les Germains avaient à peu près les mêmes mœurs que les Gaulois, sacrifiaient comme eux des victimes humaines, décidaient comme eux leurs petits différends particuliers par le duel, et avaient seulement plus de grossièreté et moins d'industrie. César, dans ses mémoires, nous apprend que leurs magiciennes réglaient toujours parmi eux le jour du combat. Il nous dit que quand un de leurs rois, Arioviste, amena cent mille de ses Germains errants pour piller les Gaules, lui qui voulait les asservir et non pas les piller, ayant envoyé deux officiers romains pour entrer en conférence avec ce barbare, Arioviste les fit charger de chaînes; que les deux officiers furent destinés à être sacrifiés aux dieux des Germains, et qu'ils allaient l'être, lorsqu'il les délivra par sa victoire.

Les familles de tous ces barbares avaient en Germanie, pour uniques retraites, des cabanes où, d'un côté, le père, la mère, les sœurs, les frères, les enfants, couchaient nus sur la paille ; et, de l'autre côté, étaient leurs animaux domestiques. Ce sont là pourtant ces mêmes peuples que nous verrons bientôt maîtres de Rome. Tacite loue les mœurs des Germains, mais comme Horace chantait celles des barbares nommés Gètes; l'un et l'autre ignoraient ce qu'ils louaient, et voulaient seulement faire la satire de Rome. Le même Tacite, au milieu de ses éloges ${ }^{123}$, avoue que tout le monde savait que les Germains aimaient mieux vivre de rapine que de cultiver la terre; et qu'après avoir pillé leurs voisins, ils retournaient chez eux manger et dormir. C'est la vie des voleurs de grands chemins d'aujourd'hui et des coupeurs de bourses, que nous punissons de la roue et de la corde ; et voilà ce que Tacite a le front de louer, pour rendre la cour des empereurs romains méprisable, par le contraste de la vertu germani-

123 Voyez Introduction, paragraphe 14. (B.) 
que ! Il appartient à un esprit aussi juste que le vôtre de regarder Tacite comme un satirique ingénieux, aussi profond dans ses idées que concis dans ses expressions, qui a fait la critique plutôt que l'histoire de son pays, et qui eût mérité l'admiration du nôtre, s'il avait été impartial.

Quand César passe en Angleterre, il trouve cette île plus sauvage encore que la Germanie. Les habitants couvraient à peine leur nudité de quelques peaux de bêtes. Les femmes d'un canton y appartenaient indifféremment à tous les hommes du même canton. Leurs demeures étaient des cabanes de roseaux, et leurs ornements des figures que les hommes et les femmes s'imprimaient sur la peau en y faisant des piqûres, et en y versant le suc des herbes, ainsi que le pratiquent encore les sauvages de l'Amérique.

Que la nature humaine ait été plongée pendant une longue suite de siècles dans cet état si approchant de celui des brutes, et inférieur à plusieurs égards, c'est ce qui n'est que trop vrai. La raison en est, comme on l'a dit ${ }^{124}$, qu'il n'est pas dans la nature de l'homme de désirer ce qu'il ne connaît pas. Il a fallu partout, non seulement un espace de temps prodigieux, mais des circonstances heureuses, pour que l'homme s'élevât au-dessus de la vie animale.

Vous avez donc grande raison de vouloir passer tout d'un coup aux nations qui ont été civilisées les premières. Il se peut que longtemps avant les empires de la Chine et des Indes il y ait eu des nations instruites, polies, puissantes, que des déluges de barbares auront ensuite replongées dans le premier état d'ignorance et de grossièreté qu'on appelle l'état de pure nature.

La seule prise de Constantinople a suffi pour anéantir l'esprit de l'ancienne Grèce ${ }^{125}$. Le génie des Romains fut détruit par les Goths. Les côtes de l'Afrique, autrefois si florissantes, ne sont presque plus que des repaires de brigands. Des changements encore plus grands ont dû arriver dans des climats moins heureux. Les causes physique sont

Voyez Introduction, paragr. 3; et Zaïre, I, I. (B.)

125 M. Daunou remarque que : «En 1453 Il ne restait à Constantinople que 1'esprit du Bas-Empire ; il y avait longtemps que l'esprit de l'ancienne Grèce avait disparu. Les Turcs n'ont guère asservi que des théologiens, des courtisans et un peuple déjà esclave. » (B.) 
dû se joindre aux causes morales ; car si l'Océan n'a pu changer entièrement son lit, du moins il est constant qu'il a couvert tour à tour et abandonné de vastes terrains. La nature a dû être exposée à un grand nombre de fléaux et de vicissitudes. Les terres les plus belles, les plus fertiles de l'Europe occidentale, toutes les campagnes basses arrosées par les fleuves ${ }^{126}$ du Rhin, de la Meuse, de la Seine, de la Loire, ont été couvertes des eaux de la mer pendant une prodigieuse multitude de siècles; c'est ce que vous avez déjà vu dans la Philosophie de l'histoire ${ }^{127}$.

Nous redirons encore qu'il n'est pas si sûr que les montagnes qui traversent l'ancien et le nouveau monde aient été autrefois des plaines couvertes par les mers, car, $1^{\circ}$ plusieurs de ces montagnes sont élevées de quinze mille pieds, et plus, au-dessus de l'Océan.

$2^{\circ}$ S'il eût été un temps où ces montagnes n'eussent pas existé, d'où seraient partis les fleuves, qui sont si nécessaires à la vie des animaux ? Ces montagnes sont les réservoirs des eaux; elles ont, dans les deux hémisphères, des directions diverses : ce sont, comme dit Platon, les os de ce grand animal appelé la Terre. Nous voyons que les moindres plantes ont une structure invariable : comment la terre serait-elle exceptée de la loi générale?

$3^{\circ} \mathrm{Si}$ les montagnes étaient supposées avoir porté des mers, ce serait une contradiction dans l'ordre de la nature, une violation des lois de la gravitation et de l'hydrostatique.

$4^{\circ}$ Le lit de l'Océan est creusé, et dans ce creux il n'est point de chaînes de montagnes d'un pôle à l'autre, ni d'orient en occident, comme sur la terre; il ne faut donc pas conclure que tout ce globe a été longtemps mer, parce que plusieurs parties du globe l'ont été. Il ne faut pas dire que l'eau a couvert les Alpes et les Cordillières, parce qu'elle a couvert la partie basse de la Gaule, de la Grèce, de la Germanie, de l'Afrique, et de l'Inde. Il ne faut pas affirmer que le mont Taurus a été navigable, parce que l'archipel des Philippines et des Moluques a été un continent. Il y a grande apparence que les hautes

126 C'est d'après l'édition de 1761 que je rétablis les onze mots qui suivent. (B.)

127 Voyez Introduction, paragraphe $\mathrm{I}^{\mathrm{er}}$. (B.) 
montagnes ont été toujours à peu près ce qu'elles sont ${ }^{128}$. Dans combien de livres n'a-t-on pas dit qu'on a trouvé une ancre de vaisseau sur la cime des montagnes de la Suisse ? cela est pourtant aussi faux que tous les contes qu'on trouve dans ces livres.

N'admettons en physique que ce qui est prouvé, et en histoire que ce qui est de la plus grande probabilité reconnue. Il se peut que les pays montagneux aient éprouvé par les volcans et par les secousses de la terre autant de changements que les pays plats; mais partout où il $\mathrm{y}$ a eu des sources de fleuves, il y a eu des montagnes. Mille révolutions locales ont certainement changé une partie du globe dans le physique et dans le moral, mais nous ne les connaissons pas; et les hommes se sont avisés si tard d'écrire l'histoire que le genre humain, tout ancien qu'il est, paraît nouveau pour nous.

D'ailleurs, vous commencez vos recherches au temps où le chaos de notre Europe commence à prendre une forme, après la chute de l'empire romain. Parcourons donc ensemble ce globe ; voyons dans quel état il était alors, en l'étudiant de la même manière qu'il paraît avoir été civilisé, c'est-à-dire depuis les pays orientaux jusqu'aux nôtres, et portons notre première attention sur un peuple qui avait une histoire suivie dans une langue déjà fixée, lorsque nous n'avions pas encore l'usage de l'écriture. 


\section{Chapitre 1}

De la Chine, de son antiquité, de ses forces, de ses lois, de ses usages et de ses sciences

L'empire de la Chine dès lors était plus vaste que celui de Charlemagne, surtout en y comprenant la Corée et le Tunquin, provinces alors tributaires des Chinois. Environ trente degrés en longitude et vingt-quatre en latitude forment son étendue. Nous avons remarqué ${ }^{129}$ que le corps de cet État subsiste avec splendeur depuis plus de quatre mille ans, sans que les lois, les mœurs, le langage, la manière même de s'habiller, aient souffert d'altération sensible.

Son histoire, incontestable dans les choses générales, la seule qui soit fondée sur des observations célestes, remonte, par la chronologie la plus sûre, jusqu'à une éclipse observée deux mille cent cinquantecinq ans avant notre ère vulgaire, et vérifiée par les mathématiciens missionnaires qui, envoyés dans les derniers siècles chez cette nation inconnue, l'ont admirée et l'ont instruite. Le P. Gaubil a examiné une suite de trente-six éclipses de soleil, rapportées dans les livres de Confutzée ; et il n'en a trouvé que deux fausses et deux douteuses. Les douteuses sont celles qui en effet sont arrivées, mais qui n'ont pu être observées du lieu où l'on suppose l'observateur; et cela même prouve qu'alors les astronomes chinois calculaient les éclipses, puisqu'ils se trompèrent dans deux calculs.

Il est vrai qu'Alexandre avait envoyé de Babylone en Grèce les observations des Chaldéens, qui remontaient un peu plus haut que les observations chinoises, et c'est sans contredit le plus beau monument de l'antiquité ; mais ces éphémérides de Babylone n'étaient point liées à l'histoire des faits : les Chinois, au contraire, ont joint l'histoire du ciel à celle de la terre, et ont ainsi justifié l'une par l'autre.

129 Introduction, paragraphe 18. (B.) 
Deux cent trente ans au delà du jour de l'éclipse dont on a parlé, leur chronologie atteint sans interruption, et par des témoignages authentiques, jusqu'à l'empereur Hiao, qui travailla lui-même à réformer l'astronomie, et qui, dans un règne d'environ quatre-vingts ans, chercha, dit-on, à rendre les hommes éclairés et heureux. Son nom est encore en vénération à la Chine, comme l'est en Europe celui des Titus, des Trajan, et des Antonins. S'il fut pour son temps un mathématicien habile, cela seul montre qu'il était né chez une nation déjà très policée. On ne voit point que les anciens chefs des bourgades germaines ou gauloises aient réformé l'astronomie: Clovis n'avait point d'observatoire.

Avant Hiao ${ }^{130}$, on trouve encore six rois, ses prédécesseurs mais la durée de leur règne est incertaine. Je crois qu'on ne peut mieux faire, dans ce silence de la chronologie, que de recourir à la règle de Newton, qui, ayant composé une année commune des années qu'ont régné les rois des différents pays, réduit chaque règne à vingt-deux ans ou environ. Suivant ce calcul, d'autant plus raisonnable qu'il est plus modéré, ces six rois auront régné à peu près cent trente ans; ce qui est bien plus conforme à l'ordre de la nature que les deux cent quarante ans qu'on donne, par exemple, aux sept rois de Rome, et que tant d'autres calculs démentis par l'expérience de tous les temps.

Le premier de ces rois, nommé Fo-hi, régnait donc plus de vingtcinq siècles avant l'ère vulgaire, au temps que les Babyloniens avaient déjà une suite d'observations astronomiques; et dès lors la Chine obéissait à un souverain. Ses quinze royaumes, réunis sous un seul homme, prouvent que longtemps auparavant cet État était très peuplé, policé, partagé en beaucoup de souverainetés : car jamais un grand État ne s'est formé que de plusieurs petits ; c'est l'ouvrage de la politique, du courage, et surtout du temps : il n'y a pas une plus grande preuve d'antiquité.

Il est rapporté dans les cinq Kings, le livre de la Chine le plus ancien et le plus autorisé, que sous l'empereur Yo, quatrième successeur de Fo-hi, on observa une conjonction de Saturne, Jupiter, Mars, Mercure, et Vénus. Nos astronomes modernes disputent entre eux sur le

${ }^{130}$ Quelle étrange conformité n’y a-t-il pas entre ce nom de Hiao et le Iao ou Jehova des Phéniciens et des Egyptiens Cependant gardons-nous de croire que ce nom de Iao ou Jehova vienne de la Chine. (V.) 
temps de cette conjonction, et ne devraient pas disputer. Mais quand même on se serait trompé à la Chine dans cette observation du ciel, il était beau même de se tromper. Les livres chinois disent expressément que de temps immémorial on savait à la Chine que Vénus et Mercure tournaient autour du soleil. Il faudrait renoncer aux plus simples lumières de la raison, pour ne pas voir que de telles connaissances supposaient une multitude de siècles antérieurs, quand même ces connaissances n'auraient été que des doutes.

Ce qui rend surtout ces premiers livres respectables, et qui leur donne une supériorité reconnue sur tous ceux qui rapportent l'origine des autres nations, c'est qu'on n'y voit aucun prodige, aucune prédiction, aucune même de ces fourberies politiques que nous attribuons aux fondateurs des autres États ; excepté peut-être ce qu'on a imputé à Fo-hi, d'avoir fait accroire qu'il avait vu ses lois écrites sur le dos d'un serpent ailé. Cette imputation même fait voir qu'on connaissait l'écriture avant Fo-hi. Enfin ce n'est pas à nous, au bout de notre Occident, à contester les archives d'une nation qui était toute policée quand nous n'étions que des sauvages.

Un tyran, nommé Chi-Hoangti, ordonna, à la vérité, qu'on brûlât tous les livres; mais cet ordre insensé et barbare avertissait de les conserver avec soin, et ils reparurent après lui. Qu'importe, après tout, que ces livres renferment ou non une chronologie toujours sûre? Je veux que nous ne sachions pas en quel temps précisément vécut Charlemagne ; dès qu'il est certain qu'il a fait de vastes conquêtes avec de grandes armées, il est clair qu'il est né chez une nation nombreuse, formée en corps de peuple par une longue suite de siècles. Puis donc que l'empereur Hiao, qui vivait incontestablement plus de deux mille quatre cents ans avant notre ère, conquit tout le pays de la Corée, il est indubitable que son peuple était de l'antiquité la plus reculée. De plus, les Chinois inventèrent un cycle, un comput, qui commence deux mille six cent deux ans avant le nôtre. Est-ce à nous à leur contester une chronologie unanimement reçue chez eux, à nous, qui avons soixante systèmes différents pour compter les temps anciens, et qui, ainsi, n'en avons pas un? 
Répétons ${ }^{131}$ que les hommes ne multiplient pas aussi aisément qu'on le pense. Le tiers des enfants est mort au bout de dix ans. Les calculateurs de la propagation de l'espèce humaine ont remarqué qu'il faut des circonstances favorables et rares pour qu'une nation s'accroisse d'un vingtième au bout de cent années; et très souvent il arrive que la peuplade diminue au lieu d'augmenter. De savants chronologistes ont supputé qu'une seule famille, après le déluge, toujours occupée à peupler, et ses enfants s'étant occupés de même, il se trouva en deux cent cinquante ans beaucoup plus d'habitants que n'en contient aujourd'hui l'univers. Il s'en faut beaucoup que le Talmud et les Mille et une Nuits contiennent rien de plus absurde. Il a déjà été dit qu'on ne fait point ainsi des enfants à coups de plume. Voyez nos colonies, voyez ces archipels immenses de l'Asie dont il ne sort personne : les Maldives, les Philippines, les Moluques, n'ont pas le nombre d'habitants nécessaire. Tout cela est encore une nouvelle preuve de la prodigieuse antiquité de la population de la Chine.

Elle était au temps de Charlemagne, comme longtemps auparavant, plus peuplée encore que vaste. Le dernier dénombrement dont nous avons connaissance, fait seulement dans les quinze provinces qui composent la Chine proprement dite, monte jusqu'à près de soixante millions d'hommes capables d'aller à la guerre ; en ne comptant ni les soldats vétérans, ni les vieillards au-dessus de soixante ans, ni la jeunesse au-dessous de vingt ans, ni les mandarins, ni la multitude des lettrés, ni les bonzes, encore moins les femmes qui sont partout en pareil nombre que les hommes, à un quinzième ou seizième près, selon les observations de ceux qui ont calculé avec plus d'exactitude ce qui concerne le genre humain. À ce compte, il paraît difficile qu'il y ait moins de cent cinquante millions d'habitants à la Chine : notre Europe n'en a pas beaucoup plus de cent millions, à compter vingt millions en France, vingt-deux en Allemagne, quatre dans la Hongrie, dix dans toute l'Italie jusqu'en Dalmatie, huit dans la Grande-Bretagne et dans l'Irlande, huit dans l'Espagne et le Portugal, dix ou douze dans la Russie européane, cinq dans la Pologne, autant dans la Turquie d'Europe, dans la Grèce et les îles, quatre dans la Suède, trois dans la Norvège et le Danemark, près de quatre dans la Hollande et les PaysBas voisins.

131 Voyez Introduction, paragraphe 24. (B.) 
On ne doit donc pas être surpris si les villes chinoises sont immenses ; si Pékin, la nouvelle capitale de l'empire, a près de six de nos grandes lieues de circonférence, et renferme environ trois millions de citoyens ; si Nankin, l'ancienne métropole, en avait autrefois davantage ; si une simple bourgade, nommée Quientzeng, où l'on fabrique la porcelaine, contient environ un million d'habitants.

Le journal de l'empire chinois, journal le plus authentique et le plus utile qu'on ait dans le monde, puisqu'il contient le détail de tous les besoins publics, des ressources et des intérêts de tous les ordres de l'État; ce journal, dis-je, rapporte que, l'an de notre ère 1725, la femme que l'empereur Yontchin déclara impératrice fit, à cette occasion, selon une ancienne coutume, des libéralités aux pauvres femmes de toute la Chine qui passaient soixante et dix ans. Le journal compte, dans la seule province de Kanton, quatre-vingt-dix-huit mille deux cent vingt-deux femmes ${ }^{132}$ de soixante et dix ans qui reçurent ces présents, quarante mille huit cent quatre-vingt-treize qui passaient quatrevingts ans, et trois mille quatre cent cinquante-trois qui approchaient de cent années. Combien de femmes ne reçurent pas ce présent! En voilà, parmi celles qui ne sont plus comptées au nombre des personnes utiles, plus de cent quarante-deux mille qui le reçurent dans une seule province. Quelle doit donc être la population de l'État! et si chacune d'elles reçut la valeur de dix livres dans toute l'étendue de l'empire, à quelles sommes dut monter cette libéralité !

Les forces de l'État consistent, selon les relations des hommes les plus intelligents qui aient jamais voyagé, dans une milice d'environ huit cent mille soldats bien entretenus. Cinq cent soixante et dix mille chevaux sont nourris, ou dans les écuries, ou dans les pâturages de l'empereur, pour monter les gens de guerre, pour les voyages de la cour, et pour les courriers publics. Plusieurs missionnaires, que l'empereur Kang-hi, dans ces derniers temps, approcha de sa personne par amour pour les sciences, rapportent qu'ils l'ont suivi dans ces chasses magnifiques vers la Grande-Tartarie, où cent mille cavaliers et soixante mille hommes de pied marchaient en ordre de bataille : c'est un usage immémorial dans ces climats.

132 Voyez les Lettres édifiantes, XIX ${ }^{\mathrm{e}}$ recueil, pages 292-293. (B.) 
Les villes chinoises n'ont jamais eu d'autres fortifications que celles que le bon sens inspirait à toutes les nations avant l'usage de l'artillerie ; un fossé, un rempart, une forte muraille, et des tours ; depuis même que les Chinois se servent de canon, ils n'ont point suivi le modèle de nos places de guerre; mais, au lieu qu'ailleurs on fortifie les places, les Chinois fortifièrent leur empire. La grande muraille qui séparait et défendait la Chine des Tartares, bâtie cent trente-sept ans avant notre ère, subsiste encore dans un contour de cinq cents lieues, s'élève sur des montagnes, descend dans des précipices, ayant presque partout vingt de nos pieds de largeur, sur plus de trente de hauteur: monument supérieur aux pyramides d'Égypte, par son utilité comme par son immensité.

Ce rempart n'a pu empêcher les Tartares de profiter, dans la suite des temps, des divisions de la Chine, et de la subjuguer ; mais la constitution de l'État n'en a été ni affaiblie ni changée. Le pays des conquérants est devenu une partie de l'État conquis; et les Tartares Mantchoux, maîtres de la Chine, n'ont fait autre chose que se soumettre, les armes à la main, aux lois du pays dont ils ont envahi le trône.

On trouve, dans le troisième livre de Confutzée, une particularité qui fait voir combien l'usage des chariots armés est ancien. De son temps, les vice-rois, ou gouverneurs de province, étaient obligés de fournir au chef de l'État, ou empereur, mille chars de guerre à quatre chevaux de front, mille quadriges. Homère, qui fleurit longtemps avant le philosophe chinois, ne parle jamais que de chars à deux ou à trois chevaux. Les Chinois avaient sans doute commencé, et étaient parvenus à se servir de quadriges; mais, ni chez les anciens Grecs, du temps de la guerre de Troie, ni chez les Chinois, on ne voit aucun usage de la simple cavalerie. Il paraît pourtant incontestable que la méthode de combattre à cheval précéda celle des chariots. Il est marqué que les Pharaons d'Égypte avaient de la cavalerie, mais ils se servaient aussi de chars de guerre : cependant il est à croire que dans un pays fangeux, comme l'Égypte, et entrecoupé de tant de canaux, le nombre de chevaux fut toujours très médiocre.

Quant aux finances, le revenu ordinaire de l'empereur se monte, selon les supputations les plus vraisemblables, à deux cents millions de taels d'argent fin. Il est à remarquer que le tael n'est pas précisément égal à notre once, et que l'once d'argent ne vaut pas cinq livres 
françaises, valeur intrinsèque, comme le dit l'histoire de la Chine, compilée par le jésuite du Halde : car il n'y a point de valeur intrinsèque numéraire ; mais deux cents millions de taels font deux cent quarante-six millions d'onces d'argent, ce qui, en mettant le marc d'argent fin à cinquante-quatre livres dix-neuf sous, revient à environ mille six cent quatre-vingt-dix millions de notre monnaie en 1768. Je dis en ce temps, car cette valeur arbitraire n'a que trop changé parmi nous, et changera peut-être encore : c'est à quoi ne prennent pas assez garde les écrivains, plus instruits des livres que des affaires, qui évaluent souvent l'argent étranger d'une manière très fautive.

Les Chinois ont eu des monnaies d'or et d'argent frappées au marteau longtemps avant que les dariques fussent fabriquées en Perse. L'empereur Kang-hi avait rassemblé une suite de trois mille de ces monnaies, parmi lesquelles il y en avait beaucoup des Indes; autre preuve de l'ancienneté des arts dans l'Asie. Mais depuis longtemps l'or n'est plus une mesure commune à la Chine, il y est marchandise comme en Hollande ; l'argent n'y est plus monnaie, le poids et le titre en font le prix ; on n'y frappe plus que du cuivre, qui seul dans ce pays a une valeur arbitraire. Le gouvernement, dans des temps difficiles, a payé en papier, comme on a fait depuis dans plus d'un État de l'Europe ; mais jamais la Chine n'a eu l'usage des banques publiques, qui augmentent les richesses d'une nation, en multipliant son crédit.

Ce pays, favorisé de la nature, possède presque tous les fruits transplantés dans notre Europe, et beaucoup d'autres qui nous manquent. Le blé, le riz, la vigne, les légumes, les arbres de toute espèce, y couvrent la terre; mais les peuples n'ont fait du vin que dans les derniers temps, satisfaits d'une liqueur assez forte qu'ils savent tirer du riz.

L'insecte précieux qui produit la soie est originaire de la Chine; c'est de là qu'il passa en Perse assez tard, avec l'art de faire des étoffes du duvet qui le couvre ; et ces étoffes étaient si rares, du temps même de Justinien, que la soie se vendait en Europe au poids de l'or.

Le papier fin et d'un blanc éclatant était fabriqué chez les Chinois de temps immémorial ; on en faisait avec des filets de bois de bambou bouilli. On ne connaît pas la première époque de la porcelaine, et de ce beau vernis qu'on commence à imiter et à égaler en Europe. 
Ils savent, depuis deux mille ans, fabriquer le verre, mais moins beau et moins transparent que le nôtre.

L'imprimerie fut inventée par eux dans le même temps. On sait que cette imprimerie est une gravure sur des planches de bois, telle que Guttenberg la pratiqua le premier à Mayence, au quinzième siècle. L'art de graver les caractères sur le bois est plus perfectionné à la Chine ; notre méthode d'employer les caractères mobiles et de fonte, beaucoup supérieure à la leur, n'a point encore été adoptée par eux ${ }^{133}$, parce qu'il aurait fallu recevoir l'alphabet et qu'ils n'ont jamais voulu quitter l'écriture symbolique : tant ils sont attachés à toutes leurs anciennes méthodes.

L'usage des cloches est chez eux de la plus haute antiquité. Nous n'en avons eu en France qu'au sixième siècle de notre ère. Ils ont cultivé la chimie ; et, sans devenir jamais bons physiciens, ils ont inventé la poudre; mais ils ne s'en servaient que dans des fêtes, dans l'art des feux d'artifice, où ils ont surpassé les autres nations. Ce furent les Portugais qui, dans ces derniers siècles, leur ont enseigné l'usage de l'artillerie, et ce sont les jésuites qui leur ont appris à fondre le canon. Si les Chinois ne s'appliquèrent pas à inventer ces instruments destructeurs, il ne faut pas en louer leur vertu, puisqu'ils n'en ont pas moins fait la guerre.

Ils ne poussèrent loin l'astronomie qu'en tant qu'elle est la science des yeux et le fruit de la patience. Ils observèrent le ciel assidûment, remarquèrent tous les phénomènes, et les transmirent à la postérité. Ils divisèrent, comme nous, le cours du soleil en trois cent soixante-cinq parties et un quart. Ils connurent, mais confusément, la précession des équinoxes et des solstices. Ce qui mérite peut-être le plus d'attention, c'est que, de temps immémorial, ils partagent le mois en semaines de sept jours. Les Indiens en usaient ainsi ; la Chaldée se conforma à cette méthode, qui passa dans le petit pays de la Judée ; mais elle ne fut point adoptée en Grèce.

On montre encore les instruments dont se servit un de leurs fameux astronomes, mille ans avant notre ère vulgaire, dans une ville qui n'est que du troisième ordre. Nankin, l'ancienne capitale, conserve un globe

133 Il paraît qu'elle ne l'est pas encore. (B.) 
de bronze que trois hommes ne peuvent embrasser, porté sur un cube de cuivre qui s'ouvre, et dans lequel on fait entrer un homme pour tourner ce globe, sur lequel sont tracés les méridiens et les parallèles.

Pékin a un observatoire rempli d'astrolabes et de sphères armillaires ; instruments, à la vérité, inférieurs aux nôtres pour l'exactitude, mais témoignages célèbres de la supériorité des Chinois sur les autres peuples d'Asie.

La boussole, qu'ils connaissaient, ne servait pas à son véritable usage de guider la route des vaisseaux. Ils ne naviguaient que près des côtes. Possesseurs d'une terre qui fournit tout, ils n'avaient pas besoin d'aller, comme nous, au bout du monde. La boussole, ainsi que la poudre à tirer, était pour eux une simple curiosité, et ils n'en étaient pas plus à plaindre.

On est étonné que ce peuple inventeur n'ait jamais percé dans la géométrie au delà des éléments. Il est certain que les Chinois connaissaient ces éléments plusieurs siècles avant qu'Euclide les eût rédigés chez les Grecs d'Alexandrie. L'empereur Kang-hi assura de nos jours au P. Parennin, l'un des plus savants et des plus sages missionnaires qui aient approché de ce prince, que l'empereur Yu s'était servi des propriétés du triangle rectangle pour lever un plan géographique d'une province, il y a plus de trois mille neuf cent soixante années; et le P. Parennin lui-même cite un livre, écrit onze cents ans avant notre ère, dans lequel il est dit que la fameuse démonstration attribuée en Occident à Pythagore était depuis longtemps au rang des théorèmes les plus connus.

On demande pourquoi les Chinois, ayant été si loin dans des temps si reculés, sont toujours restés à ce terme; pourquoi l'astronomie est chez eux si ancienne et si bornée ; pourquoi dans la musique ils ignorent encore les demi-tons. Il semble que la nature ait donné à cette espèce d'hommes, si différente de la nôtre, des organes faits pour trouver tout d'un coup tout ce qui leur était nécessaire, et incapables d'aller au-delà. Nous, au contraire, nous avons en des connaissances très tard, et nous avons tout perfectionné rapidement. Ce qui est moins étonnant, c'est la crédulité avec laquelle ces peuples ont toujours joint leurs erreurs de l'astrologie judiciaire aux vraies connaissances célestes. Cette superstition a été celle de tous les hommes; et il n'y a pas 
longtemps que nous en sommes guéris : tant l'erreur semble faite pour le genre humain.

Si on cherche pourquoi tant d'arts et de sciences, cultivés sans interruption depuis si longtemps à la Chine, ont cependant fait si peu de progrès, il y en a peut-être deux raisons : l'une est le respect prodigieux que ces peuples ont pour ce qui leur a été transmis par leurs pères, et qui rend parfait à leurs yeux tout ce qui est ancien; 1'autre est la nature de leur langue, le premier principe de toutes les connaissances.

L'art de faire connaître ses idées par l'écriture, qui devait n'être qu'une méthode très simple, est chez eux ce qu'ils ont de plus difficile. Chaque mot a des caractères différents : un savant, à la Chine, est celui qui connaît le plus de ces caractères; quelques-uns sont arrivés à la vieillesse avant que de savoir bien écrire.

Ce qu'ils ont le plus connu, le plus cultivé, le plus perfectionné, c'est la morale et les lois. Le respect des enfants pour leurs pères est le fondement du gouvernement chinois. L'autorité paternelle n'y est jamais affaiblie. Un fils ne peut plaider contre son père qu'avec le consentement de tous les parents, des amis, et des magistrats. Les mandarins lettrés y sont regardés comme les pères des villes et des provinces, et le roi, comme le père de l'empire. Cette idée, enracinée dans les cœurs, forme une famille de cet État immense.

La loi fondamentale étant donc que l'empire est une famille, on y a regardé, plus qu'ailleurs, le bien public comme le premier devoir. De là vient l'attention continuelle de l'empereur et des tribunaux à réparer les grands chemins, à joindre les rivières, à creuser des canaux, à favoriser la culture des terres et les manufactures.

Nous traiterons dans un autre chapitre du gouvernement de la Chine ; mais vous remarquerez d'avance que les voyageurs, et surtout les missionnaires, ont cru voir partout le despotisme. On juge de tout par l'extérieur : on voit des hommes qui se prosternent, et dès lors on les prend pour des esclaves. Celui devant qui l'on se prosterne doit être maître absolu de la vie et de la fortune de cent cinquante millions d'hommes ; sa seule volonté doit servir de loi. Il n'en est pourtant pas ainsi, et c'est ce que nous discuterons. Il suffit de dire ici que, dans les plus anciens temps de la monarchie, il fut permis d'écrire sur une lon- 
gue table, placée dans le palais, ce qu'on trouvait de répréhensible dans le gouvernement; que cet usage fut mis en vigueur sous le règne de Venti, deux siècles avant notre ère vulgaire; et que, dans les temps paisibles, les représentations des tribunaux ont toujours eu force de loi. Cette observation importante détruit les imputations vagues qu'on trouve dans l'Esprit des lois ${ }^{134}$ contre ce gouvernement, le plus ancien qui soit au monde.

Tous les vices existent à la Chine comme ailleurs, mais certainement plus réprimés par le frein des lois, parce que les lois sont toujours uniformes. Le savant auteur des Mémoires de l'amiral Anson témoigne du mépris et de l'aigreur contre les Chinois, sur ce que le petit peuple de Kanton trompa les Anglais autant qu'il le put; mais doit-on juger du gouvernement d'une grande nation par les mœurs de la populace des frontières? Et qu'auraient dit de nous les Chinois, s'ils eussent fait naufrage sur nos côtes maritimes dans les temps où les lois des nations d'Europe confisquaient les effets naufragés, et que la coutume permettait qu'on égorgeât les propriétaires ?

Les cérémonies continuelles qui, chez les Chinois, gênent la société, et dont l'amitié seule se défait dans l'intérieur des maisons, ont établi dans toute la nation une retenue et une honnêteté qui donnent à la fois aux mœurs de la gravité et de la douceur. Ces qualités s'étendent jusqu'aux derniers du peuple. Des missionnaires racontent que souvent, dans les marchés publics, au milieu de ces embarras et de ces confusions qui excitent dans nos contrées des clameurs si barbares et des emportements si fréquents et si odieux, ils ont vu les paysans se mettre à genoux les uns devant les autres, selon la coutume du pays, se demander pardon de l'embarras dont chacun s'accusait, s'aider l'un l'autre, et débarrasser tout avec tranquillité.

Dans les autres pays les lois punissent le crime ; à la Chine elles font plus, elles récompensent la vertu. Le bruit d'une action généreuse et rare se répand-il dans une province, le mandarin est obligé d'en avertir l'empereur; et l'empereur envoie une marque d'honneur à celui qui l'a si bien méritée. Dans nos derniers temps, un pauvre paysan, nommé Chicou, trouve une bourse remplie d'or qu'un voyageur a perdue; il se transporte jusqu'à la province de ce voyageur, et remet

134 Livre VIII, chapitre XXI. (B.) 
la bourse au magistrat du canton, sans vouloir rien pour ses peines. Le magistrat, sous peine d'être cassé, était obligé d'en avertir le tribunal suprême de Pékin; ce tribunal, obligé d'en avertir l'empereur; et le pauvre paysan fut créé mandarin du cinquième ordre : car il y a des places de mandarins pour les paysans qui se distinguent dans la morale, comme pour ceux qui réussissent le mieux dans l'agriculture. Il faut avouer que, parmi nous, on n'aurait distingué ce paysan qu'en le mettant à une taille plus forte, parce qu'on aurait jugé qu'il était à son aise. Cette morale, cette obéissance aux lois, jointes à l'adoration d'un Etre suprême, forment la religion de la Chine, celle des empereurs et des lettrés. L'empereur est, de temps immémorial, le premier pontife : c'est lui qui sacrifie au Tien, au souverain du ciel et de la terre. Il doit être le premier philosophe, le premier prédicateur de l'empire ses édits sont presque toujours des instructions et des leçons de morale. 


\section{Chapitre 2}

De la religion de la Chine. Que le gouvernement n'est point athée ; que le christianisme n'y a point été prêché au VII siècle. De quelques sectes établies dans le pays

Dans le siècle passé, nous ne connaissions pas assez la Chine. Vossius l'admirait en tout avec exagération. Renaudot, son rival, et l'ennemi des gens de lettres, poussait la contradiction jusqu'à feindre de mépriser les Chinois, et jusqu'à les calomnier : tâchons d'éviter ces excès.

Confutzée, que nous appelons Confucius ${ }^{135}$, qui vivait il y a deux mille trois cents ans, un peu avant Pythagore, rétablit cette religion, laquelle consiste à être juste. Il l'enseigna, et la pratiqua dans la grandeur et dans l'abaissement : tantôt premier ministre d'un roi tributaire de l'empereur, tantôt exilé, fugitif, et pauvre. Il eut, de son vivant, cinq mille disciples; et après sa mort ses disciples furent les empereurs, les colao, c'est-à-dire les mandarins, les lettrés, et tout ce qui n'est pas peuple. Il commence par dire dans son livre que quiconque est destiné à gouverner « doit rectifier la raison qu'il a reçue du ciel, comme on essuie un miroir terni ; qu'il doit aussi se renouveler soimême, pour renouveler le peuple par son exemple ». Tout tend à ce but; il n'est point prophète, il ne se dit point inspiré ; il ne connaît d'inspiration que l'attention continuelle à réprimer ses passions; il n'écrit qu'en sage : aussi n'est-il regardé par les Chinois que comme un sage. Sa morale est aussi pure, aussi sévère, et en même temps aussi humaine que celle d'Épictète. Il ne dit point, Ne fais pas aux autres ce que tu ne voudrais pas qu'on te fit ; mais : «Fais aux autres ce que tu veux qu'on te fasse. » Il recommande le pardon des injures, le souvenir des bienfaits, l'amitié, l'humilité. Ses disciples étaient un peuple

135 Voyez le Dictionnaire philosophique, article CHINE. (B.) 
de frères. Le temps le plus heureux et le plus respectable qui fut jamais sur la terre fut celui où l'on suivit ses lois.

Sa famille subsiste encore : et dans un pays où il n'y a d'autre noblesse que celle des services actuels, elle est distinguée des autres familles, en mémoire de son fondateur. Pour lui, il a tous les honneurs, non pas les honneurs divins, qu'on ne doit à aucun homme, mais ceux que mérite un homme qui a donné de la Divinité les idées les plus saines que puisse former l'esprit humain. C'est pourquoi le P. Le Comte et d'autres missionnaires ont écrit «que les Chinois ont connu le vrai Dieu, quand les autres peuples étaient idolâtres, et qu'ils lui ont sacrifié dans le plus ancien temple de l'univers ».

Les reproches d'athéisme, dont on charge si libéralement dans notre Occident quiconque ne pense pas comme nous, ont été prodigués aux Chinois. Il faut être aussi inconsidérés que nous le sommes dans toutes nos disputes pour avoir osé traiter d'athée un gouvernement dont presque tous les édits parlent ${ }^{136}$ " d'un être suprême, père des peuples, récompensant et punissant avec justice, qui a mis entre l'homme et lui une correspondance de prières et de bienfaits, de fautes et de châtiments ».

Le parti opposé aux jésuites a toujours prétendu que le gouvernement de la Chine était athée, parce que les jésuites en étaient favorisés : mais il faut que cette rage de parti se taise devant le testament de l'empereur Kang-hi. Le voici :

« Je suis âgé de soixante et dix ans; j'en ai régné soixante et un; je dois cette faveur à la protection du ciel, de la terre, de mes ancêtres, et au dieu de toutes les récoltes de l'empire: je ne puis l'attribuer à ma faible vertu. »

Il est vrai que leur religion n'admet point de peines et de récompenses éternelles; et c'est ce qui fait voir combien cette religion est ancienne. Le Pentateuque ne parle point de l'autre vie dans ses lois : les saducéens, chez les Juifs, ne la crurent jamais.

136 Voyez l'édit de l'empereur Yontchin, rapporté dans les Mémoires de la Chine, rédigés par le jésuite du Halde. Voyez aussi le poème de l'empereur Kienlong. (V.) 
On a cru que les lettrés chinois n'avaient pas une idée distincte d'un Dieu immatériel; mais il est injuste d'inférer de là qu'ils sont athées. Les anciens Égyptiens, ces peuples si religieux, n'adoraient pas Isis et Osiris comme de purs esprits. Tous les dieux de l'antiquité étaient adorés sous une forme humaine ; et ce qui montre bien à quel point les hommes sont injustes, c'est que chez les Grecs on flétrissait du nom d'athées ceux qui n'admettaient pas ces dieux corporels, et qui adoraient dans la Divinité une nature inconnue, invisible, inaccessible à nos sens.

Le fameux archevêque Navarrète dit que, selon tous les interprètes des livres sacrés de la Chine, "l'âme est une partie aérée, ignée, qui, en se séparant du corps, se réunit à la substance du ciel ». Ce sentiment se trouve le même que celui des stoïciens. C'est ce que Virgile développe admirablement dans son sixième livre de l'Énéide. Or, certainement, ni le Manuel d'Épictète ni l'Énéide ne sont infectés de l'athéisme : tous les premiers pères de l'Église ont pensé ainsi. Nous avons calomnié les Chinois, uniquement parce que leur métaphysique n'est pas la nôtre; nous aurions dû admirer en eux deux mérites qui condamnent à la fois les superstitions des païens et les mœurs des chrétiens. Jamais la religion des lettrés ne fut déshonorée par des fables, ni souillée par des querelles et des guerres civiles.

En imputant l'athéisme au gouvernement de ce vaste empire, nous avons eu la légèreté de lui attribuer l'idolâtrie par une accusation qui se contredit ainsi elle-même. Le grand malentendu sur les rites de la Chine est venu de ce que nous avons jugé de leurs usages par les nôtres : car nous portons au bout du monde les préjugés de notre esprit contentieux. Une génuflexion, qui n'est chez eux qu'une révérence ordinaire, nous a paru un acte d'adoration; nous avons pris une table pour un autel : c'est ainsi que nous jugeons de tout. Nous verrons, en son temps, comment nos divisions et nos disputes ont fait chasser de la Chine nos missionnaires.

Quelque temps avant Confucius, Laokium avait introduit une secte qui croit aux esprits malins, aux enchantements, aux prestiges. Une secte semblable à celle d'Épicure fut reçue et combattue à la Chine, cinq cents ans avant Jésus-Christ ; mais, dans le premier siècle de notre ère, ce pays fut inondé de la superstition des bonzes. Ils apportèrent des Indes l'idole de Fo ou Foé, adoré sous différents noms par les 
Japonais et les Tartares, prétendu dieu descendu sur la terre, à qui on rend le culte le plus ridicule, et par conséquent le plus fait pour le vulgaire. Cette religion, née dans les Indes près de mille ans avant JésusChrist, a infecté l'Asie orientale ; c'est ce dieu que prêchent les bonzes à la Chine, les talapoins à Siam, les lamas en Tartarie. C'est en son nom qu'ils promettent une vie éternelle, et que des milliers de bonzes consacrent leurs jours à des exercices de pénitence qui effrayent la nature. Quelques-uns passent leur vie enchaînés, d'autres portent un carcan de fer qui plie leur corps en deux, et tient leur front toujours baissé à terre. Leur fanatisme se subdivise à l'infini. Ils passent pour chasser des démons, pour opérer des miracles; ils vendent au peuple la rémission des péchés. Cette secte séduit quelquefois des mandarins ; et, par une fatalité qui montre que la même superstition est de tous les pays, quelques mandarins se sont fait tondre en bonzes par piété.

Ce sont eux qui, dans la Tartarie, ont à leur tête le dalaï-lama, idole vivante qu'on adore, et c'est là peut-être le triomphe de la superstition humaine.

Ce dalaï-lama, successeur et vicaire du dieu Fo, passe pour immortel. Les prêtres nourrissent toujours un jeune lama, désigné successeur secret du souverain pontife, qui prend sa place dès que celui-ci, qu'on croit immortel, est mort. Les princes tartares ne lui parlent qu'à genoux ; il décide souverainement tous les points de foi sur lesquels les lamas sont divisés; enfin il s'est depuis quelque temps fait souverain du Thibet, à l'occident de la Chine. L'empereur reçoit ses ambassadeurs, et lui envoie des présents considérables.

Ces sectes sont tolérées à la Chine pour l'usage du vulgaire, comme des aliments grossiers faits pour le nourrir ; tandis que les magistrats et les lettrés, séparés en tout du peuple, se nourrissent d'une substance plus pure ; il semble en effet que la populace ne mérite pas une religion raisonnable. Confucius gémissait pourtant de cette foule d'erreurs : il y avait beaucoup d'idolâtres de son temps. La secte de Laokium avait déjà introduit les superstitions chez le peuple. "Pourquoi, dit-il dans un de ses livres, y a-t-il plus de crimes chez la populace ignorante que parmi les lettrés ? c'est que le peuple est gouverné par les bonzes. » 
Beaucoup de lettrés sont, à la vérité, tombés dans le matérialisme ; mais leur morale n'en a point été altérée. Ils pensent que la vertu est si nécessaire aux hommes et si aimable par elle-même, qu'on n'a pas même besoin de la connaissance d'un Dieu pour la suivre. D'ailleurs il ne faut pas croire que tous les matérialistes chinois soient athées, puisque tant de pères de l'Église croyaient Dieu et les anges corporels.

Nous ne savons point au fond ce que c'est que la matière; encore moins connaissons-nous ce qui est immatériel. Les Chinois n'en savent pas sur cela plus que nous : il a suffi aux lettrés d'adorer un Être suprême, on n'en peut douter.

Croire Dieu et les esprits corporels est une ancienne erreur métaphysique ; mais ne croire absolument aucun dieu, ce serait une erreur affreuse en morale, une erreur incompatible avec un gouvernement sage. C'est une contradiction digne de nous de s'élever avec fureur, comme on a fait, contre Bayle, sur ce qu'il croit possible qu'une société d'athées subsiste ; et de crier, avec la même violence, que le plus sage empire de l'univers est fondé sur l'athéisme.

Le P. Fouquet, jésuite, qui avait passé vingt-cinq ans à la Chine, et qui en revint ennemi des jésuites, m'a dit plusieurs fois qu'il y avait à la Chine très peu de philosophes athées. Il en est de même parmi nous.

On prétend que, vers le huitième siècle, avant Charlemagne, la religion chrétienne était connue à la Chine. On assure que nos missionnaires ont trouvé dans la province de Kingt-ching ou Quen-sin une inscription en caractères syriaques et chinois. Ce monument, qu'on voit tout au long dans Kircher, atteste qu'un saint homme, nommé Olopuën ${ }^{137}$, conduit par des nuées bleues, et observant la règle des vents, vint de Tacin à la Chine, l'an 1092 de l'ère des Séleucides, qui répond à l'an 636 de notre ère ; qu'aussitôt qu'il fut arrivé au faubourg de la ville impériale, l'empereur envoya un colao au-devant de lui, et lui fit bâtir une église chrétienne.

Il est évident, par l'inscription même, que c'est une de ces fraudes pieuses qu'on s'est toujours trop aisément permises. Le sage Navarrè-

137 Voltaire reparle d'Olopuën dans la quatrième de ses Lettres chinoises, etc. (Voyez Mélanges, année 1776.) Une critique de l'opinion de Voltaire sur Olopuën se lit dans le Journal des savants, octobre 1821. (B.) 
te en convient. Ce pays de Tacin, cette ère des Séleucides, ce nom d'Olopuën, qui est, dit-on, chinois, et qui ressemble à un ancien nom espagnol, ces nuées bleues qui servent de guides, cette église chrétienne bâtie tout d'un coup à Pékin pour un prêtre de Palestine, qui ne pouvait mettre le pied à la Chine sans encourir la peine de mort, tout cela fait voir le ridicule de la supposition. Ceux qui s'efforcent de la soutenir ne font pas réflexion que les prêtres dont on trouve les noms dans ce prétendu monument étaient des nestoriens, et qu'ainsi ils ne combattent que pour des hérétiques ${ }^{138}$.

Il faut mettre cette inscription avec celle de Malabar, où il est dit que saint Thomas arriva dans le pays en qualité de charpentier, avec une règle et un pieu, et qu'il porta seul une grosse poutre pour preuve de sa mission. Il y a assez de vérités historiques, sans y mêler ces absurdes mensonges.

Il est très vrai qu'au temps de Charlemagne, la religion chrétienne, ainsi que les peuples qui la professent, avait toujours été absolument inconnue à la Chine. Il y avait des Juifs : plusieurs familles de cette nation, non moins errante que superstitieuse, s'y étaient établies deux siècles avant notre ère vulgaire ; elles y exerçaient le métier de courtier, que les Juifs ont fait dans presque tout le monde.

Je me réserve à jeter les yeux sur Siam, sur le Japon ${ }^{139}$, et sur tout ce qui est situé vers l'orient et le midi, lorsque je serai parvenu au temps où l'industrie des Européans s'est ouvert un chemin facile à ces extrémités de notre hémisphère.

${ }^{138}$ Voyez le Dictionnaire philosophique, au mot CHINE. (V.)

${ }^{139}$ Chap. 142 et 143. (B.) 


\section{Chapitre 3}

\section{Des Indes}

En suivant le cours apparent du soleil, je trouve d'abord l'Inde, ou l'Indoustan, contrée aussi vaste que la Chine, et plus connue par les denrées précieuses que l'industrie des négociants en a tirées dans tous les temps que par des relations exactes. Ce pays est l'unique dans le monde qui produise ces épiceries dont la sobriété de ses habitants peut se passer, et qui sont nécessaires à la voracité des peuples septentrionaux.

Une chaîne de montagnes, peu interrompue, semble avoir fixé les limites de l'Inde, entre la Chine, la Tartarie, et la Perse ; le reste est entouré de mers. L'Inde, en deçà du Gange, fut longtemps soumise aux Persans; et voilà pourquoi Alexandre, vengeur de la Grèce et vainqueur de Darius, poussa ses conquêtes jusqu'aux Indes, tributaires de son ennemi. Depuis Alexandre, les Indiens avaient vécu dans la liberté et dans la mollesse qu'inspirent la chaleur du climat et la richesse de la terre.

Les Grecs y voyageaient avant Alexandre, pour y chercher la science. C'est là que le célèbre Pilpay écrivit, il y a deux mille trois cents années, ses Fables morales, traduites dans presque toutes les langues du monde. Tout a été traité en fables et en allégories chez les Orientaux, et particulièrement chez les Indiens. Pythagore, disciple des gymnosophistes, serait lui seul une preuve incontestable que les véritables sciences étaient cultivées dans l'Inde. Un législateur en politique et en géométrie n'eût pas resté longtemps dans une école où l'on n'aurait enseigné que des mots. Il est très vraisemblable même que Pythagore apprit chez les Indiens les propriétés du triangle rectangle, dont on lui fait honneur. Ce qui était si connu à la Chine pouvait aisément l'être dans l'Inde. On a écrit longtemps après lui qu'il avait immolé cent bœufs pour cette découverte : cette dépense est un 
peu forte pour un philosophe. Il est digne d'un sage de remercier d'une pensée heureuse l'Être dont nous vient toute pensée, ainsi que le mouvement et la vie ; mais il est bien plus vraisemblable que Pythagore dut ce théorème aux gymnosophistes qu'il ne l'est qu'il ait immolé cent bœufs ${ }^{140}$.

Longtemps avant Pilpay, les sages de l'Inde avaient traité la morale et la philosophie en fables allégoriques, en paraboles. Voulaient-ils exprimer l'équité d'un de leurs rois, ils disaient que "les dieux qui président aux divers éléments, et qui sont en discorde entre eux, avaient pris ce roi pour leur arbitre ». Leurs anciennes traditions rapportent un jugement qui est à peu près le même que celui de Salomon. Ils ont une fable qui est précisément la même que celle de Jupiter et d'Amphitryon; mais elle est plus ingénieuse. Un sage découvre qui des deux est le dieu, et qui est l'homme ${ }^{141}$. Ces traditions montrent combien sont anciennes les paraboles qui font enfants des dieux les hommes extraordinaires. Les Grecs, dans leur mythologie, n'ont été que des disciples de l'Inde et de l'Égypte. Toutes ces fables enveloppaient autrefois un sens philosophique ; ce sens a disparu, et les fables sont restées.

140 On ne peut former que des conjectures incertaines sur ce que les Grecs ont dû de connaissances astronomiques ou géométriques, soit aux Orientaux, soit aux Égyptiens. Non seulement nous n'avons point les écrits de Pythagore ou de Thalès ; mais les ouvrages mathématiques de Platon, ceux même de ses premiers disciples ne sont point venus jusqu'à nous. Euclide, le plus ancien auteur de ce genre dont nous ayons les écrits, est postérieur d'environ trois siècles au temps où les philosophes grecs allaient étudier les sciences hors de leur pays. Ce n'était plus alors l'Égypte qui instruisait la Grèce, mais la Grèce qui fondait une école grecque dans la nouvelle capitale de l'Égypte. Observons qu'il ne s'était passé qu'environ trois siècles entre le temps de Pythagore, qui découvrit la propriété si célèbre du triangle rectangle, et Archimède. Les Grecs, dans cet intervalle, avaient fait en géométrie des progrès prodigieux ; tandis que les Indiens et les Chinois en sont encore où ils en étaient il y a deux mille ans.

Ainsi, dès qu'il s'agit de découvertes, pour peu qu'il y ait de dispute, la vraisemblance paraît devoir toujours être en faveur des Grecs.

On leur reproche leur vanité nationale, et avec raison; mais ils étaient si supérieurs à leurs voisins, ils ont été même si supérieurs à tous les autres hommes, si l'on en excepte les Européans des deux derniers siècles, que jamais la vanité nationale n'a été plus pardonnable. (K.)

141 Voyez le Dictionnaire philosophique, au mot ANGE, et surtout la Lettre à M. du $\mathrm{M}^{* * *}$, membre de plusieurs académies, sur plusieurs anecdotes, dans les Mélanges (année 1776). (K.) 
L'antiquité des arts dans l'Inde a toujours été reconnue de tous les autres peuples. Nous avons encore une relation de deux voyageurs arabes, qui allèrent aux Indes et à la Chine un peu après le règne de Charlemagne, et quatre cents ans avant le célèbre Marco-Polo. Ces Arabes prétendent avoir parlé à l'empereur de la Chine qui régnait alors ; ils rapportent que l'empereur leur dit qu'il ne comptait que cinq grands rois dans le monde, et qu'il mettait de ce nombre « le roi des éléphants et des Indiens, qu'on appelle le roi de la sagesse, parce que la sagesse vient originairement des Indes ».

J'avoue que ces deux Arabes ont rempli leurs récits de fables, comme tous les écrivains orientaux; mais enfin il résulte que les Indiens passaient pour les premiers inventeurs des arts dans tout l'Orient, soit que l'empereur chinois ait fait cet aveu aux deux Arabes, soit qu'ils aient parlé d'eux-mêmes.

Il est indubitable que les plus anciennes théologies furent inventées chez les Indiens. Ils ont deux livres écrits, il y a environ cinq mille ans, dans leur ancienne langue sacrée, nommée le Hanscrit, ou le Sanscrit. De ces deux livres, le premier est le Shasta, et le second, le Veidam. Voici le commencement du Shasta :

« L’Éternel, absorbé dans la contemplation de son existence, résolut, dans la plénitude des temps, de former des êtres participants de son essence et de sa béatitude. Ces êtres n'étaient pas : il voulut, et ils furent ${ }^{142}$. »

On voit assez que cet exorde, véritablement sublime, et qui fut longtemps inconnu aux autres nations, n'a jamais été que faiblement imité par elles.

Ces êtres nouveaux furent les demi-dieux, les esprits célestes, adoptés ensuite par les Chaldéens, et chez les Grecs par Platon. Les Juifs les admirent, quand ils furent captifs à Babylone ; ce fut là qu'ils apprirent les noms que les Chaldéens avaient donnés aux anges, et ces noms n'étaient pas ceux des Indiens. Michaël, Gabriel, Raphaël, Israël

${ }^{142}$ Voyez le Dictionnaire philosophique, aux mots AdAM, AlCORAn, Ange, ÉzOUR-VEIDAM ; et la neuvième des Lettres chinoises, dans les Mélanges (année1776). (K.) 
même, sont des mots chaldéens qui ne furent jamais connus dans l'Inde.

C'est dans le Shasta qu'on trouve l'histoire de la chute de ces anges. Voici comme le Shasta s'exprime :

« Depuis la création des Debtalog (c'est-à-dire des anges), la joie et l'harmonie environnèrent longtemps le trône de l'Éternel. Ce bonheur aurait duré jusqu'à la fin des temps ; mais l'envie entra dans le cœur de Moisaor et des anges ses suivants. Ils rejetèrent le pouvoir de perfectibilité dont l'Éternel les avait doués dans sa bonté : ils exercèrent le pouvoir d'imperfection; ils firent le mal à la vue de l'Éternel. Les anges fidèles furent saisis de tristesse. La douleur fut connue pour la première fois. »

Ensuite la rébellion des mauvais anges est décrite. Les trois ministres de Dieu, qui sont peut-être l'original de la Trinité de Platon, précipitent les mauvais anges dans l'abîme. À la fin des temps, Dieu leur fait grâce, et les envoie animer les corps des hommes.

Il n'y a rien dans l'antiquité de si majestueux et de si philosophique. Ces mystères des brachmanes percèrent enfin jusque dans la Syrie : il fallait qu'ils fussent bien connus, puisque les Juifs en entendirent parler du temps d'Hérode. Ce fut peut-être alors qu'on forgea, suivant ces principes indiens, le faux livre d'Hénoch, cité par l'apôtre Jude, dans lequel il est dit quelque chose de la chute des anges. Cette doctrine devint depuis le fondement de la religion chrétienne ${ }^{143}$.

Les esprits ont dégénéré dans l'Inde. Probablement le gouvernement tartare les a hébétés, comme le gouvernement turc a déprimé les

143 Le serpent dont il est parlé dans la Genèse devint le principal mauvais ange. On lui donna tantôt le nom de Satan, qui est un mot persan, tantôt celui de Lucifer, étoile du matin, parce que la Vulgate traduisit le mot Hélel par celui de Lucifer (voy. Introduction, paragraphe XLVIII). Isaïe, insultant à la mort d'un roi de Babylone, lui dit par une figure de rhétorique : Comment es-tu, tombée du ciel, étoile du matin, Lucifer ? On a pris ce nom pour celui du diable, et on a appliqué ce passage à la chute des anges. C'est encore le fondement du poème de Milton. Mais Milton est bien moins raisonnable que le Shasta Indien. Le Shasta ne pousse point l'extravagance jusqu'à faire déclarer la guerre à Dieu par les anges ses créatures, et à rendre quelque temps la victoire indécise. Cet excès était réservé à Milton.

$N$. B. Tout ce morceau est tiré principalement de M. Howel, qui a demeuré trente ans avec les brames, et qui entend très bien leur langue sacrée. (V.) 
Grecs, et abruti les Égyptiens. Les sciences ont presque péri de même chez les Perses, par les révolutions de l'État. Nous avons vu ${ }^{144}$ qu'elles se sont fixées à la Chine, au même point de médiocrité où elles ont été chez nous au moyen âge, par la même cause qui agissait sur nous, c'est-à-dire par un respect superstitieux pour l'antiquité, et par les règlements mêmes des écoles. Ainsi, dans tous pays, l'esprit humain trouve des obstacles à ses progrès.

Cependant, jusqu'au treizième siècle de notre ère, l'esprit vraiment philosophique ne périt pas absolument dans l'Inde. Pachimère, dans ce treizième siècle, traduisit quelques écrits d'un brame, son contemporain. Voici comme ce brame indien s'explique : le passage mérite attention.

« J'ai vu toutes les sectes s'accuser réciproquement d'imposture ; j'ai vu tous les mages disputer avec fureur du premier principe, et de la dernière fin. Je les ai tous interrogés, et je n'ai vu, dans tous ces chefs de factions, qu'une opiniâtreté inflexible, un mépris superbe pour les autres, une haine implacable. J'ai donc résolu de n'en croire aucun. Ces docteurs, en cherchant la vérité, sont comme une femme qui veut faire entrer son amant par une porte dérobée, et qui ne peut trouver la clef de la porte. Les hommes, dans leurs vaines recherches, ressemblent à celui qui monte sur un arbre où il $\mathrm{y}$ a un peu de miel; et à peine en a-t-il mangé que les serpents qui sont autour de l'arbre le dévorent. »

Telle fut la manière d'écrire des Indiens. Leur esprit paraît encore davantage dans les jeux de leur invention. Le jeu que nous appelons des échecs, par corruption, fut inventé par eux, et nous n'avons rien qui en approche : il est allégorique comme leurs fables; c'est l'image de la guerre. Les noms de shak, qui veut dire prince, et de pion, qui signifie soldat, se sont conservés encore dans cette partie de l'Orient. Les chiffres dont nous nous servons, et que les Arabes ont apportés en Europe vers le temps de Charlemagne, nous viennent de l'Inde. Les anciennes médailles, dont les curieux chinois font tant de cas, sont une preuve que plusieurs arts furent cultivés aux Indes avant d'être connus des Chinois.

144 Chapitre I ${ }^{\mathrm{er}}$. (B.) 
On y a, de temps immémorial, divisé la route annuelle du soleil en douze parties, et, dans des temps vraisemblablement encore plus reculés, la route de la lune en vingt-huit parties. L'année des brachmanes et des plus anciens gymnosophistes commença toujours quand le soleil entrait dans la constellation qu'ils nomment Moscham, et qui est pour nous le Bélier. Leurs semaines furent toujours de sept jours, divisions que les Grecs ne connurent jamais. Leurs jours portent les noms des sept planètes. Le jour du soleil est appelé chez eux Mithradinan : reste à savoir si ce mot mithra, qui, chez les Perses, signifie aussi le soleil, est originairement un terme de la langue des mages, ou de celle des sages de l'Inde.

Il est bien difficile de dire laquelle des deux nations enseigna l'autre; mais s'il s'agissait de décider entre les Indes et l'Égypte, je croirais toujours les sciences bien plus anciennes dans les Indes, comme nous l'avons déjà remarqué ${ }^{145}$. Le terrain des Indes est bien plus aisément habitable que le terrain voisin du Nil, dont les débordements durent longtemps rebuter les premiers colons, avant qu'ils eussent dompté ce fleuve en creusant des canaux. Le sol des Indes est d'ailleurs d'une fertilité bien plus variée, et qui a dû exciter davantage la curiosité et l'industrie humaine.

Quelques-uns ont cru la race des hommes originaire de l'Indoustan, alléguant que l'animal le plus faible devait naître dans le climat le plus doux, et sur une terre qui produit sans culture les fruits les plus nourrissants, les plus salutaires, comme les dattes et les cocos. Ceux-ci surtout donnent aisément à l'homme de quoi le nourrir, le vêtir, et le loger. Et de quoi d'ailleurs a besoin un habitant de cette presqu'île? tout ouvrier y travaille presque nu; deux aunes d'étoffe, tout au plus, servent à couvrir une femme qui n'a point de luxe. Les enfants restent entièrement nus, du moment où ils sont nés jusqu'à la puberté. Ces matelas, ces amas de plumes, ces rideaux à double contour, qui chez nous exigent tant de frais et de soins, seraient une incommodité intolérable pour ces peuples, qui ne peuvent dormir qu'au frais sur la natte la plus légère. Nos maisons de carnage, qu'on appelle des boucheries, où l'on vend tant de cadavres pour nourrir le nôtre, mettraient la peste dans le climat de l'Inde ; il ne faut à ces nations que des nourritures rafraîchissantes et pures; la nature leur a

145 Introduction, paragraphe 19.(B.) 
prodigué des forêts de citronniers, d'orangers, de figuiers, de palmiers, de cocotiers, et des campagnes couvertes de riz. L'homme le plus robuste peut ne dépenser qu'un ou deux sous par jour pour ses aliments. Nos ouvriers dépensent plus en un jour qu'un Malabare en un mois. Toutes ces considérations semblent fortifier l'ancienne opinion que le genre humain est originaire d'un pays où la nature a tout fait pour lui, et ne lui a laissé presque rien à faire; mais cela prouve seulement que les Indiens sont indigènes, et ne prouve point du tout que les autres espèces d'hommes viennent de ces contrées. Les blancs, et les nègres, et les rouges, et les Lapons, et les Samoyèdes, et les Albinos, ne viennent certainement pas du même sol. La différence entre toutes ces espèces est aussi marquée qu'entre un lévrier et un barbet; il n'y a donc qu'un brame mal instruit et entêté qui puisse prétendre que tous les hommes descendent de l'indien Adimo et de sa femme ${ }^{146}$.

L'Inde, au temps de Charlemagne, n'était connue que de nom; et les Indiens ignoraient qu'il y eût un Charlemagne. Les Arabes, seuls maîtres du commerce maritime, fournissaient à la fois les denrées des Indes à Constantinople et aux Francs. Venise les allait déjà chercher dans Alexandrie. Le débit n'en était pas encore considérable en France chez les particuliers ; elles furent longtemps inconnues en Allemagne, et dans tout le Nord. Les Romains avaient fait ce commerce euxmêmes, dès qu'ils furent les maîtres de l'Égypte. Ainsi les peuples occidentaux ont toujours porté dans l'Inde leur or et leur argent, et ont toujours enrichi ce pays déjà si riche par lui-même. De là vient qu'on ne vit jamais les peuples de l'Inde, non plus que les Chinois et les Gangarides, sortir de leur pays pour aller exercer le brigandage chez d'autres nations, comme les Arabes, soit Juifs, soit Sarrasins ; les Tartares et les Romains même, qui, postés dans le plus mauvais pays de l'Italie, subsistèrent d'abord de la guerre, et subsistent aujourd'hui de la religion.

Il est incontestable que le continent de l'Inde a été autrefois beaucoup plus étendu qu'il ne l'est aujourd'hui. Ces îles, ces immenses archipels qui l'avoisinent à l'orient et au midi, tenaient dans les temps reculés à la terre ferme. On s'en aperçoit encore par la mer même qui les sépare: son peu de profondeur, les arbres qui croissent sur son

146 Voyez Introduction, paragr. 17, et ci-après, chap. 4. (B.) 
fond, semblables à ceux des îles; les nouveaux terrains qu'elle laisse souvent à découvert; tout fait voir que ce continent a été inondé, et il a dû l'être insensiblement, quand l'Océan, qui gagne toujours d'un côté ce qu'il perd de l'autre, s'est retiré de nos terres occidentales.

L'Inde, dans tous les temps connus commerçante et industrieuse, avait nécessairement une grande police ; et ce peuple, chez qui Pythagore avait voyagé pour s'instruire, devait avoir de bonnes lois, sans lesquelles les arts ne sont jamais cultivés ; mais les hommes, avec des lois sages, ont toujours eu des coutumes insensées. Celle qui fait aux femmes un point d'honneur et de religion de se brûler sur le corps de leurs maris subsistait dans l'Inde de temps immémorial. Les philosophes indiens se jetaient eux-mêmes dans un bûcher, par un excès de fanatisme et de vaine gloire. Calan, ou Calanus, qui se brûla devant Alexandre, n'avait pas le premier donné cet exemple ; et cette abominable dévotion n'est pas détruite encore. La veuve du roi de Tanjaor se brûla, en 1735, sur le bûcher de son époux. M. Dumas, M. Dupleix, gouverneurs de Pondichéry, l'épouse de l'amiral Russel, ont été témoins de pareils sacrifices : c'est le dernier effort des erreurs qui pervertissent le genre humain. Le plus austère des derviches n'est qu'un lâche en comparaison d'une femme de Malabar. Il semblerait qu'une nation, chez qui les philosophes et même les femmes se dévouaient ainsi à la mort, dût être une nation guerrière et invincible ; cependant, depuis l'ancien Sésac, quiconque a attaqué l'Inde l'a aisément vaincue.

Il serait encore difficile de concilier les idées sublimes que les bramins conservent de l'Être suprême avec leurs superstitions et leur mythologie fabuleuse, si l'histoire ne nous montrait pas de pareilles contradictions chez les Grecs et chez les Romains.

Il y avait des chrétiens sur les côtes de Malabar, depuis douze cents ans, au milieu de ces nations idolâtres. Un marchand de Syrie, nommé Mar-Thomas, s'étant établi sur les côtes de Malabar avec sa famille et ses facteurs, au sixième siècle, y laissa sa religion, qui était le nestorianisme ; ces sectaires orientaux, s'étant multipliés, se nommèrent les chrétiens de saint Thomas : ils vécurent paisiblement parmi les idolâtres. Qui ne veut point remuer est rarement persécuté. Ces chrétiens n'avaient aucune connaissance de l'Église latine. 
Ce n'est pas certainement le christianisme qui florissait alors dans l'Inde, c'est le mahométisme. Il s'y était introduit par les conquêtes des califes ; et Aaron-al-Raschild, cet illustre contemporain de Charlemagne, dominateur de l'Afrique, de la Syrie, de la Perse, et d'une partie de l'Inde, envoya des missionnaires musulmans des rives du Gange aux îles del'Océan indien, et jusque chez des peuplades de nègres. Depuis ce temps il y eut beaucoup de musulmans dans l'Inde. On ne dit point que le grand Aaron convertît à sa religion les Indiens par le fer et par le feu, comme Charlemagne convertit les Saxons. On ne voit pas non plus que les Indiens aient refusé le joug et la loi d'Aaron-al-Raschild, comme les Saxons refusèrent de se soumettre à Charles.

Les Indiens ont toujours été aussi mous que nos septentrionaux étaient féroces. La mollesse inspirée par le climat ne se corrige jamais ; mais la dureté s'adoucit.

En général, les hommes du Midi oriental ont reçu de la nature des mœurs plus douces que les peuples de notre Occident; leur climat les dispose à l'abstinence des liqueurs fortes et de la chair des animaux, nourritures qui aigrissent le sang, et portent souvent à la férocité ; et, quoique la superstition et les irruptions étrangères aient corrompu la bonté de leur naturel, cependant tous les voyageurs conviennent que le caractère de ces peuples n'a rien de cette inquiétude, de cette pétulance, et de cette dureté, qu'on a eu tant de peine à contenir chez les nations du Nord.

Le physique de l'Inde différant en tant de choses du nôtre, il fallait bien que le moral différât aussi. Leurs vices étaient plus doux que les nôtres. Ils cherchaient en vain des remèdes aux dérèglements de leurs mœurs, comme nous en avons cherché. C'était, de temps immémorial, une maxime chez eux et chez les Chinois, que le sage viendrait de l'Occident. L'Europe, au contraire, disait que le sage viendrait de l'Orient : toutes les nations ont toujours eu besoin d'un sage. 


\section{Chapitre 4}

\section{Des brachmanes, du Veidam et de l'Ézour-Veidam}

Si l'Inde, de qui toute la terre a besoin, et qui seule n'a besoin de personne, doit être par cela même la contrée la plus anciennement policée, elle doit conséquemment avoir eu la plus ancienne forme de religion. Il est très vraisemblable que cette religion fut longtemps celle du gouvernement chinois, et qu'elle ne consistait que dans le culte pur d'un Être suprême, dégagé de toute superstition et de tout fanatisme.

Les premiers brachmanes avaient fondé cette religion simple, telle qu'elle fut établie à la Chine par ses premiers rois ; ces brachmanes gouvernaient l'Inde. Lorsque les chefs paisibles d'un peuple spirituel et doux sont à la tête d'une religion, elle doit être simple et raisonnable, parce que ces chefs n'ont pas besoin d'erreurs pour être obéis. Il est si naturel de croire un Dieu unique, de l'adorer, et de sentir dans le fond de son cœur qu'il faut être juste, que, quand des princes annoncent ces vérités, la foi des peuples court au-devant de leurs paroles. Il faut du temps pour établir des lois arbitraires ; mais il n'en faut point pour apprendre aux hommes rassemblés à croire un Dieu, et à écouter la voix de leur propre cœur.

Les premiers brachmanes, étant donc à la fois rois et pontifes, ne pouvaient guère établir la religion que sur la raison universelle. Il n'en est pas de même dans les pays où le pontificat n'est pas uni à la royauté. Alors les fonctions religieuses, qui appartiennent originairement aux pères de famille, forment une profession séparée ; le culte de Dieu devient un métier; et, pour faire valoir ce métier, il faut souvent des prestiges, des fourberies, et des cruautés.

La religion dégénéra donc chez les brachmanes dès qu'ils ne furent plus souverains. 
Longtemps avant Alexandre, les brachmanes ne régnaient plus dans l'Inde ; mais leur tribu, qu'on nomme Caste, était toujours la plus considérée, comme elle l'est encore aujourd'hui et c'est dans cette même tribu qu'on trouvait les sages vrais ou faux, que les Grecs appelèrent gymnosophistes. Il est difficile de nier qu'il n'y eût parmi eux, dans leur décadence, cette espèce de vertu qui s'accorde avec les illusions du fanatisme. Ils reconnaissaient toujours un Dieu suprême à travers la multitude de divinités subalternes que la superstition populaire adoptait dans tous les pays du monde. Strabon dit expressément qu'au fond les brachmanes n'adoraient qu'un seul Dieu. En cela ils étaient semblables à Confucius, à Orphée, à Socrate, à Platon, à Marc Aurèle, à Épictète, à tous les sages, à tous les hiérophantes des mystères. Les sept années de noviciat chez les brachmanes, la loi du silence pendant ces sept années, étaient en vigueur du temps de Strabon. Le célibat pendant ce temps d'épreuves, l'abstinence de la chair des animaux qui servent l'homme, étaient des lois qu'on ne transgressa jamais, et qui subsistent encore chez les brames. Ils croyaient un Dieu créateur, rémunérateur et vengeur. Ils croyaient l'homme déchu et dégénéré, et cette idée se trouve chez tous les anciens peuples. Aurea prima sala est aetas (OvID. , Met. , I, 89) est la devise de toutes les nations.

Apulée, Quinte-Curce, Clément d'Alexandrie, Philostrate, Porphyre, Pallade, s'accordent tous dans les éloges qu'ils donnent à la frugalité extrême des brachmanes, à leur vie retirée et pénitente, à leur pauvreté volontaire, à leur mépris de toutes les vanités du monde. Saint Ambroise préfère hautement leurs mœurs à celles des chrétiens de son temps. Peut-être est-ce une de ces exagérations qu'on se permet quelquefois pour faire rougir ses concitoyens de leurs désordres. On loue les brachmanes pour corriger les moines; et si saint Ambroise avait vécu dans l'Inde, il aurait probablement loué les moines pour faire honte aux brachmanes. Mais enfin il résulte de tant de témoignages que ces hommes singuliers étaient en réputation de sainteté dans toute la terre.

Cette connaissance d'un Dieu unique, dont tous les philosophes leur savaient tant de gré, ils la conservent encore aujourd'hui au milieu des pagodes et de toutes les extravagances du peuple. Un de nos 
poètes ${ }^{147}$ a dit, dans une de ses épîtres où le faux domine presque toujours :

L'Inde aujourd'hui voit l'orgueilleux brachmane

Déifier, brutalement zélé

Le diable même en bronze ciselé.

Certainement des hommes qui ne croient point au diable ne peuvent adorer le diable. Ces reproches absurdes sont intolérables; on n'a jamais adoré le diable dans aucun pays du monde; les manichéens n'ont jamais rendu de culte au mauvais principe : on ne lui en rendait aucun dans la religion de Zoroastre. Il est temps que nous quittions l'indigne usage de calomnier toutes les sectes, et d'insulter toutes les nations.

Nous avons, comme vous savez, l'Ézour-Veidam ${ }^{148}$, ancien commentaire composé par Chumontou sur ce Veidam, sur ce livre sacré que les brames prétendent avoir été donné de Dieu aux hommes. Ce commentaire a été abrégé par un brame très savant, qui a rendu beaucoup de services à notre compagnie des Indes; et il l'a traduit luimême de la langue sacrée en français ${ }^{149}$.

Dans cet Ézour-Veidam, dans ce commentaire, Chumontou combat l'idolâtrie ; il rapporte les propres paroles du Veidam. «C'est l'Être suprême qui a tout créé, le sensible et l'insensible; il y a eu quatre âges différents; tout périt à la fin de chaque âge, tout est submergé, et le déluge est un passage d'un âge à l'autre, etc.

«Lorsque Dieu existait seul, et que nul autre être n'existait avec lui, il forma le dessein de créer le monde ; il créa d'abord le temps, ensuite l'eau et la terre ; et du mélange des cinq éléments, à savoir la terre, l'eau, le feu, l'air, et la lumière, il en forma les différents corps, et leur donna la terre pour leur base. Il fit ce globe, que nous habitons, en forme ovale comme un œuf. Au milieu de la terre est la plus haute de toutes les montagnes, nommée Mérou (c'est l'Immaüs). Adimo, c'est le nom du premier homme sorti des mains de Dieu : Procriti est

147 J-B. Rousseau. (V.)

148 Voyez Introduction, paragr. 17. (B.)

149 Ce manuscrit est à la Bibliothèque du Roi, où chacun peut le consulter. Il avait été donné à l'auteur par M. de Modave, qui revenait de l'Inde. (V.) - Voyez Lettre à d'Alembert, du 8 octobre 1760. (B.) 
le nom de son épouse. D’Adimo naquit Brama ${ }^{150}$, qui fut le législateur des nations et le père des brames. »

Que de choses curieuses dans ce peu de paroles! On y aperçoit d'abord cette grande vérité, que Dieu est le créateur du monde ; on voit ensuite la source primitive de cette ancienne fable des quatre âges, d'or, d'argent, d'airain et de fer. Tous les principes de la théologie des anciens sont renfermés dans le Veidam. On y voit ce déluge de Deucalion, qui ne figure autre chose que la peine extrême qu'on a éprouvée dans tous les temps à dessécher les terres que la négligence des hommes a laissées longtemps inondées. Toutes les citations du Veidam, dans ce manuscrit, sont étonnantes ; on y trouve expressément ces paroles admirables : «Dieu ne créa jamais le vice, il ne peut en être l'auteur. Dieu, qui est la sagesse et la sainteté, ne créa jamais que la vertu. »

Voici un morceau des plus singuliers du Veidam : «Le premier homme, étant sorti des mains de Dieu, lui dit: Il y aura sur la terre différentes occupations, tous ne seront pas propres à toutes; comment les distinguer entre eux? Dieu lui répondit: Ceux qui sont nés avec plus d'esprit et de goût pour la vertu que les autres seront les brames. Ceux qui participent le plus du rosogoun, c'est-à-dire de l'ambition, seront les guerriers. Ceux qui participent le plus du tomogun, c'est-àdire de l'avarice, seront les marchands. Ceux qui participeront du comogun, c'est-à-dire qui seront robustes et bornés, seront occupés aux œuvres serviles. »

On reconnaît dans ces paroles l'origine véritable des quatre castes des Indes, ou plutôt les quatre conditions de la Société humaine. En effet, sur quoi peut être fondée l'inégalité de ces conditions, sinon sur l'inégalité primitive des talents ? Le Veidam poursuit, et dit : «L'Être suprême n'a ni corps ni figure; " et l'Ézour-Veidam ajoute: "Tous ceux qui lui donnent des pieds et des mains sont insensés. » Chumontou cite ensuite ces paroles du Veidam : «Dans le temps que Dieu tira toutes choses du néant, il créa séparément un individu de chaque espèce, et voulut qu'il portât dans lui son germe, afin qu'il pût produire : il est le principe de chaque chose ; le soleil n'est qu'un corps sans vie

150 Dans l'Introduction, paragraphe 6, il est dit qu'Adimo est fils de Brama. (B.) 
et sans connaissance ; il est entre les mains de Dieu comme une chandelle entre les mains d'un homme. »

Après cela l'auteur du commentaire, combattant l'opinion des nouveaux brames, qui admettaient plusieurs incarnations dans le dieu Brama et dans le dieu Vitsnou, s'exprime ainsi :

« Dis-moi donc, homme étourdi et insensé, qu'est-ce que ce Kochiopo et cette Odité, que tu dis avoir donné naissance à ton Dieu ? Ne sont-ils pas des hommes comme les autres ? Et ce Dieu, qui est pur de sa nature, et éternel de son essence, se serait-il abaissé jusqu'à s'anéantir dans le sein d'une femme pour s'y revêtir d'une figure humaine ? Ne rougis-tu pas de nous présenter ce Dieu en posture de suppliant devant une de ses créatures ? As-tu perdu l'esprit? ou es-tu venu à ce point d'impiété, de ne pas rougir de faire jouer à l'Être suprême le personnage de fourbe et de menteur ?.... Cesse de tromper les hommes, ce n'est qu'à cette condition que je continuerai à t'expliquer le Veidam ; car si tu restes dans les mêmes sentiments, tu es incapable de l'entendre, et ce serait le prostituer que de te l'enseigner. »

$\mathrm{Au}$ livre troisième de ce commentaire, l'auteur Chumontou réfute la fable que les nouveaux brames inventaient sur une incarnation du dieu Brama, qui, selon eux, parut dans l'Inde sous le nom de Kopilo, c'est-à-dire de pénitent; ils prétendaient qu'il avait voulu naître de Déhobuti, femme d'un homme de bien, nommé Kordomo.

« S'il est vrai, dit le commentateur, que Brama soit né sur la terre, pourquoi portait-il le nom d'Éternel ? Celui qui est souverainement heureux, et dans qui seul est notre bonheur, aurait-il voulu se soumettre à tout ce que souffre un enfant ? etc. »

On trouve ensuite une description de l'enfer, toute semblable à celle que les Égyptiens et les Grecs ont donnée depuis sous le nom de Tartare. «Que faut-il faire, dit-on, pour éviter l'enfer ? il faut aimer Dieu, " répond le commentateur Chumontou ; " il faut faire ce qui nous est ordonné par le Veidam, et le faire de la façon dont il nous le prescrit. Il y a, dit-il, quatre amours de Dieu. Le premier est de l'aimer pour lui-même, sans intérêt personnel ; le second, de l'aimer par intérêt ; le troisième, de ne l'aimer que dans les moments où l'on n'écoute pas ses passions ; le quatrième, de ne l'aimer que pour obtenir l'objet 
de ces passions mêmes; et ce quatrième amour n'en mérite pas le nom ${ }^{151}$. »

Tel est le précis des principales singularités du Veidam, livre inconnu jusques aujourd'hui à l'Europe, et à presque toute l'Asie.

Les brames ont dégénéré de plus en plus. Leur Cormo-Veidam, qui est leur rituel, est un ramas de cérémonies superstitieuses, qui font rire quiconque n'est pas né sur les bords du Gange et de l'Indus, ou plutôt quiconque, n'étant pas philosophe, s'étonne des sottises des autres peuples, et ne s'étonne point de celles de son pays.

Le détail de ces minuties est immense : c'est un assemblage de toutes les folies que la vaine étude de l'astrologie judiciaire a pu inspirer à des savants ingénieux, mais extravagants ou fourbes. Toute la vie d'un brame est consacrée à ces cérémonies superstitieuses. Il y en a pour tous les jours de l'année. Il semble que les hommes soient devenus faibles et lâches dans l'Inde, à mesure qu'ils ont été subjugués. Il $\mathrm{y}$ a grande apparence qu'à chaque conquête, les superstitions et les pénitences du peuple vaincu ont redoublé. Sésac, Madiès, les Assyriens, les Perses, Alexandre, les Arabes, les Tartares, et, de nos jours, Sha-Nadir, en venant les uns après les autres ravager ces beaux pays, ont fait un peuple pénitent d'un peuple qui n'a pas su être guerrier.

Jamais les pagodes n'ont été plus riches que dans les temps d'humiliation et de misère ; toutes ces pagodes ont des revenus considérables, et les dévots les enrichissent encore de leurs offrandes. Quand un raya passe devant une pagode, il descend de son cheval, de son chameau, ou de son éléphant, ou de son palanquin, et marche à pied jusqu'à ce qu'il ait passé le territoire du temple.

Cet ancien commentaire du Veidam, dont je viens de donner l'extrait, me paraît écrit avant les conquêtes d'Alexandre ; car on n'y trouve aucun des noms que les vainqueurs grecs imposèrent aux fleuves, aux villes, aux contrées, en prononçant à leur manière, et soumettant aux terminaisons de leurs langues les noms communs du pays. L'Inde s'appelle Zomboudipo ; le mont Immaüs est Mérou ; le Gange

151 Le Shasta est beaucoup plus sublime. Voyez le Dictionnaire philosophique, au mot ANGE. (V.) 
est nommé Zanoubi ${ }^{152}$. Ces anciens noms ne sont plus connus que des savants dans la langue sacrée.

L'ancienne pureté de la religion des premiers brachmanes ne subsiste plus que chez quelques-uns de leurs philosophes; et ceux-là ne se donnent pas la peine d'instruire un peuple qui ne veut pas être instruit, et qui ne le mérite pas. Il y aurait même du risque à vouloir les détromper: les brames ignorants se soulèveraient; les femmes, attachées à leurs pagodes, à leurs petites pratiques superstitieuses, crieraient à l'impiété. Quiconque veut enseigner la raison à ses concitoyens est persécuté, à moins qu'il ne soit le plus fort; et il arrive presque toujours que le plus fort redouble les chaînes de l'ignorance au lieu de les rompre.

La religion mahométane seule a fait dans l'Inde d'immenses progrès, surtout parmi les hommes bien élevés, parce que c'est la religion du prince, et qu'elle n'enseigne que l'unité de Dieu, conformément à l'ancienne doctrine des premiers brachmanes. Le christianisme n'a pas eu dans l'Inde le même succès, malgré l'évidence et la sainteté de sa doctrine, et malgré les grands établissements des Portugais, des Français, des Anglais, des Hollandais, des Danois. C'est même le concours de ces nations qui a nui au progrès de notre culte. Comme elles se haïssent toutes, et que plusieurs d'entre elles se font souvent la guerre dans ces climats, elles y ont fait haïr ce qu'elles enseignent. Leurs usages d'ailleurs révoltent les Indiens; ils sont scandalisés de nous voir boire du vin et manger des viandes qu'ils abhorrent. La conformation de nos organes, qui fait que nous prononçons si mal les langues de l'Asie, est encore un obstacle presque invincible; mais le plus grand est la différence des opinions qui divisent nos missionnaires. Le catholique y combat l'anglican, qui combat le luthérien combattu par le calviniste. Ainsi tous contre tous, voulant annoncer chacun la vérité, et accusant les autres de mensonge, ils étonnent un peuple simple et paisible, qui voit accourir chez lui, des extrémités occidentales de la terre, des hommes ardents pour se déchirer mutuellement sur les rives du Gange.

Nous avons eu dans ces climats, comme ailleurs, des missionnaires respectables par leur piété, et auxquels on ne peut reprocher que

152 Voyez Introduction, paragraphe 24. (B.) 
d'avoir exagéré leurs travaux et leurs triomphes. Mais tous n'ont pas été des hommes vertueux et instruits, envoyés d'Europe pour changer la croyance de l'Asie. Le célèbre Niecamp, auteur de l'histoire de la mission de Tranquebar, avoue ${ }^{153}$ «que les Portugais remplirent le séminaire de Goa de malfaiteurs condamnés au bannissement ; qu'ils en firent des missionnaires; et que ces missionnaires n'oublièrent pas leur premier métier. » Notre religion a fait peu de progrès sur les côtes, et nul dans les États soumis immédiatement au Grand-Mogol. La religion de Mahomet et celle de Brama partagent encore tout ce vaste continent. Il n'y a pas deux siècles que nous appelions toutes ces nations la paganie, tandis que les Arabes, les Turcs, les Indiens, ne nous connaissaient que sous le nom d'idolâtres. 


\section{Chapitre 5}

\section{De la Perse au temps de Mahomet le prophète, et de l'ancienne religion de Zoroastre}

En tournant vers la Perse, on y trouve, un peu avant le temps qui me sert d'époque, la plus grande et la plus prompte révolution que nous connaissions sur la terre.

Une nouvelle domination, une religion et des mœurs jusqu'alors inconnues, avaient changé la face de ces contrées ; et ce changement s'étendait déjà fort avant en Asie, en Afrique et en Europe.

Pour me faire une idée du mahométisme, qui a donné une nouvelle forme à tant d'empires, je me rappellerai d'abord les parties du monde qui lui furent les premières soumises.

La Perse avait étendu sa domination, avant Alexandre, de l'Égypte à la Bactriane, au delà du pays où est aujourd'hui Samarcande, et de la Thrace jusqu'au fleuve de l'Inde.

Divisée et resserrée sous les Séleucides, elle avait repris des accroissements sous Arsaces le Parthien, deux cent cinquante ans avant notre ère. Les Arsacides n'eurent ni la Syrie, ni les contrées qui bordent le Pont-Euxin ; mais ils disputèrent avec les Romains de l'empire de l'Orient, et leur opposèrent toujours des barrières insurmontables.

Du temps d'Alexandre Sévère, vers l'an 226 de notre ère, un simple soldat persan, qui prit le nom d'Artaxare, enleva ce royaume aux Parthes, et rétablit l'empire des Perses, dont l'étendue ne différait guère alors de ce qu'elle est de nos jours.

Vous ne voulez pas examiner ici quels étaient les premiers Babyloniens conquis par les Perses, ni comment ce peuple se vantait de quatre cent mille ans d'observations astronomiques, dont on ne put 
retrouver qu'une suite de dix-neuf cents années du temps d'Alexandre ${ }^{154}$. Vous ne voulez pas vous écarter de votre sujet pour vous rappeler l'idée de la grandeur de Babylone, et de ces monuments plus vantés que solides dont les ruines mêmes sont détruites. Si quelque reste des arts asiatiques mérite un peu notre curiosité, ce sont les ruines de Persépolis, décrites dans plusieurs livres et copiées dans plusieurs estampes. Je sais quelle admiration inspirent ces masures échappées aux flambeaux dont Alexandre et la courtisane Thaïs mirent Persépolis en cendre. Mais était-ce un chef-d'œuvre de l'art qu'un palais bâti au pied d'une chaîne de rochers arides ? Les colonnes qui sont encore debout ne sont assurément ni dans de belles proportions, ni d'un dessin élégant. Les chapiteaux, surchargés d'ornements grossiers, ont presque autant de hauteur que les fûts mêmes des colonnes. Toutes les figures sont aussi lourdes et aussi sèches que celles dont nos églises gothiques sont encore malheureusement ornées. Ce sont des monuments de grandeur, mais non pas de goût; et tout nous confirme que si l'on s'arrêtait à l'histoire des arts, on ne trouverait que quatre siècles dans les annales du monde: ceux d'Alexandre, d'Auguste, des Médicis, et de Louis XIV.

Cependant les Persans furent toujours un peuple ingénieux. Lokman, qui est le même qu'Ésope, était né à Casbin. Cette tradition est bien plus vraisemblable que celle qui le fait originaire d'Éthiopie, pays où il n'y eut jamais de philosophes. Les dogmes de l'ancien Zerdust, appelé Zoroastre par les Grecs, qui ont changé tous les noms orientaux, subsistaient encore. On leur donne neuf mille ans d'antiquité ; car les Persans, ainsi que les Égyptiens, les Indiens, les Chinois, reculent l'origine du monde autant que d'autres la rapprochent. Un second Zoroastre, sous Darius, fils d'Hystaspe, n'avait fait que perfectionner cette antique religion. C'est dans ces dogmes qu'on trouve, ainsi que dans l'Inde, l'immortalité de l'âme, et une autre vie heureuse ou malheureuse. C'est là qu'on voit expressément un enfer. Zoroastre, dans les écrits abrégés dans le Sadder, dit que Dieu lui fit voir cet enfer, et les peines réservées aux méchants. Il y voit plusieurs rois, un entre autres auquel il manquait un pied; il en demande à Dieu la raison; Dieu lui répond : "Ce roi pervers n'a fait qu'une action de bonté en sa vie. Il vit, en allant à la chasse, un dromadaire qui était lié

154 Voyez Introduction, paragraphe 10. (B.) 
trop loin de son auge, et qui, voulant y manger, ne pouvait y atteindre ; il approcha l'auge d'un coup de pied : j'ai mis son pied dans le ciel, tout le reste est ici. » Ce trait, peu connu, fait voir l'espèce de philosophie qui régnait dans ces temps reculés, philosophie toujours allégorique, et quelquefois très profonde. Nous avons rapporté ailleurs ce trait singulier, qu'on ne peut trop faire connaître ${ }^{155}$.

Vous savez que les Babyloniens furent les premiers, après les Indiens, qui admirent des êtres mitoyens entre la Divinité et l'homme. Les Juifs ne donnèrent des noms aux anges que dans le temps de leur captivité à Babylone. Le nom de Satan paraît pour la première fois dans le livre de Job ; ce nom est persan, et l'on prétend que Job l'était. Le nom de Raphaël est employé par l'auteur, quel qu'il soit, de Tobie, qui était captif de Ninive, et qui écrivit en chaldéen. Le nom d'Israël même était chaldéen, et signifiait voyant Dieu. Ce Sadder est l'abrégé du Zenda-Vesta, ou du Zend, l'un des trois plus anciens livres qui soient au monde, comme nous l'avons dit dans la Philosophie de l'histoire qui sert d'introduction à cet ouvrage. Ce mot Zenda-Vesta signifiait chez les Chaldéens le culte du feu; le Sadder est divisé en cent articles, que les Orientaux appellent Portes ou Puissances : il est important de les lire, si l'on veut connaître quelle était la morale de ces anciens peuples. Notre ignorante crédulité se figure toujours que nous avons tout inventé, que tout est venu des Juifs et de nous, qui avons succédé aux Juifs; on est bien détrompé quand on fouille un peu dans l'antiquité. Voici ${ }^{156}$ quelques-unes de ces portes qui serviront à nous tirer d'erreur.

$I^{\text {re }}$ PORTE. Le décret du très juste Dieu est que les hommes soient jugés par le bien et le mal qu'ils auront fait : leurs actions seront pesées dans les balances de l'équité. Les bons habiteront la lumière ; la foi les délivrera de Satan.

155 Ce renvoi de Voltaire, ajouté dans l'édition de 1775, ne peut regarder, comme on l'a dit avant moi, l'ouvrage intitulé : Un Chrétien contre six Juifs, qui est de 1776; il s'agit du morceau publié au moins dès 1765, et qui, dans le Dict. philosophique, forme la $\mathrm{XI}^{\mathrm{e}}$ section au mot AME. (B.)

156 Cet extrait du Sadder et les réflexions qui le suivent jusques à l'alinéa qui commence par les mots : La doctrine des deux principes, parurent pour la première fois dans les Remarques pour servir de supplément à l'Essai sur l'Histoire générale, etc. , 1763 , in- $8^{\circ}$; ils formaient la XI ${ }^{\mathrm{e}}$ remarque. (B.) 
$\mathrm{II}^{\mathrm{e}}$. Si tes vertus l'emportent sur tes péchés, le ciel est ton partage ; si tes péchés l'emportent, l'enfer est ton châtiment.

$V^{\mathrm{e}}$. Qui donne l'aumône est véritablement un homme : c'est le plus grand mérite dans notre sainte religion, etc.

$\mathrm{VI}^{\mathrm{e}}$. Célèbre quatre fois par jour le soleil ; célèbre la lune au commencement du mois.

$N$. B. Il ne dit point : Adore comme des dieux le soleil et la lune ; mais : Célèbre le soleil et la lune comme ouvrages du Créateur. Les anciens Perses n'étaient point ignicoles, mais déicoles, comme le prouve invinciblement l'historien de la religion des Perses.

VII ${ }^{\mathrm{e}}$. Dis : Ahunavar, et Ashim Vuhû, quand quelqu'un éternue.

$N$. B. On ne rapporte cet article que pour faire voir de quelle prodigieuse antiquité est l'usage de saluer ceux qui éternuent.

IX . Fuis surtout le péché contre nature ; il n'y en a point de plus grand.

N. B. Ce précepte fait bien voir combien Sextus Empiricus se trompe quand il dit que cette infamie était permise par les lois de Perse.

$\mathrm{XI}^{\mathrm{e}}$. Aie soin d'entretenir le feu sacré ; c'est l'âme du monde, etc.

$N$. B. Ce feu sacré devint un des rites de plusieurs nations.

XII ${ }^{\mathrm{e}}$. N'ensevelis point les morts dans des draps neufs, etc.

$N$. B. Ce précepte prouve combien se sont trompés tous les auteurs qui ont dit que les Perses n'ensevelissaient point leurs morts. L'usage d'enterrer ou de brûler les cadavres, ou de les exposer à l'air sur des collines, a varié souvent. Les rites changent chez tous les peuples, la morale seule ne change pas.

$\mathrm{XIII}^{\mathrm{e}}$. Aime ton père et ta mère, si tu veux vivre à jamais.

N. B. Voyez le Décalogue.

$X^{\mathrm{e}}$. Quelque chose qu'on te présente, bénis Dieu.

$\mathrm{XIX}^{\mathrm{e}}$. Marie-toi dans ta jeunesse ; ce monde n'est qu'un passage : il faut que ton fils te suive, et que la chaîne des êtres ne soit point interrompue. 
$\mathrm{XXX}^{\mathrm{e}}$. Il est certain que Dieu a dit à Zoroastre : Quand on sera dans le doute si une action est bonne ou mauvaise, qu'on ne la fasse pas.

$N$. B. Ceci est un peu contre la doctrine des opinions probables.

XXXIII ${ }^{\mathrm{e}}$. Que les grandes libéralités ne soient répandues que sur les plus dignes : ce qui est confié aux indignes est perdu.

$\mathrm{XXXV}^{\mathrm{e}}$. Mais s'il s'agit du nécessaire, quand tu manges, donne aussi à manger aux chiens.

$\mathrm{XL}^{\mathrm{e}}$. Quiconque exhorte les hommes à la pénitence doit être sans péché : qu'il ait du zèle, et que ce zèle ne soit point trompeur; qu'il ne mente jamais ; que son caractère soit bon, son âme sensible à l'amitié, son cœur et sa langue toujours d'intelligence ; qu'il soit éloigné de toute débauche, de toute injustice, de tout péché ; qu'il soit un exemple de bonté, de justice devant le peuple de Dieu.

$N$. B. Quel exemple pour les prêtres de tout pays ! et remarquez que, dans toutes les religions de l'Orient, le peuple est appelé le peuple de Dieu.

$\mathrm{XLI}^{\mathrm{e}}$. Quand les Fervardagans viendront, fais les repas d'expiation et de bienveillance ; cela est agréable au Créateur.

$N$. B. Ce précepte a quelque ressemblance avec les agapes.

LXVIII $^{\mathrm{e}}$. Ne mens jamais ; cela est infâme, quand même le mensonge serait utile.

$N$. B. Cette doctrine est bien contraire à celle du mensonge officieux.

LXIX . Point de familiarité avec les courtisanes. Ne cherche à séduire la femme de personne.

$\mathrm{LXX}^{\mathrm{e}}$. Qu'on s'abstienne de tout vol, de toute rapine.

$\mathrm{LXXI}^{\mathrm{e}}$. Que ta main, ta langue, et ta pensée, soient pures de tout péché. Dans tes afflictions, offre à Dieu ta patience; dans le bonheur, rends-lui des actions de grâce.

$\mathrm{XCI}^{\mathrm{e}}$. Jour et nuit, pense à faire du bien : la vie est courte. Si, devant servir aujourd'hui ton prochain, tu attends à demain, fais pénitence. Célèbre les six Gahambârs : car Dieu a créé le monde en six fois dans l'espace d'une année, etc. Dans le temps des six Gahambârs ne 
refuse personne. Un jour le grand roi Giemshid ordonna au chef de ses cuisines de donner à manger à tous ceux qui se présenteraient; le mauvais génie ou Satan se présenta sous la forme d'un voyageur; quand il eut dîné, il demanda encore à manger, Giemshid ordonna qu'on lui servît un bœuf; Satan ayant mangé le bœuf, Giemshid lui fit servir des chevaux; Satan en demanda encore d'autres. Alors le juste Dieu envoya l'ange Behman, qui chassa le diable; mais l'action de Giemshid fut agréable à Dieu.

$N$. B. On reconnaît bien le génie oriental dans cette allégorie.

Ce sont là les principaux dogmes des anciens Perses. Presque tous sont conformes à la religion naturelle de tous les peuples du monde ; les cérémonies sont partout différentes ; la vertu est partout la même ; c'est qu'elle vient de Dieu, le reste est des hommes.

Nous remarquerons seulement que les Parsis eurent toujours un baptême, et jamais la circoncision. Le baptême est commun à toutes les anciennes nations de l'Orient; la circoncision des Égyptiens, des Arabes et des Juifs, est infiniment postérieure : car rien n'est plus naturel que de se laver; et il a fallu bien des siècles avant d'imaginer qu'une opération contre la nature et contre la pudeur pût plaire à l'Être des êtres.

Nous passons tout ce qui concerne des cérémonies inutiles pour nous, ridicules à nos yeux, liées à des usages que nous ne connaissons plus. Nous supprimons aussi toutes les amplifications orientales, et toutes ces figures gigantesques, incohérentes et fausses, si familières à tous ces peuples, chez lesquels il n'y a peut-être jamais eu que l'auteur des fables attribuées à Ésope qui ait écrit naturellement.

Nous savons assez que le bon goût n'a jamais été connu dans l'Orient, parce que les hommes, n'y ayant jamais vécu en société avec les femmes, et ayant presque toujours été dans la retraite, n'eurent pas les mêmes occasions de se former l'esprit qu'eurent les Grecs et les Romains. Ôtez aux Arabes, aux Persans, aux Juifs, le soleil et la lune, les montagnes et les vallées, les dragons et les basilics, il ne leur reste presque plus de poésie.

Il suffit de savoir que ces préceptes de Zoroastre, rapportés dans le Sadder, sont de l'antiquité la plus haute, qu'il y est parlé de rois dont Bérose lui-même ne fait pas mention. 
Nous ne savons pas quel était le premier Zoroastre, en quel temps il vivait, si c'est le Brama des Indiens, et l'Abraham des Juifs ; mais nous savons, à n'en pouvoir douter, que sa religion enseignait la vertu. C'est le but essentiel de toutes les religions ; elles ne peuvent jamais en avoir eu d'autre ; car il n'est pas dans la nature humaine, quelque abrutie qu'elle puisse être, de croire d'abord à un homme qui viendrait enseigner le crime.

Les dogmes du Sadder nous prouvent encore que les Perses n'étaient point idolâtres. Notre ignorante témérité accusa longtemps d'idolâtrie les Persans, les Indiens, les Chinois, et jusqu'aux mahométans, si attachés à l'unité de Dieu qu'ils nous traitent nous-mêmes d'idolâtres. Tous nos anciens livres italiens, français, espagnols, appellent les mahométans païens, et leur empire la paganie. Nous ressemblions, dans ces temps-là, aux Chinois, qui se croyaient le seul peuple raisonnable, et qui n'accordaient pas aux autres hommes la figure humaine. La raison est toujours venue tard; c'est une divinité qui n'est apparue qu'à peu de personnes.

Les Juifs imputèrent aux chrétiens des repas de Thyeste, et des noces d'Edipe, comme les chrétiens aux païens; toutes les sectes s'accusèrent mutuellement des plus grands crimes : l'univers s'est calomnié.

La doctrine des deux principes est de Zoroastre. Orosmade, ou Oromaze, le dieu des jours, et Arimane, le génie des ténèbres, sont l'origine du manichéisme. C'est l'Osiris et le Typhon des Égyptiens, c'est la Pandore des Grecs ; c'est le vain effort de tous les sages pour expliquer l'origine du bien et du mal. Cette théologie des mages fut respectée dans l'Orient sous tous les gouvernements; et, au milieu de toutes les révolutions, l'ancienne religion s'était toujours soutenue en Perse : ni les dieux des Grecs, ni d'autres divinités n'avaient prévalu.

Noushirvan, ou Cosroès le Grand, sur la fin du sixième siècle, avait étendu son empire dans une partie de l'Arabie Pétrée, et de celle que l'on nommait Heureuse. Il en avait chassé les Abyssins, demichrétiens qui l'avaient envahie. Il proscrivit, autant qu'il le put, le christianisme de ses propres États, forcé à cette sévérité par le crime d'un fils de sa femme, qui, s'étant fait chrétien, se révolta contre lui. 
Les enfants du grand Noushirvan, indignes d'un tel père, désolaient la Perse par des guerres civiles et par des parricides. Les successeurs du législateur Justinien avilissaient le nom de l'empire. Maurice venait d'être détrôné par les armes de Phocas, par les intrigues du patriarche Cyriaque, par celles de quelques évêques, que Phocas punit ensuite de l'avoir servi. Le sang de Maurice et de ses cinq fils avait coulé sous la main du bourreau ; et le pape Grégoire le Grand, ennemi des patriarches de Constantinople, tâchait d'attirer le tyran Phocas dans son parti, en lui prodiguant des louanges, et en condamnant la mémoire de Maurice, qu'il avait loué pendant sa vie.

L'empire de Rome en Occident était anéanti. Un déluge de barbares, Goths, Hérules, Huns, Vandales, Francs, inondait l'Europe, quand Mahomet jetait, dans les déserts de l'Arabie, les fondements de la religion et de la puissance musulmanes. 


\section{Chapitre 6}

\section{De l'Arabie et de Mahomet ${ }^{157}$}

De tous les législateurs et de tous les conquérants, il n'en est aucun dont la vie ait été écrite avec plus d'authenticité et dans un plus grand détail par ses contemporains que celle de Mahomet. Ôtez de cette vie les prodiges dont cette partie du monde fut toujours infatuée, le reste est d'une vérité reconnue. Il naquit dans la ville de Mecca, que nous nommons la Mecque, l'an 569 de notre ère vulgaire, au mois de mai. Son père s'appelait Abdalla, sa mère Émine : il n'est pas douteux que sa famille ne fut une des plus considérées de la première tribu, qui était celle des Coracites. Mais la généalogie qui le fait descendre d'Abraham en droite ligne est une de ces fables inventées par ce désir si naturel d'en imposer aux hommes.

Les mœurs et les superstitions des premiers âges que nous connaissons s'étaient conservées dans l'Arabie. Ou le voit par le vœu que fit son grand-père Abdalla-Moutaleb de sacrifier un de ses enfants. Une prêtresse de la Mecque lui ordonna de racheter ce fils pour quelques chameaux, que l'exagération arabe fait monter au nombre de cent. Cette prêtresse était consacrée au culte d'une étoile, qu'on croit avoir été celle de Sirius, car chaque tribu avait son étoile ou sa planète ${ }^{158}$. On rendait aussi un culte à des génies, à des dieux mitoyens; mais on reconnaissait un dieu supérieur, et c'est en quoi presque tous les peuples se sont accordés.

157 Un anonyme ayant publié une Critique de l'Histoire universelle de M. de Voltaire, au sujet de Mahomet et du mahométisme, in- $4^{\circ}$ de quarante-trois pages, c'est en réponse que Voltaire fit imprimer sa Lettre civile et honnête, qu'on trouvera dans les Mélanges, année 1760. (B.)

158 Voyez le Koran et la préface du Koran, écrite par le savant et judicieux Sale, qui avait demeuré vingt-cinq ans en Arabie. (V.) 
Abdalla-Moutaleb vécut, dit-on, cent dix ans. Son petit-fils Mahomet porta les armes dès l'âge de quatorze ans dans une guerre sur les confins de la Syrie; réduit à la pauvreté, un de ses oncles le donna pour facteur à une veuve nommée Cadige, qui faisait en Syrie un négoce considérable : il avait alors vingt-cinq ans. Cette veuve épousa bientôt son facteur, et l'oncle de Mahomet, qui fit ce mariage, donna douze onces d'or à son neveu: environ neuf cents francs de notre monnaie furent tout le patrimoine de celui qui devait changer la face de la plus grande et de la plus belle partie du monde. Il vécut obscur avec sa première femme Cadige jusqu'à l'âge de quarante ans. Il ne déploya qu'à cet âge les talents qui le rendaient supérieur à ses compatriotes. Il avait une éloquence vive et forte, dépouillée d'art et de méthode, telle qu'il la fallait à des Arabes; un air d'autorité et d'insinuation, animé par des yeux perçants et par une physionomie heureuse ; l'intrépidité d'Alexandre, sa libéralité, et la sobriété dont Alexandre aurait eu besoin pour être un grand homme en tout.

L'amour, qu'un tempérament ardent lui rendait nécessaire, et qui lui donna tant de femmes et de concubines, n'affaiblit ni son courage, ni son application, ni sa santé c'est ainsi qu'en parlent les contemporains, et ce portrait est justifié par ses actions.

Après avoir bien connu le caractère de ses concitoyens, leur ignorance, leur crédulité, et leur disposition à l'enthousiasme, il vit qu'il pouvait s'ériger en prophète. Il forma le dessein d'abolir dans sa patrie le sabisme, qui consiste dans le mélange du culte de Dieu et de celui des astres ; le judaïsme, détesté de toutes les nations, et qui prenait une grande supériorité dans l'Arabie ; enfin le christianisme, qu'il ne connaissait que par les abus de plusieurs sectes répandues autour de son pays. Il prétendait rétablir le culte simple d'Abraham ou Ibrahim, dont il se disait descendu, et rappeler les hommes à l'unité d'un dieu, dogme qu'il s'imaginait être défiguré dans toutes les religions. C'est en effet ce qu'il déclare expressément dans le troisième Sura ou chapitre de son Koran. « Dieu connaît, et vous ne connaissez pas. Abraham n'était ni Juif ni chrétien, mais il était de la vraie religion. Son cœur était résigné à Dieu ; il n'était point du nombre des idolâtres. »

Il est à croire que Mahomet, comme tous les enthousiastes, violemment frappé de ses idées, les débita d'abord de bonne foi, les fortifia par des rêveries, se trompa lui-même en trompant les autres, et ap- 
puya enfin, par des fourberies nécessaires, une doctrine qu'il croyait bonne. Il commença par se faire croire dans sa maison, ce qui était probablement le plus difficile; sa femme et le jeune Ali, mari de sa fille, Fatime, furent ses premiers disciples. Ses concitoyens s'élevèrent contre lui ; il devait bien s'y attendre : sa réponse aux menaces des Coracites marque à la fois son caractère et la manière de s'exprimer commune de sa nation. "Quand vous viendriez à moi, ditil, avec le soleil à la droite et la lune à la gauche, je ne reculerais pas dans ma carrière. »

Il n'avait encore que seize disciples, en comptant quatre femmes, quand il fut obligé de les faire sortir de la Mecque, où ils étaient persécutés, et de les envoyer prêcher sa religion en Éthiopie. Pour lui, il osa rester à la Mecque, où il affronta ses ennemis, et il fit de nouveaux prosélytes qu'il envoya encore en Éthiopie, au nombre de cent. Ce qui affermit le plus sa religion naissante, ce fut la conversion d'Omar, qui l'avait longtemps persécuté. Omar, qui depuis devint un si grand conquérant, s'écria, dans une assemblée nombreuse : « J'atteste qu'il n'y a qu'un Dieu, qu'il n'a ni compagnon ni associé, et que Mahomet est son serviteur et son prophète. »

Le nombre de ses ennemis l'emportait encore sur ses partisans. Ses disciples se répandirent dans Médine; ils y formèrent une faction considérable. Mahomet, persécuté dans la Mecque, et condamné à mort, s'enfuit à Médine. Cette fuite, qu'on nomme hégire ${ }^{159}$, devint l'époque de sa gloire et de la fondation de son empire. De fugitif il devint conquérant. S'il n'avait pas été persécuté, il n'aurait peut-être pas réussi. Réfugié à Médine, il y persuada le peuple et l'asservit. Il battit d'abord, avec cent treize hommes, les Mecquois, qui étaient venus fondre sur lui au nombre de mille. Cette victoire, qui fut un miracle aux yeux de ses sectateurs, les persuada que Dieu combattait pour eux, comme eux pour lui. Dès la première victoire, ils espérèrent la conquête du monde. Mahomet prit la Mecque, vit ses persécuteurs à

159 Les auteurs de l'Art de vérifier les dates disent que l'époque de cette expulsion est le 16 juillet 622 ; mais les auteurs de la Biographie universelle font observer que le départ de Mahomet de la Mecque n'eut lieu que le 5 raby $1^{\text {er }}$ de cette année, et son arrivée à Médine le mardi 16 du même mois (28 septembre 622) Néanmoins on a fait remonter le commencement de cette ère au premier jour del'année, c'est-à-dire à soixante-huit jours avant la fuite de Mahomet. (B.) 
ses pieds, conquit en neuf ans, par la parole et par les armes, toute l'Arabie, pays aussi grand que la Perse, et que les Perses ni les Romains n'avaient pu conquérir. Il se trouvait à la tête de quarante mille hommes tous enivrés de son enthousiasme. Dans ses premiers succès, il avait écrit au roi de Perse Cosroès Second ; à l'empereur Héraclius ; au prince des Cophtes, gouverneur d'Égypte ; au roi des Abyssins ; à un roi nommé Mondar, qui régnait dans une province près du golfe Persique.

Il osa leur proposer d'embrasser sa religion; et, ce qui est étrange, c'est que de ces princes il y en eut deux qui se firent mahométans : ce furent le roi d'Abyssinie, et ce Mondar. Cosroès déchira la lettre de Mahomet avec indignation. Héraclius répondit par des présents. Le prince des Cophtes lui envoya une fille qui passait pour un chefd'œuvre de la nature, et qu'on appelait la belle Marie.

Mahomet, au bout de neuf ans, se croyant assez fort pour étendre ses conquêtes et sa religion chez les Grecs et chez les Perses, commença par attaquer la Syrie, soumise alors à Héraclius, et lui prit quelques villes. Cet empereur, entêté de disputes métaphysiques de religion, et qui avait pris le parti des monothélites, essuya en peu de temps deux propositions bien singulières, l'une de la part de Cosroès Second, qui l'avait longtemps vaincu, et l'autre de la part de Mahomet. Cosroès voulait qu'Héraclius embrassât la religion des mages, et Mahomet qu'il se fît musulman.

Le nouveau prophète donnait le choix à ceux qu'il voulait subjuguer d'embrasser sa secte, ou de payer un tribut. Ce tribut était réglé par l'Alcoran à treize dragmes d'argent par an pour chaque chef de famille. Une taxe si modique est une preuve que les peuples qu'il soumit étaient pauvres. Le tribut a augmenté depuis. De tous les législateurs qui ont fondé des religions, il est le seul qui ait étendu la sienne par les conquêtes. D'autres peuples ont porté leur culte avec le fer et le feu chez des nations étrangères; mais nul fondateur de secte n'avait été conquérant. Ce privilège unique est aux yeux des musulmans l'argument le plus fort que la Divinité prit soin elle-même de seconder leur prophète.

Enfin Mahomet, maître de l'Arabie, et redoutable à tous ses voisins, attaqué d'une maladie mortelle à Médine, à l'âge de soixante- 
trois ans et demi ${ }^{160}$, voulut que ses derniers moments parussent ceux d'un héros et d'un juste : " Que celui à qui j'ai fait violence et injustice paraisse, s'écria-t-il, et je suis prêt à lui faire réparation. »Un homme se leva, qui lui redemanda quelque argent; Mahomet le lui fit donner, et expira peu de temps après, regardé comme un grand homme par ceux même qui le connaissaient pour un imposteur, et révéré comme un prophète par tout le reste.

Ce n'était pas sans doute un ignorant, comme quelques-uns l'ont prétendu. Il fallait bien même qu'il fût très savant pour sa nation et pour son temps, puisqu'on a de lui quelques aphorismes de médecine, et qu'il réforma le calendrier des Arabes, comme César celui des Romains. Il se donne, à la vérité, le titre de prophète non lettré ; mais on peut savoir écrire, et ne pas s'arroger le nom de savant. Il était poète ; la plupart des derniers versets de ses chapitres sont rimés; le reste est en prose cadencée. La poésie ne servit pas peu à rendre son Alcoran respectable. Les Arabes faisaient un très grand cas de la poésie; et lorsqu'il y avait un bon poète dans une tribu, les autres tribus envoyaient une ambassade de félicitations à celle qui avait produit un auteur, qu'on regardait comme inspiré et comme utile. On affichait les meilleures poésies dans le temple de la Mecque ; et quand on y afficha le second chapitre de Mahomet, qui commence ainsi : "Il ne faut point douter ; c'est ici la science des justes, de ceux qui croient aux mystères, qui prient quand il le faut, qui donnent avec générosité, etc. " alors le premier poète de la Mecque, nommé Abid, déchira ses propres vers affichés au temple, admira Mahomet, et se rangea sous sa loi ${ }^{161}$. Voilà des mœurs, des usages, des faits si différents de tout ce qui se passe parmi nous qu'ils doivent nous montrer combien le tableau de l'univers est varié, et combien nous devons être en garde contre notre habitude de juger de tout par nos usages.

Les Arabes contemporains écrivirent la vie de Mahomet dans le plus grand détail. Tout y ressent la simplicité barbare des temps qu'on nomme héroïques. Son contrat de mariage avec sa première femme Cadige est exprimé en ces mots : "Attendu que Cadige est amoureuse de Mahomet, et Mahomet pareillement amoureux d'elle. » On voit quels repas apprêtaient ses femmes : on apprend le nom de ses épées

${ }^{160}$ Le $13^{\mathrm{e}}$ jour de raby $1^{\mathrm{er}}$ de la XI $\mathrm{XI}^{\mathrm{e}}$ année de l'hégire (8 juin 632). (B.)

161 Lisez le commencement du Koran; il est sublime. (V.) 
et de ses chevaux. On peut remarquer surtout dans son peuple des mœurs conformes à celles des anciens Hébreux (je ne parle ici que des mœurs) ; la même ardeur à courir au combat, au nom de la Divinité ; la même soif du butin, le même partage des dépouilles, et tout se rapportant à cet objet.

Mais, en ne considérant ici que les choses humaines, et en faisant toujours abstraction des jugements de Dieu et de ses voies inconnues, pourquoi Mahomet et ses successeurs, qui commencèrent leurs conquêtes précisément comme les Juifs, firent-ils de si grandes choses, et les Juifs de si petites? Ne serait-ce point parce que les musulmans eurent le plus grand soin de soumettre les vaincus à leur religion, tantôt par la force, tantôt par la persuasion ? Les Hébreux, au contraire, associèrent rarement les étrangers à leur culte. Les musulmans arabes incorporèrent à eux les autres nations; les Hébreux s'en tinrent toujours séparés. Il paraît enfin que les Arabes eurent un enthousiasme plus courageux, une politique plus généreuse et plus hardie. Le peuple hébreu avait en horreur les autres nations, et craignit toujours d'être asservi; le peuple arabe, au contraire, voulut attirer tout à lui, et se crut fait pour dominer.

Si ces Ismaélites ressemblaient aux Juifs par l'enthousiasme et la soif du pillage, ils étaient prodigieusement supérieurs par le courage, par la grandeur d'âme, par la magnanimité : leur histoire, ou vraie, ou fabuleuse, avant Mahomet, est remplie d'exemples d'amitié tels que la Grèce en inventa dans les fables de Pylade et d'Oreste, de Thésée et de Pirithoüs. L'histoire des Barmécides n'est qu'une suite de générosités inouïes qui élèvent l'âme. Ces traits caractérisent une nation. On ne voit, au contraire, dans toutes les annales du peuple hébreu, aucune action généreuse. Ils ne connaissent ni l'hospitalité, ni la libéralité, ni la clémence. Leur souverain bonheur est d'exercer l'usure avec les étrangers ; et cet esprit d'usure, principe de toute lâcheté, est tellement enraciné dans leurs cœurs, que c'est l'objet continuel des figures qu'ils emploient dans l'espèce d'éloquence qui leur est propre. Leur gloire est de mettre à feu et à sang les petits villages dont ils peuvent s'emparer. Ils égorgent les vieillards et les enfants; ils ne réservent que les filles nubiles ; ils assassinent leurs maîtres quand ils sont esclaves; ils ne savent jamais pardonner quand ils sont vainqueurs ; ils sont les ennemis du genre humain. Nulle politesse, nulle science, nul art perfectionné dans aucun temps chez cette nation atroce. Mais, dès 
le second siècle de l'hégire, les Arabes deviennent les précepteurs de l'Europe dans les sciences et dans les arts, malgré leur loi qui semble l'ennemie des arts.

La dernière volonté de Mahomet ne fut point exécutée. Il avait nommé Ali, son gendre, époux de Fatime, pour l'héritier de son empire. Mais l'ambition, qui l'emporte sur le fanatisme même, engagea les chefs de son armée à déclarer calife, c'est-à-dire vicaire du prophète, le vieux Abubéker, son beau-père, dans l'espérance qu'ils pourraient bientôt eux-mêmes partager la succession. Ali resta dans l'Arabie, attendant le temps de se signaler.

Cette division fut la première semence du grand schisme qui sépare aujourd'hui les sectateurs d'Omar et ceux d'Ali, les Sunni et les Chias, les Turcs et les Persans modernes.

Abubéker rassembla d'abord en un corps les feuilles éparses de l'Alcoran. On lut, en présence de tous les chefs, les chapitres de ce livre, écrits les uns sur des feuilles de palmier, les autres sur du parchemin; et on établit ainsi son authenticité invariable. Le respect superstitieux pour ce livre alla jusqu'à se persuader que l'original avait été écrit dans le ciel. Toute la question fut de savoir s'il avait été écrit de toute éternité, ou seulement au temps de Mahomet : les plus dévots se déclarèrent pour l'éternité.

Bientôt Abubéker mena ses musulmans en Palestine, et y défit le frère d'Héraclius. Il mourut peu après, avec la réputation du plus généreux de tous les hommes, n'ayant jamais pris pour lui qu'environ quarante sous de notre monnaie par jour, de tout le butin qu'on partageait, et ayant fait voir combien le mépris des petits intérêts peut s'accorder avec l'ambition que les grands intérêts inspirent.

Abubéker passe chez les Osmanlis pour un grand homme et pour un musulman fidèle: c'est un des saints de l'Alcoran. Les Arabes rapportent son testament, conçu en ces termes : «Au nom de Dieu très miséricordieux, voici le testament d'Abubéker, fait dans le temps qu'il est prêt à passer de ce monde à l'autre; dans le temps où les infidèles croient, où les impies cessent de douter, et où les menteurs disent la vérité. " Ce début semble être d'un homme persuadé. Cependant Abubéker, beau-père de Mahomet, avait vu ce prophète de bien près. Il faut qu'il ait été trompé lui-même par le prophète, ou qu'il ait été le 
complice d'une imposture illustre, qu'il regardait comme nécessaire. Sa place lui ordonnait d'en imposer aux hommes pendant sa vie et à sa mort.

Omar, élu après lui, fut un des plus rapides conquérants qui aient désolé la terre. Il prend d'abord Damas, célèbre par la fertilité de son territoire, par les ouvrages d'acier les meilleurs de l'univers, par ces étoffes de soie qui portent encore son nom. Il chasse de la Syrie et de la Phénicie les Grecs qu'on appelait Romains ${ }^{162}$. Il reçoit à composition, après un long siège, la ville de Jérusalem, presque toujours occupée par des étrangers qui se succédèrent les uns aux autres, depuis que David l'eut enlevée à ses anciens citoyens : ce qui mérite la plus grande attention, c'est qu'il laissa aux juifs et aux chrétiens, habitants de Jérusalem, une pleine liberté de conscience.

Dans le même temps, les lieutenants d'Omar s'avançaient en Perse. Le dernier des rois persans, que nous appelons Hormisdas IV, livre bataille aux Arabes, à quelques lieues de Madain, devenue la capitale de cet empire. Il perd la bataille et la vie. Les Perses passent sous la domination d'Omar, plus facilement qu'ils n'avaient subi le joug d'Alexandre.

Alors tomba cette ancienne religion des mages que le vainqueur de Darius avait respectée; car il ne toucha jamais au culte des peuples vaincus.

Les mages, adorateurs d'un seul dieu, ennemis de tout simulacre, révéraient dans le feu, qui donne la vie à la nature, l'emblème de la Divinité. Ils regardaient leur religion comme la plus ancienne et la plus pure. La connaissance qu'ils avaient des mathématiques, de l'astronomie, et de l'histoire, augmentait leur mépris pour leurs vainqueurs, alors ignorants. Ils ne purent abandonner une religion consacrée par tant de siècles, pour une secte ennemie qui venait de naître. La plupart se retirèrent aux extrémités de la Perse et de l'Inde. C'est là qu'ils vivent aujourd'hui, sous le nom de Gaures ou de Guèbres, de Parsis, d'Ignicoles; ne se mariant qu'entre eux, entretenant le feu sacré, fidèles à ce qu'ils connaissent de leur ancien culte ; mais ignorants, méprisés, et, à leur pauvreté près, semblables aux Juifs si long-

162 Année 15 de l'hégire, 637 de l'ère vulgaire. 
temps dispersés sans s'allier aux autres nations, et plus encore aux Banians, qui ne sont établis et dispersés que dans l'Inde et en Perse. Il resta un grand nombre de familles guèbres ou ignicoles à Ispahan, jusqu'au temps de Sha-Abbas qui les bannit, comme Isabelle chassa les Juifs d'Espagne. Ils ne furent tolérés dans les faubourgs de cette ville que sous ses successeurs. Les ignicoles maudissent depuis longtemps dans leurs prières Alexandre et Mahomet; il est à croire qu'ils y ont joint Sha-Abbas.

Tandis qu'un lieutenant d'Omar subjugue la Perse, un autre enlève l'Égypte entière aux Romains, et une grande partie de la Libye. C'est dans cette conquête que fut brûlée la fameuse bibliothèque d'Alexandrie, monument des connaissances et des erreurs des hommes, commencé par Ptolémée Philadelphe, et augmenté par tant de rois. Alors les Sarrasins ne voulaient de science que l'Alcoran, mais ils faisaient déjà voir que leur génie pouvait s'étendre à tout. L'entreprise de renouveler en Égypte l'ancien canal creusé par les rois, et rétabli ensuite par Trajan, et de rejoindre ainsi le Nil à la mer Rouge, est digne des siècles les plus éclairés. Un gouverneur d'Égypte entreprend ce grand travail sous le califat d'Omar, et en vient à bout. Quelle différence entre le génie des Arabes et celui des Turcs! Ceuxci ont laissé périr un ouvrage dont la conservation valait mieux que la conquête d'une grande province.

Les amateurs de l'antiquité, ceux qui se plaisent à comparer les génies des nations, verront avec plaisir combien les mœurs, les usages du temps de Mahomet, d'Abubéker, d'Omar, ressemblaient aux mœurs antiques dont Homère a été le peintre fidèle. On voit les chefs défier à un combat singulier les chefs ennemis; on les voit s'avancer hors des rangs et combattre aux yeux des deux armées, spectatrices immobiles. Ils s'interrogent l'un l'autre, ils se parlent, ils se bravent, ils invoquent Dieu avant d'en venir aux mains. On livra plusieurs combats singuliers dans ce genre au siège de Damas.

Il est évident que les combats des Amazones, dont parlent Homère et Hérodote, ne sont point fondés sur des fables. Les femmes de la tribu d'Imiar, de l'Arabie Heureuse, étaient guerrières, et combattaient dans les armées d'Abubéker et d'Omar. On ne doit pas croire qu'il y ait jamais eu un royaume des Amazones, où les femmes vécussent sans hommes; mais dans les temps et dans les pays où l'on menait 
une vie agreste et pastorale, il n'est pas surprenant que des femmes, aussi durement élevées que les hommes, aient quelquefois combattu comme eux. On voit surtout au siège de Damas une de ces femmes, de la tribu d'Imiar, venger la mort de son mari tué à ses côtés, et percer d'un coup de flèche le commandant de la ville. Rien ne justifie plus l'Arioste et le Tasse, qui dans leurs poèmes font combattre tant d'héroïnes.

L'histoire vous en présentera plus d'une dans le temps de la chevalerie. Ces usages, toujours très rares, paraissent aujourd'hui incroyables, surtout depuis que l'artillerie ne laisse plus agir la valeur, l'adresse, l'agilité de chaque combattant, et que les armées sont devenues des espèces de machines régulières qui se meuvent comme par des ressorts.

Les discours des héros arabes à la tête des armées, ou dans les combats singuliers, ou en jurant des trêves, tiennent tous de ce naturel qu'on trouve dans Homère; mais ils ont incomparablement plus d'enthousiasme et de sublime.

Vers l'an 11 de l'hégire, dans une bataille entre l'armée d'Héraclius et celle des Sarrasins, le général mahométan, nommé Dérar, est pris ; les Arabes en sont épouvantés. Rasi, un de leurs capitaines, court à eux : "Qu'importe, leur dit-il, que Dérar soit pris ou mort ? Dieu est vivant et vous regarde : combattez. » Il leur fait tourner tête, et remporte la victoire.

Un autre s'écrie : «Voilà le ciel, combattez pour Dieu, et il vous donnera la terre. »

Le général Kaled prend dans Damas la fille d'Héraclius et la renvoie sans rançon : on lui demande pourquoi il en use ainsi : "C'est, dit-il, que j'espère reprendre bientôt la fille avec le père dans Constantinople. »

Quand le calife Moavia, prêt d'expirer, l'an 60 de l'hégire, fit assurer à son fils Iesid le trône des califes, qui jusqu'alors était électif, il dit : "Grand Dieu ! si j'ai établi mon fils dans le califat, parce que je l'en ai cru digne, je te prie d'affermir mon fils sur le trône ; mais si je n'ai agi que comme père, je te prie de l'en précipiter. » 
Tout ce qui arrive alors caractérise un peuple supérieur. Les succès de ce peuple conquérant semblent dus encore plus à l'enthousiasme qui l'anime qu'à ses conducteurs : car Omar est assassiné par un esclave perse, l'an 653 de notre ère. Othman, son successeur, l'est en 655 , dans une émeute. Ali, ce fameux gendre de Mahomet, n'est élu et ne gouverne qu'au milieu des troubles. Il meurt assassiné au bout de cinq ans, comme ses prédécesseurs ; et cependant les armes musulmanes sont toujours heureuses. Ce calife Ali, que les Persans révèrent aujourd'hui, et dont ils suivent les principes, en opposition à ceux d'Omar, avait transféré le siège des califes de la ville de Médine, où Mahomet est enseveli, dans celle de Cufa, sur les bords de l'Euphrate : à peine en reste-t-il aujourd'hui des ruines. C'est le sort de Babylone, de Séleucie, et de toutes les anciennes villes de la Chaldée, qui n'étaient bâties que de briques.

Il est évident que le génie du peuple arabe, mis en mouvement par Mahomet, fit tout de lui-même pendant près de trois siècles, et ressembla en cela au génie des anciens Romains. C'est en effet sous Valid, le moins guerrier des califes, que se font les plus grandes conquêtes. Un de ses généraux étend son empire jusqu'à Samarcande, en 707. Un autre attaque en même temps l'empire des Grecs vers la mer Noire. Un autre, en 711, passe d'Égypte en Espagne, soumise aisément tour à tour par les Carthaginois, par les Romains, par les Goths et les Vandales, et enfin par ces Arabes qu'on nomme Maures. Ils y établirent d'abord le royaume de Cordoue. Le sultan d'Égypte secoue à la vérité le joug du grand calife de Bagdad; et Abdérame, gouverneur de l'Espagne conquise, ne reconnaît plus le sultan d'Égypte : cependant, tout plie encore sous les armes musulmanes.

Cet Abdérame, petit-fils du calife Hescham, prend les royaumes de Castille, de Navarre, de Portugal, d'Aragon. Il s'établit en Languedoc ; il s'empare de la Guienne et du Poitou, et sans Charles Martel, qui lui ôta la victoire et la vie, la France était une province mahométane.

Après le règne de dix-neuf califes de la maison des Ommiades commence la dynastie des califes Abassides, vers l'an 752 de notre ère. Abougiafar-Almanzor, second calife Abasside, fixa le siège de ce grand empire à Bagdad, au delà de l'Euphrate, dans la Chaldée. Les Turcs disent qu'il en jeta les fondements. Les Persans assurent qu'elle 
était très ancienne, et qu'il ne fit que la réparer. C'est cette ville qu'on appelle quelquefois Babylone, et qui a été le sujet de tant de guerres entre la Perse et la Turquie.

La domination des califes dura six cent cinquante-cinq ans. Despotiques dans la religion comme dans le gouvernement, ils n'étaient point adorés ainsi que le grand lama, mais ils avaient une autorité plus réelle; et dans le temps même de leur décadence, ils furent respectés des princes qui les persécutaient. Tous ces sultans, turcs, arabes, tartares, reçurent l'investiture des califes avec bien moins de contestation que plusieurs princes chrétiens ne l'ont reçue des papes. On ne baisait point les pieds du calife; mais on se prosternait sur le seuil de son palais.

Si jamais puissance a menacé toute la terre, c'est celle de ces califes ; car ils avaient le droit du trône et de l'autel, du glaive et de l'enthousiasme. Leurs ordres étaient autant d'oracles, et leurs soldats autant de fanatiques.

Dès l'an 671, ils assiégèrent Constantinople, qui devait un jour devenir mahométane; les divisions, presque inévitables parmi tant de chefs audacieux, n'arrêtèrent pas leurs conquêtes. Ils ressemblèrent en ce point aux anciens Romains, qui parmi leurs guerres civiles avaient subjugué l'Asie Mineure.

À mesure que les mahométans devinrent puissants, ils se polirent. Ces califes, toujours reconnus pour souverains de la religion, et, en apparence, de l'empire, par ceux qui ne reçoivent plus leurs ordres de si loin, tranquilles dans leur nouvelle Babylone, y font bientôt renaître les arts. Aaron-al-Raschild, contemporain de Charlemagne, plus respecté que ses prédécesseurs, et qui sut se faire obéir jusqu'en Espagne et aux Indes, ranima les sciences, fit fleurir les arts agréables et utiles, attira les gens de lettres, composa des vers, et fit succéder dans ses vastes États la politesse à la barbarie. Sous lui les Arabes, qui adoptaient déjà les chiffres indiens, les apportèrent en Europe. Nous ne connûmes, en Allemagne et en France, le cours des astres que par le moyen de ces mêmes Arabes. Le mot seul d'Almanach en est encore un témoignage.

L'Almageste de Ptolémée fut alors traduit du grec en arabe par l'astronome Ben-Honaïn. Le calife Almamon fit mesurer géométri- 
quement un degré du méridien, pour déterminer la grandeur de la terre : opération qui n'a été faite en France que plus de huit cents ans après, sous Louis XIV. Ce même astronome, Ben-Honaïn, poussa ses observations assez loin, reconnut ou que Ptolémée avait fixé la plus grande déclinaison du soleil trop au septentrion, ou que l'obliquité de l'écliptique avait changé. Il vit même que la période de trente-six mille ans, qu'on avait assignée au mouvement prétendu des étoiles fixes d'occident en orient, devait être beaucoup raccourcie.

La chimie et la médecine étaient cultivées par les Arabes. La chimie, perfectionnée aujourd'hui par nous, ne nous fut connue que par eux. Nous leur devons de nouveaux remèdes, qu'on nomme les minoratifs, plus doux et plus salutaires que ceux qui étaient auparavant en usage dans l'école d'Hippocrate et de Galien. L'algèbre fut une de leurs inventions. Ce terme le montre encore assez; soit qu'il dérive du mot Algiabarat, soit plutôt qu'il porte le nom du fameux Arabe Geber, qui enseignait cet art dans notre huitième siècle. Enfin, dès le second siècle de Mahomet, il fallut que les chrétiens d'Occident s'instruisissent chez les musulmans.

Une preuve infaillible de la supériorité d'une nation dans les arts de l'esprit, c'est la culture perfectionnée de la poésie. Je ne parle pas de cette poésie enflée et gigantesque, de ce ramas de lieux communs et insipides sur le soleil, la lune et les étoiles, les montagnes et les mers; mais de cette poésie sage et hardie, telle qu'elle fleurit du temps d'Auguste, telle qu'on l'a vue renaître sous Louis XIV. Cette poésie d'image et de sentiment fut connue du temps d'Aaron-alRaschild. En voici, entre autres exemples, un qui m'a frappé, et que je rapporte ici parce qu'il est court. Il s'agit de la célèbre disgrâce de Giafar le Barmécide.

Mortel, faible mortel, à qui le sort prospère

Fait goûter de ses dons les charmes dangereux,

Connais quelle est des rois la faveur passagère ;

Contemple Barmécide, et tremble d'être heureux. 
Ce dernier vers surtout est traduit mot à mot. Rien ne me parait plus beau que tremble d'être heureux. La langue arabe avait l'avantage d'être perfectionnée depuis longtemps; elle était fixée avant Mahomet, et ne s'est point altérée depuis. Aucun des jargons qu'on parlait alors en Europe n'a pas seulement laissé la moindre trace. De quelque côté que nous nous tournions, il faut avouer que nous n'existons que d'hier. Nous allons plus loin que les autres peuples en plus d'un genre; et c'est peut-être parce que nous sommes venus les derniers. 


\section{Chapitre 7}

\section{De l'Alcoran, et de la loi musulmane. Examen si la religion musulmane était nouvelle, et si elle a été persécutante}

Le précédent chapitre a pu nous donner quelque connaissance des mœurs de Mahomet et de ses Arabes, par qui une grande partie de la terre éprouva une révolution si grande et si prompte : il faut tracer à présent une peinture fidèle de leur religion.

C'est un préjugé répandu parmi nous que le mahométisme n'a fait de si grands progrès que parce qu'il favorise les inclinations voluptueuses. On ne fait pas réflexion que toutes les anciennes religions de l'Orient ont admis la pluralité des femmes. Mahomet en réduisit à quatre le nombre illimité jusqu'alors. Il est dit que David avait dixhuit femmes, et Salomon sept cents, avec trois cents concubines. Ces rois buvaient du vin avec leurs compagnes. C'était donc la religion juive qui était voluptueuse, et celle de Mahomet était sévère.

C'est un grand problème parmi les politiques, si la polygamie est utile à la société et à la propagation. L'Orient a décidé cette question dans tous les siècles, et la nature est d'accord avec les peuples orientaux, dans presque toute espèce animale chez qui plusieurs femelles n'ont qu'un mâle. Le temps perdu par les grossesses, par les couches, par les incommodités naturelles aux femmes, semble exiger que ce temps soit réparé. Les femmes, dans les climats chauds, cessent de bonne heure d'être belles et fécondes. Un chef de famille, qui met sa gloire et sa prospérité dans un grand nombre d'enfants, a besoin d'une femme qui remplace une épouse inutile. Les lois de l'Occident semblent plus favorables aux femmes; celles de l'Orient, aux hommes et à l'État : il n'est point d'objet de législation qui ne puisse être un sujet de dispute. Ce n'est pas ici la place d'une dissertation; notre objet est de peindre les hommes plutôt que de les juger. 
On déclame tous les jours contre le paradis sensuel de Mahomet; mais l'antiquité n'en avait jamais connu d'autre. Hercule épousa Hébé dans le ciel, pour récompense des peines qu'il avait éprouvées sur la terre. Les héros buvaient le nectar avec les dieux; et, puisque l'homme était supposé ressusciter avec ses sens, il était naturel de supposer aussi qu'il goûterait, soit dans un jardin, soit dans quelque autre globe, les plaisirs propres aux sens, qui doivent jouir puisqu'ils subsistent. Cette créance fut celle des pères de l'Église du second et du troisième siècle. C'est ce qu'atteste précisément saint Justin, dans la seconde partie de ses Dialogues : " Jérusalem, dit-il, sera agrandie et embellie pour recevoir les saints, qui jouiront pendant mille ans de tous les plaisirs des sens. » Enfin le mot de paradis ne désigne qu'un jardin planté d'arbres fruitiers.

Cent auteurs, qui en ont copié un, ont écrit que c'était un moine nestorien qui avait composé l'Alcoran. Les uns ont nommé ce moine Sergius, les autres Boheïra; mais il est évident que les chapitres de l'Alcoran furent écrits suivant l'occurrence, dans les voyages de Mahomet, et dans ses expéditions militaires. Avait-il toujours ce moine avec lui ? On a cru encore, sur un passage équivoque de ce livre, que Mahomet ne savait ni lire ni écrire. Comment un homme qui avait fait le commerce vingt années, un poète, un médecin, un législateur, aurait-il ignoré ce que les moindres enfants de sa tribu apprenaient?

Le Koran, que je nomme ici Alcoran, pour me conformer à notre vicieux usage, veut dire le livre ou la lecture. Ce n'est point un livre historique dans lequel on ait voulu imiter les livres des Hébreux et nos Évangiles ; ce n'est pas non plus un livre purement de lois, comme le Lévitique ou le Deutéronome, ni un recueil de psaumes et de cantiques, ni une vision prophétique et allégorique dans le goût de l'Apocalypse ; c'est un mélange de tous ces divers genres, un assemblage de sermons dans lesquels on trouve quelques faits, quelques visions, des révélations, des lois religieuses et civiles.

Le Koran est devenu le code de la jurisprudence, ainsi que la loi canonique, chez toutes les nations mahométanes. Tous les interprètes de ce livre conviennent que sa morale est contenue dans ces paroles : " Recherchez qui vous chasse; donnez à qui vous ôte; pardonnez à qui vous offense; faites du bien à tous; ne contestez point avec les ignorants. " 
Il aurait dû bien plutôt recommander de ne point disputer avec les savants ; mais dans cette partie du monde, on ne se doutait pas qu'il y eût ailleurs de la science et des lumières.

Parmi les déclamations incohérentes dont ce livre est rempli, selon le goût oriental, on ne laisse pas de trouver des morceaux qui peuvent paraitre sublimes. Mahomet, par exemple, parlant de la cessation du déluge, s'exprime ainsi : «Dieu dit: Terre, engloutis tes eaux; ciel, puise les ondes que tu as versées : le ciel et la terre obéirent. »

Sa définition de Dieu est d'un genre plus véritablement sublime. On lui demandait quel était cet Alla qu'il annonçait : "C'est celui, répondit-il, qui tient l'être de soi-même, et de qui les autres le tiennent; qui n'engendre point et qui n'est point engendré, et à qui rien n'est semblable dans toute l'étendue des êtres. » Cette fameuse réponse, consacrée dans tout l'Orient, se trouve presque mot à mot dans l'antépénultième chapitre du Koran.

Il est vrai que les contradictions, les absurdités, les anachronismes, sont répandus en foule dans ce livre. On y voit surtout une ignorance profonde de la physique la plus simple et la plus connue. C'est là la pierre de touche des livres que les fausses religions prétendent écrits par la Divinité, car Dieu n'est ni absurde, ni ignorant ; mais le peuple, qui ne voit pas ces fautes, les adore, et les imans emploient un déluge de paroles pour les pallier.

Les commentateurs du Koran distinguent toujours le sens positif et l'allégorique, la lettre et l'esprit. On reconnaît le génie arabe dans les commentaires, comme dans le texte. Un des plus autorisés commentateurs dit que « le Koran porte tantôt une face d'homme, tantôt une face de bête », pour signifier l'esprit et la lettre.

Une chose qui peut surprendre bien des lecteurs, c'est qu'il n'y eut rien de nouveau dans la loi de Mahomet, sinon que Mahomet était prophète de Dieu.

En premier lieu, l'unité d'un être suprême, créateur et conservateur, était très ancienne. Les peines et les récompenses dans une autre vie, la croyance d'un paradis et d'un enfer, avaient été admises chez les Chinois, les Indiens, les Perses, les Égyptiens, les Grecs, les Ro- 
mains, et ensuite chez les Juifs ; et surtout chez les chrétiens, dont la religion consacra cette doctrine.

L'Alcoran reconnaît des anges et des génies, et cette créance vient des anciens Perses. Celle d'une résurrection et d'un jugement dernier était visiblement puisée dans le Talmud et dans le christianisme. Les mille ans que Dieu emploiera, selon Mahomet, à juger les hommes, et la manière dont il y procédera, sont des accessoires qui n'empêchent pas que cette idée ne soit entièrement empruntée. Le pont aigu sur lequel les ressuscités passeront, et du haut duquel les réprouvés tomberont en enfer, est tiré de la doctrine allégorique des mages.

C'est chez ces mêmes mages, c'est dans leur Jannat que Mahomet a pris l'idée d'un paradis, d'un jardin, où les hommes, revivant avec tous leurs sens perfectionnés, goûteront par ces sens mêmes toutes les voluptés qui leur sont propres, sans quoi ces sens leur seraient inutiles. C'est là qu'il a puisé l'idée de ces houris, de ces femmes célestes qui seront le partage des élus, et que les mages appelaient hourani, comme on le voit dans le Sadder. Il n'exclut point les femmes de son paradis, comme on le dit souvent parmi nous. Ce n'est qu'une raillerie sans fondement, telle que tous les peuples en font les uns des autres. Il promet des jardins, c'est le nom du paradis ; mais il promet pour souveraine béatitude la vision, la communication de l'Être suprême.

Le dogme de la prédestination absolue, et de la fatalité, qui semble aujourd'hui caractériser le mahométisme, était l'opinion de toute l'antiquité: elle n'est pas moins claire dans l'Iliade que dans l'Alcoran.

À l'égard des ordonnances légales, comme la circoncision, les ablutions, les prières, le pèlerinage de la Mecque, Mahomet ne fit que se conformer, pour le fond, aux usages reçus. La circoncision était pratiquée de temps immémorial chez les Arabes, chez les anciens Égyptiens, chez les peuples de la Colchide, et chez les Hébreux. Les ablutions furent toujours recommandées dans l'Orient comme un symbole de la pureté de l'âme.

Point de religion sans prières. La loi que Mahomet porta, de prier cinq fois par jour, était gênante, et cette gêne même fut respectable. Qui aurait osé se plaindre que la créature soit obligée d'adorer cinq fois par jour son créateur? 
Quant au pèlerinage de la Mecque, aux cérémonies pratiquées dans le Kaaba et sur la pierre noire, peu de personnes ignorent que cette dévotion était chère aux Arabes depuis un grand nombre de siècles. Le Kaaba passait pour le plus ancien temple du monde ; et, quoiqu'on y vénérât alors trois cents idoles, il était principalement sanctifié par la pierre noire, qu'on disait être le tombeau d'Ismaël. Loin d'abolir ce pèlerinage, Mahomet, pour se concilier les Arabes, en fit un précepte positif.

Le jeûne était établi chez plusieurs peuples, et chez les Juifs, et chez les chrétiens. Mahomet le rendit très sévère, en l'étendant à un mois lunaire, pendant lequel il n'est pas permis de boire un verre d'eau, ni de fumer, avant le coucher du soleil ; et ce mois lunaire, arrivant souvent au plus fort de l'été, le jeûne devint par là d'une si grande rigueur qu'on a été obligé d'y apporter des adoucissements, surtout à la guerre.

Il n'y a point de religion dans laquelle on n'ait recommandé l'aumône. La mahométane est la seule qui en ait fait un précepte légal, positif, indispensable. L'Alcoran ordonne de donner deux et demi pour cent de son revenu, soit en argent, soit en denrées.

On voit évidemment que toutes les religions ont emprunté tous leurs dogmes et tous leurs rites les unes des autres.

Dans toutes ces ordonnances positives, vous ne trouverez rien qui ne soit consacré par les usages les plus antiques. Parmi les préceptes négatifs, c'est-à-dire ceux qui ordonnent de s'abstenir, vous ne trouverez que la défense générale à toute une nation de boire du vin, qui soit nouvelle et particulière au mahométisme. Cette abstinence, dont les musulmans se plaignent, et se dispensent souvent dans les climats froids, fut ordonnée dans un climat brûlant, où le vin altérait trop aisément la santé et la raison. Mais, d'ailleurs, il n'était pas nouveau que des hommes voués au service de la Divinité se fussent abstenus de cette liqueur. Plusieurs collèges de prêtres en Égypte, en Syrie, aux Indes, les nazaréens, les récabites, chez les Juifs, s'étaient imposé cette mortification ${ }^{163}$.

163 Voyez, dans le Dictionnaire philosophique, l'article Arot et MAROT. (V.) 
Elle ne fut point révoltante pour les Arabes: Mahomet ne prévoyait pas qu'elle deviendrait un jour presque insupportable à ses musulmans dans la Thrace, la Macédoine, la Bosnie, et la Servie. Il ne savait pas que les Arabes viendraient un jour jusqu'au milieu de la France, et les Turcs mahométans devant les bastions de Vienne.

Il en est de même de la défense de manger du porc, du sang, et des bêtes mortes de maladies ; ce sont des préceptes de santé : le porc surtout est une nourriture très dangereuse dans ces climats, aussi bien que dans la Palestine, qui en est voisine. Quand le mahométisme s'est étendu dans les pays plus froids, l'abstinence a cessé d'être raisonnable, et n'a pas cessé de subsister.

La prohibition de tous les jeux de hasard est peut-être la seule loi dont on ne puisse trouver d'exemple dans aucune religion. Elle ressemble à une loi de couvent plutôt qu'à une loi générale d'une nation. Il semble que Mahomet n'ait formé un peuple que pour prier, pour peupler, et pour combattre.

Toutes ces lois qui, à la polygamie près, sont si austères, et sa doctrine qui est si simple, attirèrent bientôt à sa religion le respect et la confiance. Le dogme surtout de l'unité d'un Dieu, présenté sans mystère, et proportionné à l'intelligence humaine, rangea sous sa loi une foule de nations, et jusqu'à des nègres dans l'Afrique, et à des insulaires dans l'Océan indien.

Cette religion s'appela l'Islamisme, c'est-à-dire résignation à la volonté de Dieu ; et ce seul mot devait faire beaucoup de prosélytes. Ce ne fut point par les armes que l'Islamisme s'établit dans plus de la moitié de notre hémisphère, ce fut par l'enthousiasme, par la persuasion, et surtout par l'exemple des vainqueurs, qui a tant de force sur les vaincus. Mahomet; dans ses premiers combats en Arabie contre les ennemis de son imposture, faisait tuer sans miséricorde ses compatriotes rénitents. Il n'était pas alors assez puissant pour laisser vivre ceux qui pouvaient détruire sa religion naissante ; mais sitôt qu'elle fut affermie dans l'Arabie par la prédication et par le fer, les Arabes, franchissant les limites de leur pays, dont ils n'étaient point sortis jusqu'alors, ne forcèrent jamais les étrangers à recevoir la religion musulmane. Ils donnèrent toujours le choix aux peuples subjugués d'être musulmans, ou de payer tribut. Ils voulaient piller, dominer, faire des 
esclaves, mais non pas obliger ces esclaves à croire. Quand ils furent ensuite dépossédés de l'Asie par les Turcs et par les Tartares, ils firent des prosélytes de leurs vainqueurs mêmes; et des hordes de Tartares devinrent un grand peuple musulman. Par là on voit en effet qu'ils ont converti plus de monde qu'ils n'en ont subjugué.

Le peu que je viens de dire dément bien tout ce que nos historiens, nos déclamateurs et nos préjugés nous disent ; mais la vérité doit les combattre.

Bornons-nous toujours à cette vérité historique : le législateur des musulmans, homme puissant et terrible, établit ses dogmes par son courage et par ses armes; cependant sa religion devint indulgente et tolérante. L'instituteur divin du christianisme, vivant dans l'humilité et dans la paix, prêcha le pardon des outrages; et sa sainte et douce religion est devenue, par nos fureurs, la plus intolérante de toutes, et la plus barbare ${ }^{164}$.

Les mahométans ont eu comme nous des sectes et des disputes scolastiques ; il n'est pas vrai qu'il y ait soixante et treize sectes chez eux, c'est une de leurs rêveries. Ils ont prétendu que les mages en avaient soixante et dix, les juifs soixante et onze, les chrétiens soixante et douze, et que les musulmans, comme plus parfaits, devaient en avoir soixante et treize : étrange perfection, et bien digne des scolastiques de tous les pays!

Les diverses explications de l'Alcoran formèrent chez eux les sectes qu'ils nommèrent orthodoxes, et celles qu'ils nommèrent hérétiques. Les orthodoxes sont les sonnites, c'est-à-dire les traditionnistes, docteurs attachés à la tradition la plus ancienne, laquelle sert de sup-

164 Voyez sur les Albigeois, l'Essai sur les Mours, chap. 62, l'Histoire du Parlement, chap. XIX, et l'écrit intitulé Conspirations contre les peuples (dans les Mélanges, année 1766) ; sur les Vaudois, l'Essai, chap. 138 et l'écrit sur les Conspirations ; - sur les Hussites, l'Essai, chap. 72; - sur Mérindol le chapitre XLII de Dieu et les Hommes (Mélanges, année 1769), et à opuscule sur les Conspirations ; - sur Cabrières, ce dernier écrit, sur le massacre de Vassi, l'Essai sur les Mours, chap. 171; - sur la Saint Barthélemy, 1'Essai sur les guerres civiles (à la suite de la Henriade, tome VIII), le chap XLII de Dieu et les Hommes, et l'écrit sur les Conspirations ; sur les massacres d'Irlande, ce dernier opuscule, et l'Essai sur les Mours, chapitre 180 ; - sur les massacres de douze millions d'hommes égorgés en Amérique au nom de J.-C. et de la bonne Vierge la mère, le morceau déjà cité des Conspirations contre les peuples. (B.) 
plément à l'Alcoran. Ils sont divisés en quatre sectes, dont l'une domine aujourd'hui à Constantinople, une autre en Afrique, une troisième en Arabie, et une quatrième en Tartarie et aux Indes; elles sont regardées comme également utiles pour le salut.

Les hérétiques sont ceux qui nient la prédestination absolue, ou qui diffèrent des sonnites sur quelques points de l'école. Le mahométisme a eu ses pélagiens, ses scotistes, ses thomistes, ses molinistes, ses jansénistes : toutes ces sectes n'ont pas produit plus de révolutions que parmi nous. Il faut, pour qu'une secte fasse naître de grands troubles, qu'elle attaque les fondements de la secte dominante, qu'elle la traite d'impie, d'ennemie de Dieu et des hommes, qu'elle ait un étendard que les esprits les plus grossiers puissent apercevoir sans peine, et sous lequel les peuples puissent aisément se rallier. Telle a été la secte d'Ali, rivale de la secte d'Omar; mais ce n'est que vers le seizième siècle que ce grand schisme s'est établi; et la politique y a eu beaucoup plus de part que la religion. 


\section{Chapitre 8}

\section{De l'Italie et de l'Église avant Charlemagne. Comment le christianisme s'était établi. Examen s'il a souffert autant de persécutions qu'on le dit}

Rien n'est plus digne de notre curiosité que la manière dont Dieu voulut que l'Église s'établît, en faisant concourir les causes secondes à ses décrets éternels. Laissons respectueusement ce qui est divin à ceux qui en sont les dépositaires, et attachons-nous uniquement à l'historique. Des disciples de Jean s'établissent d'abord dans l'Arabie voisine de Jérusalem; mais les disciples de Jésus vont plus loin. Les philosophes platoniciens d'Alexandrie, où il y avait tant de Juifs, se joignent aux premiers chrétiens, qui empruntent des expressions de leur philosophie, comme celle du Logos, sans emprunter toutes leurs idées. Il y avait déjà quelques chrétiens à Rome du temps de Néron : on les confondait avec les Juifs, parce qu'ils étaient leurs compatriotes, parlant la même langue, s'abstenant comme eux des aliments défendus par la loi mosaïque. Plusieurs même étaient circoncis, et observaient le sabbat. Ils étaient encore si obscurs que ni l'historien Josèphe ni Philon n'en parlent dans aucun de leurs écrits. Cependant on voit évidemment que ces demi-juifs demi-chrétiens étaient, dès le commencement, partagés en plusieurs sectes, ébionites, marcionites, carpocratiens, valentiniens, caïnites. Ceux d'Alexandrie étaient fort différents de ceux de Syrie; les Syriens différaient des Achaïens. Chaque parti avait son évangile, et les véritables Juifs étaient les ennemis irréconciliables de tous ces partis.

Ces Juifs, également rigides et fripons, étaient encore dans Rome au nombre de quatre mille. Il y en avait eu huit mille du temps d'Auguste ; mais Tibère en fit passer la moitié en Sardaigne pour peupler cette île, et pour délivrer Rome d'un trop grand nombre d'usuriers. Loin de les gêner dans leur culte, on les laissait jouir de la 
tolérance qu'on prodiguait dans Rome à toutes les religions. On leur permettait des synagogues et des juges de leur nation, comme ils en ont aujourd'hui dans Rome chrétienne, où ils sont en plus grand nombre. On les regardait du même œil que nous voyons les Nègres, comme une espèce d'hommes inférieure. Ceux qui dans les colonies juives n'avaient pas assez de talents pour s'appliquer à quelque métier utile, et qui ne pouvaient couper du cuir et faire des sandales, faisaient des fables. Ils savaient les noms des anges, de la seconde femme d'Adam et de son précepteur, et ils vendaient aux dames romaines des philtres pour se faire aimer. Leur haine pour les chrétiens, ou galiléens, ou nazaréens, comme on les nommait alors, tenait de cette rage dont tous les superstitieux sont animés contre tous ceux qui se séparent de leur communion. Ils accusèrent les Juifs chrétiens de l'incendie qui consuma une partie de Rome sous Néron. Il était aussi injuste d'imputer cet accident aux chrétiens qu'à l'empereur : ni lui, ni les chrétiens, ni les Juifs, n'avaient aucun intérêt à brûler Rome ; mais il fallait apaiser le peuple, qui se soulevait contre des étrangers également haïs des Romains et des Juifs. On abandonna quelques infortunés à la vengeance publique. Il semble qu'on n'aurait pas dû compter, parmi les persécutions faites à leur foi, cette violence passagère : elle n'avait rien de commun avec leur religion, qu'on ne connaissait pas, et que les Romains confondaient avec le judaïsme, protégé par les lois autant que méprisé.

S'il est vrai qu'on ait trouvé en Espagne des inscriptions où Néron est remercié « d'avoir aboli dans la province une superstition nouvelle, » l'antiquité de ces monuments est plus que suspecte. S'ils sont authentiques, le christianisme n'y est pas désigné ; et si enfin ces monuments outrageants regardent les chrétiens, à qui peut-on les attribuer qu'aux Juifs jaloux établis en Espagne, qui abhorraient le christianisme comme un ennemi né dans leur sein ?

Nous nous garderons bien de vouloir percer l'obscurité impénétrable qui couvre le berceau de l'Église naissante, et que l'érudition même a quelquefois redoublée.

Mais ce qui est très certain, c'est qu'il n'y a que l'ignorance, le fanatisme, l'esclavage des écrivains copistes d'un premier imposteur, qui aient pu compter parmi les papes l'apôtre Pierre, Lin, Clet, et d'autres, dans le premier siècle. 
Il n'y eut aucune hiérarchie pendant près de cent ans parmi les chrétiens. Leurs assemblées secrètes se gouvernaient comme celles des primitifs ou quakers d'aujourd'hui. Ils observaient à la lettre le précepte de leur maître: "Les princes des nations dominent, il n'en sera pas ainsi entre vous : quiconque voudra être le premier sera le dernier. » La hiérarchie ne put se former que quand la société devint nombreuse, et ce ne fut que sous Trajan qu'il y eut des surveillants, episcopoi, que nous avons traduit par le mot d'évêque; des presbyteroi, des pistoi, des énergumènes, des catéchumènes. Il n'est question du terme pape dans aucun des auteurs des premiers siècles. Ce mot grec était inconnu dans le petit nombre des demi-juifs qui prenaient à Rome le nom de chrétiens.

Il est reconnu par tous les savants que Simon Barjone, surnommé Pierre, n'alla jamais à Rome ${ }^{165}$. On rit aujourd'hui de la preuve que des idiots tirèrent d'une épître attribuée à cet apôtre, né en Galilée. Il dit dans cette épître qu'il est à Babylone. Les seuls qui parlent de son prétendu martyre sont des fabulistes décriés, un Hégésippe, un Marcel, un Abdias, copiés depuis par Eusèbe. Ils content que Simon Barjone, et un autre Simon, qu'ils appellent le magicien, disputèrent sous Néron à qui ressusciterait un mort, et à qui s'élèverait le plus haut dans l'air ; que Simon Barjone fit tomber l'autre Simon, favori de Néron, et que cet empereur irrité fit crucifier Barjone, lequel, par humilité, voulut être crucifié la tête en bas. Ces inepties sont aujourd'hui méprisées de tous les chrétiens instruits ; mais depuis Constantin, elles furent autorisées jusqu'à la renaissance des lettres et du bon sens.

Pour prouver que Pierre ne mourut point à Rome, il n'y a qu'à observer que la première basilique bâtie par les chrétiens dans cette capitale est celle de Saint-Jean de Latran : c'est la première église latine ; l'aurait-on dédiée à Jean si Pierre avait été pape ?

La liste frauduleuse des prétendus premiers papes est tirée d'un livre apocryphe, intitulé le Pontifical de Damase, qui dit en parlant de Lin, prétendu successeur de Pierre, que Lin fut pape jusqu'à la treizième année de l'empereur Néron. Or c'est précisément cette année 13 qu'on fait crucifier Pierre : il y aurait donc eu deux papes à la fois.

165 Voyez, dans le Dictionnaire philosophique, l'article Voyage DE SAINT PIERRE À ROME. (B.) 
Enfin ce qui doit trancher toute difficulté aux yeux de tous les chrétiens, c'est que ni dans les Actes des Apôtres, ni dans les Épîtres de Paul, il n'est pas dit un seul mot d'un voyage de Simon Barjone à Rome. Le terme de siège, de pontificat, de papauté, attribué à Pierre, est d'un ridicule sensible. Quel siège qu'une assemblée inconnue de quelques pauvres de la populace juive !

C'est cependant sur cette fable que la puissance papale est fondée, et se soutient encore aujourd'hui après toutes ses pertes. Qu'on juge après cela comment l'opinion gouverne le monde, comment le mensonge subjugue l'ignorance, et combien ce mensonge a été utile pour asservir les peuples, les enchaîner, et les dépouiller.

C'est ainsi qu'autrefois les annalistes barbares de l'Europe comptaient parmi les rois de France un Pharamond, et son père Marcomir, et des rois d'Espagne, de Suède, d'Écosse, depuis le déluge. Il faut avouer que l'histoire, ainsi que la physique, n'a commencé à se débrouiller que sur la fin du seizième siècle. La raison ne fait que de naître.

Ce qui est encore certain, c'est que le génie du sénat ne fut jamais de persécuter personne pour sa croyance ; que jamais aucun empereur ne voulut forcer les Juifs à changer de religion, ni après la révolte sous Vespasien, ni après celle qui éclata sous Adrien. On insulta toujours à leur culte; ou s'en moqua; on érigea des statues dans leur temple avant sa ruine; mais jamais il ne vint dans l'idée d'aucun César, ni d'aucun proconsul, ni du sénat romain, d'empêcher les Juifs de croire à leur loi. Cette seule raison sert à faire voir quelle liberté eut le christianisme de s'étendre en secret, après s'être formé obscurément dans le sein du judaïsme.

Aucun des Césars n'inquiéta les chrétiens jusqu'à Domitien. Dion Cassius dit qu'il y eut sous cet empereur quelques personnes condamnées comme athées, et comme imitant les mœurs des Juifs. Il paraît que cette vexation, sur laquelle on a d'ailleurs si peu de lumières, ne fut ni longue ni générale. On ne sait précisément ni pourquoi il y eut quelques chrétiens bannis, ni pourquoi ils furent rappelés. Comment croire Tertullien, qui, sur la foi d'Hégésippe, rapporte sérieusement que Domitien interrogea les petits-fils de l'apôtre saint Jude, de la race de David, dont il redoutait les droits au trône de Judée, et que, les 
voyant pauvres et misérables, il cessa la persécution ? S'il eût été possible qu'un empereur romain craignît des prétendus descendants de David quand Jérusalem était détruite, sa politique n'en eût donc voulu qu'aux Juifs, et non aux chrétiens. Mais comment imaginer que le maître de la terre connue ait eu des inquiétudes sur les droits de deux petits-fils de saint Jude au royaume de la Palestine, et les ait interrogés ? Voilà malheureusement comme l'histoire a été écrite par tant d'hommes plus pieux qu'éclairés ${ }^{166}$.

Nerva, Vespasien, Tite, Trajan, Adrien, les Antonins, ne furent point persécuteurs. Trajan, qui avait renouvelé les défenses portées par la loi des Douze Tables contre les associations particulières, écrit à Pline : «Il ne faut faire aucune recherche contre les chrétiens. » Ces mots essentiels, il ne faut faire aucune recherche, prouvent qu'ils purent se cacher, se maintenir avec prudence, quoique souvent l'envie des prêtres et la haine des Juifs les traînât aux tribunaux et aux supplices. Le peuple les haïssait, et surtout le peuple des provinces, toujours plus dur, plus superstitieux et plus intolérant que celui de la capitale : il excitait les magistrats contre eux ; il criait qu'on les exposât aux bêtes dans les cirques. Adrien non seulement défendit à Fondanus, proconsul de l'Asie Mineure, de les persécuter, mais son ordonnance porte : « Si on calomnie les chrétiens, châtiez sévèrement le calomniateur. »

C'est cette justice d'Adrien qui a fait si faussement imaginer qu'il était chrétien lui-même. Celui qui éleva un temple à Antinoüs en aurait-il voulu élever à Jésus-Christ ?

Marc-Aurèle ordonna qu'on ne poursuivît point les chrétiens pour cause de religion. Caracalla, Héliogabale, Alexandre, Philippe, Gallien, les protégèrent ouvertement. Ils eurent donc tout le temps d'étendre et de fortifier leur Église naissante. Ils tinrent cinq conciles dans le premier siècle, seize dans le second, et trente-six dans le troisième. Les autels étaient magnifiques dès le temps de ce troisième siècle. L'histoire ecclésiastique en remarque quelques-uns ornés de colonnes d'argent, qui pesaient ensemble trois mille marcs. Les calices, faits sur le modèle des coupes romaines, et les patènes, étaient d'or pur.

166 Voyez le Dictionnaire philosophique, article DiocLÉTIEN. (B.) 
Les chrétiens jouirent d'une si grande liberté, malgré les cris et les persécutions de leurs ennemis, qu'ils avaient publiquement, dans plusieurs provinces, des églises élevées sur les débris de quelques temples tombés ou ruinés. Origène et saint Cyprien l'avouent; et il faut bien que le repos de l'Église ait été long, puisque ces deux grands hommes reprochent déjà à leurs contemporains le luxe, la mollesse, l'avarice, suite de la félicité et de l'abondance. Saint Cyprien se plaint expressément que plusieurs évêques, imitant mal les saints exemples qu'ils avaient sous leurs yeux, "accumulaient de grandes sommes d'argent, s'enrichissaient par l'usure, et ravissaient des terres par la fraude $»$. Ce sont ses propres paroles : elles sont un témoignage évident du bonheur tranquille dont on jouissait sous les lois romaines. L'abus d'une chose en démontre l'existence.

Si Décius, Maximin, et Dioclétien, persécutèrent les chrétiens, ce fut pour des raisons d'État: Décius, parce qu'ils tenaient le parti de la maison de Philippe, soupçonné, quoique à tort, d'être chrétien luimême ; Maximin, parce qu'ils soutenaient Gordien. Ils jouirent de la plus grande liberté pendant vingt années sous Dioclétien. Non seulement ils avaient cette liberté de religion que le gouvernement romain accorda de tout temps à tous les peuples, sans adopter leurs cultes ; mais ils participaient à tous les droits des Romains. Plusieurs chrétiens étaient gouverneurs de provinces. Eusèbe cite deux chrétiens, Dorothée et Gorgonius, officiers du palais, à qui Dioclétien prodiguait sa faveur. Enfin il avait épousé une chrétienne. Tout ce que nos déclamateurs écrivent contre Dioclétien n'est donc qu'une calomnie fondée sur l'ignorance. Loin de les persécuter, il les éleva au point qu'il ne fut plus en son pouvoir de les abattre.

En 303, Maximien Galère, qui les haïssait, engage Dioclétien à faire démolir l'église cathédrale de Nicomédie, élevée vis-à-vis le palais de l'empereur. Un chrétien plus qu'indiscret déchire publiquement l'édit; on le punit. Le feu consume quelques jours après une partie du palais de Galère ; on en accuse les chrétiens : cependant il n'y eut point de peine de mort décernée contre eux. L'édit portait qu'on brûlât leurs temples et leurs livres, qu'on privât leurs personnes de tous leurs honneurs.

Jamais Dioclétien n'avait voulu jusque-là les contraindre en matière de religion. Il avait, après sa victoire sur les Perses, donné des édits 
contre les manichéens attachés aux intérêts de la Perse, et secrets ennemis de l'empire romain. La seule raison d'État fut la cause de ces édits. S'ils avaient été dictés par le zèle de la religion, zèle que les conquérants ont si rarement, les chrétiens y auraient été enveloppés. Ils ne le furent pas; ils eurent par conséquent vingt années entières sous Dioclétien même pour s'affermir, et ne furent maltraités sous lui que pendant deux années; encore Lactance, Eusèbe, et l'empereur Constantin lui-même, imputent ces violences au seul Galère, et non à Dioclétien. Il n'est pas en effet vraisemblable qu'un homme assez philosophe pour renoncer à l'empire l'ait été assez peu pour être un persécuteur fanatique.

Dioclétien n'était à la vérité qu'un soldat de fortune ; mais c'est cela même qui prouve son extrême mérite. On ne peut juger d'un prince que par ses exploits et par ses lois. Ses actions guerrières furent grandes, et ses lois justes. C'est à lui que nous devons la loi qui annule les contrats de vente dans lesquels il y a lésion d'outre-moitié. Il dit luimême que l'humanité dicte cette loi, humanum est.

Il fut le père des pupilles trop négligés ; il voulut que les capitaux de leurs biens portassent intérêt.

C'est avec autant de sagesse que d'équité qu'en protégeant les mineurs il ne voulut pas que jamais ces mineurs pussent abuser de cette protection, en trompant leurs créanciers ou leurs débiteurs. Il ordonna qu'un mineur qui aurait usé de fraude serait déchu du bénéfice de la loi. Il réprima les délateurs et les usuriers. Tel est l'homme que l'ignorance se représente d'ordinaire comme un ennemi armé sans cesse contre les fidèles, et son règne comme une Saint-Barthélemy continuelle, ou comme la persécution des Albigeois. C'est ce qui est entièrement contraire à la vérité. L'ère des martyrs, qui commence à l'avènement de Dioclétien, n'aurait donc dû être datée que deux ans avant son abdication, puisqu'il ne fit aucun martyr pendant vingt ans.

C'est une fable bien méprisable qu'il ait quitté l'empire de regret de n'avoir pu abolir le christianisme. S'il l'avait tant persécuté, il aurait au contraire continué à régner pour tâcher de le détruire; et s'il fut forcé d'abdiquer, comme on l'a dit sans preuve, il n'abdiqua donc point par dépit et par regret. Le vain plaisir d'écrire des choses extraordinaires, et de grossir le nombre des martyrs, a fait ajouter des per- 
sécutions fausses et incroyables à celles qui n'ont été que trop réelles. On a prétendu que du temps de Dioclétien, en 287, le César Maximilien Hercule envoya au martyre, au milieu des Alpes, une légion entière appelée Thébéenne, composée de six mille six cents hommes, tous chrétiens, qui tous se laissèrent massacrer sans murmurer. Cette histoire si fameuse ne fut écrite que près de deux cents ans après par l'abbé Eucher, qui la rapporte sur des ouï-dire. Mais comment Maximilien Hercule aurait-il, comme on le dit, appelé d'Orient cette légion pour aller apaiser dans les Gaules une sédition réprimée depuis une année entière ? Pourquoi se serait-il défait de six mille six cents bons soldats dont il avait besoin pour aller réprimer cette sédition? Comment tous étaient-ils chrétiens sans exception ? Pourquoi les égorger en chemin? Qui les aurait massacrés dans une gorge étroite, entre deux montagnes, près de Saint-Maurice en Valais, où l'on ne peut ranger quatre cents hommes en ordre de bataille, et où une légion résisterait aisément à la plus grande armée ? À quel propos cette boucherie dans un temps où l'on ne persécutait pas, dans l'époque de la plus grande tranquillité de l'Église, tandis que sous les yeux de Dioclétien même, à Nicomédie, vis-à-vis son palais, les chrétiens avaient un temple superbe? « La profonde paix et la liberté entière dont nous jouissions, dit Eusèbe, nous fit tomber dans le relâchement. » Cette profonde paix, cette entière liberté s'accorde-t-elle avec le massacre de six mille six cents soldats? Si ce fait incroyable pouvait être vrai ${ }^{167}$, Eusèbe l'eût-il passé sous silence? Tant de vrais martyrs ont scellé l'Évangile de leur sang qu'on ne doit point faire partager leur gloire à ceux qui n'ont pas partagé leurs souffrances. Il est certain que Dioclétien, les deux dernières années de son empire, et Galère, quelques années encore après, persécutèrent violemment les chrétiens de l'Asie Mineure et des contrées voisines. Mais dans les Espagnes, dans les Gaules, dans l'Angleterre, qui étaient alors le partage de Constance Chlore, loin d'être poursuivis, ils virent leur religion dominante ; et Eusèbe dit que Maxence, élu empereur à Rome en 306, ne persécuta personne.

Ils servirent utilement Constance Chlore, qui les protégea, et dont la concubine Hélène embrassa publiquement le christianisme. Ils fi-

167 Voyez les Éclaircissements historiques sur cette Histoire générale (dans les Mélanges, année 1763). (V.) 
rent donc alors un grand parti dans l'État. Leur argent et leurs armes contribuèrent à mettre Constantin sur le trône. C'est ce qui le rendit odieux au sénat, au peuple romain, aux prétoriens, qui tous avaient pris le parti de Maxence, son concurrent à l'empire. Nos historiens appellent Maxence tyran, parce qu'il fut malheureux. Il est pourtant certain qu'il était le véritable empereur, puisque le sénat et le peuple romain l'avaient proclamé. 


\section{Chapitre 9}

\section{Que les fausses légendes des premiers chrétiens n'ont point nui à l'établissement de la religion chrétienne}

Jésus-Christ avait permis que les faux évangiles se mêlassent aux véritables dès le commencement du christianisme; et même, pour mieux exercer la foi des fidèles, les évangiles qu'on appelle aujourd'hui apocryphes précédèrent les quatre ouvrages sacrés qui sont aujourd'hui les fondements de notre foi ; cela est si vrai que les pères des premiers siècles citent presque toujours quelqu'un de ces évangiles qui ne subsistent plus. Barnabé, Clément, Ignace, enfin tous, jusqu'à Justin, ne citent que ces évangiles apocryphes. Clément, par exemple, dans le VIII ${ }^{\mathrm{e}}$ chapitre, épître II, s'exprime ainsi : "Le Seigneur dit dans son Évangile : si vous ne gardez pas le petit, qui vous confiera le grand ? » Or ces paroles ne sont ni dans Matthieu, ni dans Marc, ni dans Luc, ni dans Jean. Nous avons vingt exemples de pareilles citations.

Il est bien évident que dans les dix ou douze sectes qui partageaient les chrétiens dès le premier siècle, un parti ne se prévalait pas des évangiles de ses adversaires, à moins que ce fut pour les combattre ; chacun n'apportait en preuves que les livres de son parti. Comment donc les pères de notre véritable Église ont-ils pu citer les évangiles qui ne sont point canoniques? Il faut bien que ces écrits fussent regardés alors comme authentiques et comme sacrés.

Ce qui paraîtrait encore plus singulier, si l'on ne savait pas de quels excès la nature humaine est capable, ce serait que dans toutes les sectes chrétiennes réprouvées par notre Église dominante, il se fût trouvé des hommes qui eussent souffert la persécution pour leurs évangiles apocryphes. Cela ne prouverait que trop que le faux zèle est martyr de l'erreur, ainsi que le véritable zèle est martyr de la vérité. 
On ne peut dissimuler les fraudes pieuses que malheureusement les premiers chrétiens de toutes les sectes employèrent pour soutenir notre religion sainte, qui n'avait pas besoin de cet appui honteux. On supposa une lettre de Pilate à Tibère, dans laquelle Pilate dit à cet empereur : "Le Dieu des Juifs leur ayant promis de leur envoyer son saint du haut du ciel, qui serait leur roi à bien juste titre, et ayant promis qu'il naîtrait d'une Vierge, le Dieu des Juifs l'a envoyé en effet, moi étant président en Judée. »

On supposa un prétendu édit de Tibère, qui mettait Jésus au rang des dieux ; on supposa des Lettres de Sénèque à Paul, et de Paul à Sénèque ; on supposa le Testament des douze patriarches, qui passa très longtemps pour authentique, et qui fut même traduit en grec par saint Jean Chrysostome ; on supposa le Testament de Moïse, celui d'Énoch, celui de Joseph ; on supposa le célèbre livre d'Énoch, que l'on regarde comme le fondement de tout le christianisme, puisque c'est dans ce seul livre qu'on rapporte l'histoire de la révolte des anges précipités dans l'enfer, et changés en diables pour tenter les hommes. Ce livre fut forgé dès le temps des apôtres, et avant même qu'on eût les Épîtres de saint Jude, qui cite les prophéties de cet Énoch, septième homme après Adam. C'est ce que nous avons déjà indiqué dans le chapitre des Indes.

On supposa une lettre ${ }^{168}$ de Jésus-Christ à un prétendu roi d'Édesse, dans le temps qu'Édesse n'avait point de roi et qu'elle appartenait aux Romains ${ }^{169}$.

On supposa les Voyages de saint Pierre, l'Apocalypse de saint Pierre, les Actes de saint Pierre, les Actes de saint Paul, les Actes de Pilate, on falsifia l'histoire de Flavien Josèphe, et l'on fut assez malavisé pour faire dire à ce Juif, si zélé pour sa religion juive, que Jésus était le Christ, le Messie.

On écrivit le roman de la querelle de saint Pierre avec Simon le magicien, d'un mort, parent de Néron, qu'ils se chargèrent de ressus-

168 Peut-être faut-il lire ici : Une lettre d'un prétendu roi d'Édesse à Jésus-Christ, et la réponse de Jésus-Christ. Voyez, dans le Dictionnaire philosophique, le mot APOCRYPHES. (B.)

169 On donne à ce prétendu roi le nom propre d'Abgare : «Le roi Abgare à Jésus ; » et Abgare était le titre des anciens princes de ce petit pays. (V.) 
citer, de leur combat dans les airs, du chien de Simon qui apportait des lettres à saint Pierre, et qui rapportait les réponses.

On supposa des vers des sibylles, qui eurent un cours si prodigieux qu'il en est encore fait mention dans les hymnes que les catholiques romains chantent dans leurs églises :

$$
\text { «Teste David cum sibylla. « }
$$

Enfin on supposa un nombre prodigieux de martyrs que l'on confondit, comme nous l'avons déjà dit, avec les véritables.

Nous avons encore les Actes du martyre de saint André l'apôtre, qui sont reconnus pour faux par les plus pieux et les plus savants critiques, de même que les Actes du martyre de saint Clément.

Eusèbe de Césarée, au quatrième siècle, recueillit une grande partie de ces légendes. C'est là qu'on voit d'abord le martyre de saint Jacques, frère aîné de Jésus-Christ, qu'on prétend avoir été un bon Juif, et même récabite, et que les Juifs de Jérusalem appelaient Jacques-leJuste. Il passait les journées entières à prier dans le temple. Il n'était donc pas de la religion de son frère. Ils le pressèrent de déclarer que son frère était un imposteur ; mais Jacques leur répondit : "Sachez qu'il est assis à la droite de la souveraine puissance de Dieu, et qu'il doit paraître au milieu des nuées, pour juger de là tout l'univers. »

Ensuite vient un Siméon, cousin germain de Jésus-Christ, fils d'un nommé Cléophas, et d'une Marie, sœur de Marie, mère de Jésus. On le fait libéralement évêque de Jérusalem. On suppose qu'il fut déféré aux Romains comme descendant en droite ligne du roi David; et l'on fait voir par là qu'il avait un droit évident au royaume de Jérusalem, aussi bien que saint Jude. On ajoute que Trajan, craignant extrêmement la race de David, ne fut pas si clément envers Siméon que Domitien l'avait été envers les petits-fils de Jude, et qu'il ne manqua pas de faire crucifier Siméon, de peur qu'il ne lui enlevât la Palestine. Il fallait que ce cousin germain de Jésus-Christ fût bien vieux, puisqu'il vivait sous Trajan dans la cent septième année de notre ère vulgaire.

On supposa une longue conversation entre Trajan et saint Ignace, à Antioche. Trajan lui dit : " Qui es-tu, esprit impur, démon infernal ?» Ignace lui répondit: «Je ne m'appelle point esprit impur; je 
m'appelle Porte-Dieu !» Cette conversation est tout à fait vraisemblable.

Vient ensuite une sainte Symphorose avec ses sept enfants qui allèrent voir familièrement l'empereur Adrien, dans le temps qu'il bâtissait sa belle maison de campagne à Tibur. Adrien, quoiqu'il ne persécutât jamais personne, fit fendre en sa présence le cadet des sept frères, de la tête en bas, et fit tuer les six autres avec la mère par des genres différents de mort, pour avoir plus de plaisir.

Sainte Félicité et ses sept enfants, car il en faut toujours sept, est interrogée avec eux, jugée et condamnée par le préfet de Rome dans le champ de Mars, où l'on ne jugeait jamais personne. Le préfet jugeait dans le prétoire ; mais on n'y regarda pas de si près.

Saint Polycarpe étant condamné au feu, on entend une voix du ciel qui lui dit: "Courage, Polycarpe, sois ferme »; et aussitôt les flammes du bûcher se divisent et forment un beau dais sur sa tête, sans le toucher.

Un cabaretier chrétien, nommé saint Théodote, rencontre dans un pré le curé Fronton auprès de la ville d'Ancyre, on ne sait pas trop quelle année, et c'est bien dommage ; mais c'est sous l'empereur Dioclétien. «Ce pré, dit la légende recueillie par le révérend père Bollandus, était d'un vert naissant, relevé par les nuances diverses que formaient les divers coloris des fleurs. " Ah ! le beau pré, s'écria le saint cabaretier, pour y bâtir une chapelle ! - Vous avez raison, dit le curé Fronton, mais il me faut des reliques. - Allez, allez, reprit Théodote, je vous en fournirai. » Il savait bien ce qu'il disait. Il y avait dans Ancyre sept vierges chrétiennes d'environ soixante-douze ans chacune. Elles furent condamnées par le gouverneur à être violées par tous les jeunes gens de la ville, selon les lois romaines ; car ces légendes supposent toujours qu'on faisait souffrir ce supplice à toutes les filles chrétiennes.

Il ne se trouva heureusement aucun jeune homme qui voulût être leur exécuteur ; il n'y eut qu'un jeune ivrogne qui eut assez de courage pour s'attaquer d'abord à sainte Técuse, la plus jeune de toutes, qui était dans sa soixante-douzième année. Técuse se jeta à ses pieds, lui montra la peau flasque de ses cuisses décharnées, et toutes ses rides pleines de crasse, etc. : cela désarma le jeune homme. Le gouverneur, 
indigné que les sept vieilles eussent conservé leur pucelage, les fit surle-champ prêtresses de Diane et de Minerve ; et elles furent obligées de servir toutes nues ces deux déesses, dont pourtant les femmes n'approchaient jamais que voilées de la tête aux pieds.

Le cabaretier Théodote, les voyant ainsi toutes nues, et ne pouvant souffrir cet attentat fait à leur pudeur, pria Dieu avec larmes qu'il eût la bonté de les faire mourir sur-le-champ : aussitôt le gouverneur les fit jeter dans le lac d'Ancyre, une pierre au cou.

La bienheureuse Técuse apparut la nuit à saint Théodote. "Vous dormez, mon fils, lui dit-elle, sans penser à nous. Ne souffrez pas, mon cher Théodote, que nos corps soient mangés par les truites. » Théodote rêva un jour entier à cette apparition.

La nuit suivante il alla au lac avec quelques-uns de ses garçons. Une lumière éclatante marchait devant eux, et cependant la nuit était fort obscure. Une pluie épouvantable tomba, et fit enfler le lac. Deux vieillards dont les cheveux, la barbe et les habits étaient blancs comme la neige, lui apparurent alors, et lui dirent: «Marchez, ne craignez rien, voici un flambeau céleste, et vous trouverez auprès du lac un cavalier céleste armé de toutes pièces, qui vous conduira. »

Aussitôt l'orage redoubla. Le cavalier céleste se présenta avec une lance énorme. Ce cavalier était le glorieux martyr Sosiandre luimême, à qui Dieu avait ordonné de descendre du ciel sur un beau cheval pour conduire le cabaretier. Il poursuivit les sentinelles du lac, la lance dans les reins : les sentinelles s'enfuirent. Théodote trouva le lac à sec, ce qui était l'effet de la pluie; on emporta les sept vierges, et les garçons cabaretiers les enterrèrent.

La légende ne manque pas de rapporter leurs noms : c'étaient sainte Técuse, sainte Alexandra, sainte Phainé, hérétiques ; et sainte Claudia, sainte Euphrasie, sainte Matrone, et sainte Julite, catholiques.

Dès qu'on sut dans la ville d'Ancyre que ces sept pucelles avaient été enterrées, toute la ville fut en alarmes et en combustion, comme vous le croyez bien. Le gouverneur fit appliquer Théodote à la question. " Voyez, disait Théodote, les biens dont Jésus-Christ comble ses serviteurs; il me donne le courage de souffrir la question, et bientôt je serai brûlé. » Il le fut en effet. Mais il avait promis des reliques au 
curé Fronton, pour mettre dans sa chapelle, et Fronton n'en avait point. Fronton monta sur un âne pour aller chercher ses reliques à Ancyre, et chargea son âne de quelques bouteilles d'excellent vin, car il s'agissait d'un cabaretier. Il rencontra des soldats, qu'il fit boire. Les soldats lui racontèrent le martyre de saint Théodote. Ils gardaient son corps, quoiqu'il eût été réduit en cendres. Il les enivra si bien qu'il eut le temps d'enlever le corps. Il l'ensevelit, et bâtit sa chapelle. «Eh bien! lui dit saint Théodote, ne t'avais-je pas bien dit que tu aurais des reliques?»

Voilà ce que les jésuites Bollandus et Papebroc ne rougirent pas de rapporter dans leur Histoire des saints : voilà ce qu'un moine, nommé dom Ruinart, a l'insolente imbécillité d'insérer dans les Actes sincères ${ }^{170}$.

Tant de fraudes, tant d'erreurs, tant de bêtises dégoûtantes, dont nous sommes inondés depuis dix-sept cents années, n'ont pu faire tort à notre religion. Elle est sans doute divine, puisque dix-sept siècles de friponneries et d'imbécillités n'ont pu la détruire; et nous révérons d'autant plus la vérité que nous méprisons le mensonge.

${ }^{170}$ Lefranc, évêque du Puy-en-Velay, dans une pastorale aux habitants de ce pays, a pris le parti de tous ces outrages ridicules faits à la raison et à la vraie piété. Que ne dit-il aussi que le prépuce de la verge de Jésus-Christ, soigneusement gardé au Puy-en-Velay, et une vieille statue d'Isis qu'on y prend pour une image de la Vierge, sont des pièces authentiques ? Quelle infamie de vouloir toujours tromper les hommes ! et quelle sottise de s'imaginer qu'on les trompe aujourd'hui. (V.) 


\section{Chapitre 10 \\ Suite de l'établissement du christianisme. Comment Constantin en fit la religion dominante. Décadence de l'ancienne Rome}

Le règne de Constantin est une époque glorieuse pour la religion chrétienne, qu'il rendit triomphante. On n'avait pas besoin d'y joindre des prodiges, comme l'apparition du labarum dans les nuées, sans qu'on dise seulement en quel pays cet étendard apparut. Il ne fallait pas écrire que les gardes du labarum ne pouvaient jamais être blessés. Le bouclier tombé du ciel dans l'ancienne Rome, l'oriflamme apportée à saint Denis par un ange, toutes ces imitations du Palladium de Troie ne servent qu'à donner à la vérité l'air de la fable. De savants antiquaires ont suffisamment réfuté ces erreurs que la philosophie désavoue, et que la critique détruit. Attachons-nous seulement à voir comment Rome cessa d'être Rome.

Pour développer l'histoire de l'esprit humain chez les peuples chrétiens, il fallait remonter jusqu'à Constantin, et même au-delà. C'est une nuit dans laquelle il faut allumer soi-même le flambeau dont on a besoin. On devrait attendre des lumières d'un homme tel qu'Eusèbe, évêque de Césarée, confident de Constantin, ennemi d'Athanase, homme d'État, homme de lettres, qui le premier fit l'histoire de l'Église.

Mais qu'on est étonné quand on veut s'instruire dans les écrits de cet homme d'État, père de l'histoire ecclésiastique !

On y trouve, à propos de l'empereur Constantin, que « Dieu a mis les nombres dans son unité ; qu'il a embelli le monde par le nombre de deux, et que par le nombre de trois il le composa de matière et de forme ; qu'ensuite ayant doublé le nombre de deux, il inventa les quatre éléments; que c'est une chose merveilleuse qu'en faisant l'addition d'un, de deux, de trois, et de quatre, on trouve le nombre de 
dix, qui est la fin, le terme et la perfection de l'unité ; et que de ce nombre dix si parfait, multiplié par le nombre plus parfait de trois, qui est l'image sensible de la Divinité, il en résulte le nombre des trente jours du mois ${ }^{171}$.»

C'est ce même Eusèbe qui rapporte la lettre dont nous avons déjà parlé ${ }^{172}$, d'un Abgare, roi d'Édesse, à Jésus-Christ, dans laquelle il lui offre sa petite ville, qui est assez propre ; et la réponse de Jésus-Christ au roi Abgare.

Il rapporte, d'après Tertullien, que sitôt que l'empereur Tibère eut appris par Pilate la mort de Jésus-Christ, Tibère, qui chassait les Juifs de Rome, ne manqua pas de proposer au sénat d'admettre au nombre des dieux de l'empire celui qu'il ne pouvait connaître encore que comme un homme de Judée; que le sénat n'en voulut rien faire, et que Tibère en fut extrêmement courroucé.

Il rapporte, d'après Justin, la prétendue statue élevée à Simon le magicien; il prend les Juifs thérapeutes pour des chrétiens.

C'est lui qui, sur la foi d'Hégésippe, prétend que les petits-neveux de Jésus-Christ par son frère Jude furent déférés à l'empereur Domitien comme des personnages très dangereux qui avaient un droit tout naturel au trône de David; que cet empereur prit lui-même la peine de les interroger ; qu'ils répondirent qu'ils étaient de bons paysans, qu'ils labouraient de leurs mains un champ de trente-neuf arpents, le seul bien qu'ils possédassent.

Il calomnie les Romains autant qu'il le peut, parce qu'il était Asiatique. Il ose dire que, de son temps, le sénat de Rome sacrifiait tous les ans un homme à Jupiter. Est-il donc permis d'imputer aux Titus, aux Trajan, aux divins Antonins, des abominations dont aucun peuple ne se souillait alors dans le monde connu?

C'est ainsi qu'on écrivait l'histoire dans ces temps où le changement de religion donna une nouvelle face à l'empire romain. Grégoire de Tours ne s'est point écarté de cette méthode, et on peut dire que jusqu'à Guichardin et Machiavel, nous n'avons pas eu une histoire

171 Eusèbe, Panégyrique de Constantin, chapitres IV et V. (V.)

172 Chapitre 9. (B.) 
bien faite ; mais la grossièreté même de tous ces monuments nous fait voir l'esprit du temps dans lequel ils ont été faits, et il n'y a pas jusqu'aux légendes qui ne puissent nous apprendre à connaître les mœurs de nos nations.

Constantin, devenu empereur malgré les Romains, ne pouvait être aimé d'eux. Il est évident que le meurtre de Licinius, son beau-frère, assassiné malgré la foi des serments ; Licinien, son neveu, massacré à l'âge de douze ans ; Maximien, son beau-père, égorgé par son ordre à Marseille; son propre fils Crispus, mis à mort après lui avoir gagné des batailles; son épouse Fausta, étouffée dans un bain; toutes ces horreurs n'adoucirent pas la haine qu'on lui portait. C'est probablement la raison qui lui fit transférer le siège de l'empire à Byzance. On trouve dans le code Théodosien un édit de Constantin, où il déclare «qu'il a fondé Constantinople par ordre de Dieu.» Il feignait ainsi une révélation pour imposer silence aux murmures : ce trait seul pourrait faire connaître son caractère. Notre avide curiosité voudrait pénétrer dans les replis du cœur d'un homme tel que Constantin, par qui tout changea bientôt dans l'empire romain : séjour du trône, mœurs de la cour, usages, langage, habillements, administration, religion. Comment démêler celui qu'un parti a peint comme le plus criminel des hommes, et un autre comme le plus vertueux ? Si l'on pense qu'il fit tout servir à ce qu'il crut son intérêt, on ne se trompera pas.

De savoir s'il fut cause de la ruine de l'empire, c'est une recherche digne de votre esprit. Il paraît évident qu'il fit la décadence de Rome. Mais en transportant le trône sur le Bosphore de Thrace, il posait dans l'Orient des barrières contre les invasions des barbares qui inondèrent l'empire sous ses successeurs, et qui trouvèrent l'Italie sans défense. Il semble qu'il ait immolé l'Occident à l'Orient. L'Italie tomba quand Constantinople s'éleva. Ce serait une étude curieuse et instructive que l'histoire politique de ces temps-là. Nous n'avons guère que des satires et des panégyriques. C'est quelquefois par les panégyriques mêmes qu'on peut trouver la vérité. Par exemple, on comble d'éloges Constantin, pour avoir fait dévorer par les bêtes féroces, dans les jeux du cirque, tous les chefs des Francs, avec tous les prisonniers qu'il avait faits dans une expédition sur le Rhin. C'est ainsi que furent traités les prédécesseurs de Clovis et de Charlemagne. Les écrivains qui ont été assez lâches pour louer des actions cruelles constatent au moins ces actions, et les lecteurs sages les jugent. Ce que nous avons 
de plus détaillé, sur l'histoire de cette révolution, est-ce qui regarde l'établissement de l'Église et ses troubles.

Ce qu'il y a de déplorable, c'est qu'à peine la religion chrétienne fut sur le trône que la sainteté en fut profanée par des chrétiens qui se livrèrent à la soif de la vengeance, lors même que leur triomphe devait leur inspirer l'esprit de paix. Ils massacrèrent dans la Syrie et dans la Palestine tous les magistrats qui avaient sévi contre eux; ils noyèrent la femme et la fille de Maximin ; ils firent périr dans les tourments ses fils et ses parents. Les querelles au sujet de la consubsantialité $d u$ Verbe troublèrent le monde et l'ensanglantèrent. Enfin Ammien Marcellin dit que «les chrétiens de son temps se déchiraient entre eux comme des bêtes féroces ${ }^{173}$ \%. Il y avait de grandes vertus qu'Ammien ne remarque pas: elles sont presque toujours cachées, surtout à des yeux ennemis, et les vices éclatent.

L'Église de Rome fut préservée de ces crimes et de ces malheurs; elle ne fut d'abord ni puissante, ni souillée ; elle resta longtemps tranquille et sage au milieu d'un sénat et d'un peuple qui la méprisaient. Il y avait dans cette capitale du monde connu sept cents temples, grands ou petits, dédiés aux dieux majorum et minorum gentium. Ils subsistèrent jusqu'à Théodose, et les peuples de la campagne persistèrent longtemps après lui dans leur ancien culte. C'est ce qui fit donner aux sectateurs de l'ancienne religion le nom de païens, pagani, du nom des bourgades appelées pagi, dans lesquelles on laissa subsister l'idolâtrie jusqu'au huitième siècle; de sorte que le nom de païen ne signifie que paysan, villageois.

On sait assez sur quelle imposture est fondée la donation de Constantin ; mais cette pièce est aussi rare que curieuse. Il est utile de la transcrire ici pour faire connaitre l'excès de l'absurde insolence de

173 N. B. Ces propres paroles se trouvent au livre XXII d'Ammien Marcellin, chap. V. Un misérable cuistre de collège, ex-jésuite, nommé Nonotte, auteur d'un libelle intitulé Erreurs de Voltaire, a osé soutenir que ces paroles ne sont point dans Ammien Marcellin. Il est utile qu'un calomniateur ignorant soit confondu. Nullas infestas hominibus bestias, ut sunt sibi ferales plerique christianorum, expertus. Ammien.

Idem dicit Chrysostomus, homelia in Ep. Pauli ad Cor. , ajoute naïvement Henri de Valois dans ses notes sur Ammien, page 301 de l'édition de 1681. (K.) 
ceux qui gouvernaient les peuples, et l'excès de l'imbécillité des gouvernés. C'est Constantin qui parle ${ }^{174}$ :

« Nous, avec nos satrapes et tout le sénat, et le peuple soumis au glorieux empire, nous avons jugé utile de donner au successeur du prince des apôtres une plus grande puissance que celle que notre sérénité et notre mansuétude ont sur la terre. Nous avons résolu de faire honorer la sacro-sainte Église romaine plus que notre puissance impériale, qui n'est que terrestre; et nous attribuons au sacré siège du bienheureux Pierre toute la dignité, toute la gloire, et toute la puissance impériale. Nous possédons les corps glorieux de saint Pierre et de saint Paul, et nous les avons honorablement mis dans des caisses d'ambre, que la force des quatre éléments ne peut casser. Nous avons donné plusieurs grandes possessions en Judée, en Grèce, dans l'Asie, dans l'Afrique, et dans l'Italie, pour fournir aux frais de leurs luminaires. Nous donnons, en outre, à Silvestre et à ses successeurs notre palais de Latran, qui est plus beau que tous les autres palais du monde.

« Nous lui donnons notre diadème, notre couronne, notre mitre, tous les habits impériaux que nous portons, et nous lui remettons la dignité impériale, et le commandement de la cavalerie. Nous voulons que les révérendissimes clercs de la sacro-sainte romaine Église jouissent de tous les droits du sénat. Nous les créons tous patrices et consuls. Nous voulons que leurs chevaux soient toujours ornés de caparaçons blancs, et que nos principaux officiers tiennent ces chevaux par la bride, comme nous avons conduit nous-même par la bride le cheval du sacré pontife.

« Nous donnons en pur don au bienheureux pontife la ville de Rome et toutes les villes occidentales de l'Italie, comme aussi les autres villes occidentales des autres pays. Nous cédons la place au saintpère ; nous nous démettons de la domination sur toutes ces provinces ; nous nous retirons de Rome, et transportons le siège de notre empire en la province de Byzance, n'étant pas juste qu'un empereur terrestre ait le moindre pouvoir dans les lieux où Dieu a établi le chef de la religion chrétienne.

174 Voyez l'ouvrage connu sous le titre de Décret de Gratien, ou cette pièce est insérée. Ce décret est une compilation faite par Gratien, bénédictin du douzième siècle. (K.) 
« Nous ordonnons que cette nôtre donation demeure ferme jusqu'à la fin du monde, et que si quelqu'un désobéit à notre décret, nous voulons qu'il soit damné éternellement, et que les apôtres Pierre et Paul lui soient contraires en cette vie et en l'autre, et qu'il soit plongé au plus profond de l'enfer avec le diable. Donné sous le consulat de Constantin et de Gallicanus. »»

Croira-t-on un jour qu'une si ridicule imposture, très digne de Gille et de Pierrot, ou de Nonotte, ait été généralement adoptée pendant plusieurs siècles ? Croira-t-on qu'en 1478 on brûla dans Strasbourg des chrétiens qui osaient douter que Constantin eût cédé l'empire romain au pape?

Constantin donna en effet, non au seul évêque de Rome, mais à la cathédrale qui était l'église de Saint-Jean, mille marcs d'or, et trente mille d'argent, avec quatorze mille sous de rente, et des terres dans la Calabre. Chaque empereur ensuite augmenta ce patrimoine. Les évêques de Rome en avaient besoin. Les missions qu'ils envoyèrent bientôt dans l'Europe païenne, les évêques chassés de leurs sièges, auxquels ils donnèrent un asile, les pauvres qu'ils nourrirent, les mettaient dans la nécessité d'être très riches. Le crédit de la place, supérieur aux richesses, fit bientôt du pasteur des chrétiens de Rome l'homme le plus considérable de l'Occident. La piété avait toujours accepté ce ministère ; l'ambition le brigua. On se disputa la chaire ; il y eut deux antipapes dès le milieu du quatrième siècle ; et le consul Prétextat, idolâtre, disait, en 466 : «Faites-moi évêque de Rome, et je me fais chrétien. »

Cependant cet évêque n'avait d'autre pouvoir que celui que peut donner la vertu, le crédit, ou l'intrigue dans des circonstances favorables. Jamais aucun pasteur de l'Église n'eut la juridiction contentieuse, encore moins les droits régaliens. Aucun n'eut ce qu'on appelle jus terrendi, ni droit de territoire, ni droit de prononcer do, dico, addico. Les empereurs restèrent les juges suprêmes de tout, hors du dogme. Ils convoquèrent les conciles. Constantin, à Nicée, reçut et jugea les accusations que les évêques portèrent les uns contre les autres. Le titre de souverain pontife resta même attaché à l'empire. 


\section{Chapitre 11}

\section{Causes de la chute de l'empire romain}

Si quelqu'un avait pu raffermir l'empire, ou du moins retarder sa chute, c'était l'empereur Julien. Il n'était point un soldat de fortune, comme les Dioclétien et les Théodose. Né dans la pourpre, élu par les armées, chéri des soldats, il n'avait point de factions à craindre ; on le regardait, depuis ses victoires en Allemagne, comme le plus grand capitaine de son siècle. Nul empereur ne fut plus équitable et ne rendit la justice plus impartialement, non pas même Marc-Aurèle. Nul philosophe ne fut plus sobre et plus continent. Il régnait donc par les lois, par la valeur, et par l'exemple. Si sa carrière eût été plus longue, il est à présumer que l'empire eût moins chancelé après sa mort.

Deux fléaux détruisirent enfin ce grand colosse : les barbares, et les disputes de religion.

Quant aux barbares, il est aussi difficile de se faire une idée nette de leurs incursions que de leur origine. Procope, Jornandès, nous ont débité des fables que tous nos auteurs copient. Mais le moyen de croire que les Huns, venus du nord de la Chine, aient passé les PalusMéotides à gué et à la suite d'une biche, et qu'ils aient chassé devant eux, comme des troupeaux de moutons, des nations belliqueuses qui habitaient les pays aujourd'hui nommés la Crimée, une partie de la Pologne, l'Ukraine, la Moldavie, la Valachie ? Ces peuples robustes et guerriers, tels qu'ils le sont encore aujourd'hui, étaient connus des Romains sous le nom général de Goths. Comment ces Goths s'enfuirent-ils sur les bords du Danube, dès qu'ils virent paraître les Huns ? Gomment demandèrent-ils à mains jointes que les Romains daignassent les recevoir? et comment, dès qu'ils furent passés, ravagèrent-ils tout jusqu'aux portes de Constantinople à main armée? 
Tout cela ressemble à des contes d'Hérodote, et à d'autres contes non moins vantés. Il est bien plus vraisemblable que tous ces peuples coururent au pillage les uns après les autres. Les Romains avaient volé les nations ; les Goths et les Huns vinrent voler les Romains.

Mais pourquoi les Romains ne les exterminèrent-ils pas, comme Marius avait exterminé les Cimbres ? c'est qu'il ne se trouvait point de Marius ; c'est que les mœurs étaient changées ; c'est que l'empire était partagé entre les ariens et les athanasiens. On ne s'occupait que de deux objets, les courses du cirque et les trois hypostases. L'empire romain avait alors plus de moines que de soldats, et ces moines couraient en troupes de ville en ville pour soutenir ou pour détruire la consubstantialité du Verbe. Il y en avait soixante et dix mille en Égypte.

Le christianisme ouvrait le ciel, mais il perdait l'empire : car non seulement les sectes nées dans son sein se combattaient avec le délire des querelles théologiques, mais toutes combattaient encore l'ancienne religion de l'empire; religion fausse, religion ridicule sans doute, mais sous laquelle Rome avait marché de victoire en victoire pendant dix siècles.

Les descendants des Scipion étant devenus des controversistes, les évêchés étant plus brigués que ne l'avaient été les couronnes triomphales, la considération personnelle ayant passé des Hortensius et des Cicéron aux Cyrille, aux Grégoire, aux Ambroise, tout fut perdu ; et si l'on doit s'étonner de quelque chose, c'est que l'empire romain ait subsisté encore un peu de temps.

Théodose, qu'on appelle le grand Théodose, paya un tribut au superbe Alaric, sous le nom de pension du trésor impérial. Alaric mit Rome à contribution la première fois qu'il parut devant les murs, et la seconde il la mit au pillage. Tel était alors l'avilissement de l'empire de Rome que ce Goth dédaigna d'être roi de Rome, tandis que le misérable empereur d'Occident, Honorius, tremblait dans Ravenne, où il s'était réfugié.

Alaric se donna le plaisir de créer dans Rome un empereur nommé Attale, qui venait recevoir ses ordres dans son antichambre. L'histoire nous a conservé deux anecdotes concernant Honorius, qui montrent bien tout l'excès de la turpitude de ces temps : la première, qu'une des 
causes du mépris où Honorius était tombé, c'est qu'il était impuissant; la seconde, c'est qu'on proposa à cet Attale, empereur, valet d'Alaric, de châtrer Honorius pour rendre son ignominie plus complète.

Après Alaric vint Attila, qui ravageait tout, de la Chine jusqu'à la Gaule. Il était si grand, et les empereurs Théodose et Valentinien III si petits, que la princesse Honoria, sœur de Valentinien III, lui proposa de l'épouser. Elle lui envoya son anneau pour gage de sa foi ; mais avant qu'elle eût réponse d'Attila, elle était déjà grosse de la façon d'un de ses domestiques.

Lorsque Attila eut détruit la ville d'Aquilée, Léon, évêque de Rome, vint mettre à ses pieds tout l'or qu'il avait pu recueillir des Romains pour racheter du pillage les environs de cette ville dans laquelle l'empereur Valentinien III était caché. L'accord étant conclu, les moines ne manquèrent pas d'écrire que le pape Léon avait fait trembler Attila ; qu'il était venu à ce Hun avec un air et un ton de maître ; qu'il était accompagné de saint Pierre et de saint Paul, armés tous deux d'épées flamboyantes, qui étaient visiblement les deux glaives de l'Église de Rome. Cette manière d'écrire l'histoire a duré, chez les chrétiens, jusqu'au seizième siècle sans interruption.

Bientôt après, des déluges de barbares inondèrent de tous côtés ce qui était échappé aux mains d'Attila.

Que faisaient cependant les empereurs? ils assemblaient des conciles. C'était tantôt pour l'ancienne querelle des partisans d'Athanase, tantôt pour les donatistes; et ces disputes agitaient l'Afrique quand le Vandale Genseric la subjugua. C'était d'ailleurs pour les arguments de Nestorius et de Cyrille, pour les subtilités d'Eutychès; et la plupart des articles de foi se décidaient quelquefois à grands coups de bâton, comme il arriva sous Théodose II, dans un concile convoqué par lui à Éphèse, concile qu'on appelle encore aujourd'hui le brigandage. Enfin, pour bien connaître l'esprit de ce malheureux temps, souvenonsnous qu'un moine ayant été rebuté un jour par Théodose II, qu'il importunait, le moine excommunia l'empereur; et que ce César fut obligé de se faire relever de l'excommunication par le patriarche de Constantinople. 
Pendant ces troubles mêmes, les Francs envahissaient la Gaule ; les Visigoths s'emparaient de l'Espagne ; les Ostrogoths, sous Théodose, dominaient en Italie, bientôt après chassés par les Lombards. L'empire romain, du temps de Clovis, n'existait plus que dans la Grèce, l'Asie Mineure et dans l'Égypte; tout le reste était la proie des barbares. Scythes, Vandales et Francs, se firent chrétiens pour mieux gouverner les provinces chrétiennes assujetties par eux; car il ne faut pas croire que ces barbares fussent sans politique ; ils en avaient beaucoup, et en ce point tous les hommes sont à peu près égaux. L'intérêt rendit donc chrétiens ces déprédateurs ; mais ils n'en furent que plus inhumains. Le jésuite Daniel, historien français, qui déguise tant de choses, n'ose dissimuler que Clovis fut beaucoup plus sanguinaire, et se souilla de plus grands crimes après son baptême que tandis qu'il était païen. Et ces crimes n'étaient pas de ces forfaits héroïques qui éblouissent l'imbécillité humaine : c'étaient des vols et des parricides. Il suborna un prince de Cologne qui assassina son père ; après quoi il fit massacrer le fils; il tua un roitelet de Cambrai qui lui montrait ses trésors. Un citoyen moins coupable eût été traîné au supplice, et Clovis fonda une monarchie. 


\section{Chapitre 12}

\section{Suite de la décadence de l'ancienne Rome}

Quand les Goths s'emparèrent de Rome après les Hérules ; quand le célèbre Théodoric, non moins puissant que le fut depuis Charlemagne, eut établi le siège de son empire à Ravenne, au commencement de notre sixième siècle, sans prendre le titre d'empereur d'Occident qu'il eût pu s'arroger, il exerça sur les Romains précisément la même autorité que les Césars ; conservant le sénat, laissant subsister la liberté de religion, soumettant également aux lois civiles, orthodoxes, ariens et idolâtres ; jugeant les Goths par les lois gothiques, et les Romains par les lois romaines ; présidant par ses commissaires aux élections des évêques; défendant la simonie, apaisant les schismes. Deux papes se disputaient la chaire épiscopale ; il nomma le pape Symmaque, et ce pape Symmaque étant accusé, il le fit juger par ses Missi dominici.

Athalaric, son petit-fils, régla les élections des papes et de tous les autres métropolitains de ses royaumes, par un édit qui fut observé ; édit rédigé par Cassiodore, son ministre, qui depuis se retira au MontCassin, et embrassa la règle de saint Benoît; édit auquel le pape Jean II se soumit sans difficulté.

Quand Bélisaire vint en Italie, et qu'il la remit sous le pouvoir impérial, on sait qu'il exila le pape Sylvère, et qu'en cela il ne passa point les bornes de son autorité, s'il passa celles de la justice. Bélisaire, et ensuite Narsès, ayant arraché Rome au joug des Goths, d'autres barbares, Gépides, Francs, Germains, inondèrent l'Italie. Tout l'empire occidental était dévasté et déchiré par des sauvages. Les Lombards établirent leur domination dans toute l'Italie citérieure. Alboin, fondateur de cette nouvelle dynastie, n'était qu'un brigand barbare ; mais bientôt les vainqueurs adoptèrent les mœurs, la politesse, la religion des vaincus. C'est ce qui n'était pas arrivé aux premiers 
Francs, aux Bourguignons, qui portèrent dans les Gaules leur langage grossier, et leurs mœurs encore plus agrestes. La nation lombarde était d'abord composée de païens et d'ariens. Leur roi Rotharic publia, vers l'an 640, un édit qui donna la liberté de professer toutes sortes de religions ; de sorte qu'il y avait dans presque toutes les villes d'Italie un évêque catholique et un évêque arien, qui laissaient vivre paisiblement les peuples nommés idolâtres, répandus encore dans les villages.

Le royaume de Lombardie s'étendit depuis le Piémont jusqu'à Brindes et à la terre d'Otrante ; il renfermait Bénévent, Bari, Tarente ; mais il n'eut ni la Pouille, ni Rome, ni Ravenne : ces pays demeurèrent annexés au faible empire d'Orient. L'Église romaine avait donc repassé de la domination des Goths à celle des Grecs. Un exarque gouvernait Rome au nom de l'empereur; mais il ne résidait point dans cette ville, presque abandonnée à elle-même. Son séjour était à Ravenne, d'où il envoyait ses ordres au duc ou préfet de Rome, et aux sénateurs, qu'on appelait encore Pères conscripts. L'apparence du gouvernement municipal subsistait toujours dans cette ancienne capitale si déchue, et les sentiments républicains n'y furent jamais éteints. Ils se soutenaient par l'exemple de Venise, république fondée d'abord par la crainte et par la misère, et bientôt élevée par le commerce et par le courage. Venise était déjà si puissante qu'elle rétablit au huitième siècle l'exarque Scolastique, qui avait été chassé de Ravenne.

Quelle était donc aux septième et huitième siècles la situation de Rome ? celle d'une ville malheureuse, mal défendue par les exarques, continuellement menacée par Lombards, et reconnaissant toujours les empereurs pour maîtres. Le crédit des papes augmentait dans la désolation de la ville. Ils en étaient souvent les consolateurs et les pères ; mais toujours sujets, ils ne pouvaient être consacrés qu'avec la permission expresse de l'exarque. Les formules par lesquelles cette permission était demandée et accordée subsistent encore ${ }^{175}$. Le clergé romain écrivait au métropolitain de Ravenne, et demandait la protection de sa béatitude auprès du gouverneur; ensuite le pape envoyait à ce métropolitain sa profession de foi.

175 Dans le Diarium romanum. (V.) 
Le roi lombard Astolfe s'empara enfin de tout l'exarchat de Ravenne, en 751, et mit fin à cette Vice-royauté impériale qui avait duré cent quatre-vingt-trois ans.

Comme le duché de Rome dépendait de l'exarchat de Ravenne, Astolfe prétendit avoir Rome par le droit de sa conquête. Le pape Étienne II, seul défenseur des malheureux Romains, envoya demander du secours à l'empereur Constantin, surnommé Copronyme. Ce misérable empereur envoya pour tout secours un officier du palais, avec une lettre pour le roi lombard. C'est cette faiblesse des empereurs grecs qui fut l'origine du nouvel empire d'Occident et de la grandeur pontificale.

Vous ne voyez avant ce temps aucun évêque qui ait aspiré à la moindre autorité temporelle, au moindre territoire. Comment l'auraient-ils osé ? leur législateur fut un pauvre qui catéchisa des pauvres. Les successeurs de ces premiers chrétiens furent pauvres.

Le clergé ne fit un corps que sous Constantin $\mathrm{I}^{\mathrm{er}}$; mais cet empereur ne souffrit pas qu'un évêque fût propriétaire d'un seul village. Ce ne peut être que dans des temps d'anarchie que les papes aient obtenu quelques seigneuries. Ces domaines furent d'abord médiocres. Tout s'agrandit, et tout tombe avec le temps.

Lorsqu'on passe de l'histoire de l'empire romain à celle des peuples qui l'ont déchiré dans l'Occident, on ressemble à un voyageur qui, au sortir d'une ville superbe, se trouve dans des déserts couverts de ronces. Vingt jargons barbares succèdent à cette belle langue latine qu'on parlait du fond de l'Illyrie au mont Atlas. Au lieu de ces sages lois qui gouvernaient la moitié de notre hémisphère, on ne trouve plus que des coutumes sauvages. Les cirques, les amphithéâtres élevés dans toutes les provinces sont changés en masures couvertes de paille. Ces grands chemins si beaux, si solides, établis du pied du Capitole jusqu'au mont Taurus, sont couverts d'eaux croupissantes. La même révolution se fait dans les esprits; et Grégoire de Tours, le moine de Saint-Gall, Frédegaire, sont nos Polybe et nos Tite-Live. L'entendement humain s'abrutit dans les superstitions les plus lâches et les plus insensées. Ces superstitions sont portées au point que des moines deviennent seigneurs et princes; ils ont des esclaves, et ces esclaves n'osent pas même se plaindre. L'Europe entière croupit dans 
cet avilissement jusqu'au seizième siècle, et n'en sort que par des convulsions terribles. 


\section{Chapitre 13}

Origine de la puissance des papes. Digression sur le sacre des rois. Lettre de Saint-Pierre à Pepin, maire de France, devenu roi. Prétendues donations au Saint-Siège.

Il n'y a que trois manières de subjuguer les hommes : celle de les policer en leur proposant des lois, celle d'employer la religion pour appuyer ces lois, celle enfin d'égorger une partie d'une nation pour gouverner l'autre; je n'en connais pas une quatrième. Toutes les trois demandent des circonstances favorables. Il faut remonter à l'antiquité la plus reculée pour trouver des exemples de la première ; encore sontils suspects. Charlemagne, Clovis, Théodoric, Alboin, Alaric, se servirent de la troisième ; les papes employèrent la seconde.

Le pape n'avait pas originairement plus de droit sur Rome que saint Augustin n'en aurait eu, par exemple, à la souveraineté de la petite ville d'Hippone. Quand même saint Pierre aurait demeuré à Rome, comme on l'a dit sur ce qu'une de ses épîtres est datée de Babylone ; quand même il eût été évêque de Rome, dans un temps où il n'y avait certainement aucun siège particulier, ce séjour dans Rome ne pouvait donner le trône des Césars; et nous avons vu que les évêques de Rome ne se regardèrent, pendant sept cents ans, que comme des sujets.

Rome, tant de fois saccagée par les barbares, abandonnée des empereurs, pressée par les Lombards, incapable de rétablir l'ancienne république, ne pouvait plus prétendre à la grandeur. Il lui fallait du repos : elle l'aurait goûté si elle avait pu dès lors être gouvernée par son évêque, comme le furent depuis tant de villes d'Allemagne; et l'anarchie eût au moins produit ce bien. Mais il n'était pas encore reçu dans l'opinion des chrétiens qu'un évêque pût être souverain, quoiqu'on eût, dans l'histoire du monde, tant d'exemples de l'union du sacerdoce et de l'empire dans d'autres religions. 
Le pape Grégoire III recourut le premier à la protection des Francs contre les Lombards et contre les empereurs. Zacharie, son successeur, animé du même esprit, reconnut Pepin ou Pipin, maire du palais, usurpateur du royaume de France, pour roi légitime. On a prétendu que Pepin, qui n'était que premier ministre, fit demander d'abord au pape quel était le vrai roi, ou de celui qui n'en avait que le droit et le nom, ou de celui qui en avait l'autorité et le mérite; et que le pape décida que le ministre devait être roi. Il n'a jamais été prouvé qu'on ait joué cette comédie ; mais ce qui est vrai, c'est que le pape Étienne III appela Pepin à son secours contre les Lombards, qu'il vint en France se jeter aux pieds de Pepin, en 754, et ensuite le couronner avec des cérémonies qu'on appelait sacre. C'était une imitation d'un ancien appareil judaïque. Samuel avait versé de l'huile sur la tête de Saül ; les rois lombards se faisaient ainsi sacrer; les ducs de Bénévent même avaient adopté cet usage, pour en imposer aux peuples. On employait l'huile dans l'installation des évêques; et on croyait imprimer un caractère de sainteté au diadème, en y joignant une cérémonie épiscopale. Un roi goth, nommé Vamba, fut sacré en Espagne avec de l'huile bénite, en 674. Mais les Arabes vainqueurs firent bientôt oublier cette cérémonie, que les Espagnols n'ont jamais renouvelée.

Pepin ne fut donc pas le premier roi sacré en Europe, comme nous l'écrivons tous les jours. Il avait déjà reçu cette onction de l'Anglais Boniface, missionnaire en Allemagne, et évêque de Mayence, qui, ayant voyagé longtemps en Lombardie, le sacra suivant l'usage de ce pays.

Remarquez attentivement que ce Boniface avait été créé évêque de Mayence par Carloman, frère de l'usurpateur Pepin, sans aucun concours du pape, sans que la cour romaine influât alors sur la nomination des évêchés dans le royaume des Francs. Rien ne vous convaincra plus que toutes les lois civiles et ecclésiastiques sont dictées par la convenance, que la force les maintient, que la faiblesse les détruit, et que le temps les change. Les évêques de Rome prétendaient une autorité suprême, et ne l'avaient pas. Les papes, sous le joug des rois lombards, auraient laissé toute la puissance ecclésiastique en France au premier Franc qui les aurait délivrés du joug en Italie.

Le pape Étienne avait plus besoin de Pepin que Pepin n'avait besoin de lui ; il y parait bien, puisque ce fut le prêtre qui vint implorer 
la protection du guerrier. Le nouveau roi fit renouveler son sacre par l'évêque de Rome dans l'église de Saint-Denys : ce fait paraît singulier. On ne se fait pas couronner deux fois quand on croit la première cérémonie suffisante. Il paraît donc que, dans l'opinion des peuples, un évêque de Rome était quelque chose de plus saint, de plus autorisé qu'un évêque d'Allemagne; que les moines de Saint-Denys, chez qui se faisait le second sacre, attachaient plus d'efficacité à l'huile répandue sur la tête d'un Franc par un évêque romain qu'à l'huile répandue par un missionnaire de Mayence ; et que le successeur de saint Pierre avait plus droit qu'un autre de légitimer une usurpation.

Pepin fut le premier roi sacré en France, et non le seul qui l'y ait été par un pontife de Rome ; car Innocent III couronna depuis, et sacra Louis-le-Jeune à Reims. Clovis n'avait été ni couronné ni sacré roi par l'évêque Remi. Il y avait longtemps qu'il régnait quand il fut baptisé. S'il avait reçu l'onction royale, ses successeurs auraient adopté une cérémonie si solennelle, devenue bientôt nécessaire. Aucun ne fut sacré jusqu'à Pepin, qui reçut l'onction dans l'abbaye de Saint-Denys.

Ce ne fut que trois cents ans après Clovis que l'archevêque de Reims, Hincmar, écrivit qu'au sacre de Clovis un pigeon avait apporté du ciel une fiole qu'on appelle la sainte ampoule. Peut-être crut-il fortifier par cette fable le droit de sacrer les rois, que ces métropolitains commençaient alors à exercer. Ce droit ne s'établit qu'avec le temps,comme tous les autres usages ; et ces prélats, longtemps après, sacrèrent constamment les rois, depuis Philippe $\mathrm{I}^{\text {er }}$ jusqu'à Henri IV, qui fut couronné à Chartres, et oint de l'ampoule de saint Martin, parce que les ligueurs étaient maîtres de l'ampoule de saint Remi.

Il est vrai que ces cérémonies n'ajoutent rien aux droits des monarques, mais elles semblent ajouter à la vénération des peuples.

Il n'est pas douteux que cette cérémonie du sacre, aussi bien que l'usage d'élever les rois francs, goths et lombards, sur un bouclier, ne vinssent de Constantinople. L'empereur Cantacuzène nous apprend lui-même que c'était un usage immémorial d'élever les empereurs sur un bouclier, soutenu par les grands officiers de l'empire et par le patriarche; après quoi l'empereur montait du trône au pupitre de l'église, et le patriarche faisait le signe de la croix sur sa tête avec un plumasseau trempé dans de l'huile bénite; les diacres apportaient la 
couronne ; le principal officier, ou le prince du sang impérial le plus proche, mettait la couronne sur la tête du nouveau César; le patriarche et le peuple criaient: "Il en est digne.» Mais au sacre des rois d'Occident, l'évêque dit au peuple : «Voulez-vous ce roi ? » et ensuite le roi fait serment au peuple, après l'avoir fait aux évêques.

Le pape Étienne ne s'en tint pas avec Pepin à cette cérémonie ; il défendit aux Français, sous peine d'excommunication, de se donner jamais des rois d'une autre race. Tandis que cet évêque, chassé de sa patrie, et suppliant dans une terre étrangère, avait le courage de donner des lois, sa politique prenait une autorité qui assurait celle de Pepin ; et ce prince, pour mieux jouir de ce qui ne lui était pas dû, laissait au pape des droits qui ne lui appartenaient pas.

Hugues Capet en France, et Conrad en Allemagne, firent voir depuis qu'une telle excommunication n'est pas une loi fondamentale.

Cependant l'opinion, qui gouverne le monde, imprima d'abord dans les esprits un si grand respect pour la cérémonie faite par le pape à Saint-Denys qu'Éginhard, secrétaire de Charlemagne, dit en termes exprès que « le roi Hilderic fut déposé par ordre du pape Étienne. »

Tous ces événements ne sont qu'un tissu d'injustice, de rapine, de fourberie. Le premier des domestiques d'un roi de France dépouillait son maître Hilderic III, l'enfermait dans le couvent de Saint-Bertin, tenait en prison le fils de son maître dans le couvent de Fontenelle en Normandie ; un pape venait de Rome consacrer ce brigandage.

On croirait que c'est une contradiction que ce pape fût venu en France se prosterner aux pieds de Pepin, et disposer ensuite de la couronne; mais non: ces prosternements n'étaient regardés alors que comme le sont aujourd'hui nos révérences; c'était l'ancien usage de l'Orient. On saluait les évêques à genoux; les évêques saluaient de même les gouverneurs de leurs diocèses. Charles, fils de Pepin, avait embrassé les pieds du pape Étienne à Saint-Maurice en Valais : Étienne embrassa ceux de Pepin. Tout cela était sans conséquence. Mais peu à peu les papes attribuèrent à eux seuls cette marque de respect. On prétend que le pape Adrien $\mathrm{I}^{\mathrm{er}}$ fut celui qui exigea qu'on ne parût jamais devant lui sans lui baiser les pieds. Les empereurs et les rois se soumirent depuis, comme les autres, à cette cérémonie, qui rendait la 
religion romaine plus vénérable à la populace, mais qui a toujours indigné tous les hommes d'un ordre supérieur.

On nous dit que Pepin passa les monts en 754 ; que le Lombard Astolfe, intimidé par la seule présence du Franc, céda aussitôt au pape tout l'exarchat de Ravenne ; que Pepin repassa les monts, et qu'à peine s'en fut-il retourné qu'Astolfe, au lieu de donner Ravenne au pape, mit le siège devant Rome. Toutes les démarches de ces temps-là étaient si irrégulières qu'il se pourrait à toute force que Pepin eût donné aux papes l'exarchat de Ravenne, qui ne lui appartenait point, et qu'il eût même fait cette donation du bien d'autrui sans prendre aucune mesure pour la faire exécuter. Cependant il est bien peu vraisemblable qu'un homme tel que Pepin, qui avait détrôné son roi, n'ait passé en Italie avec une armée que pour y aller faire des présents. Rien n'est plus douteux que cette donation citée dans tant de livres. Le bibliothécaire Anastase, qui écrivait cent quarante ans après l'expédition de Pepin, est le premier qui parle de cette donation. Mille auteurs l'ont citée, les meilleurs publicistes d'Allemagne la réfutent, la cour romaine ne peut la prouver, mais elle en jouit.

Il régnait alors dans les esprits un mélange bizarre de politique et de simplicité, de grossièreté et d'artifice, qui caractérise bien la décadence générale. Étienne feignit une lettre de saint Pierre, adressée du ciel à Pepin et à ses enfants; elle mérite d'être rapportée; la voici : «Pierre, appelé apôtre par Jésus-Christ, fils du Dieu vivant, etc... Comme par moi toute l'Église catholique, apostolique, romaine, mère de toutes les autres Églises, est fondée sur la pierre, qu'Étienne est évêque de cette douce Église romaine; et afin que la grâce et la vertu soient pleinement accordées du Seigneur notre Dieu, pour arracher l'Église de Dieu des mains des persécuteurs : à vous, excellents Pepin, Charles et Carloman, trois rois, et à tous saints évêques et abbés, prêtres et moines, et même aux ducs, aux comtes, et aux peuples, moi Pierre, apôtre, etc... je vous conjure, et la vierge Marie, qui vous aura obligation, vous avertit et vous commande, aussi bien que les trônes, les dominations... Si vous ne combattez pour moi, je vous déclare, par la sainte Trinité et par mon apostolat, que vous n'aurez jamais de part au paradis ${ }^{176}$.»

176 Comment accorder tant d'artifice et tant de bêtise ? C'est que les hommes ont toujours été fourbes, et qu'alors ils étaient fourbes et grossiers. (V.) 
La lettre eut son effet. Pepin passa les Alpes pour la seconde fois ; il assiégea Pavie, et fit encore la paix avec Astolfe. Mais est-il probable qu'il ait passé deux fois les monts uniquement pour donner des villes au pape Étienne ? Pourquoi saint Pierre, dans sa lettre, ne parlet-il pas d'un fait si important ? pourquoi ne se plaint-il pas à Pepin de n'être pas en possession de l'exarchat ? pourquoi ne le redemande-t-il pas expressément?

Tout ce qui est vrai, c'est que les Francs, qui avaient envahi les Gaules, voulurent toujours subjuguer l'Italie, objet de la cupidité de tous les barbares; non que l'Italie soit en effet un meilleur pays que les Gaules, mais alors elle était mieux cultivée ; les villes bâties, accrues, et embellies par les Romains, subsistaient; et la réputation de l'Italie tenta toujours un peuple pauvre, inquiet et guerrier. Si Pepin avait pu prendre la Lombardie, comme fit Charlemagne, il l'aurait prise sans doute; et s'il conclut un traité avec Astolfe, c'est qu'il y fut obligé. Usurpateur de la France, il n'y était pas affermi : il avait à combattre des ducs d'Aquitaine et de Gascogne, dont les droits sur ces pays valaient mieux que les siens sur la France. Comment donc auraitil donné tant de terres aux papes, quand il était forcé de revenir en France pour y soutenir son usurpation?

Le titre primordial de cette donation n'a jamais paru; on est donc réduit à douter. C'est le parti qu'il faut prendre souvent en histoire comme en philosophie. Le saint siège, d'ailleurs, n'a pas besoin de ces titres équivoques; le temps lui a donné des droits aussi réels sur ses États que les autres souverains de l'Europe en ont sur les leurs. Il est certain que les pontifes de Rome avaient dès lors de grands patrimoines dans plus d'un pays ; que ces patrimoines étaient respectés, qu'ils étaient exempts de tribut. Ils en avaient dans les Alpes, en Toscane, à Spolette, dans les Gaules, en Sicile, et jusque dans la Corse, avant que les Arabes se fussent rendus maîtres de cette île, au huitième siècle. Il est à croire que Pepin fit augmenter beaucoup ce patrimoine dans le pays de la Romagne, et qu'on l'appela le patrimoine de l'exarchat. C'est probablement ce mot patrimoine qui fut la source de la méprise. Les auteurs postérieurs supposèrent, dans des temps de ténèbres, que les papes avaient régné dans tous les pays où ils avaient seulement possédé des villes et des territoires. 
Si quelque pape, sur la fin du huitième siècle, prétendit être au rang des princes, il paraît que c'est Adrien $\mathrm{I}^{\mathrm{er}}$. La monnaie qui fut frappée en son nom (si cette monnaie fut en effet fabriquée de son temps) fait voir qu'il eut les droits régaliens ; et l'usage qu'il introduisit de se faire baiser les pieds fortifie encore cette conjecture. Cependant il reconnut toujours l'empereur grec pour son souverain. On pouvait très bien rendre à ce souverain éloigné un vain hommage, et s'attribuer une indépendance réelle, appuyée de l'autorité du ministère ecclésiastique.

Voyez par quels degrés la puissance pontificale de Rome s'est élevée. Ce sont d'abord des pauvres qui instruisent des pauvres dans les souterrains de Rome ; ils sont, au bout de deux siècles, à la tête d'un troupeau considérable. Ils sont riches et respectés sous Constantin; ils deviennent patriarches de l'Occident; ils ont d'immenses revenus et des terres ; enfin ils deviennent de grands souverains ; mais c'est ainsi que tout s'est écarté de son origine. Si les fondateurs de Rome, de l'empire des Chinois, de celui des califes, revenaient au monde, ils verraient sur leurs trônes des Goths, des Tartares, et des Turcs.

Avant d'examiner comment tout changea en Occident par la translation de l'empire, il est nécessaire de vous faire une idée de l'Église d'Orient. Les disputes de cette Église ne servirent pas peu à cette grande révolution. 


\section{Chapitre 14 \\ État de l'Église en Orient avant Charlemagne. Querelles pour les images. Révolution de Rome commencée}

Que les usages de l'Église grecque et de la latine aient été différents comme leurs langues; que la liturgie, les habillements, les ornements, la forme des temples, celle de la croix, n'aient pas été les mêmes; que les Grecs priassent debout, et les Latins à genoux ${ }^{177}$ : ce n'est pas ce que j'examine. Ces différentes coutumes ne mirent point aux prises 1'Orient et l'Occident; elles servaient seulement à nourrir l'aversion naturelle des nations devenues rivales. Les Grecs surtout, qui n'ont jamais reçu le baptême que par immersion, en se plongeant dans les cuves des baptistères, haïssaient les Latins, qui, en faveur des chrétiens septentrionaux, introduisirent le baptême par aspersion. Mais ces oppositions n'excitèrent aucun trouble.

La domination temporelle, cet éternel sujet de discorde dans l'Occident, fut inconnue aux Églises d'Orient. Les évêques sous les yeux du maître restèrent sujets; mais d'autres querelles non moins funestes y furent excitées par ces disputes interminables, nées de l'esprit sophistique des Grecs et de leurs disciples.

La simplicité des premiers temps disparut sous le grand nombre de questions que forma la curiosité humaine ; car le fondateur de la reli-

177 L'usage de prier à genoux dans les temples s'introduisit peu à peu avec l'opinion de la présence réelle; il dut par conséquent commencer dans l'Occident, où il paraît que cette opinion a pris naissance. Après avoir été une idée pieuse de dévots enthousiastes, cette opinion devint la croyance commune du peuple et d'une grande partie des théologiens, vers le quinzième siècle, et enfin un dogme de l'Église romaine, au temps du concile de Trente. L'Église de Lyon avait conservé jusqu'à ces dernières années l'ancien usage d'assister debout à la messe, sans savoir que cet usage était une preuve toujours subsistante de la nouveauté du dogme de la présence réelle. 
gion n'ayant jamais rien écrit, et les hommes voulant tout savoir, chaque mystère fit naître des opinions, et chaque opinion coûta du sang.

C'est une chose très remarquable que, de près de quatre-vingts sectes qui avaient déchiré l'Église depuis sa naissance, aucune n'avait eu un Romain pour auteur, si l'on excepte Novatien, qu'à peine encore on peut regarder comme un hérétique. Aucun Romain, dans les cinq premiers siècles, ne fut compté, ni parmi les pères de l'Église, ni parmi les hérésiarques. Il semble qu'ils ne furent que prudents. De tous les évêques de Rome, il n'yen eut qu'un seul qui favorisa un de ces systèmes condamnés par l'Église : c'est le pape Honorius $\mathrm{I}^{\mathrm{er}}$. On l'accuse encore tous les jours d'avoir été monothélite. On croit par là flétrir sa mémoire ; mais si on se donne la peine de lire sa fameuse lettre pastorale, dans laquelle il n'attribue qu'une volonté à JésusChrist, on verra un homme très sage. "Nous confessons, dit-il, une seule volonté dans Jésus-Christ. Nous ne voyons point que les conciles ni l'Écriture nous autorisent à penser autrement; mais de savoir si à cause des œuvres de divinité et d'humanité qui sont en lui, on doit entendre une opération ou deux, c'est ce que je laisse aux grammairiens, et ce qui n'importe guère ${ }^{178}$. "

Peut-être n'y a-t-il rien de plus précieux dans toutes les lettres des papes que ces paroles. Elles nous convainquent que toutes les disputes des Grecs étaient des disputes de mots, et qu'on aurait dû assoupir ces querelles de sophistes dont les suites ont été si funestes. Si on les avait abandonnées aux grammairiens, comme le veut ce judicieux pontife, l'Église eût été dans une paix inaltérable. Mais voulut-on savoir si le Fils était consubstantiel au Père, ou seulement de même nature, ou d'une nature inférieure : le monde chrétien fut partagé, la moitié persécuta l'autre et en fut persécutée. Voulut-on savoir si la mère de Jésus-Christ était la mère de Dieu ou de Jésus ; si le Christ avait deux natures et deux volontés dans une même personne, ou deux personnes et une volonté, ou une volonté et une personne ; toutes ces disputes, nées dans Constantinople, dans Antioche, dans Alexandrie, excitèrent des séditions. Un parti anathématisait l'autre; la faction dominante

178 En effet toutes les misérables querelles des théologiens n'ont jamais été que des disputes de grammaire, fondées sur des équivoques, sur des questions absurdes, inintelligibles, qu' on a mises pendant quinze cents ans à la place de la vertu. (V.) 
condamnait à l'exil, à la prison, à la mort et aux peines éternelles après la mort, l'autre faction, qui se vengeait à son tour par les mêmes armes.

De pareils troubles n'avaient point été connus dans l'ancienne religion des Grecs et des Romains, que nous appelons le paganisme ; la raison en est que les païens, dans leurs erreurs grossières, n'avaient point de dogmes, et que les prêtres des idoles, encore moins les séculiers, ne s'assemblèrent jamais juridiquement pour disputer.

Dans le huitième siècle, on agita dans les Églises d'Orient s'il fallait rendre un culte aux images : la loi de Moïse l'avait expressément défendu. Cette loi n'avait jamais été révoquée ; et les premiers chrétiens, pendant plus de deux cents ans, n'avaient même jamais souffert d'images dans leurs assemblées.

Peu à peu la coutume s'introduisit partout d'avoir chez soi des crucifix. Ensuite on eut les portraits vrais ou faux des martyrs ou des confesseurs. Il n'y avait point encore d'autels érigés pour les saints, point de messes célébrées en leur nom. Seulement, à la vue d'un crucifix et de l'image d'un homme de bien, le cœur, qui surtout dans ces climats a besoin d'objets sensibles, s'excitait à la piété.

Cet usage s'introduisit dans les églises. Quelques évêques ne l'adoptèrent pas. On voit qu'en 393, saint Épiphane arracha d'une église de Syrie une image devant laquelle on priait. Il déclara que la religion chrétienne ne permettait pas ce culte; et sa sévérité ne causa point de schisme.

Enfin cette pratique pieuse dégénéra en abus, comme toutes les choses humaines. Le peuple, toujours grossier, ne distingua point Dieu et les images; bientôt on en vint jusqu'à leur attribuer des vertus et des miracles : chaque image guérissait une maladie. On les mêla même aux sortilèges, qui ont presque toujours séduit la crédulité du vulgaire ; je dis non seulement le vulgaire du peuple, mais celui des princes, et même celui des savants.

En 727, l'empereur Léon l'Isaurien voulut, à la persuasion de quelques évêques, déraciner l'abus ; mais, par un abus peut-être plus grand, il fit effacer toutes les peintures : il abattit les statues et les représentations de Jésus-Christ avec celles des saints. En ôtant ainsi tout 
d'un coup aux peuples les objets de leur culte, il les révolta : on désobéit, il persécuta ; il devint tyran parce qu'il avait été imprudent.

Il est honteux pour notre siècle qu'il y ait encore des compilateurs et des déclamateurs, comme Maimbourg, qui répètent cette ancienne fable que deux Juifs avaient prédit l'empire à Léon, et qu'ils avaient exigé de lui qu'il abolît le culte des images ; comme s'il eût importé à des Juifs que les chrétiens eussent ou non des figures dans leurs églises. Les historiens qui croient qu'on peut ainsi prédire l'avenir sont bien indignes d'écrire ce qui s'est passé.

Son fils Constantin Copronyme fit passer en loi civile et ecclésiastique l'abolition des images. Il tint à Constantinople un concile de trois cent trente-huit évêques; ils proscrivirent d'une commune voix ce culte, reçu dans plusieurs églises, et surtout à Rome.

Cet empereur eût voulu abolir aussi aisément les moines, qu'il avait en horreur, et qu'il n'appelait que les abominables; mais il ne put y réussir : ces moines, déjà fort riches, défendirent plus habilement leurs biens que les images de leurs saints.

Les papes Grégoire II et III, et leurs successeurs, ennemis secrets des empereurs, et opposés ouvertement à leur doctrine, ne lancèrent pourtant point ces sortes d'excommunications, depuis si fréquemment et si légèrement employées. Mais soit que ce vieux respect pour les successeurs des Césars contînt encore les métropolitains de Rome, soit plutôt qu'ils vissent combien ces excommunications, ces interdits, ces dispenses du serment de fidélité seraient méprisés dans Constantinople, où l'Église patriarcale s'égalait au moins à celle de Rome, les papes tinrent deux conciles en 728 et en 732, où l'on décida que tout ennemi des images serait excommunié, sans rien de plus, et sans parler de l'empereur. Ils songèrent dès lors plus à négocier qu'à disputer. Grégoire II se rendit maître des affaires dans Rome, pendant que le peuple, soulevé contre les empereurs, ne payait plus les tributs. Grégoire III se conduisit suivant les mêmes principes. Quelques auteurs grecs postérieurs, voulant rendre les papes odieux, ont écrit que Grégoire II excommunia et déposa l'empereur, et que tout le peuple romain reconnut Grégoire II pour son souverain. Ces Grecs ne songeaient pas que les papes, qu'ils voulaient faire regarder comme des usurpateurs, auraient été dès lors les princes les plus légitimes. Ils au- 
raient tenu leur puissance des suffrages du peuple romain : ils eussent été souverains de Rome à plus juste titre que beaucoup d'empereurs. Mais il n'est ni vraisemblable ni vrai que les Romains, menacés par Léon l'Isaurien, pressés par les Lombards, eussent élu leur évêque pour seul maître, quand ils avaient besoin de guerriers. Si les papes avaient eu dès lors un si beau droit au rang des Césars, ils n'auraient pas depuis transféré ce droit à Charlemagne. 
$\underline{\text { Table des Matières }}$

\section{Chapitre 15}

De Charlemagne. Son ambition, sa politique. Il dépouille ses neveux de leurs états. Oppression et conversion des Saxons, etc.

Le royaume de Pepin, ou Pipin, s'étendait de la Bavière aux Pyrénées et aux Alpes. Karl, son fils, que nous respectons sous le nom de Charlemagne, recueillit cette succession tout entière, car un de ses frères était mort après le partage, et l'autre s'était fait moine auparavant au monastère de Saint-Silvestre. Une espèce de piété qui se mêlait à la barbarie de ces temps enferma plus d'un prince dans le cloître ; ainsi Rachis, roi des Lombards, un Carloman, frère de Pepin, un duc d'Aquitaine, avaient pris l'habit de bénédictin. Il n'y avait presque alors que cet ordre dans l'Occident. Les couvents étaient riches, puissants, respectés ; c'étaient des asiles honorables pour ceux qui cherchaient une vie paisible. Bientôt après, ces asiles furent les prisons des princes détrônés.

La réputation de Charlemagne est une des plus grandes preuves que les succès justifient l'injustice, et donnent la gloire. Pepin, son père, avait partagé en mourant ses États entre ses deux enfants, Karlman, ou Carloman, et Karl : une assemblée solennelle de la nation avait ratifié le testament. Carloman avait la Provence, le Languedoc, la Bourgogne, la Suisse, l'Alsace, et quelques pays circonvoisins; Karl, ou Charles, jouissait de tout le reste. Les deux frères furent toujours en mésintelligence. Carloman mourut subitement, et laissa une veuve et deux enfants en bas âge. Charles s'empara d'abord de leur patrimoine (771). La malheureuse mère fut obligée de fuir avec ses enfants chez le roi des Lombards, Desiderius, que nous nommons Didier, ennemi naturel des Francs : ce Didier était beau-père de Charlemagne, et ne l'en haïssait pas moins, parce qu'il le redoutait. On voit évidemment que Charlemagne ne respecta pas plus le droit naturel et les liens du sang que les autres conquérants. 
Pépin son père n'avait pas eu à beaucoup près le domaine direct de tous les États que posséda Charlemagne. L'Aquitaine, la Bavière, la Provence, la Bretagne, pays nouvellement conquis, rendaient hommage et payaient tribut.

Deux voisins pouvaient être redoutables à ce vaste État, les Germains septentrionaux et les Sarrasins. L'Angleterre, conquise par les Anglo-Saxons, partagée en sept dominations, toujours en guerre avec l'Albanie qu'on nomme Écosse, et avec les Danois, était sans politique et sans puissance. L'Italie, faible et déchirée, n'attendait qu'un nouveau maître qui voulut s'en emparer.

Les Germains septentrionaux étaient alors appelés Saxons. On connaissait sous ce nom tous les peuples qui habitaient les bords du Véser et ceux de l'Elbe, de Hambourg à la Moravie, et du bas Rhin à la mer Baltique. Ils étaient païens ainsi que tout le septentrion. Leurs mœurs et leurs lois étaient les mêmes que du temps des Romains. Chaque canton se gouvernait en république, mais ils élisaient un chef pour la guerre. Leurs lois étaient simples comme leurs mœurs, leur religion grossière : ils sacrifiaient, dans les grands dangers, des hommes à la Divinité, ainsi que tant d'autres nations ; car c'est le caractère des barbares de croire la Divinité malfaisante : les hommes font Dieu à leur image. Les Francs, quoique déjà chrétiens, eurent sous Théodebert cette superstition horrible : ils immolèrent des victimes humaines en Italie, au rapport de Procope ; et vous n'ignorez pas que trop de nations, ainsi que les Juifs, avaient commis ces sacrilèges par piété. D'ailleurs les Saxons avaient conservé les anciennes mœurs des Germains, leur simplicité, leur superstition, leur pauvreté. Quelques cantons avaient surtout gardé l'esprit de rapine, et tous mettaient dans leur liberté leur bonheur et leur gloire. Ce sont eux qui, sous le nom de Cattes, de Chérusques et de Bructères, avaient vaincu Varus, et que Germanicus avait ensuite défaits.

Une partie de ces peuples, vers le cinquième siècle, appelée par les Bretons insulaires contre les habitants de l'Écosse, subjugua la Bretagne qui touche à l'Écosse, et lui donna le nom d'Angleterre. Ils y avaient déjà passé au troisième siècle ; et au temps de Constantin, les côtes orientales de cette île étaient appelées les Côtes Saxoniques. 
Charlemagne, le plus ambitieux, le plus politique, et le plus grand guerrier de son siècle, fit la guerre aux Saxons trente années avant de les assujettir pleinement. Leur pays n'avait point encore ce qui tente aujourd'hui la cupidité des conquérants : les riches mines de Goslar et de Friedberg, dont on a tiré tant d'argent, n'étaient point découvertes ; elles ne le furent que sous Henri-l'Oiseleur. Point de richesses accumulées par une longue industrie, nulle ville digne de l'ambition d'un usurpateur. Il ne s'agissait que d'avoir pour esclaves des millions d'hommes qui cultivaient la terre sous un climat triste, qui nourrissaient leurs troupeaux, et qui ne voulaient point de maîtres.

La guerre contre les Saxons avait commencé pour un tribut de trois cents chevaux et quelques vaches que Pepin avait exigé d'eux; et cette guerre dura trente années. Quel droit les Francs avaient-ils sur eux ? le même droit que les Saxons avaient eu sur l'Angleterre.

Ils étaient mal armés, car je vois dans les Capitulaires de Charlemagne une défense rigoureuse de vendre des cuirasses aux Saxons. Cette différence des armes, jointe à la discipline, avait rendu les Romains vainqueurs de tant de peuples : elle fit triompher enfin Charlemagne.

Le général de la plupart de ces peuples était ce fameux Vitikind, dont on fait aujourd'hui descendre les principales maisons de l'Empire : homme tel qu'Arminius, mais qui eut enfin plus de faiblesse. (772) Charles prend d'abord la fameuse bourgade d'Éresbourg: car ce lieu ne méritait ni le nom de ville ni celui de forteresse. Il fait égorger les habitants; il y pille, et rase ensuite le principal temple du pays, élevé autrefois au dieu Tanfana, principe universel, si jamais ces sauvages ont connu un principe universel. Il était alors dédié au dieu Irminsul ; soit que ce dieu fut celui de la guerre, l'Arès des Grecs, le Mars des Romains ; soit qu'il eut été consacré au célèbre HermannArminius, vainqueur de Varus, et vengeur de la liberté germanique.

On y massacra les prêtres sur les débris de l'idole renversée. On pénétra jusqu'au Véser avec l'armée victorieuse. Tous ces cantons se soumirent. Charlemagne voulut les lier à son joug par le christianisme. Tandis qu'il court à l'autre bout de ses États, à d'autres conquêtes, il leur laisse des missionnaires pour les persuader, et des soldats pour les 
forcer. Presque tous ceux qui habitaient vers le Véser se trouvèrent en un an chrétiens, mais esclaves.

Vitikind, retiré chez les Danois, qui tremblaient déjà pour leur liberté et pour leurs dieux, revient au bout de quelques années. Il ranime ses compatriotes, il les rassemble. Il trouve dans Brême, capitale du pays qui porte ce nom, un évêque, une église, et ses Saxons désespérés, qu'on traîne à des autels nouveaux. Il chasse l'évêque, qui a le temps de fuir et de s'embarquer; il détruit le christianisme, qu'on n'avait embrassé que par la force ; il vient jusqu'auprès du Rhin, suivi d'une multitude de Germains ; il bat les lieutenants de Charlemagne.

Ce prince accourt : il défait à son tour Vitikind; mais il traite de révolte cet effort courageux de liberté. Il demande aux Saxons tremblants qu'on lui livre leur général ; et, sur la nouvelle qu'ils l'ont laissé retourner en Danemark, il fait massacrer quatre mille cinq cents prisonniers au bord de la petite rivière d'Aller. Si ces prisonniers avaient été des sujets rebelles, un tel châtiment aurait été une sévérité horrible; mais traiter ainsi des hommes qui combattaient pour leur liberté et pour leurs lois, c'est l'action d'un brigand, que d'illustres succès et des qualités brillantes ont d'ailleurs fait grand homme.

Il fallut encore trois victoires avant d'accabler ces peuples sous le joug. Enfin le sang cimenta le christianisme et la servitude. Vitikind lui-même, lassé de ses malheurs, fut obligé de recevoir le baptême, et de vivre désormais tributaire de son vainqueur.

(803-804) Charles, pour mieux s'assurer du pays, transporta environ dix mille familles saxonnes en Flandre, en France, et dans Rome. Il établit des colonies de Francs dans les terres des vaincus. On ne voit depuis lui aucun prince en Europe qui transporte ainsi des peuples malgré eux. Vous verrez de grandes émigrations, mais aucun souverain qui établisse ainsi des colonies suivant l'ancienne méthode romaine : c'est la preuve de l'excès du despotisme de contraindre ainsi les hommes à quitter le lieu de leur naissance. Charles joignit à cette politique la cruauté de faire poignarder par des espions les Saxons qui voulaient retourner à leur culte. Souvent les conquérants ne sont cruels que dans la guerre : la paix amène des mœurs et des lois plus douces. Charlemagne, au contraire, fit des lois qui tenaient de l'inhumanité de ses conquêtes. 
Il institua une juridiction plus abominable que l'inquisition ne le fut depuis, c'était la cour Veimique, ou la cour de Vestphalie, dont le siège subsista longtemps dans le bourg de Dortmund. Les juges prononçaient peine de mort sur des délations secrètes, sans appeler les accusés. On dénonçait un Saxon, possesseur de quelques bestiaux, de n'avoir pas jeûné en carême ; les juges le condamnaient, et on envoyait des assassins qui l'exécutaient et qui saisissaient ses vaches. Cette cour étendit bientôt son pouvoir sur toute l'Allemagne : il n'y a point d'exemple d'une telle tyrannie, et elle était exercée sur des peuples libres. Daniel ne dit pas un mot de cette cour Veimique ; et Velli, qui a écrit sa sèche histoire, n'a pas été instruit de ce fait si public : et il appelle Charlemagne religieux monarque, ornement de l'humanité! C'est ainsi parmi nous que des auteurs gagés par des libraires écrivent l'histoire ${ }^{179}$ !

Ayant vu comment ce conquérant traita les Germains, observons comment il se conduisit avec les Arabes d'Espagne. Il arrivait déjà parmi eux ce qu'on vit bientôt après en Allemagne, en France, et en Italie. Les gouverneurs se rendaient indépendants. Les émirs de Barcelone et ceux de Saragosse s'étaient mis sous la protection de Pepin. L'émir de Saragosse, nommé Ibnal Arabi, c'est-à-dire Ibnal l'Arabe, en 778, vient jusqu'à Paderborn prier Charlemagne de le soutenir contre son souverain. Le prince français prit le parti de ce musulman ; mais il se donna bien garde de le faire chrétien. D'autres intérêts, d'autres soins. Il s'allie avec des Sarrasins contre des Sarrasins ; mais, après quelques avantages sur les frontières d'Espagne, son arrièregarde est défaite à Roncevaux, vers les montagnes des Pyrénées, par les chrétiens mêmes de ces montagnes, mêlés aux musulmans. C'est là que périt Roland son neveu. Ce malheur est l'origine de ces fables qu'un moine écrivit au onzième siècle, sous le nom de l'archevêque Turpin, et qu'ensuite l'imagination de l'Arioste a embellies. On ne sait point en quel temps Charles essuya cette disgrâce ; et on ne voit

179 On peut voir dans les Capitulaires la loi par laquelle Charles établit la peine de mort contre les Saxons qui se cacheront pour ne point venir au baptême, ou qui mangeront de la chair en carême. Des fanatiques ignorants ont nié l'existence de cette loi, que Fleuri a eu la bonne foi de rapporter. Quant au tribunal Veimique, établi par Charlemagne et détruit par Maximilien, on peut consulter 1'article Tribunal secret de Vestphalie dans 1'Encyclopédie, tome XVI. On a eu soin d'y citer les historiens et les publicistes allemands qui ont parlé de cette pieuse institution de saint Charlemagne. (K.) 
point qu'il ait tiré vengeance de sa défaite. Content d'assurer ses frontières contre des ennemis trop aguerris, il n'embrasse que ce qu'il peut retenir, et règle son ambition sur les conjonctures qui la favorisent. 


\section{Chapitre 16}

\section{Charlemagne, empereur d'Occident}

C'est à Rome et à l'empire d'Occident que cette ambition aspirait. La puissance des rois de Lombardie était le seul obstacle ; l'Église de Rome, et toutes les Églises sur lesquelles elle influait, les moines déjà puissants, les peuples déjà gouvernés par eux, tout appelait Charlemagne à l'empire de Rome. Le pape Adrien, né Romain, homme d'un génie adroit et ferme, aplanit la route. D'abord il l'engage à répudier la fille du roi lombard, Didier, chez qui l'infortunée belle-sœur de Charles s'était réfugiée avec ses enfants.

Les mœurs et les lois de ce temps-là n'étaient pas gênantes, du moins pour les princes. Charles avait épousé cette fille du roi des Lombards dans le temps qu'il avait déjà, dit-on, une autre femme. Il n'était pas rare d'en avoir plusieurs à la fois. Grégoire de Tours rapporte que les rois Gontran, Caribert, Sigebert, Chilpéric, avaient plus d'une épouse. Charles répudie la fille de Didier sans aucune raison, sans aucune formalité.

Le roi lombard, qui voit cette union fatale du roi et du pape contre lui, prend un parti courageux. Il veut surprendre Rome, et s'assurer de la personne du pape ; mais l'évêque habile fait tourner la guerre en négociation. Charles envoie des ambassadeurs pour gagner du temps. Il redemande au roi de Lombardie sa belle-sœur et ses deux neveux. Non seulement Didier refuse ce sacrifice, mais il veut faire sacrer rois ces deux enfants, et leur faire rendre leur héritage. Charlemagne vient de Thionville à Genève, tient dans Genève un de ces parlements qui, en tout pays, souscrivirent toujours aux volontés d'un conquérant habile. Il passe le mont Cenis, il entre dans la Lombardie. Didier, après quelques défaites, s'enferme dans Pavie, sa capitale ; Charlemagne l'y assiège au milieu de l'hiver. La ville, réduite à l'extrémité, se rend après un siège de six mois (774). Ainsi finit ce royaume des Lom- 
bards, qui avaient détruit en Italie la puissance romaine, et qui avaient substitué leurs lois à celles des empereurs. Didier, le dernier de ces rois, fut conduit en France dans le monastère de Corbie, où il vécut et mourut captif et moine, tandis que son fils allait inutilement demander des secours dans Constantinople à ce fantôme d'empire romain, détruit en Occident par ses ancêtres. Il faut remarquer que Didier ne fut pas le seul souverain que Charlemagne enferma ; il traita ainsi un duc de Bavière et ses enfants.

La belle-sœur de Charles et ses deux enfants furent remis entre les mains du vainqueur. Les chroniques ne nous apprennent point s'ils furent aussi confinés dans un monastère, ou mis à mort. Le silence de l'histoire sur cet événement est une accusation contre Charlemagne.

Il n'osait pas encore se faire souverain de Rome; il ne prit que le titre de roi d'Italie, tel que le portaient les Lombards. Il se fit couronner comme eux dans Pavie, d'une couronne de fer qu'on garde encore dans la petite ville de Monza. La justice s'administrait toujours à Rome au nom de l'empereur grec. Les papes recevaient de lui la confirmation de leur élection: c'était l'usage que le sénat écrivît à l'empereur, ou à l'exarque de Ravenne quand il y en avait un, "Nous vous supplions d'ordonner la consécration de notre père et pasteur. » On en donnait part au métropolitain de Ravenne. L'élu était obligé de prononcer deux professions de foi. Il y a loin de là à la tiare ; mais estil quelque grandeur qui n'ait en de faibles commencements?

Charlemagne prit, ainsi que Pepin, le titre de patrice, que Théodoric et Attila avaient aussi daigné prendre. Ainsi ce nom d'empereur, qui dans son origine ne désignait qu'un général d'armée, signifiait encore le maître de l'Orient et de l'Occident. Tout vain qu'il était, on le respectait, on craignait de l'usurper ; on n'affectait que celui de patrice $^{180}$, qui autrefois voulait dire sénateur romain.

Les papes, déjà très puissants dans l'Église, très grands seigneurs à Rome, et possesseurs de plusieurs terres, n'avaient dans Rome même qu'une autorité précaire et chancelante. Le préfet, le peuple, le sénat, dont l'ombre subsistait, s'élevaient souvent contre eux. Les inimitiés

180 M. Renouard a remarqué que Voltaire confond ici le patrice avec le patricien. (B.) 
des familles qui prétendaient au pontificat remplissaient Rome de confusion.

Les deux neveux d'Adrien conspirèrent contre Léon III, son successeur, élu père et pasteur, selon l'usage, par le peuple et le clergé romains. Ils l'accusent de beaucoup de crimes; ils animent les Romains contre lui ; on traîne en prison, on accable de coups à Rome celui qui était si respecté partout ailleurs. Il s'évade, il vient se jeter aux genoux du patrice Charlemagne à Paderborn. Ce prince, qui agissait déjà en maître absolu, le renvoya avec une escorte et des commissaires pour le juger. Ils avaient ordre de le trouver innocent. Enfin Charlemagne, maître de l'Italie, comme de l'Allemagne et de la France, juge du pape, arbitre de l'Europe, vient à Rome à la fin de l'année 799. L'année commençait alors à Noël chez les Romains. Léon III le proclame empereur d'Occident pendant la messe, le jour de Noël, en 800. Le peuple joint ses acclamations à cette cérémonie. Charles feint d'être étonné, et notre abbé Velli, copiste de nos légendaires, dit que « rien ne fut égal à sa surprise ». Mais la vérité est que tout était concerté entre lui et le pape, et qu'il avait apporté des présents immenses qui lui assuraient le suffrage de l'évêque et des premiers de Rome. On voit, par des chartes accordées aux Romains en qualité de patrice, qu'il avait déjà brigué hautement l'empire ; on y lit ces propres mots : «Nous espérons que notre munificence pourra nous élever à la dignité impériale ${ }^{181}$. »

Voilà donc le fils d'un domestique, d'un de ces capitaines francs que Constantin avait condamnés aux bêtes, élevé à la dignité de Constantin. D'un côté un Franc, de l'autre une famille thrace, partagent l'empire romain. Tel est le jeu de la fortune.

On a écrit, et on écrit encore que Charles, avant même d'être empereur, avait confirmé la donation de l'exarchat de Ravenne ; qu'il y avait ajouté la Corse, la Sardaigne, la Ligurie, Parme, Mantoue, les duchés de Spolette et de Bénévent, la Sicile, Venise, et qu'il déposa l'acte de cette donation sur le tombeau dans lequel on prétend que reposent les cendres de saint Pierre et saint Paul.

181 Voyez l'annaliste Rerum Italicarum, tome II. (V.) 
On pourrait mettre cette donation à côté de celle de Constantin ${ }^{182}$. On ne voit point que jamais les papes aient possédé aucun de ces pays jusqu'au temps d'innocent III. S'ils avaient eu l'exarchat, ils auraient été souverains de Ravenne et de Rome; mais dans le testament de Charlemagne, qu'Éginhard nous a conservé, ce monarque nomme, à la tête des villes métropolitaines qui lui appartiennent, Rome et Ravenne, auxquelles il fait des présents. Il ne put donner ni la Sicile, ni la Corse, ni la Sardaigne, qu'il ne possédait pas ; ni le duché de Bénévent, dont il avait à peine la souveraineté, encore moins Venise, qui ne le reconnaissait pas pour empereur. Le duc de Venise reconnaissait alors, pour la forme, l'empereur d'Orient, et en recevait le titre d'hypatos. Les lettres du pape Adrien parlent des patrimoines de Spolette et de Bénévent; mais ces patrimoines ne se peuvent entendre que des domaines que les papes possédaient dans ces deux duchés. Grégoire VII lui-même avoue dans ses lettres que Charlemagne donnait douze cents livres de pension au saint-siège. Il n'est guère vraisemblable qu'il eut donné un tel secours à celui qui aurait possédé tant de belles provinces. Le saint-siège n'eut Bénévent que longtemps après, par la concession très équivoque qu'on croit que l'empereur Henri le Noir lui en fit vers l'an1047. Cette concession se réduisit à la ville, et ne s'étendit point jusqu'au duché. Il ne fut point question de confirmer le don de Charlemagne.

Ce qu'on peut recueillir de plus probable au milieu de tant de doutes, c'est que, du temps de Charlemagne, les papes obtinrent en propriété une partie de la Marche d'Ancône, outre les villes, les châteaux et les bourgs qu'ils avaient dans les autres pays. Voici sur quoi je pourrais me fonder. Lorsque l'empire d'Occident se renouvela dans la famille des Othons, au dixième siècle, Othon III assigna particulièrement au saint-siège la Marche d'Ancône, en confirmant toutes les concessions faites à cette Église ${ }^{183}$ : il paraît donc que Charlemagne avait donné cette Marche, et que les troubles survenus depuis en Italie avaient empêché les papes d'en jouir. Nous verrons qu'ils perdirent ensuite le domaine utile de ce petit pays sous l'empire de la maison de Souabe. Nous les verrons tantôt grands terriens, tantôt dépouillés

182 Voyez les Éclaircissements (Mélanges, année 1763). (V.)

183 On prétend que cet acte d'Othon est faux, ce qui réduirait cette opinion à une simple tradition. (V.) 
presque de tout, comme plusieurs autres souverains. Qu'il nous suffise de savoir qu'ils possèdent aujourd'hui la souveraineté reconnue d'un pays de cent quatre-vingts grands milles d'Italie en longueur, des portes de Mantoue aux confins de l'Abruzze, le long de la mer Adriatique, et qu'ils en ont plus de cent milles en largeur depuis CivitaVecchia jusqu'au rivage d'Ancône, d'une mer à l'autre. Il a fallu négocier toujours, et souvent combattre, pour s'assurer cette domination.

Tandis que Charlemagne devenait empereur d'Occident, régnait en Orient cette impératrice Irène, fameuse par son courage et par ses crimes, qui avait fait mourir son fils unique, après lui avoir arraché les yeux. Elle eut voulu perdre Charlemagne; mais, trop faible pour lui faire la guerre, elle voulut, dit-on, l'épouser, et réunir les deux empires. Ce mariage est une idée chimérique. Une révolution chasse Irène d'un trône qui lui avait tant coûté (802). Charles n'eut donc que l'empire d'Occident. Il ne posséda presque rien dans les Espagnes, car il ne faut pas compter pour domaine le vain hommage de quelques Sarrasins. Il n'avait rien sur les côtes d'Afrique. Tout le reste était sous sa domination.

S'il eut fait de Rome sa capitale, si ses successeurs y eussent fixé leur principal séjour, et surtout si l'usage de partager ses États à ses enfants n'eût point prévalu chez les barbares, il est vraisemblable qu'on eût vu renaître l'empire romain. Tout concourut depuis à démembrer ce vaste corps, que la valeur et la fortune de Charlemagne avaient formé ; mais rien n'y contribua plus que ses descendants.

Il n'avait point de capitale : seulement Aix-la-Chapelle était le séjour qui lui plaisait le plus. Ce fut là qu'il donna des audiences, avec le faste le plus imposant, aux ambassadeurs des califes et à ceux de Constantinople. D'ailleurs il était toujours en guerre ou en voyage, ainsi que vécut Charles-Quint longtemps après lui. Il partagea ses États, et même de son vivant, comme tous les rois de ce temps-là.

Mais enfin, quand de ses fils qu'il avait désignés pour régner il ne resta plus que ce Louis si connu sous le nom de Débonnaire, auquel il avait déjà donné le royaume d'Aquitaine, il l'associa à l'empire dans Aix-la-Chapelle, et lui commanda de prendre lui-même sur l'autel la couronne impériale, pour faire voir au monde que cette couronne n'était due qu'à la valeur du père et au mérite du fils, et comme s'il 
eût pressenti qu'un jour les ministres de l'autel voudraient disposer de ce diadème.

Il avait raison de déclarer son fils empereur de son vivant : car cette dignité, acquise par la fortune de Charlemagne, n'était point assurée au fils par le droit d'héritage. Mais en laissant l'empire à Louis, et en donnant l'Italie à Bernard, fils de son fils Pepin, ne déchirait-il pas luimême cet empire qu'il voulait conserver à sa postérité ? N'était-ce pas armer nécessairement ses successeurs les uns contre les autres ? Étaitil à présumer que le neveu, roi d'Italie, obéirait à son oncle empereur, ou que l'empereur voudrait bien n'être pas le maître en Italie?

Charlemagne mourut en 814, avec la réputation d'un empereur aussi heureux qu'Auguste, aussi guerrier qu'Adrien, mais non tel que les Trajan et les Antonins, auxquels nul souverain n'a été comparable.

Il y avait alors en Orient un prince qui l'égalait en gloire comme en puissance : c'était le célèbre calife Aaron-al-Raschild, qui le surpassa beaucoup en justice, en science, en humanité.

J'ose presque ajouter à ces deux hommes illustres le pape Adrien, qui, dans un rang moins élevé, dans une fortune presque privée, et avec des vertus moins héroïques, montra une prudence à laquelle ses successeurs ont dû leur agrandissement.

La curiosité des hommes, qui pénètre dans la vie privée des princes, a voulu savoir jusqu'au détail de la vie de Charlemagne, et jusqu'au secret de ses plaisirs. On a écrit qu'il avait poussé l'amour des femmes jusqu'à jouir de ses propres filles. On en a dit autant d'Auguste ; mais qu'importe au genre humain le détail de ces faiblesses qui n'ont influé en rien sur les affaires publiques ? L'Église a mis au nombre des saints cet homme qui répandit tant de sang, qui dépouilla ses neveux, et qui fut soupçonné d'inceste !

J'envisage son règne par un endroit plus digne de l'attention d'un citoyen. Les pays qui composent aujourd'hui la France et l'Allemagne jusqu'au Rhin furent tranquilles pendant près de cinquante ans, et l'Italie pendant treize, depuis son avènement à l'empire. Point de révolution, point de calamité pendant ce demi-siècle, qui par là est unique. Un bonheur si long ne suffit pas pourtant pour rendre aux hom- 
mes la politesse et les arts. La rouille de la barbarie était trop forte, et les âges suivants l'épaissirent encore. 


\section{Chapitre 17}

\section{Mours, gouvernement et usages, vers le temps de Charlemagne}

Je m'arrête à cette célèbre époque pour considérer les usages, les lois, la religion, les mœurs, qui régnaient alors. Les Francs avaient toujours été des barbares, et le furent encore après Charlemagne. Remarquons attentivement que Charlemagne paraissait ne se point regarder comme un Franc. La race de Clovis et de ses compagnons francs fut toujours distincte des Gaulois. L'Allemand Pepin et Karl son fils furent distincts des Francs. Vous en trouverez la preuve dans le capitulaire de Karl ou Charlemagne, concernant ses métairies, art. 4 : «Si les Francs commettent quelque délit dans nos possessions, qu'ils soient jugés suivant leur loi. » Il semble par cet ordre que les Francs alors n'étaient pas regardés comme la nation de Charlemagne. À Rome, la race carlovingienne passa toujours pour allemande. Le pape Adrien IV, dans sa lettre aux archevêques de Mayence, de Cologne et de Trèves, s'exprime en ces termes remarquables : "L'empire fut transféré des Grecs aux Allemands; leur roi ne fut empereur qu'après avoir été couronné par le pape... tout ce que l'empereur possède, il le tient de nous. Et comme Zacharie donna l'empire grec aux Allemands, nous pouvons donner celui des Allemands aux Grecs. »

Cependant en France le nom de Franc prévalut toujours. La race de Charlemagne fut souvent appelée Franca dans Rome même et à Constantinople. La cour grecque désignait, même du temps des Othons, les empereurs d'Occident par le nom d'usurpateurs francs, barbares francs : elle affectait pour ces Francs un mépris qu'elle n'avait pas.

Le règne seul de Charlemagne eut une lueur de politesse qui fut probablement le fruit du voyage de Rome, ou plutôt de son génie.

Ses prédécesseurs ne furent illustres que par des déprédations : ils détruisirent des villes, et n'en fondèrent aucune. Les Gaulois avaient 
été heureux d'être vaincus par les Romains. Marseille, Arles, Autun, Lyon, Trèves, étaient des villes florissantes qui jouissaient paisiblement de leurs lois municipales, subordonnées aux sages lois romaines : un grand commerce les animait. On voit, par une lettre d'un proconsul à Théodose, qu'il y avait dans Autun et dans sa banlieue vingtcinq mille chefs de famille. Mais, dès que les Bourguignons, les Goths, les Francs, arrivent dans la Gaule, on ne voit plus de grandes villes peuplées. Les cirques, les amphithéâtres construits par les Romains jusqu'au bord du Rhin, sont démolis ou négligés. Si la criminelle et malheureuse reine Brunehaut conserve quelques lieues de ces grands chemins qu'on n'imita jamais, on en est encore étonné.

Qui empêchait ces nouveaux venus de bâtir des édifices réguliers sur des modèles romains? Ils avaient la pierre, le marbre, et de plus beaux bois que nous. Les laines fines couvraient les troupeaux anglais et espagnols comme aujourd'hui : cependant les beaux draps ne se fabriquaient qu'en Italie. Pourquoi le reste de l'Europe ne faisait-il venir aucune des denrées de l'Asie ? Pourquoi toutes les commodités qui adoucissent l'amertume de la vie étaient-elles inconnues, sinon parce que les sauvages qui passèrent le Rhin rendirent les autres peuples sauvages? Qu'on en juge par ces lois saliques, ripuaires, bourguignonnes, que Charlemagne lui-même confirma, ne pouvant les abroger. La pauvreté et la rapacité avaient évalué à prix d'argent la vie des hommes, la mutilation des membres, le viol, l'inceste, l'empoisonnement. Quiconque avait quatre cents sous, c'est-à-dire quatre cents écus du temps, à donner, pouvait tuer impunément un évêque. Il en coûtait deux cents sous pour la vie d'un prêtre, autant pour le viol, autant pour avoir empoisonné avec des herbes. Une sorcière qui avait mangé de la chair humaine en était quitte pour deux cents sous; et cela prouve qu'alors les sorcières ne se trouvaient pas seulement dans la lie du peuple, comme dans nos derniers siècles, mais que ces horreurs extravagantes étaient pratiquées chez les riches. Les combats et les épreuves décidaient, comme nous le verrons, de la possession d'un héritage, de la validité d'un testament. La jurisprudence était celle de la férocité et de la superstition.

Qu'on juge des mœurs des peuples par celles des princes. Nous ne voyons aucune action magnanime. La religion chrétienne, qui devait humaniser les hommes, n'empêche point le roi Clovis de faire assassiner les petits régas, ses voisins et ses parents. Les deux enfants de 
Clodomir sont massacrés dans Paris, en 533, par un Childebert et un Clotaire, ses oncles, qu'on appelle rois de France ; et Clodoald, le frère de ces innocents égorgés, est invoqué sous le nom de saint Cloud, parce qu'on l'a fait moine. Un jeune barbare, nommé Chram, fait la guerre à Clotaire son père, réga d'une partie de la Gaule. Le père fait brûler son fils avec tous ses amis prisonniers, en 559 .

Sous un Chilpéric, roi de Soissons, en 562, les sujets esclaves désertent ce prétendu royaume, lassés de la tyrannie de leur maître, qui prenait leur pain et leur vin, ne pouvant prendre l'argent qu'ils n'avaient pas. Un Sigebert, un autre Chilpéric, sont assassinés. Brunehaut, d'arienne devenue catholique, est accusée de mille meurtres; et un Clotaire II, non moins barbare qu'elle, la fait traîner, dit-on, à la queue d'un cheval dans son camp, et la fait mourir par ce nouveau genre de supplice, en 616. Si cette aventure n'est pas vraie, il est du moins prouvé qu'elle a été crue comme une chose ordinaire, et cette opinion même atteste la barbarie du temps. Il ne reste de monuments de ces âges affreux que des fondations de monastères, et un confus souvenir de misère et de brigandages. Figurez-vous des déserts où les loups, les tigres, et les renards, égorgent un bétail épars et timide : c'est le portrait de l'Europe pendant tant de siècles.

Il ne faut pas croire que les empereurs reconnussent pour rois ces chefs sauvages qui dominaient en Bourgogne, à Soissons, à Paris, à Metz, à Orléans ; jamais ils ne leur donnèrent le titre de basileus. Ils ne le donnèrent pas même à Dagobert II, qui réunissait sous son pouvoir toute la France occidentale jusqu'auprès du Véser. Les historiens parlent beaucoup de la magnificence de ce Dagobert, et ils citent en preuve l'orfèvre saint Éloi, qui arriva, dit-on, à la cour avec une ceinture garnie de pierreries, c'est-à-dire qu'il vendait des pierreries, et qu'il les portait à sa ceinture. On parle des édifices magnifiques qu'il fit construire; où sont-ils? la vieille église de Saint-Paul n'est qu'un petit monument gothique. Ce qu'on connaît de Dagobert, c'est qu'il avait à la fois trois épouses, qu'il assemblait des conciles, et qu'il tyrannisait son pays.

Sous lui, un marchand de Sens, nommé Samon, va trafiquer en Germanie. Il passe jusque chez les Slaves, barbares qui dominaient vers la Pologne et la Bohême. Ces autres sauvages sont si étonnés de voir un homme qui a fait tant de chemin pour leur apporter les choses 
dont ils manquent qu'ils le font roi. Ce Samon fit, dit-on, la guerre à Dagobert; et si le roi des Francs eut trois femmes, le nouveau roi slavon en eut quinze.

C'est sous ce Dagobert que commence l'autorité des maires du palais. Après lui viennent les rois fainéants, la confusion, le despotisme de ces maires. C'est du temps de ces maires, au commencement du huitième siècle, que les Arabes, vainqueurs de l'Espagne, pénètrent jusqu'à Toulouse, prennent la Guienne, ravagent tout jusqu'à la Loire, et sont près d'enlever les Gaules entières aux Francs, qui les avaient enlevées aux Romains. Jugez-en quel état devaient être alors les peuples, l’Église, et les lois.

Les évêques n'eurent aucune part au gouvernement jusqu'à Pepin ou Pipin, père de Charles Martel, et grand-père de l'autre Pepin qui se fit roi. Les évêques n'assistaient point aux assemblées de la nation franque. Ils étaient tous ou Gaulois ou Italiens, peuples regardés comme serfs. En vain l'évêque Remi, qui baptisa Clovis, avait écrit à ce roi sicambre cette fameuse lettre où l'on trouve ces mots : "Gardez-vous bien surtout de prendre la préséance sur les évêques; prenez leurs conseils : tant que vous serez en intelligence avec eux, votre administration sera facile. » Ni Clovis ni ses successeurs ne firent du clergé un ordre de l'État: le gouvernement ne fut que militaire. On ne peut mieux le comparer qu'à ceux d'Alger et de Tunis, gouvernés par un chef et une milice. Seulement les rois consultaient quelquefois les évêques quand ils avaient besoin d'eux.

Mais quand les majordomes ou maires de cette milice usurpèrent insensiblement le pouvoir, ils voulurent cimenter leur autorité par le crédit des prélats et des abbés, en les appelant aux assemblées du champ de mai.

Ce fut, selon les annales de Metz, en 692 que le maire Pepin, premier du nom, procura cette prérogative au clergé : époque bien négligée par la plupart des historiens, mais époque très considérable, et premier fondement du pouvoir temporel des évêques et des abbés ; en France et en Allemagne. 


\section{Chapitre 18}

\section{Suite des usages du temps de Charlemagne, et avant lui. $S$ 'il était despotique, et le royaume héréditaire}

On demande si Charlemagne, ses prédécesseurs, et ses successeurs, étaient despotiques, et si leur royaume était héréditaire par le droit de ces temps-là. Il est certain que par le fait Charlemagne était despotique, et que par conséquent son royaume fut héréditaire, puisqu'il déclare son fils empereur en plein parlement. Le droit est un peu plus incertain que le fait ; voici sur quoi tous les droits étaient alors fondés.

Les habitants du Nord et de la Germanie étaient originairement des peuples chasseurs ; et les Gaulois, soumis par les Romains, étaient agriculteurs ou bourgeois. Des peuples chasseurs, toujours armés, doivent nécessairement subjuguer des laboureurs et des pasteurs, occupés toute l'année de leurs travaux continuels et pénibles, et encore plus aisément des bourgeois paisibles dans leurs foyers. Ainsi les Tartares ont asservi l'Asie ; ainsi les Goths sont venus à Rome. Toutes les hordes de Tartares et de Goths, de Huns, de Vandales et de Francs, avaient des chefs. Ces chefs d'émigrants étaient élus à la pluralité des voix, et cela ne pouvait être autrement; car, quel droit pourrait avoir un voleur de commander à ses camarades ? Un brigand habile et hardi, surtout heureux, dut à la longue acquérir beaucoup d'empire sur des brigands subordonnés, moins habiles, moins hardis, et moins heureux que lui. Ils avaient tous également part au butin; et c'est la loi la plus inviolable de tous les premiers peuples conquérants. Si on avait besoin de preuve pour faire connaître cette première loi des barbares, on la trouverait aisément dans l'exemple de ce guerrier franc qui ne voulut jamais permettre que Clovis ôtât du butin général un vase de l'église de Reims, et qui fendit le vase à coups de hache, sans que le chef osât l'en empêcher. 
Clovis devint despotique à mesure qu'il devint puissant; c'est la marche de la nature humaine. Il en fut ainsi de Charlemagne : il était fils d'un usurpateur. Le fils du roi légitime était rasé et condamné à dire son bréviaire dans un couvent de Normandie. Il était donc obligé à de très grands ménagements devant une nation de guerriers assemblée en parlement. " Nous vous avertissons, dit-il dans un de ses Capitulaires, qu'en considération de notre humilité, et de notre obéissance à vos conseils, que nous vous rendons par la crainte de Dieu, vous nous conserviez l'honneur que Dieu nous a accordé, comme vos ancêtres l'ont fait à l'égard de nos ancêtres. »

Ses ancêtres se réduisaient à son père, qui avait envahi le royaume : lui-même avait usurpé le partage de son frère, et avait dépouillé ses neveux. Il flattait les seigneurs en parlement ; mais, le parlement dissous, malheur à quiconque eut bravé ses volontés !

Quant à la succession, il est naturel qu'un chef de conquérants les ait engagés à élire son fils pour son successeur. Cette coutume d'élire, devenue avec le temps plus légale et plus consacrée, se maintient encore de nos jours dans l'empire d'Allemagne. L'élection était si bien regardée comme un droit du peuple conquérant que, lorsque Pepin usurpa le royaume des Francs sur le roi dont il était le domestique, le pape Étienne, avec lequel cet usurpateur était d'accord, prononça une excommunication contre ceux qui éliraient pour roi un autre qu'un descendant de la race de Pepin. Cette excommunication était à la vérité un grand exemple de superstition, comme l'entreprise de Pepin était un exemple d'audace; mais cette superstition même est une preuve du droit d'élire ; elle fait voir encore que la nation conquérante élisait, parmi les descendants d'un chef, celui qui lui plaisait davantage. Le pape ne dit pas : "Vous élirez les premiers nés de la maison de Pepin »; mais : " vous ne choisirez point ailleurs que dans sa maison ».

Charlemagne dit dans un capitulaire ${ }^{184}:$ «Si de l'un des trois princes, mes enfants, il naît un fils tel que la nation le veuille pour succéder à son père, nous voulons que ses oncles y consentent. " Il est évident, par ce titre et par plusieurs autres, que la nation des Francs eut, du moins en apparence, le droit d'élection. Cet usage a été d'abord celui de tous les peuples, dans toutes les religions, et dans tous les

184 Code diplomatique, p. 4. (V.) 
pays. On le voit s'établir chez les Juifs, chez les autres Asiatiques, chez les Romains. Les premiers successeurs de Mahomet sont élus; les soudans d'Égypte, les premiers miramolins, ne règnent que par ce droit ; et ce n'est qu'avec le temps qu'un État devient purement héréditaire. Le courage, l'habileté, et le besoin, font toutes les lois. 


\section{Chapitre 19}

\section{Suite des usages du temps de Charlemagne. Commerce, finances, sciences}

Charles Martel, usurpateur et soutien du pouvoir suprême dans une grande monarchie, vainqueur des conquérants arabes, qu'il repoussa jusqu'en Gascogne, n'est cependant appelé que sous-roitelet, subregulus, par le pape Grégoire II, qui implore sa protection contre les rois lombards. Il se dispose à aller secourir l'Église romaine ; mais il pille en attendant l'Église des Francs, il donne les biens des couvents à ses capitaines, il tient son roi Thierri en captivité. Pepin, fils de Charles Martel, lassé d'être subregulus, se fait roi, et reprend l'usage des parlements francs. Il a toujours des troupes aguerries sous le drapeau; et c'est à cet établissement que Charlemagne doit toutes ses conquêtes. Ces troupes se levaient par des ducs, gouverneurs des provinces, comme elles se lèvent aujourd'hui chez les Turcs par les béglierbeys. Ces ducs avaient été institués en Italie par Dioclétien. Les comtes, dont l'origine me paraît du temps de Théodose, commandaient sous les ducs, et assemblaient les troupes, chacun dans son canton. Les métairies, les bourgs, les villages, fournissaient un nombre de soldats proportionné à leurs forces. Douze métairies donnaient un cavalier armé d'un casque et d'une cuirasse ; les autres soldats n'en portaient point : mais tous avaient le bouclier carré long, la hache d'armes, le javelot, et l'épée. Ceux qui se servaient de flèches étaient obligés d'en avoir au moins douze dans leur carquois. La province qui fournissait la milice lui distribuait du blé et les provisions nécessaires pour six mois : le roi en fournissait pour le reste de la campagne. On faisait la revue au premier de mars, ou au premier de mai. C'est d'ordinaire dans ces temps qu'on tenait les parlements.

Dans les sièges on employait le bélier, la baliste, la tortue, et la plupart des machines des Romains. Les seigneurs, nommés barons, 
leudes, richeomes, composaient, avec leurs suivants, le peu de cavalerie qu'on voyait alors dans les armées. Les musulmans d'Afrique et d'Espagne avaient plus de cavaliers.

Charles avait des forces navales, c'est-à-dire de grands bateaux aux embouchures de toutes les grandes rivières de son empire. Avant lui on ne les connaissait pas chez les barbares; après lui on les ignora longtemps. Par ce moyen, et par sa police guerrière, il arrêta les inondations des peuples du Nord : il les contint dans leurs climats glacés ; mais, sous ses faibles descendants, ils se répandirent dans l'Europe.

Les affaires générales se réglaient dans des assemblées qui représentaient la nation. Sous lui, ses parlements n'avaient d'autre volonté que celle d'un maître qui savait commander et persuader.

Il fit fleurir le commerce, parce qu'il était le maître des mers ; ainsi les marchands des côtes de Toscane et ceux de Marseille allaient trafiquer à Constantinople chez les chrétiens, et au port d'Alexandrie chez les musulmans, qui les recevaient, et dont ils tiraient les richesses de l'Asie.

Venise et Gênes, si puissantes depuis par le négoce, n'attiraient pas encore à elles les richesses des nations; mais Venise commençait à s'enrichir et à s'agrandir. Rome, Ravenne, Milan, Lyon, Arles, Tours, avaient beaucoup de manufactures d'étoffes de laine. On damasquinait le fer, à l'exemple de l'Asie ; on fabriquait le verre ; mais les étoffes de soie n'étaient tissues dans aucune ville de l'empire d'Occident.

Les Vénitiens commençaient à les tirer de Constantinople ; mais ce ne fut que près de quatre cents ans après Charlemagne que les princes normands établirent à Palerme une manufacture de soie. Le linge était peu commun. Saint Boniface, dans une lettre à un évêque d'Allemagne, lui mande qu'il lui envoie du drap à longs poils pour se laver les pieds. Probablement ce manque de linge était la cause de toutes ces maladies de la peau, connues sous le nom de lèpre, si générales alors; car les hôpitaux nommés léproseries étaient déjà très nombreux.

La monnaie avait à peu près la même valeur que celle de l'empire romain depuis Constantin. Le sou d'or était le solidum romain. Ce sou 
d'or équivalait à quarante deniers d'argent fin. Ces deniers, tantôt plus forts, tantôt plus faibles, pesaient, l'un portant l'autre, trente grains.

Le sou d'or vaudrait aujourd'hui, en 1778, environ 14 livres 6 sous 3 deniers; le denier d'argent, à peu près 7 sous 1 denier 7/8, monnaie de compte.

Il faut toujours, en lisant les histoires, se ressouvenir qu'outre ces monnaies réelles d'or et d'argent, on se servait dans le calcul d'une autre dénomination. On s'exprimait souvent en monnaie de compte, monnaie fictive, qui n'était, comme aujourd'hui, qu'une manière de compter.

Les Asiatiques et les Grecs comptaient par mines et par talents, les Romains par grands sesterces, sans qu'il y eût aucune monnaie qui valut un grand sesterce ou un talent.

La livre numéraire, du temps de Charlemagne, était réputée le poids d'une livre d'argent de douze onces. Cette livre se divisait numériquement en vingt parties. Il y avait, à la vérité, des sous d'argent semblables à nos écus, dont chacun pesait la $20^{\mathrm{e}}, 22^{\mathrm{e}}$ ou $24^{\mathrm{e}}$ partie d'une livre de douze onces; et ce sou se divisait comme le nôtre en douze deniers. Mais Charlemagne ayant ordonné que le sou d'argent serait précisément la $20^{\mathrm{e}}$ partie de douze onces, on s'accoutuma à regarder dans les comptes numéraires vingt sous comme une livre.

Pendant deux siècles les monnaies restèrent sur le pied où Charlemagne les avait mises ; mais, petit à petit, les rois, dans leurs besoins, tantôt chargèrent les sous d'alliage, tantôt en diminuèrent le poids, de sorte que, par un changement qui est peut-être la honte des gouvernements de l'Europe, ce sou, qui était autrefois une pièce d'argent du poids d'environ cinq gros, n'est plus qu'une légère pièce de cuivre avec un $11^{\mathrm{e}} \mathrm{d}$ 'argent tout au plus; et la livre, qui était le signe représentatif de douze onces d'argent, n'est plus en France que le signe représentatif de vingt de nos sous de cuivre. Le denier, qui était la deux cent quarantième partie d'une livre d'argent de douze onces, n'est plus que le tiers de cette vile monnaie qu'on appelle un liard. Supposé donc qu'une ville de France dût à une autre, au temps de Charlemagne, cent vingt sous ou solides de rente, soixante-douze onces d'argent, elle s'acquitterait aujourd'hui de sa dette en payant ce que nous appelons un écu de six francs. 
La livre de compte des Anglais, celle des Hollandais, ont moins varié. Une livre sterling d'Angleterre vaut environ vingt-deux francs de France, et une livre de compte hollandaise vaut environ douze francs de France : ainsi les Hollandais se sont écartés moins que les Français de la loi primitive, et les Anglais encore moins.

Toutes les fois donc que l'histoire nous parle de monnaie sous le nom de livres, nous n'avons qu'à examiner ce que valait la livre au temps et dans le pays dont on parle, et la comparer à la valeur de la nôtre. Nous devons avoir la même attention en lisant l'histoire grecque et romaine. C'est, par exemple, un très grand embarras pour le lecteur d'être obligé de réformer toujours les comptes qui se trouvent dans l'Histoire ancienne d'un célèbre professeur de l'université de Paris ${ }^{185}$, dans l'Histoire ecclésiastique de Fleuri, et dans tant d'autres auteurs utiles. Quand ils veulent exprimer en monnaie de France les talents, les mines, les sesterces, ils se servent toujours de l'évaluation que quelques savants ont faite avant la mort du grand Colbert. Mais le marc de huit onces, qui valait vingt-six francs et dix sous dans les premiers temps du ministère de Colbert, vaut depuis longtemps quarante-neuf livres seize sous, ce qui fait une différence de près de la moitié. Cette différence, qui a été quelquefois beaucoup plus grande, pourra augmenter ou être réduite. Il faut songer à ces variations ; sans quoi on aurait une idée très fausse des forces des anciens États, de leur commerce, de la paye de leurs soldats, et de toute leur économie.

Il paraît qu'il y avait alors huit fois moins d'espèces circulantes en Italie, et vers les bords du Rhin, qu'il ne s'en trouve aujourd'hui. On n'en peut guère juger que par le prix des denrées nécessaires à la vie ; et je trouve la valeur de ces denrées, du temps de Charlemagne, huit fois moins chère qu'elle ne l'est de nos jours. Vingt-quatre livres de pain blanc valaient un denier d'argent, par les Capitulaires. Ce denier était la quarantième partie d'un sou d'or, qui valait environ quatorze livres six sous de notre monnaie d'aujourd'hui. Ainsi la livre de pain revenait à un liard et quelque chose; ce qui est en effet la huitième partie de notre prix ordinaire.

Dans les pays septentrionaux l'argent était beaucoup plus rare : le prix d'un bœuf y fut fixé, par exemple, à un sou d'or. Nous verrons

185 Rollin. 
dans la suite comment le commerce et les richesses se sont étendus de proche en proche.

Les sciences et les beaux-arts ne pouvaient avoir que des commencements bien faibles dans ces vastes pays tout sauvages encore. Éginhard, secrétaire de Charlemagne, nous apprend que ce conquérant ne savait pas signer son nom. Cependant il conçut, par la force de son génie, combien les belles lettres étaient nécessaires. Il fit venir de Rome des maîtres de grammaire et d'arithmétique. Les ruines de Rome fournissent tout à l'Occident, qui n'est pas encore formé. Alcuin, cet Anglais alors fameux, et Pierre de Pise, qui enseigna un peu de grammaire à Charlemagne, avaient tous deux étudié à Rome.

Il y avait des chantres dans les églises de France; et ce qui est à remarquer, c'est qu'ils s'appelaient chantres gaulois. La race des conquérants francs n'avait cultivé aucun art. Ces Gaulois prétendaient, comme aujourd'hui, disputer du chant avec les Romains. La musique grégorienne, qu'on attribue à saint Grégoire, surnommé le Grand, n'était pas sans mérite, et avait quelque dignité dans sa simplicité. Les chantres gaulois, qui n'avaient point l'usage des anciennes notes alphabétiques, avaient corrompu ce chant, et prétendaient l'avoir embelli. Charlemagne, dans un de ses voyages en Italie, les obligea de se conformer à la musique de leurs maîtres. Le pape Adrien leur donna des livres de chant notés; et deux musiciens italiens furent établis pour enseigner la note alphabétique, l'un dans Metz, l'autre dans Soissons. Il fallut encore envoyer des orgues de Rome.

Il n'y avait point d'horloge sonnante dans les villes de son empire, et il n'y en eut que vers le treizième siècle. De là vient l'ancienne coutume qui se conserve encore en Allemagne, en Flandre, en Angleterre, d'entretenir des hommes qui avertissent de l'heure pendant la nuit. Le présent que le calife Aaron-al-Raschild fit à Charlemagne d'une horloge sonnante fut regardé comme une merveille. À l'égard des sciences de l'esprit, de la saine philosophie, de la physique, de l'astronomie, des principes de la médecine, comment auraient-elles pu être connues? elles ne viennent que de naître parmi nous.

On comptait encore par nuits, et de là vient qu'en Angleterre on dit encore sept nuits, pour signifier une semaine, et quatorze nuits pour deux semaines. La langue romance commençait à se former du mé- 
lange du latin avec le tudesque. Ce langage est l'origine du français, de l'espagnol, et de l'italien. Il dura jusqu'au temps de Frédéric II, et on le parle encore dans quelques villages des Grisons, et vers la Suisse.

Les vêtements, qui ont toujours changé en Occident depuis la ruine de l'empire romain, étaient courts, excepté aux jours de cérémonie, où la saie était couverte d'un manteau souvent doublé de pelleterie. On tirait, comme aujourd'hui, ces fourrures du Nord, et surtout de la Russie. La chaussure des Romains s'était conservée. On remarque que Charlemagne se couvrait les jambes de bandes entrelacées en forme de brodequins, comme en usent encore les montagnards d'Écosse, seul peuple chez qui l'habillement guerrier des Romains s'est conservé jusqu'à nos jours. 


\section{Chapitre 20}

\section{De la religion, du temps de Charlemagne}

Si nous tournons à présent les yeux sur les maux que les hommes s'attirèrent quand ils firent de la religion un instrument de leurs passions, sur les usages consacrés, sur les abus de ces usages, la querelle des Iconoclastes et des Iconolâtres est d'abord ce qui présente le plus grand objet.

L'impératrice Irène, tutrice de son malheureux fils Constantin Porphyrogénète, pour se frayer le chemin à l'empire, flatte le peuple et les moines, à qui le culte des images, proscrit par tant d'empereurs depuis Léon l'Isaurien, plaisait encore. Elle y était elle-même attachée, parce que son mari les avait eues en horreur. On avait persuadé à Irène que, pour gouverner son époux, il fallait mettre sous le chevet de son lit les images de certaines saintes. La crédulité entre même dans les esprits politiques. L'empereur son mari avait puni les auteurs de cette superstition. Irène, après la mort de son mari, donne un libre cours à son goût et à son ambition. Voilà ce qui assemble, en 786, le second concile de Nicée, septième concile œcuménique, commencé d'abord à Constantinople. Elle fait élire pour patriarche un laïque, secrétaire d'État, nommé Taraise. Il y avait eu autrefois quelques exemples de séculiers élevés ainsi à l'évêché sans passer par les autres grades ; mais alors cette coutume ne subsistait plus.

Ce patriarche ouvrit le concile. La conduite du pape Adrien est très remarquable : il n'anathématise pas ce secrétaire d'État qui se fait patriarche ; il proteste seulement avec modestie, dans ses lettres à Irène, contre le titre de patriarche universel; mais il insiste pour qu'on lui rende les patrimoines de la Sicile ${ }^{186}$. Il redemande hautement ce peu

186 Toute cette partie des lettres du pape ne fut pas même lue dans le concile, par ménagement pour Irène et pour Taraise. M. de Voltaire a fort adouci le scan- 
de bien, tandis qu'il arrachait, ainsi que ses prédécesseurs, le domaine utile de tant de belles terres qu'il assure avoir été données par Pepin et par Charlemagne. Cependant le concile œcuménique de Nicée, auquel président les légats du pape et ce ministre patriarche, rétablit le culte des images.

C'est une chose avouée de tous les sages critiques, que les pères de ce concile, qui étaient au nombre de trois cent cinquante, y rapportèrent beaucoup de pièces évidemment fausses, beaucoup de miracles dont le récit scandaliserait dans nos jours, beaucoup de livres apocryphes. Ces pièces fausses ne firent point de tort aux vraies, sur lesquelles on décida.

Mais quand il fallut faire recevoir ce concile par Charlemagne, et par les églises de France, quel fut l'embarras du pape ! Charles s'était déclaré hautement contre les images. Il venait de faire écrire les livres qu'on nomme Carolins, dans lesquels ce culte est anathématisé. Ces livres sont écrits dans un latin assez pur : ils font voir que Charlemagne avait réussi à faire revivre les lettres ; mais ils font voir aussi qu'il n'y a jamais eu de dispute théologique sans invectives. Le titre même est une injure. " $\mathrm{Au}$ nom de notre Seigneur et Sauveur Jésus-Christ, commence le livre de l'illustrissime et excellentissime Charles, etc., contre le synode impertinent et arrogant tenu en Grèce pour adorer des images. " Le livre était attribué par le titre au roi Charles, comme on met sous le nom des rois les édits qu'ils n'ont point rédigés : il est certain que tous les peuples des royaumes de Charlemagne regardaient les Grecs comme des idolâtres.

Ce prince, en 794, assembla un concile à Francfort, auquel il présida selon l'usage des empereurs et des rois : concile composé de trois cents évêques ou abbés, tant d'Italie que de France, qui rejetèrent d'un consentement unanime le service (servitium) et l'adoration des images. Ce mot équivoque d'adoration était la source de tous ces différends ; car si les hommes définissaient les mots dont ils se servent, il y aurait moins de disputes : et plus d'un royaume a été bouleversé pour un malentendu.

dale de la conduite plus politique que religieuse d'Adrien. Voyez Fleuri, et les pièces originales de ces temps barbares, qui ont été recueillies par les érudits des derniers siècles. (K.) 
Tandis que le pape Adrien envoyait en France les actes du second concile de Nicée, il reçoit les livres Carolins opposés à ce concile; et on le presse au nom de Charles de déclarer hérétiques l'empereur de Constantinople et sa mère. On voit assez par cette conduite de Charles qu'il voulait se faire un nouveau droit de l'hérésie prétendue de l'empereur pour lui enlever Rome sous couleur de justice.

Le pape, partagé entre le concile de Nicée qu'il adoptait, et Charlemagne qu'il ménageait, prit un tempérament politique, qui devrait servir d'exemple dans toutes ces malheureuses disputes qui ont toujours divisé les chrétiens. Il explique les livres Carolins d'une manière favorable au concile de Nicée, et par là réfute le roi sans lui déplaire ; il permet qu'on ne rende point de culte aux images; ce qui était très raisonnable chez les Germains à peine sortis de l'idolâtrie, et chez les Francs encore grossiers, qui n'avaient ni sculpteurs ni peintres. Il exhorte en même temps à ne point briser ces mêmes images. Ainsi il satisfait tout le monde, et laisse au temps à confirmer ou à abolir un culte encore douteux. Attentif à ménager les hommes et à faire servir la religion à ses intérêts, il écrit à Charlemagne : « Je ne puis déclarer Irène et son fils hérétiques après le concile de Nicée ; mais je les déclarerai tels s'ils ne me rendent les biens de Sicile. »

On voit la même politique intéressée de ce pape dans une dispute encore plus délicate, et qui seule eut suffi en d'autres temps pour allumer des guerres civiles. On avait voulu savoir si le Saint-Esprit procède du Père et du Fils, ou du Père seulement.

On avait d'abord dans l'Orient ajouté au premier concile de Nicée qu'il procédait du Père. Ensuite en Espagne, et puis en France et en Allemagne, on ajouta qu'il procédait du Père et du Fils : c'était la croyance de presque tout l'empire de Charles. Ces mots du Symbole attribué aux apôtres : qui ex Patre Filioque procedit, étaient sacrés pour les Français ; mais ces mêmes mots n'avaient jamais été adoptés à Rome. On presse, de la part de Charlemagne, le pape de se déclarer. Cette question, décidée avec le temps par les lumières de l'Église romaine infaillible, semblait alors très obscure. On citait des passages des pères, et surtout celui de saint Grégoire de Nice, où il est dit « qu'une personne est cause, et l'autre vient de cause : l'une sort immédiatement de la première, l'autre en sort par le moyen du Fils, par 
lequel moyen le Fils se réserve la propriété d'unique, sans exclure l'Esprit-Saint de la relation du Père ».

Ces autorités ne parurent pas alors assez claires. Adrien $\mathrm{I}^{\mathrm{er}}$ ne décida rien : il savait qu'on pouvait être chrétien sans pénétrer dans la profondeur de tous les mystères. Il répond qu'il ne condamne point le sentiment du roi, mais ne change rien au Symbole de Rome. Il apaise la dispute en ne la jugeant pas, et en laissant à chacun ses usages. Il traite, en un mot, les affaires spirituelles en prince ; et trop de princes les ont traitées en évêques.

Dès lors la politique profonde des papes établissait peu à peu leur puissance. On fait bientôt après un recueil de faux actes connus aujourd'hui sous le nom de Fausses Décrétales ${ }^{187}$. C'est, dit-on, un Espagnol nommé Isidore Mercator, ou Piscator, ou Peccator, qui les digère. Ce sont les évêques allemands, dont la bonne foi fut trompée, qui les répandent et les font valoir. On prétend avoir aujourd'hui des preuves incontestables qu'elles furent composées par un Algeram, abbé de Senones, évêque de Metz: elles sont en manuscrit dans la bibliothèque du Vatican. Mais qu'importe leur auteur? Dans ces fausses Décrétales on suppose d'anciens canons qui ordonnent qu'on ne tiendra jamais un seul concile provincial sans la permission du pape, et que toutes les causes ecclésiastiques ressortiront à lui. On y fait parler les successeurs immédiats des apôtres, on leur suppose des écrits. Il est vrai que tout étant de ce mauvais style du huitième siècle, tout étant plein de fautes contre l'histoire et la géographie, l'artifice était grossier; mais c'étaient des hommes grossiers qu'on trompait. On avait forgé dès la naissance du christianisme, comme on l'a déjà dit ${ }^{188}$, de faux évangiles, les vers sibyllins, les livres d'Hermas, les Constitutions apostoliques, et mille autres écrits que la saine critique a réprouvés. Il est triste que pour enseigner la vérité on ait si souvent employé des actes de faussaire.

Ces fausses Décrétales ont abusé les hommes pendant huit siècles ; et enfin, quand l'erreur a été reconnue, les usages établis par elles ont subsisté dans une partie de l'Église: l'antiquité leur a tenu lieu d'authenticité.

187 Voyez, dans le Dictionnaire philosophique, l'article FAUSSES DÉCRÉTALES.
${ }^{188}$ Chapitre 9. (B.) 
Dès ces temps, les évêques d'Occident étaient des seigneurs temporels, et possédaient plusieurs terres en fief ; mais aucun n'était souverain indépendant. Les rois de France nommaient souvent aux évêchés ; plus hardis en cela et plus politiques que les empereurs des Grecs et que les rois de Lombardie, qui se contentaient d'interposer leur autorité dans les élections.

Les premières églises chrétiennes s'étaient gouvernées en républiques sur le modèle des synagogues. Ceux qui présidaient à ces assemblées avaient pris insensiblement le titre d'évêque, d'un mot grec dont les Grecs appelaient les gouverneurs de leurs colonies, et qui signifie inspecteur. Les anciens de ces assemblées se nommaient prêtres, d'un autre mot grec qui signifie vieillard.

Charlemagne, dans sa vieillesse, accorda aux évêques un droit dont son propre fils devint la victime. Ils firent accroire à ce prince que, dans le code rédigé sous Théodose, une loi portait que si de deux séculiers en procès l'un prenait un évêque pour juge, l'autre était obligé de se soumettre à ce jugement sans en pouvoir appeler. Cette loi, qui jamais n'avait été exécutée, passe chez tous les critiques pour supposée. C'est la dernière du code Théodosien; elle est sans date, sans nom de consuls. Elle a excité une guerre civile sourde entre les tribunaux de la justice et les ministres du sanctuaire; mais comme en ce temps-là tout ce qui n'était pas clergé était en Occident d'une ignorance profonde, il faut s'étonner qu'on n'ait pas donné encore plus d'empire à ceux qui, seuls étant un peu instruits, semblaient seuls mériter de juger les hommes.

Ainsi que les évêques disputaient l'autorité aux séculiers, les moines commençaient à la disputer aux évêques, qui pourtant étaient leurs maîtres par les canons. Ces moines étaient déjà trop riches pour obéir. Cette célèbre formule de Marculfe était bien souvent mise en usage : «Moi, pour le repos de mon âme, et pour n'être pas placé après ma mort parmi les boucs, je donne à tel monastère, etc. » On crut, dès le premier siècle de l'Église, que le monde allait finir; on se fondait sur un passage de saint Luc, qui met ces paroles dans la bouche de JésusChrist : " Il y aura des signes dans le soleil, dans la lune, et dans les étoiles ; les nations seront consternées ; la mer et les fleuves feront un grand bruit ; les hommes sécheront de frayeur dans l'attente de la révolution de l'univers; les puissances des cieux seront ébranlées, et 
alors ils verront le Fils de l'homme venant dans une nuée avec une grande puissance et une grande majesté. Lorsque vous verrez arriver ces choses, sachez que le royaume de Dieu est proche. Je vous dis en vérité, en vérité, que cette génération ne finira point sans que ces choses soient accomplies. »

Plusieurs personnages pieux, ayant toujours pris à la lettre cette prédiction non accomplie, en attendaient l'accomplissement : ils pensaient que l'univers allait être détruit, et voyaient clairement le jugement dernier, où Jésus-Christ devait venir dans les nuées. On se fondait aussi sur l'épître de saint Paul à ceux de Thessalonique, qui dit: «Nous qui sommes vivants, nous serons emportés dans l'air audevant de Jésus. " De là toutes ces suppositions de tant de prodiges aperçus dans les airs. Chaque génération croyait être celle qui devait voir la fin du monde, et cette opinion se fortifiant dans les siècles suivants, on donnait ses terres aux moines comme si elles eussent dû être préservées dans la conflagration générale. Beaucoup de chartes de donation commencent par ces mots, Adventante mundi vespero.

Des abbés bénédictins, longtemps avant Charlemagne, étaient assez puissants pour se révolter. Un abbé de Fontenelle avait osé se mettre à la tête d'un parti contre Charles Martel, et assembler des troupes. Le héros fit trancher la tête au religieux : exécution qui ne contribua pas peu à toutes ces révélations que tant de moines eurent depuis de la damnation de Charles Martel.

Avant ce temps on voit un abbé de Saint-Remi de Reims, et l'évêque de cette ville, susciter une guerre civile contre Childebert, au sixième siècle : crime qui n'appartient qu'aux hommes puissants.

Les évêques et les abbés avaient beaucoup d'esclaves. On reproche à l'abbé Alcuin d'en avoir eu jusqu'à vingt mille. Ce nombre n'est pas incroyable ; Alcuin possédait plusieurs abbayes, dont les terres pouvaient être habitées par vingt mille hommes. Ces esclaves, connus sous le nom de serfs, ne pouvaient se marier ni changer de demeure sans la permission de l'abbé. Ils étaient obligés de marcher cinquante lieues avec leurs charrettes quand il l'ordonnait; ils travaillaient pour lui trois jours de la semaine, et il partageait tous les fruits de la terre.

On ne pouvait, à la vérité, reprocher à ces bénédictins de violer, par leurs richesses, leur vœu de pauvreté ; car ils ne font point expressé- 
ment ce vœu: ils ne s'engagent, quand ils sont reçus dans l'ordre, qu'à obéir à leur abbé. On leur donna même souvent des terres incultes qu'ils défrichèrent de leurs mains, et qu'ils firent ensuite cultiver par des serfs. Ils formèrent des bourgades, des petites villes même autour de leurs monastères. Ils étudièrent; ils furent les seuls qui conservèrent les livres en les copiant; et enfin, dans ces temps barbares où les peuples étaient si misérables, c'était une grande consolation de trouver dans les cloîtres une retraite assurée contre la tyrannie.

En France et en Allemagne, plus d'un évêque allait au combat avec ses serfs. Charlemagne, dans une lettre à Frastade, une de ses femmes, lui parle d'un évêque qui a vaillamment combattu auprès de lui dans une bataille contre les Avares, peuples descendus des Scythes, qui habitaient vers le pays qu'on nomme à présent l'Autriche. Je vois de son temps quatorze monastères qui doivent fournir des soldats. Pour peu qu'unabbé fût guerrier, rien ne l'empêchait de les conduire lui-même. Il est vrai qu'en 803 un parlement se plaignit à Charlemagne du trop grand nombre de prêtres qu'on avait tués à la guerre. Il fut défendu alors, mais inutilement, aux ministres de l'autel d'aller aux combats.

Il n'était pas permis de se dire clerc sans l'être, de porter la tonsure sans appartenir à un évêque : de tels clercs s'appelaient acéphales. On les punissait comme vagabonds. On ignorait cet état, aujourd'hui si commun, qui n'est ni séculier, ni ecclésiastique. Le titre d'abbé, qui signifie père, n'appartenait qu'aux chefs des monastères.

Les abbés avaient dès lors le bâton pastoral que portaient les évêques, et qui avait été autrefois la marque de la dignité pontificale dans Rome païenne. Telle était la puissance de ces abbés sur les moines, qu'ils les condamnaient quelquefois aux peines afflictives les plus cruelles. Ils prirent le barbare usage des empereurs grecs de faire brûler les yeux; et il fallut qu'un concile leur défendît cet attentat, qu'ils commençaient à regarder comme un droit. 


\section{Chapitre 21}

\section{Suite des rites religieux du temps de Charlemagne}

La messe était différente de ce qu'elle est aujourd'hui, et plus encore de ce qu'elle était dans les premiers temps. Elle fut d'abord une cène, un festin nocturne ; ensuite, la majesté du culte augmentant avec le nombre des fidèles, cette assemblée de nuit se changea en une assemblée du matin: la messe devint à peu près ce qu'est la grand'messe aujourd'hui. Il n'y eut, jusqu'au seizième siècle, qu'une messe commune dans chaque église. Le nom de synaxe qu'elle a chez les Grecs, et qui signifie assemblée, les formules qui subsistent et qui s'adressent à cette assemblée, tout fait voir que les messes privées durent être longtemps inconnues. Ce sacrifice, cette assemblée, cette commune prière avait le nom de missa chez les Latins, parce que, selon quelques-uns, on renvoyait, mittebantur, les pénitents qui ne communiaient pas; et, selon d'autres, parce que la communion était envoyée, missa erat, à ceux qui ne pouvaient venir à l'église.

Il semble qu'on devrait savoir la date précise des établissements de nos rites ; mais aucune n'est connue. On ne sait en quel temps commença la messe telle qu'on la dit aujourd'hui ; on ignore l'origine précise du baptême par aspersion, de la confession auriculaire, de la communion avec du pain azyme, et sans vin; on ne sait qui donna le premier le nom de sacrement au mariage, à la confirmation, à l'onction qu'on administre aux malades.

Quand le nombre des prêtres fut augmenté, on fut obligé de dire des messes particulières. Les hommes puissants eurent des aumôniers ; Agobard, évêque de Lyon, s'en plaint au neuvième siècle. Denys-le-Petit, dans son Recueil des canons, et beaucoup d'autres, confirment que tous les fidèles communiaient à la messe publique. Ils apportaient, de son temps, le pain et le vin que le prêtre consacrait ; chacun recevait le pain dans ses mains. Ce pain était fermenté comme 
le pain ordinaire ; il y avait très peu d'églises où le pain sans levain fût en usage : on donnait ce pain aux enfants comme aux adultes. La communion sous les deux espèces était un usage universel sous Charlemagne ; il se conserva toujours chez les Grecs, et dura chez les Latins jusqu'au douzième siècle : on voit même que dans le treizième il était encore pratiqué quelquefois. L'auteur de la relation de la victoire que remporta Charles d'Anjou sur Mainfroi, en 1264, rapporte que ses chevaliers communièrent avec le pain et le vin avant la bataille. L'usage de tremper le pain dans le vin s'était établi avant Charlemagne ; celui de sucer le vin avec un chalumeau, ou un siphon de métal, ne s'introduisit qu'environ deux cents ans après, et fut bientôt aboli. Tous ces rites, toutes ces pratiques, changèrent selon la conjoncture des temps, et selon la prudence des pasteurs, ou selon le caprice, comme tout change.

L'Église latine était la seule qui priât dans une langue étrangère, inconnue au peuple. Les inondations des barbares qui avaient introduit dans l'Europe leurs idiomes en étaient cause. Les Latins étaient encore les seuls qui conférassent le baptême par la seule aspersion : indulgence très naturelle pour des enfants nés dans les climats rigoureux du septentrion, et convenance décente dans le climat chaud d'Italie. Les cérémonies du baptême des adultes, et de celui qu'on donnait aux enfants, n'étaient pas les mêmes : cette différence était indiquée par la nature.

La confession auriculaire s'était introduite, dit-on, dès le sixième siècle. Les évêques exigèrent $d$ 'abord que les clercs se confessassent à eux deux fois l'année, par les canons du concile d'Attigny, en 363 ; et c'est la première fois qu'elle fut commandée expressément. Les abbés soumirent leurs moines à ce joug, et les séculiers peu à peu le portèrent. La confession publique ne fut jamais en usage dans l'Occident; car, lorsque les barbares embrassèrent le christianisme, les abus et les scandales qu'elle entraînait après elle l'avaient abolie en Orient, sous le patriarche Nectaire, à la fin du quatrième siècle ; mais souvent les pécheurs publics faisaient des pénitences publiques dans les églises d'Occident, surtout en Espagne, où l'invasion des Sarrasins redoublait la ferveur des chrétiens humiliés. Je ne vois aucune trace, jusqu'au douzième siècle, de la formule de la confession, ni des confessionnaux établis dans les églises, ni de la nécessité préalable de se confesser immédiatement avant la communion. 
Vous observerez que la confession auriculaire n'était point reçue aux huitième et neuvième siècles dans les pays au delà de la Loire, dans le Languedoc, dans les Alpes. Alcuin s'en plaint dans ses lettres. Les peuples de ces contrées semblent avoir eu toujours quelques dispositions à s'en tenir aux usages de la primitive Église, et à rejeter les dogmes et les coutumes que l'Église plus étendue jugea convenable d'adopter.

Aux huitième et neuvième siècles il y avait trois carêmes, et quelquefois quatre, comme dans l'Église grecque; et on se confessait d'ordinaire à ces quatre temps de l'année. Les commandements de l'Église, qui ne sont bien connus qu'après le troisième concile de Latran, en 1215, imposèrent la nécessité de faire une fois l'année ce qui semblait auparavant plus arbitraire.

Au temps de Charlemagne il y avait des confesseurs dans les armées. Charles en avait un pour lui en titre d'office : il s'appelait Valdon, et était abbé d'Augie près de Constance.

Il était permis de se confesser à un laïque, et même à une femme, en cas de nécessité ${ }^{189}$. Cette permission dura très longtemps; c'est pourquoi Joinville dit qu'il confessa en Afrique un chevalier, et qu'il lui donna l'absolution, selon le pouvoir qu'il en avait. " Ceci n'est pas tout à fait un sacrement, dit saint Thomas, mais c'est comme sacrement. »

On peut regarder la confession comme le plus grand frein des crimes secrets. Les sages de l'antiquité avaient embrassé l'ombre de cette pratique salutaire. On s'était confessé dans les expiations chez les Égyptiens et chez les Grecs, et dans presque toutes les célébrations de leurs mystères. Marc-Aurèle, en s'associant aux mystères de CérèsÉleusine, se confessa à l'hiérophante.

Cet usage, si saintement établi chez les chrétiens, fut malheureusement depuis l'occasion des plus funestes abus. La faiblesse du sexe rendit quelquefois les femmes plus dépendantes de leurs confesseurs que de leurs époux. Presque tous ceux qui confessèrent les reines se servirent de cet empire secret et sacré pour entrer dans les affaires d'État. Lorsqu'un religieux domina sur la conscience d'un souverain,

189 Voyez les Éclaircissements. (Mélanges, année 1763). (V.) 
tous ses confrères s'en prévalurent; et plusieurs employèrent le crédit $\mathrm{du}$ confesseur pour se venger de leurs ennemis. Enfin il arriva que, dans les divisions entre les empereurs et les papes, dans les factions des villes, les prêtres ne donnaient pas l'absolution à ceux qui n'étaient pas de leur parti. C'est ce qu'on a vu en France du temps du roi Henri IV ; presque tous les confesseurs refusaient d'absoudre les sujets qui reconnaissaient leur roi. La facilité de séduire les jeunes personnes et de les porter au crime dans le tribunal même de la pénitence fut encore un écueil très dangereux. Telle est la déplorable condition des hommes, que les remèdes les plus divins ont été tournés en poisons.

La religion chrétienne ne s'était point encore étendue au nord plus loin que les conquêtes de Charlemagne. La Scandinavie, le Danemark, qu'on appelait le pays des Normands, avaient un culte que nous appelons ridiculement idolâtrie. La religion des idolâtres serait celle qui attribuerait la puissance divine à des figures, à des images; ce n'était pas celle des Scandinaves : ils n'avaient ni peintre ni sculpteur. Ils adoraient Odin; et ils se figuraient qu'après la mort le bonheur de l'homme consistait à boire, dans la salle d'Odin, de la bière dans le crâne de ses ennemis. On a encore de leurs anciennes chansons traduites, qui expriment cette idée. Il y avait longtemps que les peuples du Nord croyaient une autre vie. Les druides avaient enseigné aux Celtes qu'ils renaîtraient pour combattre, et les prêtres de la Scandinavie persuadaient aux hommes qu'ils boiraient de la bière après leur mort.

La Pologne n'était ni moins barbare ni moins grossière. Les Moscovites, aussi sauvages que le reste de la Grande-Tartarie, en savaient à peine assez pour être païens ; mais tous ces peuples vivaient en paix dans leur ignorance, heureux d'être inconnus à Charlemagne, qui vendait si cher la connaissance du christianisme.

Les Anglais commençaient à recevoir la religion chrétienne. Elle leur avait été apportée par Constance Chlore, protecteur secret de cette religion, alors opprimée. Elle n'y domina point; l'ancien culte du pays eut le dessus encore longtemps. Quelques missionnaires des Gaules cultivèrent grossièrement un petit nombre de ces insulaires. Le fameux Pélage, trop zélé défenseur de la nature humaine, était né en Angleterre ; mais il n'y fut point élevé, et il faut le compter parmi les Romains. 
L'Irlande, qu'on appelait Écosse, et l'Écosse connue alors sous le nom d'Albanie, ou du pays des Pictes, avaient reçu aussi quelques semences du christianisme, étouffées toujours par l'ancien culte qui dominait. Le moine Colomban, né en Irlande, était du sixième siècle ; mais il parait, par sa retraite en France, et par les monastères qu'il fonda en Bourgogne, qu'il y avait peu à faire, et beaucoup à craindre pour ceux qui cherchaient en Irlande et en Angleterre de ces établissements riches et tranquilles qu'on trouvait ailleurs à l'abri de la religion.

Après une extinction presque totale du christianisme dans l'Angleterre, l'Écosse et l'Irlande, la tendresse conjugale l'y fit renâ̂tre. Éthelbert, un des rois barbares anglo-saxons de l'heptarchie d'Angleterre, qui avait son petit royaume dans la province de Kent, où est Cantorbéry, voulut s'allier avec un roi de France. Il épousa la fille de Childebert, roi de Paris. Cette princesse chrétienne, qui passa la mer avec un évêque de Soissons, disposa son mari à recevoir le baptême, comme Clotilde avait soumis Clovis. Le pape Grégoire le Grand envoya Augustin, que les Anglais nomment Austin, avec d'autres moines romains, en 598. Ils firent peu de conversions car il faut au moins entendre la langue du pays pour en changer la religion; mais, favorisés par la reine, ils bâtirent un monastère.

Ce fut proprement la reine qui convertit le petit royaume de Cantorbéry. Ses sujets barbares, qui n'avaient point d'opinions, suivirent aisément l'exemple de leurs souverains. Cet Augustin n'eut pas de peine à se faire déclarer primat par Grégoire le Grand : il eût voulu même l'être des Gaules ; mais Grégoire lui écrivit qu'il ne pouvait lui donner de juridiction que sur l'Angleterre. Il fut donc premier archevêque de Cantorbéry, premier primat de l'Angleterre. Il donna à l'un de ses moines le titre d'évêque de Londres, à l'autre celui de Rochester. On ne peut mieux comparer ces évêques qu'à ceux d'Antioche et de Babylone, qu'on appelle évêques in partibus infidelium. Mais avec le temps, la hiérarchie d'Angleterre se forma. Les monastères surtout étaient très riches au huitième et neuvième siècle. Ils mettaient au catalogue des saints tous les grands seigneurs qui leur avaient donné des terres; d'où vient que l'on trouve parmi leurs saints de ce temps-là sept rois, sept reines, huit princes, seize princesses. Leurs chroniques disent que dix rois et onze reines finirent leurs jours dans des cloîtres. Il est croyable que ces dix rois et ces onze reines se firent seulement 
revêtir à leur mort d'habits religieux, et peut-être porter, à leurs dernières maladies, dans des couvents, comme on en a usé en Espagne ; mais non pas qu'en effet ils aient, en santé, renoncé aux affaires publiques pour vivre en cénobites. 


\section{Chapitre 22 \\ Suite des usages du temps de Charlemagne. De la justice, des lois. Coutumes singulières. Épreuves}

Des comtes nommés par le roi rendaient sommairement la justice. Ils avaient leurs districts assignés. Ils devaient être instruits des lois, qui n'étaient ni si difficiles ni si nombreuses que les nôtres. La procédure était simple, chacun plaidait sa cause en France et en Allemagne. Rome seule, et ce qui en dépendait, avait encore retenu beaucoup de lois et de formalités de l'empire romain. Les lois lombardes avaient lieu dans le reste de l'Italie citérieure.

Chaque comte avait sous lui un lieutenant, nommé viguier; sept assesseurs, scabini ; et un greffier, notarius. Les comtes publiaient dans leur juridiction l'ordre des marches pour la guerre, enrôlaient les soldats sous des centeniers, les menaient aux rendez-vous, et laissaient alors leurs lieutenants faire les fonctions de juges.

Les rois envoyaient des commissaires avec lettres expresses, missi dominici, qui examinaient la conduite des comtes. Ni ces commissaires ni ces comtes ne condamnaient presque jamais à la mort ni à aucun supplice; car, si on en excepte la Saxe, où Charlemagne fit des lois de sang, presque tous les délits se rachetaient dans le reste de son empire. Le seul crime de rébellion était puni de mort, et les rois s'en réservaient le jugement. La loi salique, celle des Lombards, celle des Ripuaires, avaient évalué à prix d'argent la plupart des autres attentats, ainsi que nous l'avons vu ${ }^{190}$.

Leur jurisprudence, qui paraît humaine, était peut-être en effet plus cruelle que la nôtre : elle laissait la liberté de mal faire à quiconque pouvait la payer. La plus douce loi est celle qui, mettant le frein le 
plus terrible à l'iniquité, prévient ainsi le plus de crimes; mais on ne connaissait pas encore la question, la torture, usage dangereux qui, comme on sait, ne sert que trop souvent à perdre l'innocent et à sauver le coupable.

Les lois saliques furent remises en vigueur par Charlemagne. Parmi ces lois saliques, il s'en trouve une qui marque bien expressément dans quel mépris étaient tombés les Romains chez les peuples barbares. Le Franc qui avait tué un citoyen romain ne payait que mille cinquante deniers ; et le Romain payait pour le sang d'un Franc deux mille cinq cents deniers.

Dans les causes criminelles indécises, on se purgeait par serment. Il fallait non seulement que la partie accusée jurât, mais elle était obligée de produire un certain nombre de témoins qui juraient avec elle. Quand les deux parties opposaient serment à serment, on permettait quelquefois le combat, tantôt à fer émoulu, tantôt à outrance.

Ces combats ${ }^{191}$ étaient appelés le jugement de Dieu ; c'est aussi le nom qu'on donnait à une des plus déplorables folies de ce gouvernement barbare. Les accusés étaient soumis à l'épreuve de l'eau froide, de l'eau bouillante, ou du fer ardent. Le célèbre Étienne Baluze a rassemblé toutes les anciennes cérémonies de ces épreuves. Elles commençaient par la messe ; on y communiait l'accusé. On bénissait l'eau froide, on l'exorcisait; ensuite l'accusé était jeté garrotté dans l'eau. S'il tombait au fond, il était réputé innocent; s'il surnageait, il était jugé coupable. M. de Fleuri, dans son Histoire ecclésiastique, dit que c'était une manière sûre de ne trouver personne criminel. J'ose croire que c'était une manière de faire périr beaucoup d'innocents. Il y a bien des gens qui ont la poitrine assez large et les poumons assez légers pour ne point enfoncer, lorsqu'une grosse corde qui les lie par plusieurs tours fait avec leur corps un volume moins pesant qu'une pareille quantité d'eau. Cette malheureuse coutume, proscrite depuis dans les grandes villes, s'est conservée jusqu'à nos jours dans beaucoup de provinces. On y a très souvent assujetti, même par sentence de juge, ceux qu'on faisait passer pour sorciers; car rien ne dure si longtemps que la superstition, et il en a coûté la vie à plus d'un malheureux.

191 Voyez le chapitre Des Duels, ci-après, chapitre 100. (V.) 
Le jugement de Dieu par l'eau chaude s'exécutait en faisant plonger le bras nu de l'accusé dans une cuve d'eau bouillante ; il fallait prendre au fond de la cuve un anneau bénit. Le juge, en présence des prêtres et du peuple, enfermait dans un sac le bras du patient, scellait le sac de son cachet; et si, trois jours après, il ne paraissait sur le bras aucune marque de brûlure, l'innocence était reconnue.

Tous les historiens rapportent l'exemple de la reine Teutberge, bru de l'empereur Lothaire, petit-fils de Charlemagne, accusée d'avoir commis un inceste avec son frère, moine et sous-diacre. Elle nomma un champion qui se soumit pour elle à l'épreuve de l'eau bouillante, en présence d'une cour nombreuse. Il prit l'anneau bénit sans se brûler. Il est certain qu'on a des secrets pour soutenir l'action d'un petit feu sans péril pendant quelques secondes : j'en ai vu des exemples. Ces secrets étaient alors d'autant plus communs qu'ils étaient plus nécessaires. Mais il n'en est point pour nous rendre absolument impassibles. Il y a grande apparence que, dans ces étranges jugements, on faisait subir l'épreuve d'une manière plus ou moins rigoureuse, selon qu'on voulait condamner ou absoudre.

Cette épreuve de l'eau bouillante était destinée particulièrement à la conviction de l'adultère. Ces coutumes sont plus anciennes, et se sont étendues plus loin qu'on ne pense.

Les savants n'ignorent pas qu'en Sicile, dans le temple des dieux Paliques, on écrivait son serment qu'on jetait dans un bassin d'eau, et que si le serment surnageait, l'accusé était absous. Le temple de Trézène était fameux par de pareilles épreuves. On trouve encore au bout de l'Orient, dans le Malabar et dans le Japon, des usages semblables, fondés sur la simplicité des premiers temps, et sur la superstition commune à toutes les nations. Ces épreuves étaient autrefois si autorisées en Phénicie qu'on voit dans le Pentateuque que lorsque les Juifs errèrent dans le désert, ils faisaient boire d'une eau mêlée avec de la cendre à leurs femmes soupçonnées d'adultère. Les coupables ne manquaient pas sans doute d'en crever, mais les femmes fidèles à leurs maris buvaient impunément. Il est dit, dans l'Évangile de saint Jacques, que le grand-prêtre ayant fait boire de cette eau à Marie et à Joseph, les deux époux se réconcilièrent. 
La troisième épreuve était celle d'une barre de fer ardent, qu'il fallait porter dans la main l'espace de neuf pas. Il était plus difficile de tromper dans cette épreuve que dans les autres; aussi je ne vois personne qui s'y soit soumis dans ces siècles grossiers. On veut savoir qui de l'Église grecque ou de la latine établit ces usages la première. On voit des exemples de ces épreuves à Constantinople jusqu'au treizième siècle, et Pachimère dit qu'il en a été témoin. Il est vraisemblable que les Grecs communiquèrent aux Latins ces superstitions orientales.

À l'égard des lois civiles, voici ce qui me paraît de plus remarquable. Un homme qui n'avait point d'enfants pouvait en adopter. Les époux pouvaient se répudier en justice; et, après le divorce, il leur était permis de passer à d'autres noces. Nous avons dans Marculfe le détail de ces lois.

Mais ce qui paraîtra peut-être plus étonnant, et ce qui n'en est pas moins vrai, c'est qu'au livre deuxième de ces formules de Marculfe, on trouve que rien n'était plus permis ni plus commun que de déroger à cette fameuse loi salique, par laquelle les filles n'héritaient pas. On amenait sa fille devant le comte ou le commissaire, et on disait : « Ma chère fille, un usage ancien et impie ôte parmi nous toute portion paternelle aux filles; mais ayant considéré cette impiété, j'ai vu que, comme vous m'avez été donnés tous de Dieu également, je dois vous aimer de même : ainsi, ma chère fille, je veux que vous héritiez par portion égale avec vos frères dans toutes mes terres, etc. »

On ne connaissait point chez les Francs, qui vivaient suivant la loi salique et ripuaire, cette distinction de nobles et de roturiers, de nobles de nom et d'armes, et de nobles $a b a v o$, ou gens vivant noblement. Il n'y avait que deux ordres de citoyens: les libres et les serfs, à peu près comme aujourd'hui dans les empires mahométans, et à la Chine. Le terme nobilis n'est employé qu'une seule fois dans les Capitulaires, au livre cinquième, pour signifier les officiers, les comtes, les centeniers.

Toutes les villes de l'Italie et de la France étaient gouvernées selon leur droit municipal. Les tributs qu'elles payaient au souverain consistaient en foderum, paratum, mansionaticum, fourrages, vivres, meubles de séjour. Les empereurs et les rois entretinrent longtemps leurs 
cours avec leurs domaines, et ces droits étaient payés en nature quand ils voyageaient. Il nous reste un capitulaire de Charlemagne concernant ses métairies. Il entre dans le plus grand détail. Il ordonne qu'on lui rende un compte exact de ses troupeaux. Un des grands biens de la campagne consistait en abeilles, ce qui prouve que beaucoup de terres restaient en friche. Enfin les plus grandes choses et les plus petites de ce temps-là nous font voir des lois, des mœurs, et des usages, dont à peine il reste des traces. 


\section{Chapitre 23 \\ Louis-le-Faible, ou le Débonnaire, déposé par ses enfants et par des prélats}

L'histoire des grands événements de ce monde n'est guère que l'histoire des crimes. Il n'est point de siècle que l'ambition des séculiers et des ecclésiastiques n'ait rempli d'horreurs.

À peine Charlemagne est-il au tombeau qu'une guerre civile désole sa famille et l'empire.

Les archevêques de Milan et de Crémone allument les premiers feux. Leur prétexte est que Bernard, roi d'Italie, est le chef de la maison carlovingienne, comme né du fils aîné de Charlemagne. Ces évêques se servent de ce roi Bernard pour exciter une guerre civile. On en voit assez la véritable raison dans cette fureur de remuer, et dans cette frénésie d'ambition qui s'autorise toujours des lois mêmes faites pour la réprimer. Un évêque d'Orléans entre dans leurs intrigues; l'empereur et Bernard, l'oncle et le neveu, lèvent des armées. On est près d'en venir aux mains à Châlon-sur-Saône; mais le parti de l'empereur gagne, par argent et par promesses, la moitié de l'armée d'Italie. On négocie, c'est-à-dire on veut tromper. Le roi est assez imprudent pour venir dans le camp de son oncle. Louis, qu'on a nommé le Débonnaire parce qu'il était faible, et qui fut cruel par faiblesse, fait crever les yeux à son neveu, qui lui demandait grâce à genoux. (819) Le malheureux roi meurt dans les tourments du corps et de l'esprit, trois jours après cette exécution cruelle. Il fut enterré à Milan, et on grava sur son tombeau : Ci gît Bernard de sainte mémoire. Il semble que le nom de saint en ce temps-là ne fut qu'un titre honorifique. Alors Louis fait tondre et enfermer dans un monastère trois de ses frères, dans la crainte qu'un jour le sang de Charlemagne, trop respecté en eux, ne suscitât des guerres. Ce ne fut pas tout. L'empereur fait arrêter tous les partisans de Bernard, que ce roi misérable avait dénon- 
cés à son oncle sous l'espoir de sa grâce. Ils éprouvent le même supplice que le roi : les ecclésiastiques sont exceptés de la sentence; on les épargne, eux qui étaient les auteurs de la guerre : la déposition ou l'exil sont leur seul châtiment. Louis ménageait l'Église, et l'Église lui fit bientôt sentir qu'il eût dû être moins cruel et plus ferme.

Dès l'an 817, Louis avait suivi le mauvais exemple de son père, en donnant des royaumes à ses enfants; et, n'ayant ni le courage d'esprit de son père, ni l'autorité que ce courage donne, il s'exposait à l'ingratitude. Oncle barbare et frère trop dur, il fut un père trop facile.

Ayant associé à l'empire son fils aîné, Lothaire, donné l'Aquitaine au second, nommé Pepin, la Bavière à Louis, son troisième fils, il lui restait un jeune enfant d'une nouvelle femme. C'est ce Charles-leChauve, qui fut depuis empereur. Il voulut, après le partage, ne pas laisser sans États cet enfant d'une femme qu'il aimait.

Une des sources du malheur de Louis-le-Faible, et de tant de désastres plus grands qui depuis ont affligé l'Europe, fut cet abus qui commençait à naître, d'accorder de la puissance dans le monde à ceux qui ont renoncé au monde.

Vala, abbé de Corbie, son parent par bâtardise, commença cette scène mémorable. C'était un homme furieux par zèle ou par esprit de faction, ou par tous les deux ensemble, et l'un de ces chefs de parti qu'on a vus si souvent faire le mal en prêchant la vertu et troubler tout par l'esprit de la règle.

Dans un parlement tenu en 829 à Aix-la-Chapelle, parlement où étaient entrés les abbés parce qu'ils étaient seigneurs de grandes terres, ce Vala reproche publiquement à l'empereur tous les désordres de l'État. C'est vous, lui dit-il, qui en êtes coupable. Il parle ensuite en particulier à chaque membre du parlement avec plus de sédition. Il ose accuser l'impératrice Judith d'adultère. Il veut prévenir et empêcher les dons que l'empereur veut faire à ce fils qu'il a eu de l'impératrice. Il déshonore et trouble la famille royale, et par conséquent l'État, sous prétexte du bien de l'État même.

Enfin l'empereur irrité renvoie Vala dans son monastère, d'où il n'eût jamais dû sortir. Il se résout, pour satisfaire sa femme, à donner 
à son fils une petite partie de l'Allemagne vers le Rhin, le pays des Suisses, et la Franche-Comté.

Si dans l'Europe les lois avaient été fondées sur la puissance paternelle, si les esprits eussent été pénétrés de la nécessité du respect filial comme du premier de tous les devoirs, ainsi que je l'ai remarqué de la Chine ${ }^{192}$, les trois enfants de l'empereur, qui avaient reçu de lui des couronnes, ne se seraient point révoltés contre leur père, qui donnait un héritage à un enfant du second lit.

D'abord ils se plaignirent: aussitôt l'abbé de Corbie se joint à l'abbé de Saint-Denis, plus factieux encore, et qui, ayant les abbayes de Saint-Médard de Soissons et de Saint-Germain-des Prés, pouvait lever des troupes, et en leva ensuite. Les évêques de Vienne, de Lyon, d'Amiens, unis à ces moines, poussent les princes à la guerre civile, en déclarant rebelles à Dieu et à l'Église ceux qui ne seront pas de leur parti. En vain Louis-le-Débonnaire, au lieu d'assembler des armées, convoque quatre conciles, dans lesquels on fait de bonnes et d'inutiles lois. Ses trois fils prennent les armes. C'est, je crois, la première fois qu'on a vu trois enfants soulevés ensemble contre leur père. L'empereur arme à la fin. On voit deux camps remplis d'évêques, d'abbés, et de moines. Mais du côté des princes est le pape Grégoire IV, dont le nom donne un grand poids à leur parti. C'était déjà l'intérêt des papes d'abaisser les empereurs. Déjà Étienne, prédécesseur de Grégoire, s'était installé dans la chaire pontificale sans l'agrément de Louis-le-Débonnaire. Brouiller le père avec les enfants semblait le moyen de s'agrandir sur leurs ruines. Le pape Grégoire vient donc en France, et menace l'empereur de l'excommunier. Cette cérémonie d'excommunication n'emportait pas encore l'idée qu'on voulut lui attacher depuis. On n'osait pas prétendre qu'un excommunié dût être privé de ses biens par la seule excommunication ; mais on croyait rendre un homme exécrable, et rompre par ce glaive tous les liens qui peuvent attacher les hommes à lui.

(829) Les évêques du parti de l'empereur se servent de leur droit, et font dire courageusement au pape : si excommunicaturus veniet, excommunicatus abibit ; "s'il vient pour excommunier, il retournera excommunié lui-même ». Ils lui écrivent avec fermeté, en le traitant, à 
la vérité, de pape, mais en même temps de frère. Grégoire, plus fier encore, leur mande : «Le terme de frère sent trop l'égalité, tenezvous-en à celui de pape: reconnaissez ma supériorité ; sachez que l'autorité de ma chaire est au-dessus de celle du trône de Louis. » Enfin il élude dans cette lettre le serment qu'il a fait à l'empereur.

La guerre tourne en négociation. Le pontife se rend arbitre. Il va trouver l'empereur dans son camp. Il y a le même avantage que Louis avait eu autrefois sur Bernard. Il séduit ses troupes, ou il souffre qu'elles soient séduites; il trompe Louis, ou il est trompé lui-même par les rebelles, au nom desquels il porte la parole. À peine le pape est-il sorti du camp que, la nuit même, la moitié des troupes impériales passe du côté de Lothaire, son fils (830). Cette désertion arriva près de Bâle, sur les confins de l'Alsace ; et la plaine où le pape avait négocié s'appelle encore le champ du mensonge, nom qui pourrait être commun à plusieurs lieux où l'on a négocié. Alors le monarque malheureux se rend prisonnier à ses fils rebelles, avec sa femme Judith, objet de leur haine. Il leur livre son fils Charles, âgé de dix ans, prétexte innocent de la guerre. Dans des temps plus barbares, comme sous Clovis et ses enfants, ou dans des pays tels que Constantinople, je ne serais point surpris qu'on eût fait périr Judith et son fils, et même l'empereur. Les vainqueurs se contentèrent de faire raser l'impératrice, de la mettre en prison en Lombardie, de renfermer le jeune Charles dans le couvent de Prum, au milieu de la forêt des Ardennes, et de détrôner leur père. Il me semble qu'en lisant le désastre de ce père trop bon, on ressent au moins une satisfaction secrète, quand on voit que ses fils ne furent guère moins ingrats envers cet abbé Vala, le premier auteur de ces troubles, et envers le pape qui les avait si bien soutenus. Le pontife retourna à Rome, méprisé des vainqueurs, et Vala se renferma dans un monastère en Italie.

Lothaire, d'autant plus coupable qu'il était associé à l'empire, traîne son père prisonnier à Compiègne. Il y avait alors un abus funeste introduit dans l'Église, qui défendait de porter les armes et d'exercer les fonctions civiles pendant le temps de la pénitence publique. Ces pénitences étaient rares, et ne tombaient guère que sur quelques malheureux de la lie du peuple. On résolut de faire subir à l'empereur ce supplice infamant, sous le voile d'une humiliation chrétienne et volontaire, et de lui imposer une pénitence perpétuelle, qui le dégraderait pour toujours. 
(833) Louis est intimidé : il a la lâcheté de condescendre à cette proposition qu'on a la hardiesse de lui faire. Un archevêque de Reims, nommé Ebbon, tiré de la condition servile, élevé à cette dignité par Louis même, malgré les lois, dépose ainsi son souverain et son bienfaiteur. On fait comparaître le souverain, entouré de trente évêques, de chanoines, de moines, dans l'église de Notre-Dame de Soissons. Son fils Lothaire, présent, y jouit de l'humiliation de son père. On fait étendre un cilice devant l'autel. L'archevêque ordonne à l'empereur d'ôter son baudrier, son épée, son habit, et de se prosterner sur ce cilice. Louis, le visage contre terre, demande lui-même la pénitence publique, qu'il ne méritait que trop en s'y soumettant. L'archevêque le force de lire à haute voix un écrit dans lequel il s'accuse de sacrilège et d'homicide. Le malheureux lit posément la liste de ses crimes, parmi lesquels il est spécifié qu'il avait fait marcher ses troupes en carême, et indiqué un parlement un jeudi saint. On dresse un procès-verbal de toute cette action : monument encore subsistant d'insolence et de bassesse. Dans ce procès-verbal on ne daigne pas seulement nommer Louis du nom d'empereur : il y est appelé «Dominus Ludovicus, noble homme, vénérable homme »: c'est le titre qu'on donne aujourd'hui aux marguilliers de paroisse.

On tâche toujours d'appuyer par des exemples les entreprises extraordinaires. Cette pénitence de Louis fut autorisée par le souvenir d'un certain roi visigoth, nommé Vamba, qui régnait en Espagne, en 681. C'est le même qui avait été oint à son couronnement. Il devint imbécile, et fut soumis à la pénitence publique dans un concile de Tolède. Il s'était mis dans un cloître. Son successeur, Hervique, avait reconnu qu'il tenait sa couronne des évêques. Ce fait était cité, comme si un exemple pouvait justifier un attentat. On alléguait encore la pénitence de l'empereur Théodose ; mais elle fut bien différente. Il avait fait massacrer quinze mille citoyens à Thessalonique, non pas dans un mouvement de colère, comme on le dit tous les jours très faussement dans de vains panégyriques, mais après une longue délibération. Ce crime réfléchi pouvait attirer sur lui la vengeance des peuples, qui ne l'avaient pas élu pour en être égorgés. Saint Ambroise fit une très belle action en lui refusant l'entrée de l'église, et Théodose en fit une très sage d'apaiser un peu la haine de l'empire, en s'abstenant d'entrer dans l'église pendant huit mois. Est-ce une satisfaction pour le forfait 
le plus horrible dont jamais un souverain se soit souillé, d'être huit mois sans entendre la grand-messe ?

Louis fut enfermé un an dans une cellule du couvent de SaintMédard de Soissons, vêtu du sac de pénitent, sans domestiques, sans consolation, mort pour le reste du monde. S'il n'avait eu qu'un fils, il était perdu pour toujours ; mais ses trois enfants disputant ses dépouilles, leur désunion rendit au père sa liberté et sa couronne.

(834) Transféré à Saint-Denys, deux de ses fils, Louis et Pepin, vinrent le rétablir, et remettre en ses bras sa femme et son fils Charles. L'assemblée de Soissons est anathématisée par une autre à Thionville ; mais il n'en coûta à l'archevêque de Reims que la perte de son siège ; encore fut-il jugé et déposé dans la sacristie : l'empereur l'avait été en public, au pied de l'autel. Quelques évêques furent déposés aussi. L'empereur ne put ou n'osa les punir davantage.

Bientôt après, un de ces mêmes enfants qui l'avaient rétabli, Louis de Bavière, se révolte encore. Le malheureux père mourut de chagrin dans une tente, auprès de Mayence, en disant : « Je pardonne à Louis ; mais qu'il sache qu'il m'a donné la mort. » (20 juin 840 .)

Il confirma, dit-on, solennellement par son testament la donation de Pepin et de Charlemagne à l'Église de Rome.

Les mêmes doutes s'élèvent sur cette confirmation, et sur les dons qu'elle ratifie. Il est difficile de croire que Charlemagne et son fils aient donné aux papes Venise, la Sicile, la Sardaigne, et la Corse, pays sur lesquels ils n'avaient, tout au plus, que la prétention disputée du domaine suprême. Et dans quel temps Louis eût-il donné la Sicile, qui appartenait aux empereurs grecs, et qui était infestée par les descentes continuelles des Arabes? 


\section{Chapitre 24}

État de l'Europe après la mort de Louis-le-Débonnaire ou le Faible. L'Allemagne pour toujours séparée de l'empire franc ou français

Après la mort du fils de Charlemagne, son empire éprouva ce qui était arrivé à celui d'Alexandre, et que nous verrons bientôt être la destinée de celui des califes. Fondé avec précipitation, il s'écroula de même : les guerres intestines le divisèrent.

Il n'est pas surprenant que des princes qui avaient détrôné leur père se soient voulu exterminer l'un l'autre. C'était à qui dépouillerait son frère. Lothaire, empereur, voulait tout. Charles le Chauve, roi de France, et Louis, roi de Bavière, s'unissent contre lui. Un fils de Pepin, ce roi d'Aquitaine, fils du Débonnaire, et devenu roi après la mort de son père, se joint à Lothaire. Ils désolent l'empire ; ils l'épuisent de soldats (841). Enfin deux rois contre deux rois, dont trois sont frères, et dont l'autre est leur neveu; se livrent une bataille à Fontenai, dans l'Auxerrois, dont l'horreur est digne des guerres civiles. Plusieurs auteurs assurent qu'il y périt cent mille hommes (842). Il est vrai que ces auteurs ne sont pas contemporains, et que du moins il est permis de douter que tant de sang ait été répandu. L'empereur Lothaire fut vaincu. Cette bataille, comme tant d'autres, ne décida de rien. Il faut observer seulement que les évêques qui avaient combattu dans l'armée de Charles et de Louis firent jeûner leurs troupes et prier Dieu pour les morts, et qu'il eût été plus chrétien de ne les point tuer que de prier pour eux. Lothaire donna alors au monde l'exemple d'une politique toute contraire à celle de Charlemagne.

Le vainqueur des Saxons les avait assujettis au christianisme, comme à un frein nécessaire. Quelques révoltes, et de fréquents retours à leur culte, avaient marqué leur horreur pour une religion qu'ils regardaient comme leur châtiment. Lothaire, pour se les attacher, leur donne une liberté entière de conscience. La moitié du pays redevint 
idolâtre, mais fidèle à son roi. Cette conduite, et celle de Charlemagne, son grand-père, firent voir aux hommes combien diversement les princes plient la religion à leurs intérêts. Ces intérêts font toujours la destinée de la terre. Un Franc, un Salien avait fondé le royaume de France ; un fils du maire ou majordome, Pepin, avait fondé l'empire franc. Trois frères le divisent à jamais. Ces trois enfants dénaturés, Lothaire, Louis de Bavière, et Charles-le-Chauve, après avoir versé tant de sang à Fontenai, démembrent enfin l'empire de Charlemagne par la fameuse paix de Verdun. Charles II, surnommé le Chauve, eut la France ; Lothaire, l'Italie, la Provence, le Dauphiné, le Languedoc, la Suisse, la Lorraine, l'Alsace, la Flandre ; Louis de Bavière, ou le Germanique, eut l'Allemagne (843).

C'est à cette époque que les savants dans l'histoire commencent à donner le nom de Français aux Francs ; c'est alors que l'Allemagne a ses lois particulières ; c'est l'origine de son droit public, et en même temps de la haine entre les Français et les Allemands. Chacun des trois frères fut troublé dans son partage par des querelles ecclésiastiques, autant que par les divisions qui arrivent toujours entre des ennemis qui ont fait la paix malgré eux.

C'est au milieu de ces discordes que Charles-le-Chauve, premier roi de la seule France, et Louis-le-Germanique, premier roi de la seule Allemagne, assemblèrent un concile à Aix-la-Chapelle contre Lothaire ; et ce Lothaire est le premier empereur franc privé de l'Allemagne et de la France.

Les prélats, d'un commun accord, déclarèrent Lothaire déchu de son droit à la couronne, et ses sujets déliés du serment de fidélité. «Promettez-vous de mieux gouverner que lui ? disent-ils aux deux frères Charles et Louis. - Nous le promettons, répondirent les deux rois. - Et nous, dit l'évêque qui présidait, nous vous permettons par l'autorité divine, et nous vous commandons de régner à sa place. » $\mathrm{Ce}$ commandement ridicule n'eut alors aucune suite.

En voyant les évêques donner ainsi les couronnes, on se tromperait si on croyait qu'ils fussent alors tels que des électeurs de l'Empire. Ils s'étaient rendus puissants, à la vérité, mais aucun n'était souverain. L'autorité de leur caractère et le respect des peuples étaient des instruments dont les rois se servaient à leur gré. Il y avait dans ces ecclé- 
siastiques bien plus de faiblesse que de grandeur à décider ainsi du droit des rois suivant les ordres du plus fort.

On ne doit pas être surpris que, quelques années après, un archevêque de Sens, avec vingt autres évêques, ait osé, dans des conjonctures pareilles, déposer Charles-le-Chauve, roi de France. Cet attentat fut commis pour plaire à Louis de Bavière. Ces monarques, aussi méchants rois que frères dénaturés, ne pouvant se faire périr l'un l'autre, se faisaient anathématiser tour à tour. Mais ce qui surprend, c'est l'aveu que fait Charles-le-Chauve, dans un écrit qu'il daigna publier contre l'archevêque de Sens : «Au moins, cet archevêque ne devait pas me déposer avant que j'eusse comparu devant les évêques qui m'avaient sacré roi ; il fallait qu'auparavant j'eusse subi leur jugement, ayant toujours été prêt à me soumettre à leurs corrections paternelles et à leur châtiment. » La race de Charlemagne, réduite à parler ainsi, marchait visiblement à sa ruine.

Je reviens à Lothaire, qui avait toujours un grand parti en Germanie, et qui était maître paisible en Italie. Il passe les Alpes, fait couronner son fils Louis, qui vient juger dans Rome le pape Sergius II. Le pontife comparaît, répond juridiquement aux accusations d'un évêque de Metz, se justifie, et prête ensuite serment de fidélité à ce même Lothaire, déposé par ses évêques. Lothaire même fit cette célèbre et inutile ordonnance, que, « pour éviter les séditions trop fréquentes, le pape ne sera plus élu par le peuple, et que l'on avertira l'empereur de la vacance du saint-siège $»$.

On s'étonne de voir l'empereur tantôt si humble, et tantôt si fier ; mais il avait une armée auprès de Rome quand le pape lui jura obéissance, et n'en avait point à Aix-la-Chapelle quand les évêques le détrônèrent.

Leur sentence ne fut qu'un scandale de plus ajouté aux désolations de l'Europe. Les provinces depuis les Alpes au Rhin ne savaient plus à qui elles devaient obéir. Les villes changeaient chaque jour de tyrans, les campagnes étaient ravagées tour à tour par différents partis. On n'entendait parler que de combats; et dans ces combats il y avait toujours des moines, des abbés, des évêques, qui périssaient les armes à la main. Hugues, un des fils de Charlemagne, forcé jadis à être moi- 
ne, devenu depuis abbé de Saint-Quentin, fut tué devant Toulouse, avec l'abbé de Ferrière : deux évêques y furent faits prisonniers.

Cet incendie s'arrêta un moment pour recommencer avec plus de fureur. Les trois frères, Lothaire, Charles, et Louis, firent de nouveaux partages, qui ne furent que de nouveaux sujets de divisions et de guerre.

(855) L'empereur Lothaire, après avoir bouleversé l'Europe sans succès et sans gloire, se sentant affaibli, vint se faire moine dans l'abbaye de Prum. Il ne vécut dans le froc que six jours, et mourut imbécile après avoir régné en tyran.

À la mort de ce troisième empereur d'Occident, il s'éleva de nouveaux royaumes en Europe, comme des monceaux de terre après les secousses d'un grand tremblement.

Un autre Lothaire, fils de cet empereur, donna le nom de Lotharinge à une assez grande étendue de pays, nommée depuis, par contraction, Lorraine, entre le Rhin, l'Escaut, la Meuse, et la mer. Le Brabant fut appelé la Basse-Lorraine; le reste fut connu sous le nom de la Haute. Aujourd'hui, de cette Haute-Lorraine il ne reste qu'une petite province de ce nom, engloutie depuis peu dans le royaume de France.

Un second fils de l'empereur Lothaire, nommé Charles, eut la Savoie, le Dauphiné, une partie du Lyonnais, de la Provence, et du Languedoc. Cet État composa le royaume d'Arles, du nom de la capitale, ville autrefois opulente et embellie par les Romains, mais alors petite, pauvre, ainsi que toutes les villes en-deçà des Alpes.

Un barbare, qu'on nomme Salomon, se fit bientôt après roi de la Bretagne, dont une partie était encore païenne ; mais tous ces royaumes tombèrent presque aussi promptement qu'ils furent élevés.

Le fantôme d'empire romain subsistait. Louis, second fils de Lothaire, qui avait eu en partage une partie de l'Italie, fut proclamé empereur par l'évêque de Rome, Sergius II, en 855 . Il ne résidait point à Rome ; il ne possédait pas la neuvième partie de l'empire de Charlemagne, et n'avait en Italie qu'une autorité contestée par les papes et par les ducs de Bénévent, qui possédaient alors un État considérable. 
Après sa mort, arrivée en 875 , si la loi salique avait été en vigueur dans la maison de Charlemagne, c'était à l'aîné de la maison qu'appartenait l'empire. Louis de Germanie, aîné de la maison de Charlemagne, devait succéder à son neveu, mort sans enfants; mais des troupes et de l'argent firent les droits de Charles-le-Chauve. Il ferma les passages des Alpes à son frère, et se hâta d'aller à Rome avec quelques troupes. Réginus, les Annales de Metz et de Fulde, assurent qu'il acheta l'empire du pape Jean VIII. Le pape non seulement se fit payer, mais profitant de la conjoncture, il donna l'empire en souverain ; et Charles le reçut en vassal, protestant qu'il le tenait du pape, ainsi qu'il avait protesté auparavant en France, en 859, qu'il devait subir le jugement des évêques, laissant toujours avilir sa dignité pour en jouir.

Sous lui, l'empire romain était donc composé de la France et de l'Italie. On dit qu'il mourut empoisonné par son médecin, un Juif, nommé Sédécias ; mais personne n'a jamais dit par quelle raison ce médecin commit ce crime. Que pouvait-il gagner en empoisonnant son maître ? Auprès de qui eût-il trouvé une plus belle fortune ? Aucun auteur ne parle du supplice de ce médecin : il faut donc douter de l'empoisonnement, et faire réflexion seulement que l'Europe chrétienne était si ignorante que les rois étaient obligés de choisir pour leurs médecins des Juifs et des Arabes.

On voulait toujours saisir cette ombre d'empire romain ; et Louisle-Bègue, roi de France, fils de Charles-le-Chauve, le disputait aux autres descendants de Charlemagne ; c'était toujours au pape qu'on le demandait. Un duc de Spolette, un marquis de Toscane, investis de ces États par Charles-le-Chauve, se saisirent du pape Jean VIII, et pillèrent une partie de Rome, pour le forcer, disaient-ils, à donner l'empire au roi de Bavière, Carloman, l'aîné de la race de Charlemagne. Non seulement le pape Jean VIII était ainsi persécuté dans Rome par des Italiens, mais il venait, en 877 , de payer vingt-cinq mille livres pesant d'argent aux mahométans possesseurs de la Sicile et du Garillan : c'était l'argent dont Charles-le-Chauve avait acheté l'empire. Il passa bientôt des mains du pape en celles des Sarrasins; et le pape même s'obligea, par un traité authentique, à leur en payer autant tous les ans. 
Cependant ce pontife, tributaire des musulmans, et prisonnier dans Rome, s'échappe, s'embarque, et passe en France. Il vient sacrer empereur Louis le Bègue, dans la ville de Troyes, à l'exemple de Léon III, d'Adrien, et d'Étienne III, persécutés chez eux, et donnant ailleurs des couronnes.

Sous Charles-le-Gros, empereur et roi de France, la désolation de l'Europe redoubla. Plus le sang de Charlemagne s'éloignait de sa source, et plus il dégénérait. (887) Charles-le-Gros fut déclaré incapable de régner par une assemblée de seigneurs français et allemands, qui le déposèrent auprès de Mayence, dans une diète convoquée par lui-même. Ce ne sont point ici des évêques qui, en servant la passion d'un prince, semblent disposer d'une couronne ; ce furent les principaux seigneurs qui crurent avoir le droit de nommer celui qui devait les gouverner et combattre à leur tête. On dit que le cerveau de Charles-le-Gros était affaibli ; il le fut toujours sans doute, puisqu'il se mit au point d'être détrôné sans résistance, de perdre à la fois l'Allemagne, la France et l'Italie, et de n'avoir enfin pour subsistance que la charité de l'archevêque de Mayence, qui daigna le nourrir. Il paraît bien qu'alors l'ordre de la succession était compté pour rien, puisque Arnould, bâtard de Carloman, fils de Louis-le-Bègue, fut déclaré empereur, et qu'Eudes ou Odon, comte de Paris, fut roi de France. Il n'y avait alors ni droit de naissance, ni droit d'élection reconnu. L'Europe était un chaos dans lequel le plus fort s'élevait sur les ruines du plus faible, pour être ensuite précipité par d'autres. Toute cette histoire n'est que celle de quelques capitaines barbares qui disputaient avec des évêques la domination sur des serfs imbéciles. Il manquait aux hommes deux choses nécessaires pour se soustraire à tant d'horreurs : la raison et le courage. 


\section{Chapitre 25}

\section{Des Normands vers le IX $\mathrm{X}^{e}$ siècle}

Tout étant divisé, tout était malheureux et faible. Cette confusion ouvrit un passage aux peuples de la Scandinavie et aux habitants des bords de la mer Baltique. Ces sauvages trop nombreux, n'ayant à cultiver que des terres ingrates, manquant de manufactures, et privés des arts, ne cherchaient qu'à se répandre loin de leur patrie. Le brigandage et la piraterie leur étaient nécessaires, comme le carnage aux bêtes féroces. En Allemagne on les appelait Normands, hommes du Nord, sans distinction, comme nous disons encore en général les corsaires de Barbarie. Dès le quatrième siècle ils se mêlèrent aux flots des autres barbares, qui portèrent la désolation jusqu'à Rome et en Afrique. On a vu que, resserrés sous Charlemagne, ils craignirent l'esclavage. Dès le temps de Louis-le-Débonnaire, ils commencèrent leurs courses. Les forêts, dont ces pays étaient hérissés, leur fournissaient assez de bois pour construire leurs barques à deux voiles et à rames. Environ cent hommes tenaient dans ces bâtiments, avec leurs provisions de bière, de biscuit de mer, de fromage, et de viande fumée. Ils côtoyaient les terres, descendaient où ils ne trouvaient point de résistance, et retournaient chez eux avec leur butin, qu'ils partageaient ensuite selon les lois du brigandage, ainsi qu'il se pratique en Barbarie. Dès l'an 843 ils entrèrent en France par l'embouchure de la rivière de Seine, et mirent la ville de Rouen au pillage. Une autre flotte entra par la Loire, et dévasta tout jusqu'en Touraine. Ils emmenaient les hommes en esclavage, ils partageaient entre eux les femmes et les filles, prenant jusqu'aux enfants pour les élever dans leur métier de pirates. Les bestiaux, les meubles, tout était emporté. Ils vendaient quelquefois sur une côte ce qu'ils avaient pillé sur une autre. Leurs premiers gains excitèrent la cupidité de leurs compatriotes indigents. Les habitants des côtes germaniques et gauloises se joignirent à eux, 
ainsi que tant de rénégats de Provence et de Sicile ont servi sur les vaisseaux d'Alger.

En 844 ils couvrirent la mer de vaisseaux. On les vit descendre presque à la fois en Angleterre, en France et en Espagne. Il faut que le gouvernement des Français et des Anglais fût moins bon que celui des mahométans qui régnaient en Espagne ; car il n'y eut nulle mesure prise par les Français ni par les Anglais pour empêcher ces irruptions ; mais en Espagne les Arabes gardèrent leurs côtes, et repoussèrent enfin les pirates.

En 845, les Normands pillèrent Hambourg, et pénétrèrent avant dans l'Allemagne. Ce n'était plus alors un ramas de corsaires sans ordre : c'était une flotte de six cents bateaux, qui portait une armée formidable. Un roi de Danemark, nommé Éric, était à leur tête. Il gagna deux batailles avant de se rembarquer. Ce roi des pirates, après être retourné chez lui avec les dépouilles allemandes, envoie en France un des chefs des corsaires, à qui les histoires donnent le nom de Régnier. Il remonte la Seine avec cent vingt voiles. Il n'y a point d'apparence que ces cent vingt voiles portassent dix mille hommes. Cependant, avec un nombre probablement inférieur, il pille Rouen une seconde fois, et vient jusqu'à Paris. Dans de pareilles invasions, quand la faiblesse du gouvernement n'a pourvu à rien, la terreur du peuple augmente le péril, et le plus grand nombre fuit devant le plus petit. Les Parisiens, qui se défendirent dans d'autres temps avec tant de courage, abandonnèrent alors leur ville ; et les Normands n'y trouvèrent que des maisons de bois, qu'ils brûlèrent. Le malheureux roi, Charles-leChauve, retranché à Saint-Denys avec peu de troupes, au lieu de s'opposer à ces barbares, acheta de quatorze mille marcs d'argent la retraite qu'ils daignèrent faire. Il est croyable que ces marcs étaient ce qu'on a appelé longtemps des marques, marcas, qui valaient environ un de nos demi-écus. On est indigné quand on lit dans nos auteurs que plusieurs de ces barbares furent punis de mort subite pour avoir pillé l'église de Saint-Germain-des-Prés. Ni les peuples, ni leurs saints, ne se défendirent; mais les vaincus se donnent toujours la honteuse consolation de supposer des miracles opérés contre leurs vainqueurs.

Charles-le-Chauve, en achetant ainsi la paix, ne faisait que donner à ces pirates de nouveaux moyens de faire la guerre, et s'ôter celui de la soutenir. Les Normands se servirent de cet argent pour aller assié- 
ger Bordeaux, qu'ils pillèrent. Pour comble d'humiliation et d'horreur, un descendant de Charlemagne, Pepin, roi d'Aquitaine, n'ayant pu leur résister, s'unit avec eux ; et alors la France, vers l'an 858 , fut entièrement ravagée. Les Normands, fortifiés de tout ce qui se joignait à eux, désolèrent longtemps l'Allemagne, la Flandre, l'Angleterre. Nous avons vu depuis peu des armées de cent mille hommes pouvoir à peine prendre deux villes après des victoires signalées : tant l'art de fortifier les places et de préparer les ressources a été perfectionné. Mais alors des barbares, combattant d'autres barbares désunis, ne trouvaient, après le premier succès, presque rien qui arrêtât leurs courses. Vaincus quelquefois, ils reparaissaient avec de nouvelles forces.

Godefroy, prince de Danemark, à qui Charles-le-Gros céda enfin une partie de la Hollande, en 882, pénètre de la Hollande en Flandre ; ses Normands passent de la Somme à l'Oise sans résistance, prennent et brûlent Pontoise, et arrivent par eau et par terre devant Paris.

(885) Les Parisiens, qui s'attendaient alors à l'irruption des barbares, n'abandonnèrent point la ville, comme autrefois. Le comte de Paris, Odon ou Eudes, que sa valeur éleva depuis sur le trône de France, mit dans la ville un ordre qui anima les courages, et qui leur tint lieu de tours et de remparts.

Sigefroy, chef des Normands, pressa le siège avec une fureur opiniâtre, mais non destituée d'art. Les Normands se servirent du bélier pour battre les murs. Cette invention est presque aussi ancienne que celle des murailles ; car les hommes sont aussi industrieux pour détruire que pour édifier. Je ne m'écarterai ici qu'un moment de mon sujet, pour observer que le cheval de Troie n'était précisément que la même machine, laquelle on armait d'une tête de cheval de métal, comme on y mit depuis une tête de bélier; et c'est ce que Pausanias nous apprend dans sa description de la Grèce. Ils firent brèche, et donnèrent trois assauts. Les Parisiens les soutinrent avec un courage inébranlable. Ils avaient à leur tête non seulement le comte Eudes, mais encore leur évêque Goslin, qui chaque jour, après avoir donné la bénédiction à son peuple, se mettait sur la brèche, le casque en tête, un carquois sur le dos, et une hache à sa ceinture, et, ayant planté la croix sur le rempart, combattait à sa vue. Il paraît que cet évêque avait dans la ville autant d'autorité, pour le moins, que le comte Eudes, puisque 
ce fut à lui que Sigefroy s'était d'abord adressé pour entrer par sa permission dans Paris. Ce prélat mourut de ses fatigues au milieu du siège, laissant une mémoire respectable et chère : car s'il arma des mains que la religion réservait seulement au ministère de l'autel, il les arma pour cet autel même et pour ses citoyens, dans la cause la plus juste, et pour la défense la plus nécessaire, première loi naturelle, qui est toujours au-dessus des lois de convention. Ses confrères ne s'étaient armés que dans des guerres civiles et contre des chrétiens. Peut-être, si l'apothéose est due à quelques hommes, eût-il mieux valu mettre dans le ciel ce prélat qui combattit et mourut pour son pays que tant d'hommes obscurs dont la vertu, s'ils en ont eu, a été pour le moins inutile au monde.

Les Normands tinrent la ville assiégée une année et demie : les Parisiens éprouvèrent toutes les horreurs qu'entraînent dans un long siège la famine et la contagion qui en sont les suites, et ne furent point ébranlés. Au bout de ce temps, l'empereur Charles-le-Gros, roi de France, parut enfin à leur secours, sur le mont de Mars, qu'on appelle aujourd'hui Montmartre; mais il n'osa pas attaquer les Normands : il ne vint que pour acheter encore une trêve honteuse. Ces barbares quittèrent Paris pour aller assiéger Sens et piller la Bourgogne, tandis que Charles alla dans Mayence assembler ce parlement qui lui ôta un trône dont il était si indigne.

Les Normands continuèrent leurs dévastations ; mais, quoique ennemis du nom chrétien, il ne leur vint jamais en pensée de forcer personne à renoncer au christianisme. Ils étaient à peu près tels que les Francs, les Goths, les Alains, les Huns, les Hérules, qui, en cherchant au cinquième siècle de nouvelles terres, loin d'imposer une religion aux Romains, s'accommodèrent aisément de la leur : ainsi les Turcs, en pillant l'empire des califes, se sont soumis à la religion mahométane.

Enfin Rollon ou Raoul, le plus illustre de ces brigands du Nord, après avoir été chassé du Danemark, ayant rassemblé en Scandinavie tous ceux qui voulurent s'attacher à sa fortune, tenta de nouvelles aventures, et fonda l'espérance de sa grandeur sur la faiblesse de l'Europe. Il aborda l'Angleterre, où ses compatriotes étaient déjà établis ; mais, après deux victoires inutiles, il tourna du côté de la France, 
que d'autres Normands savaient ruiner, mais qu'ils ne savaient pas asservir.

Rollon fut le seul de ces barbares qui cessa d'en mériter le nom, en cherchant un établissement fixe. Maître de Rouen sans peine, au lieu de la détruire il en fit relever les murailles et les tours. Rouen devint sa place d'armes ; de là il volait tantôt en Angleterre ; tantôt en France, faisant la guerre avec politique comme avec fureur. La France était expirante sous le règne de Charles-le-Simple, roi de nom, et dont la monarchie était encore plus démembrée par les ducs, par les comtes, et par les barons, ses sujets, que par les Normands. Charles-le-Gros n'avait donné que de l'or aux barbares: Charles-le-Simple offrit à Rollon sa fille et des provinces.

(912) Rollon demanda d'abord la Normandie; et on fut trop heureux de la lui céder. Il demanda ensuite la Bretagne : on disputa; mais il fallut la céder encore avec des clauses que le plus fort explique toujours à son avantage. Ainsi la Bretagne, qui était tout à l'heure un royaume, devient un fief de la Neustrie; et la Neustrie, qu'on s'accoutuma bientôt à nommer Normandie, du nom de ses usurpateurs, fut un État séparé, dont les ducs rendaient un vain hommage à la couronne de France.

L'archevêque de Rouen sut persuader à Rollon de se faire chrétien. Ce prince embrassa volontiers une religion qui affermissait sa puissance.

Les véritables conquérants sont ceux qui savent faire des lois. Leur puissance est stable ; les autres sont des torrents qui passent. Rollon, paisible, fut le seul législateur de son temps dans le continent chrétien. On sait avec quelle inflexibilité il rendit la justice. Il abolit le vol chez les Danois, qui n'avaient jusque-là vécu que de rapine. Longtemps après lui, son nom prononcé était un ordre aux officiers de justice d'accourir pour réprimer la violence ; et de là est venu cet usage de la clameur de haro, si connue en Normandie. Le sang des Danois et des Francs mêlés ensemble produisit ensuite dans ce pays ces héros qu'on verra conquérir l'Angleterre, Naples, et la Sicile. 


\section{Chapitre 26}

\section{De l'Angleterre vers le IX $X^{e}$ siècle. Alfred-le-Grand}

Les Anglais, ce peuple devenu puissant, célèbre par le commerce et par la guerre, gouverné par l'amour de ses propres lois et de la vraie liberté, qui consiste à n'obéir qu'aux lois, n'étaient rien alors de ce qu'ils sont aujourd'hui.

Ils n'étaient échappés du joug des Romains que pour tomber sous celui de ces Saxons qui, ayant conquis l'Angleterre vers le sixième siècle, furent conquis au huitième par Charlemagne dans leur propre pays natal. (828) Ces usurpateurs partagèrent l'Angleterre en sept petits cantons malheureux, qu'on appela royaumes. Ces sept provinces s'étaient enfin réunies sous le roi Egbert, de la race saxonne, lorsque les Normands vinrent ravager l'Angleterre, aussi bien que la France. On prétend qu'en 852 ils remontèrent la Tamise avec trois cents voiles. Les Anglais ne se défendirent guère mieux que les Francs. Ils payèrent comme eux leurs vainqueurs. Un roi, nommé Éthelbert, suivit le malheureux exemple de Charles-le-Chauve: il donna de l'argent; la même faute eut la même punition. Les pirates se servirent de cet argent pour mieux subjuguer le pays. Ils conquirent la moitié de l'Angleterre. Il fallait que les Anglais, nés courageux, et défendus par leur situation, eussent dans leur gouvernement des vices bien essentiels, puisqu'ils furent toujours assujettis par des peuples qui ne devaient pas aborder impunément chez eux. Ce qu'on raconte des horribles dévastations qui désolèrent cette île surpasse encore ce qu'on vient de voir en France. Il y a des temps où la terre entière n'est qu'un théâtre de carnage, et ces temps sont trop fréquents.

Le lecteur respire enfin un peu lorsque, dans ces horreurs, il voit s'élever quelque grand homme qui tire sa patrie de la servitude, et qui la gouverne en bon roi. 
Je ne sais s'il y a jamais eu sur la terre un homme plus digne des respects de la postérité qu'Alfred-le-Grand, qui rendit ces services à sa patrie, supposé que tout ce qu'on raconte de lui soit véritable.

(872) Il succédait à son frère Éthelred $\mathrm{I}^{\mathrm{er}}$, qui ne lui laissa qu'un droit contesté sur l'Angleterre, partagée plus que jamais en souverainetés, dont plusieurs étaient possédées par les Danois. De nouveaux pirates venaient encore presque chaque année disputer aux premiers usurpateurs le peu de dépouilles qui pouvaient rester.

Alfred, n'ayant pour lui qu'une province de l'ouest, fut vaincu d'abord en bataille rangée par ces barbares, et abandonné de tout le monde. Il ne se retira point à Rome dans le collège anglais, comme Butred son oncle, devenu roi d'une petite province, et chassé par les Danois ; mais, seul et sans secours, il voulut périr ou venger sa patrie. Il se cacha six mois chez un berger dans une chaumière environnée de marais. Le seul comte de Dévon, qui défendait encore un faible château, savait son secret. Enfin, ce comte ayant rassemblé des troupes et gagné quelque avantage, Alfred, couvert des haillons d'un berger, osa se rendre dans le camp des Danois, en jouant de la harpe. Voyant ainsi par ses yeux la situation du camp et ses défauts, instruit d'une fête que les barbares devaient célébrer, il court au comte de Dévon, qui avait des milices prêtes; il revient aux Danois avec une petite troupe, mais déterminée; il les surprend, et remporte une victoire complète. La discorde divisait alors les Danois. Alfred sut négocier comme combattre ; et, ce qui est étrange, les Anglais et les Danois le reconnurent unanimement pour roi. Il n'y avait plus à réduire que Londres; il la prit, la fortifia, l'embellit, équipa des flottes, contint les Danois d'Angleterre, s'opposa aux descentes des autres, et s'appliqua ensuite, pendant douze années d'une possession paisible, à policer sa patrie. Ses lois furent douces, mais sévèrement exécutées. C'est lui qui fonda les jurés, qui partagea l'Angleterre en shires ou comtés, et qui le premier encouragea ses sujets à commercer. Il prêta des vaisseaux et de l'argent à des hommes entreprenants et sages, qui allèrent jusqu'à Alexandrie, et de là, passant l'isthme de Suez, trafiquèrent dans la mer de Perse. Il institua des milices, il établit divers conseils, mit partout la règle, et la paix qui en est la suite.

Qui croirait même que cet Alfred, dans des temps d'une ignorance générale, osa envoyer un vaisseau pour tenter de trouver un passage 
aux Indes par le nord de l'Europe et de l'Asie? On a la relation de ce voyage écrite en anglo-saxon, et traduite en latin, à Copenhague, à la prière du comte de Plelo, ambassadeur de Louis XV. Alfred est le premier auteur de ces tentatives hardies que les Anglais, les Hollandais, et les Russes, ont faites dans nos derniers temps. On voit par là combien ce prince était au-dessus de son siècle.

Il n'est point de véritablement grand homme qui n'ait un bon esprit. Alfred jeta les fondements de l'Académie d'Oxford. Il fit venir des livres de Rome : l'Angleterre, toute barbare, n'en avait presque point. Il se plaignait qu'il n'y eût pas alors un prêtre anglais qui sût le latin. Pour lui, il le savait : il était même assez bon géomètre pour ce temps-là. Il possédait l'histoire : on dit même qu'il faisait des vers en anglo-saxon. Les moments qu'il ne donnait pas aux soins de l'État, il les donnait à l'étude. Une sage économie le mit en état d'être libéral. On voit qu'il rebâtit plusieurs églises, mais aucun monastère. Il pensait sans doute que, dans un État désolé qu'il fallait repeupler, il eût mal servi sa patrie en favorisant trop ces familles immenses sans père et sans enfants, qui se perpétuent aux dépens de la nation : aussi ne fut-il pas mis au nombre des saints ; mais l'histoire, qui d'ailleurs ne lui reproche ni défaut ni faiblesse, le met au premier rang des héros utiles au genre humain, qui, sans ces hommes extraordinaires, eût toujours été semblable aux bêtes farouches. 


\section{Chapitre 27 \\ De l'Espagne et des Musulmans maures aux VIII' et IX ${ }^{e}$ siècles}

Vous avez vu des États bien malheureux et bien mal gouvernés; mais l'Espagne, dont il faut tracer le tableau, fut plongée longtemps dans un état plus déplorable. Les barbares dont l'Europe fut inondée au commencement du cinquième siècle ravagèrent l'Espagne comme les autres pays. Pourquoi l'Espagne, qui s'était si bien défendue contre les Romains, céda-t-elle tout d'un coup aux barbares ? C'est qu'elle était composée de patriotes lorsque les Romains l'attaquèrent; mais sous le joug des Romains, elle ne fut plus composée que d'esclaves maltraités par des maîtres amollis; elle fut donc tout d'un coup la proie des Suèves, des Alains, des Vandales. Aux Vandales succédèrent les Visigoths, qui commencèrent à s'établir dans l'Aquitaine et dans la Catalogne, tandis que les Ostrogoths détruisaient le siège de l'empire romain en Italie. Ces Ostrogoths et ces Visigoths étaient, comme on sait, chrétiens ; non pas de la communion romaine, non pas de la communion des empereurs d'Orient qui régnaient alors, mais de celle qui avait été longtemps reçue de l'Église grecque, et qui croyait au Christ, sans le croire égal à Dieu. Les Espagnols, au contraire, étaient attachés au rite romain ; ainsi les vainqueurs étaient d'une religion, et les vaincus d'une autre, ce qui appesantissait encore l'esclavage. Les diocèses étaient partagés en évêques ariens et en évêques athanasiens, comme en Italie ; partage qui augmentait encore les malheurs publics. Les rois visigoths voulurent faire en Espagne ce que fit, comme nous l'avons vu ${ }^{193}$, le roi lombard Rotharic en Italie, et ce qu'avait fait Constantin à son avènement à l'empire : c'était de réunir par la liberté de conscience les peuples divisés par les dogmes.

193 Chapitre 12.(B.) 
Le roi visigoth, Leuvigilde, prétendit réunir ceux qui croyaient à la consubstantialité et ceux qui n'y croyaient pas. Son fils Herminigilde se révolta contre lui. Il y avait encore alors un roitelet suève qui possédait la Galice et quelques places aux environs : le fils rebelle se ligua avec ce Suève, et fit longtemps la guerre à son père; enfin, n'ayant jamais voulu se soumettre, il fut vaincu, pris dans Cordoue, et tué par un officier du roi. L'Église romaine en a fait un saint, ne considérant en lui que la religion romaine, qui fut le prétexte de sa révolte.

Cette mémorable aventure arriva en 584 , et je ne la rapporte que comme un des exemples de l'état funeste où l'Espagne était réduite.

Ce royaume des Visigoths n'était point héréditaire; les évêques, qui eurent d'abord en Espagne la même autorité qu'ils acquirent en France du temps des Carlovingiens, faisaient et défaisaient les rois, avec les principaux seigneurs. Ce fut une nouvelle source de troubles continuels ; par exemple, ils élurent le bâtard Liuva, au mépris de ses frères légitimes ; et ce Liuva ayant été assassiné par un capitaine goth nommé Vitteric, ils élurent ce Vitteric sans difficulté.

Un de leurs meilleurs rois, nommé Vamba, dont nous avons déjà parlé ${ }^{194}$, étant tombé malade, fut revêtu d'un sac de pénitent, et se soumit à la pénitence publique, qui devait, dit-on, le guérir : il guérit en effet ; mais, en qualité de pénitent, on lui déclara qu'il n'était pas capable des fonctions de la royauté, et il fut mis sept jours dans un monastère. Cet exemple fut cité en France, à la déposition de Louisle-Faible ${ }^{195}$.

Ce n'était pas ainsi que se laissaient traiter les premiers conquérants goths, qui subjuguèrent les Espagnes. Ils fondèrent un empire qui s'étendit de la Provence et du Languedoc à Ceuta et à Tanger en

194 Chapitre 13. (B.)

195 Il est le premier roi qui ait cru ajouter à ses droits en se faisant sacrer, et il fut le premier que les prêtres chassèrent du trône. Obligé, en qualité de pénitent et de moine, de quitter la royauté, il choisit un successeur qui assembla un concile à Tolède. Ce concile formé, comme tous ceux d'Espagne et des Gaules du même temps, d'un grand nombre d'évêques et de quelques seigneurs laïques, déclara les sujets de Vamba dégagés envers lui du serment de fidélité, et anathématisa quiconque ne reconnaîtrait point le nouveau roi, qui se garda bien de se faire sacrer. L'aventure de Vamba dégoûta les rois d'Espagne de cette cérémonie. (K.) 
Afrique ; mais cet empire si mal gouverné périt bientôt. Il y eut tant de rébellions en Espagne, qu'enfin le roi Vitiza désarma une partie des sujets, et fit abattre les murailles de plusieurs villes. Par cette conduite il forçait à l'obéissance, mais il se privait lui-même de secours et de retraites. Pour mettre le clergé dans son parti, il rendit dans une assemblée de la nation un édit par lequel il était permis aux évêques et aux prêtres de se marier.

Rodrigue, dont il avait assassiné le père, l'assassina à son tour, et fut encore plus méchant que lui. Il ne faut pas chercher ailleurs la cause de la supériorité des musulmans en Espagne. Je ne sais s'il est bien vrai que Rodrigue eût violé Florinde, nommée la Cava ou la Méchante, fille malheureusement célèbre du comte Julien, et si ce fut pour venger son honneur que ce comte appela les Maures. Peut-être l'aventure de la Cava est copiée en partie sur celle de Lucrèce; et ni l'une ni l'autre ne paraît appuyée sur des monuments bien authentiques. Il paraît que, pour appeler les Africains, on n'avait pas besoin du prétexte d'un viol, qui est d'ordinaire aussi difficile à prouver qu'à faire. Déjà, sous le roi Vamba, le comte Hervig, depuis roi, avait fait venir une armée de Maures. Opas, archevêque de Séville, qui fut le principal instrument de la grande révolution, avait des intérêts plus chers à soutenir que la pudeur d'une fille. Cet évêque, fils de l'usurpateur Vitiza, détrôné et assassiné par l'usurpateur Rodrigue, fut celui dont l'ambition fit venir les Maures pour la seconde fois. Le comte Julien, gendre de Vitiza, trouvait dans cette seule alliance assez de raisons pour se soulever contre le tyran. Un autre évêque, nommé Torizo, entre dans la conspiration d'Opas et du comte. Y a-t-il apparence que deux évêques se fussent ligués ainsi avec les ennemis du nom chrétien, s'il ne s'était agi que d'une fille?

Les mahométans étaient maîtres, comme ils le sont encore, de toute cette partie de l'Afrique qui avait appartenu aux Romains. Ils venaient d'y jeter les premiers fondements de la ville de Maroc, près du mont Atlas. Le calife Valid Almanzor, maître de cette belle partie de la terre, résidait à Damas en Syrie. Son vice-roi, Muzza, qui gouvernait l'Afrique, fit par un de ses lieutenants la conquête de toute l'Espagne. Il y envoya d'abord son général Tarik, qui gagna, en 714, cette célèbre bataille dans les plaines de Xérès, où Rodrigue perdit la vie. On prétend que les Sarrasins ne tinrent pas leurs promesses à Julien, dont ils se défiaient sans doute. L'archevêque Opas fut plus satisfait d'eux. Il 
prêta serment de fidélité aux mahométans, et conserva sous eux beaucoup d'autorité sur les églises chrétiennes, que les vainqueurs toléraient.

Pour le roi Rodrigue, il fut si peu regretté que sa veuve Égilone épousa publiquement le jeune Abdélazis, fils du conquérant Muzza, dont les armes avaient fait périr son mari, et réduit en servitude son pays et sa religion.

Les vainqueurs n'abusèrent point du succès de leurs armes; ils laissèrent aux vaincus leurs biens, leurs lois, leur culte, satisfaits d'un tribut et de l'honneur de commander. Non seulement la veuve du roi Rodrigue épousa le jeune Abdélazis, mais, à son exemple, le sang des Maures et des Espagnols se mêla souvent. Les Espagnols, si scrupuleusement attachés depuis à leur religion, la quittèrent en assez grand nombre pour qu'on leur donnât alors le nom de Mosarabes, qui signifiait, dit-on, moitié Arabes, au lieu de celui de Visigoths que portait auparavant leur royaume. Ce nom de Mosarabes n'était point outrageant, puisque les Arabes étaient les plus cléments de tous les conquérants de la terre, et qu'ils apportèrent en Espagne de nouvelles sciences et de nouveaux arts.

L'Espagne avait été soumise en quatorze mois à l'empire des califes, à la réserve des cavernes et des rochers de l'Asturie. Le Goth Pélage Teudomer, parent du dernier roi Rodrigue, caché dans ces retraites, y conserva sa liberté. Je ne sais comment on a pu donner le nom de roi à ce prince, qui en était peut-être digne, mais dont toute la royauté se borna à n'être point captif. Les historiens espagnols, et ceux qui les ont suivis, lui font remporter de grandes victoires, imaginent des miracles en sa faveur, lui établissent une cour, lui donnent son fils Favila et son gendre Alfonse pour successeurs tranquilles dans ce prétendu royaume. Mais comment dans ce temps-là même les mahométans, qui, sous Abdérame, vers l'an 734, subjuguèrent la moitié de la France, auraient-ils laissé subsister derrière les Pyrénées ce royaume des Asturies ? C'était beaucoup pour les chrétiens de pouvoir se réfugier dans ces montagnes et d'y vivre de leurs courses, en payant tribut aux mahométans. Ce ne fut que vers l'an 759 que les chrétiens commencèrent à tenir tête à leurs vainqueurs, affaiblis par les victoires de Charles Martel et par leurs divisions; mais euxmêmes, plus divisés entre eux que les mahométans, retombèrent bien- 
tôt sous le joug. (783) Mauregat, à qui il a plu aux historiens de donner le titre de roi, eut la permission de gouverner les Asturies et quelques terres voisines, en rendant hommage et en payant tribut. Il se soumit surtout à fournir cent belles filles tous les ans pour le sérail d'Abdérame. Ce fut longtemps la coutume des Arabes d'exiger de pareils tributs; et aujourd'hui les caravanes, dans les présents qu'elles font aux Arabes du désert, offrent toujours des filles nubiles.

Cette coutume est immémoriale. Un des anciens livres juifs, nommé en grec Exode, rapporte qu'un Éléazar prit trente-deux mille pucelles dans le désert affreux du Madian. De ces trente-deux mille vierges on n'en sacrifia que trente-deux au dieu d'Éléazar : le reste fut abandonné aux prêtres et aux soldats pour peupler.

On donne pour successeur à ce Mauregat un diacre nommé Vérémond, chef de ces montagnards réfugiés, faisant le même hommage et payant le même nombre de filles qu'il était obligé de fournir souvent. Est-ce là un royaume, et sont-ce là des rois ?

Après la mort d'Abdérame, les émirs des provinces d'Espagne voulurent être indépendants. On a vu dans l'article de Charlemagne qu'un d'eux, nommé Ibna, eut l'imprudence d'appeler ce conquérant à son secours. S'il y avait eu alors un véritable royaume chrétien en Espagne, Charles n'eût-il pas protégé ce royaume par ses armes, plutôt que de se joindre à des mahométans ? Il prit cet émir sous sa protection, et se fit rendre hommage des terres qui sont entre l'Èbre et les Pyrénées, que les musulmans gardèrent. On voit, en794, le Maure Abufar rendre hommage à Louis-le-Débonnaire, qui gouvernait l'Aquitaine sous son père avec le titre de roi.

Quelque temps après, les divisions augmentèrent chez les Maures d'Espagne. Le conseil de Louis-le-Débonnaire en profita ; ses troupes assiégèrent deux ans Barcelone, et Louis y entra en triomphe en 796. Voilà le commencement de la décadence des Maures. Ces vainqueurs n'étaient plus soutenus par les Africains et par les califes, dont ils avaient secoué le joug. Les successeurs d'Abdérame, ayant établi le siège de leur royaume à Cordoue, étaient mal obéis des gouverneurs des autres provinces.

Alfonse, de la race de Pélage, commença, dans ces conjonctures heureuses, à rendre considérables les chrétiens espagnols retirés dans 
les Asturies. Il refusa le tribut ordinaire à des maîtres contre lesquels il pouvait combattre ; et après quelques victoires, il se vit maître paisible des Asturies et de Léon, au commencement du neuvième siècle.

C'est par lui qu'il faut commencer de retrouver en Espagne des rois chrétiens. Cet Alfonse était artificieux et cruel. On l'appelle le Chaste, parce qu'il fut le premier qui refusa les cent filles aux Maures. On ne songe pas qu'il ne soutint point la guerre pour avoir refusé le tribut, mais que, voulant se soustraire à la domination des Maures, et ne plus être tributaire, il fallait bien qu'il refusât les cent filles ainsi que le reste.

Les succès d'Alfonse, malgré beaucoup de traverses, enhardirent les chrétiens de Navarre à se donner un roi. Les Aragonais levèrent l'étendard sous un comte : ainsi, sur la fin de Louis-le-Débonnaire, ni les Maures, ni les Français, n'eurent plus rien dans ces contrées stériles ; mais le reste de l'Espagne obéissait aux rois musulmans. Ce fut alors que les Normands ravagèrent les côtes d'Espagne; mais, étant repoussés, ils retournèrent piller la France et l'Angleterre.

On ne doit point être surpris que les Espagnols des Asturies, de Léon, d'Aragon, aient été alors des barbares. La guerre, qui avait succédé à la servitude, ne les avait pas polis. Ils étaient dans une si profonde ignorance qu'un autre Alfonse, roi de Léon et des Asturies, surnommé le Grand, fut obligé de livrer l'éducation de son fils à des précepteurs mahométans.

Je ne cesse d'être étonné quand je vois quels titres les historiens prodiguent aux rois. Cet Alfonse, qu'ils appellent le Grand, fit crever les yeux à ses quatre frères. Sa vie n'est qu'un tissu de cruautés et de perfidies. Ce roi finit par faire révolter contre lui ses sujets, et fut obligé de céder son petit royaume à son fils don Garcie, l'an 910.

Ce titre de Don ${ }^{196}$ était un abrégé de Dominus, titre qui parut trop ambitieux à l'empereur Auguste, parce qu'il signifiait Maître, et que depuis on donna aux bénédictins, aux seigneurs espagnols, et enfin aux rois de ce pays. Les seigneurs de terres commencèrent alors à prendre le titre de rich-homes, ricos hombres : riche signifiait posses-

196 Le Dictionnaire de l'Académie, édition de 1762, dit que le Dom est pour les religieux. (B.) 
seur de terres ; car dans ces temps-là il n'y avait point parmi les chrétiens d'Espagne d'autres richesses. La grandesse n'était point encore connue. Le titre de grand ne fut en usage que trois siècles après, sous Alfonse le Sage, dixième du nom, roi de Castille, dans le temps que l'Espagne commençait à devenir florissante. 


\section{Chapitre 28}

\section{Puissance des musulmans en Asie et en Europe aux VIII et IX $X^{e}$ siècles. L'Italie attaquée par eux. Conduite magnanime du pape Léon IV}

Les mahométans, qui perdaient cette partie de l'Espagne qui confine à la France, s'étendaient partout ailleurs. Si j'envisage leur religion, je la vois embrassée dans l'Inde et sur les côtes orientales de 1'Afrique, où ils trafiquaient. Si je regarde leurs conquêtes, d'abord le calife Aaron-al-Raschild, ou le Juste, impose en 782 un tribut de soixante et dix mille écus d'or par an à l'impératrice Irène. L'empereur Nicéphore ayant ensuite refusé de payer le tribut, Aaron prend l'île de Chypre, et vient ravager la Grèce. Almamon, son petitfils, prince d'ailleurs si recommandable par son amour pour les sciences et par son savoir, s'empare par ses lieutenants de l'île de Crète, en 826. Les musulmans bâtirent Candie, qu'ils ont reprise de nos jours.

En 828, les mêmes Africains qui avaient subjugué 1'Espagne, et fait des incursions en Sicile, reviennent encore désoler cette île fertile, encouragés par un Sicilien nommé Euphemius, qui, ayant, à l'exemple de son empereur, Michel, épousé une religieuse, poursuivi par les lois que l'empereur s'était rendues favorables, fit à peu près en Sicile ce que le comte Julien avait fait en Espagne.

Ni les empereurs grecs, ni ceux d'Occident, ne purent alors chasser de Sicile les musulmans ; tant l'Orient et l'Occident étaient mal gouvernés. Ces conquérants allaient se rendre maîtres de l'Italie, s'ils avaient été unis ; mais leurs fautes sauvèrent Rome, comme celles des Carthaginois la sauvèrent autrefois. Ils partent de Sicile, en 846, avec une flotte nombreuse. Ils entrent par l'embouchure du Tibre, et, ne trouvant qu'un pays presque désert, ils vont assiéger Rome. Ils prirent les dehors, et ayant pillé la riche église de Saint-Pierre hors des murs, ils levèrent le siège pour aller combattre une armée de Français qui 
venait secourir Rome, sous un général de l'empereur Lothaire. L'armée française fut battue, mais la ville, rafraîchie, fut manquée ; et cette expédition, qui devait être une conquête, ne devint, par la mésintelligence, qu'une incursion de barbares. Ils revinrent bientôt après avec une armée formidable, qui semblait devoir détruire l'Italie, et faire une bourgade mahométane de la capitale du christianisme. Le pape Léon IV, prenant dans ce danger une autorité que les généraux de l'empereur Lothaire semblaient abandonner, se montra digne, en défendant Rome, d'y commander en souverain. Il avait employé les richesses de l'Église à réparer les murailles, à élever des tours, à tendre des chaînes sur le Tibre. Il arma les milices à ses dépens, engagea les habitants de Naples et de Gaiète à venir défendre les côtes et le port d'Ostie, sans manquer à la sage précaution de prendre d'eux des otages, sachant bien que ceux qui sont assez puissants pour nous secourir le sont assez pour nous nuire. Il visita lui-même tous les postes, et reçut les Sarrasins à leur descente, non pas en équipage de guerrier, ainsi qu'en avait usé Goslin, évêque de Paris, dans une occasion encore plus pressante ${ }^{197}$, mais comme un pontife qui exhortait un peuple chrétien, et comme un roi qui veillait à la sûreté de ses sujets. Il était né Romain (849). Le courage des premiers âges de la république revivait en lui dans un temps de lâcheté et de corruption, tel qu'un des beaux monuments de l'ancienne Rome, qu' on trouve quelquefois dans les ruines de la nouvelle.

Son courage et ses soins furent secondés. On reçut les Sarrasins courageusement à leur descente ; et la tempête ayant dissipé la moitié de leurs vaisseaux, une partie de ces conquérants échappés au naufrage fut mise à la chaîne. Le pape rendit sa victoire utile en faisant travailler aux fortifications de Rome et à ses embellissements les mêmes mains qui devaient les détruire. Les mahométans restèrent cependant maîtres du Garillan, entre Capoue et Gaïète, mais plutôt comme une colonie de corsaires indépendants que comme des conquérants disciplinés.

Je vois donc, au neuvième siècle, les musulmans redoutables à la fois à Rome et à Constantinople, maîtres de la Perse, de la Syrie, de l'Arabie, de toutes les côtes d'Afrique jusqu'au mont Atlas, des trois quarts de l'Espagne ; mais ces conquérants ne forment pas une nation,

197 Voyez chapitre 25. 
comme les Romains, qui, étendus presque autant qu'eux, n'avaient fait qu'un seul peuple.

Sous le fameux calife Almamon, vers 1'an 815, un peu après la mort de Charlemagne, l'Égypte était indépendante, et le Grand-Caire fut la résidence d'un autre calife. Le prince de la Mauritanie Tangitane, sous le titre de Miramolin, étant maître absolu de l'empire de Maroc, la Nubie et la Libye obéissaient à un autre calife. Les Abdérames, qui avaient fondé le royaume de Cordoue, ne purent empêcher d'autres mahométans de fonder celui de Tolède. Toutes ces nouvelles dynasties révéraient dans le calife le successeur de leur prophète. Ainsi que les chrétiens allaient en foule en pèlerinage à Rome, les mahométans de toutes les parties du monde allaient à la Mecque, gouvernée par un shérif que nommait le calife ; et c'était principalement par ce pèlerinage que le calife, maître de la Mecque, était vénérable à tous les princes de sa croyance. Mais ces princes, distinguant la religion de leurs intérêts, dépouillaient le calife en lui rendant hommage. 


\section{Chapitre 29}

\section{De l'empire de Constantinople aux VIII ${ }^{e}$ et IX $X^{e}$ siècles}

Tandis que l'empire de Charlemagne se démembrait, que les inondations des Sarrasins et des Normands désolaient l'Occident, l'empire de Constantinople subsistait comme un grand arbre, vigoureux encore, mais déjà vieux, dépouillé de quelques racines, et assailli de tous côtés par la tempête. Cet empire n'avait plus rien en Afrique; la Syrie et une partie de l'Asie Mineure lui étaient enlevées. Il défendait contre les musulmans ses frontières vers l'orient de la mer Noire; et, tantôt vaincu, tantôt vainqueur, il aurait pu au moins se fortifier contre eux par cet usage continuel de la guerre. Mais du côté du Danube, et vers le bord occidental de la mer Noire, d'autres ennemis le ravageaient. Une nation de Scythes, nommés les Abares ou Avares, les Bulgares, autres Scythes, dont la Bulgarie tient son nom, désolaient tous ces beaux climats de la Romanie où Adrien et Trajan avaient construit de si belles villes, et ces grands chemins, desquels ils ne subsiste plus que quelques chaussées.

Les Abares surtout, répandus dans la Hongrie et dans l'Autriche, se jetaient tantôt sur l'empire d'Orient, tantôt sur celui de Charlemagne. Ainsi, des frontières de la Perse à celles de France, la terre était en proie à des incursions presque continuelles.

Si les frontières de l'empire grec étaient toujours resserrées et toujours désolées, la capitale était le théâtre des révolutions et des crimes. Un mélange de l'artifice des Grecs et de la férocité des Thraces formait le caractère qui régnait à la cour. En effet, quel spectacle nous présente Constantinople? Maurice et ses cinq enfants massacrés; Phocas assassiné pour prix de ses meurtres et de ses incestes ; Constantin empoisonné par l'impératrice Martine, à qui on arrache la langue, tandis qu'on coupe le nez à Héracléonas son fils ; Constant qui fait égorger son frère ; Constant assommé dans un bain par ses domes- 
tiques ; Constantin Pogonat qui fait crever les yeux à ses deux frères ; Justinien II, son fils, prêt à faire à Constantinople ce que Théodose fit à Thessalonique, surpris, mutilé et enchaîné par Léonce, au moment qu'il allait faire égorger les principaux citoyens ; Léonce bientôt traité lui-même comme il avait traité Justinien II ; ce Justinien rétabli, faisant couler sous ses yeux, dans la place publique, le sang de ses ennemis, et périssant enfin sous la main d'un bourreau ; Philippe Bardane détrôné et condamné à perdre les yeux ; Léon l'Isaurien et Constantin Copronyme morts, à la vérité, dans leur lit, mais après un règne sanguinaire, aussi malheureux pour le prince que pour les sujets; l'impératrice Irène, la première femme qui monta sur le trône des Césars, et la première qui fit périr son fils pour régner; Nicéphore, son successeur, détesté de ses sujets, pris par les Bulgares, décollé, servant de pâture aux bêtes, tandis que son crâne sert de coupe à son vainqueur; enfin Michel Curopalate, contemporain de Charlemagne, confiné dans un cloître, et mourant ainsi moins cruellement, mais plus honteusement que ses prédécesseurs. C'est ainsi que l'empire est gouverné pendant trois cents ans. Quelle histoire de brigands obscurs, punis en place publique pour leurs crimes, est plus horrible et plus dégoûtante?

Cependant il faut poursuivre: il faut voir, au neuvième siècle, Léon l'Arménien, brave guerrier, mais ennemi des images, assassiné à la messe dans le temps qu'il chantait une antienne: ses assassins, s'applaudissant d'avoir tué un hérétique, vont tirer de prison un officier, nommé Michel le Bègue, condamné à la mort par le sénat, et qui, au lieu d'être exécuté, reçoit la pourpre impériale. Ce fut lui qui, étant amoureux d'une religieuse, se fit prier par le sénat de l'épouser, sans qu'aucun évêque osât être d'un sentiment contraire. Ce fait est d'autant plus digne d'attention que, presque en même temps, on voit Euphemius, en Sicile, poursuivi criminellement pour un semblable mariage ; et, quelque temps après, on condamne à Constantinople le mariage très légitime de l'empereur Léon le Philosophe. Où est donc le pays où l'on trouve alors des lois et des mœurs ? ce n'est pas dans notre Occident.

Cette ancienne querelle des images troublait toujours l'empire. La cour était tantôt favorable, tantôt contraire à leur culte, selon qu'elle voyait pencher l'esprit du plus grand nombre. Michel le Bègue commença par les consacrer, et finit par les abattre. 
Son successeur Théophile, qui régna environ douze ans, depuis 829 jusqu'à 842 , se déclara contre ce culte : on a écrit qu'il ne croyait point à la résurrection, qu'il niait l'existence des démons, et qu'il n'admettait pas Jésus-Christ pour Dieu. Il se peut faire qu'un empereur pensât ainsi ; mais faut-il croire, je ne dis pas sur les princes seulement, mais sur les particuliers, la voix des ennemis, qui, sans prouver aucun fait, décrient la religion et les mœurs des hommes qui n'ont pas pensé comme eux?

Ce Théophile, fils de Michel le Bègue, fut presque le seul empereur qui eut succédé paisiblement à son père depuis deux siècles. Sous lui les adorateurs des images furent plus persécutés que jamais. On conçoit aisément, par ces longues persécutions, que tous les citoyens étaient divisés.

Il est remarquable que deux femmes aient rétabli les images. L'une est l'impératrice Irène, veuve de Léon IV; et l'autre, l'impératrice Théodora, veuve de Théophile.

Théodora, maîtresse de l'empire d'Orient sous le jeune Michel, son fils, persécuta à son tour les ennemis des images. Elle porta son zèle ou sa politique plus loin. Il y avait encore dans l'Asie Mineure un grand nombre de manichéens qui vivaient paisibles, parce que la fureur d'enthousiasme, qui n'est guère que dans les sectes naissantes, était passée. Ils étaient riches par le commerce. Soit qu'on en voulût à leurs opinions ou à leurs biens, on fit contre eux des édits sévères, qui furent exécutés avec cruauté. La persécution leur rendit leur premier fanatisme. (846) On en fit périr des milliers dans les supplices ; le reste, désespéré, se révolta. Il en passa plus de quarante mille chez les musulmans ; et ces manichéens, auparavant si tranquilles, devinrent des ennemis irréconciliables qui, joints aux Sarrasins, ravagèrent 1'Asie Mineure jusqu'aux portes de la ville impériale, dépeuplée par une peste horrible, en 842 , et devenue un objet de pitié.

La peste, proprement dite, est une maladie particulière aux peuples de l'Afrique, comme la petite vérole. C'est de ces pays qu'elle vient toujours par des vaisseaux marchands. Elle inonderait l'Europe, sans les sages précautions qu'on prend dans nos ports; et probablement l'inattention du gouvernement laissa entrer la contagion dans la ville impériale. 
Cette même inattention exposa l'empire à un autre fléau. Les Russes s'embarquèrent vers le port qu'on nomme aujourd'hui Azof, sur la mer Noire, et vinrent ravager tous les rivages du Pont-Euxin. Les Arabes, d'un autre côté, poussèrent encore leurs conquêtes par delà l'Arménie, et dans l'Asie Mineure. Enfin Michel-le-Jeune, après un règne cruel et infortuné, fut assassiné par Basile, qu'il avait tiré de la plus basse condition pour l'associer à l'empire (867).

L'administration de Basile ne fut guère plus heureuse. C'est sous son règne qu'est l'époque du grand schisme qui divisa l'Église grecque de la latine. C'est cet assassin qu'on regarda comme juste, quand il fit déposer le patriarche Photius.

Les malheurs de l'empire ne furent pas beaucoup réparés sous Léon, qu'on appela le Philosophe ; non qu'il fût un Antonin, un MarcAurèle, un Julien, un Aaron-al-Raschild, un Alfred, mais parce qu'il était savant. Il passe pour avoir le premier ouvert un chemin aux Turcs, qui, si longtemps après, ont pris Constantinople.

Les Turcs, qui combattirent depuis les Sarrasins, et qui, mêlés à eux, furent leur soutien et les destructeurs de l'empire grec, avaient-ils déjà envoyé des colonies dans ces contrées voisines du Danube ? On n'a guère d'histoires véritables de ces émigrations des barbares.

Il n'y a que trop d'apparence que les hommes ont ainsi vécu longtemps. À peine un pays était un peu cultivé, qu'il était envahi par une nation affamée, chassée à son tour par une autre. Les Gaulois n'étaient-ils pas descendus en Italie ? n'avaient-ils pas couru jusque dans l'Asie Mineure ? vingt peuples de la Grande Tartarie n'ont-ils pas cherché de nouvelles terres ? les Suisses n'avaient-ils pas mis le feu à leurs bourgades, pour aller se transplanter en Languedoc, quand César les contraignit de retourner labourer leurs terres ? Et qu'étaient Pharamond et Clovis, sinon des barbares transplantés qui ne trouvèrent point de César?

Malgré tant de désastres, Constantinople fut encore longtemps la ville chrétienne la plus opulente, la plus peuplée, la plus recommandable par les arts. Sa situation seule, par laquelle elle domine sur deux mers, la rendait nécessairement commerçante. La peste de 842 , toute destructive qu'elle avait été, ne fut qu'un fléau passager. Les villes de commerce, et où la cour réside, se repeuplent toujours par l'affluence 
des voisins. Les arts mécaniques et les beaux-arts même ne périssent point dans une vaste capitale qui est le séjour des riches.

Toutes ces révolutions subites du palais, les crimes de tant d'empereurs égorgés les uns par les autres, sont des orages qui ne tombent guère sur des hommes cachés qui cultivent en paix des professions qu'on n'envie point.

Les richesses n'étaient point épuisées : on dit qu'en 857, Théodora, mère de Michel, en se démettant malgré elle de la régence, et traitée à peu près par son fils comme Marie de Médicis le fut de nos jours par Louis XIII, fit voir à l'empereur qu'il y avait dans le trésor cent neuf mille livres pesant d'or, et trois cent mille livres d'argent.

Un gouvernement sage pouvait donc encore maintenir l'empire dans sa puissance. Il était resserré, mais non tout à fait démembré ; changeant d'empereurs, mais toujours uni sous celui qui se revêtait de la pourpre; enfin plus riche, plus plein de ressources, plus puissant que celui d'Allemagne. Cependant il n'est plus, et l'empire d'Allemagne subsiste encore.

Les horribles révolutions qu'on vient de voir effrayent et dégoûtent ; cependant il faut convenir que depuis Constantin, surnommé le Grand, l'empire de Constantinople n'avait guère été autrement gouverné ; et, si vous en exceptez Julien et deux ou trois autres, quel empereur ne souilla pas le trône d'abominations et de crimes? 


\section{Chapitre 30 \\ De l'Italie ; des papes ; du divorce de Lothaire, roi de Lorraine ; et des autres affaires de l'église, aux VIII et IX $X^{e}$ siècles}

Pour ne pas perdre le fil qui lie tant d'événements, souvenons-nous avec quelle prudence les papes se conduisirent sous Pepin et sous Charlemagne, comme ils assoupirent habilement les querelles de religion, et comme chacun d'eux établit sourdement les fondements de la grandeur pontificale.

Leur pouvoir était déjà très grand, puisque Grégoire IV rebâtit le port d'Ostie, et que Léon IV fortifia Rome à ses dépens ; mais tous les papes ne pouvaient être de grands hommes, et toutes les conjonctures ne pouvaient leur être favorables. Chaque vacance de siège causait les mêmes troubles que l'élection d'un roi en produit en Pologne. Le pape élu avait à ménager à la fois le sénat romain, le peuple, et l'empereur. La noblesse romaine avait grande part au gouvernement : elle élisait alors deux consuls tous les ans. Elle créait un préfet, qui était une espèce de tribun du peuple. Il y avait un tribunal de douze sénateurs; et c'étaient ces sénateurs qui nommaient les principaux officiers du duché de Rome. Ce gouvernement municipal avait tantôt plus, tantôt moins d'autorité. Les papes avaient à Rome plutôt un grand crédit qu'une puissance législative.

S'ils n'étaient pas souverains de Rome, ils ne perdaient aucune occasion d'agir en souverains de l'Église d'Occident. Les évêques se constituaient juges des rois; et les papes, juges des évêques. Tant de conflits d'autorité, ce mélange de religion, de superstition, de faiblesse, de méchanceté dans toutes les cours, l'insuffisance des lois, tout cela ne peut être mieux connu que par l'aventure du mariage et du divorce de Lothaire, roi de Lorraine, neveu de Charles-le-Chauve. 
Charlemagne avait répudié une de ses femmes, et en avait épousé une autre, non seulement avec l'approbation du pape Étienne, mais sur ses pressantes sollicitations. Les rois francs, Gontran, Caribert, Sigebert, Chilpéric, Dagobert, avaient eu plusieurs femmes à la fois, sans qu'on eût murmuré ; et si c'était un scandale, il était sans trouble. Le temps change tout. Lothaire, marié avec Teutberge, fille d'un duc de la Bourgogne Transjurane, prétend la répudier pour un inceste avec son frère, dont elle est accusée, et épouser sa maîtresse Valrade. Toute la suite de cette aventure est d'une singularité nouvelle. D'abord la reine Teutberge se justifie par l'épreuve de l'eau bouillante. Son avocat plonge la main dans un vase, au fond duquel il ramasse impunément un anneau bénit. Le roi se plaint qu'on a employé la fourberie dans cette épreuve. Il est bien sûr que si elle fut faite, l'avocat de la reine était instruit d'un secret de préparer la peau à soutenir l'action de l'eau bouillante. Aucune académie des sciences n'a, de nos jours, tenté de connaître sur ces épreuves ce que savaient alors les charlatans.

(862) Le succès de cette épreuve passait pour un miracle, pour le jugement de Dieu même ; et cependant Teutberge, que le ciel justifie, avoue à plusieurs évêques, en présence de son confesseur, qu'elle est coupable. Il n'y a guère d'apparence qu'un roi qui voulait se séparer de sa femme sur une imputation d'adultère eût imaginé de l'accuser d'un inceste avec son frère, si le fait n'avait pas été public. On ne va pas supposer un crime si recherché, si rare, si difficile à prouver : il faut d'ailleurs que, dans ces temps-là, ce qu'on appelle aujourd'hui honneur ne fût point du tout connu. Le roi et la reine se couvrent tous deux de honte, l'un par son accusation, l'autre par son aveu. Deux conciles nationaux sont assemblés, qui permettent le divorce.

Le pape Nicolas $\mathrm{I}^{\mathrm{er}}$ casse les deux conciles. Il dépose Gontier, archevêque de Cologne, qui avait été le plus ardent dans l'affaire du divorce. Gontier écrit aussitôt à toutes les églises : "Quoique le seigneur Nicolas, qu'on nomme pape, et qui se compte pape et empereur, nous ait excommunié, nous avons résisté à sa folie. » Ensuite dans son écrit, s'adressant au pape même : "Nous ne recevons point, dit-il, votre maudite sentence; nous la méprisons; nous vous rejetons vousmême de notre communion, nous contentant de celle des évêques, nos frères, que vous méprisez, etc. » 
Un frère de l'archevêque de Cologne porta lui-même cette protestation à Rome, et la mit, l'épée à la main, sur le tombeau où les Romains prétendent que reposent les cendres de saint Pierre. Mais bientôt après, l'état politique des affaires ayant changé, ce même archevêque changea aussi. Il vint au mont Cassin se jeter aux genoux du pape Adrien II, successeur de Nicolas. "Je déclare, dit-il, devant Dieu et devant ses saints, à vous monseigneur Adrien, souverain pontife, aux évêques qui vous sont soumis, et à toute l'assemblée, que je supporte humblement la sentence de déposition donnée canoniquement contre moi par le pape Nicolas, etc. » On sent combien un exemple de cette espèce affermissait la supériorité de l'Église romaine ; et les conjonctures rendaient ces exemples fréquents.

Ce même Nicolas $\mathrm{I}^{\mathrm{er}}$ excommunie la seconde femme de Lothaire, et ordonne à ce prince de reprendre la première. Toute l'Europe prend part à ces événements. L'empereur Louis II, frère de Charles-leChauve, et oncle de Lothaire, se déclare d'abord violemment pour son neveu contre le pape. Cet empereur, qui résidait alors en Italie, menace Nicolas $\mathrm{I}^{\mathrm{er}}$; il y a du sang de répandu, et l'Italie est en alarme. On négocie, on cabale de tous côtés. Teutberge va plaider à Rome; Valrade, sa rivale, entreprend le voyage, et n'ose l'achever. Lothaire, excommunié, s'y transporte, et va demander pardon à Adrien, successeur de Nicolas, dans la crainte où il est que son oncle le Chauve, armé contre lui au nom de l'Église, ne s'empare de son royaume de Lorraine. Adrien II, en lui donnant la communion dans Rome, lui fait jurer qu'il n'a point usé des droits du mariage avec Valrade depuis l'ordre que le pape Nicolas lui avait donné de s'en abstenir. Lothaire fait serment, communie, et meurt quelque temps après. Tous les historiens ne manquent pas de dire qu'il est mort en punition de son parjure, et que les domestiques qui ont juré avec lui sont morts dans l'année.

Le droit qu'exercèrent en cette occasion Nicolas $\mathrm{I}^{\mathrm{er}}$ et Adrien II était fondé sur les fausses Décrétales, déjà regardées comme un code universel. Le contrat civil qui unit deux époux, étant devenu un sacrement, était soumis au jugement de l'Église.

Cette aventure est le premier scandale touchant le mariage des têtes couronnées en Occident. On a vu depuis les rois de France Robert, Philippe $\mathrm{I}^{\mathrm{er}}$, Philippe-Auguste, excommuniés par les papes pour des 
causes à peu près semblables, ou même pour des mariages contractés entre parents très éloignés. Les évêques nationaux prétendirent longtemps devoir être les juges de ces causes : les pontifes de Rome les évoquèrent toujours à eux.

On n'examine point ici si cette nouvelle jurisprudence est utile ou dangereuse : on n'écrit ni comme jurisconsulte, ni comme controversiste ; mais toutes les provinces chrétiennes ont été troublées par ces scandales. Les anciens Romains et les peuples orientaux furent plus heureux en ce point. Les droits des pères de famille, le secret de leur lit, n'y furent jamais en proie à la curiosité publique. On ne connaît point chez eux de pareils procès au sujet d'un mariage ou d'un divorce.

Ce descendant de Charlemagne fut le premier qui alla plaider à trois cents lieues de chez lui devant un juge étranger, pour savoir quelle femme il devait aimer. Les peuples furent sur le point d'être les victimes de ce différend. Louis-le-Débonnaire avait été le premier exemple du pouvoir des évêques sur les empereurs; Lothaire de Lorraine fut l'époque du pouvoir des papes sur les évêques. Il résulte de toute l'histoire de ces temps-là que la société avait peu de règles certaines chez les nations occidentales, que les États avaient peu de lois, et que l'Église voulait leur en donner. 


\section{Chapitre 31}

\section{De Photius, et du schisme entre l'Orient et l'Occident}

(858) La plus grande affaire que l'Église eût alors, et qui en est encore une très importante aujourd'hui, fut l'origine de la séparation totale des Grecs et des Latins. La chaire patriarcale de Constantinople étant, ainsi que le trône, l'objet de l'ambition, était sujette aux mêmes révolutions. L'empereur Michel III, mécontent du patriarche Ignace, l'obligea à signer lui-même sa déposition, et mit à sa place Photius, eunuque du palais, homme d'une grande qualité, d'un vaste génie, et d'une science universelle. Il était grand écuyer et ministre d'État. Les évêques, pour l'ordonner patriarche, le firent passer en six jours par tous les degrés. Le premier jour on le fit moine, parce que les moines étaient regardés dans l'Église grecque comme faisant partie de la hiérarchie ; le second jour, il fut lecteur; le troisième, sous-diacre puis diacre, prêtre, et enfin patriarche, le jour de Noël, en 858 .

Le pape Nicolas prit le parti d'Ignace, et excommunia Photius. Il lui reprochait surtout d'avoir passé de l'état de laïque à celui d'évêque avec tant de rapidité ; mais Photius répondait avec raison que saint Ambroise, gouverneur de Milan, et à peine chrétien, avait joint la dignité d'évêque à celle de gouverneur plus rapidement encore. Photius excommunia donc le pape à son tour, et le déclara déposé. Il prit le titre de patriarche œcuménique, et accusa hautement d'hérésie les évêques d'Occident de la communion du pape. Le plus grand reproche qu'il leur faisait roulait sur la procession du Père et du Fils. «Des hommes, dit-il dans une de ses lettres, sortis des ténèbres de l'Occident, ont tout corrompu par leur ignorance. Le comble de leur impiété est d'ajouter de nouvelles paroles au sacré symbole autorisé par tous les conciles, en disant que le Saint-Esprit ne procède pas du Père seulement, mais encore du Fils ; ce qui est renoncer au christianisme. » 
On voit, par ce passage et par beaucoup d'autres, quelle supériorité les Grecs affectaient en tout sur les Latins. Ils prétendaient que l'Église romaine devait tout à la grecque, jusqu'aux noms des usages, des cérémonies, des mystères, des dignités. Baptême, eucharistie, liturgie, diocèse, paroisse, évêque, prêtre, diacre, moine, église, tout est grec. Ils regardaient les Latins comme des disciples ignorants, révoltés contre leurs maîtres, dont ils ne savaient pas même la langue. Ils nous accusaient d'ignorer le catéchisme, enfin de n'être pas chrétiens.

Les autres sujets d'anathème étaient que les Latins se servaient alors communément de pain non levé pour l'eucharistie, mangeaient des œufs et du fromage en carême, et que leurs prêtres ne se faisaient point raser la barbe. Étranges raisons pour brouiller l'Occident avec l'Orient !

Mais quiconque est juste avouera que Photius était non seulement le plus savant homme de l'Église, mais un grand évêque. (867) Il se conduisit comme saint Ambroise quand Basile, assassin de l'empereur Michel, se présenta dans l'église de Sophie. "Vous êtes indigne d'approcher des saints mystères, lui dit-il à haute voix, vous qui avez les mains encore souillées du sang de votre bienfaiteur. » Photius ne trouva pas un Théodose dans Basile. Ce tyran fit une chose juste par vengeance. Il rétablit Ignace dans le siège patriarcal, et chassa Photius. (869) Rome profita de cette conjoncture pour faire assembler à Constantinople le huitième concile œcuménique, composé de trois cents évêques. Les légats du pape présidèrent, mais ils ne savaient pas le grec, et parmi les autres évêques, très peu savaient le latin. Photius y fut universellement condamné comme intrus, et soumis à la pénitence publique. On signa pour les cinq patriarches avant de signer pour le pape, ce qui est fort extraordinaire : car, puisque les légats eurent la première place, ils devaient signer les premiers. Mais, en tout cela, les questions qui partageaient l'Orient et l'Occident ne furent point agitées : on ne voulait que déposer Photius.

Quelque temps après, le vrai patriarche Ignace étant mort, Photius eut l'adresse de se faire rétablir par l'empereur Basile. Le pape Jean VIII le reçut à sa communion, le reconnut, lui écrivit ; et, malgré ce huitième concile œcuménique qui avait anathématisé ce patriarche, (879) le pape envoya ses légats à un autre concile à Constantinople, dans lequel Photius fut reconnu innocent par quatre cents évêques, 
dont trois cents l'avaient auparavant condamné. Les légats de ce même siège de Rome, qui l'avaient anathématisé, servirent eux-mêmes à casser le huitième concile œcuménique.

Combien tout change chez les hommes! combien ce qui était faux devient vrai selon les temps! Les légats de Jean VIII s'écrient en plein concile : "Si quelqu'un ne reconnaît pas Photius, que son partage soit avec Judas. » Le concile s'écrie : «Longues années au patriarche Photius, et au patriarche de Rome, Jean!»

Enfin, à la suite des actes du concile on voit une lettre du pape à ce savant patriarche, dans laquelle il lui dit: "Nous pensons comme vous ; nous tenons pour transgresseurs de la parole de Dieu, nous rangeons avec Judas, ceux qui ont ajouté au symbole que le Saint-Esprit procède du Père et du Fils ; mais nous croyons qu'il faut user de douceur avec eux, et les exhorter à renoncer à ce blasphème. »

Il est donc clair que l'Église romaine et la grecque pensaient alors différemment de ce qu'on pense aujourd'hui. L'Église romaine adopta depuis la procession du Père et du Fils; et il arriva même qu'en 1274 l'empereur des Grecs, Michel Paléologue, implorant contre les Turcs une nouvelle croisade, envoya au second concile de Lyon son patriarche et son chancelier, qui chantèrent avec le concile, en latin, qui ex Patre Filioque procedit. Mais l'Église grecque retourna encore à son opinion, et sembla la quitter encore dans la réunion passagère qui se fit avec Eugène IV. Que les hommes apprennent de là à se tolérer les uns les autres. Voilà des variations et des disputes sur un point fondamental, qui n'ont ni excité de troubles, ni rempli les prisons, ni allumé les bûchers.

On a blâmé les déférences du pape Jean VIII pour le patriarche Photius ; on n'a pas assez songé que ce pontife avait alors besoin de l'empereur Basile. Un roi de Bulgarie, nommé Bogoris, gagné par l'habileté de sa femme, qui était chrétienne, s'était converti, à l'exemple de Clovis et du roi Egbert. Il s'agissait de savoir de quel patriarcat cette nouvelle province chrétienne dépendrait. Constantinople et Rome se la disputaient. La décision dépendait de l'empereur Basile. Voilà en partie le sujet des complaisances qu'eut l'évêque de Rome pour celui de Constantinople. 
Il ne faut pas oublier que dans ce concile, ainsi que dans le précédent, il y eut des cardinaux. On nommait ainsi des prêtres et des diacres qui servaient de conseils aux métropolitains. Il y en avait à Rome comme dans d'autres Églises. Ils étaient déjà distingués, mais ils signaient après les évêques et les abbés.

Le pape donna, par ses lettres et par ses légats, le titre de votre sainteté au patriarche Photius. Les autres patriarches sont aussi appelés papes dans ce concile. C'est un nom grec, commun à tous les prêtres, et qui peu à peu est devenu le titre distinctif du métropolitain de Rome.

Il paraît que Jean VIII se conduisait avec prudence ; car ses successeurs s'étant brouillés avec l'empire grec, et ayant adopté le huitième concile œcuménique de 869 , et rejeté l'autre, qui absolvait Photius, la paix établie par Jean VIII fut alors rompue. Photius éclata contre l'Église romaine, la traita d'hérétique au sujet de cet article du Filioque procedit, des œufs en carême, de l'eucharistie faite avec du pain sans levain, et de plusieurs autres usages. Mais le grand point de la division était la primatie. Photius et ses successeurs voulaient être les premiers évêques du christianisme, et ne pouvaient souffrir que l'évêque de Rome, d'une ville qu'ils regardaient alors comme barbare, séparée de l'empire par sa rébellion, et en proie à qui voudrait s'en emparer, jouît de la préséance sur l'évêque de la ville impériale. Le patriarche de Constantinople avait alors dans son district toutes les églises de la Sicile et de la Pouille ; et le siège romain, en passant sous une domination étrangère, avait perdu à la fois dans ces provinces son patrimoine et ses droits de métropolitain. L'Église grecque méprisait l'Église romaine. Les sciences florissaient à Constantinople; mais à Rome tout tombait, jusqu'à la langue latine ; et quoiqu'on y fût plus instruit que dans tout le reste de l'Occident, ce peu de science se ressentait de ces temps malheureux. Les Grecs se vengeaient bien de la supériorité que les Romains avaient eue sur eux depuis le temps de Lucrèce et de Cicéron jusqu'à Corneille Tacite. Ils ne parlaient des Romains qu'avec ironie. L'évêque Luitprand, envoyé depuis en ambassade à Constantinople par les Othons, rapporte que les Grecs n'appelaient saint Grégoire-le-Grand que Grégoire-Dialogue, parcequ'en effet ses dialogues sont d'un homme trop simple. Le temps a tout changé. Les papes sont devenus de grands souverains, Rome le centre de la politesse et des arts, l'Église latine savante ; et le patriar- 
che de Constantinople n'est plus qu'un esclave, évêque d'un peuple esclave.

Photius, qui eut dans sa vie plus de revers que de gloire, fut déposé par des intrigues de cour, et mourut malheureux ; mais ses successeurs, attachés à ses prétentions, les soutinrent avec vigueur.

(882) Le pape Jean VIII mourut encore plus malheureusement. Les annales de Fulde disent qu'il fut assassiné à coups de marteau. Les temps suivants nous feront voir le siège pontifical souvent ensanglanté, et Rome toujours un grand objet pour les nations, mais toujours à plaindre.

Le dogme ne troubla point encore l'Église d'Occident : à peine a-ton conservé la mémoire d'une petite dispute excitée en 846 par un bénédictin, nommé Jean Godescalc, sur la prédestination et sur la grâce : l'événement fit voir combien il est dangereux de traiter ces matières, et surtout de disputer contre un adversaire puissant. Ce moine, prenant à la lettre plusieurs expressions de saint Augustin, enseignait la prédestination absolue et éternelle du petit nombre des élus, et du grand nombre des réprouvés. L'archevêque de Reims, Hincmar, homme violent dans les affaires ecclésiastiques comme dans les civiles, lui dit « qu'il était prédestiné à être condamné et à être fouetté ». En effet, il le fit anathématiser dans un petit concile, en 850. On l'exposa tout nu en présence de l'empereur Charles-le-Chauve, et il fut fouetté depuis les épaules jusqu'aux jambes par des moines.

Cette dispute impertinente, dans laquelle les deux partis ont également tort, ne s'est que trop renouvelée. Vous verrez chez les Hollandais un synode de Dordrecht, composé des partisans de l'opinion de Godescalc, faire pis que fouetter les sectateurs d'Hincmar ${ }^{198}$. Vous verrez au contraire, en France, les jésuites du parti d'Hincmar poursuivre autant qu'ils le pourront les jansénistes attachés aux dogmes de Godescalc; et ces querelles, qui sont la honte des nations policées, ne finiront que quand il y aura plus de philosophes que de docteurs.

Je ne ferais aucune mention d'une folie épidémique qui saisit le peuple de Dijon, en 844, à l'occasion d'un saint Bénigne, qui donnait, disait-on, des convulsions à ceux qui priaient sur son tombeau : je ne

198 Allusion à la mort de Barneveldt. Voyez chapitre 187. 
parlerais pas, dis-je, de cette superstition populaire, si elle ne s'était renouvelée de nos jours avec fureur, dans des circonstances toutes pareilles ${ }^{199}$. Les mêmes folies semblent être destinées à reparaître de temps en temps sur la scène du monde; mais aussi le bon sens est le même dans tous les temps, et on n'a rien dit de si sage sur les miracles modernes opérés au tombeau de je ne sais quel diacre de Paris, que ce que dit, en 844, un évêque de Lyon sur ceux de Dijon : "Voilà un étrange saint, qui estropie ceux qui ont recours à lui : il me semble que les miracles devraient être faits pour guérir les maladies, et non pour en donner. »

Ces minuties ne troublaient point la paix en Occident, et les querelles théologiques y étaient alors comptées pour rien, parce qu'on ne pensait qu'à s'agrandir. Elles avaient plus de poids en Orient, parce que les prélats, n'y ayant jamais eu de puissance temporelle, cherchaient à se faire valoir par les guerres de plume. Il y a encore une autre cause de la paix théologique en Occident : c'est l'ignorance, qui au moins produisit ce bien parmi les maux infinis dont elle était cause.

199 Sur les convulsionnaires modernes voyez une note du Pauvre Diable et une note des Cabales (tome X) ; le chapitre XXXVII du Siècle de Louis XIV; et le Dictionnaire philosophique, au mot Convulsions. (B.) 


\section{Chapitre 32}

État de l'empire d'Occident à la fin du IX $X^{e}$ siècle

L'empire d'Occident ne subsista plus que de nom. (888) Arnould, Arnolfe, ou Arnold, bâtard de Carloman, se rendit maitre de l'Allemagne; mais l'Italie était partagée entre deux seigneurs, tous deux du sang de Charlemagne par les femmes : l'un était un duc de Spolette, nommé Gui ; l'autre Bérenger, duc de Frioul, tous deux investis de ces duchés par Charles-le-Chauve, tous deux prétendants à l'empire aussi bien qu'au royaume de France. Arnould, en qualité d'empereur, regardait aussi la France comme lui appartenant de droit, tandis que la France, détachée de l'empire, était partagée entre Charles-le-Simple, qui la perdait, et le roi Eudes, grand-oncle de Hugues Capet, qui l'usurpait.

Un Bozon, roi d'Arles, disputait encore l'empire. Le pape Formose, évêque peu accrédité de la malheureuse Rome, ne pouvait que donner l'onction sacrée au plus fort. Il couronna ce Gui de Spolette. (894) L'année d'après, il couronna Bérenger vainqueur ; et il fut forcé de sacrer enfin cet Arnould, qui vint assiéger Rome, et la prit d'assaut. Le serment équivoque que reçut Arnould des Romains prouve que déjà les papes prétendaient à la souveraineté de Rome. Tel était ce serment : « Je jure par les saints mystères que, sauf mon honneur, ma loi, et ma fidélité à monseigneur Formose, pape, je serai fidèle à l'empereur Arnould. »

Les papes étaient alors en quelque sorte semblables aux califes de Bagdad, qui, révérés dans tous les États musulmans comme les chefs de la religion, n'avaient plus guère d'autre droit que celui de donner 
les investitures des royaumes à ceux qui les demandaient les armes à la main ; mais il y avait entre les califes et les papes cette différence que les califes étaient tombés du premier trône de la terre, et que les papes s'élevaient insensiblement.

Il n'y avait réellement plus d'empire, ni de droit, ni de fait. Les Romains, qui s'étaient donnés à Charlemagne par acclamation, ne voulaient plus reconnaître des bâtards, des étrangers, à peine maîtres d'une partie de la Germanie.

Le peuple romain, dans son abaissement, dans son mélange avec tant d'étrangers, conservait encore, comme aujourd'hui, cette fierté secrète que donne la grandeur passée. Il trouvait insupportable que des Bructères, des Cattes, des Marcomans, se dissent les successeurs des Césars, et que les rives du Mein et la forêt Hercynie fussent le centre de l'empire de Titus et de Trajan.

On frémissait à Rome d'indignation, et on riait en même temps de pitié, lorsqu'on apprenait qu'après la mort d'Arnould, son fils Hiludovic, que nous appelons Louis, avait été désigné empereur des Romains à l'âge de trois ou quatre ans, dans un village barbare nommé Forcheim, par quelques leudes et évêques germains. Cet enfant ne fut jamais compté parmi les empereurs; mais on le regardait dans 1'Allemagne comme celui qui devait succéder à Charlemagne et aux Césars. C'était en effet un étrange empire romain que ce gouvernement qui n'avait alors ni les pays entre le Rhin et la Meuse, ni la France, ni la Bourgogne, ni l'Espagne, ni rien enfin dans l'Italie, et pas même une maison dans Rome qu'on pût dire appartenir à l'empereur.

Du temps de ce Louis, dernier prince allemand du sang de Charlemagne par bâtardise, mort en 912, l'Allemagne fut ce qu'était la France, une contrée dévastée par les guerres civiles et étrangères, sous un prince élu en tumulte et mal obéi.

Tout est révolution dans les gouvernements : c'en est une frappante que de voir une partie de ces Saxons sauvages, traités par Charlemagne comme les Ilotes par les Lacédémoniens, donner ou prendre au bout de cent douze ans cette même dignité qui n'était plus dans la maison de leur vainqueur. (912) Othon, duc de Saxe, après la mort de Louis, met, dit-on, par son crédit, la couronne d'Allemagne sur la tête de Conrad, duc de Franconie ; et après la mort de Conrad, le fils du 
duc Othon de Saxe, Henri-l'Oiseleur, est élu (919). Tous ceux qui s'étaient faits princes héréditaires en Germanie, joints aux évêques, faisaient ces sélections, et y appelaient alors les principaux citoyens des bourgades. 


\section{Chapitre 33}

\section{Des Fiefs, et de l'Empire}

La force, qui a tout fait dans ce monde, avait donné l'Italie et les Gaules aux Romains : les barbares usurpèrent leurs conquêtes; le père de Charlemagne usurpa les Gaules sur les rois francs; les gouverneurs, sous la race de Charlemagne, usurpèrent tout ce qu'ils purent. Les rois lombards avaient déjà établi des fiefs en Italie ; ce fut le modèle sur lequel se réglèrent les ducs et les comtes dès le temps de Charles-le-Chauve. Peu à peu leurs gouvernements devinrent des patrimoines. Les évêques de plusieurs grands sièges, déjà puissants par leur dignité, n'avaient plus qu'un pas à faire pour être princes; et ce pas fut bientôt fait. De là vient la puissance séculière des évêques de Mayence, de Cologne, de Trèves, de Vurtzbourg, et de tant d'autres en Allemagne et en France. Les archevêques de Reims, de Lyon, de Beauvais, de Langres, de Laon, s'attribuèrent les droits régaliens. Cette puissance des ecclésiastiques ne dura pas en France ; mais en Allemagne elle est affermie pour longtemps. Enfin les moines eux-mêmes devinrent princes : les abbés de Fulde, de Saint-Gall, de Kempten, de Corbie, etc. , étaient de petits rois dans les pays où, quatre-vingts ans auparavant, ils défrichaient de leurs mains quelques terres que des propriétaires charitables leur avaient données. Tous ces seigneurs, ducs, comtes, marquis, évêques, abbés, rendaient hommage au souverain. On a longtemps cherché l'origine de ce gouvernement féodal. Il est à croire qu'il n'en a point d'autre que l'ancienne coutume de toutes les nations d'imposer un hommage et un tribut au plus faible. On sait qu'ensuite les empereurs romains donnèrent des terres à perpétuité, à de certaines conditions : on en trouve des exemples dans les vies d'Alexandre Sévère et de Probus. Les Lombards furent les premiers qui érigèrent des duchés dans un temps de troubles, vers 576 ; et lorsque la monarchie se rétablit, ces duchés en relevèrent comme fiefs. 
Spolette et Bénévent furent, sous les rois lombards, des duchés héréditaires.

Avant Charlemagne, Tassillon possédait le duché de Bavière, à condition d'un hommage ; et ce duché eût appartenu à ses descendants si Charlemagne, ayant vaincu ce prince, n'eût dépouillé le père et les enfants.

Bientôt point de ville libre en Allemagne, ainsi point de commerce, point de grandes richesses : les villes au delà du Rhin n'avaient pas même de murailles. Cet État, qui pouvait être si puissant, était devenu si faible par le nombre et la division de ses maîtres que l'empereur Conrad fut obligé de promettre un tribut annuel aux Hongrois, Huns, ou Pannoniens, si bien contenus par Charlemagne, et soumis depuis par les empereurs de la maison d'Autriche. Mais alors ils semblaient être ce qu'ils avaient été sous Attila : ils ravageaient l'Allemagne, les frontières de la France; ils descendaient en Italie par le Tyrol, après avoir pillé la Bavière, et revenaient ensuite avec les dépouilles de tant de nations.

C'est au règne de Henri-1'Oiseleur que se débrouilla un peu le chaos de l'Allemagne. Ses limites étaient alors le fleuve de l'Oder, la Bohême, la Moravie, la Hongrie, les rivages du Rhin, de l'Escaut, de la Moselle, de la Meuse ; et vers le septentrion, la Poméranie et le Holstein étaient ses barrières.

Il faut que Henri-l'Oiseleur fût un des rois les plus dignes de régner. Sous lui les seigneurs de l'Allemagne, si divisés, sont réunis. (920) Le premier fruit de cette réunion est l'affranchissement du tribut qu'on payait aux Hongrois, et une grande victoire remportée sur cette nation terrible. Il fit entourer de murailles la plupart des villes d'Allemagne ; il institua des milices : on lui attribua même l'invention de quelques jeux militaires qui donnaient quelque idée des tournois. Enfin l'Allemagne respirait; mais il ne paraît pas qu'elle prétendît être l'empire romain. L'archevêque de Mayence avait sacré Henril'Oiseleur ; aucun légat du pape, aucun envoyé des Romains n'y avait assisté. L'Allemagne sembla pendant tout ce règne oublier l'Italie.

Il n'en fut pas ainsi sous Othon-le-Grand, que les princes allemands, les évêques, et les abbés, élurent unanimement après la mort de Henri, son père. L'héritier reconnu d'un prince puissant, qui a fon- 
dé ou rétabli un État, est toujours plus puissant que son père, s'il ne manque pas de courage : car il entre dans une carrière déjà ouverte, il commence où son prédécesseur a fini. Ainsi Alexandre avait été plus loin que Philippe son père; Charlemagne, plus loin que Pépin; et Othon-le-Grand passa de beaucoup Henri-l'Oiseleur. 


\section{Chapitre 34}

\section{D'Othon-le-Grand au $X^{e}$ siècle}

Othon, qui rétablit une partie de l'empire de Charlemagne, étendit comme lui la religion chrétienne en Germanie par des victoires. (948) Il força les Danois, les armes à la main, à payer tribut, et à recevoir le baptême, qui leur avait été prêché un siècle auparavant, et qui était presque entièrement aboli.

Ces Danois ou Normands, qui avaient conquis la Neustrie et l'Angleterre, ravagé la France et l'Allemagne, reçurent des lois d'Othon. Il établit des évêques en Danemark, qui furent alors soumis à l'archevêque de Hambourg, métropolitain des églises des barbares, fondées depuis peu dans le Holstein, dans la Suède, dans le Danemark. Tout le christianisme consistait à faire le signe de la croix. Il soumit la Bohême après une guerre opiniâtre. C'est depuis lui que la Bohême, et même le Danemark, furent réputés provinces de l'empire ; mais les Danois secouèrent bientôt le joug.

Othon s'était ainsi rendu l'homme le plus considérable de l'Occident, et l'arbitre des princes. Son autorité était si grande, et l'état de la France si déplorable alors, que Louis-d'Outremer, fils de Charles-le-Simple, descendant de Charlemagne, était venu, en 948, à un concile d'évêques que tenait Othon près de Mayence; ce roi de France dit ces propres mots rédigés dans les actes : " J'ai été reconnu roi, et sacré par les suffrages de tous les seigneurs et de toute la noblesse de France. Hugues toutefois m'a chassé, m'a pris frauduleusement, et m'a retenu prisonnier un an entier; et je n'ai pu obtenir ma liberté qu'en lui laissant la ville de Laon, qui restait seule à la reine Gerberge pour y tenir sa cour avec mes serviteurs. Si on prétend que j'aie commis quelque crime qui méritât un tel traitement, je suis prêt à m'en purger, au jugement d'un concile, et suivant l'ordre du roi Othon, ou par le combat singulier. » 
Ce discours important prouve à la fois bien des choses les prétentions des empereurs de juger les rois, la puissance d'Othon, la faiblesse de la France, la coutume des combats singuliers, et enfin l'usage qui s'établissait de donner les couronnes, non par le droit du sang, mais par les suffrages des seigneurs, usage bientôt après aboli en France.

Tel était le pouvoir d'Othon-le-Grand, quand il fut invité à passer les Alpes par les Italiens mêmes, qui, toujours factieux et faibles, ne pouvaient ni obéir à leurs compatriotes, ni être libres, ni se défendre à la fois contre les Sarrasins et les Hongrois, dont les incursions infestaient encore leur pays.

L'Italie, qui dans ses ruines était toujours la plus riche et la plus florissante contrée de l'Occident, était déchirée sans cesse par des tyrans. Mais Rome, dans ces divisions, donnait encore le mouvement aux autres villes d'Italie. Qu'on songe à ce qu'était Paris dans le temps de la Fronde, et plus encore sous Charles-l'Insensé, et à ce qu'était Londres sous l'infortuné Charles I ${ }^{\mathrm{er}}$, ou dans les guerres civiles des York et des Lancastre, on aura quelque idée de l'état de Rome au dixième siècle. La chaire pontificale était opprimée, déshonorée, et sanglante. L'élection des papes se faisait d'une manière dont on n'a guère d'exemples ni avant, ni après. 


\section{Chapitre 35}

\section{De la papauté au $X^{e}$ siècle, avant qu'Othon-le-Grand se rendît maître de Rome}

Les scandales et les troubles intestins qui affligèrent Rome et son Église au dixième siècle, et qui continuèrent longtemps après, n'étaient arrivés ni sous les empereurs grecs et latins, ni sous les rois goths, ni sous les rois lombards, ni sous Charlemagne : ils sont visiblement la suite de l'anarchie; et cette anarchie eut sa source dans ce que les papes avaient fait pour la prévenir, dans la politique qu'ils avaient eue d'appeler les Francs en Italie. S'ils avaient en effet possédé toutes les terres qu'on prétend que Charlemagne leur donna, ils auraient été plus grands souverains qu'ils ne le sont aujourd'hui. L'ordre et la règle eussent été dans les élections et dans le gouvernement, comme on les y voit. Mais on leur disputa tout ce qu'ils voulurent avoir ; l'Italie fut toujours l'objet de l'ambition des étrangers; le sort de Rome, fut toujours incertain. Il ne faut jamais perdre de vue que le grand but des Romains était de rétablir l'ancienne république, que des tyrans s'élevaient dans l'Italie et dans Rome, que les élections des évêques ne furent presque jamais libres, et que tout était abandonné aux factions.

Formose, fils du prêtre Léon, étant évêque de Porto, avait été à la tête d'une faction contre Jean VIII, et deux fois excommunié par ce pape ; mais ces excommunications, qui furent bientôt après si terribles aux têtes couronnées, le furent si peu pour Formose qu'il se fit élire pape en 890.

Étienne VI ou VII, aussi fils de prêtre, successeur de Formose, homme qui joignit l'esprit du fanatisme à celui de la faction, ayant toujours été l'ennemi de Formose, fit exhumer son corps qui était embaumé, et, l'ayant revêtu des habits pontificaux, le fit comparaître dans un concile assemblé pour juger sa mémoire. On donna au mort 
un avocat; on lui fit son procès en forme, le cadavre fut déclaré coupable d'avoir changé d'évêché, et d'avoir quitté celui de Porto pour celui de Rome ; et pour réparation de ce crime, on lui trancha la tête par la main du bourreau, on lui coupa trois doigts, et on le jeta dans le Tibre.

Le pape Étienne VI ou VII se rendit si odieux par cette farce aussi horrible que folle, que les amis de Formose, ayant soulevé les citoyens, le chargèrent de fers, et l'étranglèrent en prison.

La faction ennemie de cet Étienne fit repêcher le corps de Formose, et le fit enterrer pontificalement une seconde fois.

Cette querelle échauffait les esprits. Sergius III, qui remplissait Rome de ses brigues pour se faire pape, (907) fut exilé par son rival, Jean IX, ami de Formose; mais, reconnu pape après la mort de Jean IX, il condamna Formose encore. Dans ces troubles, Théodora, mère de Marozie, qu'elle maria depuis au marquis de Toscanelle, et d'une autre Théodora, toutes trois célèbres par leurs galanteries, avait à Rome la principale autorité. Sergius n'avait été élu que par les intrigues de Théodora la mère. Il eut, étant pape, un fils de Marozie, qu'il éleva publiquement dans son palais. Il ne paraît pas qu'il fût haï des Romains, qui, naturellement voluptueux, suivaient ses exemples plus qu'ils ne les blâmaient.

Après sa mort et celle de l'imbécile Anastase, les deux sœurs Marozie et Théodora procurèrent la chaire de Rome à un de leurs favoris nommé Landon (913); mais ce Landon étant mort (914), la jeune Théodora fit élire pape son amant, Jean X, évêque de Bologne, puis de Ravenne, et enfin de Rome. On ne lui reprocha point, comme à Formose, d'avoir changé d'évêché. Ces papes, condamnés par la postérité comme évêques peu religieux, n'étaient point d'indignes princes, il s'en faut beaucoup. Ce Jean X, que l'amour fit pape, était un homme de génie et de courage : il fit ce que tous les papes ses prédécesseurs n'avaient pu faire; il chassa les Sarrasins de cette partie de l'Italie nommée le Garillan.

Pour réussir dans cette expédition, il eut l'adresse d'obtenir des troupes de l'empereur de Constantinople, quoique cet empereur eût à se plaindre autant des Romains rebelles que des Sarrasins. Il fit armer le comte de Capoue ; il obtint des milices de Toscane, et marcha lui- 
même à la tête de cette armée, menant avec lui un jeune fils de Marozie et du marquis Adelbert. Ayant chassé les mahométans du voisinage de Rome, il voulait aussi délivrer l'Italie des Allemands et des autres étrangers.

L'Italie était envahie presque à la fois par les Bérengers, par un roi de Bourgogne, par un roi d'Arles. Il les empêcha tous de dominer dans Rome. Mais au bout de quelques années, Guido, frère utérin de Hugo, roi d'Arles, tyran de l'Italie, ayant épousé Marozie toutepuissante à Rome, cette même Marozie conspira contre le pape, si longtemps amant de sa sœur. Il fut surpris, mis aux fers, et étouffé entre deux matelas.

(928) Marozie, maîtresse de Rome, fit élire pape un nommé Léon, qu'elle fit mourir en prison au bout de quelques mois. Ensuite, ayant donné le siège de Rome à un homme obscur, qui ne vécut que deux ans, (931) elle mit enfin sur la chaire pontificale Jean XI, son propre fils, qu'elle avait eu de son adultère avec Sergius III.

Jean XI n'avait que vingt-quatre ans quand sa mère le fit pape ; elle ne lui conféra cette dignité qu'à condition qu'il s'en tiendrait uniquement aux fonctions d'évêque, et qu'il ne serait que le chapelain de sa mère.

On prétend que Marozie empoisonna alors son mari Guido, marquis de Toscanelle. Ce qui est vrai, c'est qu'elle épousa le frère de son mari, Hugo, roi de Lombardie, et le mit en possession de Rome, se flattant d'être avec lui impératrice ; mais un fils du premier lit de Marozie se mit alors à la tête des Romains contre sa mère, chassa Hugo de Rome, renferma Marozie et le pape son fils dans le môle d'Adrien, qu'on appelle aujourd'hui le château Saint-Ange. On prétend que Jean XI y mourut empoisonné.

Un Étienne VIII ou IX, Allemand de naissance, élu en 939, fut par cette naissance seule si odieux aux Romains que, dans une sédition, le peuple lui balafra le visage au point qu'il ne put jamais depuis paraître en public.

(956) Quelque temps après, un petit-fils de Marozie, nommé Octavien Sporco, fut élu pape à l'âge de dix-huit ans par le crédit de sa famille. Il prit le nom de Jean XII, en mémoire de Jean XI, son oncle. 
C'est le premier pape qui ait changé son nom à son avènement au pontificat. Il n'était point dans les ordres quand sa famille le fit pontife. Ce Jean était patrice de Rome, et, ayant la même dignité qu'avait eue Charlemagne, il réunissait par le siège pontifical les droits des deux puissances et le pouvoir le plus légitime ; mais il était jeune, livré à la débauche, et n'était pas d'ailleurs un puissant prince.

On s'étonne que sous tant de papes si scandaleux et si peu puissants l'Église romaine ne perdît ni ses prérogatives, ni ses prétentions; mais alors presque toutes les autres Églises étaient ainsi gouvernées. Le clergé d'Italie pouvait mépriser de tels papes, mais il respectait la papauté d'autant plus qu'il y aspirait ; enfin, dans l'opinion des hommes, la place était sacrée, quand la personne était odieuse.

Pendant que Rome et l'Église étaient ainsi déchirées, Bérenger, qu'on appelle le Jeune, disputait l'Italie à Hugues d'Arles. Les Italiens, comme le dit Luitprand, contemporain, voulaient toujours avoir deux maîtres pour n'en avoir réellement aucun fausse et malheureuse politique qui les faisait changer de tyrans et de malheurs. Tel était l'état déplorable de ce beau pays, lorsque Othon-le-Grand y fut appelé par les plaintes de presque toutes les villes, et même par ce jeune pape Jean XII, réduit à faire venir les Allemands, qu'il ne pouvait souffrir.

FIN DU PREMIER VOLUME

DE L'ESSAI SUR LES MEURS 